ADALTO DE FARIAS

AVALIAÇÃO DO PROCESSAMENTO POR ATRITO LINEAR EM CHAPAS DA LIGA DE TITÂNIO Ti-6AI-4V

São Paulo

2015 


\section{AVALIAÇÃO DO PROCESSAMENTO POR ATRITO LINEAR EM CHAPAS DA LIGA DE TITÂNIO Ti-6AI-4V}

Tese apresentada à Escola Politécnica da Universidade de São Paulo para obtenção do título de Doutor em Ciências

Área de concentração: Engenharia Mecânica de Projeto e Fabricação

Orientador: Prof. Dr. Gilmar Ferreira Batalha

São Paulo

2015 
Este exemplar foi revisado e corrigido em relação à versão original, sob responsabilidade única do autor e com a anuência de seu orientador.

São Paulo, de de

Assinatura do autor:

Assinatura do orientador:

Catalogação-na-publicação

Farias, Adalto de

AVALIAÇÃO DO PROCESSAMENTO POR ATRITO LINEAR EM

CHAPAS DA LIGA DE TITÂNIO Ti-6Al-4V / A. Farias -- versão corr. -- São

Paulo, 2015.

$250 \mathrm{p}$.

Tese (Doutorado) - Escola Politécnica da Universidade de São Paulo. Departamento de Engenharia Mecânica.

1.Atrito 2.Chapas 3.Ligas leves 4. Titânio 5.Soldagem I.Universidade de São Paulo. Escola Politécnica. Departamento de Engenharia Mecânica II.t. 


\section{DEDICATÓRIA}

À minha esposa Evelin, minhas filhas Alice e Eliza por sua compreensão, carinho, presença e incansável apoio ao longo do período de elaboração deste trabalho. 


\section{AGRADECIMENTOS}

Ao Prof. Dr. Gilmar Ferreira Batalha, pela brilhante orientação, pela constante dedicação e amizade durante todo o trabalho.

Ao Prof. Dr. Sérgio Delijaicov, pela co-orientação deste trabalho, pela competente ajuda nos momentos de dúvidas e sua grande amizade.

À empresa Polimold Ind. S/A, pela grande oportunidade de executar este trabalho, por todo o suporte dado tanto em material quanto em tempo.

Ao Prof. Dr. Roberto Bortolussi da FEI pelo apoio no uso dos equipamentos laboratoriais utilizados neste trabalho.

Ao Prof. Ed Claudio Bordinassi e Andrea Franchi pela grande ajuda com a preparação das metalografias.

Ao doutorando Márcio Wagner pela valorosa ajuda e pelos bons momentos de trabalho durante os ensaios.

Aos Amigos do CLM da FEI pela ajuda com os corpos de provas e ferramentas.

Aos Amigos do Laboratório de Estruturas Leves-LEL de São José dos Campos pela breve mas valorosa estadia no laboratório.

A todos os colegas que direta ou indiretamente contribuíram para realização deste trabalho, e, especialmente a Deus por mais esta realização. 


\section{RESUMO}

Esta tese tem por objetivo a aplicação do processamento por atrito linear na liga de titânio Ti-6Al-4V. Derivado da solda por atrito linear, é um processo recente desenvolvido na década de 90 para união de alumínio. Sua aplicação em outros tipos de materiais como aços e ligas de alto desempenho, em especial o titânio, tem interessado a industria. A metodologia utilizada nesta tese para avaliar o processamento por atrito linear, consistiu na execução de ensaios mecânicos de tração em condições mistas em chapas da liga de titânio Ti-6Al-4V. A máquina utilizada para o processamento das chapas foi um centro de usinagem CNC convencional, adaptado com dispositivos especiais. Além dos ensaios de tração em condições mistas, foram executadas medições de microdurezas nas regiões atingidas pelo processo, avaliação das microestruturas resultantes e medições de tensão residual para uma caracterização mais ampla do processo. As microestruturas na região processada são caracterizadas por uma estrutura $\beta$ totalmente transformada. As temperaturas de pico na região processada excederam a temperatura $\beta$-transus durante o processamento e a transformação da fase $\beta \rightarrow \alpha+\beta$ ocorreu durante a fase de resfriamento. $A$ transformação da fase $\beta$ para $\alpha$ resultou na formação de agulhas de fase a nos contornos e pelo interior dos grãos da fase $\beta$. Pequenas regiões com estrutura equiaxial de grãos ( $\alpha$ globular) foram observados na zona de processamento. A abordagem dos resultados quantitativos foi feita de forma estatística, visando identificar os parâmetros de maior interação com os resultados observados. Foi identificado nesta tese que a rotação da ferramenta apresentou a maior influência nos resultados de tensão residual, microdureza e tensão de escoamento. Uma importante contribuição à modelagem da tensão de escoamento para materiais anisotrópicos é proposta, baseado em um critério de escoamento ortotrópico. Equações complementares baseadas nos testes mistos de tração e cisalhamento são propostas para modificar o modelo ortotrópico. O intuito deste modelo é indicar em que condições o material tem seu regime de escoamento atingido, podendo servir de base para simulações práticas de peças em condições similares.

Palavras chave: Solda por atrito linear, processamento por atrito linear, titânio, ARCAN, ensaio biaxial, ensaio misto. 


\section{ABSTRACT}

This thesis aims at the application of friction stir processing (FSP) in Ti-6Al-4V titanium alloy. Derived from friction stir welding (FSW), it is a recent process developed in the 90 s for aluminum joining. Its application to other types of materials such as steel and high performance alloys, in particular titanium, has interested industry. The methodology applied in this thesis to evaluate FSP, consisted in the execution of tensile test at mixed conditions to Ti-6Al-4V sheets 4 . The machine used for processing the sheet was a conventional CNC milling machine, assembled with special fixture devices. In addition to tensile tests, measurements have been performed to the regions affected by the process such as evaluation of microhardness, microstructure and residual stress condition. The microstructures at the processed region are characterized by a transformed $\beta$ structure. The peak temperatures, in the processed region, exceeded the $\beta$-transus temperature during the processing and transformation of the phase $\beta \rightarrow \alpha+\beta$ occurred during the cooling phase. This transformation resulted in the formation of boundary and intergranular $\alpha$ phase (Widmanstätten) at the $\beta$ grains. Small regions of equiaxed grain structure (globular $\alpha$ ) were observed in the processed zone. The approach to the quantitative results was made in statistical form aiming to identify the parameters interaction with the observed results. It was identified in this thesis that the tool spinning rotation showed the highest influence on the results of residual stress, hardness and yield strength. An important contribution to the modeling of anisotropic materials yield stress is proposed based on an orthotropic yield criterion. Additional equations based on the mixed tests for tensile and shear are proposed to modify the orthotropic model. The purpose of this model is to indicate the conditions under which the material has reached its yield regime, and may be a basis for practical simulations in similar conditions.

Key words: Friction stir welding, friction stir processing, titanium, ARCAN, formability, biaxial testing. 


\section{Lista de Figuras}

Figura 1-1 Turbina de avião (INTEREMPRESAS, 2015) 30

Figura 1-2 - (a) Motocicleta da Ducati 998, (b) detalhe do quadro de fixação do banco de uma motocicleta feito em liga de titânio grau 9 (COLOMBO, 2015) ..........31 Figura 1-3 Bicicleta de competição feita de titânio (FAIRWHEELBIKES, 2015) .......31 Figura 1-4 - Implante femoral feito em liga de titânio (QUADRILCIRURGIA, 2015).. 31 Figura 1-5 - Implante de crânio e face feito em liga de titânio (ADV-TI, 2015) ..........32 Figura 1-6 - Implante de parafuso de titânio para maxila (GORDANA, 2015) 32 Figura 1-7 - Exemplo de sinergia entre o processo FSW e superplasticidade em ligas de titânio. (a)(c) A região processada possui maior plasticidade do que o material original, e em (b)(d) exemplo de região processada com menor plasticidade do que o material original (EDWARDS e RAMULU, 2009).......................................35

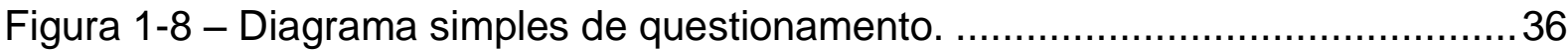

Figura 2-1 - Ligas de titânio no diagrama de fases CCT (DONACHIE JR., 2000)....41 Figura 2-2 - (a) Estrutura para fase $\alpha$, (b) Estrutura da fase $\beta$ adaptado de (REVILBAUDARD, 2010).

Figura 2-3 - Relações cristalográficas no rearranjo de átomos durante a transformação $\beta \leftrightarrow \alpha$, adaptado de (BURGERS, 1934). .44

Figura 2-4 - Transformação alotrópica entre fase cúbica $\beta$ e fase hexagonal $\alpha$. As pilhas $A$ e $B$ são mostradas na célula cúbica, respectivamente em vermelho e azul (REVIL-BAUDARD, 2010)

Figura 2-5 - Microestruturas resultantes na liga Ti-6Al-4V em função da transformação de fases $\beta \leftrightarrow \alpha+\beta$ no resfriamento adaptado de (DONACHIE, 2000) . 45 Figura 2-6 - Perfil da microdureza pela distância à superfície (FÉLIX, 2008). 46

Figura 2-7 - Perfil de microdureza (-) e concentração de elementos residuais (-•-) em amostras de titânio fundidas em moldes de $\mathrm{ZrO}_{2}$ (a) e $\mathrm{SiO}_{2}$ (b) (BARBOSA et al., 2001).

Figura 2-8 - Perfil de distribuição do oxigênio nas amostras fundidas em moldes de (-a) $\mathrm{ZrO}_{2}$ 47

Figura 2-9 - Diagrama de Ellingham de óxidos de titânio, adaptado de (UC, 2008). 48

Figura 2-10 - Energia livre de formação de óxidos de titânio (UC, 2008). .49 
Figura 2-11 - Diagrama esquemático de Pourbaix para o elemento titânio em meio úmido adaptado de (VALENTE, 2011).

Figura 2-12 - Diagrama de Pourbaix para o elemento titânio em meio úmido (PROJECT, 2015) .50

Figura 2-13 - Etapas da solda por atrito (MINTON, 2008). .52

Figura 2-14 -Detalhes do Processo FSW (ELBANHAWY et al., 2013). 53

Figura 2-15 - Etapas do processo de FSP e FSW (MASHININI, 2010). 53

Figura 2-16 - Inclinação para geração de ângulo de ataque (MASHININI, 2010). ...54 Figura 2-17 - Representação esquemática das possíveis combinações de deformação, temperatura e seus resultados na estrutura do Ti-6Al-4V. Adaptado de (BUFFA et al., 2012; KITAMURA et al., 2013). .56

Figura 2-18 - Diferentes estruturas formadas na liga Ti-6Al-4V em função da temperatura e do tempo (SURAND, 2013)

Figura 2-19 - Possíveis microestruturas resultantes em processos envolvendo temperatura e deformação para titânio (SURAND, 2013). .58

Figura 2-20 - Diagrama CCT para liga de titânio Ti-6Al-4V resfriado a partir da fase $\alpha+\beta$ a $950^{\circ} \mathrm{C}$ (DĄBROWSKI, 2011a). .59

Figura 2-21 - Micrografias da liga Ti-6Al-4V resfriada de $950^{\circ} \mathrm{C}$ à uma taxa de: $7,1^{\circ} \mathrm{C} / \mathrm{s}$ (a), $3,2^{\circ} \mathrm{C} / \mathrm{s}$ (b), $0,9^{\circ} \mathrm{C} / \mathrm{s}$ (c), $0,23^{\circ} \mathrm{C} / \mathrm{s}$ (d), $0,061^{\circ} \mathrm{C}$, (e) e $0,011^{\circ} \mathrm{C} / \mathrm{s}$ (f) (DĄBROWSKI, 2011a) 60

Figura 2-22 - Diagrama CCT para liga de titânio Ti-6Al-4V resfriado a partir da fase $\beta$ (DAZBROWSKI, 2011b).

Figura 2-23 - Micrografias da liga Ti-6Al-4V resfriada de $1020^{\circ} \mathrm{C}$ à uma taxa de: $23.1^{\circ} \mathrm{C} / \mathrm{s}$ (a), $7.3^{\circ} \mathrm{C} / \mathrm{s}$ (b), $2.5^{\circ} \mathrm{C} / \mathrm{s}$ (c), $0.94^{\circ} \mathrm{C} / \mathrm{s}$ (d), $0.065^{\circ} \mathrm{C} / \mathrm{s}$ (e), $0.030^{\circ} \mathrm{C} / \mathrm{s}$ (f), $0.015^{\circ} \mathrm{C} / \mathrm{s}$ (g) e $0.012^{\circ} \mathrm{C} / \mathrm{s}$ (h) (DĄBROWSKI, 2011b).

Figura 2-24 - Possíveis microestruturas para a liga Ti-6Al-4V: (a) martensitica, (b) globular,(c) lamelar grossa, (d) lamelar fina, (e) bimodal (KUBIAK; SIENIAWSKI, 1998). 63

Figura 2-25 - Mapa microestrutural da liga Ti-6Al-4V, adaptado de (BABU, 2008)...64 Figura 2-26 - O processo de deformação entre fases, fragmentação da fase $\alpha$ lamelar e sua globularização (Seshacharyulu et al., 2002). 64

Figura 2-27 - Microestruturas da liga Ti-6Al-4V após forjamento em matriz com temperatura acima da $\beta$-transus (Kubiak e Sieniawski, 1998). .65 
Figura 2-28 - Esquema geométrico básico de uma ferramenta para FSW e FSP (EDWARDS e RAMULU, 2009)

Figura 2-29 - Geometrias especiais para ferramentas FSW e FSP (MISHRA e MAHONEY, 2007).

Figura 2-30 - (a) Peça conformada por superplasticidade, (b) detalhe da região modificada por FSP, (c) e (d) fotografia dos defeitos gerados pelo processo (SANDERS, RAMULU, et al., 2010). .71

Figura 2-31 - Parâmetros envolvidos no FSW e FSP. .72

Figura 2-32 - Defeito causado por falta de controle da força axial (EDWARDS e RAMULU, 2009).

Figura 2-33 - Região processada com controle de todos os parâmetros envolvidos, (a) superfície e (b) estrutura livre de defeitos (EDWARDS e RAMULU, 2009). .73 Figura 2-34 - Região processada com diferentes condições, RPM=750 e $\mathrm{f}=200 \mathrm{~mm} / \mathrm{min}$ (EDWARDS e RAMULU, 2009). .74

Figura 2-35 - Em (a): variação da rotação em função da distância a ser processada. Em (b): a variação da velocidade em função da distância a ser processada (MASHININI, 2010).

Figura 2-36 - Esquema para instalação de termopares em placa de apoio para FSW e FSP, dimensões em [mm] (EDWARDS e RAMULU, 2010b). .75

Figura 2-37 - Medição com termopares em placa Ti-6AI-4V (EDWARDS e RAMULU, 2010b) .76

Figura 2-38 - Simulação em elementos finitos de distribuição da temperatura durante FSW em material Ti-6Al-4V, (a) rotação da ferramenta de 700RPM $\times 35 \mathrm{~mm} / \mathrm{min}$ e (b) rotação da ferramenta de 300RPMx50mm/min (BUFFA et al., 2013).....................77

Figura 2-39 - Modelagem geral de um processo/sistema(ANTONY, 2003) ............78 Figura 2-40 - Avaliação de interação entre dois parâmetros em um mesmo experimento. Adaptado de (ANTONY, 2003). 79

Figura 3-1 - Diferentes abordagens e corpos de prova utilizados em estudos experimentais de caracterização (WAGNER et al., 2012)

Figura 3-2 - Dispositivo de teste de tensão biaxial (a), em (b) corpo de provas em formato cruciforme.(KUWABARA et al., 1998)

Figura 3-3 - Ensaio de cisalhamento de acordo com Miyauchi: (a) corpo de provas, (b) sistema de fixação (RICKHEY et al., 2015). .86 
Figura 3-4 - Variação do ensaio de cisalhamento de Miyauchi: (a) corpo de provas, (b) sistema de fixação (HORA et al., 2000).

Figura 3-5 - (a) Máquina biaxial de testes de Twente, (b) corpo de provas de Twente (PIJLMAN, 2001).

Figura 3-6 - Possibilidades de ensaio Arcan, modos I, II e misto, adaptado de (CERVEIRA, 2008) .88

Figura 3-7 - Exemplo de dispositivo de ensaio Arcan. .88

Figura 3-8 Comparação da curva tensãoxdeformação para corpos de prova de alumínio 6056T78 submetidos ao ensaio de Arcan e ao ensaio de tração (BLANCHARD et al., 2006).... 89

Figura 3-9 Configurações para o ensaio de Arcan (MOHR; DOYOYO, 2003). .90

Figura 3-10 (a) Diagrama de forças resultantes no corpo-de-prova do ensaio Arcan (DOYOYO; MOHR, 2003), (b) Corte de uma metade do corpo-de-prova (MOHR; DOYOYO, 2002) .90

Figura 4-1 Princípio funcional do Aramis®. (GOM, 2001). .93

Figura 4-2 Montagem para uma medição 3D em (a) e em (b) determinação do ponto de medição. (GOM, 2001)

Figura 4-3 Medição da distorção de uma faceta usando interpolação de spline. (KNOCKAERT, 2001) apud (FLORES, 2005) .95

Figura 5-1 - Representação esquemática da distribuição da tensão residual em processos FSW (KUMAR et al., 2014). .96

Figura 5-2 - Distribuição de tensão residual longitudinal em função da distância da linha central da solda na liga Ti-6Al-4V (PASTA; REYNOLDS, 2008a). .97

Figura 5-3 - Difração de raios-X em cristais simples carregados e descarregados (Brinksmeier et al, 1982). .98

Figura 5-4 Estado plano de tensões (Prevéy, 1996). .99

Figura 5-5 Elipsóide das deformações (Prevéy, 1996). 100

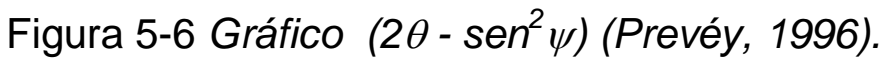
101

Figura 6-1 Condições de tensão principal associadas ao início do escoamento de um material, (PIJLMAN, 2001) 102

Figura 6-2 - Regimes de encruamento (a) isotrópico, (b) cinemático (PLUNKETT, 2005). 103

Figura 6-3 - Critérios CPB06 em comparação com valores experimentais de tração e compressão para Ti-6Al-4V (símbolos) (GILLES et al., 2011). 
Figura 6-4 Projeções do plano de tensão-torção pelo critério proposto CPB06 para vários valores de $\mathrm{k}$ e $\mathrm{a}=2$, comparação com Tresca e Von Mises ( $\mathrm{k}=0, \mathrm{a}=2)$ (CAZACU et al., 2006).

Figura 7-1 - Geometria dos corpos de prova para experimento de FSP, dimensões em milímetros.

Figura 7-2 - Sentido do FSP

Figura 7-3 Centro de usinagem utilizado para o FSP nos CDPs de titânio.

Figura 7-4 - (a) Vista da placa do dispositivo de fixação; (b) detalhe da lâmina de liga de WC no centro do dispositivo; (c) Barras para fixação das chapas no dispositivo. 120

Figura 7-5 - (a) Chapa posicionada no dispositivo, (b) fixação completa. 120

Figura 7-6 - Detalhe dos pinos de posicionamento do corpo de prova. 121

Figura 7-7 - Detalhe da área a ser processada. 121

Figura 7-8 - Detalhe para simulação da inclinação da ferramenta 122

Figura 7-9 - Ferramenta para FSW em titânio, diâmetro do ombro 16mm e pino de diâmetro $4 \mathrm{mmx} 1,6 \mathrm{~mm}$ cônico com $30^{\circ}$.

Figura 7-10 - Ferramenta montada no suporte de fixação. 123

Figura 7-11 - Alinhamento da base do dispositivo na mesa da máquina. 123

Figura 7-12 - Suporte montado no cabeçote (a) e em (b) verificação do batimento da ferramenta. 124

Figura 7-13 - Furo piloto para entrada da ferramenta de FSP. 125

Figura 7-14 - (a) Rampa de redução de rotação e (b) rampa de aumento do avanço, utilizados nos ensaios.

Figura 7-15 - Corpo de prova processado com $350 \mathrm{RPM}$, f: $75 \mathrm{~mm} / \mathrm{min}$ e $a_{\mathrm{p}}$ : $1,85 \mathrm{~mm}$. 126

Figura 7-16 - Ferramenta danificada utilizada no primeiro ensaio. 127

Figura 7-17 - Ferramenta executando o trajeto linear sobre o corpo de provas.....128 Figura 7-18 - Corpo de prova processado com 350 RPM, f: $50 \mathrm{~mm} / \mathrm{min}$ e $a_{p}$ : $1,65 \mathrm{~mm}$.

Figura 7-19 - Detalhe da região processada no segundo ensaio. 129

Figura 7-20 - Ferramenta danificada utilizada no segundo ensaio. 129

Figura 7-21 - Evidências da reatividade do material da ferramenta do primeiro ensaio com o material da peça. 130

Figura 7-22 - Fratura na ponta da ferramenta do segundo ensaio. 
Figura 7-23 - Desgaste acentuado da ponta da ferramenta do primeiro ensaio..... 131

Figura 7-24 - Desgaste acentuado na ponta da ferramenta do segundo ensaio....132 Figura 7-25 - Região da entrada do primeiro ensaio com rotação de 350 RPM, f de $75 \mathrm{~mm} / \mathrm{min}$ e $a_{p}$ de $1,85 \mathrm{~mm}$. 132

Figura 7-26 - Diagrama de causa e efeito para o caso de desgaste na ponta da ferramenta. 133

Figura 7-27 Segunda máquina utilizada para os ensaios. 135

Figura 7-28 (a) Ferramenta nova, (b) ferramenta após o processo FSW. 137

Figura 7-29 Placa de Ti-6Al-4V (260mmx50mm) após o processamento, AS: sentido de avanço da ferramenta, RS: sentido de retrocesso da ferramenta. 137

Figura 7-30 Equipamento de difração de raios X da Shimadzu XRD-7000. 138

Figura 7-31 Medição na parte posterior da chapa. 138

Figura 7-32 Tensão residual na condição-1, 1100 RPM e 40 mm/min de avanço. . 139 Figura 7-33 Tensão residual na condição-3, 1200 RPM e 50 mm/min de avanço. . 139 Figura 7-34 Tensão residual na condição-5, 1000 RPM e 50 mm/min de avanço. . 140 Figura 7-35 Condição 1 com 1100 RPM e 40 mm/min de avanço......................... 140 Figura 7-36 Condição 5 com 1000 RPM e 40 mm/min de avanço..........................141

Figura 7-37 Microdureza em função da posição nas amostra. ..............................142

Figura 7-38 Chapa processada com ferramenta de WLa ................................... 143

Figura 7-39 Ferramenta de WLa após o ensaio com 1600RPM x 50mm/min.........143 Figura 7-40 Microdureza em função da região transversal do ensaio, 1600 RPM x 50 $\mathrm{mm} / \mathrm{min}(\mathrm{a})$, (b) até (f) metalografias dos pontos característicos da amostra. Figura 7-41 - (a)Máquina para FSW do IPT de São José dos Campos, (b) detalhe do cabeçote especial com células de carga embutidas 145

Figura 7-42 - Curva de esforços na ferramenta em para um FSW com rotação de 1600RPM e avanço de $50 \mathrm{~mm} / \mathrm{min}$. 146

Figura 8-1 Corpo de prova para ensaio de ARCAN (dimensões em mm). 147

Figura 8-2 - Geometria dos corpos de prova para experimento de FSP, dimensões em milímetros.

Figura 8-3 - Sentido do FSP 149

Figura 8-4 - Vista geral do interior da máquina preparada. 150

Figura 8-5 - Detalhe do dispositivo de fixação montado 150

Figura 8-6 - Ferramenta simulando a descida na chapa (a) e (b). 150

Figura 8-7 - (a) Cilindro de argônio, (b) regulador de fluxo e pressão. 151 
Figura 8-8 - Ensaio sendo executado.

Figura 8-9 - (a)Montagem do equipamento de medição por infravermelho, (b) ponto para medição da temperatura.

Figura 8-10 - Processo de conserto da geometria da ferramenta, (a)da ponta da ferramenta desgastada, (b) torneamento da ponta e (c) ferramenta com geometria reconstituida 154

Figura 8-11 - Chapas processadas nas condições do planejamento robusto. 155

Figura 8-12 - continuação. Chapas processadas nas condições do planejamento robusto. 155

Figura 8-13 - Dispositivo de ARCAN montado. 157

Figura 8-14 Corpo de prova para ensaio de ARCAN, espessura de $2 \mathrm{~mm}$. 157

Figura 8-15 Usinagem dos corpos de prova. 158

Figura 8-16 Máquina de tração Instron para $50 \mathrm{kN}$ com as garras montadas. 158

Figura 8-17 (a) Controlador de potência e (b) resistência montada. 159

Figura 8-18 Pirômetro infravermelho com mira laser. 159

Figura 8-19 Sistema de câmeras e iluminação do Aramis. 160

Figura 8-20 Software Aramis - módulo de aquisição de imagens. 161

Figura 8-21 Condição de tração pura. 161

Figura 8-22 Condição de cisalhamento puro. 162

Figura 8-23 Condição de cisalhamento com temperatura de $340^{\circ} \mathrm{C}$. 162

Figura 8-24 Condição mista a $45^{\circ}$, rompida. 163

Figura 8-25 Módulo de avaliação do software GOM Aramis 164

Figura 9-1 - Sentido de rotação e avanço da ferramenta. 165

Figura 9-2 - Esquema para nomenclatura das regiões nas metalografias. 166 Figura 9-3 - Simulação em elementos finitos da distribuição das temperaturas médias para o conjunto ferramenta-dispositivo-peça. 167

Figura 9-4 - Distribuição das temperaturas ao longo da chapa de Ti-6Al-4V. 167 Figura 9-5 - (a) Metalografia ótica do corte na transversal da amostra processada com 1350RPM com avanço de $50 \mathrm{~mm} / \mathrm{min}$, (b) ZTA no lado de retrocesso, (c) ZTA no lado de avanço e (d) região de processamento. 168 Figura 9-6 - Metalografia ótica do corte na transversal da amostra processada com 1350RPM com avanço de $50 \mathrm{~mm} / \mathrm{min}$, (a) ZTMA no topo, (b) ZTMA na base, (c) transição ZTMA/ZTA no lado de retrocesso e (d) transição ZTMA/ZTA no lado de avanço. 169 
Figura 9-7 Imagem de elétrons retoespalhados da ZTMA.

Figura 9-8 - Imagem de elétrons retoespalhados da ZTMA com formação de a globular. 172

Figura 9-9 Imagem de elétrons retoespalhados ampliada, de outra região de processamento com formação de a globular. 173

Figura 9-10 Imagem de elétrons retoespalhados da região do metal de base. 173

Figura 9-11 Imagem de elétrons retoespalhados da região ZTA. 174

Figura 9-12 Imagem de elétrons retroespalhados e EDS na amostra processada com 1500RPM e $50 \mathrm{~mm} / \mathrm{min}$. 175

Figura 9-13 - Esquema de medição de durezas nas amostras embutidas, exemplo para condição B. 176

Figura 9-14 - Perfil de microdureza da chapa FSP na condição 1350RPM e $50 \mathrm{~mm} / \mathrm{min}$ de avanço. 176

Figura 9-15 - Perfil de microdureza da chapa FSP na condição 1350RPM e $60 \mathrm{~mm} / \mathrm{min}$ de avanço.

Figura 9-16 - Perfil de microdureza da chapa FSP na condição 1350RPM e $70 \mathrm{~mm} / \mathrm{min}$ de avanço. 177

Figura 9-17 - Perfil de microdureza da chapa FSP na condição 1500RPM e $50 \mathrm{~mm} / \mathrm{min}$ de avanço. 177

Figura 9-18 - Perfil de microdureza da chapa FSP na condição 1500RPM e $60 \mathrm{~mm} / \mathrm{min}$ de avanço. 178

Figura 9-19 - Perfil de microdureza da chapa FSP na condição 1500RPM e $70 \mathrm{~mm} / \mathrm{min}$ de avanço. 178

Figura 9-20 - Perfil de microdureza da chapa FSP na condição1650RPM e $50 \mathrm{~mm} / \mathrm{min}$ de avanço. 178

Figura 9-21 - Perfil de microdureza da chapa FSP na condição 1650RPM e $60 \mathrm{~mm} / \mathrm{min}$ de avanço. 179

Figura 9-22 - Perfil de microdureza da chapa FSP na condição 1650RPM e $70 \mathrm{~mm} / \mathrm{min}$ de avanço.

Figura 9-23 - Relação de dependência da microdureza em função das variáveis rotação $S$ e avanço $f$. 180

Figura 9-24 - Gráfico de Interações para microdureza em função das variáveis rotação $S$ e avanço $f$. 180

Figura 9-25 - Avaliação dos resíduos do estudo estatístico 
Figura 9-26 - (a) Perfil de microdureza superficial da chapa FSP na condição 1350RPM e $50 \mathrm{~mm} / \mathrm{min}$ de avanço, (b) metalografia de uma medição (do total de três) na chapa a partir da superfície.

Figura 9-27 - Perfil de microdureza superficial da chapa FSP na condição 1500RPM e $50 \mathrm{~mm} / \mathrm{min}$ de avanço, desvio padrão de +/- 9HV0,1. 183

Figura 9-28 - Perfil de microdureza superficial da chapa FSP na condição 1650RPM e $50 \mathrm{~mm} / \mathrm{min}$ de avanço, desvio padrão de +/- 9HV0,1.

Figura 9-29 - Perfil de tensão residual da chapa FSP na condição 1350RPM e $50 \mathrm{~mm} / \mathrm{min}$ de avanço.

Figura 9-30 - Perfil de tensão residual da chapa FSP na condição 1350RPM e $60 \mathrm{~mm} / \mathrm{min}$ de avanço. 185

Figura 9-31 - Perfil de tensão residual da chapa FSP na condição 1350RPM e $70 \mathrm{~mm} / \mathrm{min}$ de avanço. 185

Figura 9-32 - Perfil de tensão residual da chapa FSP na condição 1500RPM e $50 \mathrm{~mm} / \mathrm{min}$ de avanço. 186

Figura 9-33 - Perfil de tensão residual da chapa FSP na condição 1500RPM e $60 \mathrm{~mm} / \mathrm{min}$ de avanço. 186

Figura 9-34 - Perfil de tensão residual da chapa FSP na condição 1500RPM e $70 \mathrm{~mm} / \mathrm{min}$ de avanço. 187

Figura 9-35 - Perfil de tensão residual da chapa FSP na condição1650RPM e $50 \mathrm{~mm} / \mathrm{min}$ de avanço.

Figura 9-36 - Perfil de tensão residual da chapa FSP na condição 1650RPM e $60 \mathrm{~mm} / \mathrm{min}$ de avanço.

Figura 9-37 - Perfil de tensão residual da chapa FSP na condição 1650RPM e $70 \mathrm{~mm} / \mathrm{min}$ de avanço. 188

Figura 9-38 - Relação de dependência tensão residual em função das variáveis rotação $S$ e avanço $f$. 189

Figura 9-39 - Gráfico de Interações para tensão residual em função das variáveis rotação e avanço.

Figura 9-40 - Avaliação dos resíduos do estudo estatístico. 190

Figura 9-41 - Curva tensão $x$ deformação para o caso do ensaio na condição F1 fornecida pelo software Aramis.

Figura 9-42 - Relação de dependência tensão de escoamento em função das variáveis rotação $\mathrm{S}$, avanço $\mathrm{f}$, taxa $e$ de tração e temperatura $\mathrm{T}$. 193 
Figura 9-43 - Gráfico de Interações para tensão de escoamento, (a) interação entre Sxf, (b) interação entre Sxe (c), interação entre SxT (d) interação entre fxe (e) interação entre fxT e (f) interação entre exT.

Figura 9-44 - Avaliação dos resíduos do estudo estatístico (Q-Q plot) 195

Figura 9-45 - Curvas do ensaio de tração na condição 1350RPM, $50 \mathrm{~mm} / \mathrm{min}$ de avanço, taxa de tração $0.1 \mathrm{~mm} / \mathrm{s}$ e temperatura de ensaio de $25^{\circ} \mathrm{C}$. 196

Figura 9-46 - Curvas do ensaio de tração na condição 1350RPM, $60 \mathrm{~mm} / \mathrm{min}$ de avanço, taxa de tração $0.01 \mathrm{~mm} / \mathrm{s}$ e temperatura de ensaio de $200^{\circ} \mathrm{C}$ 196 Figura 9-47 - Curvas do ensaio de tração na condição 1350RPM, $70 \mathrm{~mm} / \mathrm{min}$ de avanço, taxa de tração $0.001 \mathrm{~mm} / \mathrm{s}$ e temperatura de ensaio de $340^{\circ} \mathrm{C}$. 197

Figura 9-48 - Curvas do ensaio de tração na condição 1500RPM, $50 \mathrm{~mm} / \mathrm{min}$ de avanço, taxa de tração $0.01 \mathrm{~mm} / \mathrm{s}$ e temperatura de ensaio de $340^{\circ} \mathrm{C}$. 197

Figura 9-49 - Curvas do ensaio de tração na condição 1500RPM, $60 \mathrm{~mm} / \mathrm{min}$ de avanço, taxa de tração $0.001 \mathrm{~mm} / \mathrm{s}$ e temperatura de ensaio de $25^{\circ} \mathrm{C}$. 198 Figura 9-50 - Curvas do ensaio de tração na condição 1500RPM, $70 \mathrm{~mm} / \mathrm{min}$ de avanço, taxa de tração $0.1 \mathrm{~mm} / \mathrm{s}$ e temperatura de ensaio de $200^{\circ} \mathrm{C}$ 198 Figura 9-51 - Curvas do ensaio de tração na condição 1650RPM, 60mm/min de avanço, taxa de tração $0.1 \mathrm{~mm} / \mathrm{s}$ e temperatura de ensaio de $340^{\circ} \mathrm{C}$ 199 Figura 9-52 - Curvas do ensaio de tração na condição 1650RPM, $70 \mathrm{~mm} / \mathrm{min}$ de avanço, taxa de tração $0.01 \mathrm{~mm} / \mathrm{s}$ e temperatura de ensaio de $25^{\circ} \mathrm{C}$. 199 Figura 9-53 - Curva de plasticidade retirada do experimento F1: tração pura 1500RPM, $70 \mathrm{~mm} / \mathrm{min}$ de avanço, taxa de tração $0.1 \mathrm{~mm} / \mathrm{s}$ e temperatura de ensaio de $200^{\circ} \mathrm{C}$

Figura 9-54 - Simulação em EF da condição F1 em tensão plana (tração pura 1500RPM, $70 \mathrm{~mm} / \mathrm{min}$ de avanço, taxa de tração $0.1 \mathrm{~mm} / \mathrm{s}$ e temperatura de ensaio de $\left.200^{\circ} \mathrm{C}\right)$ 201

Figura 9-55 - Medição real da condição F1 para comparação com EF (tração pura 1500RPM, $70 \mathrm{~mm} / \mathrm{min}$ de avanço, taxa de tração $0.1 \mathrm{~mm} / \mathrm{s}$ e temperatura de ensaio de $\left.200^{\circ} \mathrm{C}\right)$

Figura 9-56 Diagrama de forças atuantes no ensaio de ARCAN, (MOHR; DOYOYO, 2003) 202

Figura 9-57 - Critério CPB06 em diversas condições em conjunto com os valores de alguns ensaios efetuados. 206 
Figura 9-58 - Superfície de escoamento para a chapa FSP processadas na condição 1350RPM, $50 \mathrm{~mm} / \mathrm{min}$ de avanço, taxa de tração $0.1 \mathrm{~mm} / \mathrm{s}$ e temperatura de ensaio de $25^{\circ} \mathrm{C}$

Figura 9-59 - Superfície de escoamento para a chapa FSP processadas na condição 1350RPM, $60 \mathrm{~mm} / \mathrm{min}$ de avanço, taxa de tração $0.01 \mathrm{~mm} / \mathrm{s}$ e temperatura de ensaio de $200^{\circ} \mathrm{C}$ 208

Figura 9-60 - Superfície de escoamento para a chapa FSP processadas na condição 1350RPM, $70 \mathrm{~mm} / \mathrm{min}$ de avanço, taxa de tração $0.001 \mathrm{~mm} / \mathrm{s}$ e temperatura de ensaio de $340^{\circ} \mathrm{C}$. 209

Figura 9-61 - Superfície de escoamento para a chapa FSP processadas na condição 1500RPM, $50 \mathrm{~mm} / \mathrm{min}$ de avanço, taxa de tração $0.01 \mathrm{~mm} / \mathrm{s}$ e temperatura de ensaio de $340^{\circ} \mathrm{C}$ 209

Figura 9-62 - Superfície de escoamento para a chapa FSP processadas na condição 1500RPM, $60 \mathrm{~mm} / \mathrm{min}$ de avanço, taxa de tração $0.001 \mathrm{~mm} / \mathrm{s}$ e temperatura de ensaio de $25^{\circ} \mathrm{C}$. 210

Figura 9-63 - Superfície de escoamento para a chapa FSP processadas na condição 1500RPM, $70 \mathrm{~mm} / \mathrm{min}$ de avanço, taxa de tração $0.1 \mathrm{~mm} / \mathrm{s}$ e temperatura de ensaio de $200^{\circ} \mathrm{C}$

Figura 9-64 - Superfície de escoamento para a chapa FSP processadas na condição 1650RPM, $60 \mathrm{~mm} / \mathrm{min}$ de avanço, taxa de tração $0.1 \mathrm{~mm} / \mathrm{s}$ e temperatura de ensaio de $340^{\circ} \mathrm{C}$

Figura 9-65 - Superfície de escoamento para a chapa FSP processadas na condição 1650RPM, $70 \mathrm{~mm} / \mathrm{min}$ de avanço, taxa de tração $0.01 \mathrm{~mm} / \mathrm{s}$ e temperatura de ensaio de $25^{\circ} \mathrm{C}$ 


\section{Lista de Tabelas}

Tabela 2-1 - Propriedades do titânio policristalino na fase a com alto índice de pureza (>99.9\%) entre 20 e $25^{\circ} \mathrm{C}$. (JOSHI, 2006) (LEYENS e PETERS, 2003) 39 Tabela 2-2 - Tabela periódica de elementos estabilizadores da fase $\alpha$ e $\beta$ (adaptado de JOSHI, 2006). .40

Tabela 2-3 - Propriedades mecânicas das ligas.(LEYENS e PETERS, 2003) 51

Tabela 2-4 - Materiais de ferramenta atualmente utilizados para processos FSW, . 68

Tabela 2-5 - Janela de parâmetros FSW e FSP para titânio - diversas fontes. 70

Tabela 2-6 - Taxa de calor em função da rotação e velocidade de avanço (MASHININI, 2010).Sendo AS sentido de avanço e RS sentido de retrocesso. .76

Tabela 2-7 - Fatores e níveis para estudo de FSW em ligas de alumínio (ELANGOVAN, BALASUBRAMANIAN e BABU, 2008). .81

Tabela 3-1 - Comparação de testes multiaxiais (adaptado de FLORES, 2005). 91

Tabela 7-1 Matriz para o planejamento preliminar 117

Tabela 7-2 Características da máquina utilizada. 119

Tabela 7-3 - Matriz do planejamento preliminar com valores de ensaio 125

Tabela 7-4 Características da segunda máquina utilizada. 135

Tabela 7-5 Matriz para o segundo planejamento preliminar 136

Tabela 8-1 Matriz robusta para o experimento FSP principal. 148

Tabela 8-2 - Medição das temperaturas médias no FSP. 152

Tabela 8-3 - Taxa de resfriamento da chapa para tempo $=10 \mathrm{~min}(600 \mathrm{~s})$ 153

Tabela 8-4 - Planejamento para os ensaios de tração. 156

Tabela 8-5 Referência para os ângulos testados. 156

Tabela 9-1 Tabela de Análise de Variância para Microdureza ..............................179

Tabela 9-2 - Tabela de Análise de Variância para Tensão Residual ...................... 188

Tabela 9-3 Dados dos ensaios de tração ARCAN................................................ 192

Tabela 9-4 Tabela de Análise de Variância para Tensão de Escoamento ..............193

Tabela 9-5 Valor das constantes de anisotropia para cada condição ensaiada .....207

Tabela 13-1 - Classes de metal duro (MACHADO, COELHO, et al., 2009)...........234

Tabela 13-2 Valores medidos e tabelados por condição de corpo de provas 241 


\section{LISTA DE SIGLAS}

A Lado de avanço

ACR Adjusted Compliance Ratio method

AS Sentido de avanço

CCC Cúbico de corpo centrado

CCT Continuous Cooling Transformation

CDP Corpo de provas

CPB06 Critério ortotrópico Cazacu

CSP Conformação superplástica

DIC Digital Image Correlation - Correlação Digital de Imagens

EBW Electron beam welding

EDS Energy dispersive spectroscopy

FSW Friction Stir Welding - Solda por atrito linear

FSP Friction Stir Processing - Processamento por atrito linear

GTAW Gas Tungsten Arc Welding

GMAW Gas Metal Arc Welding

HCP Hexagonal closed packed - Hexagonal densamente empacotado

MB Metal de base

MIG Metal Inert Gás

O $\quad$ câmera DIC 1

$\mathrm{O}_{2} \quad$ câmera DIC 2

P ponto de medição DIC

$\mathrm{P}_{1} \quad$ ponto relativo 1 do ponto $P$

$\mathrm{P}_{2} \quad$ ponto relativo 2 do ponto $\mathrm{P}$

PAW Plasma arc welding

PEF Planejamento experimental fatorial

PCBN Polycrystalline cubic boron nitride

R Retrocesso

RS Sentido de retrocesso

RPM Rotação por minuto

SPF Superplastic Forming

TIG Tungsten Inert Gas

TWI The Welding Institute 
WC Carboneto de Tungstênio

WLa Tungstênio-lantânio

$\mathrm{x}_{1} \mathrm{y}_{1} \quad$ plano de medição DIC 1

$\mathrm{x}_{2} \mathrm{y}_{2} \quad$ plano de medição DIC 2

ZTA Zona termicamente afetada

ZTMA Zona termomecanicamente afetada 


\section{LISTA DE SÍMBOLOS}

$\mathrm{a}_{\mathrm{p}} \quad$ Profundidade de penetração $\mathrm{mm}$

f Velocidade de avanço $\mathrm{mm}$

E Módulo de Young GPa

F Força N

K Temperatura absoluta-Kelvin K

Lr $\quad$ Lado em retrocesso

La Lado em avanço

Lpin Altura do pino

$\mathrm{mm}$

Ms Martensítica inicial

Mf Martensítica final

Rs Raio do ombro

$\mathrm{mm}$

Rp Raio do pino na base mm

Rpt Raio do pino na ponta $\mathrm{mm}$

S Rotação

RPM

$\mathrm{T}$ Temperatura em graus Celsius $\quad{ }^{\circ} \mathrm{C}$

$\mathrm{u}$ Deslocamento $\mathrm{mm}$

Vc Velocidade de corte tangencial $\mathrm{m} / \mathrm{min}$

a $\quad$ Fase alfa

$\alpha^{\prime} \quad$ Fase $\alpha$ martensítica tipo 1

a" $\quad$ Fase a martensítica tipo 2

$\alpha_{\mathrm{GB}} \quad$ Fase a prim. fronteiras

$\alpha_{\mathrm{pn}} \quad$ Fase a primária nodular

$\alpha_{\mathrm{s}} \quad$ Fase $\alpha$ secundário

$\alpha_{W G B} \quad$ Fase a Widmanstätten no contorno de grão

$\alpha_{W l} \quad$ Fase $\alpha$ intra-primária Widmanstätten

$\beta \quad$ Fase beta

$\beta_{\mathrm{m}} \quad$ Fase $\beta$ metaestável

$\beta_{p} \quad$ Fase $\beta$ primária

$\beta_{\mathrm{s}} \quad$ Fase $\beta$ estável em T ambiente

$\beta_{\mathrm{t}} \quad$ Fase $\beta$ transformado

$\varepsilon$ deformação 


\begin{tabular}{|c|c|c|}
\hline$\varepsilon_{1}$ & deformação na direção principal 1 & $\mu \mathrm{m}$ \\
\hline$\varepsilon_{2}$ & deformação na direção principal 2 & $\mu \mathrm{m}$ \\
\hline$\varepsilon_{3}$ & deformação na direção principal 3 & $\mu \mathrm{m}$ \\
\hline$-\Delta \mathrm{G}^{\circ}$ & Energia livre de formação & $\mathrm{kJ} \cdot \mathrm{mol}^{-1}$ \\
\hline$\theta$ & Ângulo de ataque & $\circ$ \\
\hline$\varphi$ & ângulo de inclinação da ferramenta & $\circ$ \\
\hline$\gamma$ & ângulo entre as câmeras $\mathrm{O}_{1}$ e $\mathrm{O}_{2}$ & $\circ$ \\
\hline$\sigma_{1}$ & Tensão principal & $\mathrm{MPa}$ \\
\hline$\sigma_{2}$ & Tensão secundária & $\mathrm{MPa}$ \\
\hline$\sigma_{\mathrm{BI}}$ & Tensão na condição de ensaio biaxial & $\mathrm{MPa}$ \\
\hline$\sigma_{\mathrm{PS}}$ & Tensão na condição de ensaio plano & $\mathrm{MPa}$ \\
\hline$\sigma_{\mathrm{SH}}$ & Tensão na condição de ensaio de cisalhamento & $\mathrm{MPa}$ \\
\hline$\sigma_{\mathrm{T}}$ & Tensão de tração & $\mathrm{MPa}$ \\
\hline$\sigma_{\mathrm{UN}}$ & Tensão na condição de ensaio uniaxial & $\mathrm{MPa}$ \\
\hline$\sigma_{\mathrm{i}}$ & Tensão na direção j & $\mathrm{MPa}$ \\
\hline$\sigma_{\mathrm{j}}$ & Tensão na direção j & $\mathrm{MPa}$ \\
\hline$\sigma_{\mathrm{k}}$ & Tensão na direção k & $\mathrm{MPa}$ \\
\hline$\sigma_{\emptyset}$ & Tensão na direção $\varnothing$ & $\mathrm{MPa}$ \\
\hline$\sigma_{\mathrm{Y}}$ & Tensão de escoamento & $\mathrm{MPa}$ \\
\hline$\varnothing$ & ângulo qualquer da deformação $\varepsilon$ & $\circ$ \\
\hline$\psi$ & ângulo entre a reta normal à superfície da peça & $\circ$ \\
\hline$\rho_{1}$ & ângulo complementar da câmera $\mathrm{O}_{1}$ & $\circ$ \\
\hline$\rho_{2}$ & ângulo complementar da câmera $\mathrm{O}_{2}$ & $\circ$ \\
\hline$\tau$ & Tensão de cisalhamento & $\mathrm{MPa}$ \\
\hline$v$ & coeficiente de Poisson & \\
\hline
\end{tabular}




\section{Sumário}

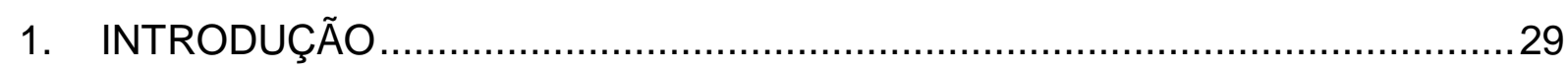

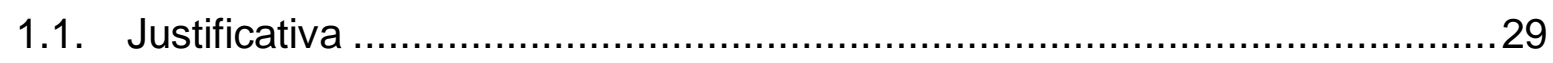

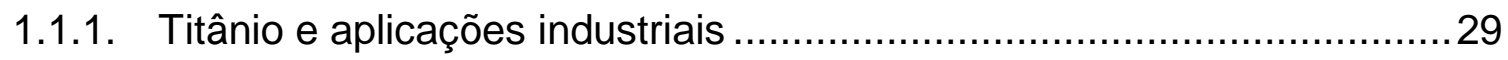

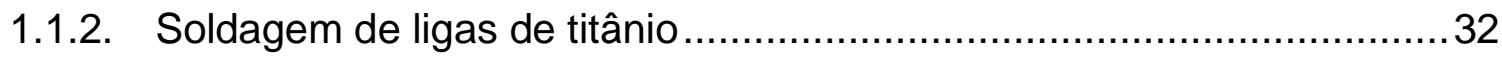

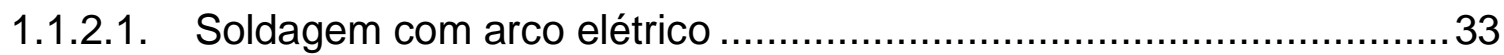

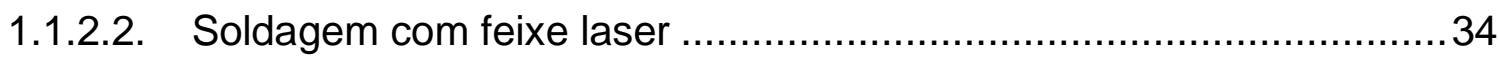

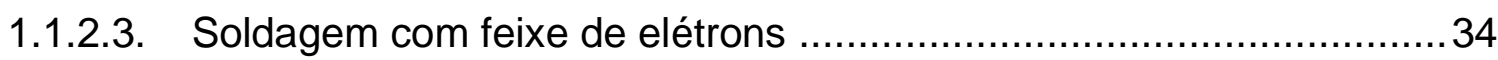

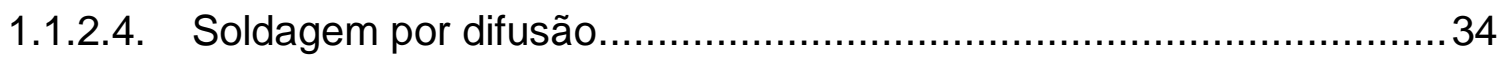

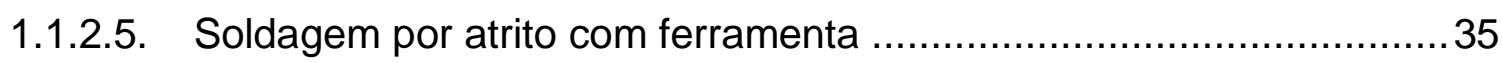

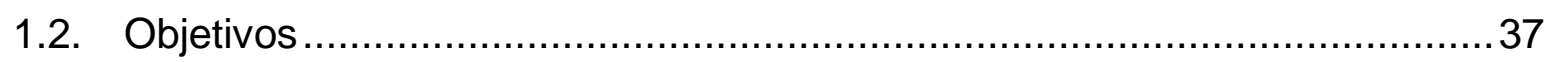

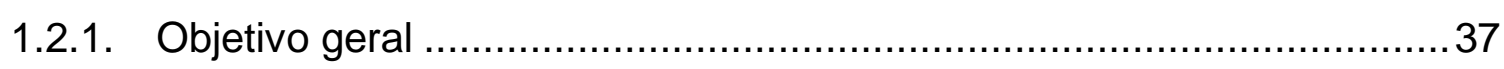

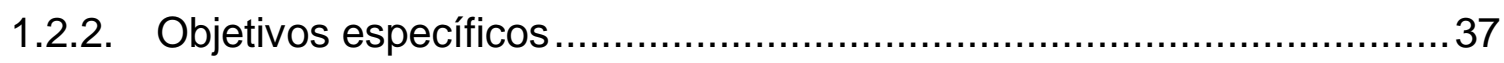

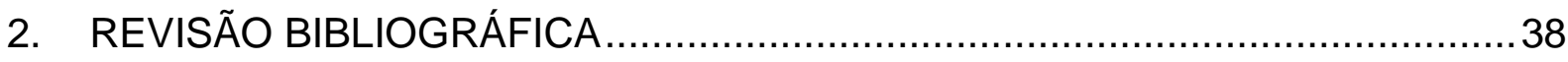

2.1. Revisão fundamental sobre o metal Titânio e suas ligas .............................38

2.1.1. Propriedades físicas do elemento titânio ............................................39

2.1.2. Solubilidade de elementos de liga no titânio ......................................39

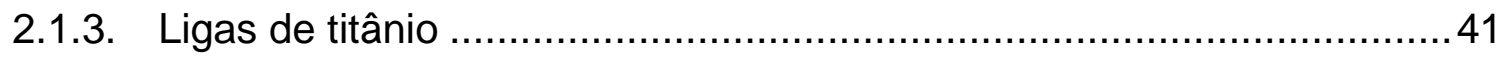

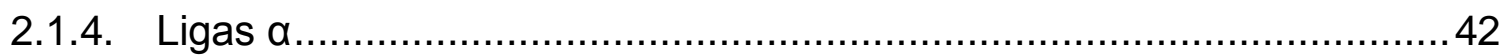

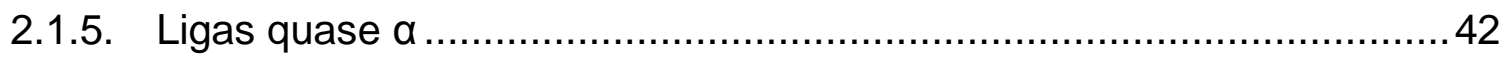

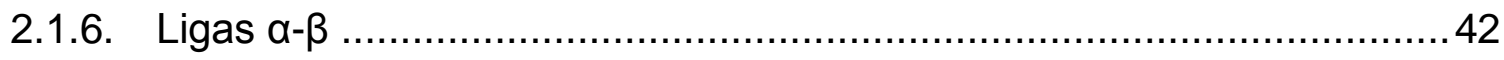

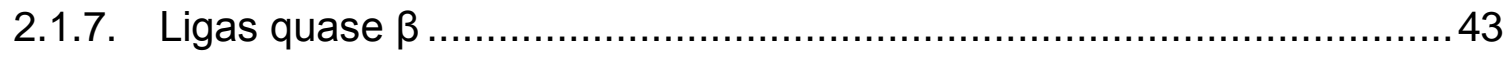

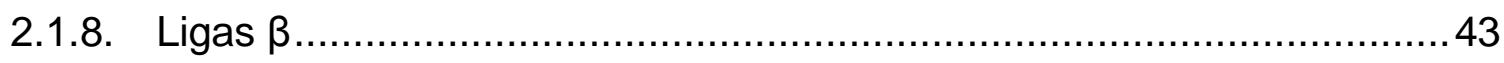

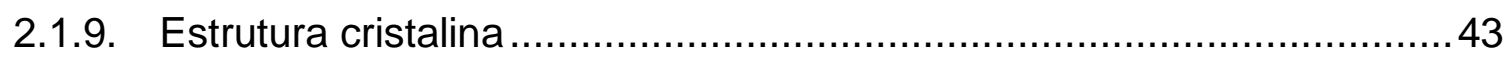

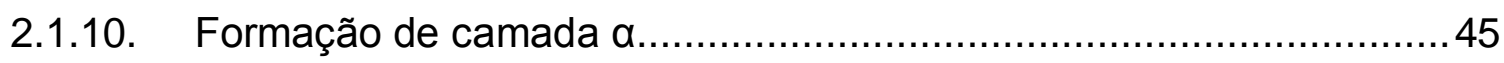

2.1.11. Energia livre de formação de óxidos.............................................. 48 
2.1.12. Diagrama de Pourbaix

2.1.13. Propriedades das ligas de titânio......................................................51

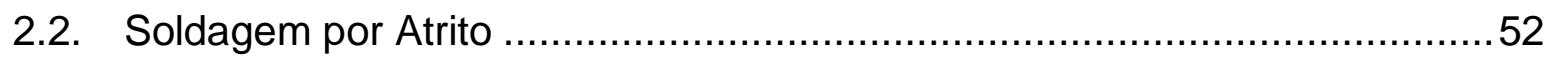

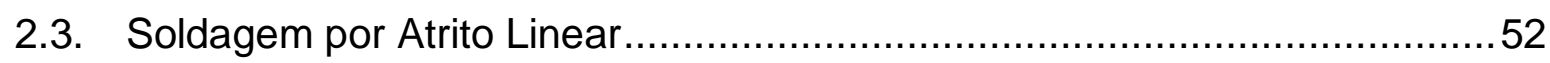

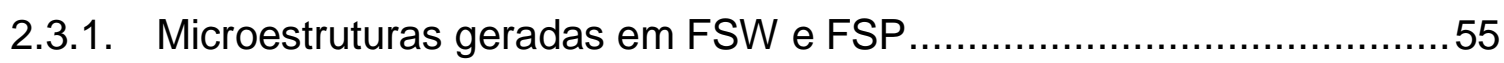

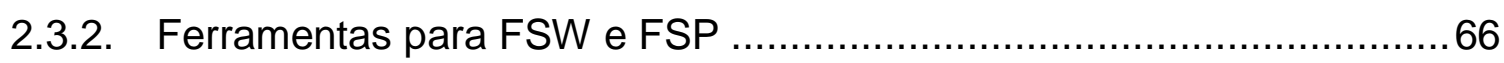

2.3.3. Materiais para fabricação de ferramentas de FSW/FSP para ligas de titânio 68

2.3.4. Parâmetros para o Processamento por Atrito Linear de titânio ..............70

2.3.5. Temperatura no processo de FSW e FSP ……............................... 74

2.4. Planejamento experimental fatorial ...................................................... 77

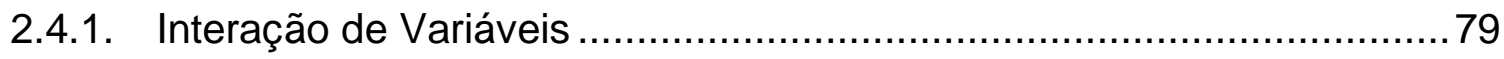

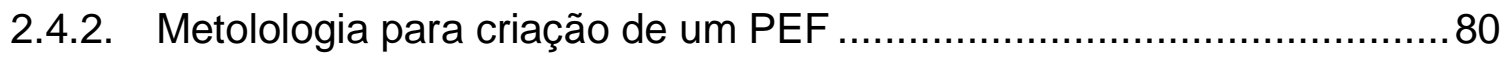

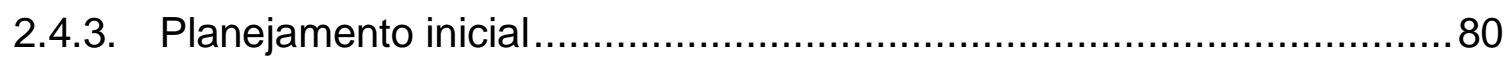

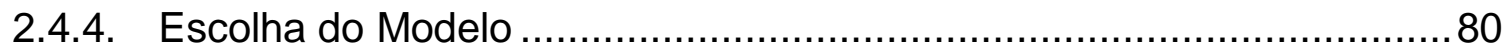

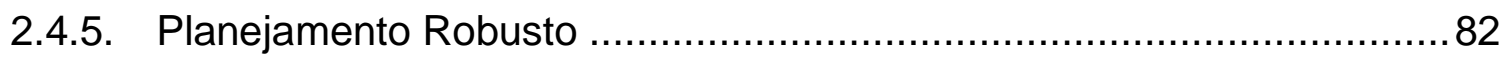

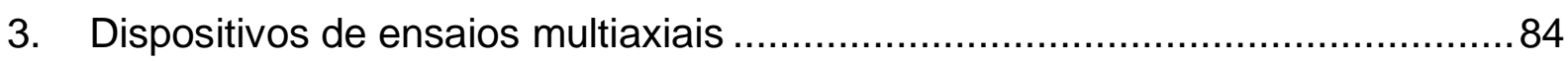

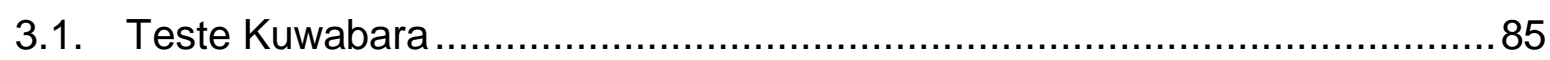

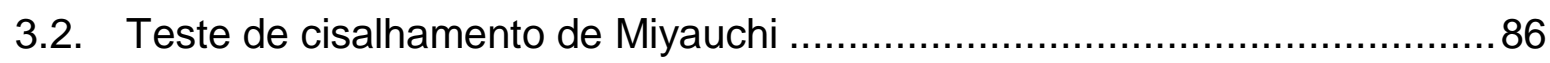

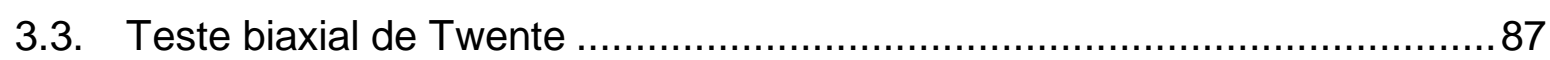

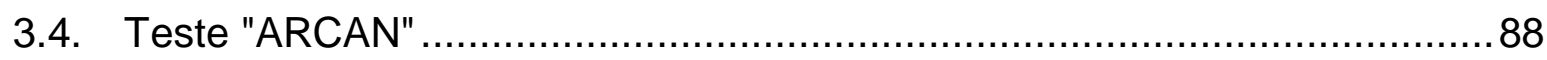

4. Correlação digital de imagens 3D .......................................................... 92

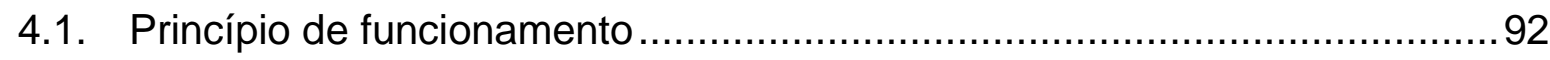

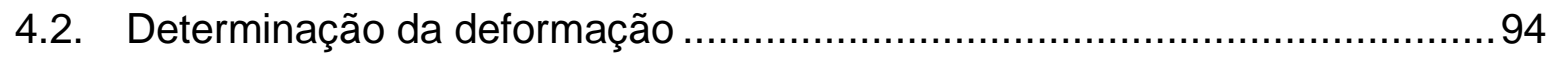

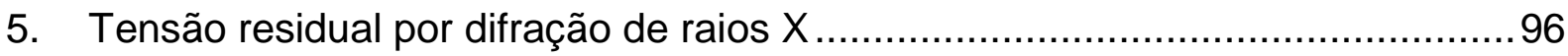

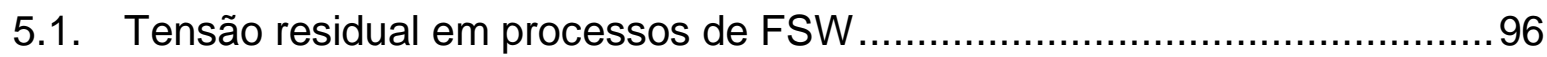

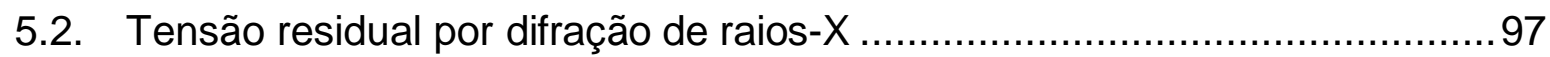




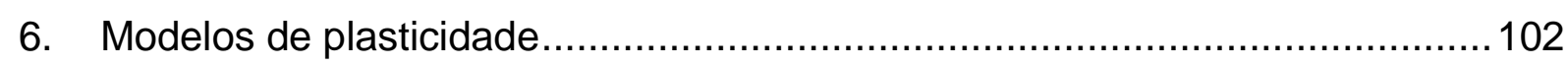

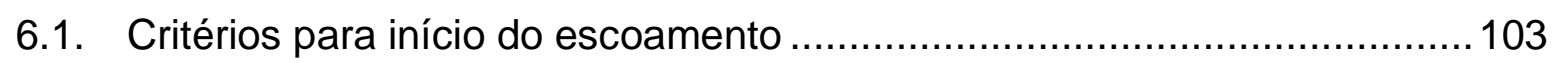

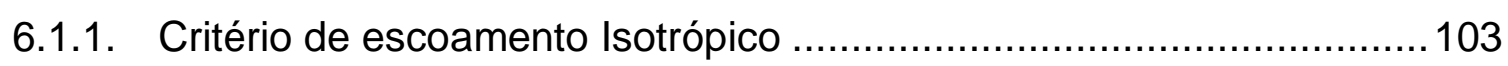

6.1.2. Critérios de escoamento Ortotrópico ..............................................105

6.2. Critério de escoamento ortotrópico para metais HCP e suas constantes de

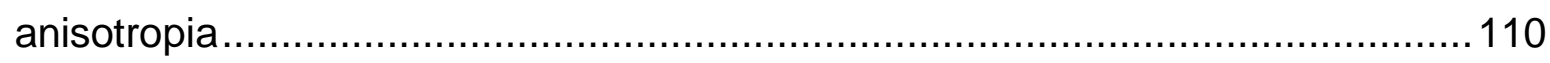

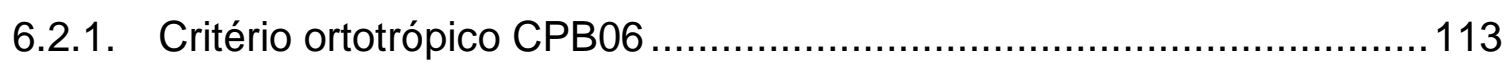

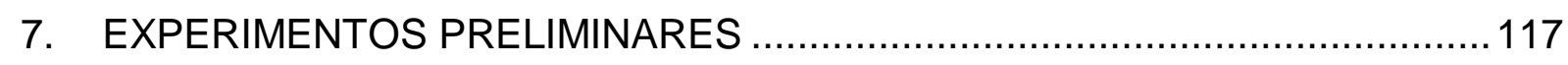

7.1. Materiais e métodos: Experimentos preliminares ….............................117

7.1.1. Parâmetros e condições variáveis ................................................117

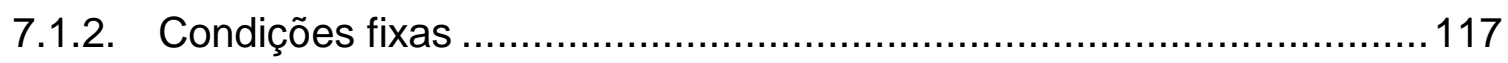

7.1.3. Resultados dependentes do experimento .......................................118

7.1.4. Corpos de prova para ensaio de FSP ..............................................118

7.1.5. Máquina utilizada no ensaio preliminar ........................................... 118

7.1.6. Construção do dispositivo de fixação............................................... 120

7.1.7. Ferramenta para o ensaio de preliminar .........................................122

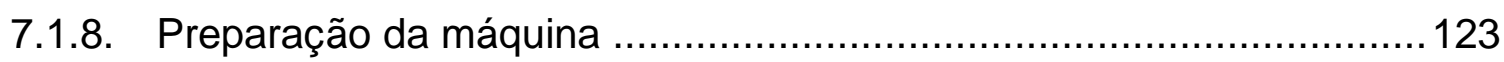

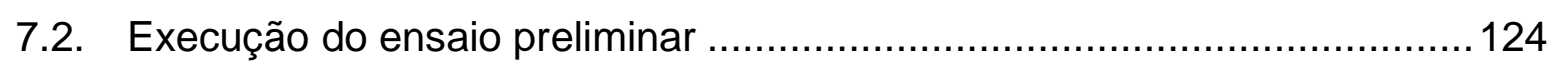

7.2.1. Avaliação do experimento preliminar ...............................................130

7.3. Readequação do Planejamento preliminar ..............................................133

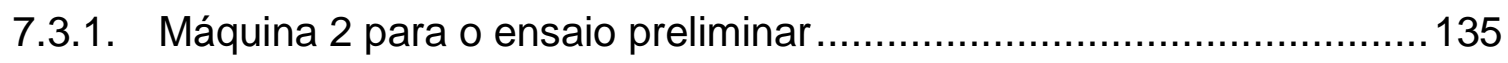

7.3.2. Ferramenta para o segundo ensaio de FSP ....................................136

7.4. Execução do segundo ensaio preliminar .............................................136

7.4.1. Avaliação preliminar do segundo ensaio............................................137

7.5. Medições em laboratório para o ensaio preliminar ...................................138

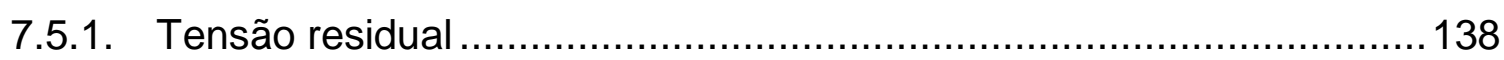

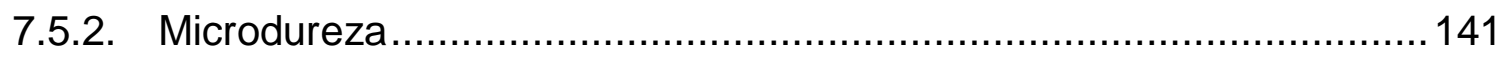


7.6. Teste com ferramenta de material alternativo WLa ................................142

7.7. Medição de esforços na ferramenta ...................................................145

7.8. Considerações sobre os ensaios preliminares ...................................... 146

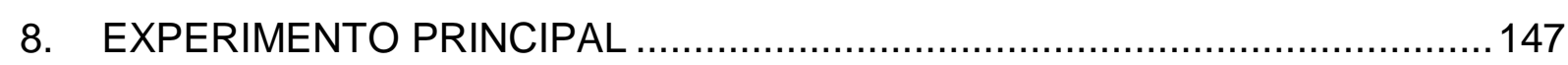

8.1. Planejamento previsto para os Experimentos ........................................ 147

8.2. Material e métodos para o ensaio principal ........................................... 148

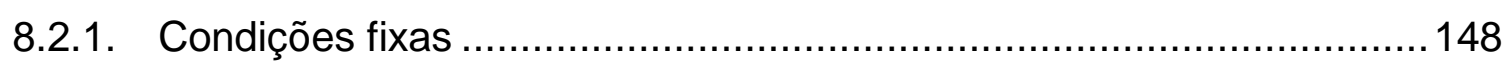

8.2.2. Resultados dependentes do experimento ......................................... 148

8.2.3. Corpos de prova para ensaio de FSP ........................................... 149

8.2.4. Preparação da máquina dispositivo e ferramenta ...............................149

8.3. Execução do processamento .......................................................... 151

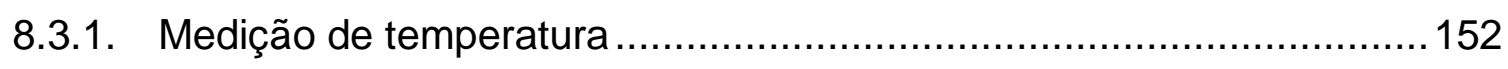

8.3.2. Avaliação das chapas processadas po FSP .................................... 154

8.4. Ensaio de solicitação multiaxial ARCAN ..............................................156

8.4.1. Garras para máquina de tração .................................................... 156

8.4.2. Corpos de prova para o ensaio de ARCAN .......................................157

8.4.3. Execução dos ensaios de tração ARCAN ......................................... 158

8.4.4. Pós-processamento das imagens digitais ......................................... 163

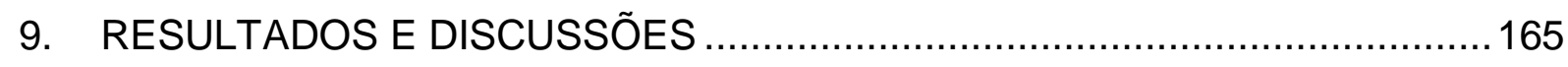

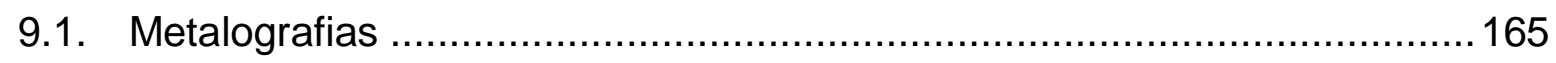

9.2. Microdureza no ensaio principal..................................................... 175

9.2.1. Microdureza na camada superficial ................................................ 181

9.3. Tensão residual no ensaio principal ................................................... 184

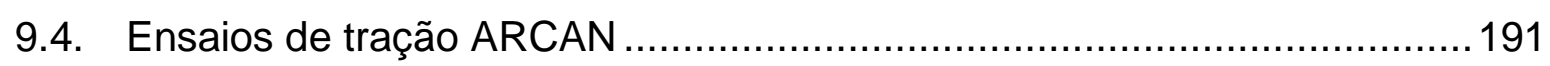

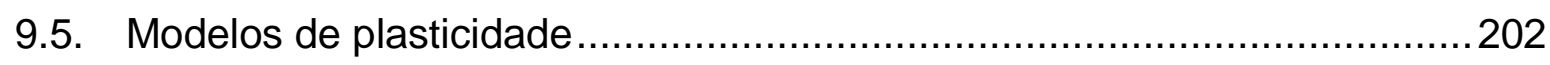

9.5.1. Proposição de um sistema de equações para condição mista .............202

9.5.1.1. Implementação do sistema de equações na condição mista ............205 


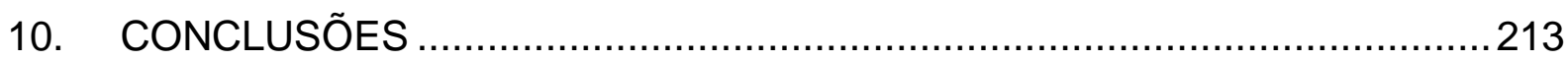

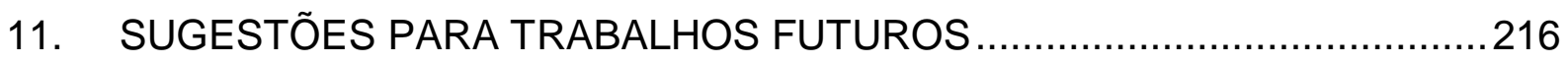

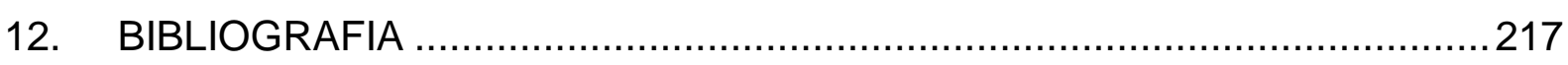

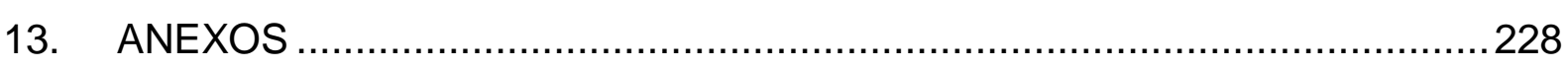

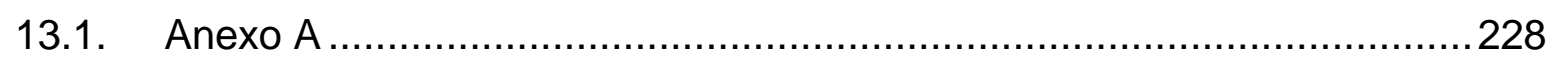

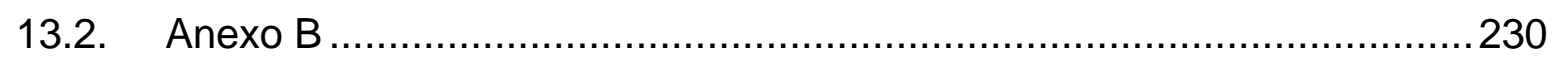

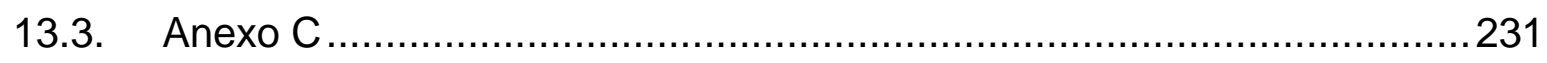

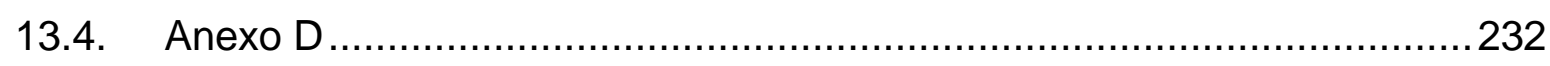

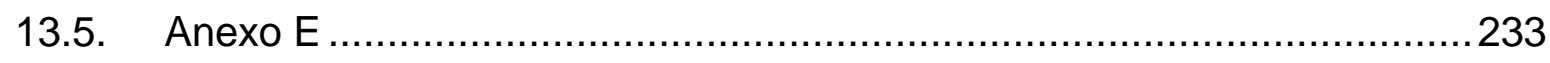

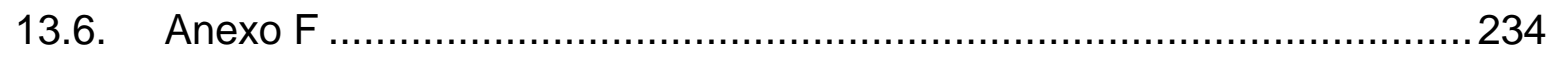

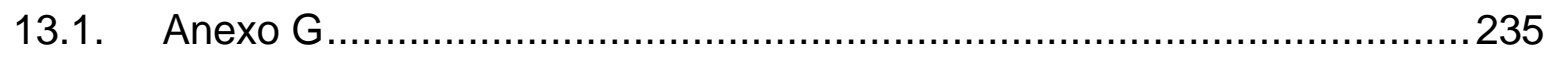

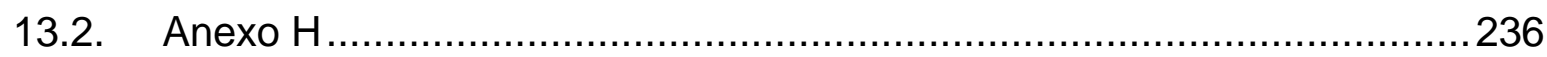

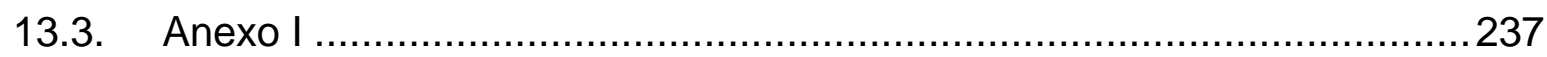

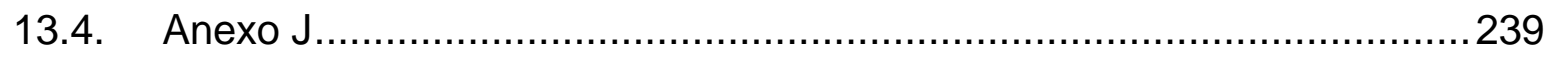

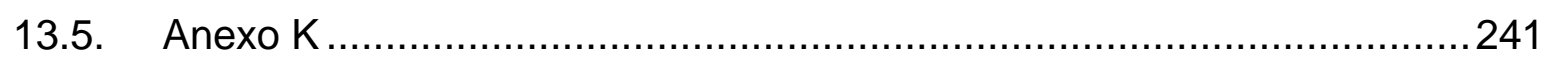

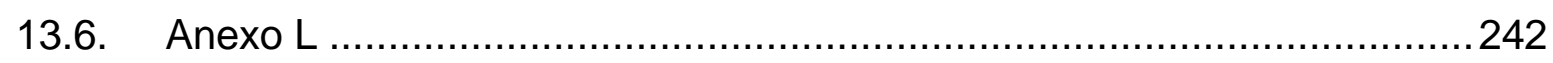

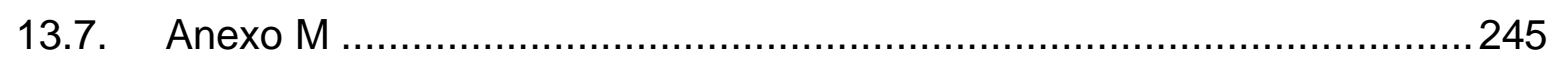




\section{INTRODUÇÃO}

Soldagem por Atrito Linear (FSW) do original Friction Stir Welding é um processo de união em estado sólido. Foi patenteada (Thomas et al, 1991) em 1991 pelo TWI (The Welding Institute) no Reino Unido, inicialmente para união de alumínio. Entre as vantagens mais relevantes do FSW estão: facilidade para automação, menor distorção, menores tensões residuais e boas propriedades mecânicas na região da junção (MISHRA; MA, 2005). FSW é uma abordagem recente para a junção de metais e apesar de inicialmente prevista para as ligas de alumínio, já é pesquisada em uma grande variedade de materiais, incluindo aços e polímeros. (MURR et al., 1997)

Um aspecto característico deste processo é a possibilidade do refinamento dos grãos na região processada (DING et al., 1994). Quando a união de materiais não é o alvo de estudo, mas sim a modificação de uma região do material, o melhor termo para sua definição passa a ser Processamento por Atrito Linear (FSP) do original Friction Stir Processing.

\subsection{Justificativa}

\subsubsection{Titânio e aplicações industriais}

O titânio é um metal que possui excelente resistência à corrosão, uma relação de resistência/peso elevada e boas propriedades para atuar em altas temperaturas. Titânio puro é um material alotrópico, com estrutura cristalina hexagonal compacta (fase $\alpha$ ) em baixas temperaturas e uma estrutura cristalina cúbica de corpo centrado (fase $\beta$ ) acima de $882^{\circ} \mathrm{C}$. As adições de elementos de liga provocam o efeito de endurecimento por solução sólida no titânio e alteram a temperatura de transformação alotrópica. A liga Ti-6Al-4V é um exemplo de sistema bifásico $(\alpha+\beta)$ e é a mais utilizada na indústria aeroespacial onde sua relação de resistência/peso elevada é uma grande vantagem para economia de combustível (CERVEIRA, 2008).

A Figura 1-1 apresenta uma turbina de avião onde a liga Ti-6Al-4V é bastante empregada em diversos componentes desde parafusos até suas pás. 


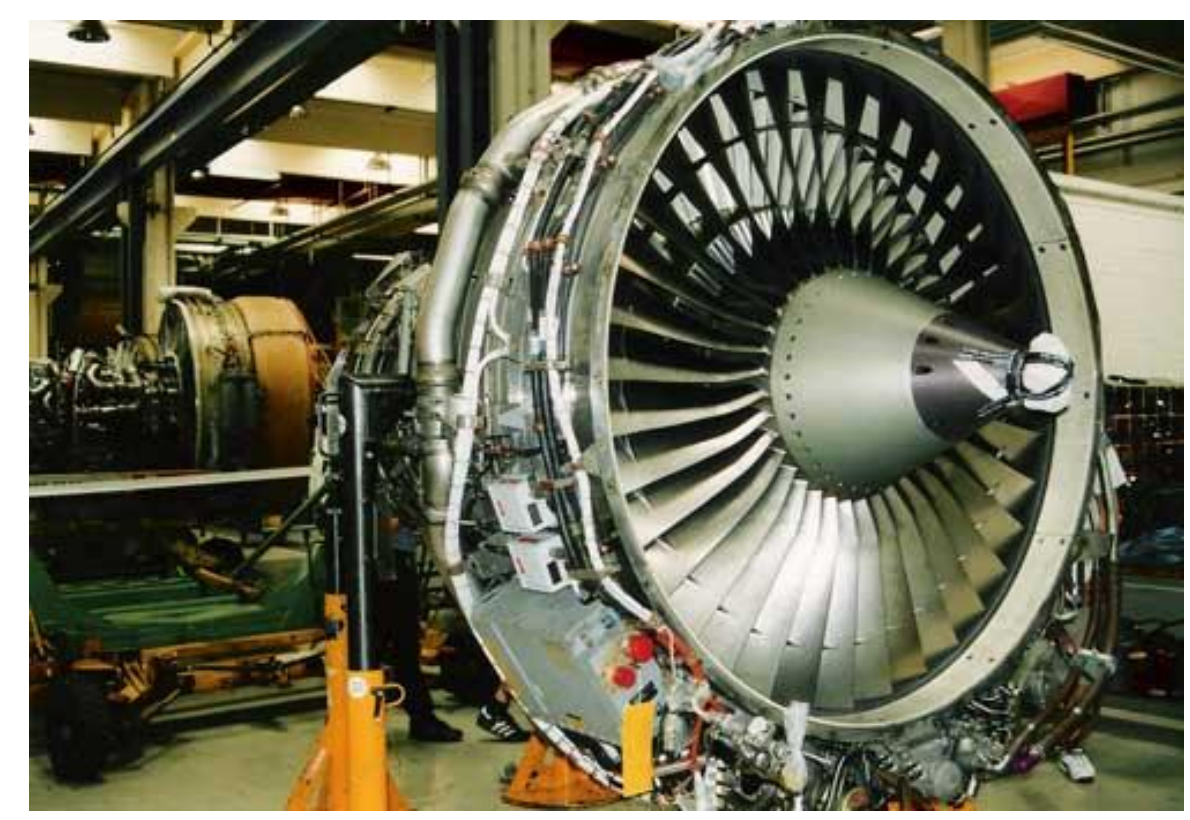

Figura 1-1 Turbina de avião (INTEREMPRESAS, 2015).

Segundo Donachie (Donachie, 2000) o titânio e suas ligas apresentam propriedades interessantes: baixa densidade (massa específica da ordem de 4,5 $\mathrm{g} / \mathrm{cm}^{3}$ ), boa resistência mecânica à tração (entre 200 e $1370 \mathrm{MPa}$, comparável à de muitos aços ligados) e resistência à corrosão garantida pela formação de uma camada passivada de $\mathrm{TiO}_{2}$. É um material com relativa abundância na natureza (é o nono metal mais abundante), geralmente sob a forma de minerais oxidados. Seu número atômico é 22 , e sua massa atômica é $47,88 \mathrm{~g} / \mathrm{mol}$. O ponto de fusão do titânio puro é $1724^{\circ} \mathrm{C}$, portanto superior ao do ferro (cerca de $1520^{\circ} \mathrm{C}$ ) e muito superior ao do alumínio $\left(660^{\circ} \mathrm{C}\right)$. Sua condutividade térmica é baixa, pois corresponde a apenas $93 \%$ da condutividade térmica do aço inoxidável e a 12,5\% da condutividade térmica do alumínio (LEYENS e PETERS, 2003).

Além da industria aeronáutica existem outras aplicações para o titânio, como por exemplo na industria de motocicletas de alto desempenho ou para competições esportivas (COLOMBO, 2015). A Figura 1-2 apresenta a motocicleta da Ducati 998 onde além do quadro, diversos componentes do motor são fabricados em ligas de titânio. 


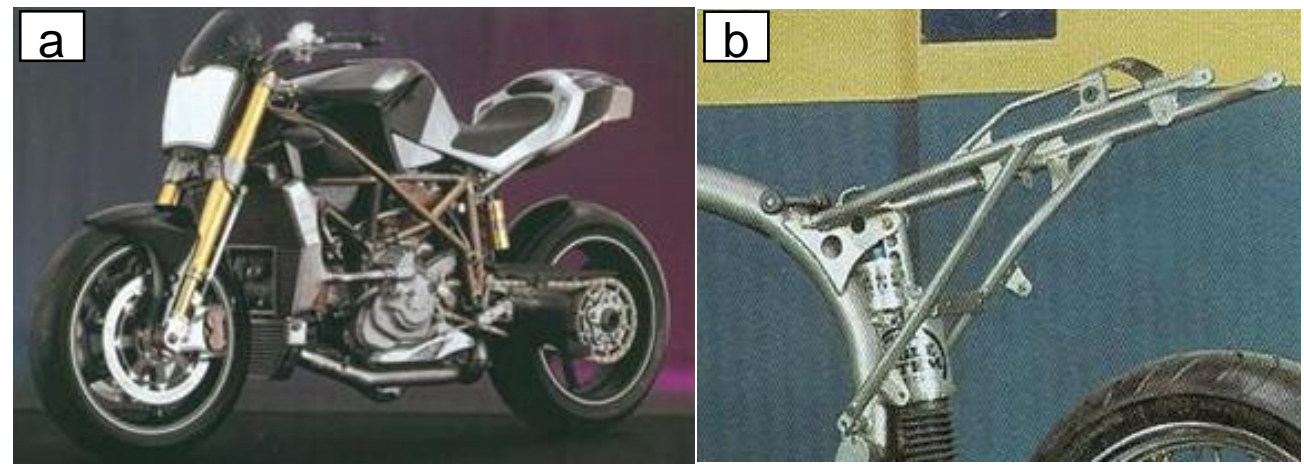

Figura 1-2 - (a) Motocicleta da Ducati 998, (b) detalhe do quadro de fixação do banco de uma motocicleta feito em liga de titânio grau 9 (COLOMBO, 2015)

Ainda no segmento esportivo, os fabricantes de bicicletas para competição encontraram nas ligas de titânio o equilíbrio entre resistência e baixo peso, especialmente na construção dos quadros, como a bicicleta da Figura 1-3.

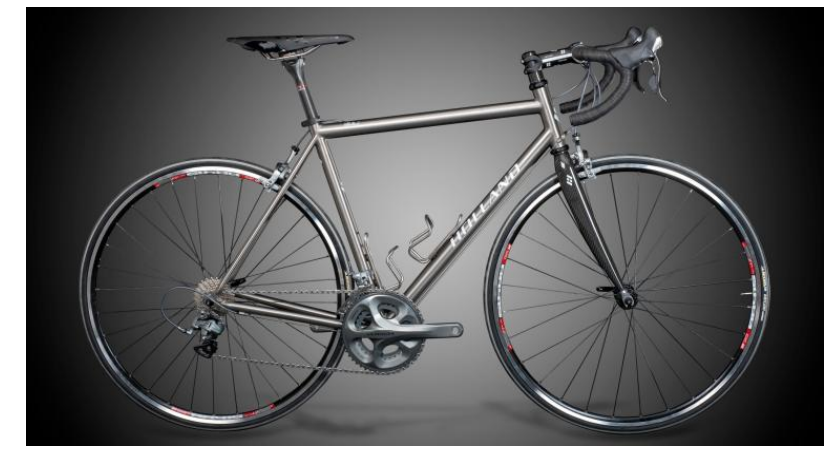

Figura 1-3 Bicicleta de competição feita de titânio (FAIRWHEELBIKES, 2015)

Além de todas as características listadas acima que fazem do titânio um material excepcional, ele exibe ainda uma grande vantagem no uso medicinal: Ser totalmente biocompatível.

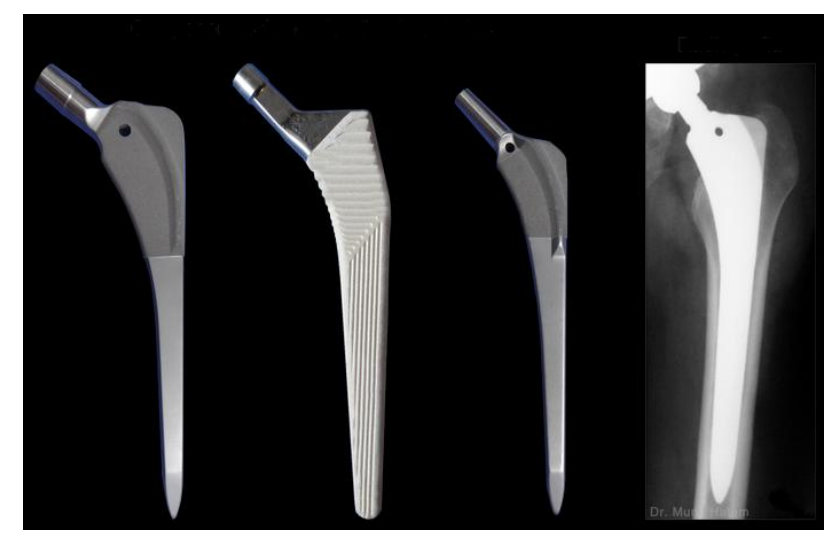

Figura 1-4 - Implante femoral feito em liga de titânio (QUADRILCIRURGIA, 2015) 
O titânio é um dos poucos materiais que são inertes à corrosão por todos os líquidos e tecidos do corpo, uma das grandes exigências para a implantação no corpo humano. São algumas das suas aplicações medicinais: Ortopédico: próteses para joelho, quadril (Figura 1-4), maxilo-facial e crânio (Figura 1-5); Ortodôntico: implantes dentais (Figura 1-6- "raiz de titânio") onde um parafuso de titânio é introduzido no osso da maxila para a osseointegração, a estrutura do dente é construída então no implante para dar uma recolocação eficaz (LEYENS e PETERS, 2003).

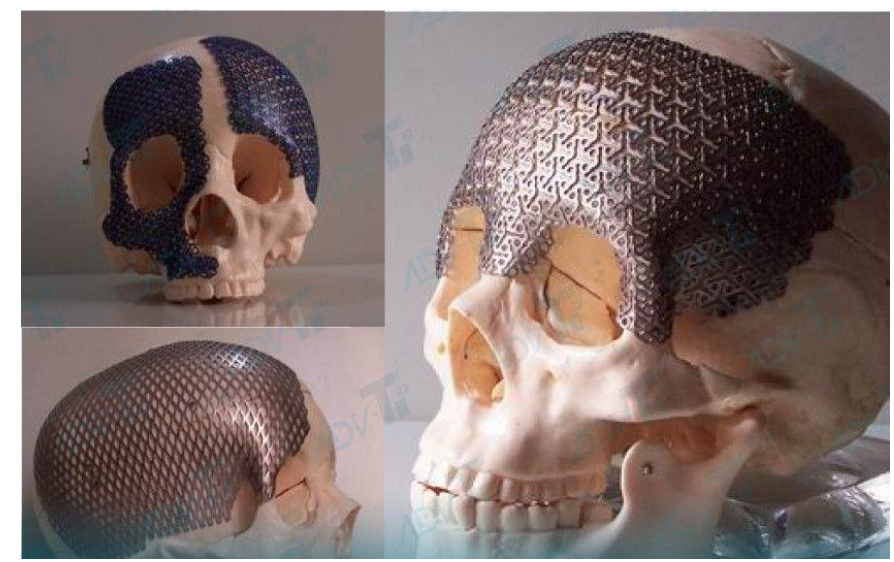

Figura 1-5 - Implante de crânio e face feito em liga de titânio (ADV-TI, 2015)

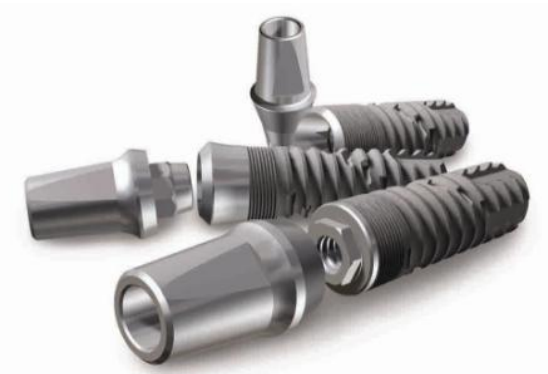

Figura 1-6 - Implante de parafuso de titânio para maxila (GORDANA, 2015)

\subsubsection{Soldagem de ligas de titânio}

No trabalho com ligas de titânio em geral e especificamente na indústria aeronáutica, a natureza dos processos de soldagem estão imersas num cenário de poucas unidades de produção, necessidade de extrema confiabilidade em condições severas e elevado custo unitário. Em geral, a soldagem de ligas de titânio requer processos com fontes de calor mais concentradas, como soldagem com arcoplasma, laser e feixe de elétrons. 


\subsubsection{Soldagem com arco elétrico}

Nos processos de soldagem com arco elétrico a união do material é efetuada pelo calor gerado por um arco elétrico, gerado entre um eletrodo e as peças. $O$ eletrodo é protegido por uma capa através da qual um gás inerte (argônio, hélio ou $\mathrm{CO}_{2}$ ) é aplicado. O gás tem a função de tornar a região da solda protegida contra a oxidação, melhorar o controle e qualidade da solda. Existem três tipos de soldagem a arco mais empregados (HEDLUND, 2005):

- Soldagem a arco com eletrodo de tungstênio (GTAW ou TIG) é o processo mais usado para o titânio e suas ligas. Um arco elétrico entre o eletrodo de tungstênio e o material cria a fusão na região da solda, enquanto um gás inerte protege o eletrodo de tungstênio e a poça do metal fundido contra oxidação. Além da proteção, o gás inerte pode ajudar a aumentar a penetração ou a velocidade. As soldas podem ser executadas sem a adição de outros materiais ou com a adição de um fio denominado de material consumível.

- O processo de soldagem a arco com fio contínuo (GMAW ou MIG) não é tão aplicado em titânio como em metais ferrosos e outras ligas não ferrosas. No processo MIG um arco elétrico é gerado entre um eletrodo consumível continuamente alimentado e a peça de trabalho. A transferência do material atomizado ocorre acima de uma densidade crítica de corrente elétrica e requer a utilização corrente contínua com o eletrodo positivo. Este processo exige altas correntes e portanto altas velocidades de soldagem.

- A soldagem com arco plasma (PAW) produz um arco estreito entre um eletrodo não consumível e a poça de fusão. Além do gás de proteção, existe o gás gerador do plasma que ao passar pelo orifício injetor se ioniza produzindo a característica do jato de plasma ionizado. Se a intensidade calor no plasma é alta o suficiente, então esse processo pode operar em um regime semelhante a soldagem a laser ou da soldagem por feixe de elétrons, com uma grande penetração. 


\subsubsection{Soldagem com feixe laser}

A solda com feixe laser produz uma fonte de calor extremamente concentrada na região da soldagem, trazendo vantagens como maior precisão de posicionamento, controle da profundidade, qualidade da solda e menores distorções nas peças. Este processo é considerado como ideal para soldagem de componentes de motores a jato feitos de ligas resistentes ao calor. Este processo, juntamente com a soldagem por feixe de elétrons, são os que geram a menor distorção final nas peças soldadas (HEDLUND, 2005).

\subsubsection{Soldagem com feixe de elétrons}

Outro processo utilizado na industria aeronáutica é a soldagem por feixe de elétrons (EBW). O EBW gera pouca distorção no material soldado. Este processo tem uma vantagem sobre a soldagem a laser, por não haver problemas com a reflexão do feixe no metal fundido. Esta característica torna o processo particularmente útil para a soldagem de ligas de titânio que não podem ser soldadas numa atmosfera aberta. O EBW é um processo de soldagem por fusão através de um feixe de elétrons (alta energia) que aquecem a área a ser soldada. Os eletrons do feixe são elevados a um estado de alta energia, acelerados de $30 \%$ a $70 \%$ da velocidade da luz, o que produz energia térmica suficiente para soldar os metais e especialmente ligas de titânio (HEDLUND, 2005).

\subsubsection{Soldagem por difusão}

A soldagem por difusão é um processo que liga materiais por meio de aplicação simultânea de pressão e calor. Quando ocorre uma deformação plástica entre duas superfícies em contato por ação de calor, as camadas de átomos que compõem a estrutura cristalina do metal vibram e se movimentam em várias direções, ocupando lugares diferentes nos planos cristalinos. A essa movimentação dá-se o nome de difusão. O contato entre as superfícies provoca difusão dos átomos, que se movimentam pelo interior das superfícies, promovendo a ligação perfeita das partes (SHIRZADI, 1997, 2015). A operação pode ser feita no vácuo, sob proteção de gás ou fluido e, de preferência, sem material de adição. O processo 
por difusão é utilizado para unir materiais com composição química semelhante ou materiais dissimilares, predominantemente os metálicos, e foi desenvolvido originalmente para ser aplicado na construção de peças para a indústria aeronáutica e espacial. É aplicada preferencialmente nas situações em que a união por processos de soldagem convencionais não é possível.

\subsubsection{Soldagem por atrito com ferramenta}

Recentemente, os métodos de FSW em ligas de alta temperatura, incluindo aços, aços inoxidáveis, as ligas de titânio e ligas de níquel têm chamado cada vez mais a atenção da indústria aeroespacial, naval e petroquímica. No entanto, o desenvolvimento e implantação de tal tecnologia de união de materiais continuam como um desafio, pois o desenvolvimento de ferramentas acessíveis e confiáveis que suportem as condições térmicas e mecânicas impostas permanece como uma das barreiras que precisam ser superadas (MISHRA; MAHONEY, 2007).

Apesar das qualidades inicialmente observadas, para determinadas aplicações como conformação plástica, a análise das propriedades mecânicas resultantes de FSP é preponderante para correta aplicação do processo. Um exemplo é encontrado na Figura 1-7.
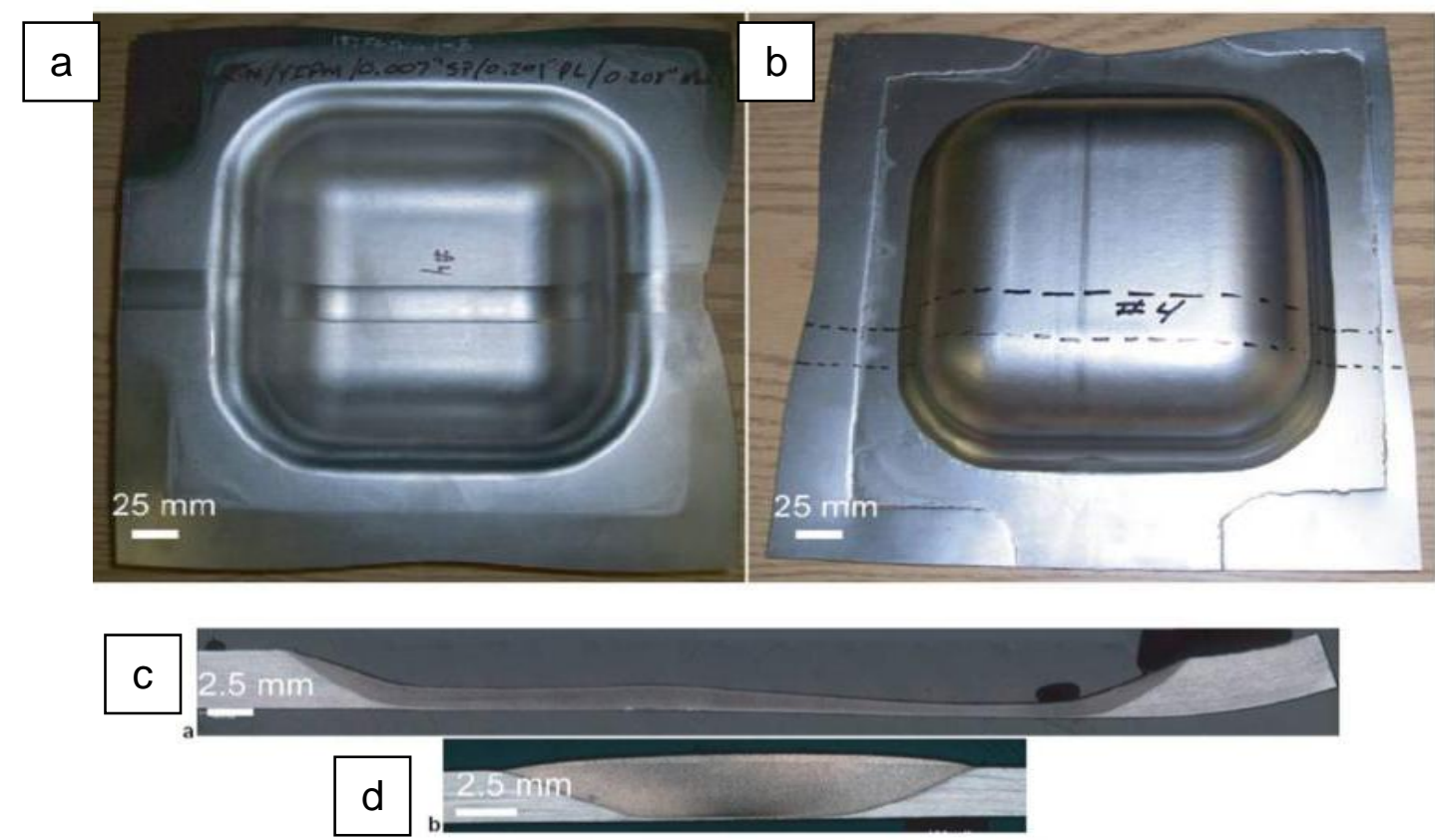

Figura 1-7 - Exemplo de sinergia entre o processo FSW e superplasticidade em ligas de titânio. (a)(c) A região processada possui maior plasticidade do que o material original, e em (b)(d) exemplo de região processada com menor plasticidade do que o material original (EDWARDS e RAMULU, 2009). 
Na Figura 1-7, se observa a diferença entre o material original e uma região que sofreu um FSP. Em (a) e (c) a região processada possui maior plasticidade do que o material original, em (b) e (d) a região processada possui menor plasticidade do que o material original (EDWARDS e RAMULU, 2009).

Os parâmetros no processamento por FSP ou FSW irão influenciar fortemente o processamento posterior nos materiais resultantes. A Figura 1-8 apresenta um diagrama simples para questionamento das propriedades envolvidas no processo de FSW e FSP. Para chegar ao resultado final onde as características deverão ser semelhantes, deve-se conhecer e controlar os parâmetros envolvidos no processo.

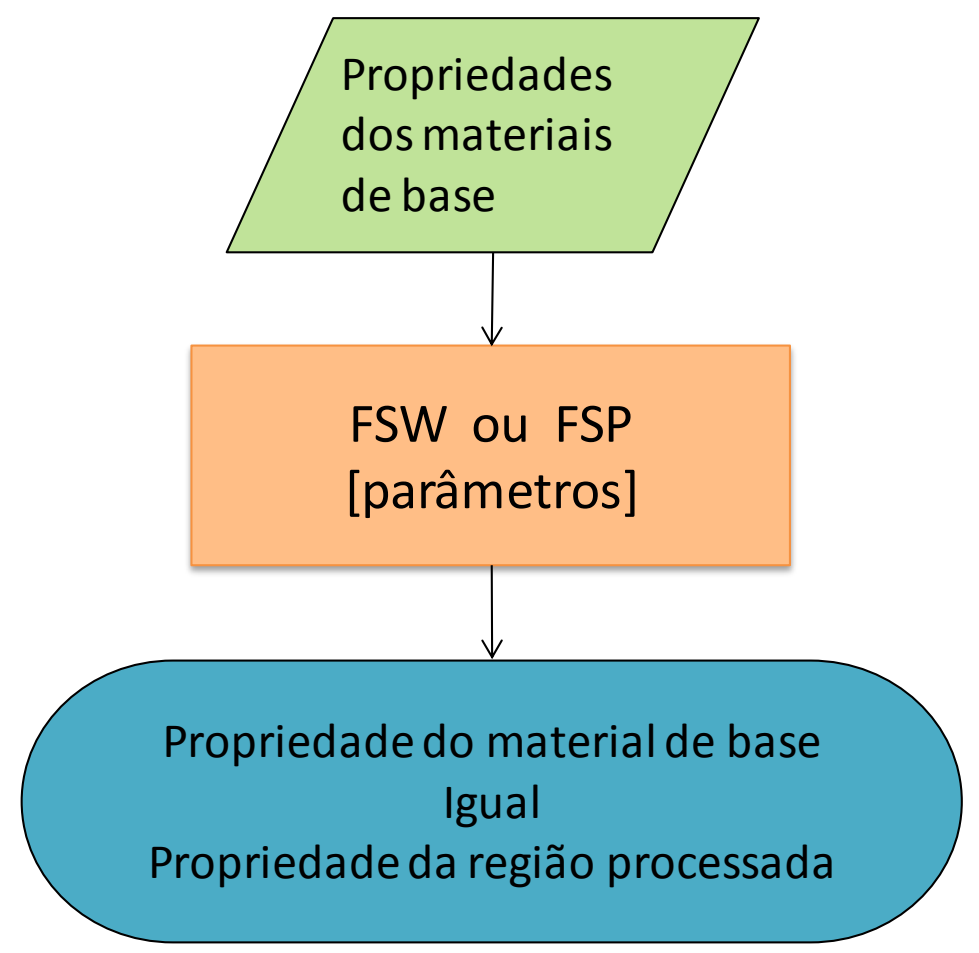

Figura 1-8 - Diagrama simples de questionamento.

Onde o ideal, se o material possuir fases posteriores de conformação, é a obtenção de uma região processada ou soldada que possua preferencialmente as mesmas propriedades do material de base. E propriedades diferentes na região processada, para casos onde é necessária um aumento ou diminuição de resistência em uma determinada parte da peça. 


\subsection{Objetivos}

Esta tese tem por objetivo estudar os parâmetros fixos e variáveis envolvidos no processo de FSP. Como parâmetros fixos serão avaliados a máquina, geometria de ferramenta e material de ferramenta. Como parâmetros variáveis serão avaliados a rotação e avanço linear da ferramenta.

\subsubsection{Objetivo geral}

Modelar uma lei comportamental que leve em conta os resultados dos ensaios mecânicos multiaxiais, dependentes dos parâmetros variáveis envolvidos no processo de processamento por atrito linear da liga de titânio Ti-6Al-4V.

\subsubsection{Objetivos específicos}

- Execução de ensaios de FSP em corpos de prova da liga Ti-6Al-4V;

- Ensaios de tração mistos para avaliação do processamento por atrito linear na liga Ti-6Al-4V;

- Avaliação da microestrutura resultante do processamento por atrito linear;

- Avaliação das propriedades mecânicas resultantes do processamento por atrito linear;

- Levantamento da condição de tensão residual nos corpos de provas; 


\section{REVISÃO BIBLIOGRÁFICA}

\subsection{Revisão fundamental sobre o metal Titânio e suas ligas}

Em 1791 o reverendo britânico William Gregor, mineralogista e químico descobriu o titânio. Examinando as propriedades magnéticas da areia do rio local chamado Helford no vale Menachan em Cornwall, Inglaterra, ele isolou a "areia preta" mineral atualmente conhecido como ilmenita $\left(\mathrm{FeTiO}_{3}\right)$. Ao remover o ferro através de um processo magnético e tratar a areia com ácido hidroclorídrico, ele produziu o óxido impuro de um elemento inicialmente chamado de "Mechanite". (LEYENS e PETERS, 2003) (JOSHI, 2006).

Quatro anos mais tarde, o químico Martin Heinrich Klaproth isolou independentemente o óxido de titânio a partir de um mineral húngaro, conhecido atualmente como rutilo $\left(\mathrm{TiO}_{2}\right)$. O nome titânio vem da mitologia grega, da história dos filhos de Uranos e Gaia, os titãs. Os titãs eram odiados por seu pai, assim foram aprisionados na crosta terrestre para não serem libertados facilmente. Semelhante à dificuldade de se extrair tal elemento do minério encontrado, o químico Martin Heinrich Klaproth o nomeou de titânio (LEYENS e PETERS, 2003) (JOSHI, 2006).

Em 1910 o pesquisador Matthew Albert Hunter do instituto Politécnico de Rensselaer, em Troy, Nova lorque, EUA, foi capaz de isolar o metal titânio por aquecimento do tetracloreto de titânio $\left(\mathrm{TiCl}_{4}\right)$ com sódio em uma caldeira de aço. Porém, somente em 1932 Wilhelm Justin Kroll na cidade de Luxemburgo passou a ser reconhecido como pai da indústria de titânio, por ter produzido quantidades significativas de titânio, combinando $\mathrm{TiCl}_{4}$ com cálcio. O processo é conhecido como Kroll e é empregado até hoje (LEYENS e PETERS, 2003).

O elemento titânio não é uma substância rara, está classificada como o nono elemento mais abundante e quarto metal estrutural mais abundante da crosta terrestre, ultrapassado apenas pelo alumínio, ferro e o magnésio. Raramente é encontrado em altas concentrações e nunca encontrado em um estado puro. Assim, devido à dificuldade de seu processamento a partir dos minérios ilmenita $\left(\mathrm{FeTiO}_{3}\right)$ e rutilo $\left(\mathrm{TiO}_{2}\right)$, seu custo final é alto (JOSHI, 2006). 


\subsubsection{Propriedades físicas do elemento titânio}

As duas estruturas cristalinas do titânio são comumente conhecidas como fase alfa $(\alpha)$ e fase beta $(\beta)$. A fase a se refere a uma disposição estrutural cristalina hexagonal compacta, puro ou em liga, enquanto a fase $\beta$ indica uma disposição estrutural cristalina cúbica de corpo centrado, puro ou em liga.

No titânio puro a fase $\beta$ ocorre em temperaturas altas, sendo estável entre $882^{\circ} \mathrm{C}$ e seu ponto de fusão a $1668^{\circ} \mathrm{C}$. A fase a do titânio puro é estável em temperaturas abaixo de $882^{\circ} \mathrm{C}$ (DONACHIE JR., 2000).

O titânio é um dos metais de transição da tabela periódica. A Tabela 2-1 resume algumas propriedades físicas importantes para o titânio com alto índice de pureza (também conhecido como titânio comercialmente puro).

Tabela 2-1 - Propriedades do titânio policristalino na fase $\alpha$ com alto índice de pureza (>99.9\%) entre 20 e $25^{\circ} \mathrm{C}$. (JOSHI, 2006) (LEYENS e PETERS, 2003)

\begin{tabular}{lcc}
\hline \multicolumn{1}{c}{ Característica } & Valor & Unidade \\
\hline Número atômico & 22 & \\
Peso atômico & 47,867 & $\mathrm{~g} / \mathrm{mol}$ \\
Temperatura de fusão & 1668 & ${ }^{\circ} \mathrm{C}$ \\
Temperatura de transição $\alpha-\beta$ & 882 & ${ }^{\circ} \mathrm{C}$ \\
Coeficiente de dilatação térmica & $8,36 \times 10^{-6}$ & $\mathrm{~K}^{-1}$ \\
Condutividade térmica & 14,99 & $\mathrm{~W} / \mathrm{mK}$ \\
Calor específico & 523 & $\mathrm{~J} / \mathrm{kgK}$ \\
Resistividade elétrica & $564,9 \times 10^{-9}$ & $\Omega \mathrm{m}$ \\
Coeficiente de Poisson & 0,33 & \\
Massa específica & $4,54 \times 10^{3}$ & $\mathrm{~kg} / \mathrm{m}^{3}$ \\
\hline
\end{tabular}

\subsubsection{Solubilidade de elementos de liga no titânio}

O elemento titânio permite a formação de soluções sólidas com a maioria dos elementos de liga que possuam um fator de tamanho dentro de $\pm 20 \%$. Elementos como carbono, oxigênio, boro, nitrogênio e hidrogênio formam estruturas intersticiais devido à grande diferença de tamanho dos seus átomos para o átomo de titânio.

Uma classificação geral é apresentada por Kornilov (1970 apud JOSHI, 2006) para alguns elementos da tabela periódica em quatro grandes grupos, dependendo de sua interação com titânio:

- Grupo 1 - Formação de solução sólida contínua com titânio a ou ß: zircônio e háfnio possuem uma configuração eletrônica idêntica à do titânio. A estrutura 
é, portanto, isomórfica ao titânio. Assim, os diagramas de fase com esses elementos mostram soluções sólidas contínuas em fases $\alpha$ e $\beta$. Vanádio, nióbio, tântalo e molibdênio são isomorfos ao titânio na fase $\beta$ e formam uma solução sólida contínua neste caso. Estes elementos possuem solubilidade limitada na fase $\alpha$.

- Grupo 2 - Formação limitada de solução sólida com titânio $\alpha$ ou $\beta$ : manganês cromo, ferro, cobalto, níquel e cobre sofrem transformação eutetóide (uma fase sólida se transforma em duas fases sólidas) e abaixam a temperatura de transição $\alpha-\beta$. Alumínio, gálio, e índio apresentam uma reação peritectóide (duas fases sólidas se combinam em uma fase sólida) e aumentam a temperatura de transição $\alpha-\beta$. Maior solubilidade na fase $\alpha$.

- Grupo 3 - Formação iônica e covalente de elementos: Flúor, cloro, bromo, iodo, enxofre, selênio, telúrio e fósforo formam compostos iônicos e covalentes com titânio. Eles não entram em solução sólida na fase $\alpha$ ou $\beta$.

- Grupo 4 - Elementos que não interagem com o titânio: Exceto berílio, que possui solubilidade limitada na fase $\beta$, nenhum metal alcalino-terroso ou alcalino interage com titânio.

A Tabela 2-2 apresenta de forma sucinta os elementos estabilizadores (Grupos1 e 2) das fases $\alpha$ e $\beta$ e também os elementos neutros (Grupo 4).

Tabela 2-2 - Tabela periódica de elementos estabilizadores da fase a e $\beta$ (adaptado de JOSHI, 2006).

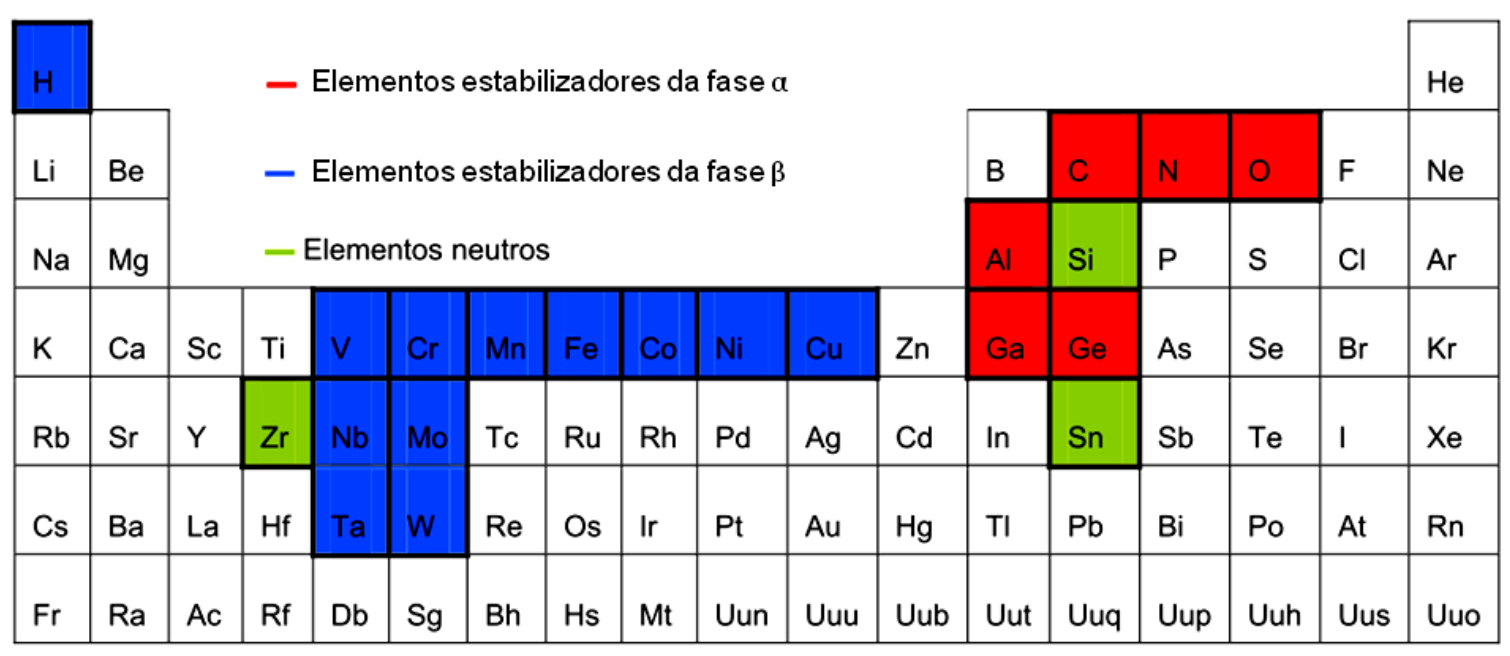




\subsubsection{Ligas de titânio}

Vários elementos que formam solução sólida com titânio são classificados com base em seu efeito sobre a solubilidade nas fases $\alpha$ ou $\beta$. Elementos que estabilizam a fase a são conhecidos como estabilizadores $\alpha(\mathrm{Al}, \mathrm{Ga}, \mathrm{O}, \mathrm{N}, \mathrm{C})$, e elementos de estabilização da fase $\beta$ são conhecidos como estabilizadores $\beta$ ( $\mathrm{V}, \mathrm{Mo}, \mathrm{Nb}, \mathrm{Fe}, \mathrm{Cr}$, $\mathrm{Ni)}$. Alguns dos elementos como Sn e Zr são neutros, pois eles não estabilizam nem a fase $\alpha$ ou $\beta$, eles somente entram em solução sólida com titânio. O alumínio é o único estabilizador $\alpha$ de importância comercial, e é encontrado na maioria das ligas comerciais de titânio (JOSHI, 2006). O teor de alumínio em ligas de titânio comercial é normalmente restrito entre $7 \%$ a $9 \%$ para evitar a precipitação da fase intermetálica $\mathrm{Ti}_{3} \mathrm{Al}$ (alumineto de titânio), o que leva a uma condição de fragilização.

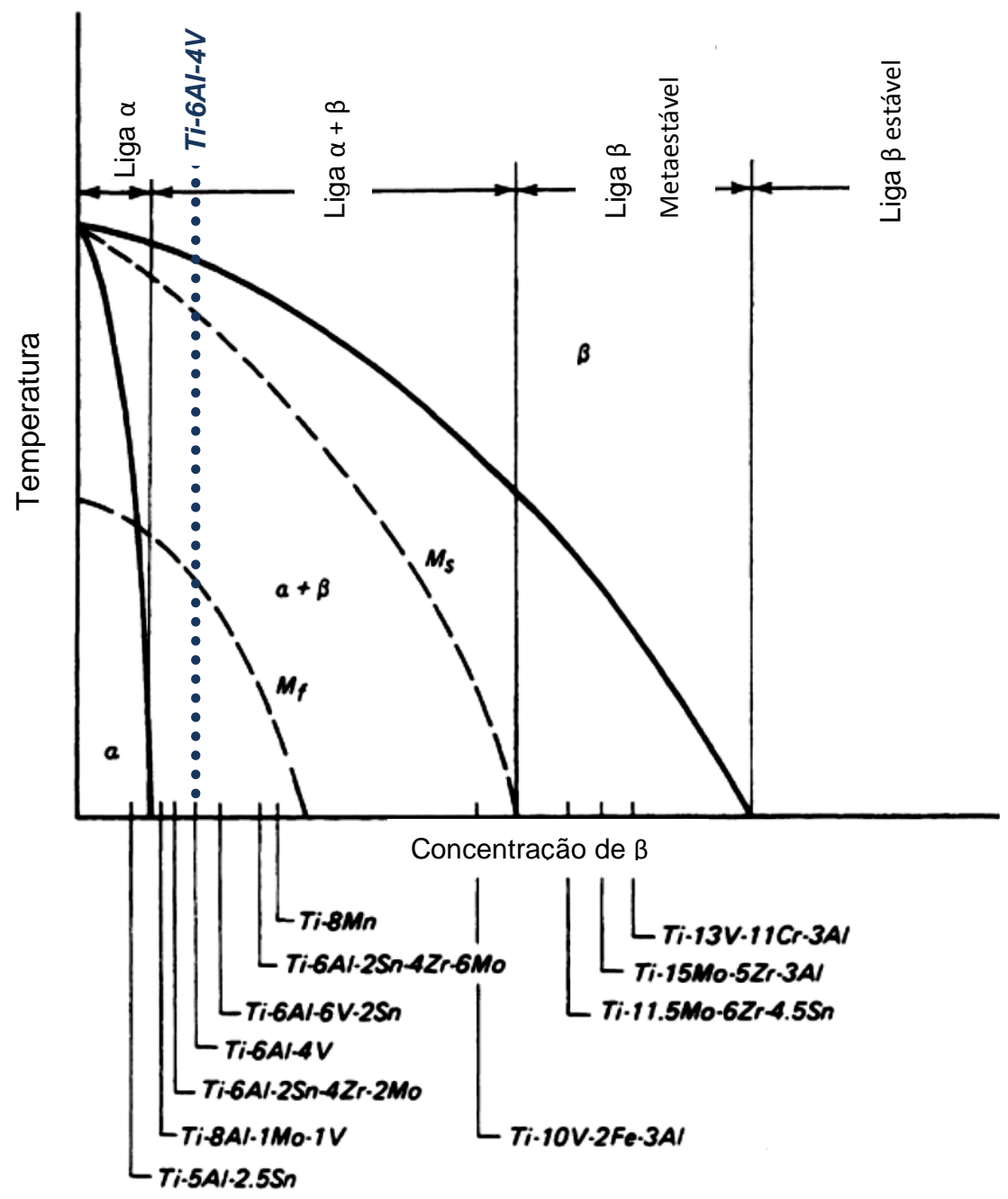

Figura 2-1 - Ligas de titânio no diagrama de fases CCT (DONACHIE JR., 2000). 
As relações de fase nos sistemas das ligas de titânio podem ser representadas por diagramas CCT. A Figura 2-1 mostra as composições de algumas ligas comerciais dispostas em um diagrama de fases CCT, onde o eixo da abscissa representa a composição de estabilizador $\beta$ na liga, as curvas tracejadas indicam a região de início de formação martensitica $\left(M_{s}\right)$ e final de formação martensitica $\left(M_{f}\right)$ e as curvas contínuas indicam o limite de região de fase $\alpha$, fase $\alpha+\beta$ e região de fase $\beta$.

As fases $\alpha$ e $\beta$ são a base para as quatro classes de ligas de titânio geralmente aceitas: ligas $\alpha$, quase- $\alpha, \alpha-\beta$ e ligas $\beta$ (nesta última classe estão inclusas a condições $\beta$ estável e $\beta$ metaestável) (DONACHIE JR., 2000). Abaixo são apresentadas as principais características das quatros ligas em questão.

\subsubsection{Ligas $\alpha$}

Estas ligas são monofásicas, compostas de uma solução sólida reforçada pela adição de estabilizadores a ou elementos neutros de liga. As ligas a possuem boa estabilidade e boas propriedades em altas temperaturas, mas não são passíveis de tratamento térmico para modificações de propriedades microestruturais.

\subsubsection{Ligas quase $\alpha$}

Pequenas adições de $1 \%$ a $2 \%$ de estabilizadores $\beta$ melhoram as propriedades como resistência e conformabilidade (DONACHIE JR., 2000), garantindo uma boa relação entre a maior resistência de ligas $\alpha+\beta$ e a resistência à fluência das ligas $\alpha$. As ligas comerciais mais utilizadas em alta temperatura para aplicação em motores aeronáuticos pertencem a esta classe.

\subsubsection{Ligas $\alpha-\beta$}

Estas ligas contêm grandes quantidades de estabilizadores $\beta$ (4\% a $6 \%$ ). As ligas $\alpha+\beta$ podem ser tratadas termicamente para apresentar uma boa variedade de microestruturas e combinações de propriedades mecânicas. A liga Ti-6Al-4V é uma das mais utilizadas, e pertence esta classe. 


\subsubsection{Ligas quase $\beta$}

Em ligas contendo $10 \%$ a $15 \%$ de estabilizadores $\beta$, a fase $\beta$ fica mantida em uma condição metaestável mesmo em temperatura ambiente. Esta liga $\beta$, metaestável, pode ser envelhecida para formar precipitados muito finos de fase $\alpha$ na matriz enriquecida da fase $\beta$. Essas ligas possuem alta resistência, tenacidade, excelente temperabilidade, e boa forjabilidade em uma ampla faixa de temperaturas.

\subsubsection{Ligas $\beta$}

Altas concentrações de estabilizadores $\beta(30 \%)$ resultam em fase $\beta$ totalmente estável à temperatura ambiente. Ligas $\beta$ se assemelham a metais refratários em suas altas densidades e baixa ductilidade, são usados em aplicações específicas onde as peças necessitem de alta resistência à temperatura e corrosão.

\subsubsection{Estrutura cristalina}

$\mathrm{Na}$ temperatura ambiente, o titânio puro possui uma estrutura hexagonal compacta, chamada de fase a (Figura 2-2-a). Os parâmetros da célula hexagonal são $\mathrm{a}=0,295 \mathrm{~nm}$ e $\mathrm{c}=0,468 \mathrm{~nm}$. Os planos presentes no cristal são expressos em termos dos vetores de direção $\overrightarrow{a 1}, \overrightarrow{a 2}, \overrightarrow{a 3}$ e $\vec{c}$. Acima da temperatura de $882^{\circ} \mathrm{C}$ e até a temperatura de fusão (aproximadamente $1670^{\circ} \mathrm{C}$ ), a estrutura de titânio puro é cúbica de corpo centrada (Figura 2-2-b), chamada fase $\beta$. O parâmetro a é igual a $0,332 \mathrm{~nm}$ na temperatura de $900^{\circ} \mathrm{C}$.
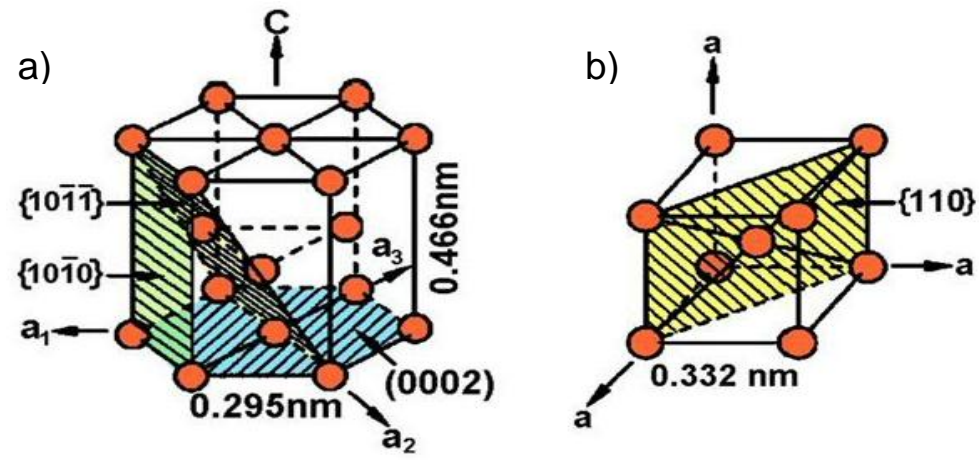

Figura 2-2 - (a) Estrutura para fase $\alpha$, (b) Estrutura da fase $\beta$ adaptado de (REVIL-BAUDARD, 2010). 
A transformação alotrópica $\beta \leftrightarrow \alpha$ (Figura 2-3), ativada no resfriamento do titânio, é caracterizada por uma transformação martensítica (REVIL-BAUDARD, 2010). A forma cúbica centrada passa para a forma hexagonal compacta com um pequeno deslocamento e rearranjo de átomos (Figura 2-4). Um cristal cúbico centrado pode ter doze direções diferentes em uma estrutura hexagonal compacta (HCP). Segundo Benoit (REVIL-BAUDARD, 2010) não há difusão na transformação alotrópica, no entanto, durante um resfriamento lento, um processo de difusão que envolve a nucleação pode intervir na decomposição da fase $\beta$.

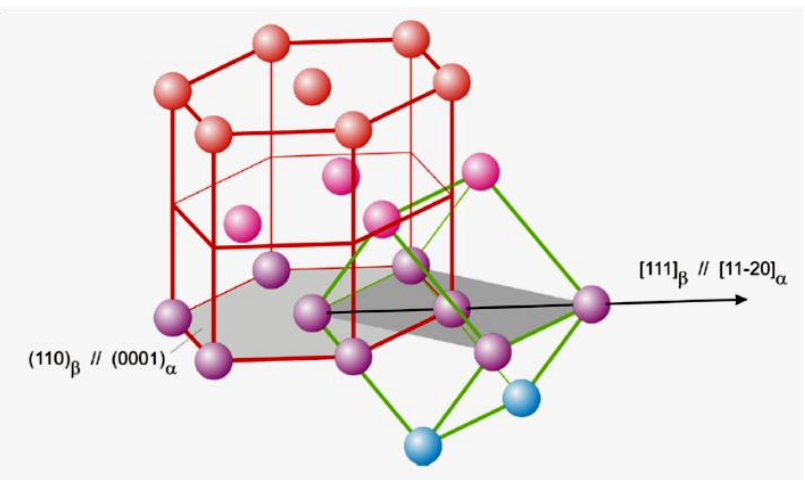

Figura 2-3 - Relações cristalográficas no rearranjo de átomos durante a transformação $\beta \leftrightarrow \alpha$, adaptado de (BURGERS, 1934).

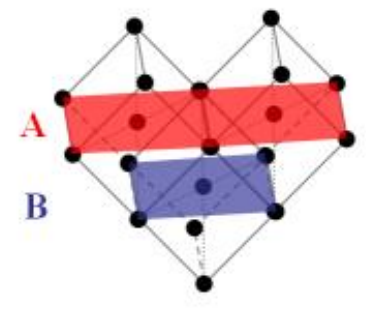

Fase $\beta$

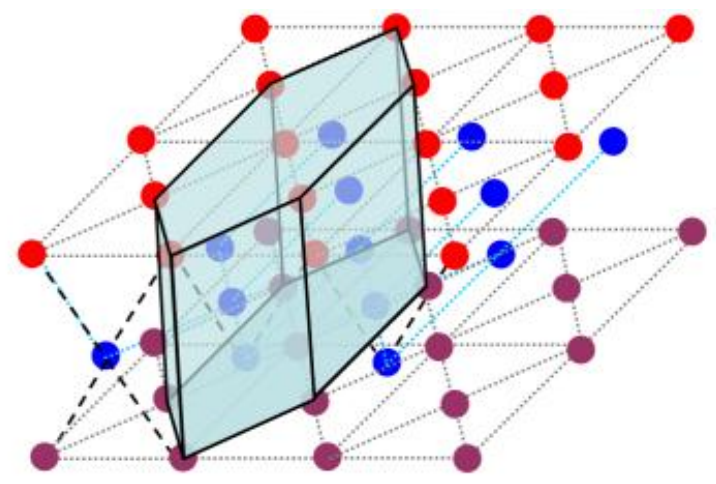

B

A

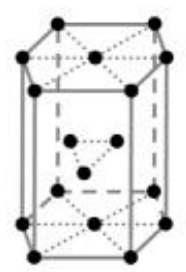

Fase $\alpha$

Figura 2-4 - Transformação alotrópica entre fase cúbica $\beta$ e fase hexagonal $\alpha$. As pilhas $A$ e $B$ são mostradas na célula cúbica, respectivamente em vermelho e azul (REVIL-BAUDARD, 2010).

A Figura 2-5 apresenta a sequência de mudança de fase a partir do resfriamento da liga Ti-6Al-4V. O rearranjo dos cristais se inicia nos contornos dos grãos de $\beta$ com a nucleação das lamelas da estrutura $\alpha$. 


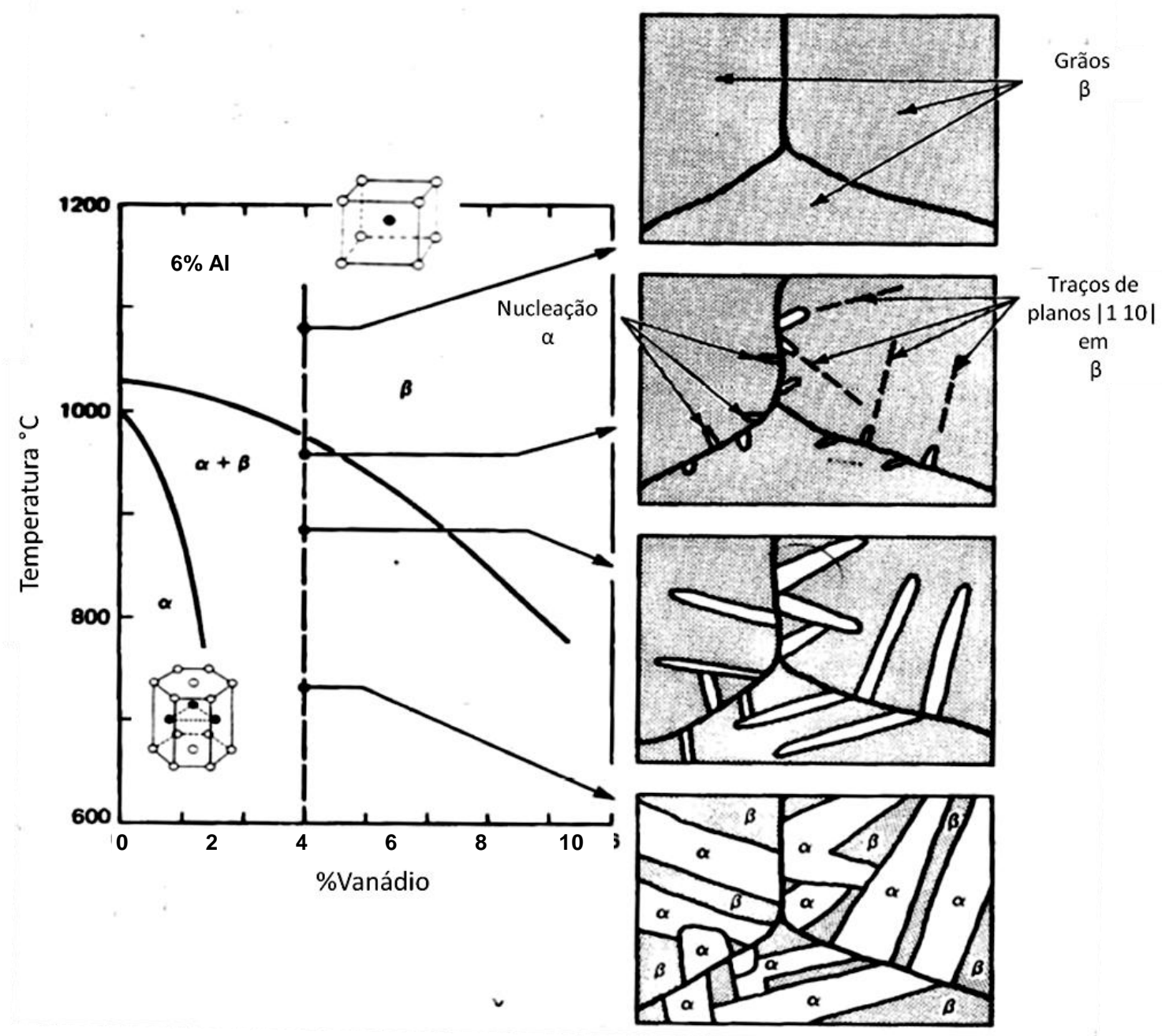

Figura 2-5 - Microestruturas resultantes na liga Ti-6Al-4V em função da transformação de fases $\beta \leftrightarrow \alpha+\beta$ no resfriamento adaptado de (DONACHIE, 2000)

\subsubsection{Formação de camada $\alpha$}

O titânio e as suas ligas quando submetidos à altas temperaturas dissolvem intersticialmente uma grande quantidade de elementos, tais como, oxigênio e nitrogênio que são estabilizadores $\alpha$, mas que em grande quantidade ou de forma desbalanceada, degradam as propriedades mecânicas e físicas das ligas (Kostov, Friedrich, 2005). Como consequência da dissolução do oxigênio no metal durante a sua solidificação, acontece na superfície a formação de uma zona rica em oxigênio usualmente designada por camada a (advinda da definição das ligas $\alpha$ ). Segundo Barbosa et al (BARBOSA et al., 2001) esta camada dura e frágil reduz a ductilidade do material podendo ser iniciadora de trincas que se propagam por fadiga, e deve ser eliminada através de um processo de remoção mecânico ou químico. 
A extensão e espessura da camada a depende de vários fatores, entre os quais se destaca o tempo de contato entre o metal e o meio oxidante a elevadas temperaturas. Em temperaturas inferiores a $500^{\circ} \mathrm{C}$, pode se considerar desprezível a difusão do oxigênio no titânio (BARBOSA et al., 2001).

Os fatores que controlam a velocidade de resfriamento do metal são diretamente responsáveis pelo tempo de contato metal/oxigênio em temperaturas elevadas e consequentemente pela extensão da camada contaminada. Uma maneira de se determinar a extensão da camada $\alpha$, é a realização da medição da microdureza ao longo da espessura da peça, gerando um perfil de microdurezas. $O$ perfil de microdurezas de uma liga de titânio com camada $\alpha$ apresenta normalmente uma curva característica de microdureza pela distância da superfície como apresentado na Figura 2-6. A curva de variação de microdurezas em função da distância da superfície do fundido acompanha a curva de variação do teor de oxigênio ao longo da mesma zona (BARBOSA et al., 2001).

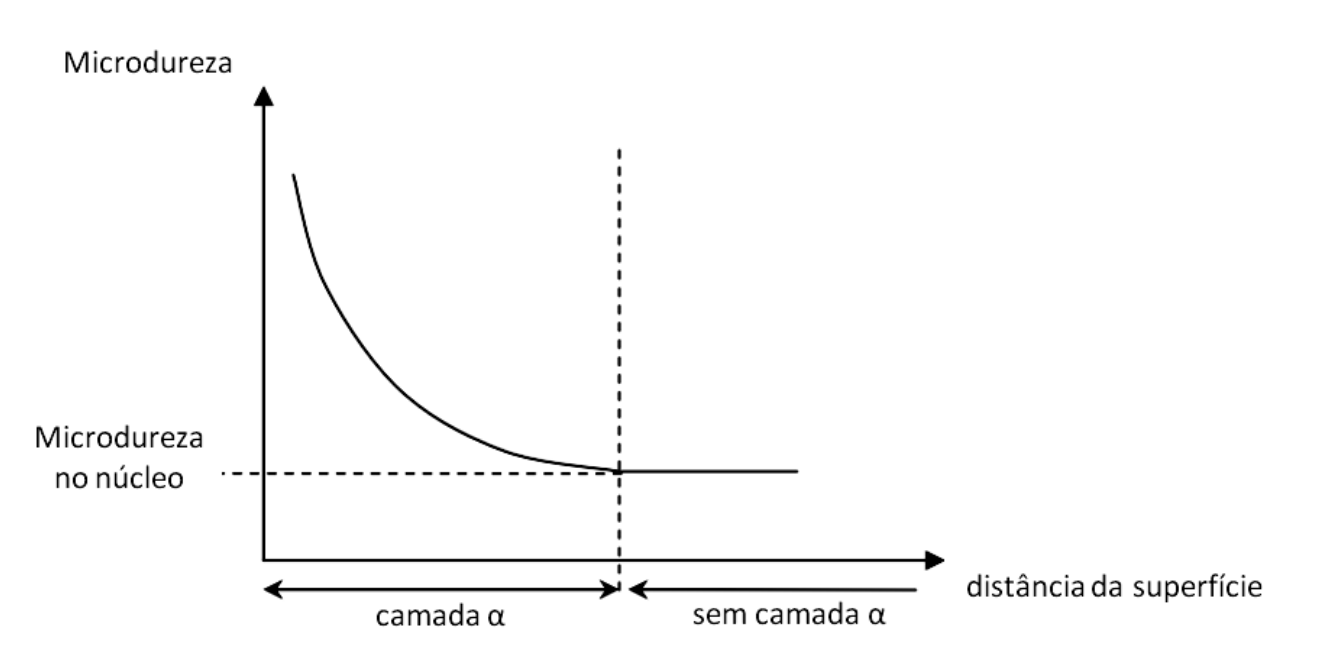

Figura 2-6 - Perfil da microdureza pela distância à superfície (FÉLIX, 2008).

Em seu trabalho Barbosa et al (BARBOSA et al., 2001), executa o levantamento da condição superficial da camada $\alpha$ em amostras fundidas de titânio na seguinte proporção: lingotes de $100 \mathrm{~g}$ de titânio grau II mais alumínio comercial com $99,8 \%$ de pureza. Ele correlaciona a dureza encontrada na camada $\alpha$ com a quantidade de oxigênio encontrado na superfície das amostras contaminadas pela cerâmica dos moldes. Na Figura 2-7 é possível verificar o perfil de microdureza que se inicia em (a) $360 \mathrm{HV}$ na superfície e termina em aproximadamente $300 \mathrm{HV}$ a 50 
$\mu \mathrm{m}$ de profundidade para o material do molde em zirconia $\left(\mathrm{ZrO}_{2}\right)$ e em (b) inicia com $410 \mathrm{HV}$ na superfície e termina em aproximadamente $290 \mathrm{HV}$ a $250 \mu \mathrm{m}$ de profundidade para o material do molde em silica $\left(\mathrm{SiO}_{2}\right)$.

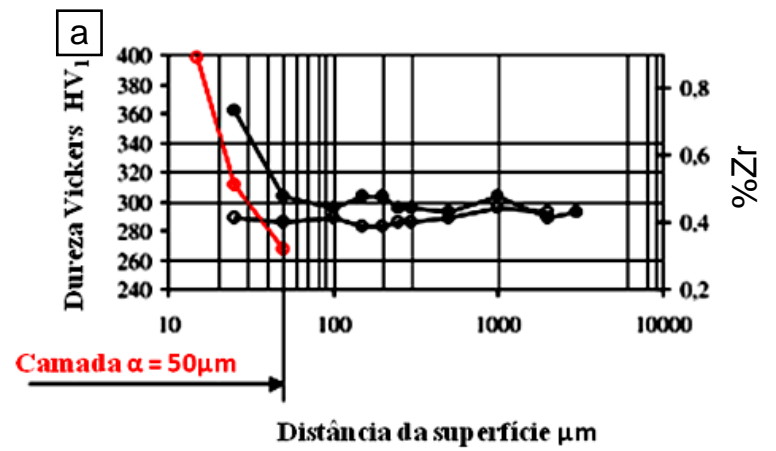

$\mathrm{b}$

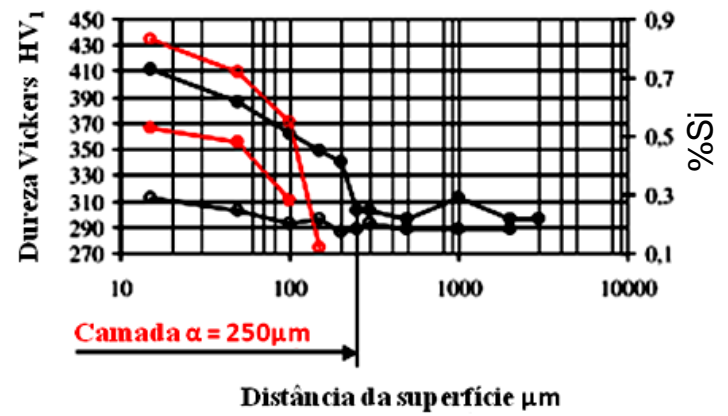

Figura 2-7 - Perfil de microdureza (-_) e concentração de elementos residuais (- - ) em amostras de titânio fundidas em moldes de $\mathrm{ZrO}_{2}(\mathrm{a})$ e $\mathrm{SiO}_{2}$ (b) (BARBOSA et al., 2001).

Ambos os corpos de prova apresentaram teor de contaminação por oxigênio como apresenta a Figura 2-8, inclusive é possível notar uma boa correlação na profundidade atingida pela contaminação com oxigênio que se mostrou próxima àquela relativa do seu perfil de durezas.

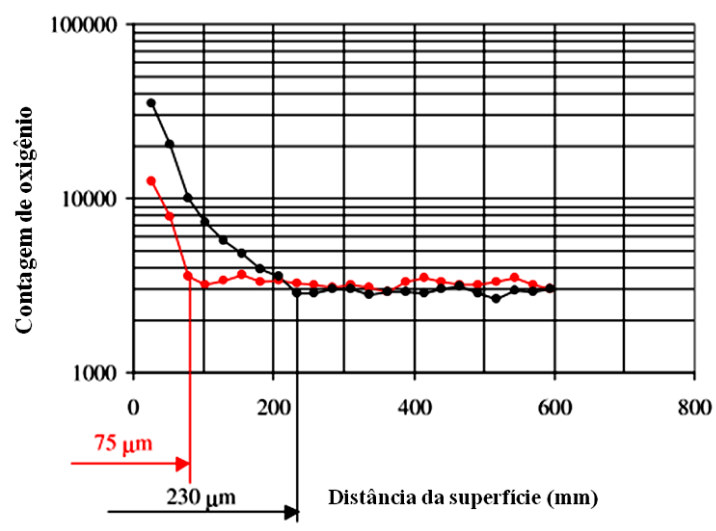

Figura 2-8 - Perfil de distribuição do oxigênio nas amostras fundidas em moldes de (- (-) $\mathrm{ZrO}_{2}$ e (-_-) $\mathrm{SiO}_{2}$ (BARBOSA et al., 2001).

Em outro trabalho semelhante Nurul (NURUL AMIN, 2012) também utiliza uma correlação entre o perfil de dureza encontrado em uma amostra fundida e contaminada pelo material do molde com a formação da camada a. Em seus resultados é apresentado uma diferença entre a dureza do núcleo da amostra para superfície de $200 \mathrm{HV}$ e uma espessura de camada aproximada de $0.5 \mathrm{~mm}$. 


\subsubsection{Energia livre de formação de óxidos}

A energia livre de formação (- $\left.\Delta \mathrm{G}^{\circ}\right)$, quanto mais negativa for maior será a estabilidade do óxido formado. Uma forma de avaliar estas interações é a análise do diagrama de Ellingham (ELLINGHAM, 1944), que nos dá indicações sobre a variação da energia livre em função da temperatura e as respectivas reações de redução e oxidação. No caso de uma soldagem convencional em ligas reativas como as da liga Ti-6Al-4V, surgem os óxidos metálicos com valores muito negativos de energia livre de formação, tal como se pode ver na Figura 2-9.

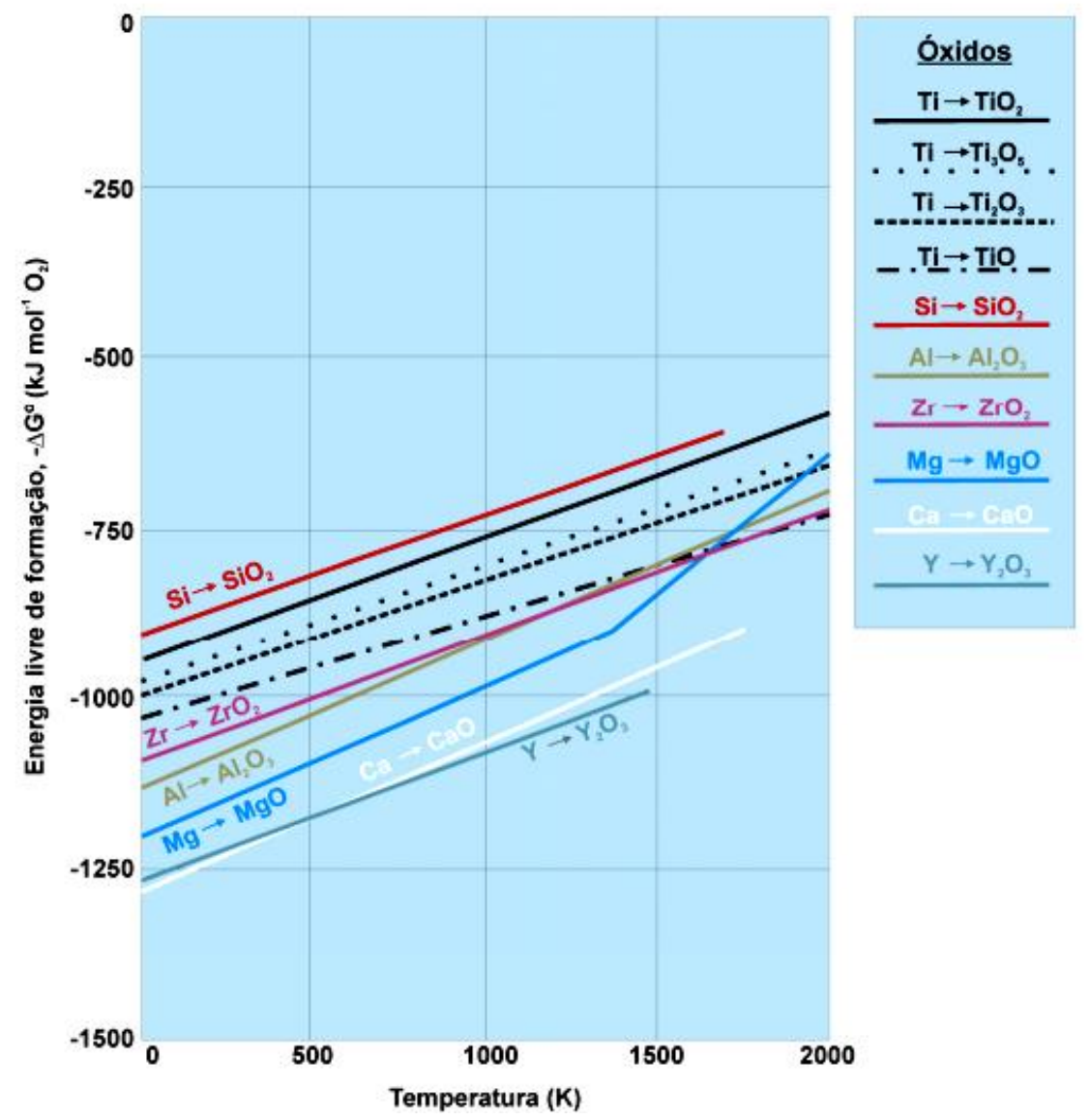

Figura 2-9 - Diagrama de Ellingham de óxidos de titânio, adaptado de (UC, 2008).

$\mathrm{Na}$ análise do diagrama de Ellingham (Figura 2-9), observa-se que a estabilidade do óxido é tanto maior quanto mais abaixo no diagrama ele estiver. Assim sendo para verificar a compatibilidade entre um óxido e um elemento, devemos ter em consideração que a curva de energia livre do óxido deve estar sempre abaixo da curva de energia livre relativa aos óxidos do elemento em questão, caso contrário, o óxido pode ser reduzido pelo elemento (Barbosa, 2001). 


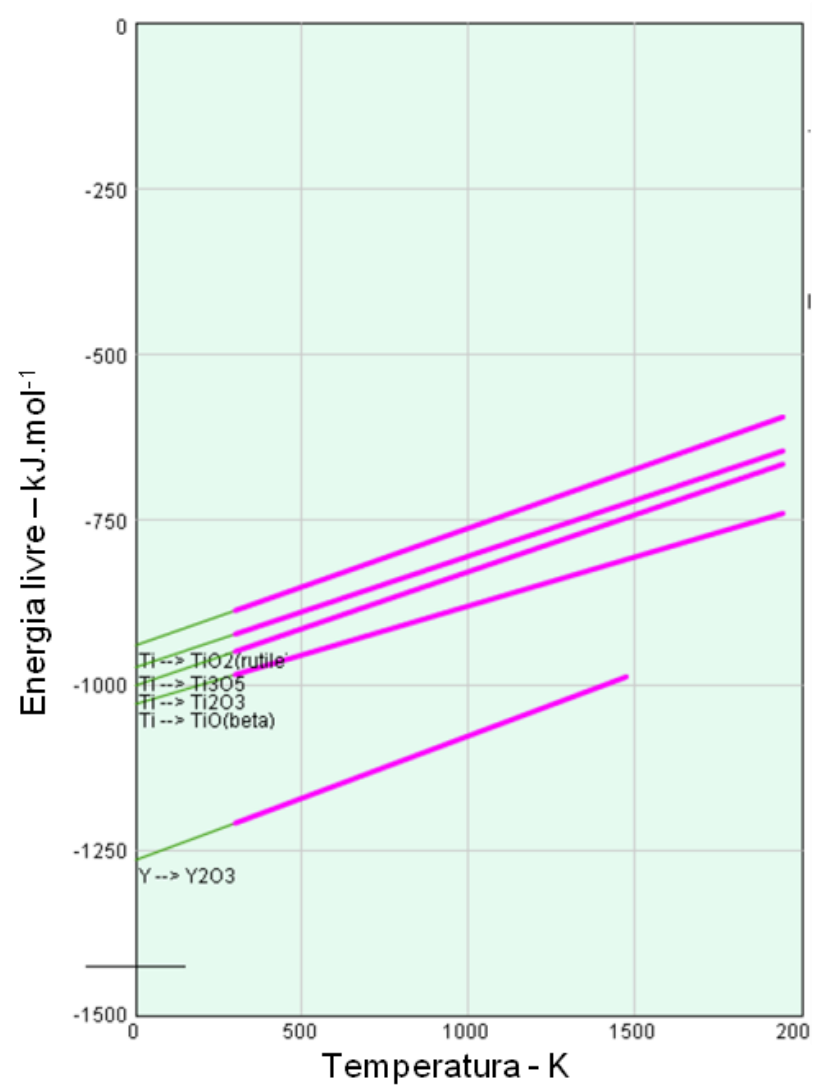

Figura 2-10 - Energia livre de formação de óxidos de titânio (UC, 2008).

\subsubsection{Diagrama de Pourbaix}

Nas Figura 2-11 e Figura 2-12 é apresentado o diagrama de Pourbaix para o titânio em meio úmido para potenciais de equilíbrio em termos do potencial aplicado em relação ao potencial de hidrogênio $(\mathrm{pH})$. $\mathrm{O}$ diagrama de Pourbaix é dividido em regiões que identificam a estabilidade termodinâmica das inúmeras fases do titânio segundo $\mathrm{o} \mathrm{pH}$ do meio e o potencial do eletrodo. Essas informações, de modo prático, permitem atribuir relações entre as regiões do diagrama de Pourbaix com as regiões de dissolução, passividade ou imunidade apresentada pelos metais. Contudo, o diagrama de Pourbaix é termodinâmico e não fornece informações quanto à cinética das reações ocorridas. Segundo o diagrama de Pourbaix, a região estabelecida pelas linhas tracejadas A e B representam a região onde ocorre 0 domínio de estabilidade da água, já as linhas contínuas estabelecem a região onde ocorre o domínio das substâncias citadas (VALENTE, 2011). 


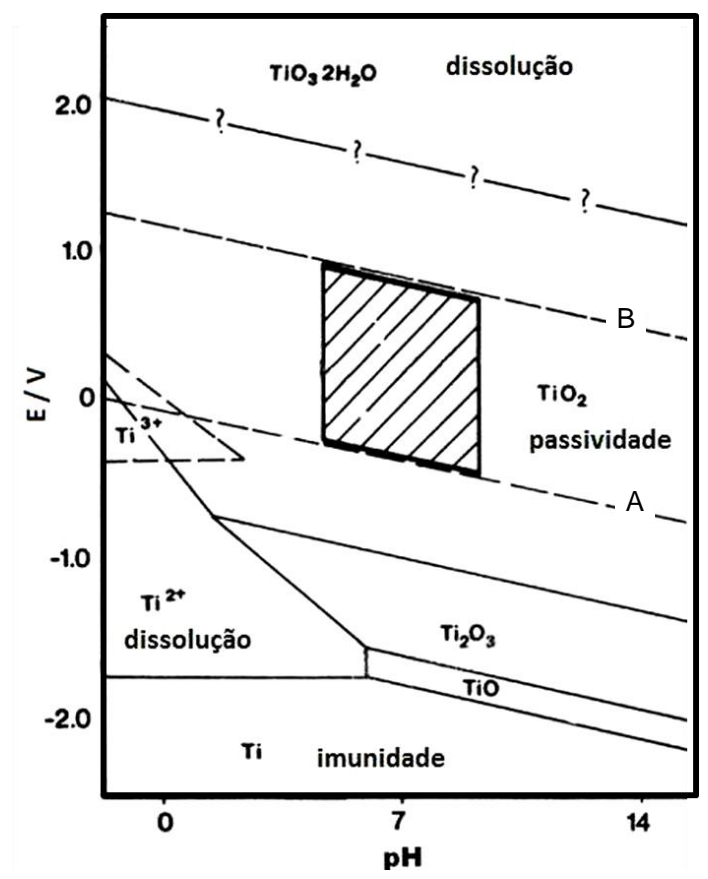

Figura 2-11 - Diagrama esquemático de Pourbaix para o elemento titânio em meio úmido adaptado de (VALENTE, 2011).

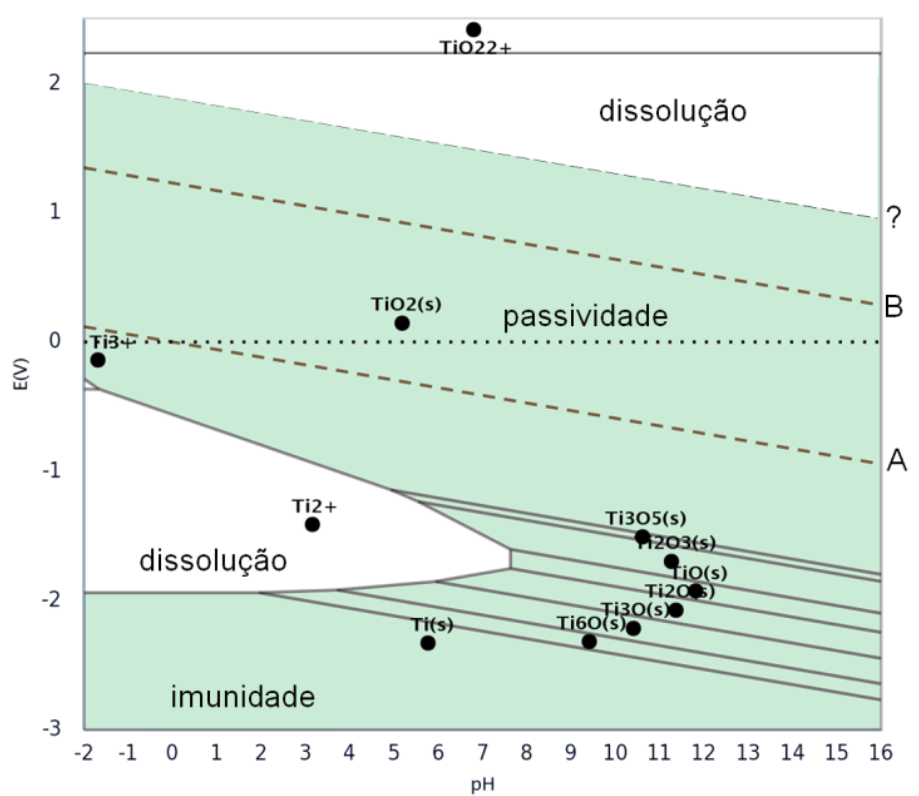

Figura 2-12 - Diagrama de Pourbaix para o elemento titânio em meio úmido (PROJECT, 2015)

Observando o diagrama de Pourbaix da Figura 2-12, a imunidade surge na região de estabilidade do $\mathrm{Ti}$. A passividade corresponde à região de estabilidade dos óxidos $\mathrm{TiO}, \mathrm{TiO}_{2}$ e $\mathrm{TiO}_{3}$. Em soluções com pH ácido, entre 0 e 5, o processo de corrosão é bastante acentuado para potenciais entre 0 e -2 eV. É possível observar também que, em presença de umidade, o óxido mais provável de ocorrer é o $\mathrm{TiO}_{2}$ (VALENTE, 2011). 


\subsubsection{Propriedades das ligas de titânio}

Algumas propriedades como a exclusiva relação de alta resistência com baixo peso, boa conformabilidade, e resistência à fadiga leva ao uso do titânio em diversas aplicações especiais onde grandes solicitações (físicas, químicas e/ou mecânicas) restringem o uso de materiais convencionais. Titânio e suas ligas são usados na indústria aeroespacial, naval, química, petroquímica e biomédicas porque apresentam uma surpreendente gama de propriedades (JOSHI, 2006). Atualmente mais de cem ligas de titânio são conhecidas, das quais, no entanto, apenas de vinte a trinta são produzidas comercialmente. Destes, a liga Ti-6Al-4V cobre mais de 50\% de utilização na indústria. Os outros $20 \%$ a $30 \%$ são para titânio puro (LEYENS e PETERS, 2003). A Tabela 2-3 apresenta as ligas de titânio atualmente mais utilizadas categorizadas por classes. Nela constam as propriedades mecânicas mais importantes, composição química, nome comercial e a temperatura de transição $\beta$.

Entre as ligas $\alpha+\beta$, a liga Ti-6Al-4V é, de longe, a liga de titânio mais utilizada. A liga foi desenvolvida no início dos anos 50 nos Estados Unidos no Instituto de Tecnologia de llinois. Existem basicamente duas razões para o sucesso da liga Ti6Al-4V: Em primeiro lugar, o bom equilíbrio de suas propriedades, como pode ser visto a partir da Tabela 2-3. Segundo, é de longe a liga de titânio mais estudada, pesquisada e testada o que é uma grande vantagem especialmente na indústria aeroespacial.

Tabela 2-3 - Propriedades mecânicas das ligas.(LEYENS e PETERS, 2003)

\begin{tabular}{lccccc}
\hline \multicolumn{1}{c}{ Liga } & Tipo & $\mathbf{E}(\mathbf{G P a})$ & $\boldsymbol{\sigma}_{\mathbf{Y}}(\mathbf{M P a})$ & $\boldsymbol{\sigma}_{\mathbf{T}}(\mathbf{M P a})$ & $\mathbf{e}(\%)$ \\
\hline Grau 1 & $\alpha$ & 100 & $170-310$ & 240 & 24 \\
Grau 2 & $\alpha$ & 103 & $275-450$ & 345 & 20 \\
Grau 3 & $\alpha$ & 105 & $380-550$ & 440 & 18 \\
Grau 4 & $\alpha$ & $100-120$ & $480-655$ & 550 & 18 \\
Grau 6 & $\alpha$ & 109 & 827 & 861 & 15 \\
Grau 9 & quase- $\alpha$ & $95-105$ & 480 & 620 & 15 \\
TIMETAL & quase- $\alpha$ & 112 & $900-950$ & $1010-1050$ & $10-16$ \\
Ti-64 & $\alpha+\beta$ & $110-140$ & $800-1100$ & $900-1200$ & $13-16$ \\
Ti-6246 & $\alpha+\beta$ & 114 & $1000-1100$ & $1100-1200$ & $13-16$ \\
Ti-662 & $\alpha+\beta$ & $110-117$ & $950-1050$ & $1000-1100$ & $10-19$ \\
Ti-1023 & quase- $\beta$ & 110 & $1000-1200$ & $1000-1400$ & $6-16$ \\
Ti-1313 & quase- $\beta$ & 77 & $836-908$ & $973-1037$ & $10-16$ \\
TNZT & $B$ & 55 & 547 & 596 & 19 \\
TMZF & $B$ & $74-85$ & $100-1060$ & $1060-1100$ & $18-22$ \\
\hline
\end{tabular}




\subsection{Soldagem por Atrito}

Soldagem por atrito, mostrada na Figura 2-13, é um processo de união que se encontra em desenvolvimento há mais de 100 anos (MINTON, 2008). Esta forma de união é mais adequada a geometrias de material com forma de haste ou na forma de tubo. Consiste em girar ou oscilar um lado da peça a ser unida contra a outra parte que permanece fixa (Figura 2-13 a). Este processo de atrito gera calor, e quando gerado calor suficiente, as duas hastes são empurradas em conjunto com uma força que forja as duas seções das peças em conjunto (Figura 2-13 b,c). O excesso de material extrudado na circunferência da junção pode então ser removido por um processo convencional deixando uma secção soldada uniforme (Figura 2-13 d) (MINTON, 2008).

a

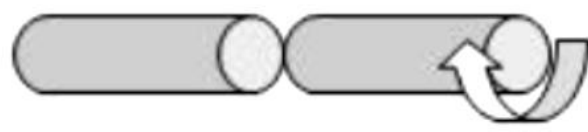

c

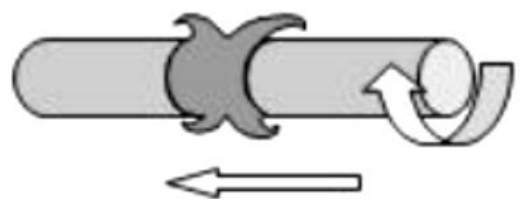

b

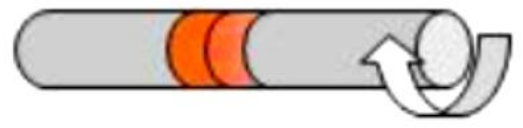

d

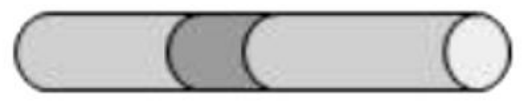

Figura 2-13 - Etapas da solda por atrito (MINTON, 2008).

\subsection{Soldagem por Atrito Linear}

Soldagem por Atrito Linear (FSW) do original Friction Stir Welding (FSW), foi inventada em 1991 no TWI (The Welding Institute), Reino Unido, inicialmente para união de alumínio. O conceito básico do FSW consiste na rotação de uma ferramenta de material não consumível com uma geometria especialmente concebida, composta por um pino e um rebaixo (ombro). Esta ferramenta é inserida girando em seu eixo de rotação nas bordas adjacentes de chapas ou placas a serem unidas, e, posteriormente, percorre o trajeto ao longo da linha de união (Figura 2-14). A Figura 2-15 ilustra o processo e apresenta definições para a ferramenta e peça. (MISHRA e MAHONEY, 2007). 


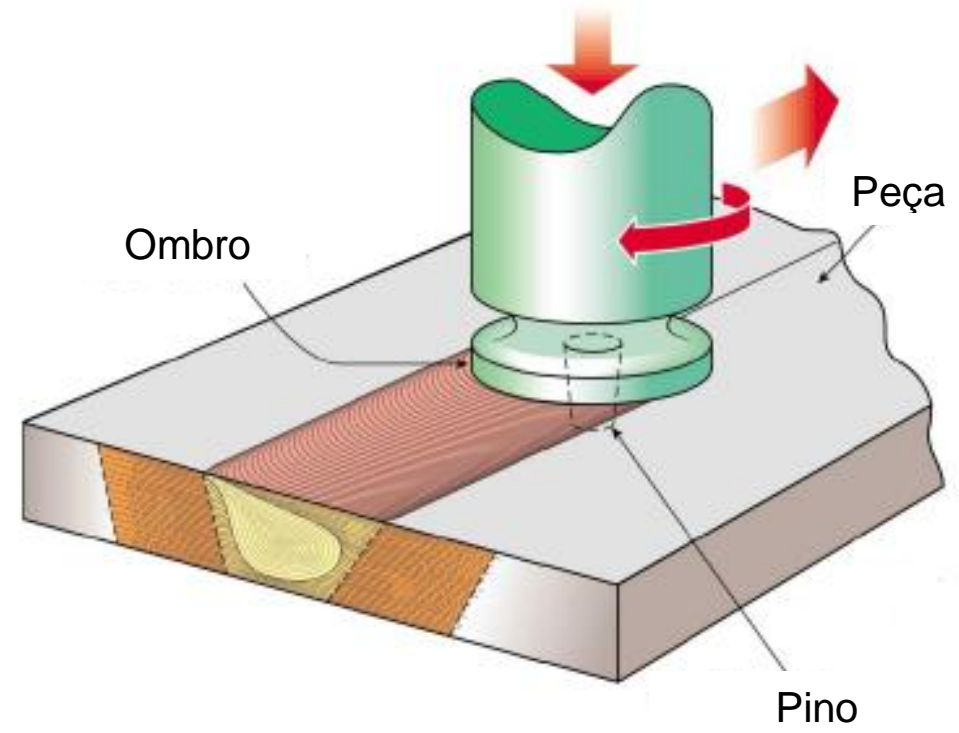

Figura 2-14 -Detalhes do Processo FSW (ELBANHAWY et al., 2013).

A Figura 2-15 apresenta as etapas típicas de um processo por atrito linear: i) movimento de descida para penetração no material; ii) penetração no material; iii) tempo para geração de calor para deformação; iv) movimento linear sobre a peça no sentido do processamento; v) fim do processamento e retração da ferramenta.

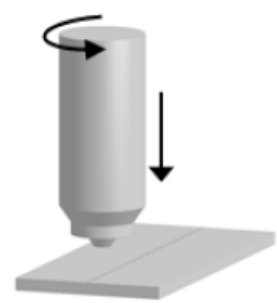

i)

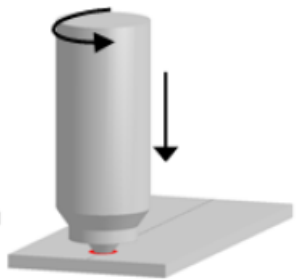

ii)

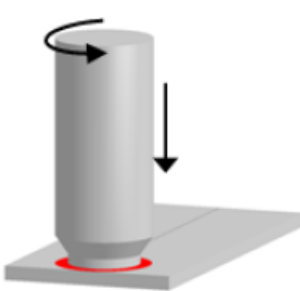

iii)

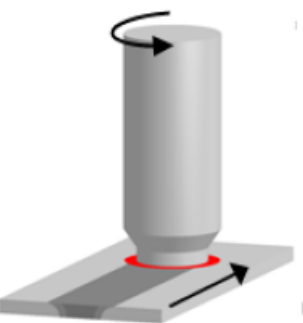

iv)

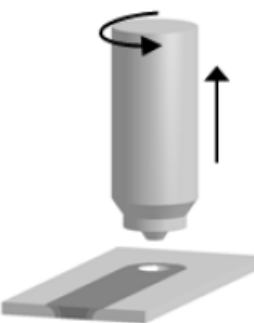

v)

Figura 2-15 - Etapas do processo de FSP e FSW (MASHININI, 2010).

O eixo de rotação da ferramenta define com as peças a soldar um ângulo de ataque (Figura 2-16). Este ângulo serve para receber o material que vai ser processado sob a base da ferramenta e aumentar gradualmente o efeito de forjamento imposto pela base durante a passagem da ferramenta. Este procedimento evita que o material em fluxo plástico escape, garantindo um fecho do cordão na parte de trás do pino. 


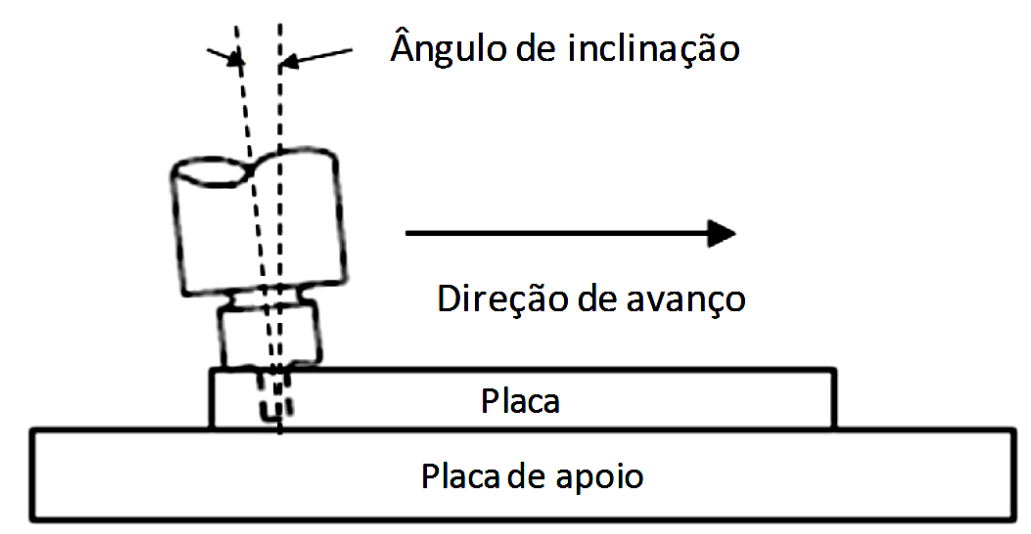

Figura 2-16 - Inclinação para geração de ângulo de ataque (MASHININI, 2010).

Soldagem por atrito linear é uma tecnologia relativamente nova, com muitas vantagens sobre as técnicas convencionais de soldagem. Devido aos benefícios que apresenta, encontra-se em inúmeras aplicações industriais, como por exemplo, aeroespacial, construção naval e automotiva. Durante o atrito e mistura no processo FSW, a degradação das propriedades mecânicas devido ao calor de entrada é minimizada e uma microestrutura contendo material com grãos finos e recristalizados é produzida. Soldagem por atrito Linear (FSW) é um processamento em estado sólido, que produz uma microestrutura similar à de um material forjado e em oposição às microestruturas formadas em fusão e soldas (tipo de grãos grandes e grosseiros).

Desde a sua criação em 1991, foi aplicado com sucesso na união de metais como alumínio, magnésio, cobre e até mesmo aço. Recentemente FSW tem sido aplicado à união de Ti-6Al-4V devido às dificuldades associadas com a união de altas ligas e a identificação de materiais de ferramentas capazes de suportar a solicitação ao desgaste que este material impõe (EDWARDS e RAMULU, 2009). Quando pensado em processo o melhor termo para sua definição passa a ser Processamento por Atrito Linear (FSP).

Segundo Vilaça da Silva (VILAÇA DA SILVA, 2003), a eficiência do processo de FSW é elevada, como de uma forma geral em todos os processos de união no estado sólido, pois a transformação da energia aplicada mecanicamente pela ferramenta em calor, ocorre no interior dos materiais a soldar. Esta transformação de energia ocorre numa vizinhança pequena do pino, exatamente na zona onde ela é utilizada para reduzir a resistência mecânica do material e assim permitir o fluxo plástico localizado em redor do pino. A parte de material em fluxo plástico é 
condicionada pela base da ferramenta, pela base suporte das peças a soldar e pelo material restante das peças a unir que se encontram em um domínio elástico (material mais frio) (VILAÇA DA SILVA, 2003).

Principais vantagens (MARQUES, 2009):

- Evita os problemas causados pela soldagem por fusão dos materiais, como a diminuição da zona de solda e fissuração durante a solidificação, formação de porosidades (devidas à volatilização de elementos de baixo ponto de fusão), libertação de gases e respingos;

- Reduz a distorção uma vez que o processo se desenrola no estado sólido;

- Evita a formação de porosidades e de óxidos localizados, uma vez que a ferramenta rotativa os dispersa;

- Não é necessária limpeza prévia das superfícies;

- Conduz a excelentes propriedades metalúrgicas da junta soldada;

- Não necessita de material de adição;

- Não necessita de proteção de gás durante a soldagem;

- Tem boa repetibilidade do processo;

- Não existe a necessidade de tratamentos posteriores da região soldada;

- Consegue unir metais diferentes entre si como aço, cobre ou alumínio, bem como de espessuras diferentes.

Algumas desvantagens (MARQUES, 2009):

- A necessidade de as peças estarem bem fixadas durante o processo;

- Não permite produzir juntas onde é necessário um material de adição;

- Deixa sempre um furo quando a ferramenta é retirada. O furo, no entanto pode ser preenchido ou então ser cortada a parte do material que o contém;

- A geometria do pino e o diâmetro da base variam conforme a espessura a soldar;

\subsubsection{Microestruturas geradas em FSW e FSP}

O controle sobre a microestrutura, ou seja, a capacidade de refinar grãos para microgrãos ou tamanhos submicrométricos, é essencial para alcançar a combinação desejada de resistência e tenacidade em materiais metálicos que serão utilizados em aplicações avançadas. Em ligas de titânio é difícil de se atingir essas estruturas 
de grão ultrafino devido à rápida taxa de crescimento dos grãos nestas ligas. A liga Ti-6Al-4V apresenta uma estrutura bimodal composta das fases a e $\beta$. Assim, o controle e a otimização da microestrutura de uma liga bifásica $\alpha-\beta$ são questões importantes para se atingir as propriedades finais desejadas (SHA; MALINOV, 2009). A taxa de resfriamento determina as características da microestrutura lamelar, elas são (i) o tamanho das lamelas $\alpha$ (placas $\alpha$ ), (ii) o tamanho da colônia $\alpha$ e (iii) a espessura das lamelas $\alpha$ nos limites dos grãos $\beta$ primários. Em geral, pode afirmar-se que os parâmetros da microestrutura lamelar tendem a diminuir com o aumento da velocidade de resfriamento (SHA; MALINOV, 2009).

Segundo Kitamura et al (KITAMURA et al., 2013) o FSP influencia as transformações de fase, e suas respectivas microestruturas, devido ao inerente aumento da temperatura durante o processamento. Esquematicamente, pode ser visto na Figura 2-17 a formação de uma microestrutura $\alpha$-lamelar no grão $\beta$ para temperaturas acima da $\beta$-transus. Em temperaturas abaixo da $\beta$-transus são formadas microestruturas $\alpha$-globulares com contornos formados de fase $\beta$. Na liga Ti-6Al-4V com FSP, diferentes microestruturas (ou todas elas) podem ser criadas nas diferentes regiões (zona de mistura, zona afetada termo-mecânica e zona afetada pelo calor), dependendo principalmente da temperatura de pico em relação à temperatura $\beta$-transus e da taxa de resfriamento (SATO et al., 2007; KITAMURA et al., 2013).

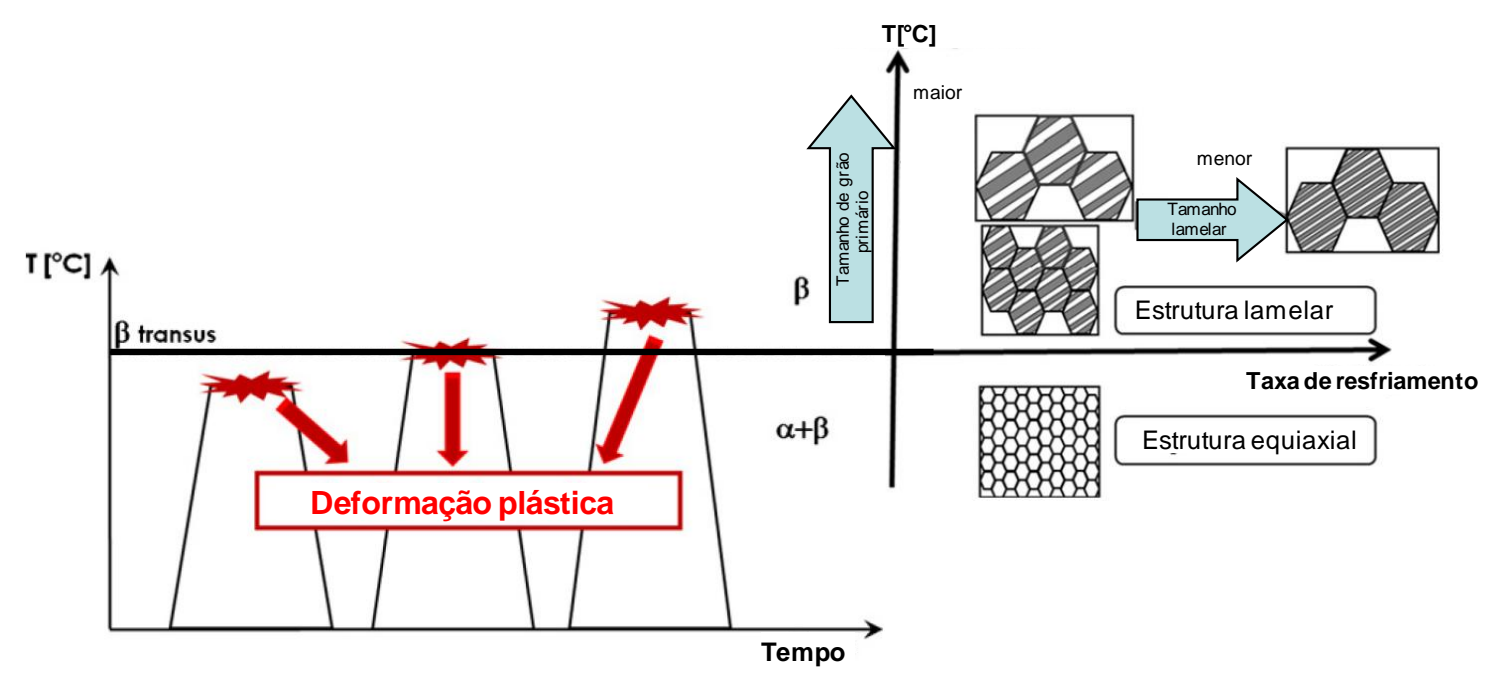

Figura 2-17 - Representação esquemática das possíveis combinações de deformação, temperatura e seus resultados na estrutura do Ti-6Al-4V. Adaptado de (BUFFA et al., 2012; KITAMURA et al., 2013).

Neste sentido, a microestrutura final da liga Ti-6Al-4V trabalhada com FSP, não pode ser facilmente prevista apenas por análise dos diagramas de fases de 
equilíbrio, ou mesmo com diagramas de curvas de resfriamento contínuo CCT (Continuous Cooling Transformation) como o da Figura 2-20 (DĄBROWSKI, 2011a, 2012; GRUJICIC et al., 2011; BUFFA et al., 2012).

No caso da liga Ti-6Al-4V a adição de $6 \%$ de alumínio e $4 \%$ de vanádio leva a temperatura beta-transus para aproximadamente $950^{\circ} \mathrm{C}$. Consequentemente, a liga Ti-6Al-4V pode conter em temperatura ambiente diferentes quantidades relativas das duas fases. Segundo Surand (SURAND, 2013) a temperatura de início de resfriamento e a taxa de resfriamento no pós-processamento do titânio também interfere na estrutura e propriedades mecânicas finais (Figura 2-18). As microestruturas resultantes de processos envolvendo temperatura e deformação são classificadas como (SURAND, 2013):

- $\beta$ primária $\left(\beta_{\mathrm{p}}\right)$

- $\beta$ metaestável $\left(\beta_{\mathrm{m}}\right)$

- $\beta$ estável em T ambiente $\left(\beta_{\mathrm{s}}\right)$

- $\beta$ transformado $\left(\beta_{t}\right)$

- $\alpha$ primária nodular $\left(\alpha_{\mathrm{pn}}\right)$
- a prim. fronteiras $\left(\alpha_{\mathrm{GB}}\right)$

- a Widmanstätten-cont. grão ( $\left.\alpha_{W G B}\right)$

- $\quad \alpha$ intra-prim. Widmanstätten $\left(\alpha_{w 1}\right)$

- a secundário $\left(\alpha_{\mathrm{s}}\right)$

- martensíticas: $\alpha^{\prime}$ e $\alpha^{\prime \prime}$

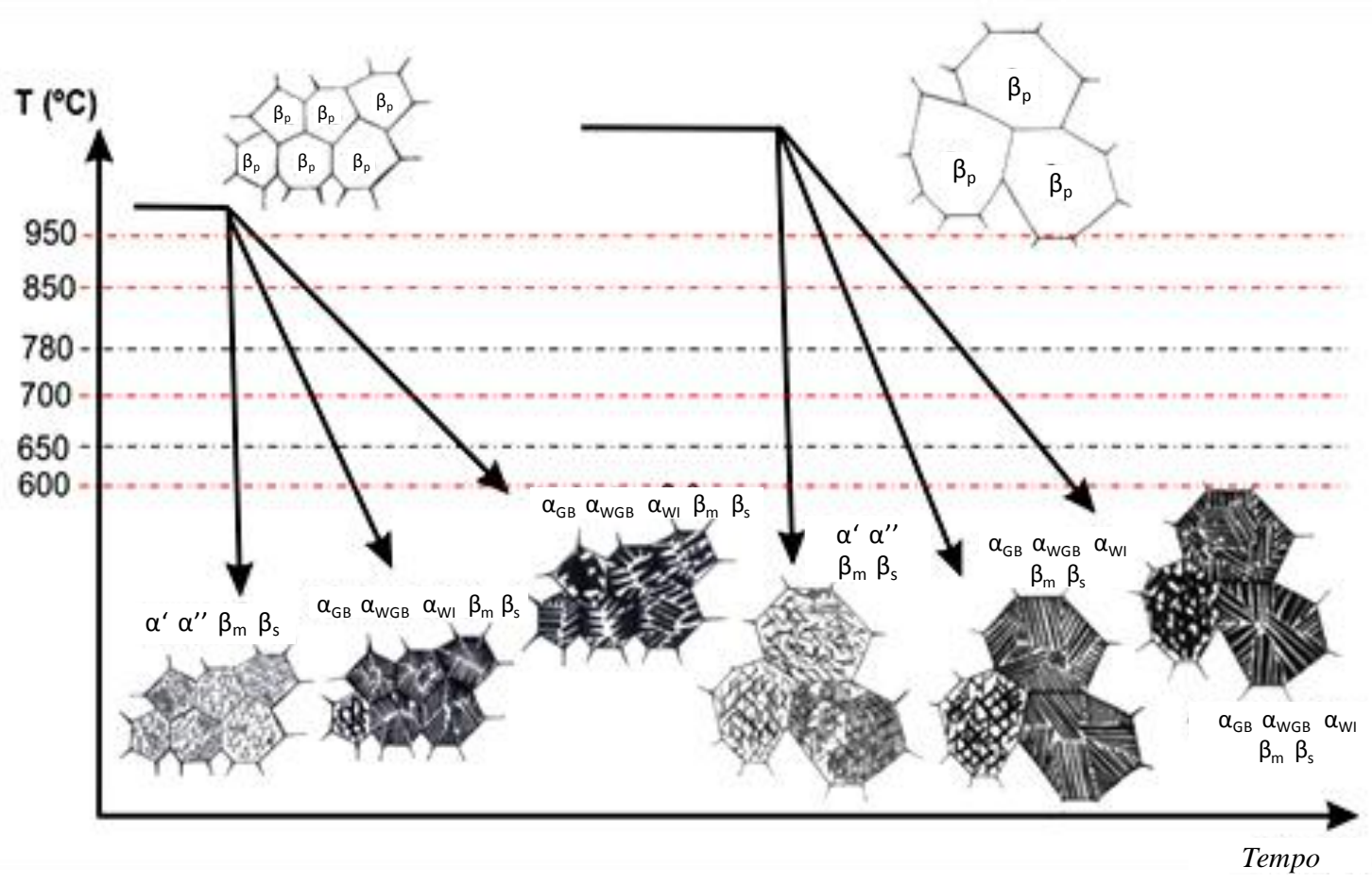

Figura 2-18 - Diferentes estruturas formadas na liga Ti-6Al-4V em função da temperatura e do tempo (SURAND, 2013) 
Uma visão geral sobre as transformações de fase, da liga de titânio Ti-6Al-4V, é necessária para entender o efeito dos parâmetros do processo FSW na microestrutura e suas propriedades nas diferentes zonas resultantes do processamento por atrito linear.

A Figura 2-19 apresenta as correlações básicas entre as fases presentes e suas morfologias (SURAND, 2013). As condições térmicas e mecânicas nas quais as fases da Figura 2-19 são formadas, o efeito da história térmica e mecânica do material sobre a sua microestrutura são representados esquematicamente na Figura $2-17$.

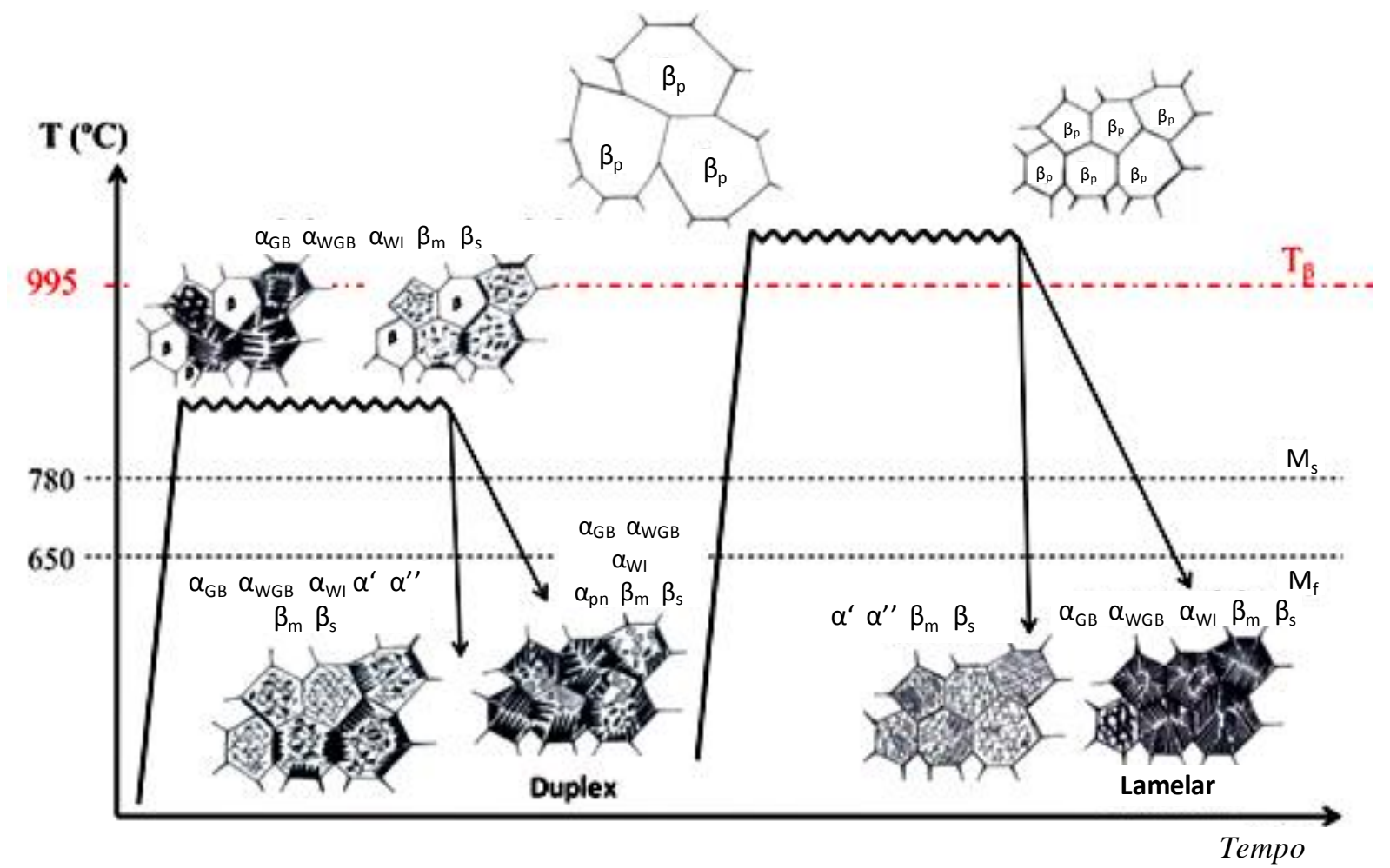

Figura 2-19 - Possíveis microestruturas resultantes em processos envolvendo temperatura e deformação para titânio (SURAND, 2013).

O diagrama de transformação CCT da Figura 2-20 apresenta os resultados para liga de titânio Ti-6Al-4V $\alpha+\beta$ a partir de $950^{\circ} \mathrm{C}$. A análise da cinética de transformação de fase durante o resfriamento partindo de $950^{\circ} \mathrm{C}$ segundo o pesquisador Dabrowski (DĄBROWSKI, 2011a) é justificada, pois as ligas de titânio bifásicas são tratadas a partir desta temperatura.

Na Figura 2-20, uma transformação sempre ocorre dentro de toda a gama de velocidades de resfriamento aplicado, partindo de $7.1^{\circ} \mathrm{C} / \mathrm{s}$ (resfriamento ao ar) até $0.011^{\circ} \mathrm{C} / \mathrm{s}$ (resfriamento em ambiente controlado), entre as linhas de início de transformação $T_{\beta \rightarrow \alpha}^{s}$ e final de transformação $T_{\beta \rightarrow \alpha}^{\dagger}$. 


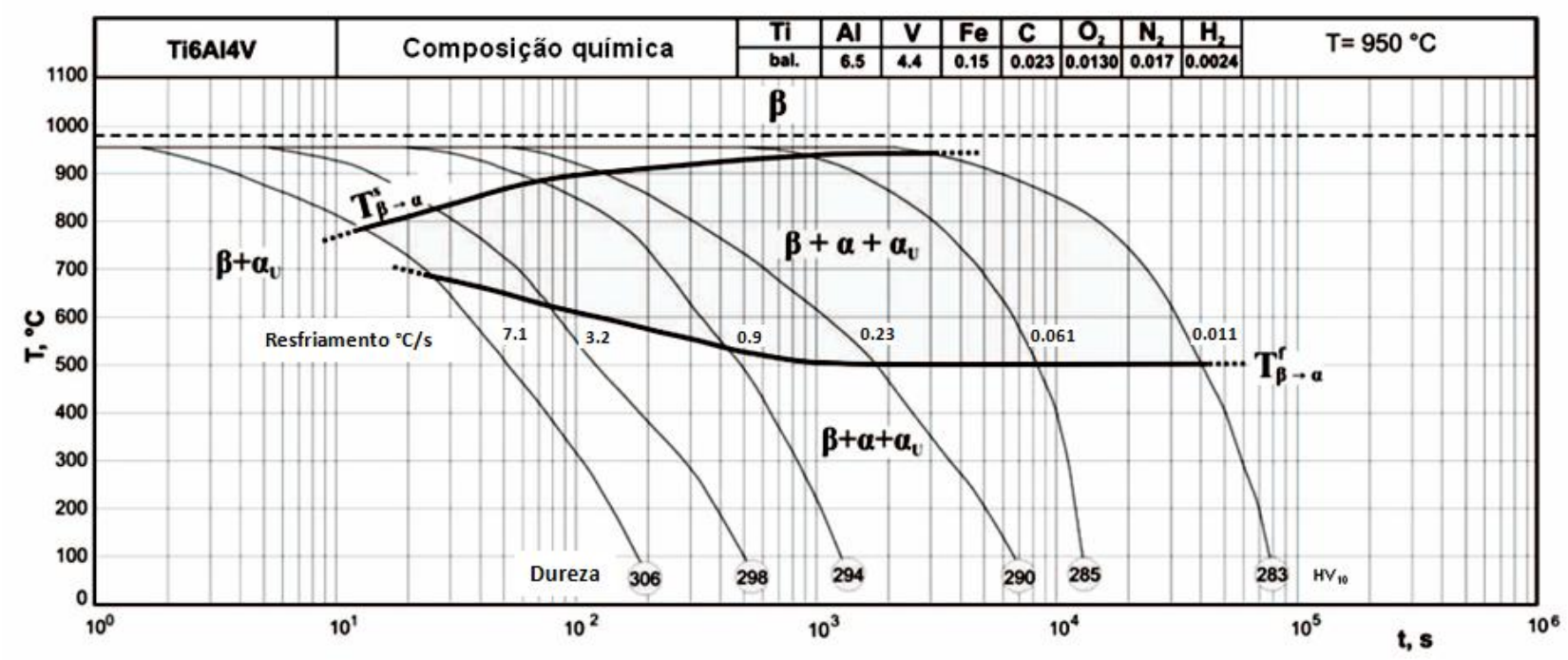

Figura 2-20 - Diagrama CCT para liga de titânio Ti-6Al-4V resfriado a partir da fase $\alpha+\beta$ a $950^{\circ} \mathrm{C}$ (DĄBROWSKI, 2011a).

A fase $\alpha_{u}$ é composta por grãos equiaxiais de fase $\alpha$ que permaneceram não dissolvidos na fase $\beta$ a $950^{\circ} \mathrm{C}$. O aumento da taxa de resfriamento de $0.011^{\circ} \mathrm{C} / \mathrm{s}$ para $7.1^{\circ} \mathrm{C} / \mathrm{s}$ reduz a faixa de transformação e aumenta levemente a dureza final da liga de 283 para 306 HV (DĄBROWSKI, 2011a).

As microestruturas resultantes são mostradas na Figura 2-21. Na Figura 2-21-a a fase $\alpha$ precipita no contato e limites dos grãos de fase $\beta$ primários. Além dos grãos não dissolvidos da fase $\alpha$ equiaxiais, lamelas orientadas de fase a são formadas devido à transformação $\beta \rightarrow \alpha$. Deste modo, deve ser esperado, que a nova fase $\beta$, enriquecida com estabilizadores $\beta$ (rejeitados de $\alpha$ ), irá ocorrer entre as lamelas de fase a (AHMED; RACK, 1998).

Uma diminuição na velocidade de resfriamento de $7,1^{\circ} \mathrm{C} / \mathrm{s}$ para $3,2^{\circ} \mathrm{C} / \mathrm{s}$ e posteriormente para $0,9^{\circ} \mathrm{C} / \mathrm{s}$ (Figura $2-21-\mathrm{a}, \mathrm{b}, \mathrm{c}$ ) resulta em uma pequena queda na dureza para 298 e $294 \mathrm{HV}$, respectivamente. As lamelas da fase a precipitam na estrutura Widmannstatten (JOSHI, 2006) formando colônias dentro de cada grão $\beta$ (Figura 2-21-b, c). Uma nova redução da taxa de resfriamento de $0,23^{\circ} \mathrm{C} / \mathrm{s}$ (Figura 2-21-d) induz um "crescimento volumétrico" da fase a e muda sua morfologia do tipo agulha para equiaxial. A aplicação de taxas de resfriamento ainda mais baixas, isto é entre $0.061^{\circ} \mathrm{C} / \mathrm{s}$ e $0,011^{\circ} \mathrm{C} / \mathrm{s}$ (Figura 2-21-e, f) aparentemente aumentam o tamanho de grão suprimindo a forma lamelar de da fase $\alpha$. 

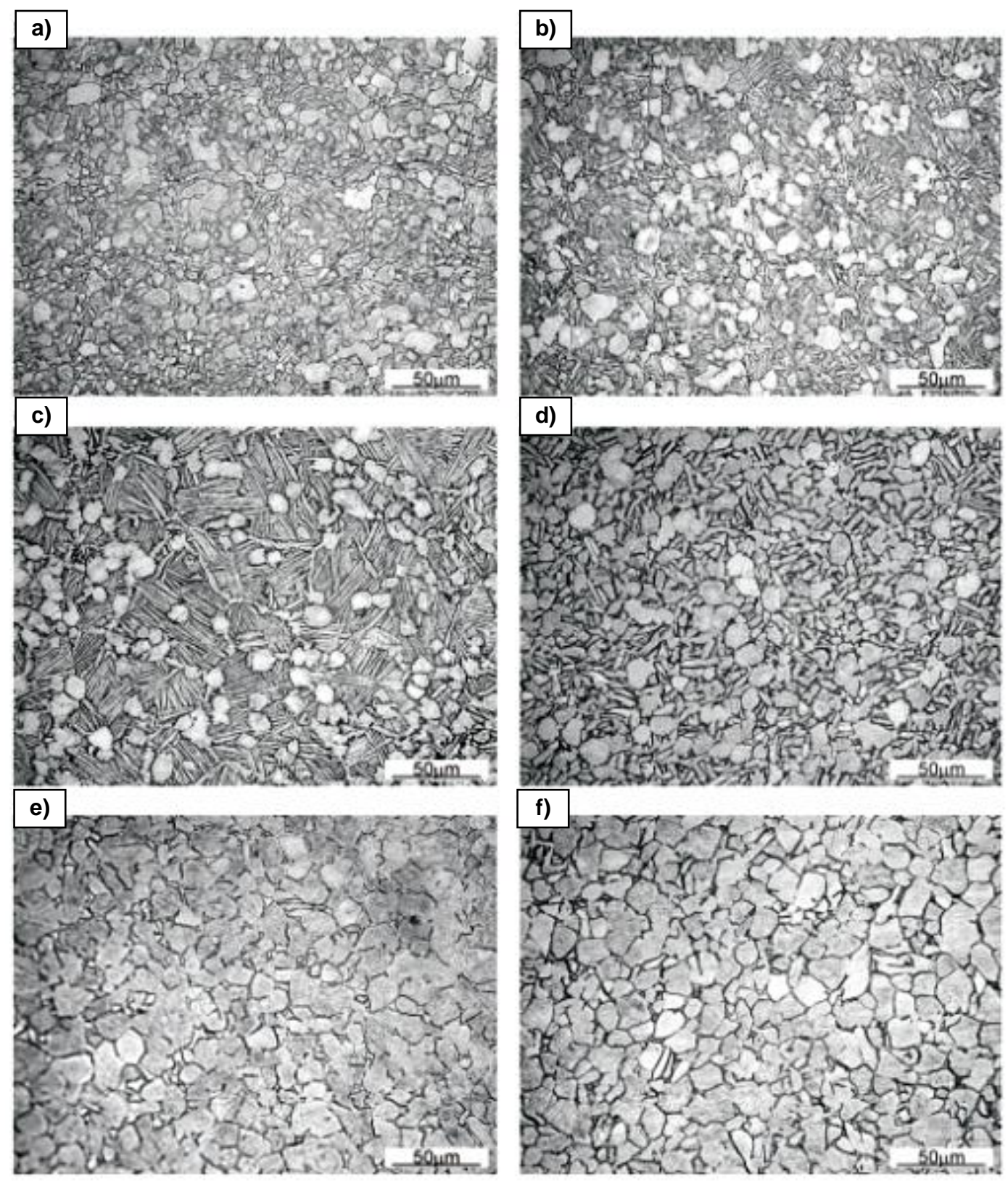

Figura 2-21 - Micrografias da liga Ti-6Al-4V resfriada de $950^{\circ} \mathrm{C}$ à uma taxa de: $7,1^{\circ} \mathrm{C} / \mathrm{s}(\mathrm{a}), 3,2^{\circ} \mathrm{C} / \mathrm{s}(\mathrm{b})$, $0,9^{\circ} \mathrm{C} / \mathrm{s}(\mathrm{c}), 0,23^{\circ} \mathrm{C} / \mathrm{s}(\mathrm{d}), 0,061^{\circ} \mathrm{C},(\mathrm{e})$ e $0,011^{\circ} \mathrm{C} / \mathrm{s}$ (f) (DAZBROWSKI, 2011a)

As ilhas mais escuras entre os grãos a (Figura 2-21-f) são presumivelmente resíduo de fase $\beta$ não transformada. Ensaios de dureza em corpos de prova resfriados nestas condições de $0,061^{\circ} \mathrm{C} / \mathrm{s}$ e $0,011^{\circ} \mathrm{C} / \mathrm{s}$ apresentaram os valores de 285 e $283 \mathrm{HV}$, respectivamente.

A Figura 2-22 apresenta os resultados de resfriamento a partir de $1020^{\circ} \mathrm{C}$ para liga de titânio Ti-6Al-4V. A análise da cinética de transformação de fase durante o resfriamento partindo de $1020^{\circ} \mathrm{C}$ se faz interessante para os casos onde existe um processamento cujas temperaturas superam a temperatura $\beta$-transus desta liga. 


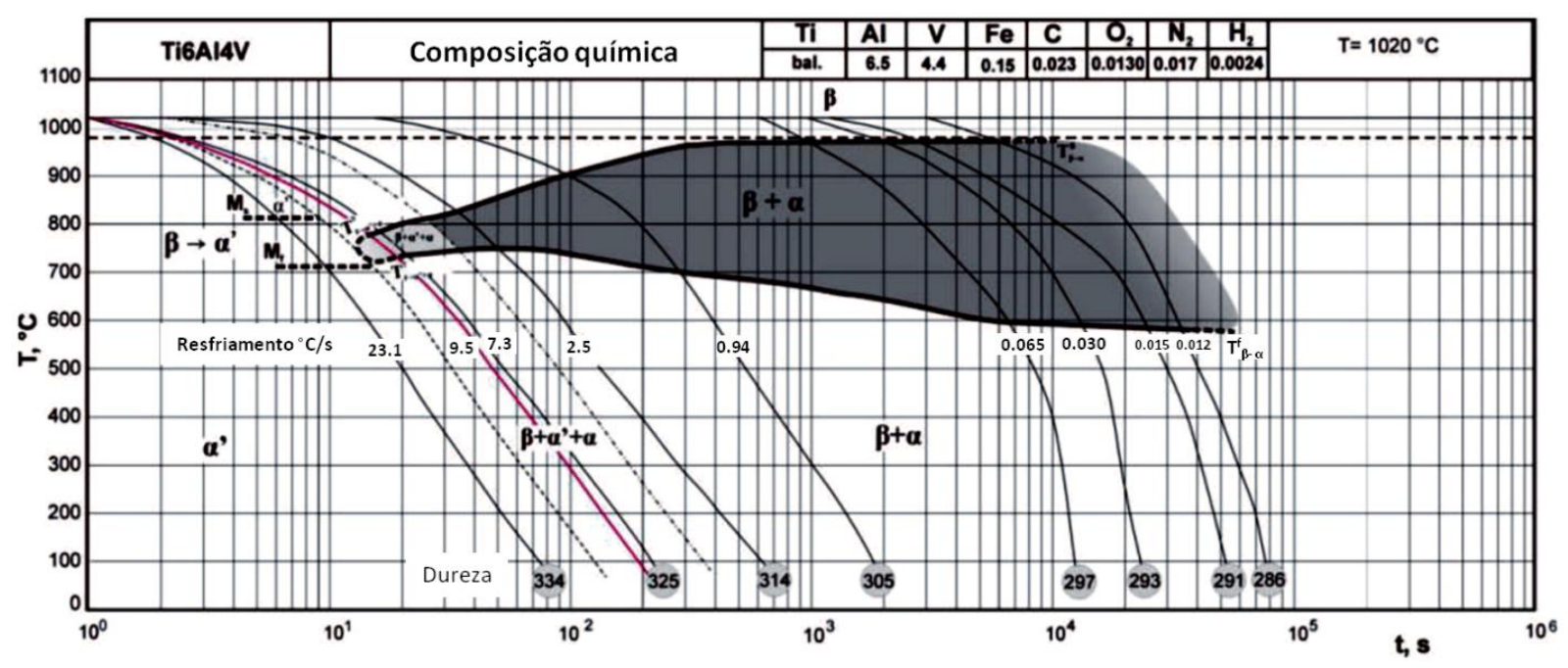

Figura 2-22 - Diagrama CCT para liga de titânio Ti-6Al-4V resfriado a partir da fase $\beta$ (DĄBROWSKI, 2011b).

Durante o resfriamento a $7,3^{\circ} \mathrm{C} / \mathrm{s}$ acontece a reação martensitica $\beta \rightarrow \alpha^{\prime}$ que coincide com a transformação o difusional $\beta \rightarrow \alpha$, na Figura 2-23(a) precipitados de $\alpha^{\prime}$ foram verificados justificando esta transformação na microestrutura. Entre as linhas tracejadas e linhas traço-ponto no diagrama CCT as temperaturas iniciais de finais de transformação foram marcados como $T_{\beta \rightarrow \alpha^{\prime+\alpha}}^{\mathrm{s}}$ e $T_{\beta \rightarrow \alpha^{\prime}+\alpha}^{\dagger}$, respectivamente. Além da linha traço-ponto, para taxas de resfriamento menores do que $2,5^{\circ} \mathrm{C} / \mathrm{s}$, apenas a transformação difusional $\beta \rightarrow \alpha$ ocorreu.

As microestruturas das amostras utilizadas para preparar o diagrama CCT são apresentados na Figura 2-23. Ao diminuir a velocidade de resfriamento de $23,1^{\circ} \mathrm{C} / \mathrm{s}$ para $7,3^{\circ} \mathrm{C} / \mathrm{s}$, surgem alterações significativas na microestrutura da liga Ti-6Al-4V (Figura 2-23-a). A microestrutura da Figura 2-23-b revelou inclusões escassas de fase $\alpha$ ' entre a fase $\alpha$ lamelar Widmannstatten. $\mathrm{Na}$ taxa de $2,5^{\circ} \mathrm{C} / \mathrm{s}$ placas orientadas da fase a precipitam e crescem como colônias Widmannstatten nos limites dos grãos $\beta$ primários para o centro do grão, mas uma fase $\alpha$ também ocorre como contorno de grão (Figura 2-23-c). Uma diminuição nas taxas de resfriamento de 0,94 a $0,065^{\circ} \mathrm{C} / \mathrm{s}$ resultam na ampliação das lamelas a (Figura 2-23-d -e). O resfriamento em $0,030^{\circ} \mathrm{C} / \mathrm{s}$ (Figura 2-23-f) ou mais lento (Figura 2-23-g) causa a mudança no aparecimento de fase a lamelar para granular acompanhado pelo crescimento de grãos (Figura 2-23-h). 

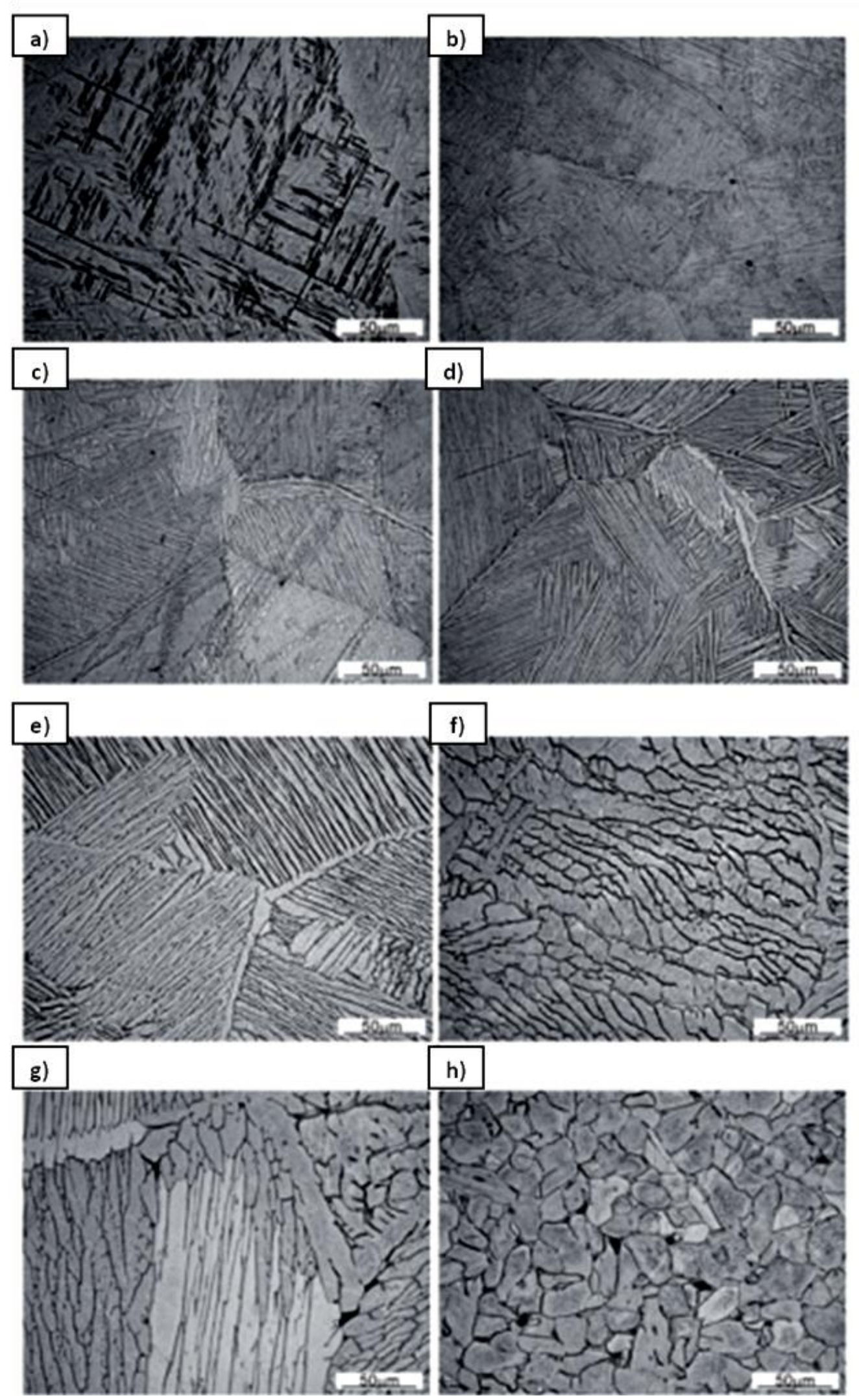

Figura 2-23 - Micrografias da liga Ti-6Al-4V resfriada de $1020^{\circ} \mathrm{C}$ à uma taxa de: $23.1^{\circ} \mathrm{C} / \mathrm{s}(\mathrm{a}), 7.3^{\circ} \mathrm{C} / \mathrm{s}$ (b), $2.5^{\circ} \mathrm{C} / \mathrm{s}(\mathrm{c}), 0.94^{\circ} \mathrm{C} / \mathrm{s}(\mathrm{d}), 0.065^{\circ} \mathrm{C} / \mathrm{s}(\mathrm{e}), 0.030^{\circ} \mathrm{C} / \mathrm{s}$ (f), $0.015^{\circ} \mathrm{C} / \mathrm{s}(\mathrm{g})$ e $0.012^{\circ} \mathrm{C} / \mathrm{s}$ (h) (DĄBROWSKI, 2011b). 
Não só a temperatura mas a deformação no material causam mudanças na microestrutura final, segundo Lütjering (LÜTJERING, 1998), além da temperatura a deformação plástica sofrida pelo material devido ao método de processamento também pode influenciar a microestrutura resultante (Figura 2-25). Em seu estudo Lütjering apresenta relações entre processamento por forjamento e microestrutura de ligas de titânio Ti-6Al-4V. Processos de trabalho a quente, em conjunto ou não com tratamento térmico, em especial na liga Ti-6Al-4V, permitem a obtenção de vários tipos de microestrutura como apresentados nas Figura 2-24a-e, (MOTYKA et al., 2007).

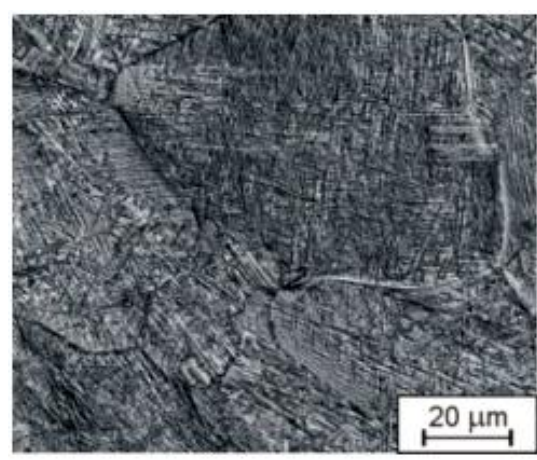

a)

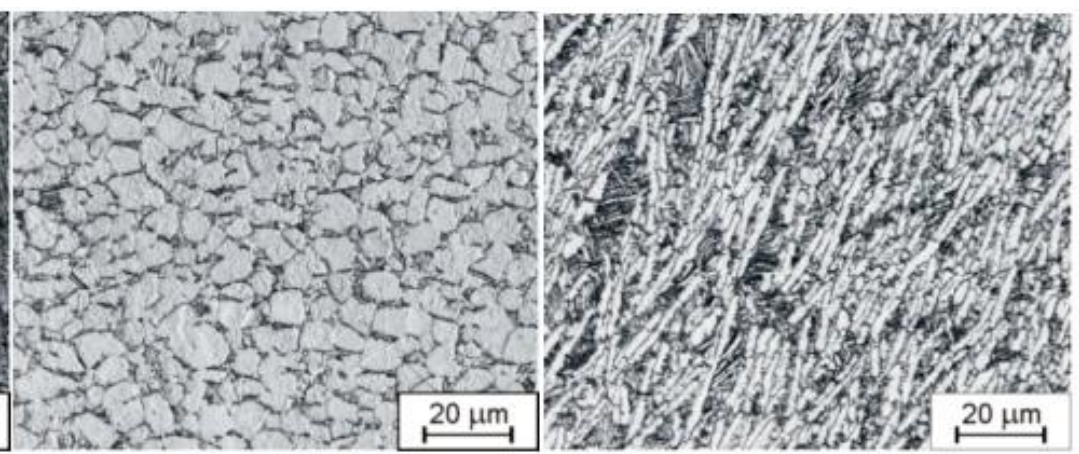

b) c)

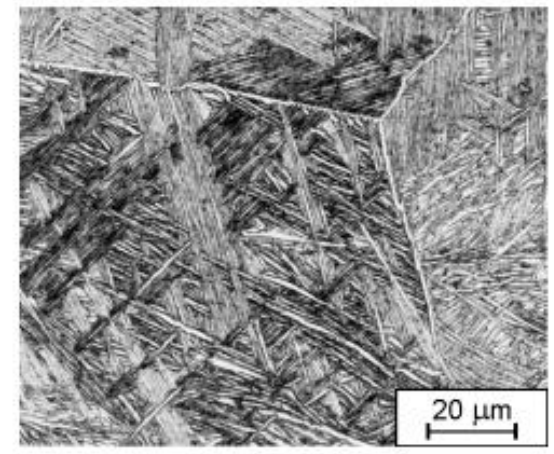

d)

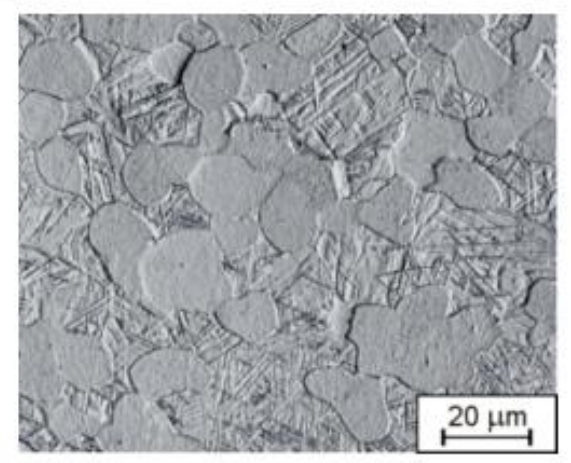

e)

Figura 2-24 - Possíveis microestruturas para a liga Ti-6Al-4V: (a) martensitica, (b) globular,(c) lamelar grossa, (d) lamelar fina, (e) bimodal (KUBIAK; SIENIAWSKI, 1998).

A deformação em uma liga de titânio com duas fases gera a distorção dos grãos da fase $\alpha$ e $\beta$, fragmentação dos grãos de $\alpha$ e sua posterior globularização conforme proposto por Seshacharyulu et al (SESHACHARYULU et al., 2000). 


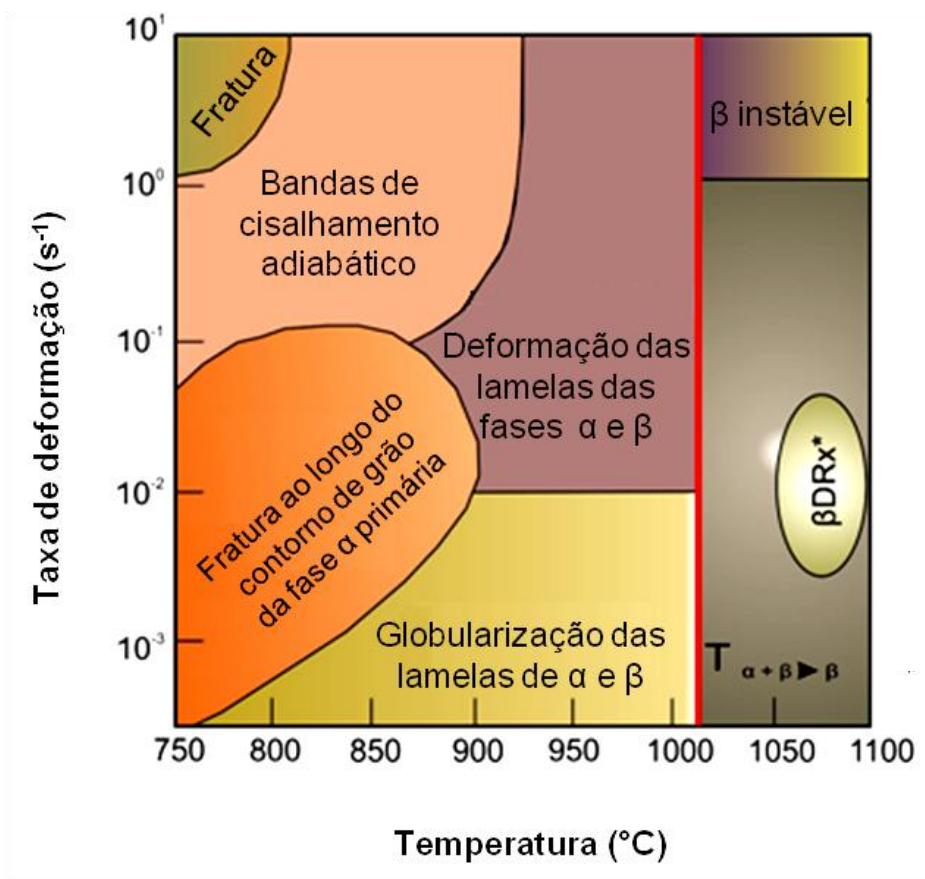

Figura 2-25 - Mapa microestrutural da liga Ti-6AI-4V, adaptado de (BABU, 2008).

*Recristalização dinâmica da fase $\beta$

O pesquisador Babu (BABU, 2008) propôs o mapa da Figura 2-25 relacionando as possíveis microestruturas resultantes das diversas combinações entre taxa de deformação e temperatura envolvidas em processos de conformação para o material da liga Ti-6Al-4V. Como resultado destes processos (Figura 2-26), grãos de fase $\alpha$ alongados se desenvolvem com uma orientação preferencial, geralmente dispostos ao longo da direção da deformação máxima. Acontece a geração de discordâncias de ambos os sinais ao longo da linha de cisalhamento, seguida de uma recuperação simultânea por deslizamento cruzado que leva à aniquilação das discordância de sinal oposto na intersecção de planos de deslizamento, deixando para trás grupos de deslocamentos com o mesmo sinal para nucleação de uma interface ao longo da linha de cisalhamento. Em seguida acontece uma migração de interfaces por difusão para minimizar a energia de superfície formando as estruturas globulares (SESHACHARYULU et al., 2000).

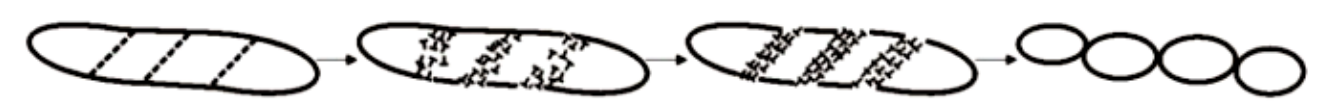

Figura 2-26 - O processo de deformação entre fases, fragmentação da fase $\alpha$ lamelar e sua globularização (Seshacharyulu et al., 2002). 
Kubiak e Sieniawski (KUBIAK; SIENIAWSKI, 1998) apresentam uma caracterização para liga Ti-6Al-4V após processo de deformação na temperatura acima da $\beta$-transus com posterior resfriamento ao ar. As seguintes microestruturas de fase $\alpha$ foram observadas (Figura 2-27):

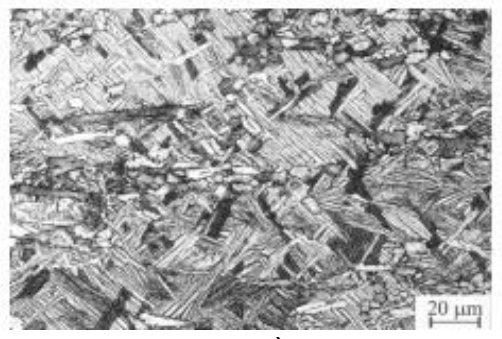

a)

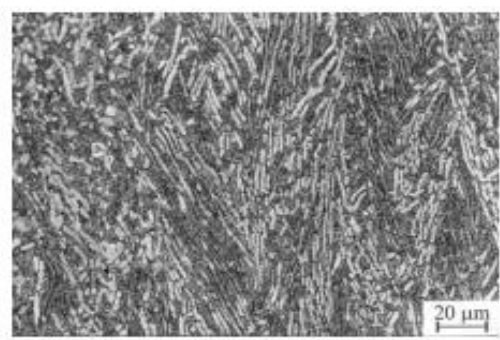

d)

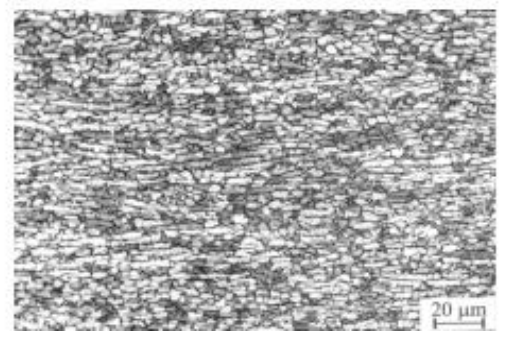

b)

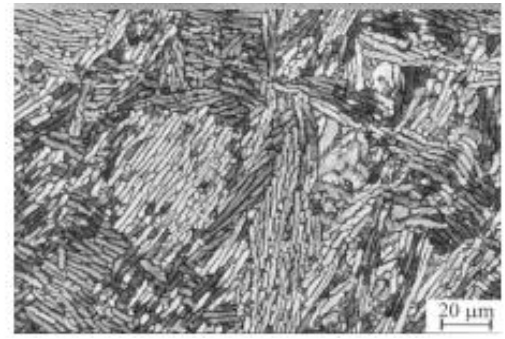

e)

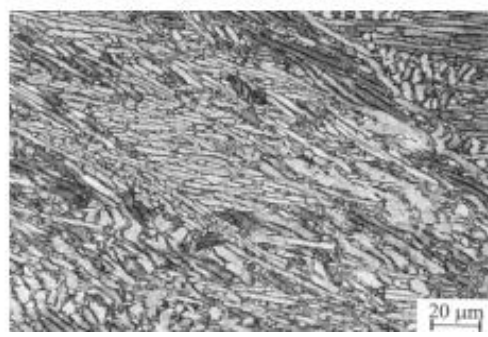

c)

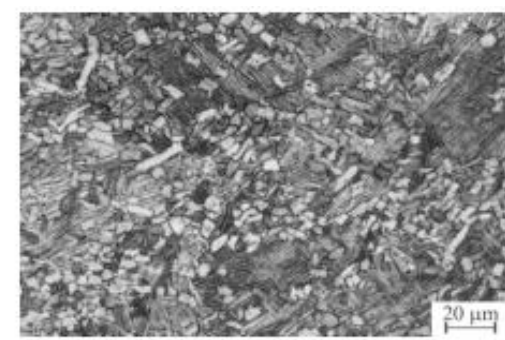

f)

Figura 2-27 - Microestruturas da liga Ti-6Al-4V após forjamento em matriz com temperatura acima da $\beta$-transus (Kubiak e Sieniawski, 1998).

- Grosseira lamelar, Widmanstätten- não deformada ou ligeiramente deformada, grande tamanho de lamelas de fase $\alpha$ primária. (Figura 2-27-c-e),

- Lamelar fina, Widmanstätten- lamelas de fase a formadas por resfriamento a partir de temperatura superior a $\beta$-transus à uma taxa de resfriamento ligeiramente inferior à 18K/s (Figura 2-27-a),

- Lamelar distorcida - (Figura 2-27-d) lamelas de fase a primária que foram fragmentadas e deformadas,

- Equiaxial - grãos de fase a formados por resfriamento lento a partir de temperatura superior à temperatura de transformação $\alpha+\beta \leftrightarrow \beta$ (Figura 2-27-b),

- Distorcida equiaxial - grãos de fase a distorcidos formados por resfriamento a partir de temperatura inferior à temperatura de transformação $\alpha+\beta \leftrightarrow \beta$ (Figura 2-27-f). 


\subsubsection{Ferramentas para FSW e FSP}

Processamento ou solda por atrito linear consistem em um processo de deformação termomecânico onde a temperatura na região em contato com a ferramenta se aproxima da temperatura solidus da peça.

A produção de uma região processada de qualidade exige a seleção de um material adequado para a ferramenta. O projeto da ferramenta é definido de acordo com a aplicação desejada, ou seja, é projetada para uma função específica. Muitas características diferentes nos materiais podem ser consideradas importantes para FSW, mas a classificação vai depender do material da peça, expectativa de vida da ferramenta, equipamento a ser utilizado e a experiência e conhecimento anterior do usuário. Além das propriedades físicas de um material, algumas considerações práticas podem auxiliar a seleção de materiais para ferramenta (MISHRA e MAHONEY, 2007, p. 7-35).

- Resistência em temperatura ambiente e em temperatura elevada: $O$ material da ferramenta deve ser capaz de resistir às altas cargas de compressão quando executa o primeiro contato com a peça. $E$ também deve possuir resistência suficiente ao cisalhamento em temperaturas enquanto durar o processo para evitar a fratura ou distorção da ferramenta. Atualmente a definição de materiais para ferramenta exige simulações computacionais complexas. No mínimo, o material candidato deve apresentar uma tensão de escoamento que suporte as tensões impostas durante o processo.

- Estabilidade em temperatura elevada: Além da resistência em temperatura elevada, a ferramenta deve ser capaz de manter a estabilidade dimensional durante o tempo de uso. Fluência é uma ocorrência típica em processamentos com comprimentos longos de percurso. Uma baixa resistência à fluência mudaria as dimensões da ferramenta durante a soldagem. Materiais para ferramentas de que derivam sua resistência de precipitados (materiais temperados ou trabalhados a frio) possuem temperaturas máximas definidas de uso. Ferramentas utilizadas acima destas temperaturas exibem com o tempo a perda de suas propriedades iniciais. 
- Resistência ao desgaste: Quando excessivo muda a geometria da ferramenta (mudando as características), alterando assim a qualidade da região processada e aumentando a probabilidade de defeitos. $O$ desgaste da ferramenta pode ocorrer por mecanismos como adesão, desgaste abrasivo ou a soma dos dois. O mecanismo de desgaste exato depende da interação entre o material da peça, da ferramenta e os parâmetros selecionados do processo.

- Reatividade da ferramenta: Materiais para ferramentas não devem reagir com a peça ou o ambiente, as propriedades da superfície da ferramenta geralmente mudarão de maneira negativa. $O$ titânio é bem conhecido por ser reativo em temperaturas elevadas. Reage com a maioria dos materiais convencionais de ferramenta, portanto a pesquisa por novas ligas para este material é importante.

- Tenacidade à fratura: Tenacidade à fratura da ferramenta desempenha um papel importante durante o mergulho da ferramenta e o processamento. As tensões locais e as tensões produzidas quando a ferramenta toca a peça são suficientes para quebrar uma ferramenta, mesmo quando métodos de atenuação são usados (furo-piloto, velocidade lenta na entrada e préaquecimento da peça de trabalho). É geralmente aceito que o movimento de mergulho produz os maiores danos a uma ferramenta. A excentricidade do eixo da máquina (movimento lateral durante a rotação do eixo) também deve ser considerada ao selecionar um material da ferramenta.

- Usinabilidade: Ferramentas FSW são projetadas com características que devem ser usinadas, retificadas ou eletroerudidas. Qualquer material que não pode ser processado para a fabricação de ferramentas FSW não deve ser considerado.

- Uniformidade e densidade na microestrutura: Materiais para ferramentas não são úteis se existirem variações locais na microestrutura ou densidade. Essas pequenas variações produzem regiões dentro da ferramenta, onde uma ruptura prematura pode ocorrer. Através da metalurgia do pó podemos fabricar ferramentas com diferentes densidades.

- Disponibilidade de materiais: Um material não é útil se um suprimento constante deste material não está disponível para fabricação das ferramentas. 
Isto é especialmente verdadeiro em um ambiente de produção, nos quais as especificações de produção determinam o uso de um material específico. $\mathrm{Na}$ Tabela 2-4 encontra-se um resumo dos materiais de ferramenta atualmente utilizados para processos FSW nos materiais e espessuras indicados.

\begin{tabular}{|c|c|c|}
\hline Ligas de & $\begin{array}{l}\text { Espessura } \\
{[\mathrm{mm}]}\end{array}$ & Material \\
\hline Alumínio & $<12$ & Aço Ferramenta, WC \\
\hline Magnésio & $<6$ & Aco Ferramenta, WC \\
\hline Cobre & $<50$ & Liga de Tungstênio, PCBN \\
\hline Titânio & $<6$ & Liga de W \\
\hline Aço Inoxidável & $<6$ & Liga de Tungstênio, PCBN \\
\hline Aço com baixa liga & $<10$ & PCBN, WC \\
\hline Níquel & $<6$ & PCBN \\
\hline
\end{tabular}

\subsubsection{Materiais para fabricação de ferramentas de FSW/FSP para ligas de titânio}

Ligas a base de tungstênio têm sido usados no FSW e FSP de ligas de niquelalumínio e ligas de titânio. Segundo Sanders e Ramulu et al. (SANDERS, RAMULU, et al., 2010, p. 7-35) e Mashinini (MASHININI, 2010) quatro materiais à base de tungstênio foram citados especificamente para construção de ferramentas: WC, W+25\%Re, Densimet (PLANSEE, 2011), e W+1\% $\mathrm{LaO}_{2}$. Ferramentas de tungstêniorênio tem uma alta temperatura operacional, mas sua construção é mais trabalhosa pois necessita de usinagem com retificação (mais difícil do que a usinagem convencional), e os materiais rênio e tungstênio possuem um custo elevado. Densimet consiste de pequenas esferas de tungstênio ligados em uma matriz contendo um ou outro material como níquel-ferro ou níquel-cobre. Esta liga não possui alta temperatura operacional (em relação a outras ligas tungstênio), no entanto, ao contrário de outras ligas de tungstênio (por exemplo tungstênio-rênio), Densimet é facilmente usinado por métodos convencionais e possui um custo menor. Outra liga a base de tungstênio é $\mathrm{W}+1 \% \mathrm{LaO}_{2}$, que tem o custo e a usinabilidade do Densimet mas a faixa de temperatura da liga tungstênio-rênio.

A Figura 2-28 apresenta a geometria básica para uma ferramenta para FSW e FSP para titânio onde: $R_{s}$ : Raio do ombro, $R_{p}$ : Raio do pino na base, $R_{p t}$ : Raio do pino na ponta, $L_{\text {pin }}$ altura do pino e $\alpha$ : Ângulo de conicidade. 


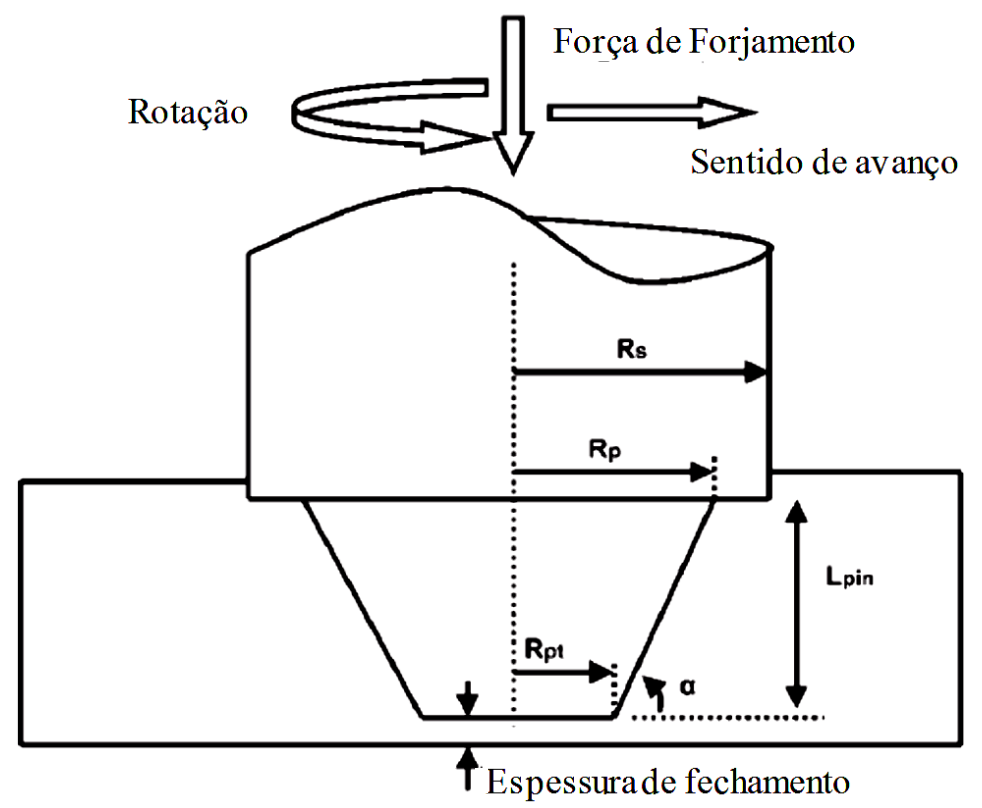

Figura 2-28 - Esquema geométrico básico de uma ferramenta para FSW e FSP (EDWARDS e RAMULU, 2009).

Segundo Edwards e Ramulu (2009) uma ferramenta cônica é necessária devido à baixa condutividade térmica do titânio. Ferramenta com projeto de dimensão de ombro grande e uma dimensão pequena no pino de geometria cilíndrica não é suficiente para titânio, porque o calor gerado no ombro não é capaz de fluir para a raiz da junta e permitir a mistura do material na região inferior da chapa.

Geralmente para ligas de titânio não são utilizados geometrias complexas no pino como, por exemplo, os vistos na Figura 2-29. Um dos motivos para este fato é a dificuldade em se usinar formas muito complexas em ferramentas de ligas de tungstênio.
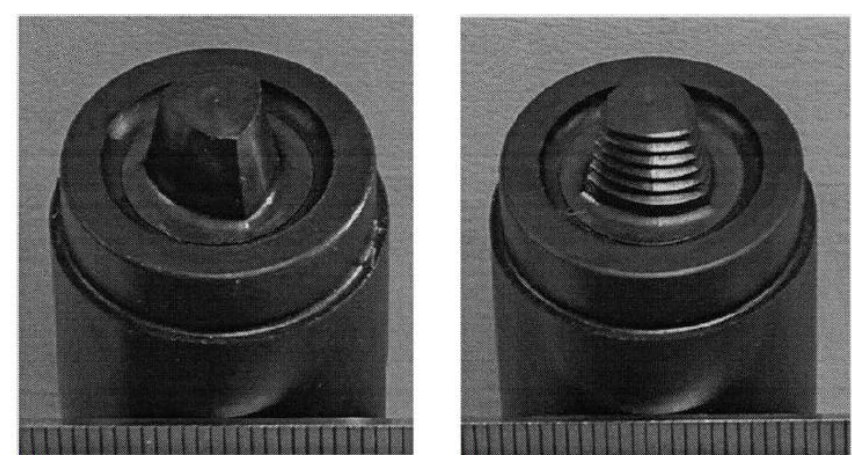

Figura 2-29 - Geometrias especiais para ferramentas FSW e FSP (MISHRA e MAHONEY, 2007) 


\subsubsection{Parâmetros para o Processamento por Atrito Linear de titânio}

O processamento de ligas de alta resistência como titânio envolve uma série de verificações prévias devido à suas características intrínsecas (grande resistência mecânica, baixa condutibilidade térmica e alta solubilidade com muitos materiais como visto no capítulo 2.1.2) que impõem dificuldades no seu processamento e conformação. O estudo e a correta aplicação dos parâmetros de processamento no FSW e FSP, como velocidade de tangencial $\left(\mathrm{V}_{\mathrm{C}}\right)$ que influencia a rotação da ferramenta e taxa de calor/energia envolvida, a velocidade de avanço (f) que está relacionada a taxa de deformação, são essenciais para a avaliação final da estrutura.

Diferentemente do alumínio, onde se encontra uma vasta gama de artigos publicados com FSW, o titânio ainda carece de mais estudos e desenvolvimento relacionados aos parâmetros empregados. A Tabela 2-5 apresenta as janelas de valores para o processamento de titânio, na literatura de FSW e FSP não se faz uso do parâmetro velocidade tangencial $\left(\mathrm{V}_{\mathrm{C}}\right)$, ao contrario é comum o uso da rotação da ferramenta como um parâmetro, existe neste conceito uma dependência implícita com a geometria do perfil utilizado. Na opinião deste autor o parâmetro $V_{C}$ seria o mais apropriado, pois sua dimensão independe da geometria de ferramenta utilizada. Na Tabela 2-5 são apresentados os valores em rotação tangencial (RPM, rotações por minuto), pois em algumas fontes a geometria da ferramenta não é apresentada, provavelmente por motivos de sigilo industrial.

Tabela 2-5 - Janela de parâmetros FSW e FSP para titânio - diversas fontes.

\begin{tabular}{|c|c|c|}
\hline Rotação [RPM] & $f[\mathrm{~mm} / \mathrm{min}]$ & the rus \\
\hline 200 & 100 & $\begin{array}{c}\text { Jata e Reynolds apud (SENKOV, MIRACLE e } \\
\text { FIRSTOV, 2004) }\end{array}$ \\
\hline 275 & 170 & $\begin{array}{c}\text { Lienert apud (MISHRA e MAHONEY, 2007, p. 123- } \\
\text { 154) }\end{array}$ \\
\hline $\begin{array}{l}150 \text { a } 750 \\
200 \text { a } 300\end{array}$ & $\begin{array}{l}50 \text { a } 200 \\
50 \text { a } 150\end{array}$ & $\begin{array}{l}\text { (EDWARDS e RAMULU, 2009) } \\
\text { (EDWARDS e RAMULU, 2010b) }\end{array}$ \\
\hline 400 a 500 & 60 a 80 & (RUSSELL, THREADGILL, et al., 2007) \\
\hline 140 a 320 & 40 a 130 & (GRUJICIC, ARAKERE, et al., 2011) \\
\hline 400 & 25 a 100 & (LIU, ZHOU e LIU, 2010) \\
\hline 150 a 400 & 50 a 300 & (SANDERS, RAMULU, et al., 2010) \\
\hline 450 a 950 & 55 a 160 & (MASHININI, 2010) \\
\hline
\end{tabular}

Além destas fontes é possível encontrar em (EDWARDS e RAMULU, 2010a) outras fontes de referências para parâmetros de processamento de ligas de titânio. 
Embora algumas das fontes citadas apresentem uma ampla faixa de valores ensaiados para cada parâmetro, os melhores resultados do processo acontecem em uma pequena faixa ou um único par de parâmetros (RPM e f).

Sanders e Ramulu et al (2010) em seu estudo avaliaram a capacidade de geração de microestruturas superplásticas a partir de FSP. Segundo Sanders, parâmetros de processo para a realização do FSP em titânio para geração de estrutura com uma deformação equivalente superplástica entre o material de base e a região processada se encontram em um intervalo de 150 a 400 RPM e velocidade de avanço entre 50 a $300 \mathrm{~mm} / \mathrm{min}$. Neste mesmo estudo ele apresenta resultados específicos para o par de parâmetros rotação de 325RPM e avanço $f$ de $100 \mathrm{~mm} / \mathrm{min}$, onde as amostras após o processo foram conformadas para avaliação do produto final. Devido aos parâmetros e condições utilizados foram encontrados defeitos após a conformação superplástica como pode ser visto na Figura 2-30.

O que se conclui é que a escolha dos parâmetros é de fundamental importância para se conseguir um bom resultado na conformação superplástica.

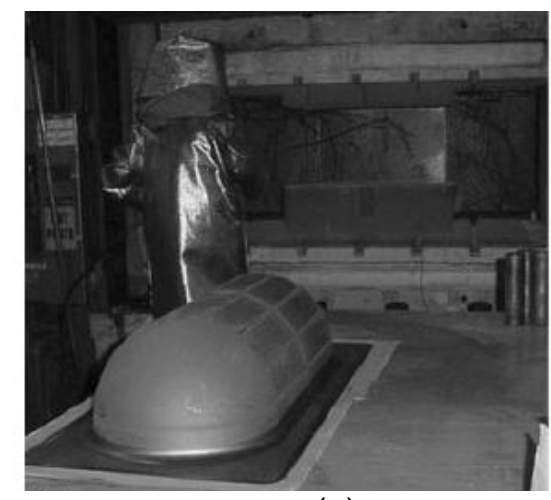

(a)

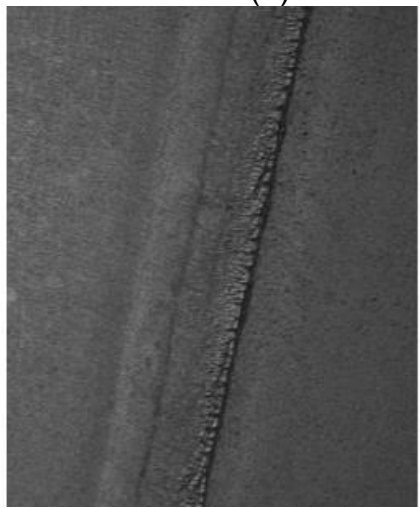

(c)

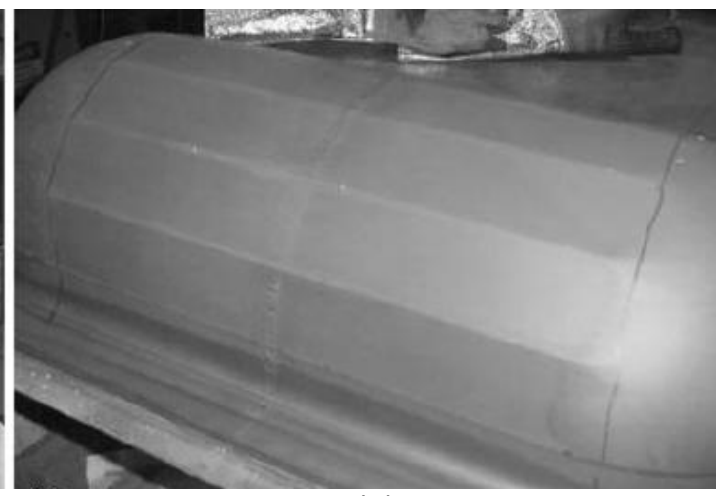

(b)

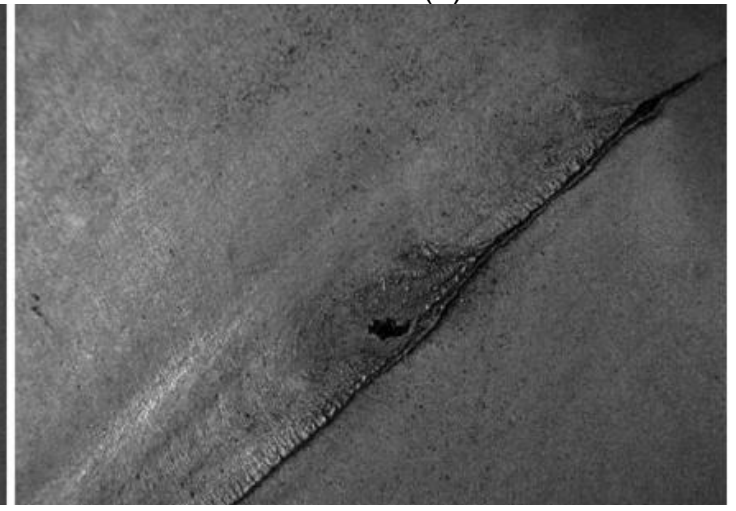

(d)

Figura 2-30 - (a) Peça conformada por superplasticidade, (b) detalhe da região modificada por FSP, (c) e (d) fotografia dos defeitos gerados pelo processo (SANDERS, RAMULU, et al., 2010). 
Além dos parâmetros principais que são a rotação e a velocidade de avanço, existe a necessidade do controle de outros fatores que exercem influência no resultado do processamento por FSW e FSP. Na Figura 2-31 encontramos mais seis parâmetros secundários envolvidos no processo que também podem ser responsáveis pela qualidade da região que sofreu o processamento:

$\mathrm{f}_{\mathrm{m}}$ : velocidade de mergulho, $\Phi$ : ângulo de inclinação, $F$ : força axial, $L_{r}$ : lado em retrocesso, $\mathrm{L}_{\mathrm{a}}$ : lado em avanço.

A velocidade de mergulho ou penetração é a responsável por iniciar o processo de preaquecimento da região a ser trabalhada para que se consiga uma poça de deformação, semelhante ao processo de solda tradicional. Deve ser imposta de maneira que $o$ atrito da ponta da ferramenta na peça seja suficiente para elevação da temperatura no local, e que não ocasione a fratura da ponta da ferramenta devido a algum esforço excessivo.
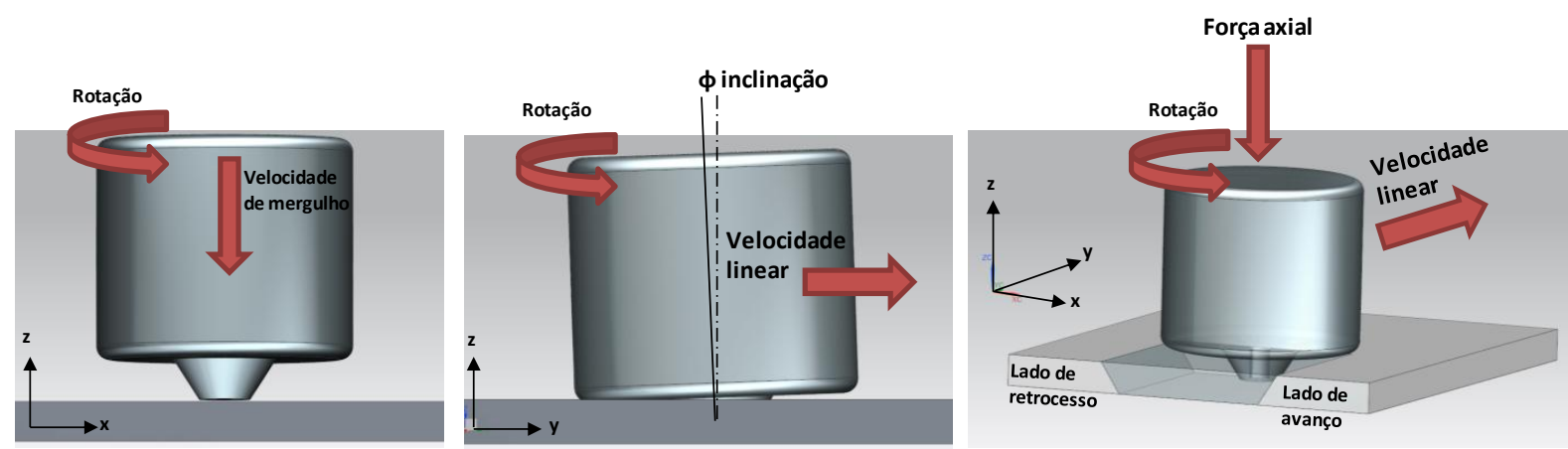

Figura 2-31 - Parâmetros envolvidos no FSW e FSP.

O ângulo de inclinação é utilizado para ajudar na conformação descendente do material abaixo da ferramenta. Semelhante a um processo de extrusão, com a diferença de que neste caso a ferramenta é quem gira, o material que está sofrendo a deformação plástica é coletado na frente da ferramenta devido à abertura provida pelo ângulo $\varphi$, é rotacionado entre os lados de avanço $\left(L_{a}\right)$ e lado de retrocesso $\left(L_{r}\right)$ e empurrado para baixo na posição onde a ferramenta está pressionando a peça devido à profundidade de penetração imposta na traseira da ferramenta.

A força axial é responsável por manter a rigidez do conjunto no processo e promover a contrapartida à força ascendente sofrida pela ponta e ombro da ferramenta, provinda da intensa conformação plástica na região. Com a deformação o material da peça força a ponta da ferramenta em um movimento ascendente, o que pode causar defeitos na superfície trabalhada como mostra a Figura 2-32. 
Fluxo insuficiente de Material

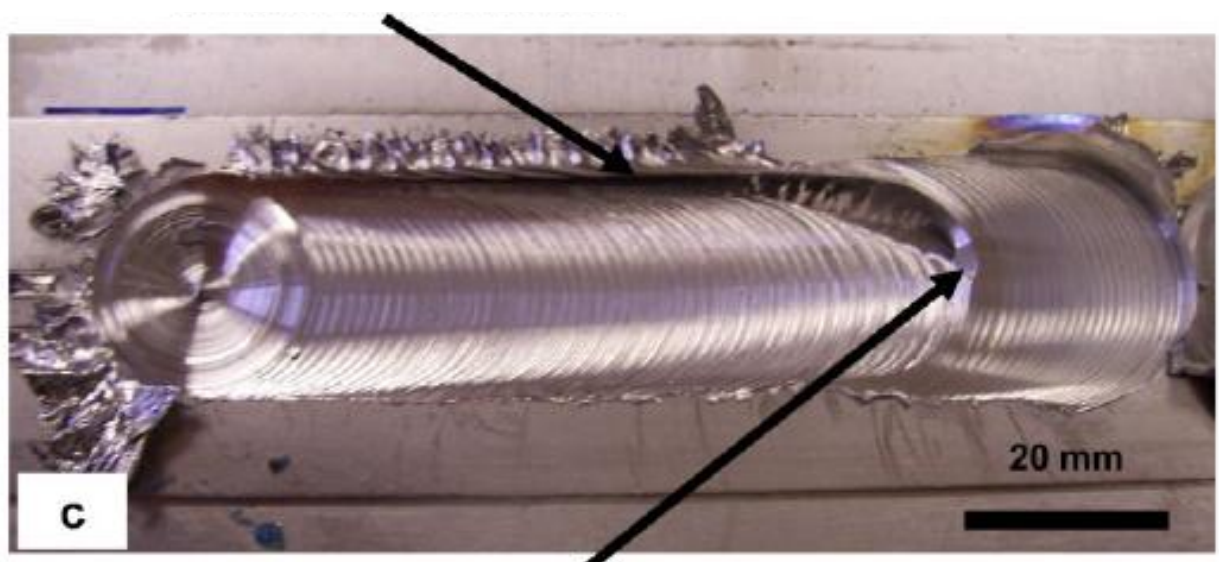

Ferramenta perdeu contato

Figura 2-32 - Defeito causado por falta de controle da força axial (EDWARDS e RAMULU, 2009).

Se todos os parâmetros são controlados de forma adequada a manter uma taxa de deformação constante o resultado é uma região processada e livre de defeitos internos como mostra a Figura 2-33, que apresenta o processamento executado em uma liga de titânio Ti-6Al-4V com rotação de 300RPM e $f$ de $100 \mathrm{~mm} / \mathrm{min}$.

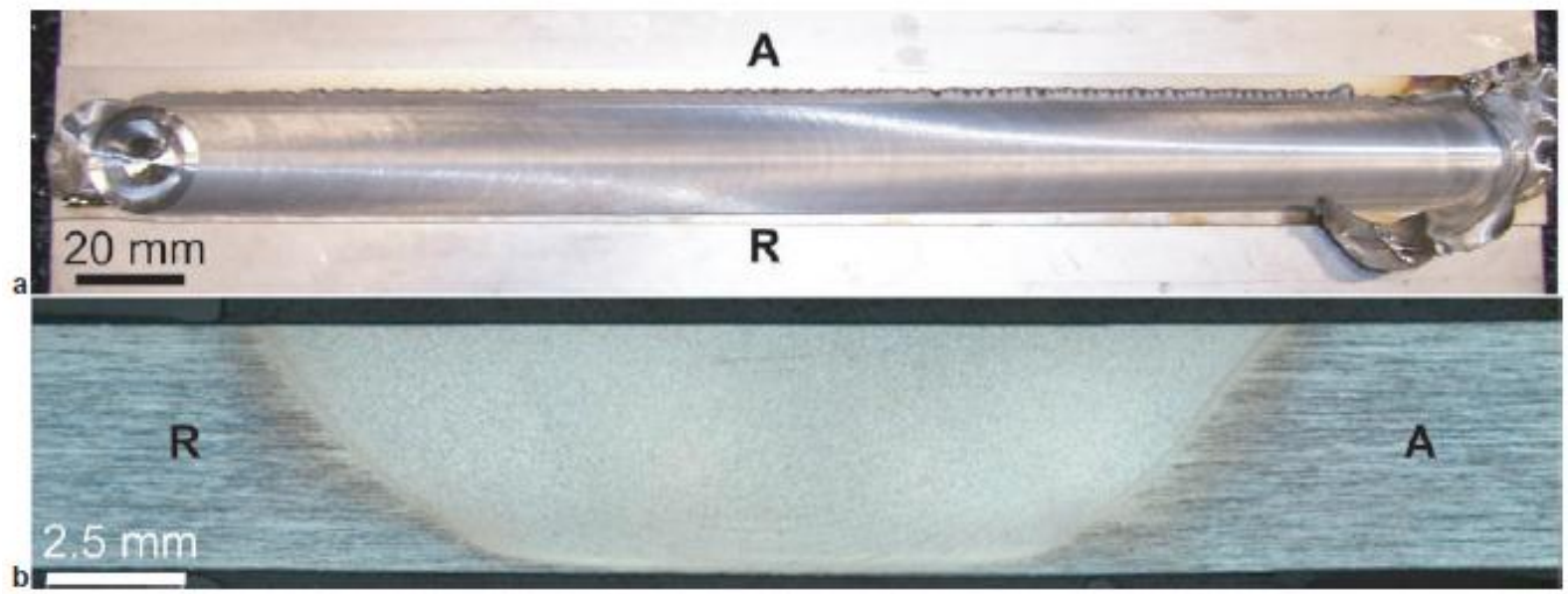

Figura 2-33 - Região processada com controle de todos os parâmetros envolvidos, (a) superfície e (b) estrutura livre de defeitos (EDWARDS e RAMULU, 2009).

A Figura 2-34 apresenta a mesma liga com defeitos internos na estrutura, os defeitos se encontram na região processada por condições não adequadas, estes defeitos irão causar provavelmente o refugo da peça final. 


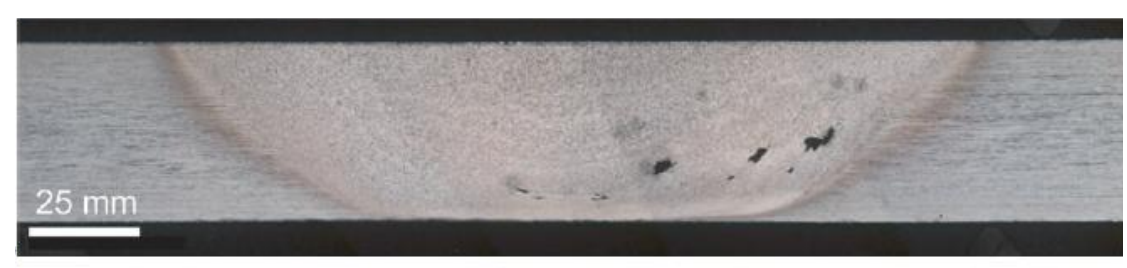

Figura 2-34 - Região processada com diferentes condições, RPM=750 e f=200mm $/ \mathrm{min}$ (EDWARDS e RAMULU, 2009).

Visando a redução de defeitos e falhas na entrada da ferramenta e no início do avanço para execução do FSW, Mashinini (2010) propôs a utilização de uma metodologia de rampa para estabilizar a rotação e a velocidade em função do comprimento a ser processado. A Figura 2-35a apresenta a rampa de estabilização da rotação em função da distância a ser processada e na Figura 2-35b a rampa de estabilização da velocidade de avanço em função da distância a ser processada. Este procedimento também ajuda a evitar sobrecargas que podem ocasionar a quebra da ferramenta.
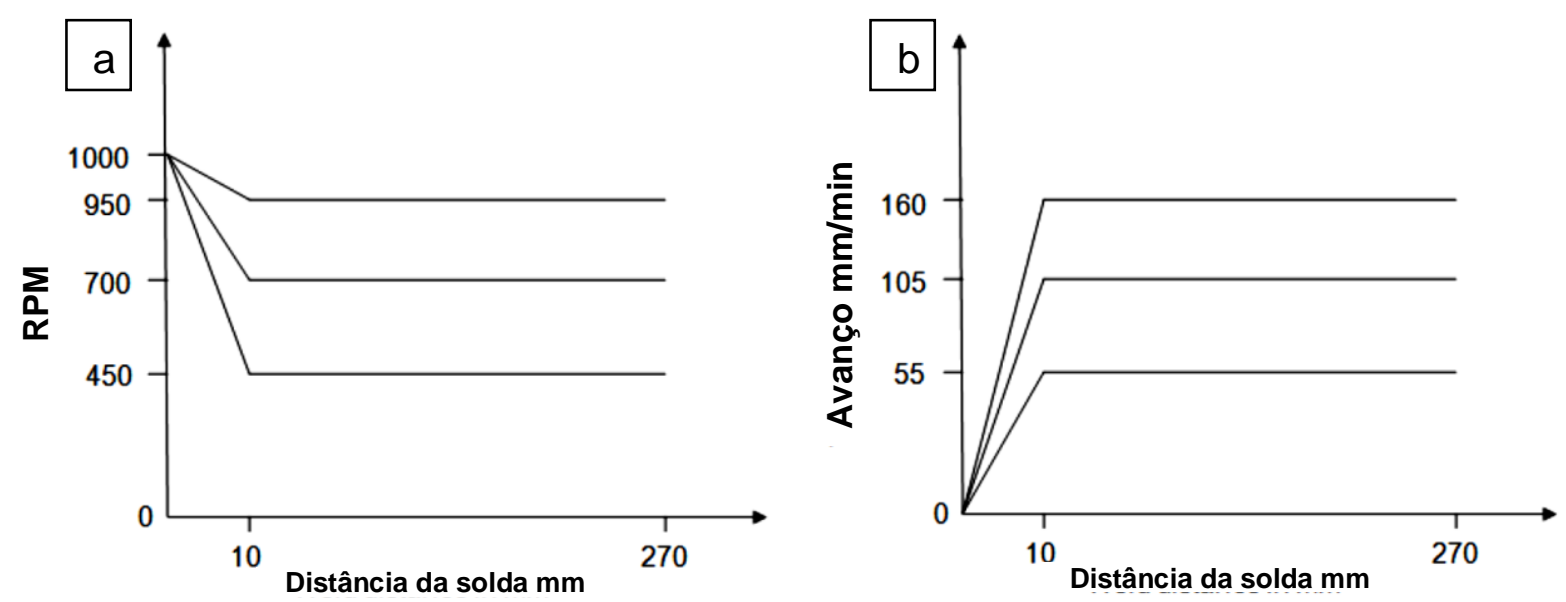

Figura 2-35 - Em (a): variação da rotação em função da distância a ser processada. Em (b): a variação da velocidade em função da distância a ser processada (MASHININI, 2010).

\subsubsection{Temperatura no processo de FSW e FSP}

O controle da temperatura durante o processamento é um fator de grande preocupação, pois não se trata de um parâmetro plenamente controlável, mas sim dependente de todas as condições envolvidas no processamento. A temperatura é um fator que resulta predominantemente do atrito ocorrido no par ferramenta-peça e pode ser relacionado aos parâmetros de rotação e velocidade de avanço. A medição da temperatura não é um procedimento simples de ser executado. Devido às 
características do processo e especialmente da ferramenta, os pontos ideais para medição ficam sem acesso aos dispositivos usuais como pirômetros e câmeras de infravermelho, pois se situam abaixo do ombro da ferramenta. A instalação de termopares no dispositivo de fixação é uma solução parcial, pois uma distância deve ser mantida para que ao passar na área do termopar a ferramenta não o danifique. $A$ instalação do termopar na ponta da ferramenta é um processo complicado, pois no caso de ferramentas em ligas de tungstênio é necessário a usinagem especializada com eletroerosão. Para a aquisição dos dados, é necessário o uso de um equipamento sem fio (wireless) por causa do movimento de rotação da ferramenta.

Em seus estudos Edwards e Ramulu (EDWARDS e RAMULU, 2010b) optaram pelas medições de temperatura com termopares efetuadas próximas da região onde acontece a deformação plástica provendo somente uma estimativa do que ocorre no interior da zona de processamento. A Figura 2-36 apresenta o projeto para instalação de termopares em uma placa de apoio para FSW em chapas de titânio.

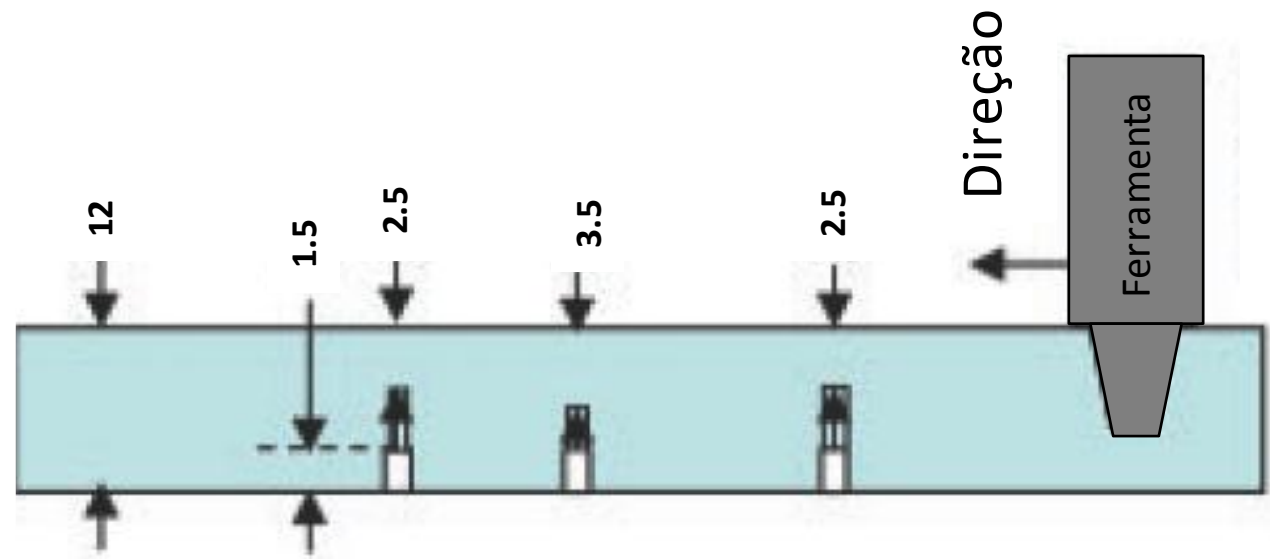

Figura 2-36 - Esquema para instalação de termopares em placa de apoio para FSW e FSP, dimensões em [mm] (EDWARDS e RAMULU, 2010b).

A Figura 2-37 apresenta as medições com termopares obtidas por Edwards e Ramulu Ramulu (EDWARDS e RAMULU, 2010b). Para a mesma condição de rotação e velocidades de avanço diferentes foram observados aproximadamente os mesmos valores de temperatura da ordem de $1000^{\circ} \mathrm{C}$. Apesar da variação na velocidade de avanço as temperaturas observadas não se alteraram significativamente. 


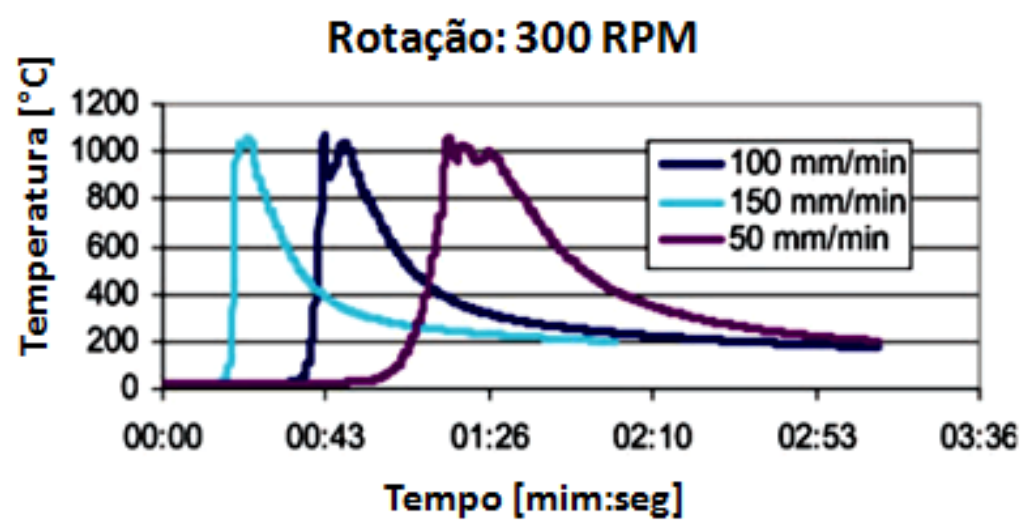

Figura 2-37 - Medição com termopares em placa Ti-6AI-4V (EDWARDS e RAMULU, 2010b) .

Em seu estudo Mashinini (2010), apresenta uma relação direta entre o valores de rotação e velocidade de avanço em função de uma estimativa de cálculo analítico da taxa de calor aplicada. A Tabela 2-6 apresenta na última coluna os resultados taxa de calor aplicado, quanto maior foi a taxa, maior foi a temperatura envolvida no processo. Embora Mashinini (2010) tenha proposto uma modelagem para o aporte de calor em seu estudo, efetivamente ele não efetuou a medição da temperatura envolvida nos seus ensaios.

Tabela 2-6 - Taxa de calor em função da rotação e velocidade de avanço (MASHININI, 2010).Sendo AS sentido de avanço e RS sentido de retrocesso.

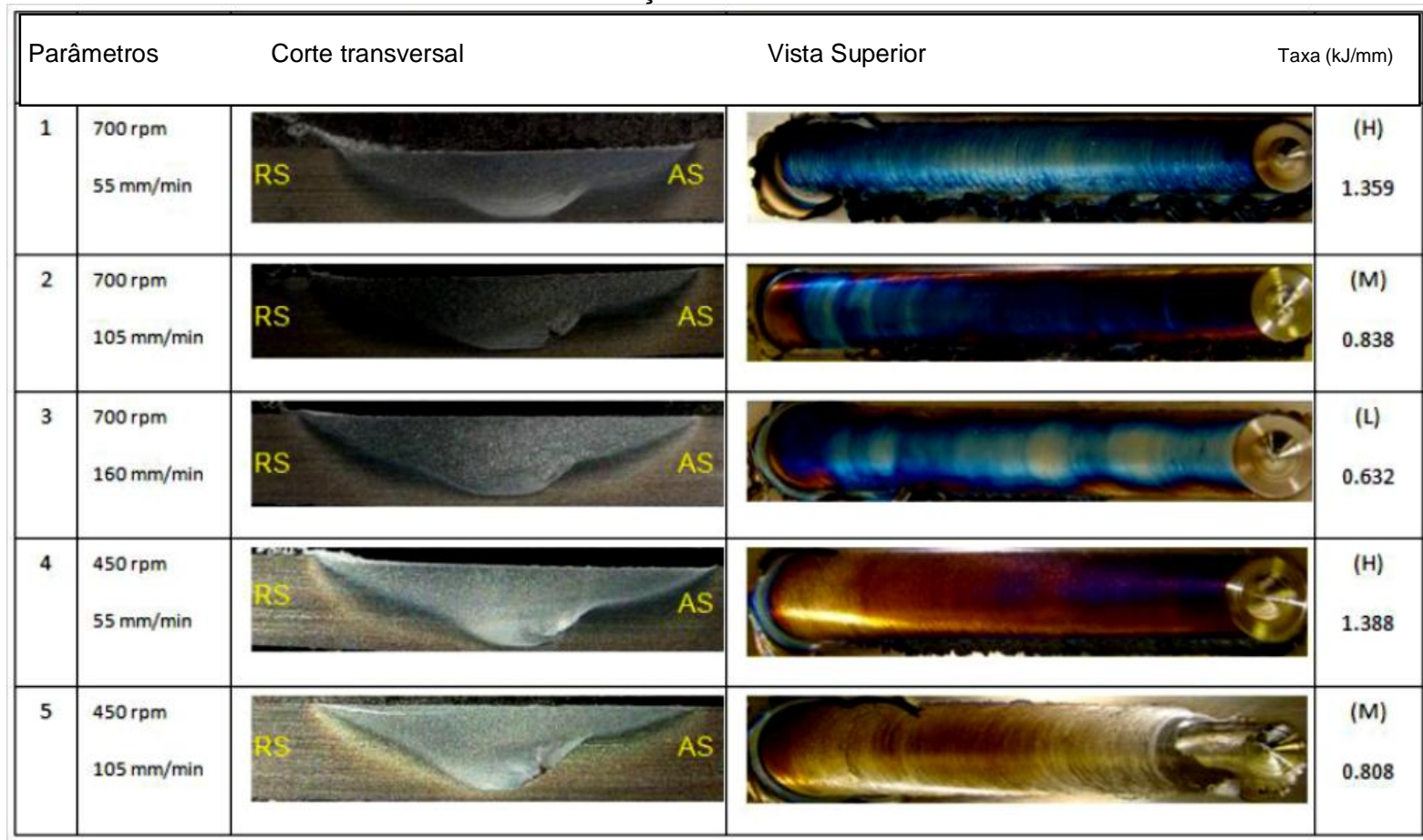


Alternativamente métodos numéricos também são empregados visando obter a distribuição da temperatura no interior do material e sua correlação com os parâmetros experimentais. A Figura 2-38 apresenta o resultado da simulação obtida por Buffa et al. (BUFFA et al., 2013) na liga Ti-6Al-4V em duas condições de aporte térmico: em (a) para condição de 700RPM com $35 \mathrm{~mm} / \mathrm{min}$ e em (b) para condição de 300RPM com $50 \mathrm{~mm} / \mathrm{min}$. É possível observar na Figura 2-38 a diferença e amplitude da temperatura nos dois casos, função dos diferentes valores de rotação e velocidade de avanço utilizados.

a)
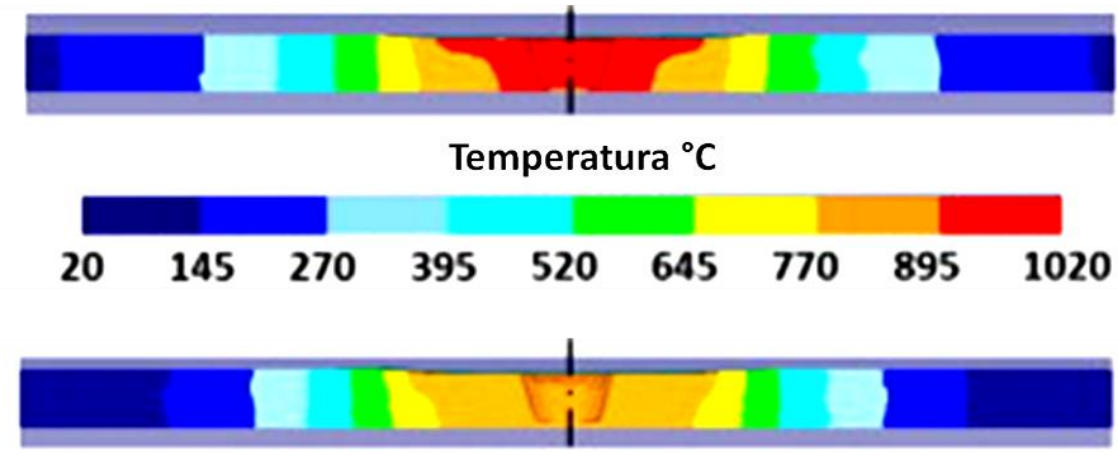

b)

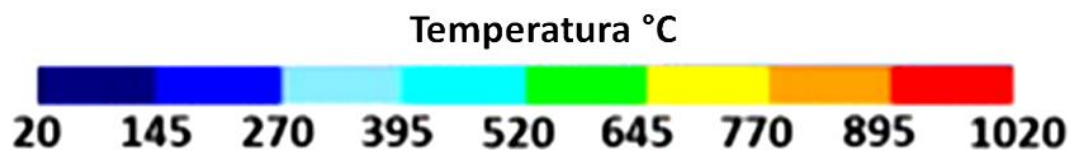

Figura 2-38 - Simulação em elementos finitos de distribuição da temperatura durante FSW em material Ti-6Al-4V, (a) rotação da ferramenta de 700RPMx35mm $/ \mathrm{min}$ e (b) rotação da ferramenta de 300RPMx50mm/min (BUFFA et al., 2013).

\subsection{Planejamento experimental fatorial}

A grande vantagem de se utilizar um planejamento experimental fatorial (PEF) de experimentos é a possibilidade de se estudar várias condições com um número reduzido de testes, o que gera uma grande economia em termos de valores e tempo sem perder a confiabilidade. A Figura 2-39 apresenta as relações existentes em um planejamento experimental onde o objetivo é obter a relação de dependência entre a saída e as variáveis estudadas.

Os princípios básicos de um planejamento experimental fatorial (PEF) compreendem o processo de planejamento dos experimentos, o processo de escolha do modelo e o processo de análise estatística. Os tipos de variáveis que podemos trabalhar em um planejamento podem ser: Quantitativas quando temos, 
por exemplo, valores reais ou janela de valores reais; e Qualitativa quando temos valores subjetivos como, por exemplo, marcas de produtos ou material de um produto.

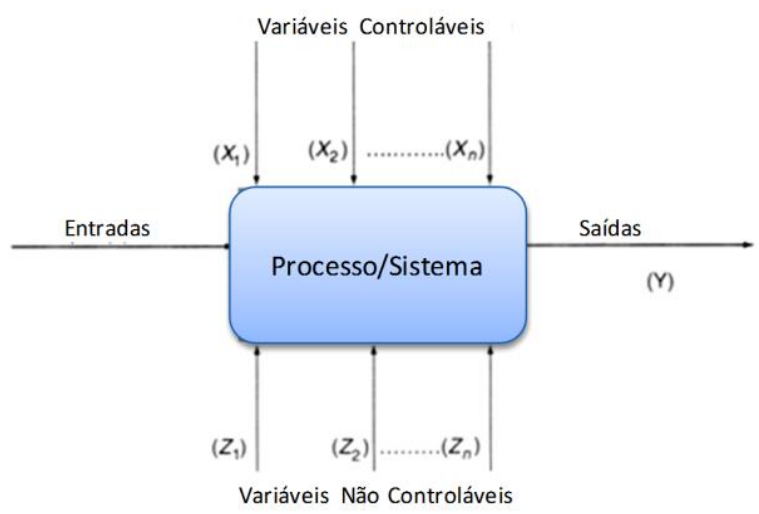

Figura 2-39 - Modelagem geral de um processo/sistema(ANTONY, 2003).

Segundo Antony (2003) e Montgomery (2001) existem três princípios básicos para se conseguir um PEF com elevado nível de confiança, são eles: Randomização, Replicação e quando necessário o Agrupamento.

- Randomização: Consiste em alterar a ordem dos experimentos. Visa atenuar "ruídos" no processo: vibrações, erros de operação, flutuação do ambiente, diferenças entre o material ou fatores que são difíceis de controlar. A randomização garante que todos os níveis dos parâmetros tenham chance de ser afetados pelos ruídos. É muitas vezes considerada uma política de garantia para os pesquisadores. Pode-se randomizar restritamente (os valores ou os parâmetros) para economia de tempo. Entretanto deve-se sempre considerar alguns fatores como: qual o custo para randomização, qual será o tempo e dificuldade de preparação (setup) entre as trocas, quantos e quais fatores são caros ou difíceis de controlar. Nos casos onde processo é muito estável ou se for incorporada a análise de ruídos ao experimento a randomização pode ser excluída.

- Replicação: Consiste em replicar todo o experimento ou uma parte do mesmo, possibilita a obtenção de uma estimativa do erro experimental e possibilita a obtenção mais precisa da estimativa dos efeitos da interação entre os parâmetros. A replicação aumenta o tempo e custo do experimento, portanto deve ser bem avaliada. Replicar é diferente de repetir, replicar consiste em passar por todo o planejamento da corrida uma vez e depois 
repetir novamente. Já repetir consiste em executar a mesma corrida n vezes e depois passar para próxima. Esta opção é mais econômica, pois há redução na preparação (setup) do experimento. Deve ser utilizada com cautela, pois pode vir a mascarar os erros provenientes da preparação do ensaio.

- Agrupamento: O objetivo principal é eliminar fontes de erro devido às diferenças de lote entre os lotes, de dia após dias de testes, entre os turnos e outros fatores que podem atribuir tendências aos experimentos. $O$ agrupamento é menos usado, pois é geralmente aplicado em longos experimentos.

\subsubsection{Interação de Variáveis}

Em processos industriais a interação entre variáveis ou parâmetros de processos é uma grande preocupação. Em muitos casos a interação de fatores é o principal gerador do efeito a ser estudado até mais do que um parâmetro somente.

Interações ocorrem quando o efeito de um parâmetro depende do nível de outro parâmetro do processo. A avaliação das interações é facilmente observada graficamente como mostra a Figura 2-40, se as linhas fossem paralelas não existiria interação, ou seja, variando um parâmetro não afeto o outro. Se não forem paralelas haverá interação, e, quanto menos paralelas maior será a interação.

A avaliação do grau de interação pode ser Sinergistica: quando as linhas não se cruzam gerando uma interação aproximadamente baixa; ou Antagonista: As linhas se cruzam gerando uma interação aproximadamente alta.

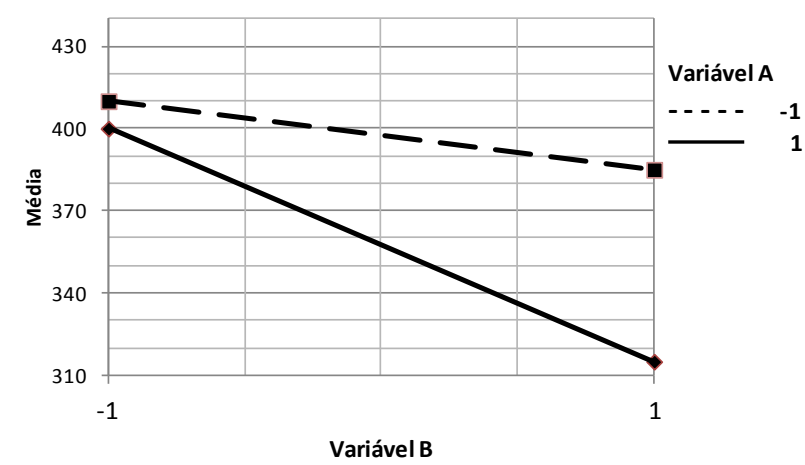

Figura 2-40 - Avaliação de interação entre dois parâmetros em um mesmo experimento. Adaptado de (ANTONY, 2003). 


\subsubsection{Metolologia para criação de um PEF}

A metodologia para criação de um planejamento experimental fatorial pode ser dividida em quatro fases (MONTGOMERY, 2001). A primeira sendo o planejamento inicial, segunda é a escolha do modelo, a terceira é a condução do experimento e por fim analise dos resultados. Esta divisão sistemática ajuda a compreender o problema e a definir a melhor maneira de analisar os diferentes parâmetros envolvidos no processo. Ao fim do processo os resultados são enriquecidos por embasamentos estatísticos que eliminam possíveis subjetividades e opiniões tendenciosas, que invariavelmente acontecem no decorrer de trabalhos extensos onde muita informação é processada.

\subsubsection{Planejamento inicial}

Todo o planejamento começa com a identificação do problema e sua formulação, passando pelo desenvolvimento e análise da situação atual. Na seleção das respostas, devemos pensar no que é importante a ser obtido visando eliminar fatores que não trarão resultados. Seleção das variáveis/parâmetros pertinentes ao processo, neste ponto conhecimento prévio do processo ajuda com histórico sobre as variáveis envolvidas, se um parâmetro importante é deixado de lado toda a análise pode ser comprometida.

\subsubsection{Escolha do Modelo}

- Planejamento fatorial completo: consiste em um experimento com todas as possíveis combinações para todos os fatores. O numero total de experimentos para estudar $k$ fatores em dois níveis é $2^{k}$. Para estudos iniciais utiliza-se um número de fatores $\mathrm{k}$ menor ou igual a quatro. Uma das premissas é que as respostas são uma função linear dos fatores envolvidos.

- Planejamento fatorial fracionado: Comumente pesquisadores não possuem tempo adequado, recursos e orçamento para efetuar planejamento fatorial completo. Se os pesquisadores podem assumir razoavelmente que certa interação entre fatores de ordem grande (terceira ordem ou mais) pode ocorrer e não são importantes, então a informação sobre os fatores principais e a interação 
entre segunda ordem pode ser obtida com o uso somente de uma fração do experimento fatorial completo. Um tipo de matriz ortogonal que possibilita o estudo dos fatores principais e suas interações em um número reduzido de experimento é chamado de planejamento fatorial fracionado.

- Níveis para os fatores: planejamentos fatoriais com mais de dois níveis $(\geq 3)$ não são muito utilizados na indústria onde uma relação linear é mais prática (dois níveis). Quantidade de níveis maiores do que dois são importantes quando se esperam uma curvatura na função de resposta, a função resposta se torna quadrática. Porém duas observações importantes são que: planejamentos fatoriais de $3^{k}$ não são o meio mais eficiente para se estudar função quadrática, modelos por superfície de resposta são superiores (MONTGOMERY, 2001).

- Adição de pontos centrais ao planejamento fatorial $2^{\mathrm{K}}$ : $\mathrm{A}$ presunção de linearidade da função resposta em um fatorial $2^{k}$ é uma potencial fonte de incerteza. Fenômenos lineares são plenamente descritos com um sistema $2^{k}$ em uma elevada precisão. Se os termos de interação são adicionados a um modelo de primeira ordem então teremos um modelo capaz de representar alguma curvatura na função resposta. Existe um método de replicação de certos pontos em um fatorial $2^{\mathrm{K}}$ que promovem proteção contra efeitos de curvatura de segunda ordem e possibilitam estimativas independentes de erro.

No estudo de Elangovan et al (2008) que avaliou juntas de alumínio unidas por FSW para modelar o comportamento de resistência à tração, propuseram um planejamento fatorial composto centrado para análise dos quatro fatores mais importantes segundo seu critério e em cinco níveis diferentes. A Tabela 2-7 apresenta os parâmetros e seus níveis.

Tabela 2-7 - Fatores e níveis para estudo de FSW em ligas de alumínio (ELANGOVAN, BALASUBRAMANIAN e BABU, 2008).

\begin{tabular}{cccccccc}
\hline & & \multicolumn{5}{c}{ Níveis } \\
\hline $\mathrm{N}^{\mathbf{0}}$ & Parâmetro & Unidade & $\mathbf{( - 2})$ & $\mathbf{( - 1 )}$ & $\mathbf{( 0 )}$ & $\mathbf{( - 1 )}$ & $\mathbf{( - 2 )}$ \\
\hline $\mathbf{1}$ & $\begin{array}{c}\text { Perfil da } \\
\text { Ferramentata }\end{array}$ & - & Cilíndrica & Roscada & Quadrada & Triangular & Facetada \\
\hline $\mathbf{2}$ & RPM & $\mathrm{RPM}$ & 1400 & 1500 & 1600 & 1700 & 1800 \\
\hline $\mathbf{3}$ & Avanço & $\mathrm{mm} / \mathrm{s}$ & 0.25 & 0.5 & 0.75 & 1.0 & 1.25 \\
\hline $\mathbf{4}$ & Força Axial & $\mathrm{kN}$ & 8 & 10 & 12 & 14 & 16 \\
\hline
\end{tabular}


É possível verificar que a Tabela 2-7 possui parâmetros quantitativos (rotação, velocidade de avanço e força axial) e parâmetros qualitativos como o perfil da ferramenta utilizada. Esta versatilidade do planejamento experimental fatorial em avaliar parâmetros qualitativos é de grande ajuda na composição das conclusões dos resultados. Ela enriquece os resultados com um embasamento estatístico evitando assim inferências subjetivas. O modelamento da disposição dos níveis pode ser encontrado em referências mais específicas para o estudo de PEF (BOX, HUNTER e HUNTER, 2005). Neste exemplo foram utilizados trinta e um ensaios e mais condições foram avaliadas com os cinco níveis dos parâmetros, se comparado com o ensaio de Koç ET al (2011) foram economizados quatorze ensaios, o que certamente gerou uma economia final sem perda de qualidade estatística na análise dos resultados.

\subsubsection{Planejamento Robusto}

Um aspecto importante de qualquer processo de produção é o controle da sua qualidade. Tipicamente, isto é realizado durante a fase de produção do processo. Várias formas de inspeção por amostragem podem ser aplicadas para garantir que o produto atenda à determinadas características específicas e que também o processo está sob controle (HINKELMANN; KEMPTHORNE, 2005).

Planejamento robusto, é um método de engenharia para projeto de produto ou processo que se concentra em minimizar a variação e/ou sensibilidade a ruídos. Quando utilizado corretamente, proporciona um método poderoso e eficaz para a criação de produtos que operem de forma consistente e de forma ótima sobre uma variedade de condições. O principal objetivo é encontrar configurações de fatores que minimizam a variação de resposta. Depois de determinar que fatores afetam a variação, você pode tentar encontrar definições para fatores controláveis que reduzem a variação. Um processo desenvolvido com este objetivo irá produzir uma saída mais uniforme e um desempenho mais consistente, independentemente do ambiente em que é utilizado.

O conhecimento prévio do processo deve orientar a seleção de fatores e as respostas (FOWLKES; CREVELING, 1995). Quando as interações entre os fatores de controle são susceptíveis ou não bem compreendidas, você deve escolher um planejamento que seja capaz de estimar essas interações. Fatores de ruído para o 
planejamento também devem ser cuidadosamente selecionados e podem exigir um teste preliminar. Os níveis de ruído selecionados devem refletir a variedade de condições em que a variável resposta deve permanecer coerente.

O planejamento robusto usa matrizes ortogonais, que the permite analisar vários fatores com poucos experimentos. São equilibradas, isto é, não possuem variação na ponderação para mais ou menos numa experiência, permitindo assim que os fatores a sejam analisados de forma independente um do outro. 


\section{Dispositivos de ensaios multiaxiais}

A caracterização do comportamento mecânico dos materiais pode ser obtida com a realização de ensaios padronizados, sendo os mais básicos deles o ensaio de tração e compressão uniaxial. Embora bastante empregado o ensaio de tração uniaxial fornece informação para uma condição carregamento e em uma direção somente, e para uma caracterização mais abrangente, próxima das condições reais de utilização de um componente, outras condições devem ser levadas em consideração (KUWABARA, 2014). Segundo Wagner et al, (WAGNER et al., 2012) a caracterização experimental da condição de escoamento de um material e sua descrição da superfície de escoamento, tais como em chapas é um desafio científico, e, em especial na condição de materiais que apresentam assimetria entre situações de tensão e compressão.

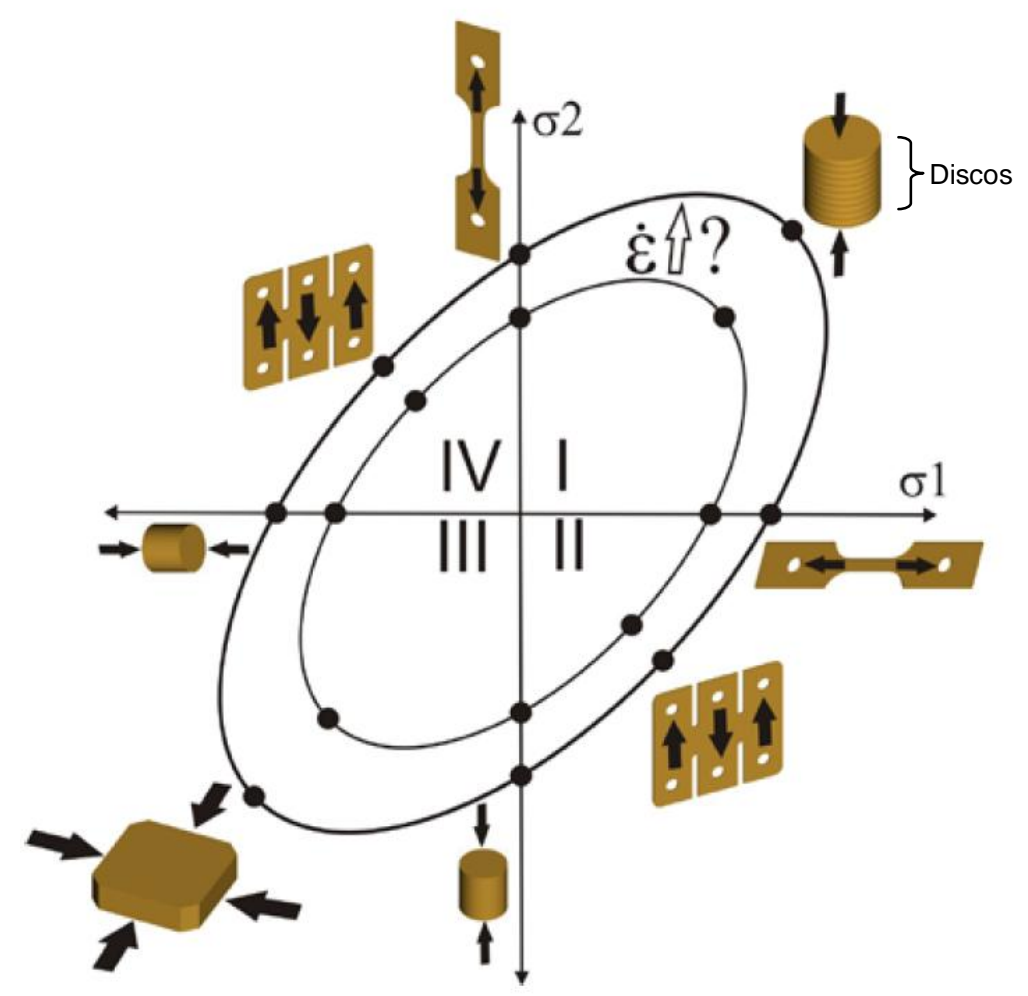

Figura 3-1 - Diferentes abordagens e corpos de prova utilizados em estudos experimentais de caracterização (WAGNER et al., 2012)

A Figura 3-1 apresenta as possíveis abordagens experimentais para caracterizar a superfície de escoamento de materiais. Os diferentes corpos de prova utilizados nestes estudos de diferentes estados de tensão também são apresentados esquematicamente. 
Diversos equipamentos de testes capazes de representar estados planos de deformação em estados simples de tração, cisalhamento e em condição multiaxial têm sido propostos (PIJLMAN, 2001; FLORES, 2005; KUWABARA, 2007, 2014). Abaixo são apresentados alguns exemplos juntamente com uma comparação em função de sua empregabilidade. O desempenho do equipamento é avaliado de acordo com a flexibilidade e a simplicidade do desenho do corpo de prova (FLORES, 2005).

\subsection{Teste Kuwabara}

A Figura 3-2a mostra o dispositivo de teste de tensão biaxial utilizado por Kuwabara et al., 1998. Constituído de pares de cilindros hidráulicos conectados a linhas hidráulicas comuns, de modo a serem submetidos à mesma pressão hidráulica, controlados independentemente por um servo acionamento. Os deslocamentos dos cilindros hidráulicos opostos são equalizados usando um mecanismo de ligação do tipo pantógrafo, mantendo o centro da amostra cruciforme (Figura 3-2b) no centro da máquina de teste durante os testes biaxiais. Para cada direção de carregamento existe uma célula de carga incluída na montagem. As componentes de deformação biaxial na seção da amostra são medidos através de extensômetros biaxiais.
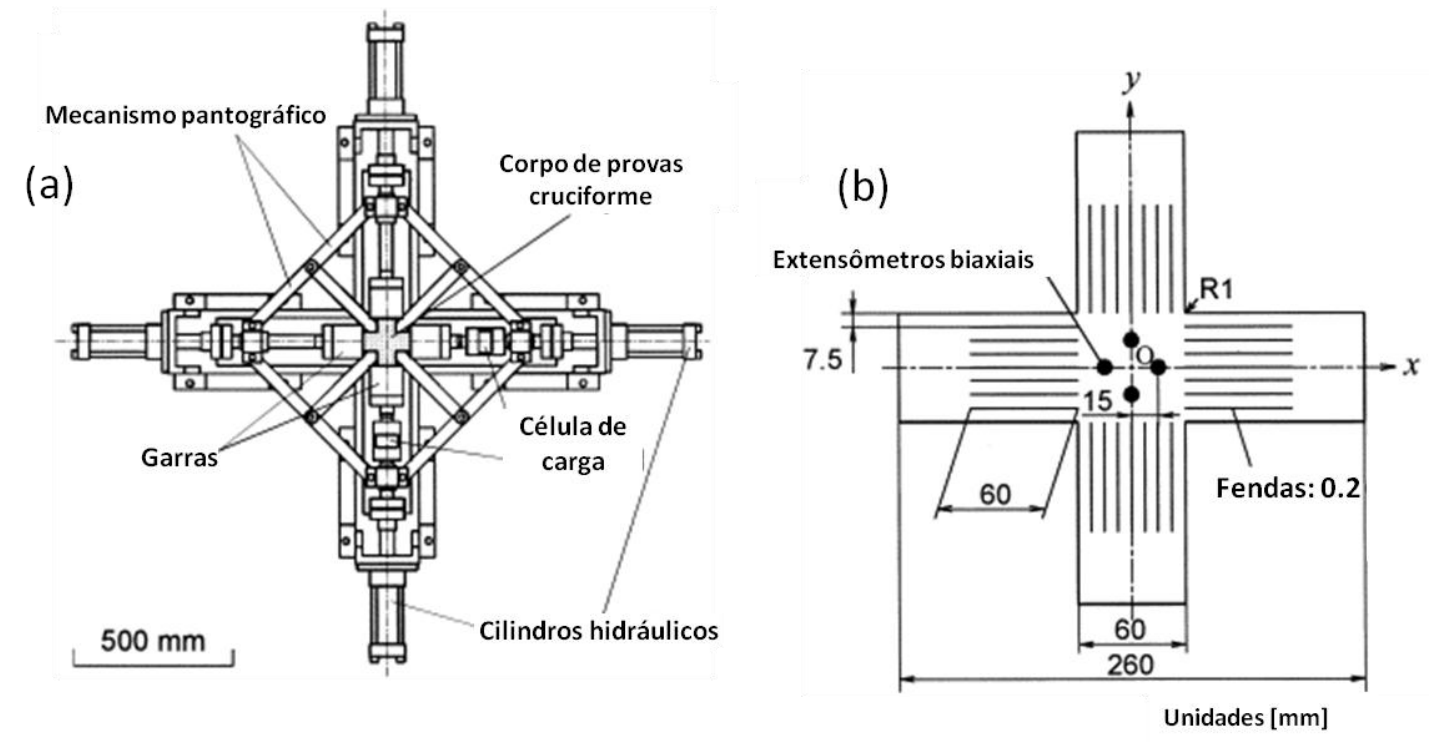

Figura 3-2 - Dispositivo de teste de tensão biaxial (a), em (b) corpo de provas em formato cruciforme.(KUWABARA et al., 1998) 


\subsection{Teste de cisalhamento de Miyauchi}

Este teste foi proposto por Miyauchi (MIYAUCHI, 1984), o sistema de fixação e o corpo de provas estão apresentados na Figura 3-3a, Figura 3-3b, Figura 3-4a e Figura 3-4b. Este teste pode ser usado para estudar o efeito Bauschinger e execução de testes com altos valores de deformação.

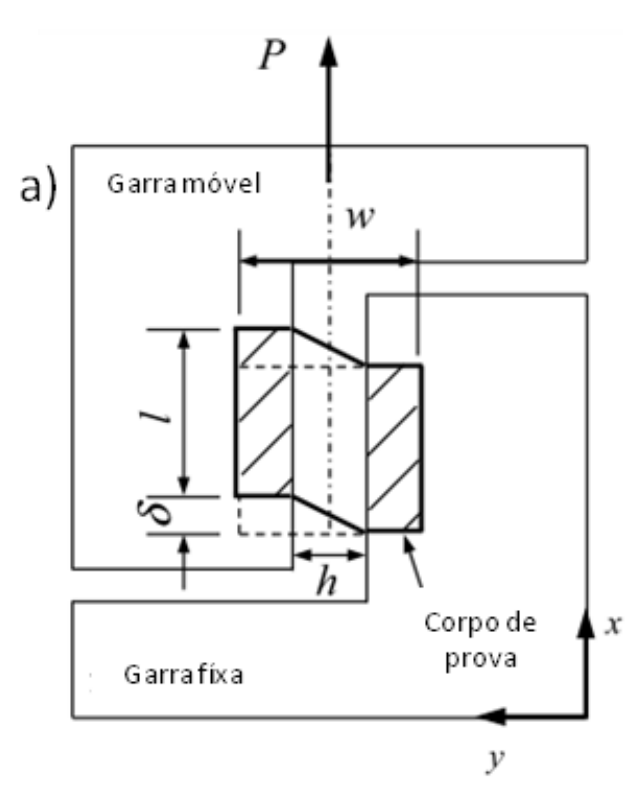

b)

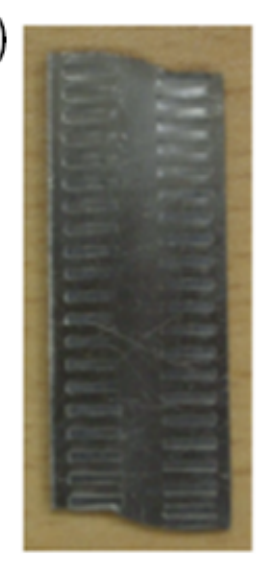

Figura 3-3 - Ensaio de cisalhamento de acordo com Miyauchi: (a) corpo de provas, (b) sistema de fixação (RICKHEY et al., 2015).
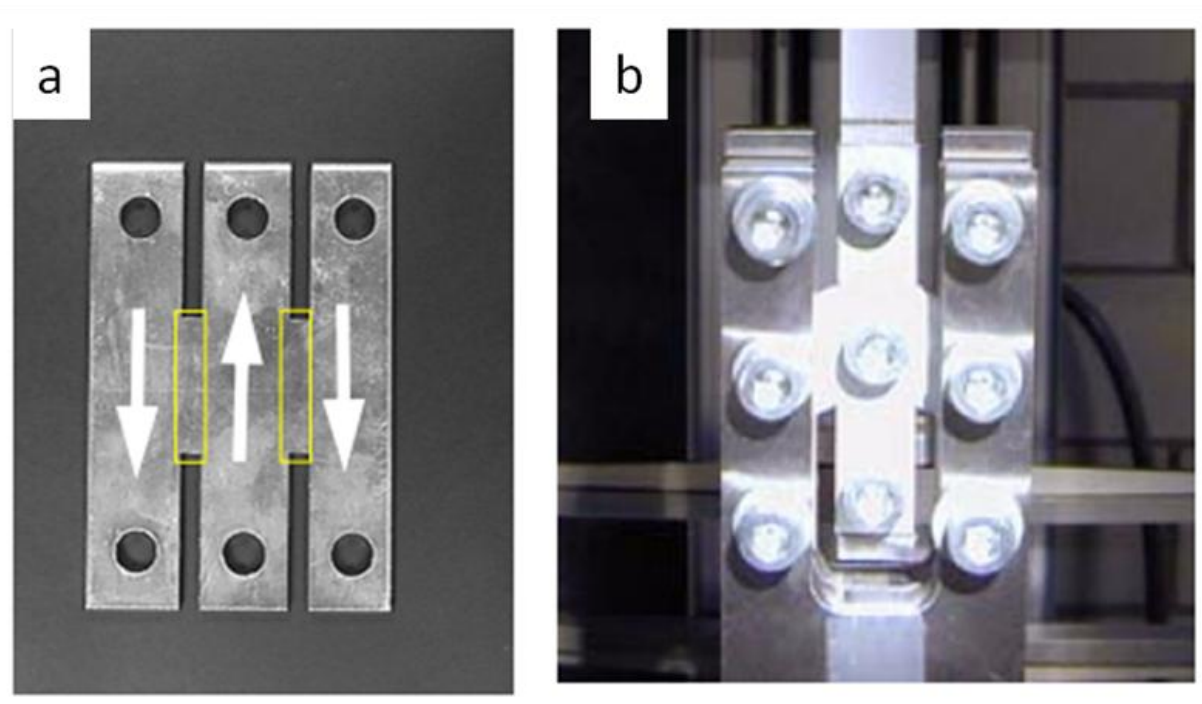

Figura 3-4 - Variação do ensaio de cisalhamento de Miyauchi: (a) corpo de provas, (b) sistema de fixação (HORA et al., 2000). 


\subsection{Teste biaxial de Twente}

Este teste foi desenvolvido na Universidade de Twente (Pijlman, 2001). Ele consiste de uma máquina biaxial, capaz de combinar cisalhamento com estado plano de deformação. A principal vantagem da utilização de uma máquina biaxial é a possibilidade de testar o comportamento dos corpos de provas em chapas sob várias cargas multiaxiais, não proporcionais, e para estudar o efeito de mudança de caminho das deformações, sem retirar a peça de ensaio.

O esquema desta máquina de teste é apresentado na Figura 3-5a. As setas indicam a direção do movimento acionado por motores elétricos. O movimento horizontal impõe um ensaio de cisalhamento simples, enquanto o movimento vertical, uma deformação plana.

O corpo de provas que usado nesta máquina é mostrado na Figura 3-5b. É possível realizar testes simples de deformação plana, teste de cisalhamento simples (ou cíclico), ambos separadamente ou simultaneamente.

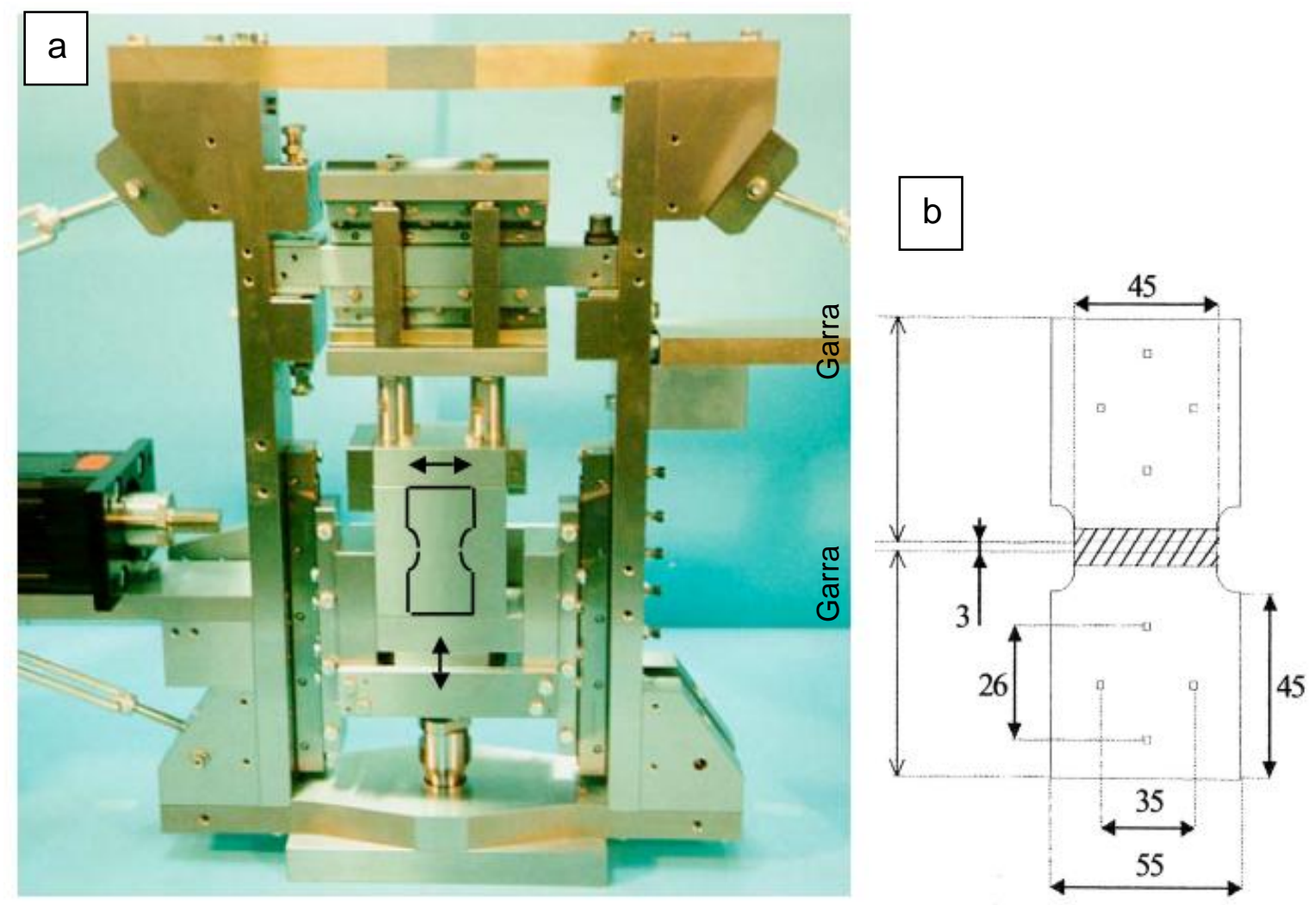

Figura 3-5 - (a) Máquina biaxial de testes de Twente, (b) corpo de provas de Twente (PIJLMAN, 2001). 


\subsection{Teste "ARCAN"}

O ensaio de Arcan (ARCAN et al., 1978) consiste em um dispositivo que possibilita obter uma carga de tração, cisalhamento ou uma combinação de ambos (Figura 3-6 - modos I, II e misto) utilizando uma máquina de ensaios de tração convencional. Dessa forma é possível, por exemplo, caracterizar o comportamento não linear de materiais heterogêneos (BLANCHARD et al., 2006). Segundo o trabalho realizado, no ensaio de Arcan, é possível caracterizar o comportamento do material e identificar parâmetros para modelos constitutivos; entretanto alguns parâmetros, como o coeficiente de Poisson, não podem ser identificados. Esse dispositivo permite o ajustes em diferentes ângulos, fazendo com que o ensaio varie de uma condição de cisalhamento puro até o ensaio de tração puro (KAVAMURA; BATALHA, 2008). Na Figura 3-7 pode-se observar um projeto de dispositivo para ensaio de Arcan.

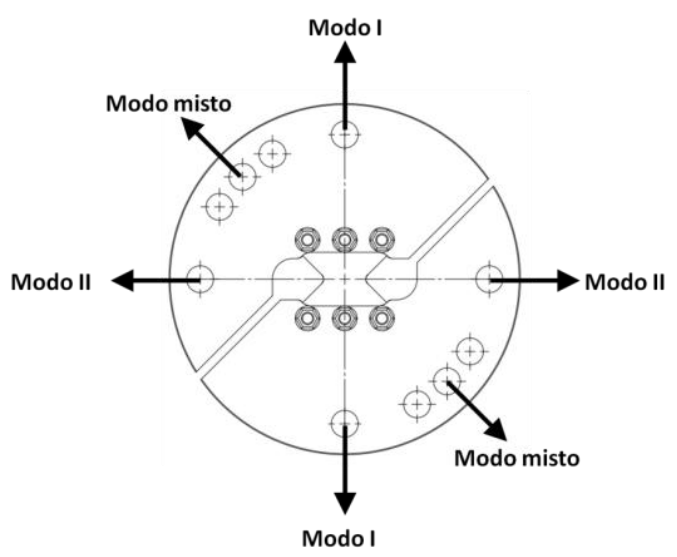

Figura 3-6 - Possibilidades de ensaio Arcan, modos I, II e misto, adaptado de (CERVEIRA, 2008)

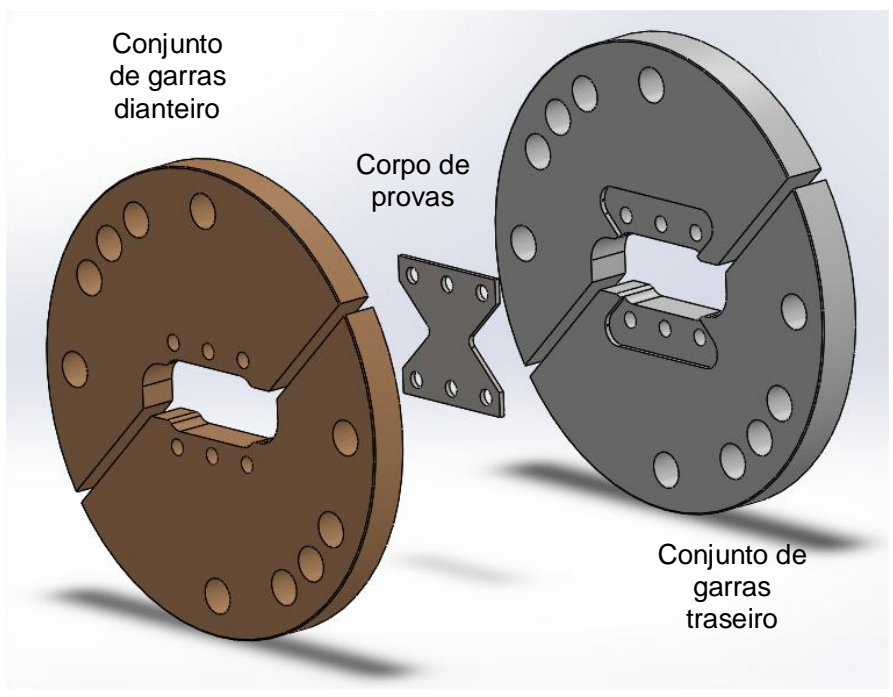

Figura 3-7 - Exemplo de dispositivo de ensaio Arcan. 
Outra utilização comum do ensaio de Arcan é a análise de deslocamento de abertura da trinca, como por exemplo em (MAHGOUB et al., 2003). Os autores utilizam uma simulação em MEF do ensaio de Arcan para avaliar trincas planas e oblíquas sob carregamento em modo I em ligas AA2024-T3 e entender o fato da trinca plana carregada em modo I tender a crescer de forma oblíqua. Segundo Blanchard et al. (BLANCHARD et al., 2006) ficou provado que o ensaio de Arcan permite a caracterização do comportamento do material com FSW e a identificação de parâmetros de modelos constitutivos pode ser feita através do ensaio na configuração de tração pura. Na Figura 3-8 pode-se observar as curvas tensãoxdeformação, do material alumínio 6056T78, ensaiado pelo dispositivo de Arcan e ensaiado com um corpo de provas de tração comum. Nota-se a correlação dos resultados até o momento em que ocorre a estricção do material.

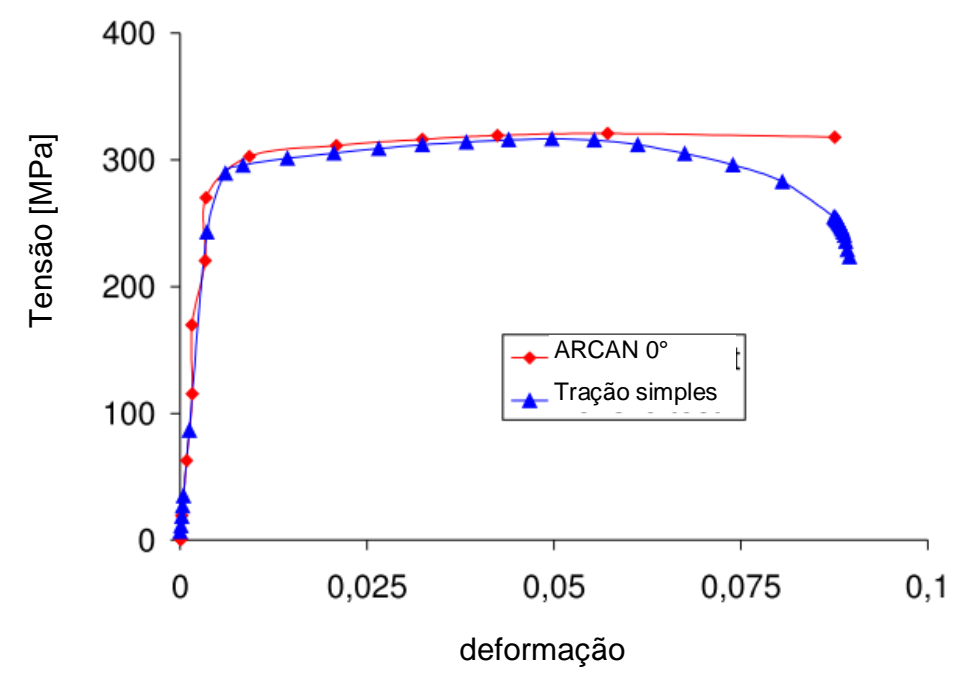

Figura 3-8 Comparação da curva tensãoxdeformação para corpos de prova de alumínio 6056T78 submetidos ao ensaio de Arcan e ao ensaio de tração (BLANCHARD et al., 2006).

Ainda no mesmo trabalho, são apresentados os resultados de ensaios de Arcan para a situação de cisalhamento puro e tração pura, e demonstra-se que o material soldado por FSW chega a ser de 15 a $20 \%$ menos resistente do que o material de base.

O corpo de prova em formato borboleta garante um campo de deformações homogêneo, que possui um máximo de tensão local exatamente sobre a região central. Existem duas formas (Figura 3-9) de se montar o arranjo experimental na máquina de ensaios (MOHR; DOYOYO, 2003). $\mathrm{Na}$ 
condição tradicional, a garra Arcan pode rotacionar, pois ela está presa em somente um ponto com rotação livre sobre seu eixo. Na forma modificada proposta por (MOHR; DOYOYO, 2003), a garra perde o grau de liberdade de rotação, pois é presa em dois pontos distintos. Dessa forma, é criada uma nova reação perpendicular à força aplicada pela máquina de ensaio. Esse tipo de arranjo pode ser muito útil em chapas de baixa resistência mecânica onde pode existir uma maior tendência a ocorrer alguma instabilidade durante o ensaio, fazendo com que ocorra torção durante o ensaio e prejudicando assim o resultado final. Tendo em vista as reações no corpo de prova tem-se a situação descrita na Figura 3-10 (a) e (b), sendo que a força $F H$ só existe na configuração com o grau de liberdade de rotação restrito.

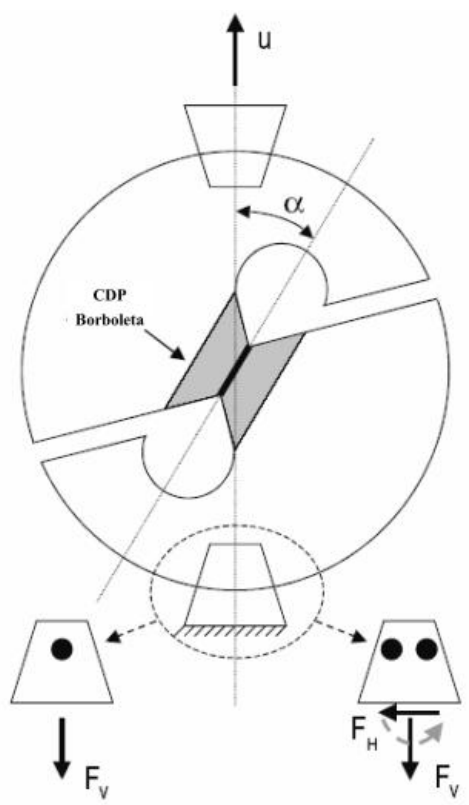

Figura 3-9 Configurações para o ensaio de Arcan (MOHR; DOYOYO, 2003).

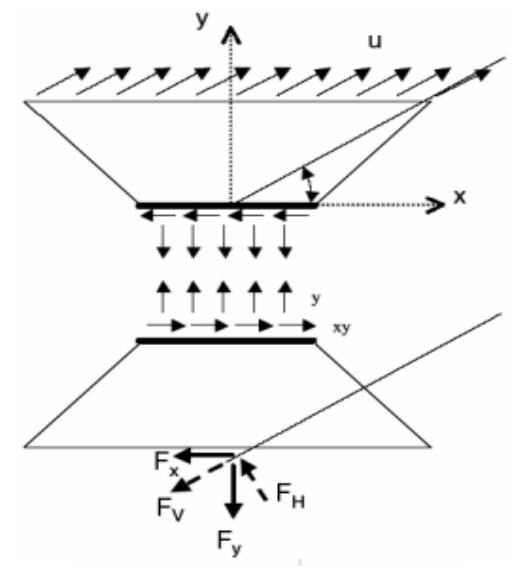

(a)

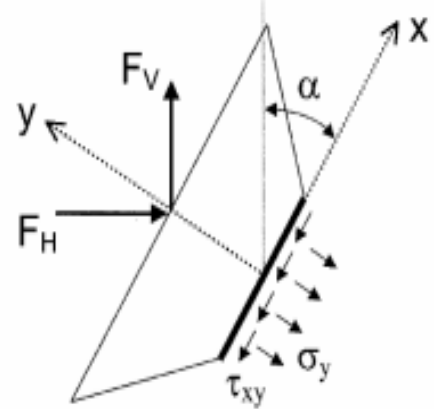

(b)

Figura 3-10 (a) Diagrama de forças resultantes no corpo-de-prova do ensaio Arcan (DOYOYO; MOHR, 2003), (b) Corte de uma metade do corpo-de-prova (MOHR; DOYOYO, 2002) 
As tensões normal e de cisalhamento na região crítica do corpo de prova podem ser calculadas na forma das equações 3.1 e 3.2, respectivamente:

$$
\begin{gathered}
\sigma_{y}=\frac{F_{V}}{A} \operatorname{sen} \alpha-\frac{F_{H}}{A} \cos \alpha, \\
\tau_{x y}=\frac{F_{V}}{A} \cos \alpha+\frac{F_{H}}{A} \operatorname{sen} \alpha,
\end{gathered}
$$

Sendo $A$ igual a área da seção transversal em estudo e $\alpha$ o ângulo formado entre a força aplicada pela garra e a direção da seção central de estudo. Deve-se ressaltar que a força $\mathrm{FH}$ é zero para garras Arcan sem restrição de rotação.

A Tabela 3-1 apresenta de forma resumida a comparação das habilidades para cada tipo de teste descrito acima. O teste de Arcan é um dos mais abrangentes e de maior facilidade construtiva, motivos decisivos para sua escolha neste trabalho.

Tabela 3-1 - Comparação de testes multiaxiais (adaptado de FLORES, 2005).

\begin{tabular}{ccccc}
\hline Teste & Kuwabara & Miyauchi & Twente & Arcan \\
\hline Altas taxas & -- & Ok & Ok & Ok \\
\hline $\begin{array}{c}\text { Carregamento } \\
\text { reverso }\end{array}$ & -- & Ok & Ok & Ok \\
\hline $\begin{array}{c}\text { Cargas } \\
\text { combinadas }\end{array}$ & Ok & -- & Ok & Ok \\
\hline $\begin{array}{c}\text { Facilidade de } \\
\text { fabricação do } \\
\text { CP }\end{array}$ & -- & Ok & Ok & Ok \\
\hline $\begin{array}{c}\text { Facilidade de } \\
\text { fabricação do } \\
\text { dispositivo }\end{array}$ & -- & Ok & -- & Ok \\
\hline $\begin{array}{c}\text { Controle das } \\
\text { cargas }\end{array}$ & Ok & Ok & Ok & Ok \\
\hline
\end{tabular}




\section{Correlação digital de imagens 3D}

Um sistema de correlação de imagem digital trabalha a partir de imagens obtidas por câmeras fotográficas (dedicadas ou não) associadas a um software para efetuar a medição de uma grandeza específica. Para medição de deformações utiliza-se uma câmera ou um conjunto de câmeras para detectar os deslocamentos e uma vez que o deslocamento foi determinado as deformações do material podem ser calculadas. O sistema de medição óptico chamado Aramis ${ }^{\circledR}(\mathrm{GOM}, 2013)(\mathrm{GOM}$, 2001) foi escolhido para medir a deformação do corpo de prova nos ensaios de tração. Demonstrou-se que o desempenho de tal sistema é ideal para a medição de deformação em situações complexas (FLORES, 2005) (ORTEU, 2009). Além disso, um sistema óptico evita os possíveis erros que aparecem devido aos escorregamentos existentes entre as garras e o corpo de prova.

\subsection{Princípio de funcionamento}

O aplicativo GOM Aramis ${ }^{\circledR}$ detecta deslocamentos utilizando técnicas de medição óptica. Uma vez que o deslocamento foi determinado a deformação do material pode ser calculada. O software GOM Aramis ${ }^{\circledR}$ reconhece a estrutura superficial em imagens digitais e pode alocar coordenadas para cada pixel da imagem. As coordenadas iniciais são contabilizadas como a imagem de referência, indicando o objeto de medição em seu estado não deformado. Após o objeto de medição ser deformado, uma segunda imagem é gravada. Nesse ponto, o GOM Aramis ${ }^{\circledR}$ compara as imagens e pode registrar qualquer deslocamento característico do objeto (GOM, 2001). Todas as imagens de correlação usam um padrão aleatório de modo que o aspecto da superfície, em um ponto, são únicas. Em seguida, é possível reconhecer e localizar um determinado ponto em várias imagens. $\mathrm{Na}$ prática, as imagens são divididas em pequenos quadrados chamados "facetas". Essas facetas são caracterizadas pela sua distribuição dos níveis de cinza. Este processo pode ser resumido como se segue ((KNOCKAERT, 2001) apud (FLORES, 2005)): Imagens da peça são tomadas antes e depois da deformação. Como mencionado anteriormente, uma imagem de configuração não deformada é feita como um referência e dividida em pequenos quadrados chamados "facetas". 
tamanho das facetas deve ser escolhida com respeito ao aspecto da superfície. Em seguida, o sistema tenta corresponder a distribuição dos níveis de cinza destas facetas com a distribuição cinza nível em torno de um ponto da imagem deformada. Esta operação de harmonização é possível graças a uma transformação aplicada às facetas. Esta transformação é uma combinação de uma tradução, uma rotação e uma distorção. A análise pode ser feita em 2D ou 3D. Para o caso 2D, a superfície analisada deve permanecer plana e a uma distância constante da câmara como na Figura 4-1.

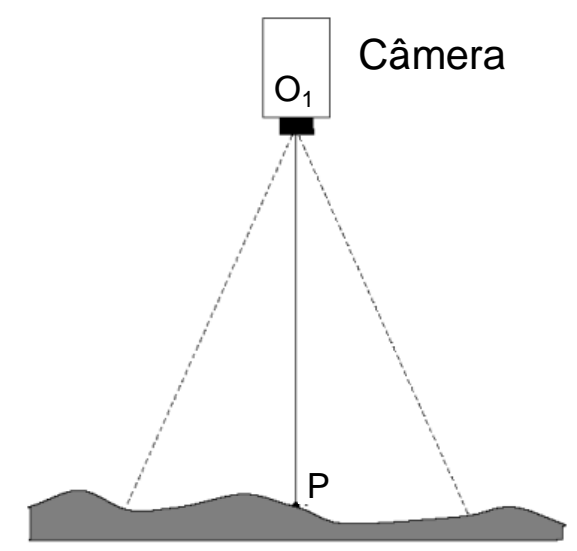

Figura 4-1 Princípio funcional do Aramis®. (GOM, 2001).

As medições em 3D exigem duas câmeras, que reconstituem uma imagem 3D usando imagens 2D como na Figura 4-2 (a). As localizações dos pontos no espaço, são determinados por triangulação de feixes direcionais. As coordenadas 3D de um ponto-objeto podem ser determinadas pelo ponto de intersecção das linhas retas, Figura 4-2 (b).

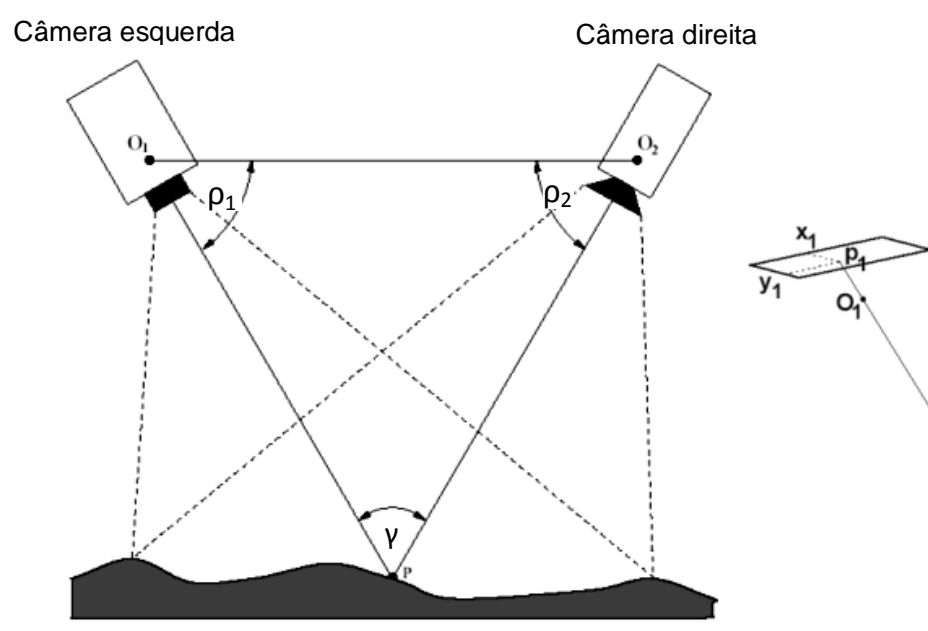

(a)

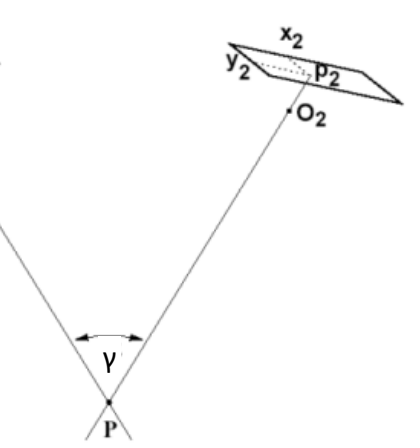

(b)

Figura 4-2 Montagem para uma medição 3D em (a) e em (b) determinação do ponto de medição. (GOM, 2001) 
Onde $O_{1}$ é a câmera $1, O_{2}$ é a câmera $2, P$ é o ponto de medição, $P_{1}$ ponto relativo 1 do ponto $P, P_{2}$ ponto relativo 2 do ponto $P, x_{1} y_{1}$ plano de medição $1, x_{2} y_{2}$ plano de medição 2, $\gamma$ é o ângulo entre as câmeras $O_{1}$ e $O_{2}, \rho_{1}$ é o angulo complementar da câmera $\mathrm{O}_{1}$ e $\rho_{2}$ é o angulo complementar da câmera $\mathrm{O}_{2}$.

É necessário calibrar antes de efetuar uma aquisição de imagem. A calibração é utilizada para identificar os parâmetros geométricos necessários para a transformação (distância e ângulo entre câmeras), e para quantificar os erros ópticos, a fim de levá-los em conta no cálculo de deslocamentos ou deformações. Um objeto para calibração similar ou o próprio corpo de provas com uma determinada disposição dos pontos é medido e registrado a partir de posições diferentes no que diz respeito ao sistema de medição (Figura 4-2). Os pontos individuais do objeto de calibração são identificados $e$ as suas respectivas coordenadas são determinadas com precisão de subpixels. Em seguida, os parâmetros das câmeras e as coordenadas de todos os pontos envolvidos na calibração são determinados usando o método de ajuste dos mínimos quadrados.

\subsection{Determinação da deformação}

Os deslocamentos relativos dos pontos são utilizados para o cálculo das deformações exercidas sobre a superfície do corpo de prova. Vários métodos estão disponíveis no software Aramis ${ }^{\circledR}$. Uma delas consiste em calcular o comprimento dos lados constituídos de linhas (splines) de uma faceta definida por quatro nós. Esta abordagem permite um cálculo preciso do comprimento real dos lados. Estes comprimentos são utilizados para construir um quadrilátero no espaço bidimensional. $\mathbf{O}$ gradiente de deformação $\mathbf{D}$ é então calculado para o centro de gravidade da faceta pelo método dos mínimos quadrados (KNOCKAERT, 2001) apud (FLORES, 2005), ver Figura 4-3.

Uma decomposição polar de $\mathbf{D}$ torna possível calcular o tensor $\mathbf{U}$ de deformação, que tem a seguinte forma definida por (GOM, 2001):

$$
\mathbf{U}=\left[\begin{array}{ll}
u_{11} & u_{12} \\
u_{22} & u_{22}
\end{array}\right]=\left[\begin{array}{cc}
1+\varepsilon_{x x} & \varepsilon_{x y} \\
\varepsilon_{x y} & 1+\varepsilon_{y y}
\end{array}\right] .
$$




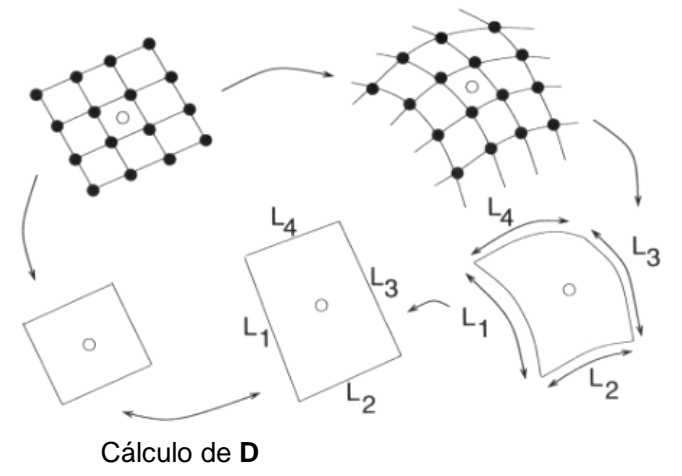

Figura 4-3 Medição da distorção de uma faceta usando interpolação de spline. (KNOCKAERT, 2001) apud (FLORES, 2005)

A transformação de $\mathbf{U}$ em forma diagonal leva ao cálculo das taxas de estiramento principais:

$$
\lambda_{1}=1+\frac{\varepsilon_{x x}+\varepsilon_{y y}}{2}+\sqrt{\left(\frac{\varepsilon_{x x}+\varepsilon_{y y}}{2}\right)^{2}-\left(\varepsilon_{x x} \varepsilon_{y y}-\varepsilon_{x y}^{2}\right)},
$$

e

$$
\lambda_{2}=1+\frac{\varepsilon_{x x}+\varepsilon_{y y}}{2}-\sqrt{\left(\frac{\varepsilon_{x x}+\varepsilon_{y y}}{2}\right)^{2}-\left(\varepsilon_{x x} \varepsilon_{y y}-\varepsilon_{x y}^{2}\right)} .
$$

As deformações principais podem ser então obtidas para as várias definições a seguir:

- Deformação de engenharia (Technical strains):

$\varepsilon_{i}^{T}=\lambda_{i}-1$,

- Deformação real ou logarítmica (Logarithmic strains):

$\varepsilon_{i}^{\ln }=\ln \left(\lambda_{i}\right)$,

- Deformação de Green-Lagrange (Green-Lagrange strains):

$$
\begin{aligned}
\varepsilon_{i}^{G L}= & \frac{1}{2}\left(\lambda_{i}^{2}-1\right), \\
& \text { onde } \mathrm{i}=1 \text { ou } 2 .
\end{aligned}
$$

O terceiro componente é calculado assumindo a conservação de volume durante a deformação plástica, isto é:

$$
\lambda_{1} \lambda_{2} \lambda_{3}=1 .
$$




\section{Tensão residual por difração de raios $X$}

\subsection{Tensão residual em processos de FSW}

Segundo Kumar (KUMAR et al., 2014), a tensão residual em materiais processados por FSW tem sido extensivamente investigadas em ligas à base de alumínio. A razão para este foco em ligas de alumínio está relacionada com a sua ampla utilização nas indústrias automobilística e aeroespacial. Em ligas de alta resistência, muito pouco tem sido feito para a compreensão da tensão residual, especialmente em ligas de titânio. Ligas ferrosas também não têm recebido muita atenção devido à dificuldade associada com a alta temperatura atingida no seu processo.

Independente do material estudado, o processo de FSW/FSP impõe à região unida um perfil característico de tensão residual como pode ser visto na Figura 5-1. Segundo (KUMAR et al., 2014) com base nas observações feitas nos processos de soldagens de diferentes, ligas ferrosas e não ferrosas, a tendência dos valores pode ser representada esquematicamente como se mostrado na Figura 5-1. A descontinuidade ao longo do eixo vertical significa um gradiente de tensão residual acentuado, mas não uma descontinuidade real.

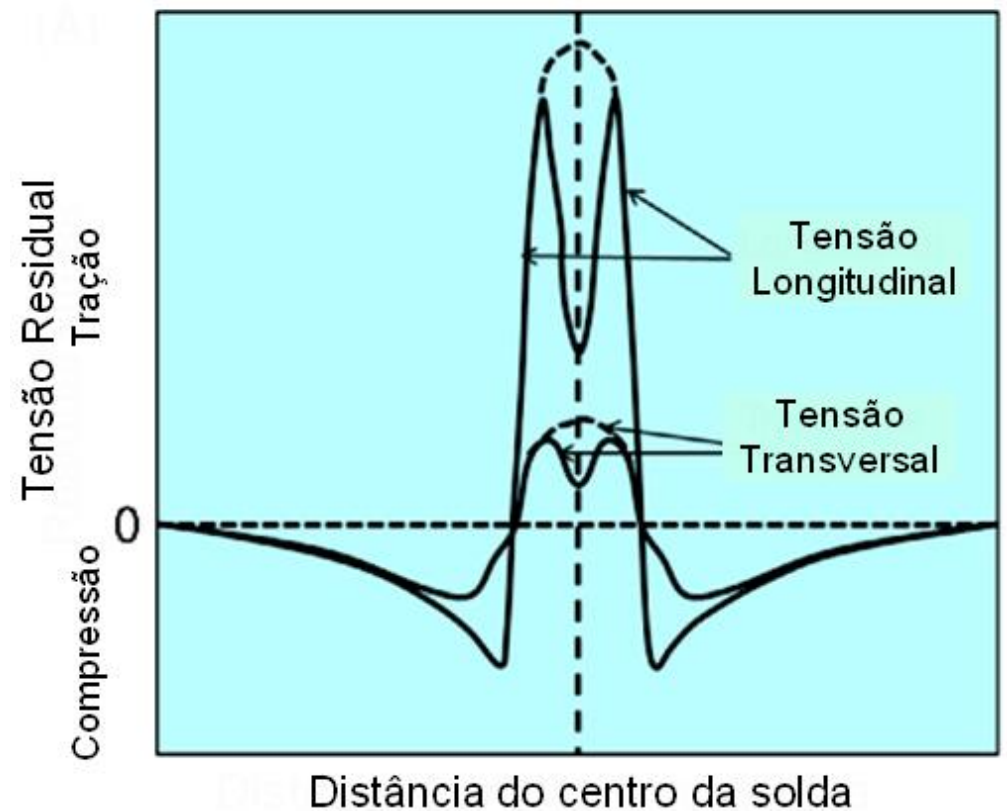

Figura 5-1 - Representação esquemática da distribuição da tensão residual em processos FSW (KUMAR et al., 2014). 
Valores de tensão residual para ligas de titânio não estão tão disponíveis na literatura comparativamente às ligas de alumínio, devido ao mesmo problema de temperatura enfrentado em processos de solda com metais ferrosos.

Em seus trabalhos Pasta e Reynolds ((PASTA; REYNOLDS, 2008a, 2008b) efetuaram medições de tensão residual na liga Ti-6Al-4V, pelo método ACR (adjusted compliance ratio method), que é utilizado para a determinação dos efeitos da tensão residual durante um teste de fadiga. Seus resultados podem ser vistos na Figura 5-2.

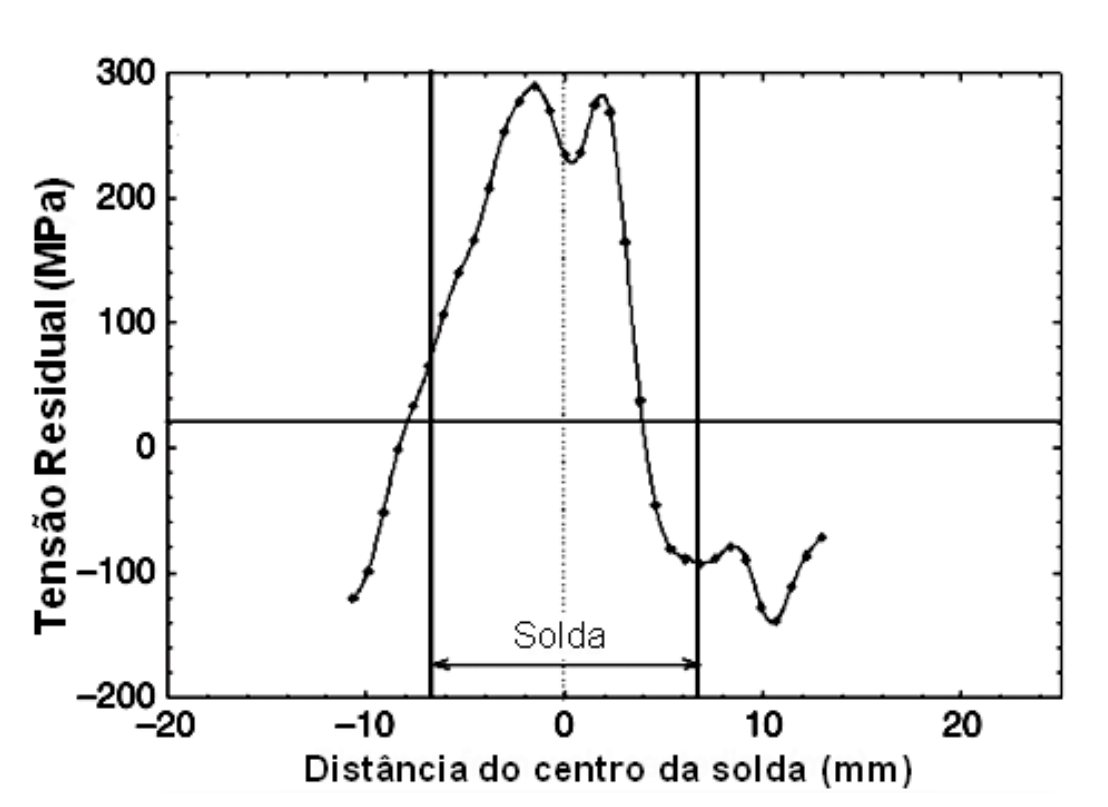

Figura 5-2 - Distribuição de tensão residual longitudinal em função da distância da linha central da solda na liga Ti-6Al-4V (PASTA; REYNOLDS, 2008a).

\subsection{Tensão residual por difração de raios- $X$}

Através da técnica de difração de raios- $X$, a deformação causada na superfície é obtida pela razão da variação da distância interplanar d (Figura 5-3) pela distância interplanar livre de deformação. A variação no retículo cristalino induzida pela presença de tensões, é medida com base na lei de Bragg e as tensões são calculadas assumindo-se que a distorção ocorre no regime linear elástico (LIMA, 2001). É uma técnica não destrutiva, que devido à forte absorção dos raios-x pela matéria, é limitada às camadas superficiais onde estes percorrem distâncias da ordem de $10 \mu \mathrm{m}$. A Figura 5-3 ilustra esta condição, somente a parte elástica do campo de deformações é medida, uma vez que a deformação plástica não afeta os parâmetros cristalinos (LIMA, 1991). 

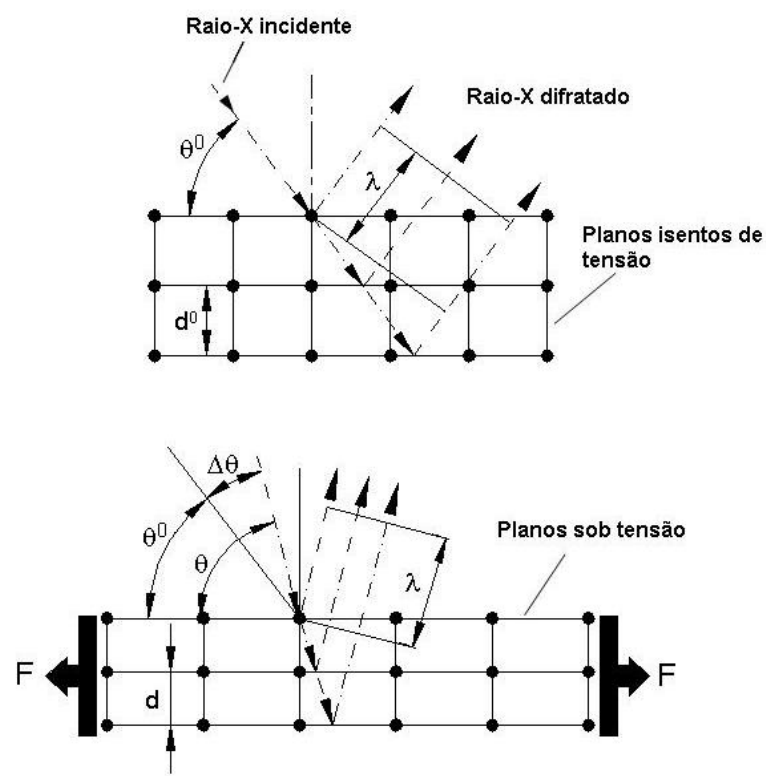

Figura 5-3 - Difração de raios-X em cristais simples carregados e descarregados (Brinksmeier et al, 1982).

A lei de Bragg descreve a difração de raios-X como uma reflexão seletiva segundo certos planos cristalográficos, de acordo com a seguinte lei:

$2 d \operatorname{sen} \theta=\lambda$

Onde $d$ é um parâmetro do reticulado, $\theta$ é o ângulo de refração e $\lambda$ é o comprimento de onda dos raios- $X$.

A derivada da expressão de Bragg indica que:

$$
\frac{\Delta d}{d}+\frac{\cos \theta}{\operatorname{sen} \theta} \cdot \Delta \theta=0
$$

$$
\varepsilon=-\Delta \theta \cdot \cot g \theta
$$

$$
\Delta \theta=\theta_{\text {com tensão }}-\theta_{\text {sem tensão }}
$$

Medindo-se $\Delta \theta$ pode-se calcular a deformação $\varepsilon$, e consequentemente a respectiva tensão residual $\sigma$. 
Vários métodos são propostos para determinação das deformações $\varepsilon$ segundo a difração de raios-X (Damasceno, 1999, Brinksmeier et al, 1982):

- Método do $\operatorname{sen}^{2} \psi$;

- Método de Glocker ou método do $0^{\circ}-45^{\circ}$;

- Método de Schall ou método da única incidência de $45^{\circ}$;

- Método $\theta-2 \theta$;

- Método $\theta$ ou método do eixo fixo.

Não faz parte dos objetivos deste trabalho o detalhamento de todos os possíveis métodos existentes, portanto somente o método do $\operatorname{sen}^{2} \psi$ será estudado por ser utilizado na parte experimental.

\section{- Método do $\operatorname{sen}^{2} \psi$}

Na Figura 80 pode-se observar os princípios do método do $\operatorname{sen}^{2} \psi$ ( $\psi$ é o ângulo entre a reta normal à superfície da peça e a reta normal ao plano de parâmetro "d"). Para cada orientação $\psi$, certos planos cristalográficos se colocam em posição de difração, conforme se observa através da Figura 5-4 e Figura 5-5. A penetração dos raios-X é extremamente rasa $(<10 \mu \mathrm{m})$, portanto a condição de estado plano de tensões é assumida na camada da superfície de difração (Prevéy, 1996). Segundo Bordinassi (2006), esta técnica é utilizada e recomendada quando se deseja grande exatidão nas medidas e quando a amostra apresenta certo grau de textura.

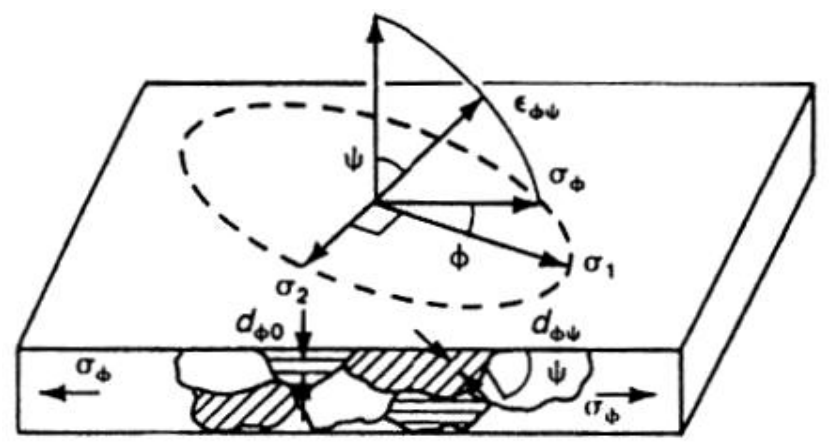

Figura 5-4 Estado plano de tensões (Prevéy, 1996). 


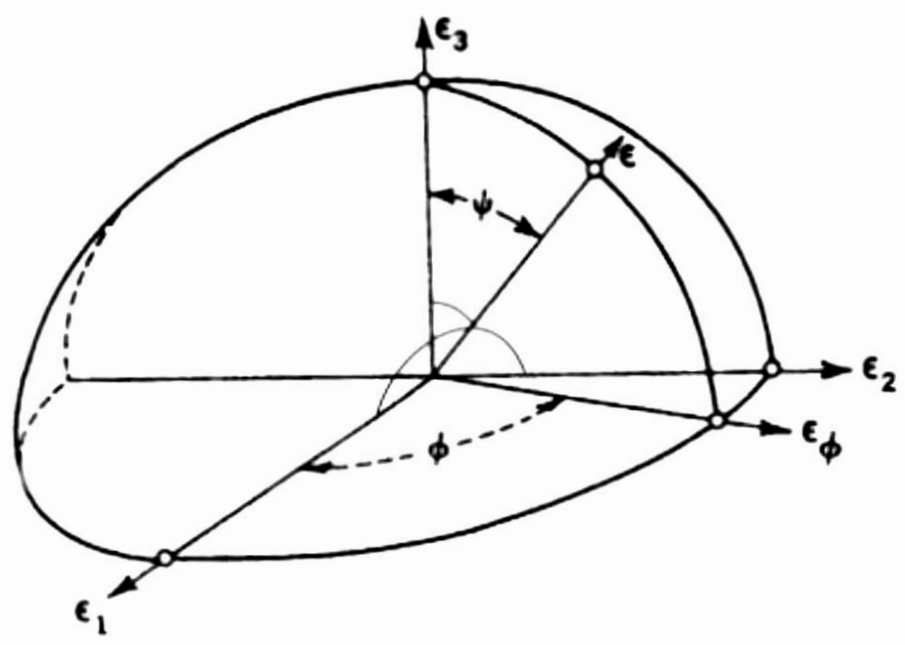

Figura 5-5 Elipsóide das deformações (Prevéy, 1996).

As direções principais das figuras anteriores podem ser dadas pelas Equações de 24 a 26 :

$$
\alpha_{1}=\cos \phi \cdot \operatorname{sen} \psi
$$

$\alpha_{2}=\operatorname{sen} \phi \cdot \operatorname{sen} \psi$

$$
\left.\alpha_{3}=\cos \psi=\sqrt{\left(1-\operatorname{sen}^{2}\right.} \psi\right)
$$

A lei da transformação do tensor das deformações em relação às direções principais é escrita como:

$$
\varepsilon=\alpha_{1}^{2} \cdot \varepsilon_{1}+\alpha_{2}^{2} \cdot \varepsilon_{2}+\alpha_{3}^{2} \cdot \varepsilon_{3}
$$

Sabendo que:

$\varepsilon_{t}=\frac{1}{E} \cdot\left[\sigma_{i}-v\left(\sigma_{j}+\sigma_{k}\right)\right.$

\section{Para $\boldsymbol{i}, \boldsymbol{j}, \boldsymbol{k}=1,2,3$}

Após transformação obtemos:

$\varepsilon=\frac{\Delta d}{d}=\left(\frac{1+v}{E}\right) \sigma_{\phi} \operatorname{sen}^{2} \psi-\left(\frac{v}{E}\right)\left(\sigma_{1}+\sigma_{2}\right)$

Onde: 
Derivando-se a expressão de $\varepsilon$ em relação a $\operatorname{sen}^{2} \psi$, obtem-se:

$$
\sigma_{\bullet}=\frac{E}{(1+v)} \cdot \frac{\partial\left(\frac{\Delta d}{d}\right)}{\partial\left(\operatorname{sen}^{2} \psi\right)}
$$

E substituindo com a Lei de Bragg:

$$
\sigma_{\ominus}=-\frac{E}{2(1+v)} \cdot \frac{\pi}{180} \cdot \cot g \theta \cdot \frac{\partial(2 \theta)}{\partial\left(\operatorname{sen}^{2} \psi\right)}
$$

Ou ainda:

$$
\sigma_{\diamond}=-K . \varphi
$$

Onde:

$$
\varphi=\frac{\partial(2 \theta)}{\partial\left(\operatorname{sen}^{2} \psi\right)}
$$

Sendo $K$ um fator constante tabelado para o plano de difração escolhido em função do material do corpo de prova, $\varphi$ é o coeficiente angular da reta $(2 \theta$ $\operatorname{sen}^{2} \psi$ ), obtida pela plotagem das variações dos ângulos de difração $2 \theta$ com as variações dos ângulos de incidência dos raios-X (Figura 5-6 Gráfico $\left(2 \theta-\operatorname{sen}^{2} \psi\right)$ (Prevéy, 1996).Figura 5-6).

O método consiste em variar o ângulo $\psi$ de $-60^{\circ} \mathrm{a}+60^{\circ}$, em incrementos de $10^{\circ}$, obter os respectivos ângulos de difração e traçar uma reta por regressão, pelo método os mínimos quadrados, através destes pontos.

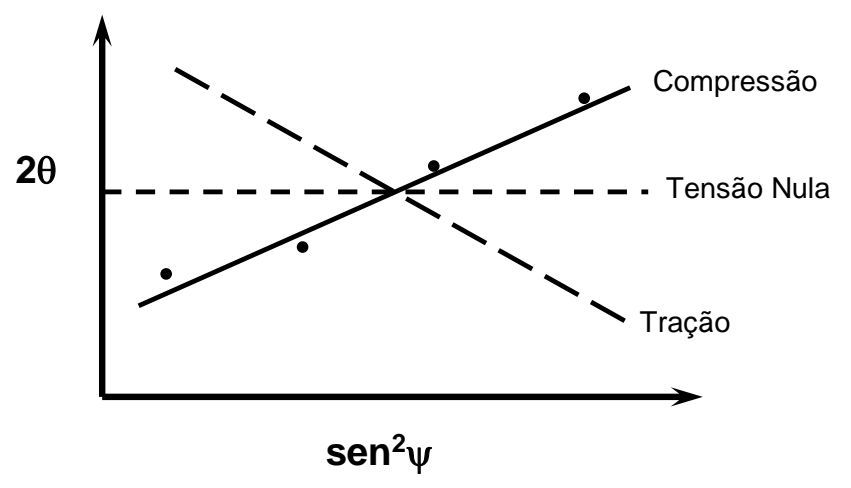

Figura 5-6 Gráfico (20- $\left.\operatorname{sen}^{2} \psi\right)$ (Prevéy, 1996). 


\section{Modelos de plasticidade}

Segundo Pijlman (PIJLMAN, 2001) a maioria dos processos de conformação do metal envolvem deformações de moderadas a grandes. Um bom modelo constitutivo de deformações deve envolver os diversos aspectos e características do material estudado. As leis constitutivas fenomenológicas utilizados ao longo deste trabalho, visam lidar com uma deformação finita, elasto-plastica e com deformação em diversas temperaturas nos ensaios. Um dos objetivos é estabelecer um modelo capaz de identificar o início do escoamento do material Ti-6Al-4V.

Uma superfície de escoamento divide (Figura 6-1) no espaço de deformação nos domínios elásticos e plásticos, sendo o início do escoamento a fronteira entre os dois domínios.

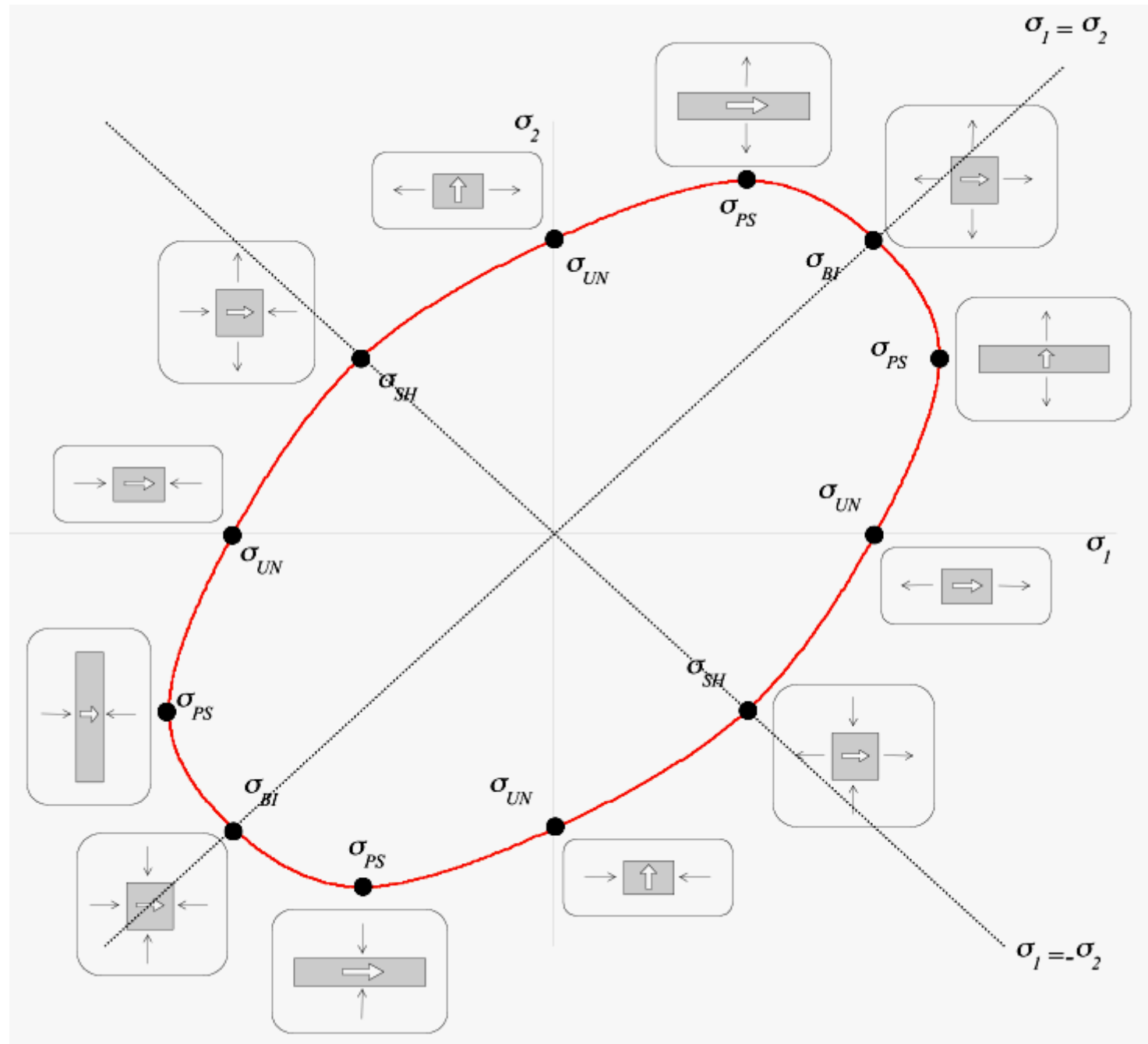

Figura 6-1 Condições de tensão principal associadas ao início do escoamento de um material, (PIJLMAN, 2001) 
Um critério de escoamento define a forma e o tamanho da superfície de escoamento. A evolução dessa superfície durante a deformação plástica pode ser descrita por uma lei de encruamento (isotrópica, cinemática ou a junção da duas) associada à equação constitutiva em estudo (PIJLMAN, 2001).

O comportamento plástico de um metal para um estado multiaxial de tensão é descrito por um critério de escoamento, e uma lei de encruamento. Os dois regimes mais comuns são o encruamento isotrópico e cinemático que estão apresentados na Figura 6-2.

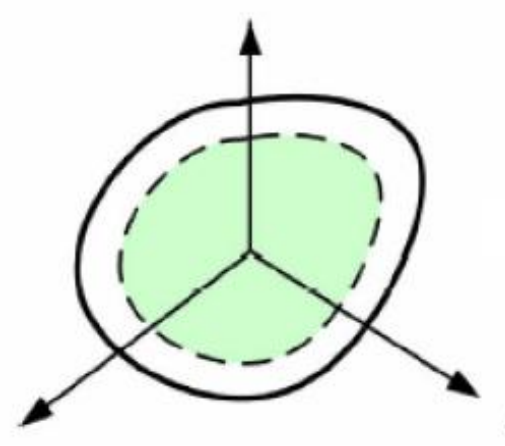

(a)

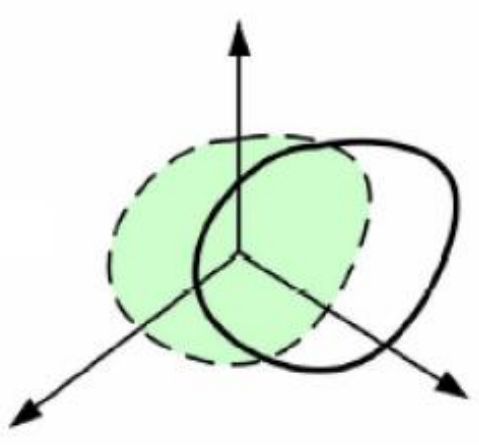

(b)

Figura 6-2 - Regimes de encruamento (a) isotrópico, (b) cinemático (PLUNKETT, 2005).

Encruamento isotrópico assume que a superfície de escoamento mantém a sua forma, mas que se expande com a deformação plástica acumulada, encruamento cinemático permite uma translação da superfície sem alterar seu tamanho ou forma. Ambas podem acontecer mediante determinadas condições da estrutura do material, em especial materiais de estrutura hexagonal compacta (HCP). Neste caso modelos que não levam em conta a possibilidade da ocorrência conjunta dos dois regimes de encruamento isotrópico e cinemático, não possuem precisão para descrever o escoamento (PLUNKETT, 2005).

\subsection{Critérios para início do escoamento}

\subsubsection{Critério de escoamento Isotrópico}

Para valores suficientemente pequenos de tensão e deformação, um metal irá retornar à sua forma original após descarregamento das cargas. Quando carregado para além desta zona reversível (elástica), o mesmo não irá reassumir a sua forma 
original após a descarga, mas apresentará uma deformação (plástica) permanente. $\mathrm{Na}$ região plástica, tipicamente para materiais que apresentam encruamento, a tensão de escoamento aumenta monotonicamente com deformação plástica acumulada. Depois que um material foi submetido a uma tensão superior ao limite de escoamento, o qual separa as faixas elástica e plástica, a tensão atuante tornase o novo limite de escoamento, caso o material seja descarregado. Para um estado multiaxial de tensão, o limite de escoamento de um material é descrito matematicamente por um critério de escoamento.

O critério de escoamento mais antigo é o proposto por Tresca em 1864. De acordo com o critério de Tresca, o material escoa em um estado plástico quando a tensão máxima de cisalhamento atinge um valor crítico. O critério de Tresca é dado pela equação:

$$
\operatorname{máx}\left\{\left|\sigma_{1}-\sigma_{2}\right|,\left|\sigma_{2}-\sigma_{3}\right|,\left|\sigma_{3}-\sigma_{1}\right|\right\}=Y
$$

onde $\sigma_{1}, \sigma_{2}$ e $\sigma_{3}$ são as tensões principais, e $Y$ é a tensão de escoamento, em tração uniaxial. A projeção da superfície de escoamento de Tresca sobre o plano $\sigma_{1}$, $\sigma_{2}$ resulta em um hexágono centrado na origem cujo tamanho depende da magnitude de $\mathrm{Y}$.

O critério de escoamento isotrópico mais utilizado foi o proposto por von Mises em 1913, e Hencky em 1924. Este critério é normalmente referido como o critério de von Mises. O critério de von Mises baseia-se na observação de que uma pressão hidrostática não causa escoamento do material. O estado plástico corresponde a um valor crítico da energia elástica de deformação, isto é:

$$
J_{2}=k^{2}
$$

Onde $k$ é uma constante e $J_{2}$ é o segundo invariante de Cauchy da tensão deviatórica dado por:

$$
J_{2}=\frac{1}{6}\left[\left(\sigma_{1}-\sigma_{2}\right)^{2}+\left(\sigma_{2}-\sigma_{3}\right)^{2}+\left(\sigma_{3}-\sigma_{1}\right)^{2}\right]
$$


A maioria dos metais isotrópicos com estrutura cristalina cúbica apresentam escoamento previsto pelos critérios de Tresca e de von Mises. De modo a representar o comportamento de determinados metais (por exemplo, ligas de alumínio) para os quais o início do escoamento está localizado entre o critério de Tresca e von Mises, Drucker (DRUCKER, 1949) propôs o seguinte critério:

$$
J_{2}^{3}-c J_{3}^{2}=F
$$

Onde $J_{3}$ é o terceiro invariante da tensão de desvio de Cauchy, c e $F$ são constantes do material. A fim de assegurar que a superfície de escoamento é convexa, c é limitado a um determinado intervalo numérico: c $\epsilon$ [27/8, 2,25].

\subsubsection{Critérios de escoamento Ortotrópico}

Devido aos processamentos para fabricação (muitos deles termomecânicos), chapas metálicas apresentam simetria ortotrópica em relação aos sentidos de processamento, sendo alinhados com a direção de laminação, no sentido transversal e direção normal ao plano da folha (x, y, e z, respectivamente). Em 1948, Hill (HILL, 1948) propôs uma generalização do critério de escoamento de von Mises isotrópico para ortotropia. Dessa forma, este critério de escoamento é expresso por uma função quadrática da forma:

$$
F\left(\sigma_{y}-\sigma_{z}\right)^{2}+G\left(\sigma_{z}-\sigma_{x}\right)^{2}+H\left(\sigma_{x}-\sigma_{y}\right)^{2}+2 L \tau_{y z}^{2}+2 M \tau_{z x}^{2}+2 N \tau_{x y}^{2}=1
$$

Onde $F, G, H, L, M$ e N são constantes de anisotropia, $x, y$, e z são os eixos de ortotropia (eixos perpendiculares aos três planos mutuamente ortogonais de simetria) do material. Quando $F=L=H=1 / 6 k^{2}$ e $L=M=N=1 / 2 k^{2}$, a equação reduz-se ao critério de von Mises.

Os coeficientes envolvidos na expressão do critério de escoamento de Hill podem ser determinados a partir de ensaios mecânicos simples. Denotando as tensões de escoamento de tração nos sentidos de $\mathrm{x}, \mathrm{y}, \mathrm{z}$ como $\mathrm{X}, \mathrm{Y}, \mathrm{e} \mathrm{Z}$, respectivamente, pode ser demonstrado que, de acordo com a teoria de Hill: 


$$
X=\sqrt{\frac{1}{G+H}}, Y=\sqrt{\frac{1}{H+F}}, Z=\sqrt{\frac{1}{F+G}},
$$

portanto,

$$
2 F=\frac{1}{Y^{2}}+\frac{1}{Z^{2}}-\frac{1}{X^{2}} ; 2 G=\frac{1}{Z^{2}}+\frac{1}{X^{2}}-\frac{1}{Y^{2}} ; 2 H=\frac{1}{X^{2}}+\frac{1}{Y^{2}}-\frac{1}{Z^{2}}
$$

Denotando $R$, S e T como a tensão de cisalhamento no escoamento nas direções yz, zx, e xy respectivamente:

$$
2 L=\frac{1}{R^{2}} ; 2 M=\frac{1}{S^{2}} ; 2 N=\frac{1}{T^{2}}
$$

A resistência à estricção nas chapas de metal é geralmente caracterizada pelo coeficiente de Lankford, r. Os coeficientes de Lankford são definidos como a razão entre a largura e a espessura da chapa durante um teste uniaxial. Na plasticidade clássica, o incremento de deformação plástica é derivado a partir de um potencial plástico (PLUNKETT, 2005), para os metais geralmente supõe-se coincidir com a função de escoamento associada de tal modo que:

$$
d \varepsilon^{p}=d \lambda \frac{\partial f}{\partial \boldsymbol{\sigma}}
$$

Onde $d \varepsilon^{p}$ é o incremento de deformação plástica, $\lambda$ é uma variável escalar, e f é a função de escoamento. Portanto, o vetor de incremento é ortogonal à superfície do escoamento. Assumindo incompressibilidade plástica, o coeficiente de Lankford para uma situação de tração uniaxial na direção x pode ser escrito como:

$$
r_{x x}=\frac{d \varepsilon_{y y}}{d \varepsilon_{z z}}=-\frac{d \varepsilon_{y y}}{d \varepsilon_{x x}+d \varepsilon_{y y}}=-\frac{\frac{\partial f}{\partial \sigma_{y y}}}{\frac{\partial f}{\partial \sigma_{x x}}+\frac{\partial f}{\partial \sigma_{y y}}}
$$


Da mesma forma, $r_{\alpha}$, é a razão de deformação correspondente a uma carga de tração uniaxial em um ângulo arbitrário $\alpha$ em relação a direção $x$ (direção de laminação), e é dada por:

$$
r_{\alpha}=-\frac{\sin ^{2} \alpha \frac{\partial f}{\partial \sigma_{x x}}-\sin 2 \alpha \frac{\partial f}{\partial \sigma_{x y}}+\cos ^{2} \alpha \frac{\partial f}{\partial \sigma_{y y}}}{\frac{\partial f}{\partial \sigma_{x x}}+\frac{\partial f}{\partial \sigma_{y y}}}
$$

De acordo com o critério de Hill, o coeficiente de Lankford pode ser expresso em termos dos coeficientes de anisotropia:

$$
r_{0}=\frac{H}{G}, r_{90}=\frac{H}{F} ; r_{45}=\frac{N}{F+G}-\frac{1}{2}
$$

Assim, os coeficientes de anisotropia podem ser expressos em termos de tensões de escoamento na direção de laminação, a 45 graus em relação à laminação, nas direções transversais ou como funções destes valores.

O critério de escoamento de Hill é um critério amplamente utilizado para descrever escoamento de metais texturizados (CAZACU; BARLAT, 2003). No entanto, não representa adequadamente o comportamento de certas ligas de alumínio (e outras ligas de estrutura não cúbicas), que têm valores médios de coeficientes Lankford menores do que 1 e mais o limite de elasticidade em tensão biaxial maior do que o limite de elasticidade em tensão uniaxial (BANABIC, 2010). Portanto, a fim de representar melhor o escoamento de ligas de alumínio, Hill desenvolveu um outro critério de escoamento em 1979 (HILL, 2008):

$$
\begin{aligned}
& F\left|\sigma_{2}-\sigma_{3}\right|^{m}+G\left|\sigma_{3}-\sigma_{1}\right|^{m}+H\left|\sigma_{1}-\sigma_{2}\right|^{m}+L\left|2 \sigma_{1}-\sigma_{2}-\sigma_{3}\right|^{m} \\
& +M\left|2 \sigma_{2}-\sigma_{3}-\sigma_{1}\right|^{m}+N\left|2 \sigma_{3}-\sigma_{1}-\sigma_{2}\right|^{m}=Y^{m}
\end{aligned}
$$

Este critério tem uma grande limitação, uma vez que é escrito em termos de tensões principais Cauchy. Para que este critério seja válido, os eixos principais e eixos de anisotropia deve ser sobrepostos, assim, qualquer estado envolvendo tensões de cisalhamento não podem ser contabilizados (PLUNKETT, 2005). 
Barlat (BARLAT et al., 1991) propôs um critério de escoamento com seis componentes chamado Yld91, que estende o critério isotrópico Hershey e Hosford para ortotropia. A extensão para ortotropia é conseguida substituindo os valores principais do tensor de tensão de Cauchy na expressão do critério isotrópico por uma transformada dos tensores de tensão. O tensor tensão transformado é obtido a partir do tensor das tensões de Cauchy modificado com coeficientes de ponderação. Este procedimento é equivalente à aplicação de um operador de transformação linear de quarta ordem sobre o tensor de tensão de Cauchy. O critério é escrito como:

$$
\left(\Sigma_{1}-\Sigma_{2}\right)^{m}+\left(\Sigma_{2}-\Sigma_{3}\right)^{m}+\left(\Sigma_{3}-\Sigma_{1}\right)^{m}=2 Y^{m}
$$

onde,

$\Sigma=\boldsymbol{L} \sigma$,

$\Sigma_{1}, \Sigma_{2}$ e $\Sigma_{3}$ são os valores principais de $\Sigma$, $\sigma$ é o tensor de tensões de Cauchy, $L$ é um tensor de quarta ordem de simetria ortotrópico. Considerando os eixos principais de simetria $(\mathrm{x}, \mathrm{y}, \mathrm{z})$ :

$$
\boldsymbol{L}=\frac{1}{3}\left[\begin{array}{cccccc}
c_{2}+c_{3} & -c_{3} & -c_{2} & & & \\
-c_{3} & c_{3}+c_{1} & -c_{1} & & & \\
-c_{2} & -c_{1} & c_{1}+c_{2} & & & \\
& & & 3 c_{4} & & \\
& & & & 3 c_{5} & \\
& & & & & 3 c_{6}
\end{array}\right]
$$

Onde $c_{1}, c_{2}, c_{3}, \ldots, c_{6}$ são constantes. Note-se que a anisotropia é representada pelo mesmo número de coeficientes como no critério de Hill. Barlat (BARLAT, 2005) mostrou que qualquer função de escoamento isotrópico independente escrita em termos dos valores principais da tensão de desvio de Cauchy pode ser generalizada para anisotropia através de uma transformação linear que atua sobre o tensor de tensão de Cauchy. Os valores principais do tensor transformado substituem os valores principais da tensão de desvio de Cauchy do critério de escoamento isotrópico:

$$
\Sigma=C s=C T \sigma=L \sigma
$$


Onde, $\Sigma$ é o tensor transformado, $C$ é um tensor linear anisotrópico, e $T$ transforma o tensor Cauchy $\sigma$ em seu deviatórico $s$. Barlat et al. (2005) também propõem um outro critério ortotrópico (chamado Yld2004-18p) que envolve 18 coeficientes de anisotropia. Este critério ortotrópico é uma generalização do critério Hershey e Hosford em que anisotropia é introduzida através de duas transformações lineares contendo cada uma nove coeficientes independentes. A expressão deste critério de escoamento é:

$$
\begin{aligned}
& \left|\Sigma_{1}^{\prime}-\Sigma_{1}^{\prime \prime}\right|^{a}+\left|\Sigma_{1}^{\prime}-\Sigma_{2}^{\prime \prime}\right|^{a}+\left|\Sigma_{1}^{\prime}-\Sigma_{3}^{\prime \prime}\right|^{a}+ \\
& \left|\Sigma_{2}^{\prime}-\Sigma_{1}^{\prime \prime}\right|^{a}+\left|\Sigma_{2}^{\prime}-\Sigma_{2}^{\prime \prime}\right|^{a}+\left|\Sigma_{2}^{\prime}-\Sigma_{3}^{\prime \prime}\right|^{a}+ \\
& \left|\Sigma_{3}^{\prime}-\Sigma_{1}^{\prime \prime}\right|^{a}+\left|\Sigma_{3}^{\prime}-\Sigma_{2}^{\prime \prime}\right|^{a}+\left|\Sigma_{3}^{\prime}-\Sigma_{3}^{\prime \prime}\right|^{a}=4 Y^{a}
\end{aligned}
$$

Onde,

$$
\begin{aligned}
& \boldsymbol{\Sigma}^{\prime}=\boldsymbol{C}^{\prime} \boldsymbol{s}=\boldsymbol{C}^{\prime} \boldsymbol{T} \boldsymbol{\sigma}=\boldsymbol{L}^{\prime} \boldsymbol{\sigma} \\
& \mathrm{e} \\
& \boldsymbol{\Sigma}^{\prime \prime}=\boldsymbol{C}^{\prime \prime} \boldsymbol{s}=\boldsymbol{C}^{\prime \prime} \boldsymbol{T} \boldsymbol{\sigma}=\boldsymbol{L}^{\prime \prime} \boldsymbol{\sigma}
\end{aligned}
$$

Quando $C^{\prime}=C^{\prime \prime}$ (ou $L^{\prime}=L^{\prime \prime}$ ), e o número de coeficientes independentes é reduzido para seis, Yld2004-18p se reduz a Yld91. Este critério modela a superfície de escoamento para ligas de alumínio com boa precisão (BARLAT, 2005).

Outra abordagem para estender qualquer critério isotrópico para anisotropia é através dos invariantes generalizados (CAZACU; BARLAT, 2003), utilizando a teoria da representação de funções de tensor. Com a abordagem dos invariantes generalizados, Cazacu e Barlat (2003) estenderam o critério de escoamento isotrópico de Drucker (1949) para ortotropia da seguinte forma:

$$
\left(J_{2}^{0}\right)^{3}-c\left(J_{3}^{0}\right)^{2}=F
$$


Onde,

$J_{2}^{0}=\frac{a_{1}}{6}\left(\sigma_{x}-\sigma_{y}\right)^{2}+\frac{a_{2}}{6}\left(\sigma_{y}-\sigma_{z}\right)^{2}+\frac{a_{3}}{6}\left(\sigma_{x}-\sigma_{z}\right)^{2}+a_{4} \tau_{x y}^{2}+a_{5} \tau_{x z}^{2}+a_{6} \tau_{y z}^{2}$

e

$J_{3}^{0}=\frac{1}{27}\left(b_{1}+b_{2}\right) \sigma_{x}^{3}+\frac{1}{27}\left(b_{3}+b_{4}\right) \sigma_{y}^{3}+2 b_{11} \sigma_{x y} \sigma_{x z} \sigma_{y z}+\frac{1}{27}\left(2\left(b_{1}+b_{4}\right)-b_{2}-b_{3}\right) \sigma_{z}^{3}$

$+\frac{2}{9}\left(b_{1}+b_{4}\right) \sigma_{x} \sigma_{y} \sigma_{z}-\frac{1}{9}\left(b_{1} \sigma_{y}+b_{2} \sigma_{z}\right) \sigma_{x}^{2}-\frac{1}{9}\left(b_{3} \sigma_{z}+b_{4} \sigma_{x}\right) \sigma_{y}^{2}$

$-\frac{1}{9}\left[\left(b_{1}-b_{2}+b_{4}\right) \sigma_{x}+\left(b_{1}-b_{3}+b_{4}\right) \sigma_{y}\right] \sigma_{z}^{2}-\frac{\sigma_{x z}^{2}}{3}\left[2 b_{9} \sigma_{y}-b_{8} \sigma_{z}-\left(2 b_{9}-b_{8}\right) \sigma_{x}\right]$

$-\frac{\sigma_{x y}^{2}}{3}\left[2 b_{10} \sigma_{z}-b_{5} \sigma_{y}-\left(2 b_{10}-b_{5}\right) \sigma_{x}\right]-\frac{\sigma_{y z}^{2}}{3}\left[\left(b_{6}-b_{7}\right) \sigma_{x}-b_{6} \sigma_{y}-b_{7} \sigma_{z}\right]$

Todos os critérios de escoamento discutidos até aqui, tanto isotrópico quanto anisotrópico, partem do pressuposto de que os valores de tensão e compressão coincidem. Este pressuposto básico faz com que esses critérios sejam inadequados para modelagem de escoamento em metais de estrutura hexagonal compacta (HCP - hexagonal closed packed).

\subsection{Critério de escoamento ortotrópico para metais HCP e suas constantes de anisotropia}

As ligas de titânio consistem basicamente de estruturas HCP (fase- $\alpha$ ) com fase- $\beta$ (CCC - cúbico de corpo centrado) dispersa entre os grãos de fase- $\alpha$. Estes metais com estrutura (HCP) dominantes são conhecidos por exibir forte anisotropia plástica em condição de tensão e compressão. Isto por causa da interação entre deslizamentos cristalográficos de escorregamento e maclação (CAZACU et al., 2006). A maclação é conhecida por ser dependente do sinal das tensões de cisalhamento (HOSFORD, 1998). Além disso, a anisotropia nestas ligas se dá devido, principalmente, à forte textura cristalográfica induzida durante a produção (HOSFORD, 2005). Portanto, a modelagem multiaxial destas ligas de titânio anisotrópica HCP não podem ser realizadas utilizando definições nas teorias isotrópicas do segundo invariante de Cauchy $\left(\mathrm{J}_{2}\right)$ (KHAN et al., 2007). 
A anisotropia foi estudada em grande detalhe por pesquisadores nos últimos anos. Hill (1948) foi o primeiro a determinar quantitativamente a superfície de escoamento para materiais anisotrópicos. Embora seu modelo tenha sido útil devido à sua simplicidade, não foi capaz de capturar em conjunto a anisotropia observada entre tensão e compressão. A maioria dos critérios anisotrópicos desenvolvidos nos últimos anos são para metais com estruturas cúbicas. Os mais proeminentes destes critérios de rendimento anisotrópicos para metais cúbicos são aqueles desenvolvidos por Hosford em (1979)(HOSFORD, 2005), Barlat e colaboradores (CAZACU; BARLAT, 2003)(BARLAT, 2005), (KARAFILLIS; BOYCE, 1993)(YOON; CAZACU, 2007). Estes critérios assumem igualdade de valores das tensões de escoamento em tração e compressão. No entanto, este não é o caso para os metais HCP. Critérios para metais anisotrópicos com estruturas HCP são poucos. Alguns modelos anisotrópicos têm sido propostos e utilizados na literatura para policristais HCP (KHAN et al., 2007). Em 2004 Cazacu e Barlat (CAZACU, 2004) propuseram um critério de anisotropia e escoamento diferencial para metais insensíveis à pressão chamado de CPB06. Eles usaram os dados publicados de Kelly e Hosford (1968), para validar o modelo para materiais HCP. Cazacu (CAZACU et al., 2006), propôs um outro critério de escoamento ortotrópico generalizado para prever a tensão onde utilizou a abordagem de transformação linear de Barlat (BARLAT et al., 1997). Sendo a forma geral do critério CPB06 expressa como:

$$
\left(\left|S_{1}\right|-k S_{1}\right)^{a}+\left(\left|S_{2}\right|-k S_{2}\right)^{a}+\left(\left|S_{3}\right|-k S_{3}\right)^{a}=F
$$

Entre todos os modelos ortotrópicos, o de Cazacu (CAZACU et al., 2006) é o que mais se aproxima dos valores reais de ensaios. Vários pesquisadores vem empregando a metodologia proposta por Cazacu para a modelagem do comportamento em escoamento de materiais HCP, especialmente ligas de titânio: (FLORES, 2005), (REVIL-BAUDARD, 2010), (VASQUEZ, 2014), (TUNINETTI et al., 2013), (GILLES, G et al., 2010), (GILLES et al., 2011), (KHAN et al., 2007).

As Figura 6-3 e Figura 6-4 apresentam o início dos trabalhos com o modelo ortotrópico proposto por Cazacu. Estas figuras foram levantadas por (CAZACU et al., 2006) e Gilles (2011) para chapas lisas em ensaios de tração e compressão, em conjunto estão os valores levantados em ensaios experimentais para liga Ti-6Al-4V 
nas condições de tração e compressão. É possível notar uma boa correlação entre o critério de escoamento proposto por Cazacu (2006) e os valores experimentais.

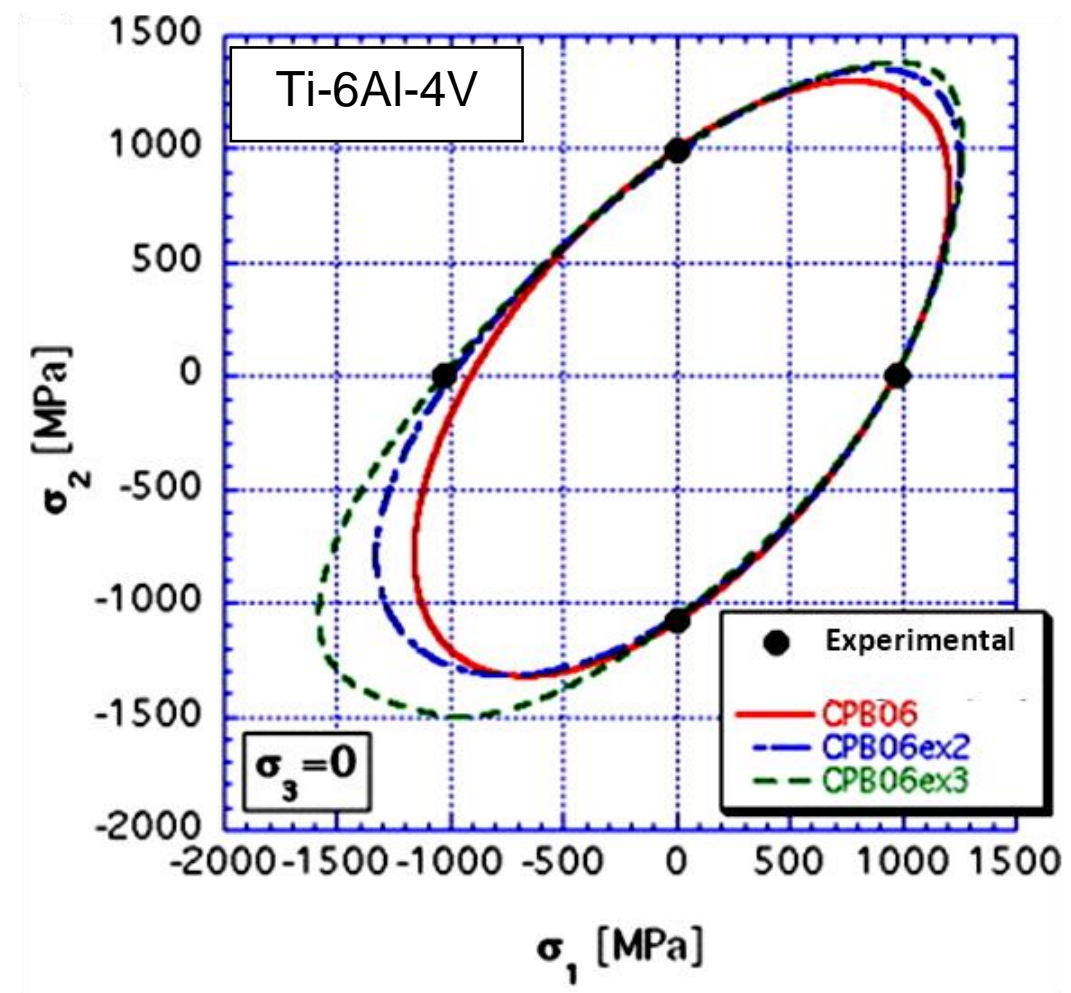

Figura 6-3 - Critérios CPB06 em comparação com valores experimentais de tração e compressão para Ti-6Al-4V (símbolos) (GILLES et al., 2011).

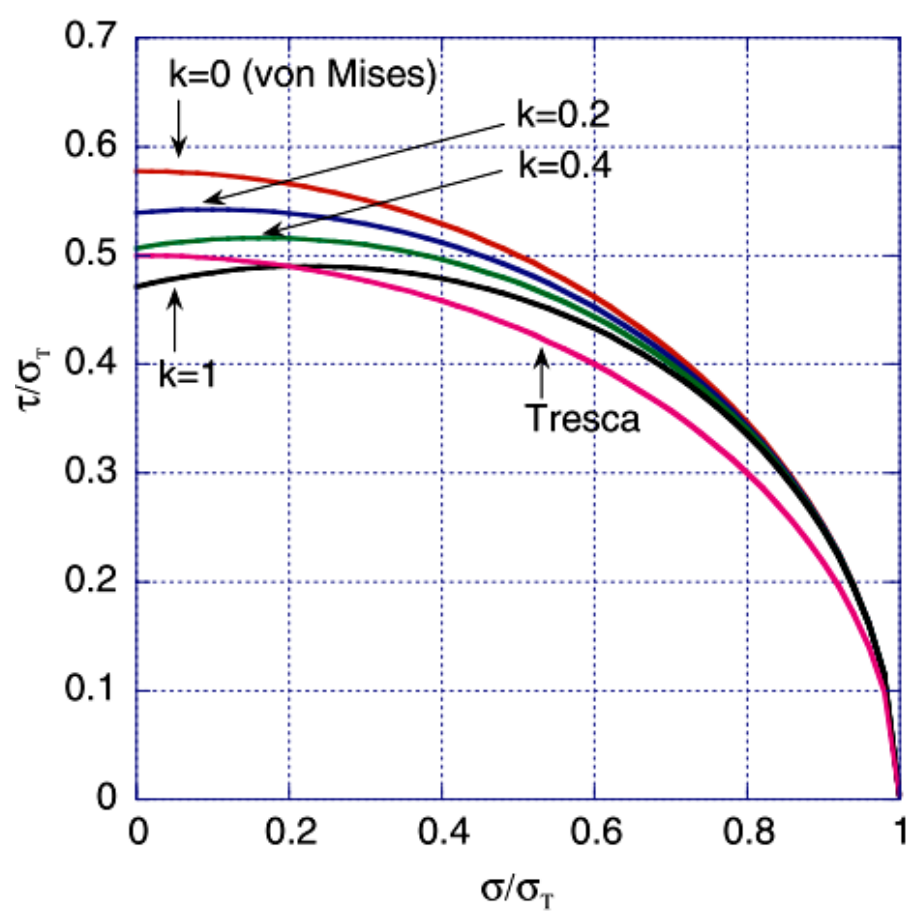

Figura 6-4 Projeções do plano de tensão-torção pelo critério proposto CPB06 para vários valores de $\mathrm{k}$ e $a=2$, comparação com Tresca e Von Mises $(k=0, a=2)$ (CAZACU et al., 2006). 


\subsubsection{Critério ortotrópico CPB06}

Para utilização do critério CPB06 é necessária a caracterização dos ensaios que servirão de base para dedução das equações necessárias à montagem do sistema de equações que irão gerar as constantes do modelo. Em geral para o critério CPB06 são necessárias 7 equações para levantamento das 7 constantes que identificam a anisotropia no material.

Para estender a ortotropia no critério proposto por Cazacu (2006), uma transformação linear sobre a tensão de desvio $S$ foi empregada, ou seja, na expressão do critério isotrópico CPB06, os valores principais da tensão de desvio de Cauchy $S_{1}, S_{2}$ e $S_{3}$ são substituídos pelos valores principais do tensor transformado $\Sigma$ definidos como:

$$
\Sigma=\boldsymbol{C}[\boldsymbol{S}]
$$

Onde C é um tensor constante de $4^{a}$ ordem. Assim, o critério ortotrópico proposto tem a forma:

$$
\left(\left|\Sigma_{1}\right|-k \cdot \Sigma_{1}\right)^{a}+\left(\left|\Sigma_{2}\right|-k \cdot \Sigma_{2}\right)^{a}+\left(\left|\Sigma_{3}\right|-k \cdot \Sigma_{3}\right)^{a}=F,
$$

Onde $\Sigma_{1}, \Sigma_{2}, \Sigma_{3}$, são os valores principais do Tensor $\Sigma$.

O expoente a no critério de escoamento deve ser um número inteiro positivo. parâmetro $k$ é uma constante de material, para um valor de a fixo, é determinado pela razão entre a tensão de tração e compressão. A função $F$, dá o tamanho da superfície de escoamento. $O$ valor de $F$ pode ser definido como uma constante ou uma função da deformação plástica total (encruamento isotrópico). O parâmetro k, é definido como:

$$
k=\frac{1-h}{1+h}
$$


Onde $h$ é expresso por:

$$
h\left(\frac{\sigma_{t}}{\sigma_{c}}\right)=\left[\frac{\left[-2^{a}+2\left(\frac{\sigma_{t}}{\sigma_{c}}\right)^{a}\right]}{\left[2-2^{a}\left(\frac{\sigma_{t}}{\sigma_{c}}\right)^{a}\right]}\right]^{1 / a}
$$

Considerando um estado plano de tensão para trabalho com chapas finas, teremos o tensor de transformação $C$ dado por:

$$
\boldsymbol{C}=\left[\begin{array}{llll}
C_{11} & C_{12} & C_{13} & \\
C_{12} & C_{22} & C_{23} & \\
C_{13} & C_{23} & C_{33} & \\
& & & C_{66}
\end{array}\right]
$$

As componentes principais dos tensores de tensão anisotrópicos são dadas como:

$$
\begin{aligned}
& \Sigma_{1}=\frac{\Sigma_{x x}+\Sigma_{y y}}{2}+\sqrt{\left(\frac{\Sigma_{x x}-\Sigma_{y y}}{2}\right)^{2}+\Sigma_{x y}^{2}} \\
& \Sigma_{2}=\frac{\Sigma_{x x}+\Sigma_{y y}}{2}-\sqrt{\left(\frac{\Sigma_{x x}-\Sigma_{y y}}{2}\right)^{2}+\Sigma_{x y}^{2}} \\
& \Sigma_{3}=\Sigma_{z z}
\end{aligned}
$$

De acordo com a transformação linear, $\Sigma=\mathrm{C}[\mathrm{S}]$ os componentes não-nulos do tensor de tensões anisotrópicas são dadas como:

$$
\left[\begin{array}{c}
\Sigma_{x x} \\
\Sigma_{y y} \\
\Sigma_{z z} \\
\Sigma_{x y}
\end{array}\right]=\left[\begin{array}{llll}
C_{11} & C_{12} & C_{13} & 0 \\
C_{12} & C_{22} & C_{23} & 0 \\
C_{13} & C_{23} & C_{33} & 0 \\
0 & 0 & 0 & C_{66}
\end{array}\right] \times\left[\begin{array}{l}
s_{x} \\
s_{y} \\
s_{z} \\
s_{x y}
\end{array}\right]
$$

Onde, $s_{x}, s_{y}, s_{x y}$ e $s_{z}$ são os componentes deviatóricos do tensor de tensões de Cauchy. Após a expansão da transformação acima temos: 


$$
\begin{aligned}
& \Sigma_{x x}=\left(\frac{2}{3} C_{11}-\frac{1}{3} C_{12}-\frac{1}{3} C_{13}\right) \sigma_{x x}+\left(-\frac{1}{3} C_{11}+\frac{2}{3} C_{12}-\frac{1}{3} C_{13}\right) \sigma_{y y} \\
& \Sigma_{y y}=\left(\frac{2}{3} C_{12}-\frac{1}{3} C_{22}-\frac{1}{3} C_{23}\right) \sigma_{x x}+\left(-\frac{1}{3} C_{12}+\frac{2}{3} C_{22}-\frac{1}{3} C_{23}\right) \sigma_{y y} \\
& \Sigma_{z z}=\left(\frac{2}{3} C_{13}-\frac{1}{3} C_{23}-\frac{1}{3} C_{33}\right) \sigma_{x x}+\left(-\frac{1}{3} C_{13}+\frac{2}{3} C_{23}-\frac{1}{3} C_{33}\right) \sigma_{y y} \\
& \Sigma_{x y}=C_{66} . \sigma_{x y}
\end{aligned}
$$

Aplicando as diferentes condições de carregamento dos ensaios experimentais podemos deduzir as equações a partir do critério acima que fornecerão os valores das constantes de anisotropia.

Para o caso de tração uniaxial na direção de $x$ (coincidente com a direção de laminação para chapas lisas) teremos $\sigma_{y y}=\sigma_{x y}=0$, a equação resultante fica:

$$
\sigma_{0}^{T}=\left\{\frac{F}{\left[\left|\Phi_{1}\right|-k . \Phi_{1}\right]^{a}+\left[\left|\Phi_{2}\right|-k \cdot \Phi_{2}\right]^{a}+\left[\left|\Phi_{3}\right|-k . \Phi_{3}\right]^{a}}\right\}^{1 / a}
$$

Onde,

$$
\begin{aligned}
& \Phi_{1}=\left(\frac{2}{3} C_{11}-\frac{1}{3} C_{12}-\frac{1}{3} C_{13}\right) \\
& \Phi_{2}=\left(\frac{2}{3} C_{12}-\frac{1}{3} C_{22}-\frac{1}{3} C_{23}\right) \\
& \Phi_{3}=\left(\frac{2}{3} C_{13}-\frac{1}{3} C_{23}-\frac{1}{3} C_{33}\right)
\end{aligned}
$$

Para o caso de tração uniaxial na direção de $y$ (transversal à direção de laminação para chapas lisas) teremos $\sigma_{x x}=\sigma_{x y}=0$ e a equação resultante fica:

$$
\sigma_{90}^{T}=\left\{\frac{F}{\left[\left|\Psi_{1}\right|-k \cdot \Psi_{1}\right]^{a}+\left[\left|\Psi_{2}\right|-k \cdot \Psi_{2}\right]^{a}+\left[\left|\Psi_{3}\right|-k \cdot \Psi_{3}\right]^{a}}\right\}^{1 / a}
$$

Onde:

$$
\begin{aligned}
& \Psi_{1}=\left(-\frac{1}{3} C_{11}+\frac{2}{3} C_{12}-\frac{1}{3} C_{13}\right) \\
& \Psi_{2}=\left(-\frac{1}{3} C_{12}+\frac{2}{3} C_{22}-\frac{1}{3} C_{23}\right) \\
& \Psi_{3}=\left(-\frac{1}{3} C_{13}+\frac{2}{3} C_{23}-\frac{1}{3} C_{33}\right)
\end{aligned}
$$


Para condição de cisalhamento puro temos $\sigma_{x x}=\sigma_{y y}=0$, a equação resultante fica:

$$
\sigma_{x y}=\left\{\frac{F}{\left[\left|C_{66}\right|+k \cdot C_{66}\right]^{a}+\left[\left|C_{66}\right|-k \cdot C_{66}\right]^{a}}\right\}^{1 / a}
$$

Denotando $r$ como o coeficiente de Lankford (razão de deformação da largura pela espessura) sob tensão uniaxial em um ângulo relativo à direção de laminação (ou processamento), teremos que para direção coincidente em tração:

$$
r_{0}^{\mathrm{T}}=-\frac{(1-k)^{a} \Phi_{1}^{a-1} \Psi_{1}+(-1-k)^{a}\left(\Phi_{2}^{a-1} \Psi_{2}+\Phi_{3}^{a-1} \Psi_{3}\right)}{(1-k)^{a} \Phi_{1}^{a-1}\left(\Psi_{1}+\Phi_{1}\right)+(-1-k)^{a}\left(\Phi_{2}^{a-1} \Psi_{2}+\Phi_{3}^{a-1} \Psi_{3}+\Phi_{2}^{a}+\Phi_{3}^{a}\right)}
$$

As equações deduzidas acima servem para os casos de tração, compressão e cisalhamento puro. Para o critério CPB06 é necessário compatibilizar os sete parâmetros de anisotropia com os valores de ensaios reais efetuados no material de estudo. O método utilizado para resolução deve ser por minimização de uma ou mias funções de erro por métodos interativos. Para isto se faz necessário uma montagem de um sistema de sete equações ou compatível em função do método de minimização escolhido.

Para ensaios em situações convencionais a proposta de Cazacu et al (2006) é ensaiar o material em duas direções principais (Laminação $0^{\circ}$ e Transversal $90^{\circ}$ ) tanto em tração como compressão. Isto resulta em um sistema de seis equações se considerados os dois ângulos em tração e compressão mais as equações de anisotropia. Portanto o sistema linear fica incompleto, sobrando um parâmetro a ser resolvido. Em seus estudos Cazacu et al (2006) utiliza um critério para eliminar esta dificuldade adotando um dos parâmetros como fixo e igual a um. Outros autores (KHAN et al., 2007; GILLES, G. et al., 2010; KOTKUNDE et al., 2014) adotam outros procedimentos de minimização ou trabalham com mais condições de ensaios e eliminam a necessidade desta estimativa. 


\section{EXPERIMENTOS PRELIMINARES}

O trabalho experimental preliminar, consistiu na execução do processamento por atrito linear em chapas da liga de titânio Ti-6Al-4V em caráter exploratório. Esta etapa teve a intenção de identificar quais deveriam ser os parâmetros mais apropriados para execução dos testes principais.

\subsection{Materiais e métodos: Experimentos preliminares}

Para aproximação dos dados e primeiro contato com o processo, este planejamento auxiliou no conhecimento inicial das condições que foram utilizadas nos experimentos principais.

A Tabela 7-1 apresenta a matriz resultante para o planejamento preliminar de FSP, a matriz se encontra randomizada entre a sequência de ensaio e a sequência padrão, sem duplicação, para estudo dos níveis iniciais mais adequados, $[4 c p+1 a x]=5$ chapas de prova.

Tabela 7-1 Matriz para o planejamento preliminar

\begin{tabular}{ccccc}
\hline $\begin{array}{c}\text { Sequência } \\
\text { padrão }\end{array}$ & $\begin{array}{c}\text { Sequência } \\
\text { de ensaio }\end{array}$ & $\begin{array}{c}\text { Rotação } \\
\text { [RPM] }\end{array}$ & $\begin{array}{c}\mathbf{f} \\
\text { [mm/min] }\end{array}$ & $\begin{array}{c}\mathbf{a}_{\mathbf{p}} \\
\text { [mm] }\end{array}$ \\
\hline 4 & 1 & 1 & 1 & 1 \\
5 & 2 & 0 & 0 & 0 \\
3 & 3 & -1 & 1 & -1 \\
2 & 4 & 1 & -1 & -1 \\
1 & 5 & -1 & -1 & 1 \\
\hline
\end{tabular}

\subsubsection{Parâmetros e condições variáveis}
a) Rotação (RPM)
: Nível -1, Nível 1 e Nível 0.
b) Avanço (f)
: Nível -1, Nível 1 e Nível 0.
c) Profundidade de penetração $\left(a_{p}\right)$ : Nível -1 e Nível 1.

\subsubsection{Condições fixas}

a) Inclinação da ferramenta: $1^{\circ}$

b) Máquina utilizada: Centro de usinagem vertical CNC MAZAK - MTV515/40N

c) Controle de posição da ferramenta. 


\subsubsection{Resultados dependentes do experimento}
a) Tensão residual;
b) Microestrutura da região processada;
c) Microdureza da região processada.

\subsubsection{Corpos de prova para ensaio de FSP}

a) Material do corpo de prova: Ti-6Al-4V grau 5 ASTM B265 (vide Anexo D)

b) Geometria dos corpos de prova para experimento de tração: Figura 7-1

c) Espessura $=2 \mathrm{~mm}$

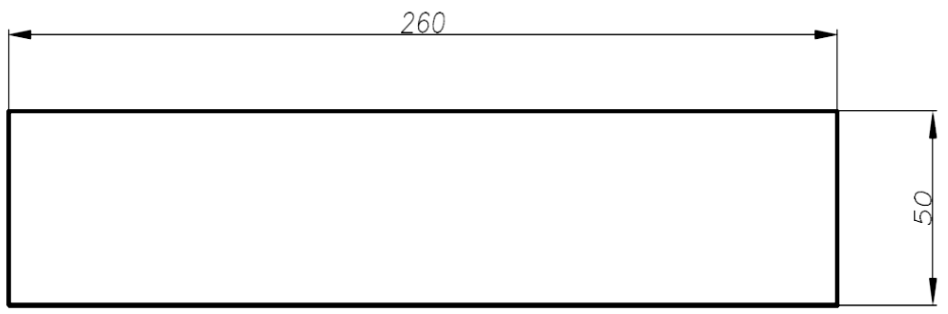

Figura 7-1 - Geometria dos corpos de prova para experimento de FSP, dimensões em milímetros.

\section{Observações:}

- Os Corpos de Prova foram cortados nas dimensões em milímetros especificadas, sem rebarbas nas laterais;

- Recortar todos os Corpos de Prova da mesma chapa para evitar variação de composição química;

- Recortar os Corpos de Prova das chapas sempre no mesmo sentido para garantir a uniformidade do sentido da estrutura do material;

- Sentido do FSP que será executado (Figura 7-2):

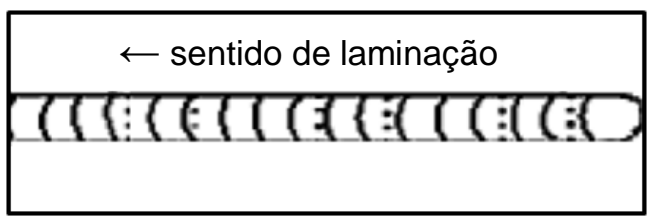

Figura 7-2 - Sentido do FSP

\subsubsection{Máquina utilizada no ensaio preliminar}

A máquina utilizada para execução dos ensaios de FSP em titânio foi um centro de usinagem do fabricante Mazak modelo V515/40N (Figura 7-3) pertencente 
à empresa Polimold. É uma máquina de médio porte, com três eixos de movimento e o cabeçote em balanço apoiado na coluna móvel.

A Tabela 7-2 apresenta as características básicas para a máquina utilizada, a máquina apresenta uma construção sólida e bastante estável e seu peso demonstra uma boa rigidez. É uma máquina dotada de um comando numérico computadorizado onde é possível o controle de todos os movimentos e rotações da máquina através programação em linguagem de máquina. Este comando também apresenta uma visualização da carga aplicada em cada eixo e no cabeçote, na forma de um gráfico de barras com valores em porcentagem, porém sem a possibilidade de registro dos valores. O Anexo $\mathrm{E}$ apresenta o exemplo do programa utilizado nos ensaios preliminares.

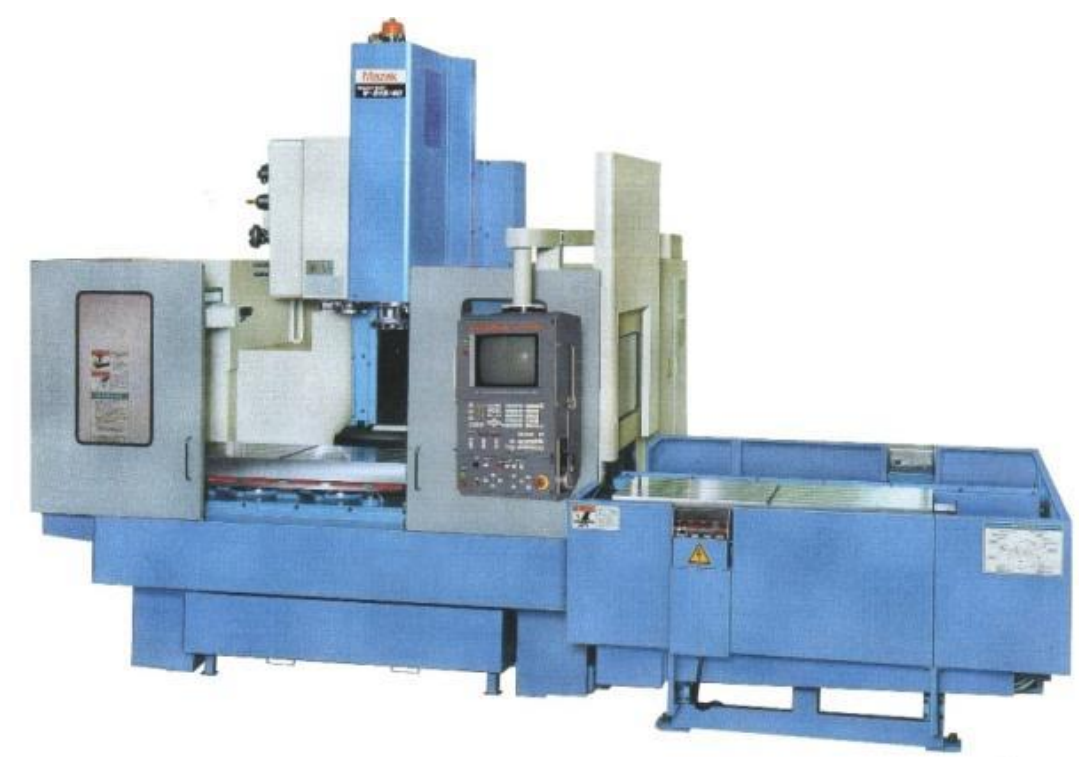

Figura 7-3 Centro de usinagem utilizado para o FSP nos CDPs de titânio.

Tabela 7-2 Características da máquina utilizada.

\begin{tabular}{lcl}
\hline \multicolumn{1}{c}{ Característica } & Valor & Unidade \\
\hline Curso no eixo X & 1050 & $\mathrm{~mm}$ \\
Curso no eixo Y & 510 & $\mathrm{~mm}$ \\
Curso no eixo Z & 560 & $\mathrm{~mm}$ \\
Potencia do motor do fuso & 15 & $\mathrm{~kW}$ \\
Torque do motor & $737,5(75,2)$ & $\mathrm{N} . \mathrm{m}(\mathrm{kgf} . \mathrm{m})$ \\
Rotação máxima & 6.000 & $\mathrm{RPM}$ \\
Avanço programado máximo & 8.000 & $\mathrm{~mm} / \mathrm{min}$ \\
Dimensão geral da máquina & Comprimento: 4.735 & \\
& Largura: 3.680 & $\mathrm{~mm}$ \\
Peso & Altura: 3.245 & \\
\hline
\end{tabular}




\subsubsection{Construção do dispositivo de fixação}

Para fixação das chapas de titânio na mesa da máquina foi necessária a construção de uma base especial projetada para fixar ambos os corpos de prova previstos para o ensaio. No Anexo A encontram-se os desenhos do projeto do dispositivo, a base do dispositivo. As garras foram construidas em aço ABNT 1045. $\mathrm{Na}$ região central (área onde ocorre o processamento) foi usinado um alojamento para montagem de réguas de um material mais resistente, devido à alta temperatura envolvida no processo (aproximadamente $900^{\circ} \mathrm{C}$ ) optou-se por utilizar insertos de metal duro para usinagem da classe S01 (vide Anexo F), cuja composição exata não foi divulgada pelo fabricante. A Figura 7-4 apresenta os componentes do dispositivo de fixação separadamente.

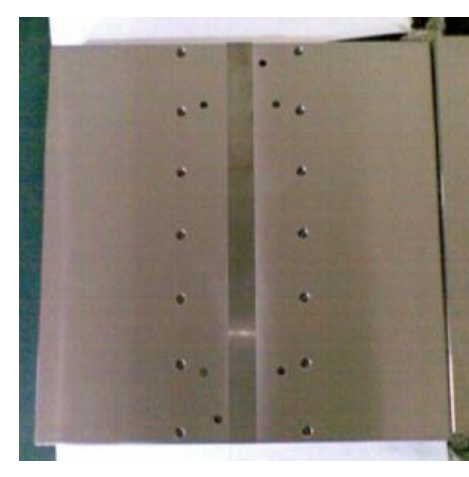

(a)

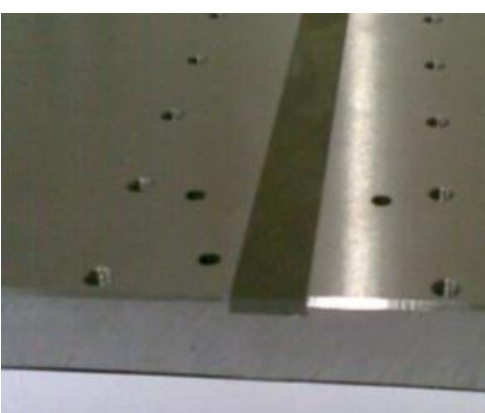

(b)

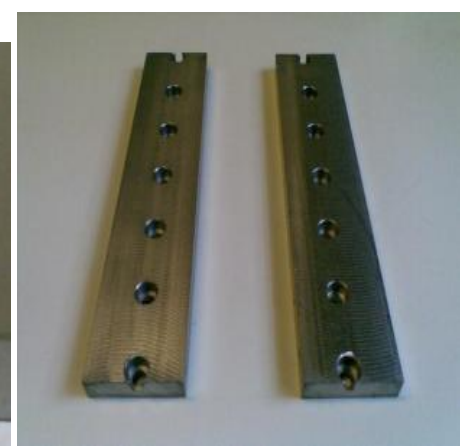

(c)

Figura 7-4 - (a) Vista da placa do dispositivo de fixação; (b) detalhe da lâmina de liga de WC no centro do dispositivo; (c) Barras para fixação das chapas no dispositivo.

A Figura 7-5(a) apresenta o dispositivo já fixado na mesa da máquina com um corpo de prova posicionado, a Figura 7-5(b) mostra a fixação completa.

(a)

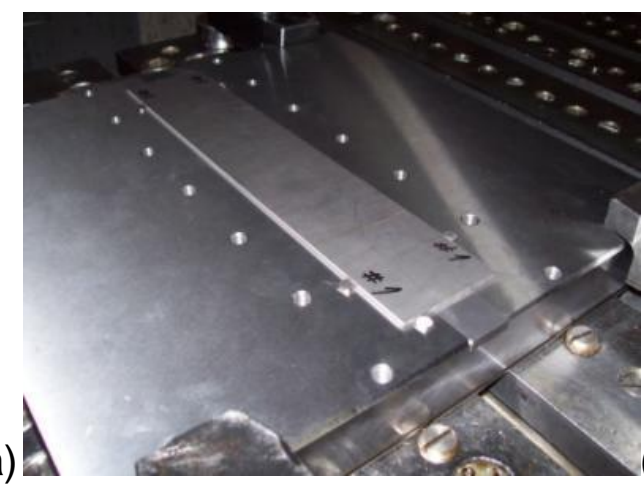

(b)

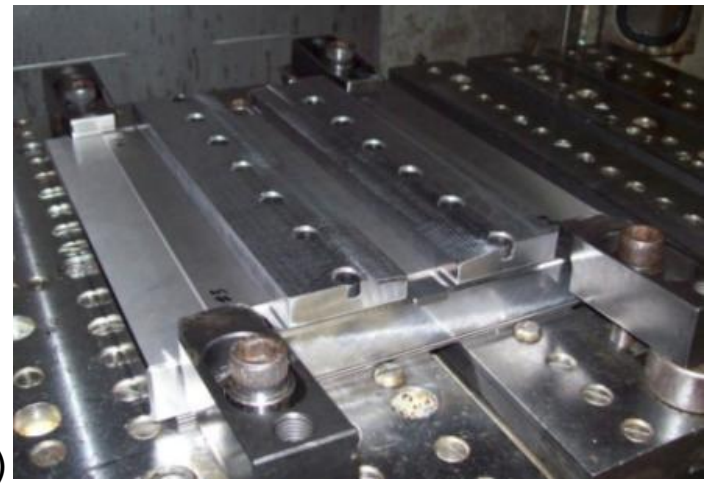

Figura 7-5 - (a) Chapa posicionada no dispositivo, (b) fixação completa. 
Na Figura 7-6 é possível verificar a existência de pinos de localização para garantir a correta montagem dos corpos de provas sempre na mesma posição e também para restringir a movimentação horizontal do corpo de prova durante o processamento.

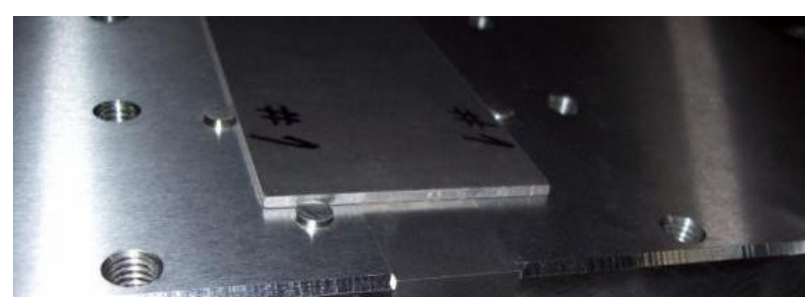

Figura 7-6 - Detalhe dos pinos de posicionamento do corpo de prova.

A Figura 7-7 mostra a condição da área em que a ferramenta percorre no processamento, as garras de fixação do corpo de prova foram projetadas de forma a minimizar a possibilidade de movimento vertical da peça durante o processamento. O vão entre uma garra e outra é de $30 \mathrm{~mm}$, valor suficiente para que não exista colisão da ferramenta na sua passagem.

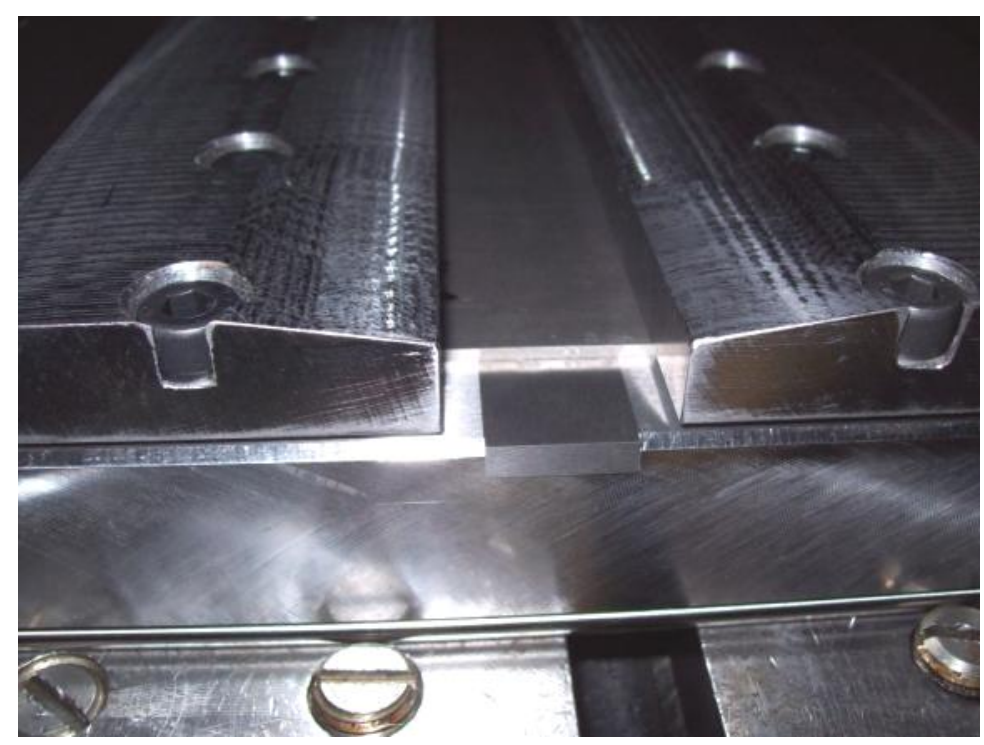

Figura 7-7 - Detalhe da área a ser processada.

A inclinação do eixo da ferramenta foi simulada mediante a inclinação da base de fixação, para tanto um cilindro de $5,2 \mathrm{~mm}$ de diâmetro (vide Anexo B) foi adicionado em uma das extremidades da base e fixado rigidamente. Para evitar algum movimento vertical da base devido a uma possível pressão vertical da 
ferramenta, cilindros de diâmetros de $3 \mathrm{~mm}$ e $2 \mathrm{~mm}$ foram posicionados sob a base no vão resultante da inclinação.

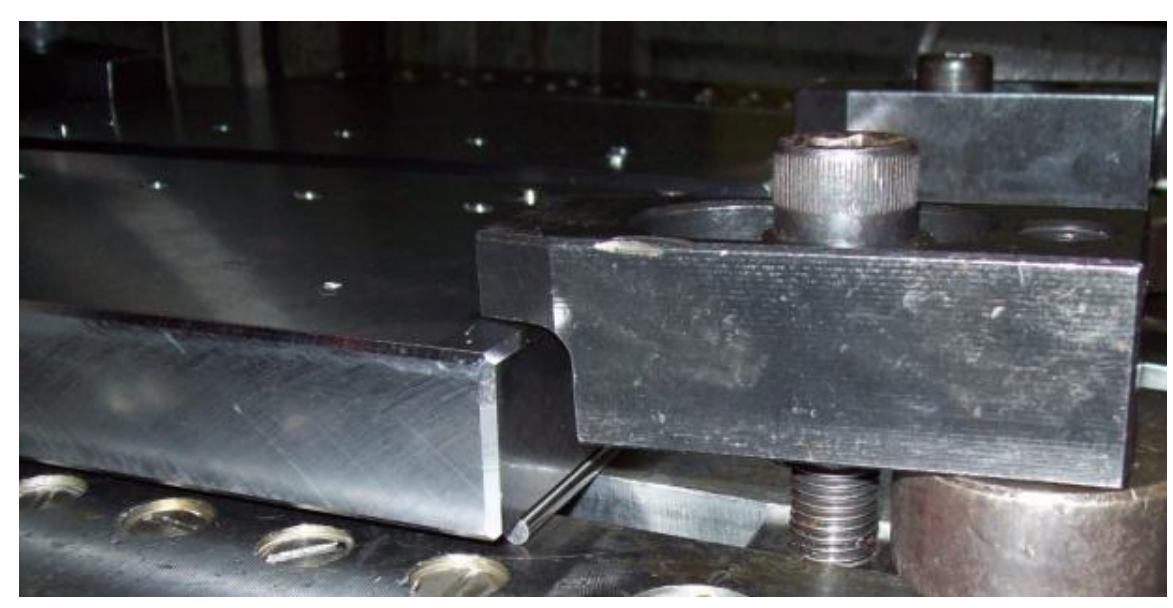

Figura 7-8 - Detalhe para simulação da inclinação da ferramenta

\subsubsection{Ferramenta para o ensaio de preliminar}

Com objetivo de desenvolver uma ferramenta que suporte o processamento por atrito linear em chapas de titânio, a empresa colaboradora Uniwidia preparou duas ferramentas conforme o projeto constante no Anexo $\mathrm{C}$ na liga de WC+TaC. Esta liga é utilizada com sucesso no processamento de furos em chapas de aço no setor automobilístico para montagem de grampos e parafuso na carcaça de veículos. Foi escolhida como primeira opção, pois neste processamento de furos as temperaturas envolvidas são da ordem de $900^{\circ} \mathrm{C}$ a $1.000^{\circ} \mathrm{C}$. Os ensaios preliminares foram executados com esta ferramenta para definição da janela de parâmetros iniciais e testes específicos de resistência ao desgaste. A Figura 7-9 apresenta as ferramentas desmontadas do suporte. Trata-se de uma ferramenta inteiriça, ou seja, tanto o pino como o ombro são da mesma composição de WC+TaC.
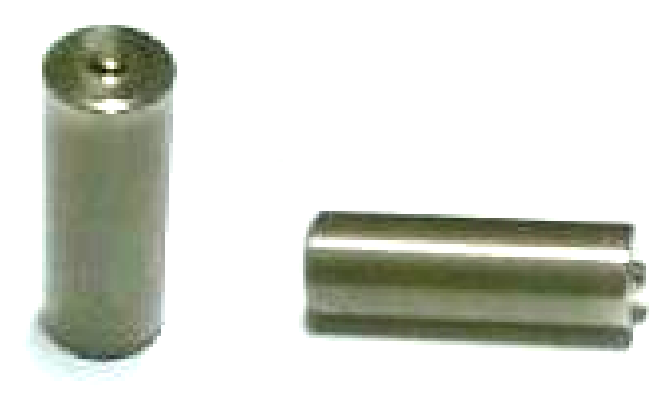

Figura 7-9 - Ferramenta para FSW em titânio, diâmetro do ombro 16mm e pino de diâmetro $4 \mathrm{~mm} \times 1,6 \mathrm{~mm}$ cônico com $30^{\circ}$. 
Na Figura 7-10 a ferramenta é montada em um suporte de aço que é fixado no fuso da máquina. A fixação da ferramenta no suporte é feita através de um parafuso de fixação sem cabeça com sextavado interno de tamanho de rosca M8. O suporte é fixado no fuso da máquina por um dispositivo composto por molas prato.

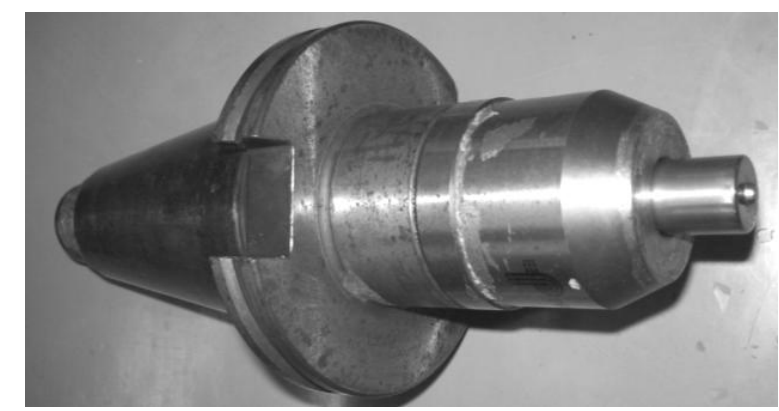

Figura 7-10 - Ferramenta montada no suporte de fixação.

\subsubsection{Preparação da máquina}

Para garantir o alinhamento da base na mesa da máquina foi efetuado um procedimento de alinhamento com um relógio comparador centesimal, que foi movimentado no mesmo sentido (eixo $\mathrm{Y}$ ) do percurso da ferramenta. $\mathrm{O}$ máximo desalinhamento encontrado foi de $0,01 \mathrm{~mm}$. Este alinhamento é importante para garantir que o trajeto da ferramenta seja executado em cima das lâminas de apoio de tungstênio.

A Figura 7-11 apresenta o procedimento de alinhamento com o relógio centesimal. Foi utilizada uma base magnética para fixação do relógio no cabeçote da máquina.

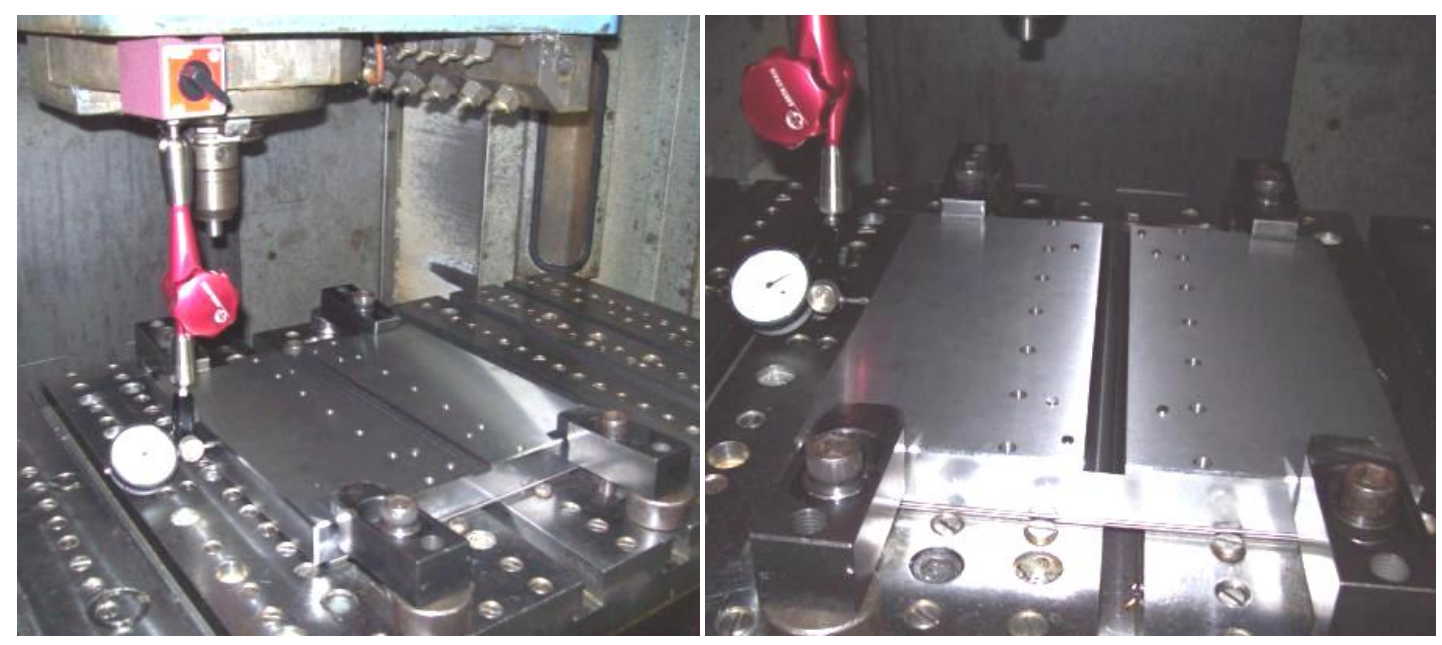

Figura 7-11 - Alinhamento da base do dispositivo na mesa da máquina. 
O suporte com a ferramenta foi montado no cabeçote da máquina através de sujeição por molas prato (Figura 7-12a). Para verificação da concentricidade (batimento) entre o centro de giro do cabeçote e o suporte da ferramenta foi utilizado um relógio centesimal (Figura 7-12b). O valor encontrado foi de $0,03 \mathrm{~mm}$ e como não foram encontradas nas referências citadas valores de tolerância para esta medição este valor foi considerado como aceitável para a montagem.

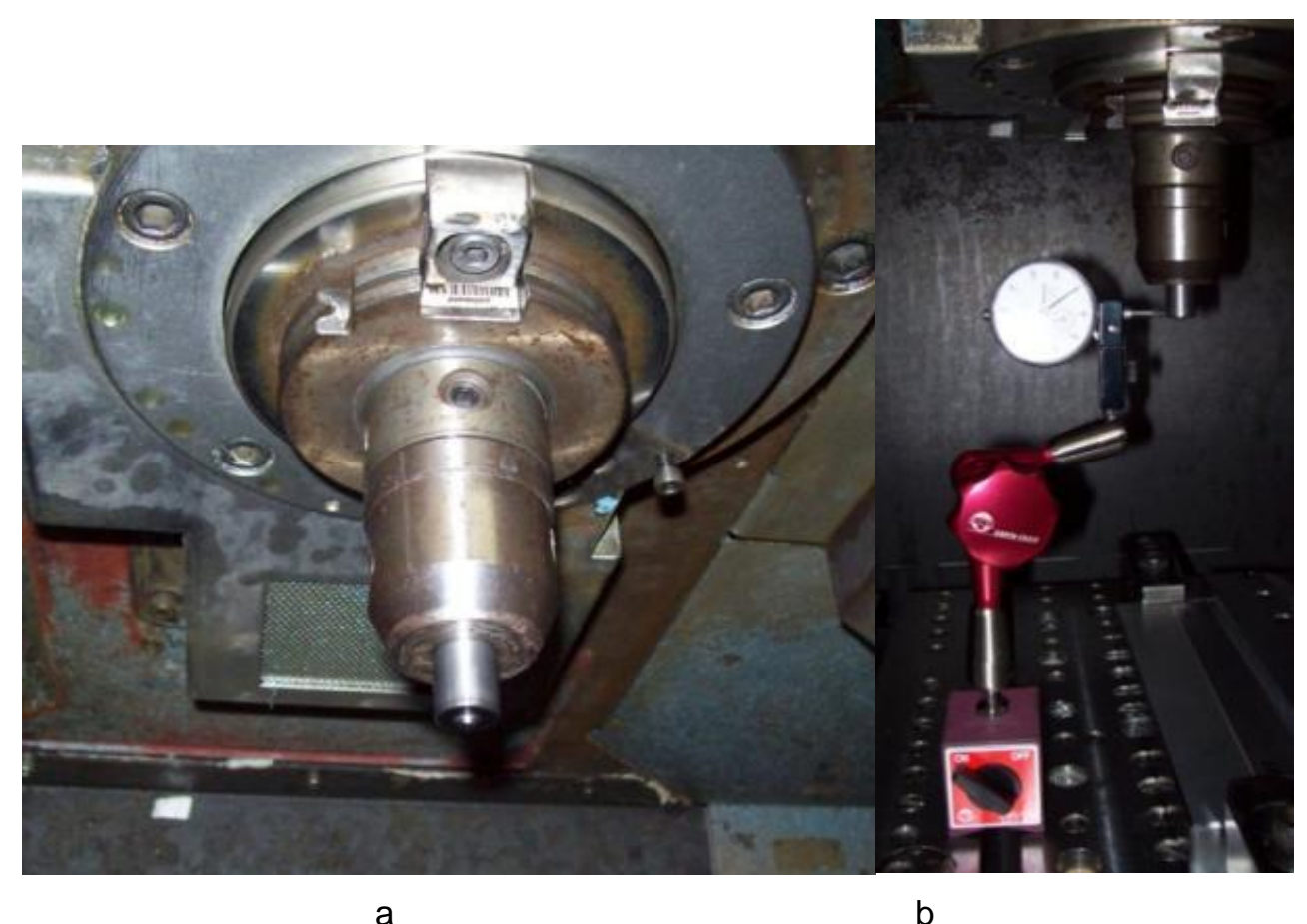

Figura 7-12 - Suporte montado no cabeçote (a) e em (b) verificação do batimento da ferramenta.

\subsection{Execução do ensaio preliminar}

Para execução do ensaio preliminar foram selecionados valores com base nas bibliografias pesquisadas no capítulo 2.3.3 como parâmetros iniciais para um primeiro entendimento do processo. A Tabela 7-3 apresenta a matriz da composição dos ensaios. Os valores foram escolhidos de modo a evitar condições extremas, condições que no ensaio preliminar poderiam induzir interações não desejáveis entre os parâmetros. Outro fator importante foi avaliar o projeto da liga utilizados na ferramenta, pois para o sucesso dos ensaios, a ferramenta deveria ser capaz de efetuar o percurso sem sofrer desgaste e sem quebrar. 
Tabela 7-3 - Matriz do planejamento preliminar com valores de ensaio

\begin{tabular}{ccccc}
\hline $\begin{array}{c}\text { Sequência } \\
\text { padrão }\end{array}$ & $\begin{array}{c}\text { Sequência } \\
\text { de ensaio }\end{array}$ & $\begin{array}{c}\text { Rotação } \\
\text { [RPM] }\end{array}$ & $\begin{array}{c}\mathbf{f} \\
\text { [mm/min] }\end{array}$ & $\begin{array}{c}\mathbf{a}_{\mathbf{p}} \\
{[\mathbf{m m}]}\end{array}$ \\
\hline 4 & 1 & 350 & 75,0 & 1,85 \\
5 & 2 & 325 & 62,5 & 1,75 \\
3 & 3 & 300 & 75,0 & 1,65 \\
2 & 4 & 350 & 50,0 & 1,65 \\
1 & 5 & 300 & 50,0 & 1,85 \\
\hline
\end{tabular}

Visando minimizar os esforços e fornecer uma guia inicial para a ponta da ferramenta, foi executado um furo piloto com broca helicoidal na profundidade de 1,60 mm (Figura 7-13). O diâmetro da broca $(3,8 \mathrm{~mm})$ foi selecionado de forma a ser menor do que a ponta da ferramenta $(4,0 \mathrm{~mm})$, com isso a ponta da ferramenta ao executar a penetração, gera atrito com a lateral do furo guia fornecendo calor ao processo.

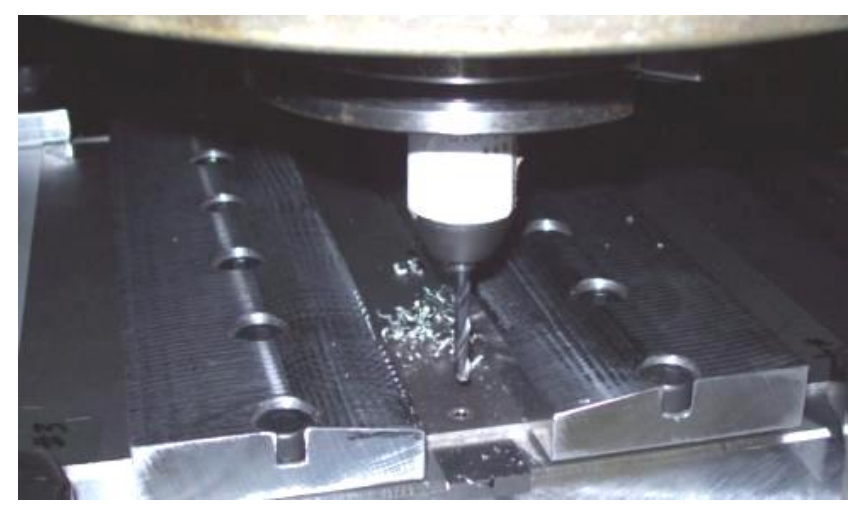

Figura 7-13 - Furo piloto para entrada da ferramenta de FSP.

O programa do Anexo $E$ foi então preparado com os parâmetros da sequência de ensaio número um (rotação: 350 RPM, f: $75 \mathrm{~mm} / \mathrm{min}$ e $a_{p}: 1,85 \mathrm{~mm}$ ). A velocidade de descida (penetração) da ferramenta na peça foi estipulada em $5 \mathrm{~mm} / \mathrm{min}$.

Após o posicionamento da ferramenta e início da rotação do eixo da máquina a ferramenta iniciou a penetração no material com a velocidade de avanço programada de $5 \mathrm{~mm} / \mathrm{min}$. Observou-se no painel da máquina uma elevação brusca no esforço do eixo $Z$ (de até $40 \%$ da carga no eixo do movimento de penetração) e uma vibração moderada no cabeçote da máquina. Ao final do movimento de penetração foi possível observar um grande fluxo de material escapando pela periferia da ferramenta. Após uma pausa de 4 segundos foi efetuada uma tomada de temperatura com um equipamento infravermelho da marca Raytek, modelo Marathon MT, o valor observado apresentou uma oscilação entre $800^{\circ} \mathrm{C}$ a $960^{\circ} \mathrm{C}$. 
O próximo passo foi iniciar o movimento de deslocamento sobre a peça para efetuar o trajeto linear total no corpo de prova. Visando a redução de defeitos e falhas na entrada da ferramenta e no início do avanço para execução do FSP, conforme proposto por Mashinini (2010), foi utilizada a metodologia conforme Figura 7-14 para definir a rotação e a velocidade em função do comprimento a ser processado. A Figura 7-14a apresenta a variação da rotação em função da distância a ser processada e na Figura 7-14b a variação da velocidade em função da distância a ser processada. Este procedimento também ajuda a evitar sobrecargas que podem ocasionar a quebra da ferramenta.

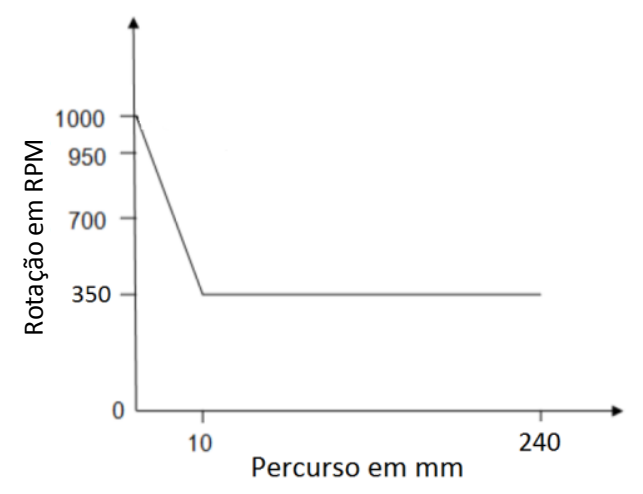

(a)

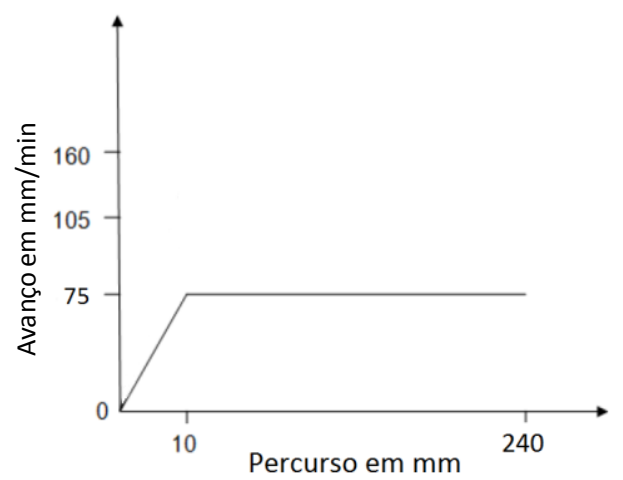

(b)

Figura 7-14 - (a) Rampa de redução de rotação e (b) rampa de aumento do avanço, utilizados nos ensaios.

Logo após o início do movimento linear sobre a peça o nível de vibração do cabeçote passa a ser mais intenso e em aproximadamente $2 \mathrm{~mm}$ efetuados do percurso a ferramenta apresenta sinal de quebra (na ponta e no corpo). Ao se quebrar a ferramenta passa a remover o material como em um processo de usinagem, abrindo um canal irregular na peça como pode ser obsevado na Figura 7-15. É possível verificar que houve uma grande deformação plástica ainda na entrada da ferramenta.

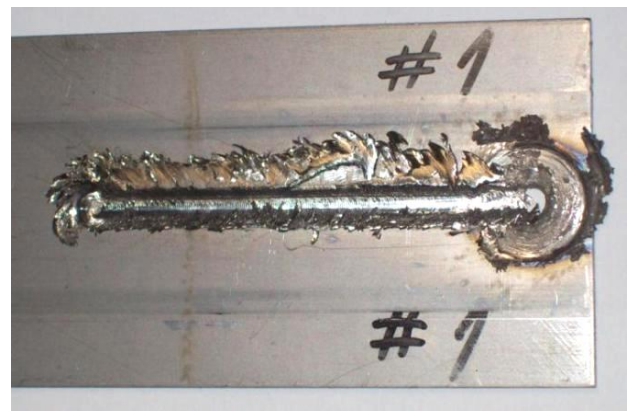

Figura 7-15 - Corpo de prova processado com 350 RPM, f: 75 mm/min e $a_{p}: 1,85 \mathrm{~mm}$. 
O processo foi interrompido após $60 \mathrm{~mm}$ do percurso e a ferramenta foi retraída lentamente para evitar um possível o travamento brusco no cabeçote da máquina. Ao desmontar a ferramenta do suporte foi observado que houve uma quebra na haste e na ponta da ferramenta conforme apresentado na Figura 7-16. A provável causa pode estar associada ao esforço evidenciado pelo nível de vibração no cabeçote da máquina.

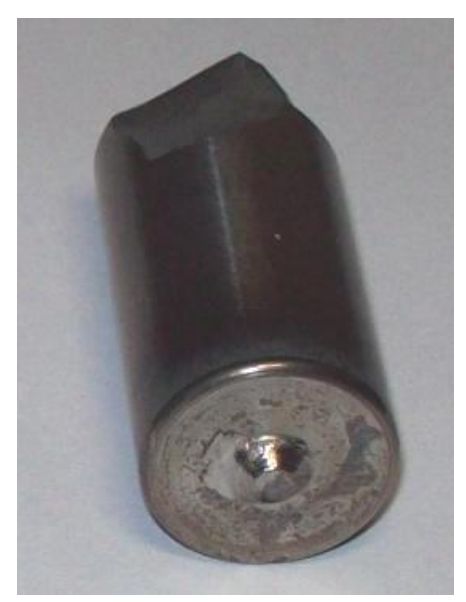

Figura 7-16 - Ferramenta danificada utilizada no primeiro ensaio.

No seguinte ensaio uma segunda ferramenta idêntica à primeira foi montada no suporte em fixada no cabeçote da máquina. Efetuada a medição da concentricidade de giro na montagem encontrou-se o valor de $0,01 \mathrm{~mm}$ que se mostrou melhor do que a condição da primeira ferramenta.

Visando economia de material a mesma chapa utilizada no primeiro ensaio foi fixada no dispositivo após um giro de $180^{\circ}$ para utilização da outra extremidade ainda não processada. Após a constatação de que as condições do primeiro ensaio impuseram um nível elevado de esforços no cabeçote, decidiu-se então minimizar as probabilidades de repetição desta condição. Portanto, a sequência de ensaios do planejamento foi abandonada e utilizou-se os valores da sequência de ensaio número quatro constantes na Tabela 7-3, rotação de 350 RPM, velocidade de avanço de $50 \mathrm{~mm} / \mathrm{min}$ e $a_{p}$ de 1,65 mm. A velocidade de penetração foi alterada no programa para $1 \mathrm{~mm} / \mathrm{min}$ visando diminuir ou eliminar a vibração durante a entrada na peça. Executou-se o furo piloto conforme o primeiro ensaio, porém o equipamento de medição da temperatura não foi montado para este ensaio. Após a 
observação das ocorrências do primeiro ensaio a meta para o segundo ensaio seria conseguir executar um trajeto linear maior sem quebrar a ferramenta.

A entrada da ferramenta na peça no segundo ensaio apresentou um comportamento diferente do primeiro ensaio. Não houve um aumento brusco no esforço do eixo Z (menor do que 20\%, com aumento aparentemente linear), os níveis de vibração do cabeçote não foram notados durante a entrada da ferramenta.

A mesma metodologia de rampas para redução da rotação e aumento do avanço foi adotada e antes do movimento linear foi executada uma pausa no avanço de 3 segundos com a ferramenta girando. Ao iniciar o movimento linear foi observada inicio de vibração moderada no cabeçote da máquina. O comportamento inicial da ferramenta se apresentou estável e condizente com o processo, porém com a redução da rotação e aumento do avanço, devido à metodologia aplicada da rampa, houve um aumento no esforço do eixo $Z$ visualizado no painel da máquina (aproximadamente em $+10 \%$ ).

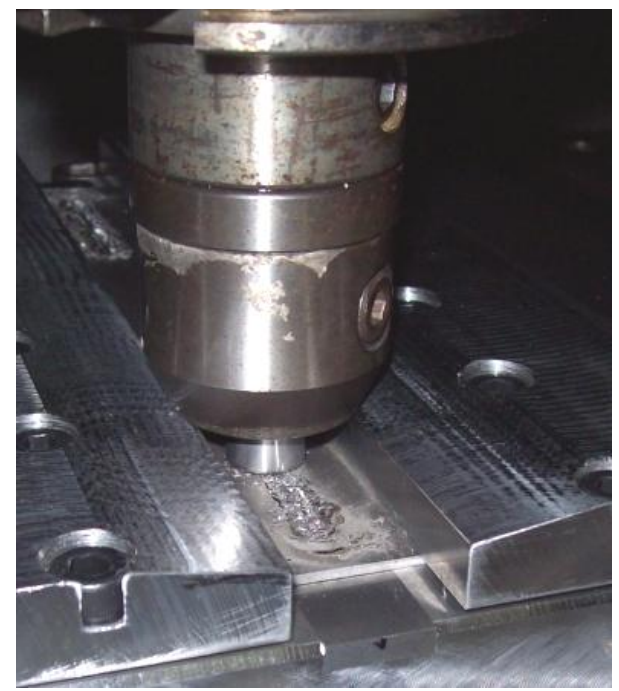

Figura 7-17 - Ferramenta executando o trajeto linear sobre o corpo de provas.

Após o percurso de aproximadamente $5 \mathrm{~mm}$ a ferramenta apresentou sinais de quebra Figura 7-18 e iniciou a formação de um canal como no primeiro ensaio. A Figura 7-18 apresenta o resultado do ensaio para as condições selecionadas. É possível notar que os parâmetros empregados nos dois ensaios provocaram resultados diferentes nos corpos de prova. 


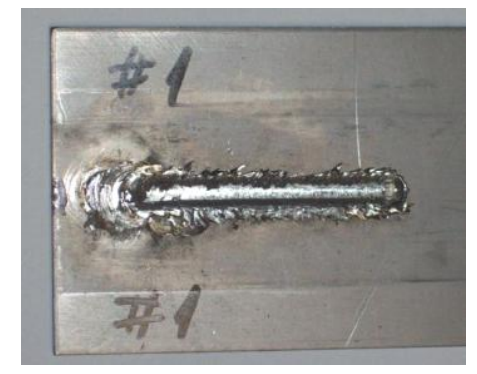

Figura 7-18 - Corpo de prova processado com 350 RPM, f: 50 mm/min e $a_{p}: 1,65 m m$.

A Figura 7-19 apresenta em detalhe a região processada no segundo ensaio. É possível verificar a formação de uma região altamente deformada e não se observa vestígio da posição de entrada da ferramenta com visto na Figura 7-15.

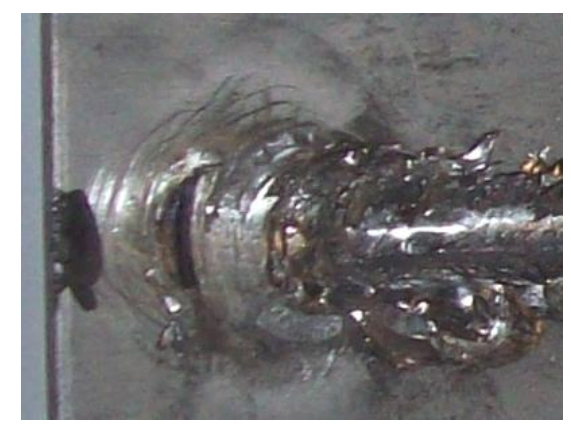

Figura 7-19 - Detalhe da região processada no segundo ensaio.

Em ambos os casos houve a falha da ferramenta, provendo indícios de que a liga utilizada de WC+TaC pode não ser indicada para o processamento da liga de titânio Ti-6Al-4V. A Figura 7-20 apresenta a ferramenta danificada no segundo ensaio. Em ambos os casos o pino central da ferramenta perdeu sua geometria inicial.

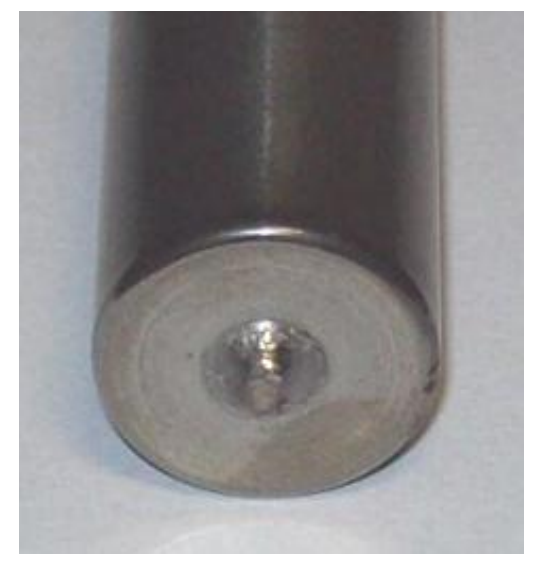

Figura 7-20 - Ferramenta danificada utilizada no segundo ensaio. 


\subsubsection{Avaliação do experimento preliminar}

Uma análise inicial da ferramenta utilizada no primeiro ensaio indica que a liga utilizada para construção apresentou uma forte reatividade com o material Ti-6Al-4V do corpo de prova. A Figura 7-21 apresenta as fotografias da ponta da ferramenta do primeiro ensaio. É possível observar um vestígio de adesão do material do corpo de prova na ponta da ferramenta, mesmo depois de manuseada fora do suporte o vestígio de material não se descolou da ponta da ferramenta. Na região do ombro, precisamente na face, houve também o arranque do material da ferramenta por adesão no material da peça seguida de forte deformação. Na ponta da ferramenta foi possível observar que houve uma fratura, e foi esta região fraturada na ponta da ferramenta a responsável pela formação do canal observado no corpo de provas.

No segundo ensaio a profundidade utilizada como parâmetro não foi suficiente para provocar o toque completo do ombro da ferramenta com a peça, apenas a porção perto do pino encostou e provavelmente devido ao levantamento de material que foi deformado. A Figura 7-22 apresenta a fotografia da ponta da ferramenta do segundo ensaio, onde é possível observar a fratura na ponta devido ao esforço concentrado na região. O esforço concentrado provavelmente é o resultado da falta de calor no processo devido à baixa profundidade utilizada no segundo ensaio $(1,65$ $\mathrm{mm}$ ). Uma das funções do ombro é gerar atrito com a peça para geração de calor no sistema.

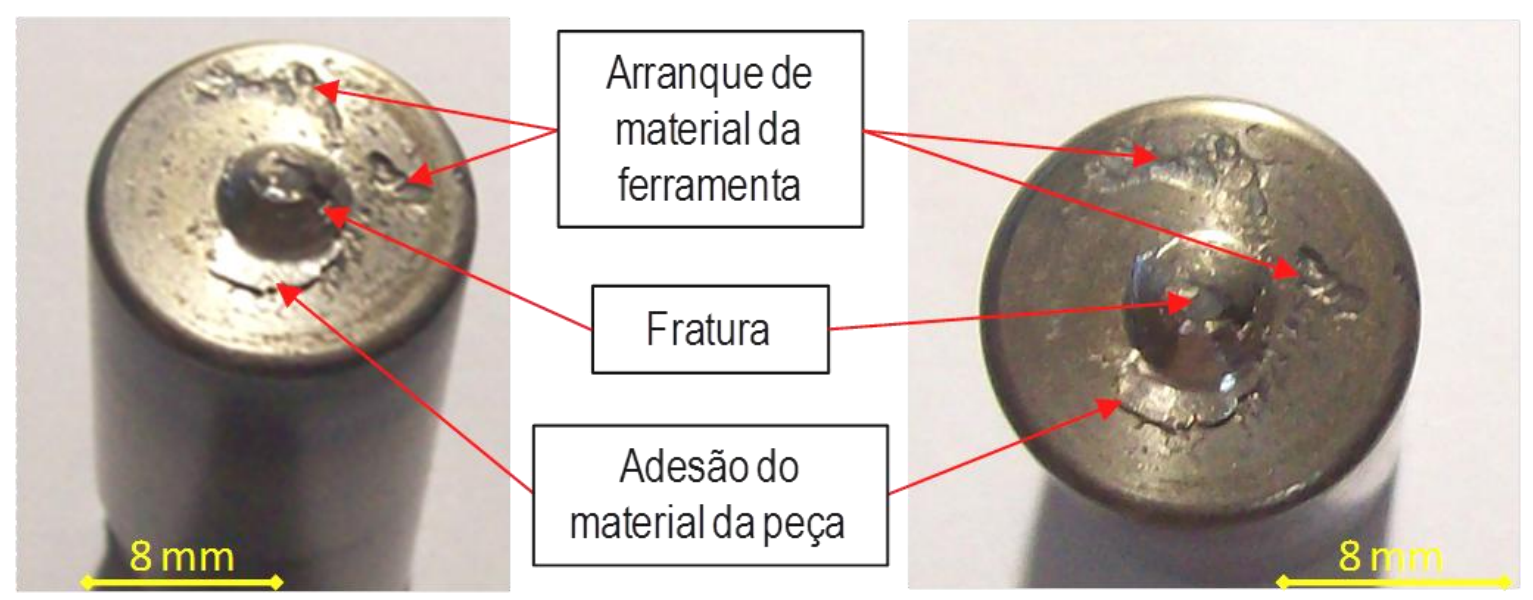

Figura 7-21 - Evidências da reatividade do material da ferramenta do primeiro ensaio com o material da peça. 
Na Figura 7-22 é possível verificar marcas circulares ao redor do pino indicando que houve o contato do material com o ombro.

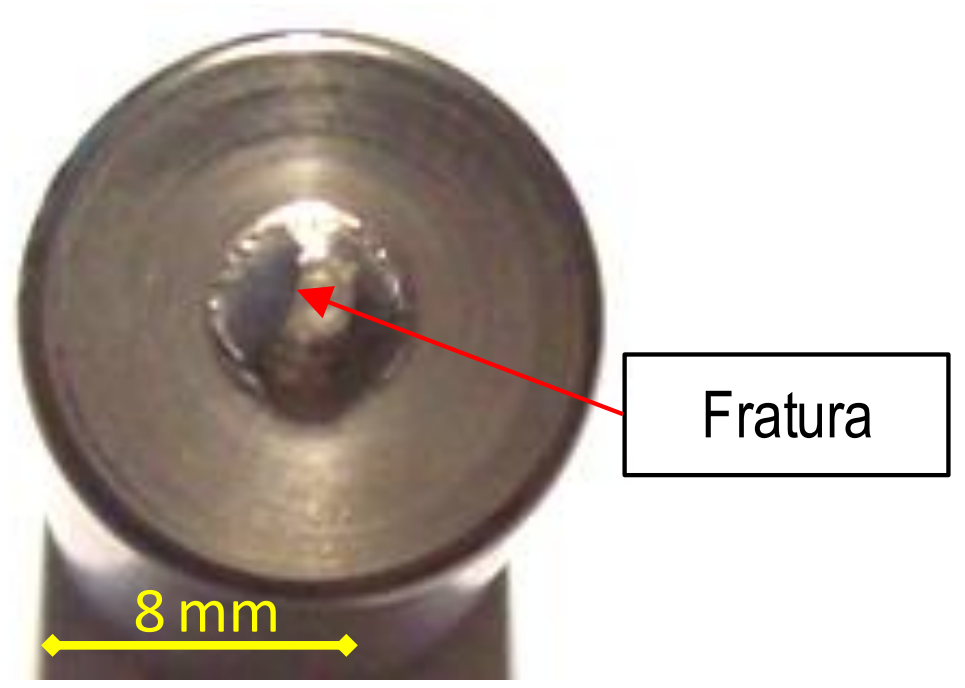

Figura 7-22 - Fratura na ponta da ferramenta do segundo ensaio.

A Figura 7-23 e Figura 7-24 apresentam a estimativa de desgaste na ponta das ferramentas, as linhas do esboço da geometria da ferramenta na condição de nova foram acrescentadas de forma a sobrepor a região desgastada. Estima-se uma perda em massa de $5 \%$ e é possível observar a perda da característica geométrica inicial, o que impossibilita o uso da ferramenta em outro ensaio.

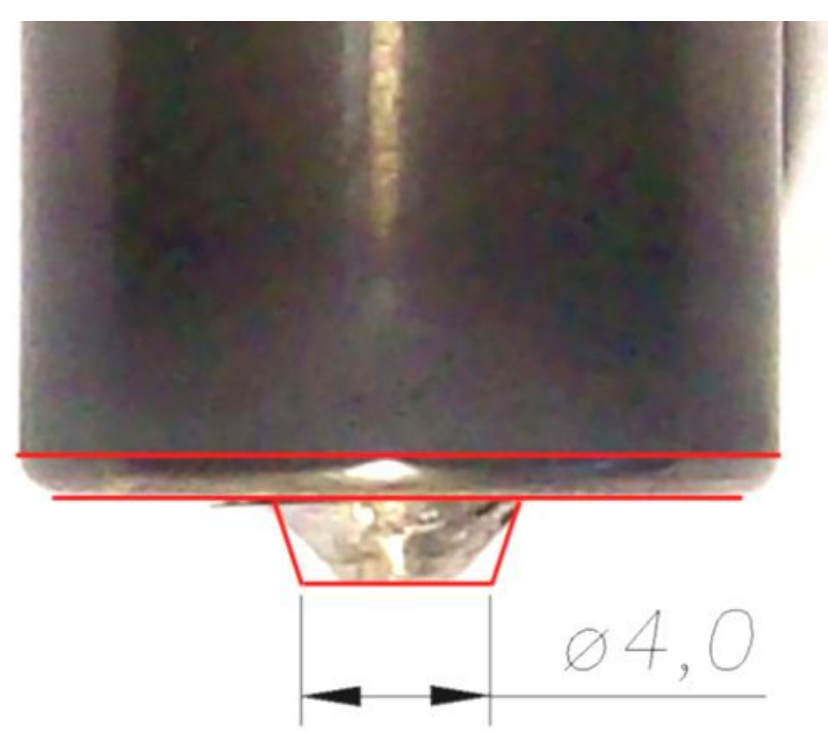

Figura 7-23 - Desgaste acentuado da ponta da ferramenta do primeiro ensaio. 


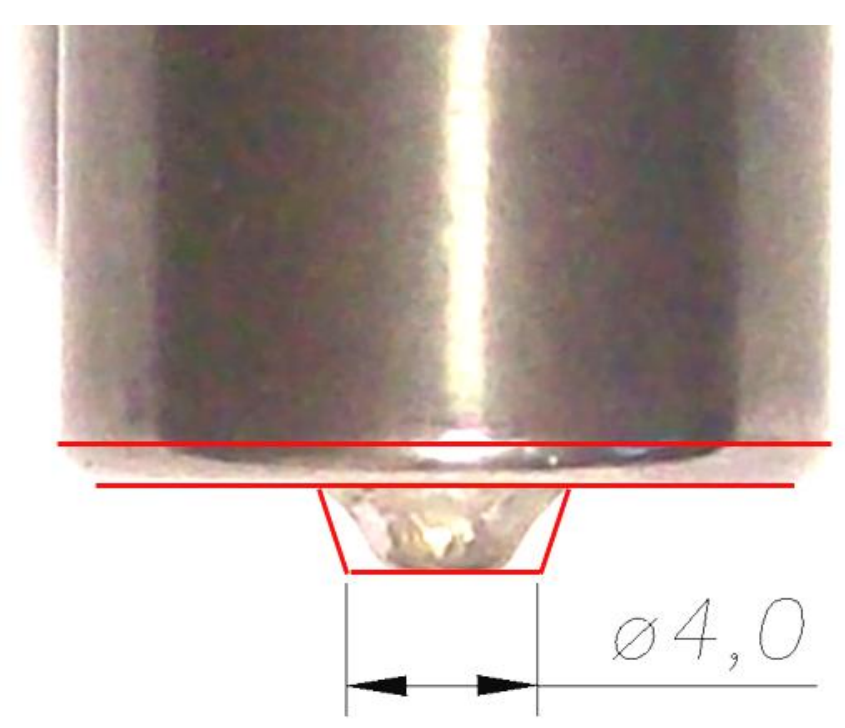

Figura 7-24 - Desgaste acentuado na ponta da ferramenta do segundo ensaio.

Em ambas as condições de ensaio executadas houve uma forte reação de adesão entre a peça e a ferramenta. E a região da ponta devida sua característica geométrica ficou sujeita às maiores condições de temperatura (aproximadamente $1000^{\circ} \mathrm{C}$ ) o que acelera ainda mais o processo de reação nos materiais.

Na Figura 7-23 e Figura 7-24 é possível também observar que o desgaste na base do pino foi menor do que na ponta. Este fato pode estar associado ao aumento de massa e a proximidade do ombro que funcionaram como dissipadores de calor.

A análise preliminar da região do corpo de prova utilizado no primeiro ensaio é apresentada na Figura 7-25. Observando a entrada da ferramenta, é possível identificar que a profundidade $a_{p}$ de $1,85 \mathrm{~mm}$ foi excessiva pois a ponta da ferramenta rompeu inicialmente a espessura da peça e houve contato total do ombro da ferramenta com a peça. Esta amostra não serve como referência para estudo de microestrutura ou outro resultado que possa ser identificado por qualquer tipo de ensaio metalográfico.

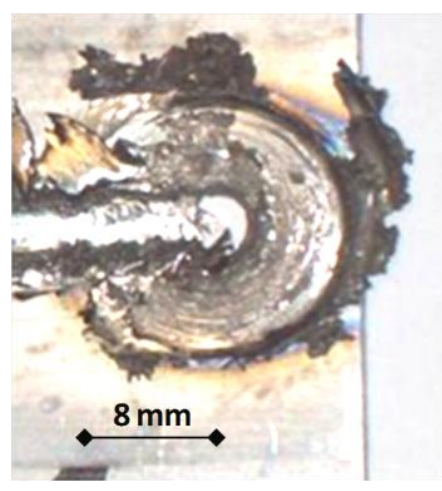

Figura 7-25 - Região da entrada do primeiro ensaio com rotação de $350 \mathrm{RPM}$, f de $75 \mathrm{~mm} / \mathrm{min}$ e $\mathrm{a}_{\mathrm{p}}$ de $1,85 \mathrm{~mm}$. 
O ensaio preliminar foi prejudicado pela falha prematura da ferramenta projetada para o experimento. De acordo com as análises efetuadas acima é possível concluir que a liga utilizada na fabricação da ferramenta $(\mathrm{WC}+\mathrm{TaC})$ não é própria para a utilização com a liga de titânio Ti-6Al-4V. Devido à verificação de perda de geometria na ponta da ferramenta por desgaste, lascamento e quebra. Uma mudança de dimensões deverá ser prevista para reforçar a ponta da ferramenta contra o desgaste e quebra. A dissipação de temperatura pode ser melhorada se a geometria do ombro for alterada, a possível adição de ranhuras na lateral da ferramenta pode aumentar a área para transferência de calor durante o processo. Durante os ensaios foi possível notar vibração no cabeçote da máquina. Embora não mensurada, esta vibração pode ter influenciado nas fraturas observadas nas pontas das ferramentas. A máquina utilizada, como visto no capitulo 7.1.5 possui seu cabeçote de usinagem em balanço, o que favorece uma maior deflexão se um esforço é aplicado em sua extremidade.

\subsection{Readequação do Planejamento preliminar}

Para o processamento por atrito linear da liga de titânio Ti-6Al-4V o projeto da ferramenta tem um papel preponderante como observado nas análises e conclusões.

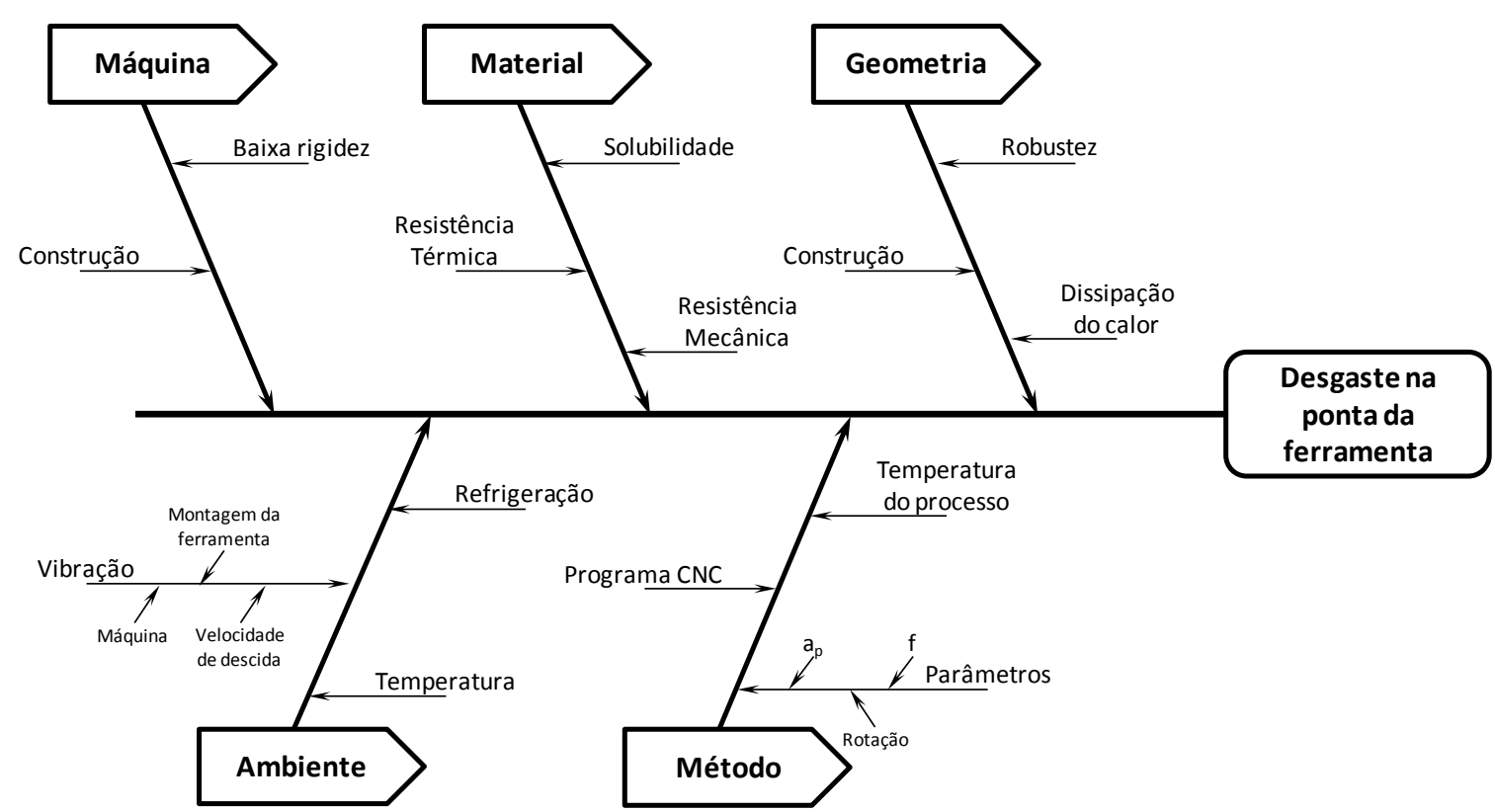

Figura 7-26 - Diagrama de causa e efeito para o caso de desgaste na ponta da ferramenta. 
Antes de qualquer outro passo este problema do desgaste na ponta da ferramenta deveria ser superado. E para uma visualização dos fatores envolvidos no problema de desgaste da ferramenta, um diagrama de causa e efeito foi proposto na Figura 7-26.

O diagrama apresenta a relação das prováveis causas a serem trabalhadas, portanto inicialmente deve-se trabalhar em cada grupo de causas sistematicamente para eliminação ou controle do efeito desgaste na ponta da ferramenta:

- Máquina: buscar outro tipo de construção de máquina com maior rigidez;

- Material: pesquisar por nova composição para fabricação de nova ferramenta com menor solubilidade e maior resistência;

- Geometria: novo projeto de ferramenta mais robusto e com perfil maior predisposto a uma maior dissipação de calor;

- Ambiente: avaliar uso de refrigeração na ferramenta e condições para diminuição ou eliminação de vibração;

- Método: reavaliar os parâmetros selecionados e a montagem do programa da máquina, pois podem exercer influência na temperatura da ferramenta e no início do movimento do processamento linear.

Após a avaliação detalhada do diagrama da Figura 7-26, foram observados os itens que mais surtiriam efeito para um próximo ensaio preliminar, estes itens foram disponibilizados e configurados para proporcionar o melhor resultado nos corpos de prova, sendo eles:

- Máquina: máquina com maior rigidez;

- Material: nova composição para fabricação de nova ferramenta;

- Geometria: novo projeto de ferramenta mais robusta;

- Método: mudança de parâmetros com aumento da rotação em RPM. A rotação da ferramenta pode exercer influência na temperatura da ferramenta e também no início do movimento do processamento linear.

- Ambiente: evitar o uso de refrigeração na ferramenta, devido a possibilidade de choque térmico e contaminação do material; 


\subsubsection{Máquina 2 para o ensaio preliminar}

Na Figura 7-27 é apresentada a segunda máquina do mesmo fabricante utilizada no ensaio (2). O conceito desta máquina se diferencia especialmente por ser uma máquina tipo pórtico onde a rigidez do seu cabeçote é muito maior quando comparada com a anterior (Figura 7-3), que possui um cabeçote em balanço. $\mathrm{Na}$ Tabela 7-4 são apresentados as características desta máquina, comparativamente com a anterior (Tabela 7-2) se trata de uma máquina maior e com mais massa, o que ajuda na estabilidade do processo.

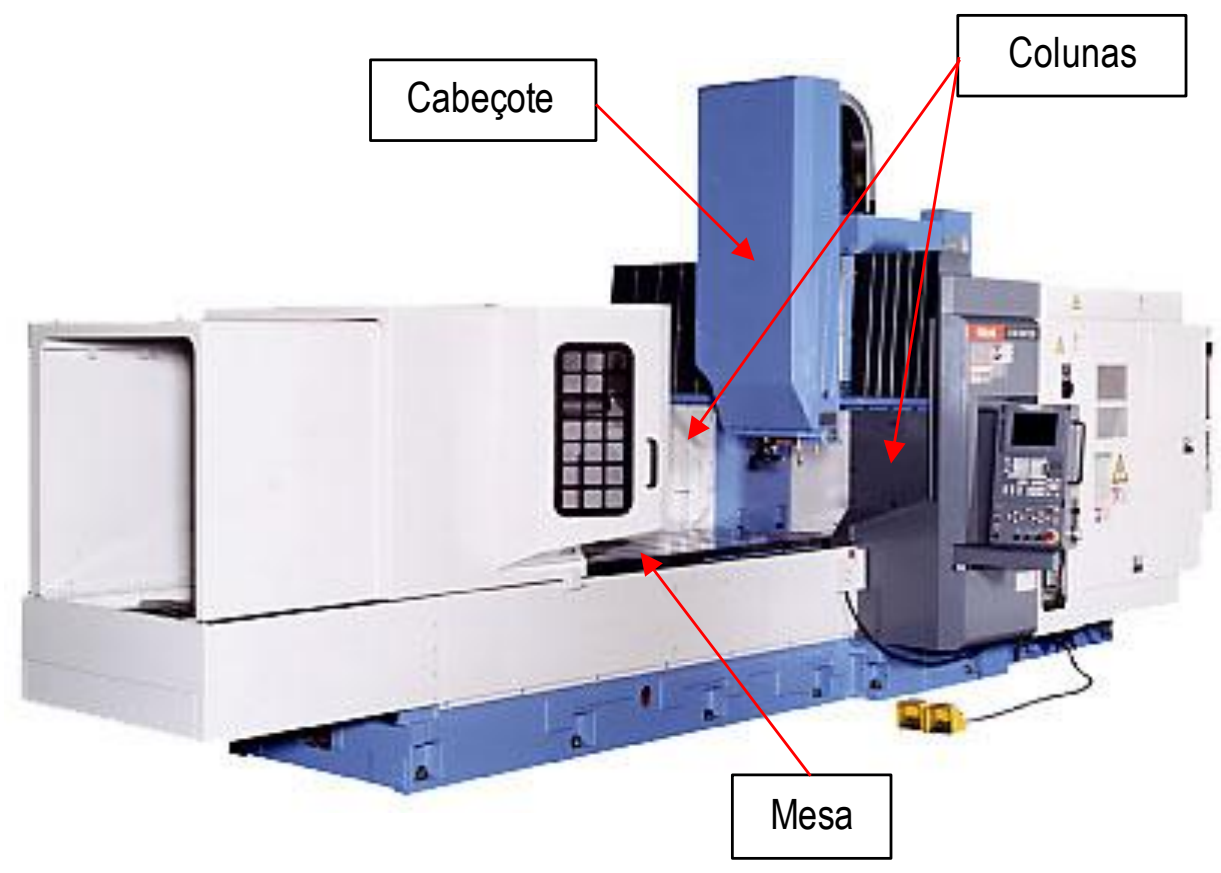

Figura 7-27 Segunda máquina utilizada para os ensaios.

Tabela 7-4 Características da segunda máquina utilizada.

\begin{tabular}{lcl}
\hline \multicolumn{1}{c}{ Característica } & Valor & Unidade \\
\hline Curso no eixo X & 1500 & $\mathrm{~mm}$ \\
Curso no eixo Y & 800 & $\mathrm{~mm}$ \\
Curso no eixo Z & 580 & $\mathrm{~mm}$ \\
Potencia motor do fuso & 26 & $\mathrm{~kW}$ \\
Torque do motor & $530(54)$ & $\mathrm{N} . \mathrm{m}(\mathrm{kgf} . \mathrm{m})$ \\
Rotação máxima & 6.000 & $\mathrm{RPM}$ \\
Avanço máx programado & 18.000 & $\mathrm{~mm} / \mathrm{min}$ \\
Peso & 13.000 & $\mathrm{~kg}$ \\
\hline
\end{tabular}




\subsubsection{Ferramenta para o segundo ensaio de FSP}

Visando desenvolver uma ferramenta que suporte o processamento por atrito linear em chapas de titânio, a empresa colaboradora Uniwidia preparou duas ferramentas com as dimensões de ombro de $20 \mathrm{~mm}$, pino com Ø5mm cônico, ângulo de $30^{\circ}$ e altura do pino de $1,6 \mathrm{~mm}$ no material carboneto de tungstênio (WC+6\% $\mathrm{Co}$ ). Os ensaios foram executados com esta ferramenta para definição da janela de parâmetros iniciais e testes específicos de resistência ao desgaste.

\subsection{Execução do segundo ensaio preliminar}

Os valores da Tabela 7-5 foram escolhidos de modo a evitar condições extremas, condições que no ensaio preliminar poderiam induzir interações não desejáveis entre os parâmetros. Outro fator importante é executar uma avaliação do projeto e da liga utilizados na ferramenta, pois para o sucesso dos ensaios a ferramenta deverá ser capaz de efetuar o percurso sem sofrer desgaste e sem quebrar.

Tabela 7-5 Matriz para o segundo planejamento preliminar

\begin{tabular}{ccccc}
\hline $\begin{array}{c}\text { Sequência } \\
\text { padrão }\end{array}$ & $\begin{array}{c}\text { Sequência } \\
\text { de ensaio }\end{array}$ & $\begin{array}{c}\text { Rotação } \\
\text { [RPM] }\end{array}$ & [mm/min] & [mm] \\
\hline $\mathbf{4}$ & 1 & 1100 & 40 & 1,65 \\
$\mathbf{5}$ & 2 & 1000 & 50 & 1,65 \\
$\mathbf{3}$ & 3 & 1200 & 50 & 1,60 \\
$\mathbf{2}$ & 4 & 1200 & 60 & 1,65 \\
$\mathbf{1}$ & 5 & 1000 & 50 & 1,65 \\
\hline
\end{tabular}

O ensaio foi conduzido sem nenhum tipo de refrigeração sobre a ferramenta visando não diminuir a temperatura do processo. Para minimizar os esforços e fornecer uma guia inicial para a ponta da ferramenta foi executado um furo piloto com broca helicoidal na profundidade de $1,60 \mathrm{~mm}$. O diâmetro da broca $(4,8 \mathrm{~mm})$ foi selecionado de forma a ser menor do que a ponta da ferramenta $(50 \mathrm{~mm})$, com isso a ponta da ferramenta ao executar a penetração irá gerar atrito com a lateral fornecendo calor inicial ao processo.

Apesar de ser empregado na fabricação de ferramentas onde 0 atrito e a temperatura são elevadas, o WC apresentou desgaste acentuado. A Figura 7-28(a) apresenta a ferramenta com diâmetro de ombro de $20 \mathrm{~mm}$ nova e a Figura 7-28(b) 
apresenta a mesma ferramenta após o processo de FSW. É nítido o desgaste na ponta a ferramenta que refletiu em um acabamento ruim na superfície da peça como mostra a Figura 7-29.

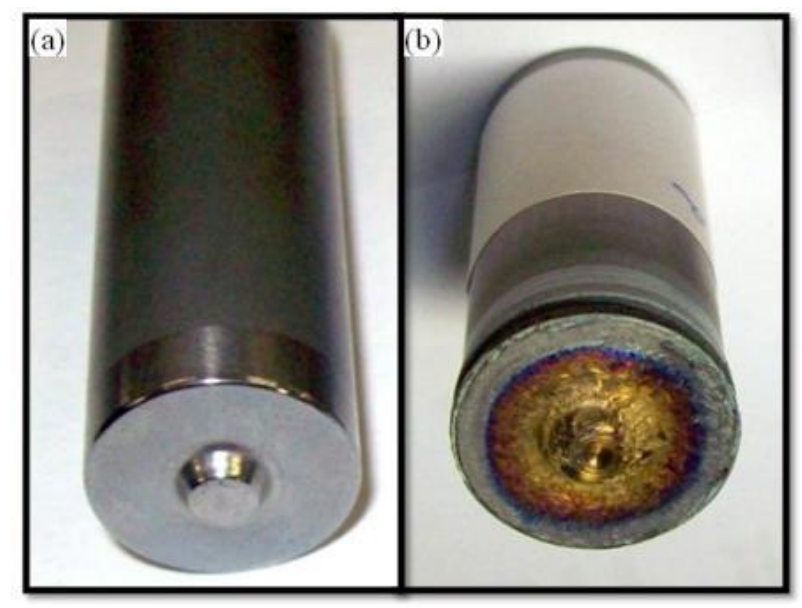

Figura 7-28 (a) Ferramenta nova, (b) ferramenta após o processo FSW.

\subsubsection{Avaliação preliminar do segundo ensaio}

Devido às condições do processo, pedaços da ferramenta se desprenderam causando o arranhamento na superfície da peça. No interior da solda também houve desprendimento de partículas da ferramenta, estas ficando no interior da chapa. Além da superfície irregular, houve um excesso de formação de rebarbas o que resultou na necessidade de um posterior processamento de limpeza da superfície.

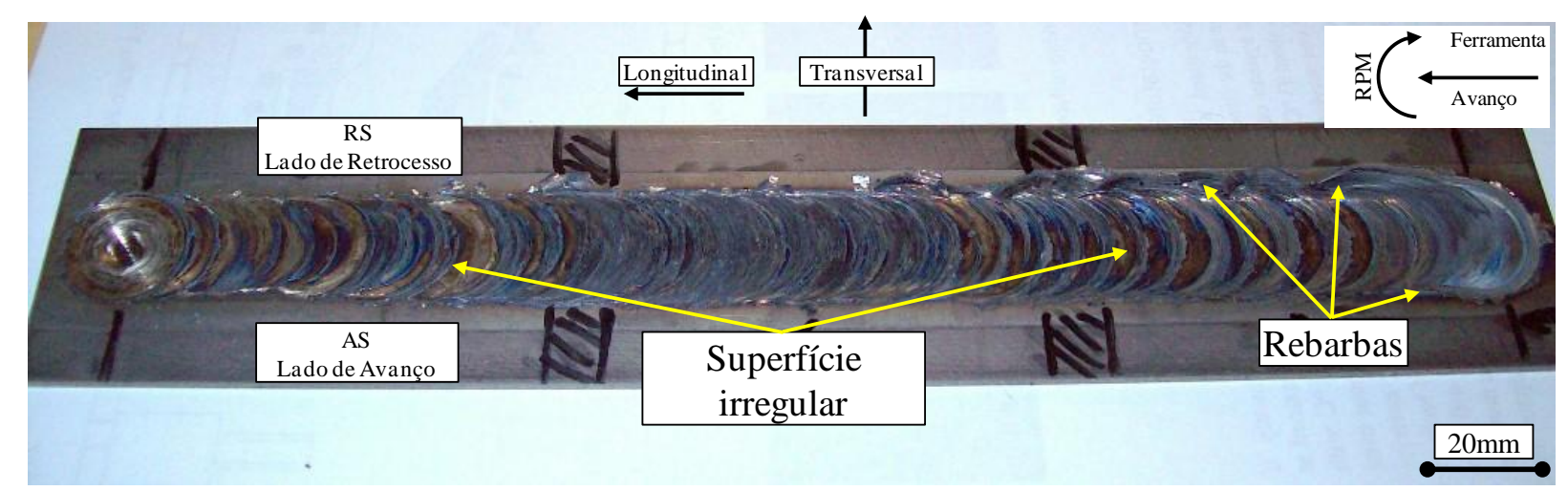

Figura 7-29 Placa de Ti-6Al-4V (260mmx50mm) após o processamento, AS: sentido de avanço da ferramenta, RS: sentido de retrocesso da ferramenta. 


\subsection{Medições em laboratório para o ensaio preliminar}

\subsubsection{Tensão residual}

Visando o levantamento de dados experimentais para a avaliação das propriedades da solda efetuada, a condição de tensão residual da região processada foi levantada.

Foram executados ensaios de tensão residual nas amostras preliminares com um equipamento de difração de raios X da Shimadzu XRD-7000 (Figura 7-30).

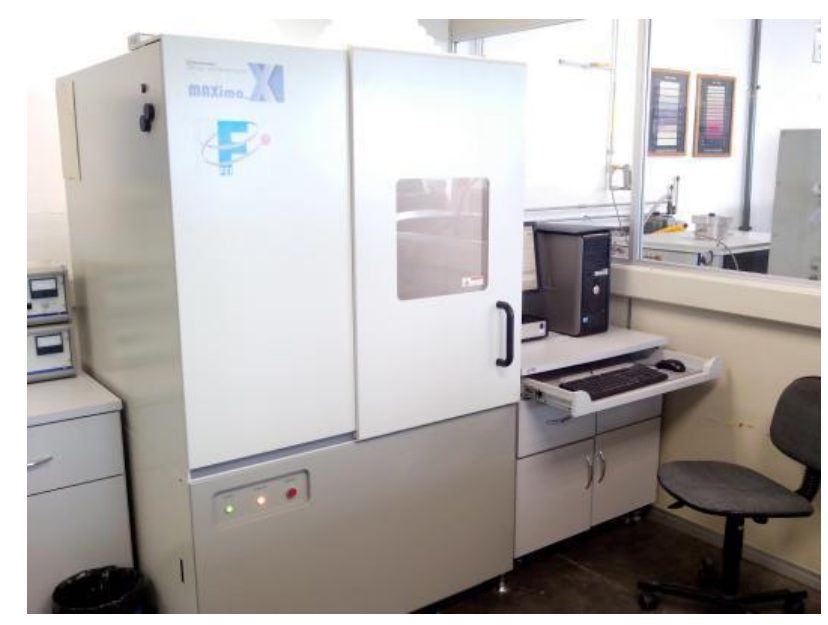

Figura 7-30 Equipamento de difração de raios X da Shimadzu XRD-7000.

As medições foram executadas na parte inferior da placa para evitar que os defeitos superficiais causados pela ferramenta interferissem nos resultados.

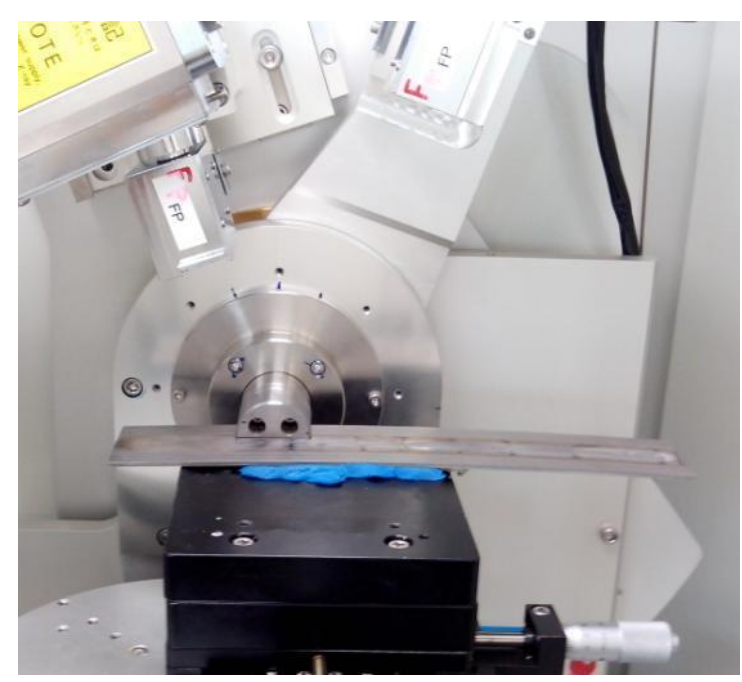

Figura 7-31 Medição na parte posterior da chapa. 
A Figura 7-32, Figura 7-33 e Figura 7-34 apresentam o resultado da medição de três corpos de prova. A tensão residual foi medida nos sentidos transversal, longitudinal e a $45^{\circ}$ visando verificação da tensão principal resultante do processo. A tensão residual principal resultante $\mathrm{T} 1$ na área processada é coincidente com o sentido longitudinal do corpo de provas, o sentido longitudinal é o sentido onde a ferramenta executou o trajeto linear. É possível verificar que diferentes condições de processamento resultaram em diferentes valores de tensão residual.

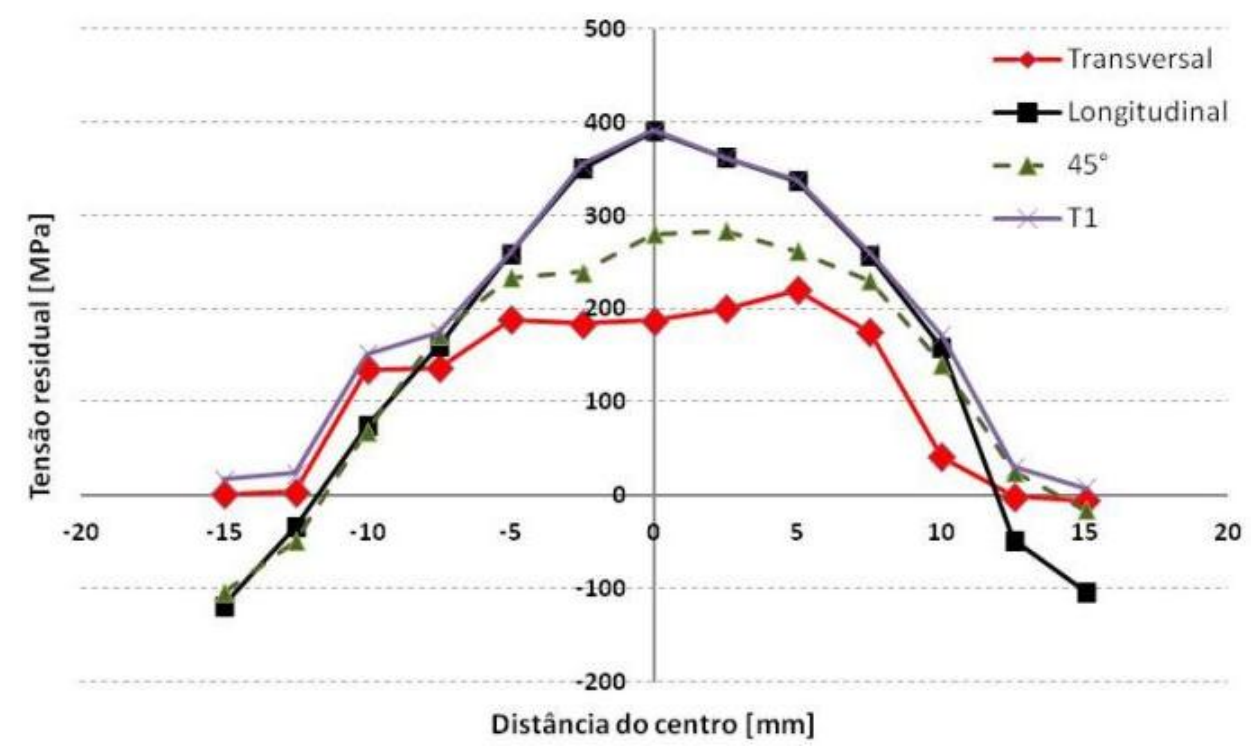

Figura 7-32 Tensão residual na condição-1, 1100 RPM e 40 mm/min de avanço.

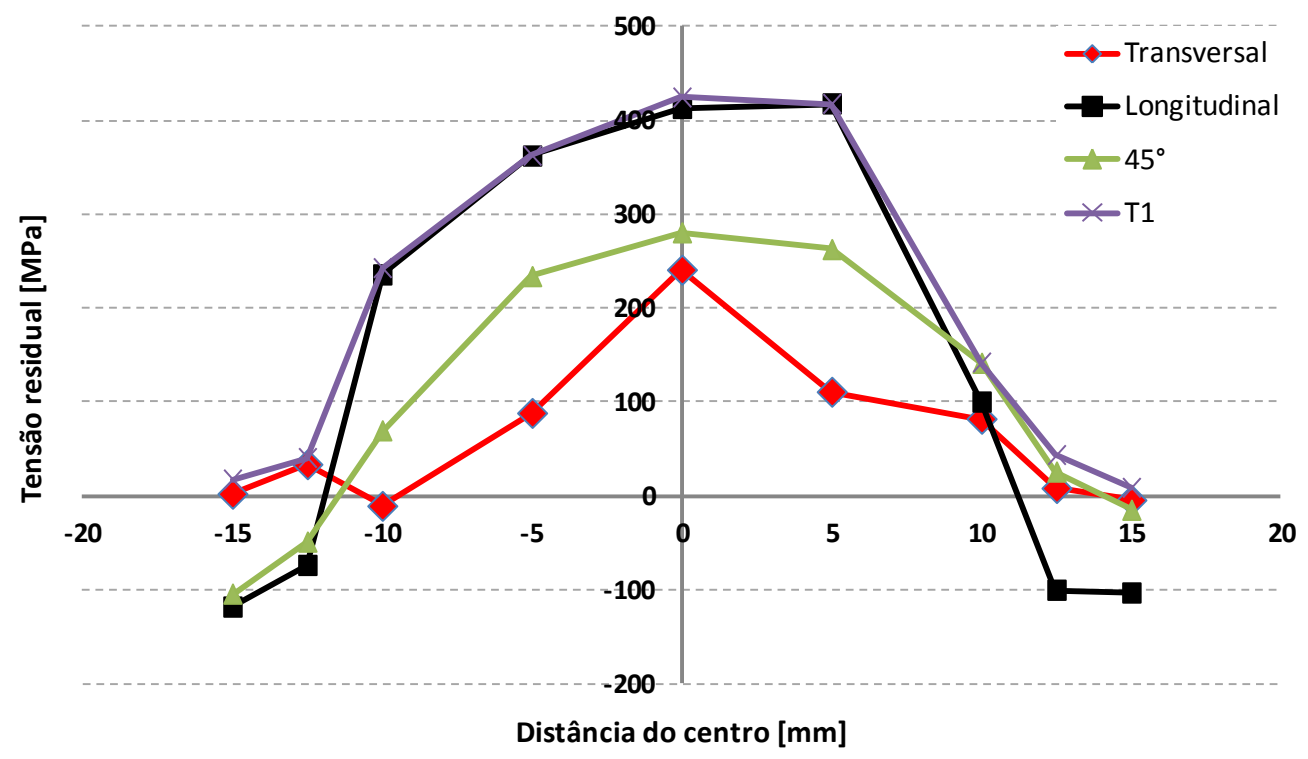

Figura 7-33 Tensão residual na condição-3, 1200 RPM e 50 mm/min de avanço. 


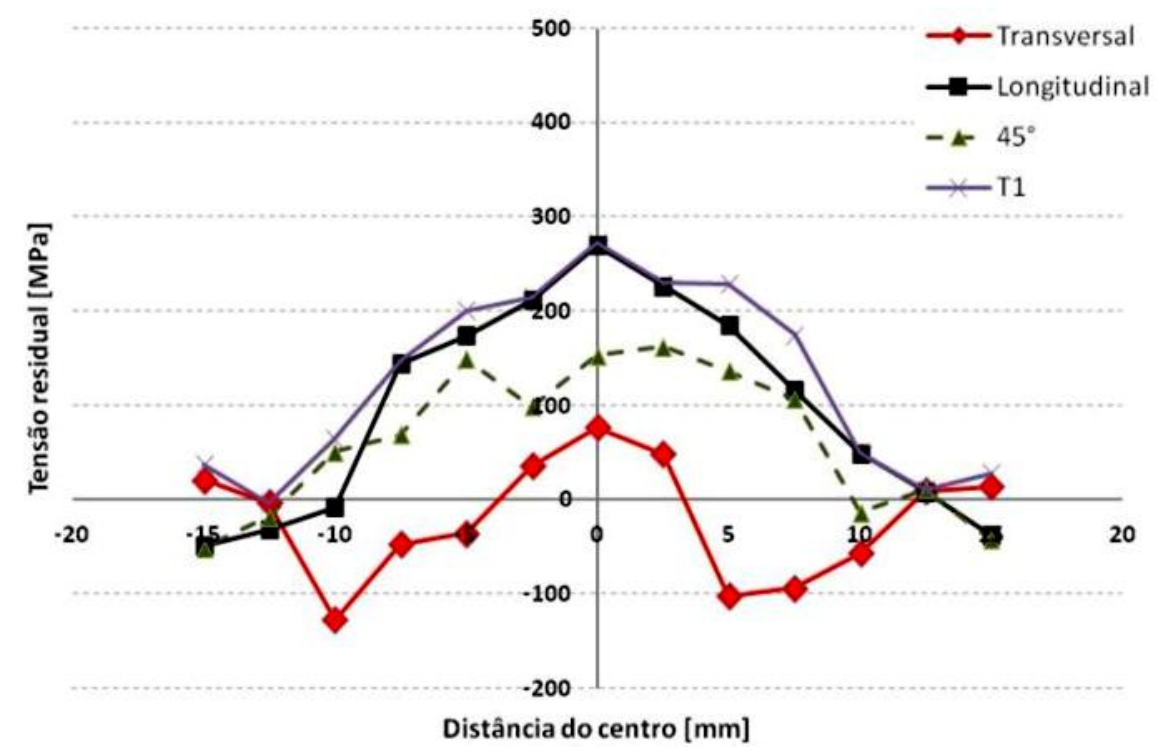

Figura 7-34 Tensão residual na condição-5, 1000 RPM e 50 mm/min de avanço.

A Figura 7-35 apresenta as metalografias para condição 1, onde é possível observar fragmentos da ferramenta dispersos no interior da estrutura na região da solda. É possível observar também regiões de vazios deixados por estes fragmentos decorrente do processo de preparação metalográfica. Na região avaliada o tamanho de grãos se encontra na faixa definida por Giuliano (Giuliano, 2011) como fina (aproximadamente $10 \mu \mathrm{m}$ ). É possível verificar o fluxo do material devido à passagem da ferramenta girando e avançando, a princípio o sentido de avanço (AS) provoca uma mistura mais heterogênea do material quando comparado com o sentido de retrocesso.

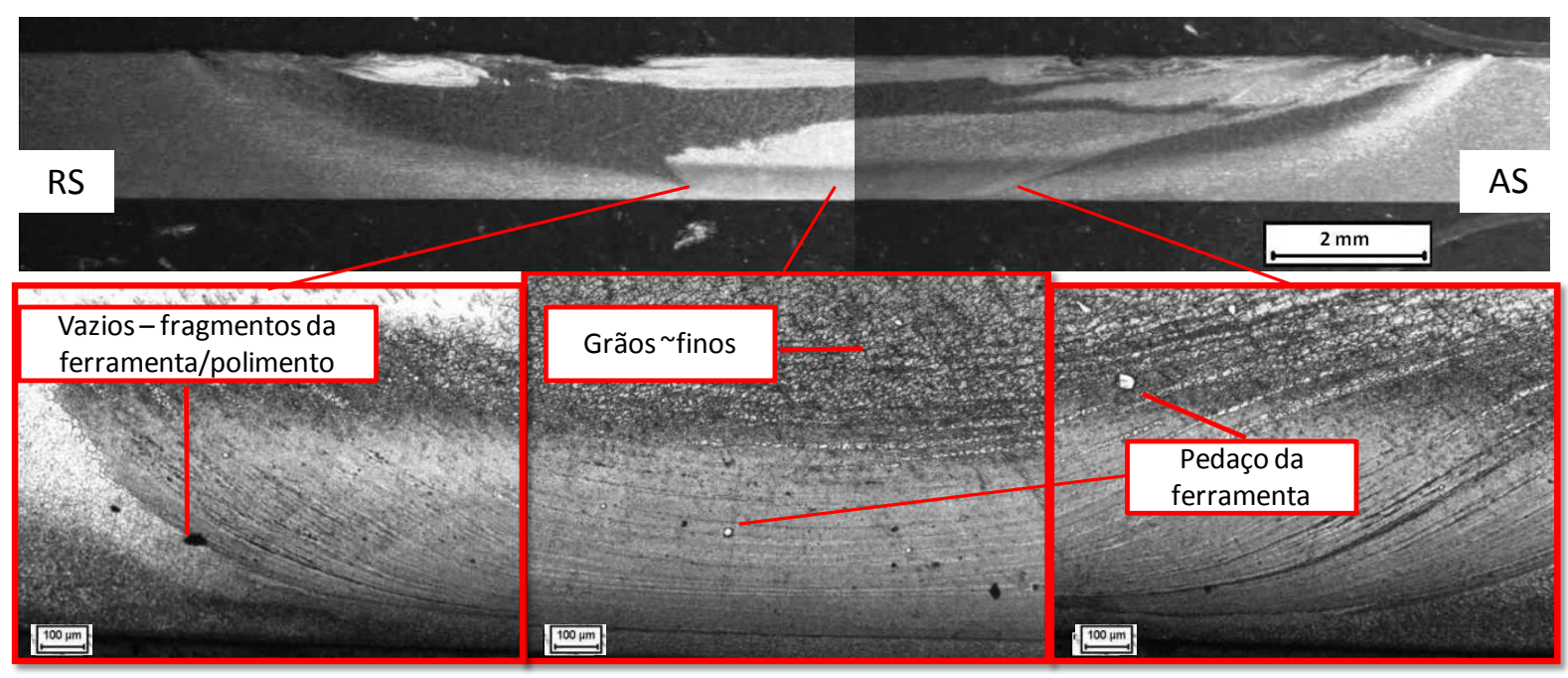

Figura 7-35 Condição 1 com 1100 RPM e 40 mm/min de avanço. 
A Figura 7-36 apresenta a metalografia da condição 5, onde é possível observar que esta condição não foi favorável, pois defeitos de má formação da solda são observados e trincas superficiais também são visíveis indicando que os dados utilizados não são adequados para geração de uma solda de qualidade. O tamanho médio (aproximadamente $30 \mu \mathrm{m}$ ) de grão também não é o ideal para obtenção de uma estrutura superplástica o que iria gerar a necessidade um novo processamento para obtenção de uma estrutura com grãos mais refinados. As análises metalográficas do interior das soldas não apresentaram defeitos de vazios ou má formação interna devido ao processamento, somente defeitos superficiais que podem causar perda de qualidade da solda. $O$ acentuado desgaste provocou inclusões de fragmentos, internamente no corpo de prova, e perda de qualidade superficial.

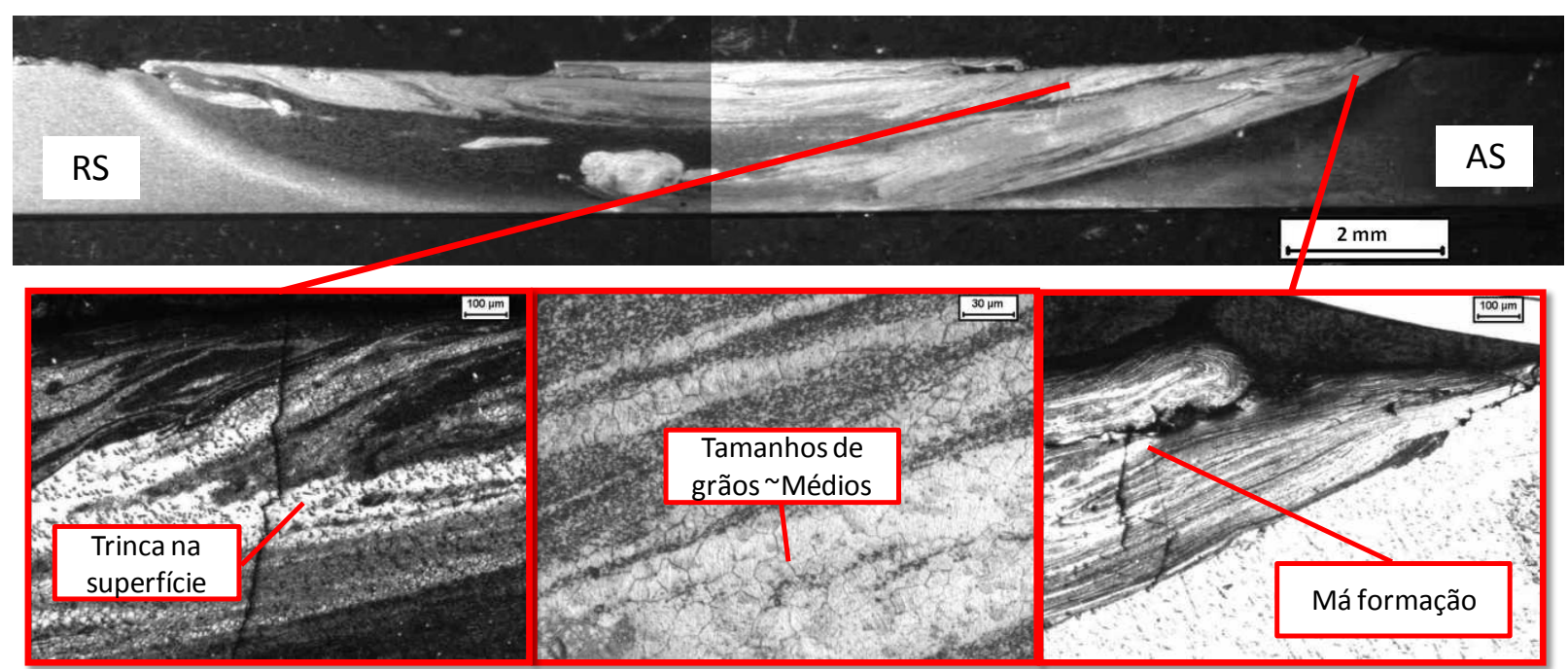

Figura 7-36 Condição 5 com 1000 RPM e 40 mm/min de avanço.

\subsubsection{Microdureza}

A Figura 7-37 apresenta a microdureza como uma função da posição ao longo da direção transversal das amostras. O ensaio foi realizado com um microdurômetro da Shimadzu com carga de $10 \mathrm{~N}$. Estes gráficos mostram claramente um aumento de dureza na região processada. Este comportamento pode ser atribuído em função da rotação e avanços empregados que resultam em uma estrutura lamelar. Kitamura et al. (KITAMURA, 2013) mostra que existe variação da estrutura lamelar em função da variação do avanço de processamento do ensaio, e especificamente diminuição da taxa de resfriamento com o avanço, resultando em uma estrutura lamelar. 

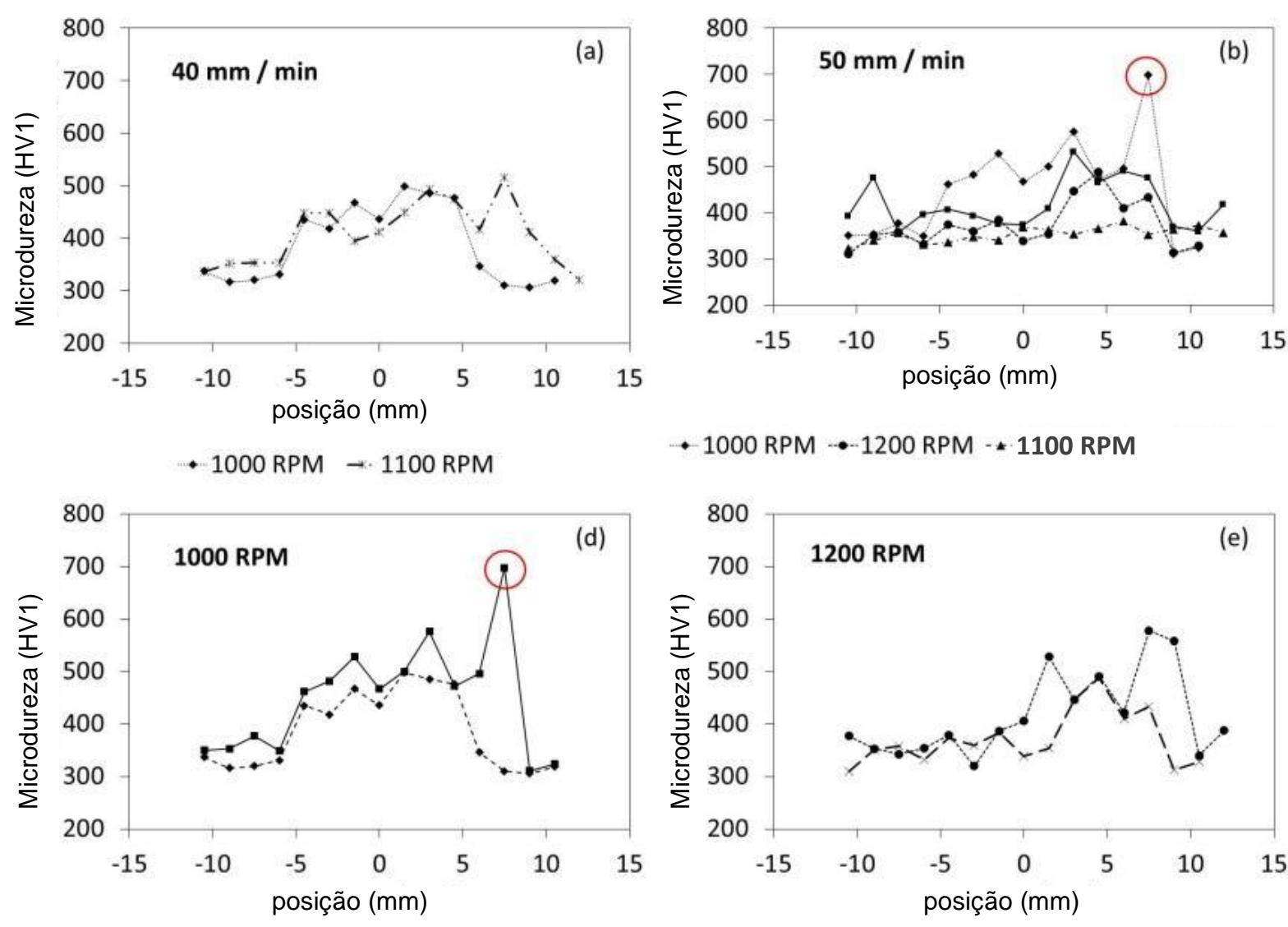

$\bullet 1000$ RPM $\cdots 1200$ RPM - $\bullet 1100$ RPM

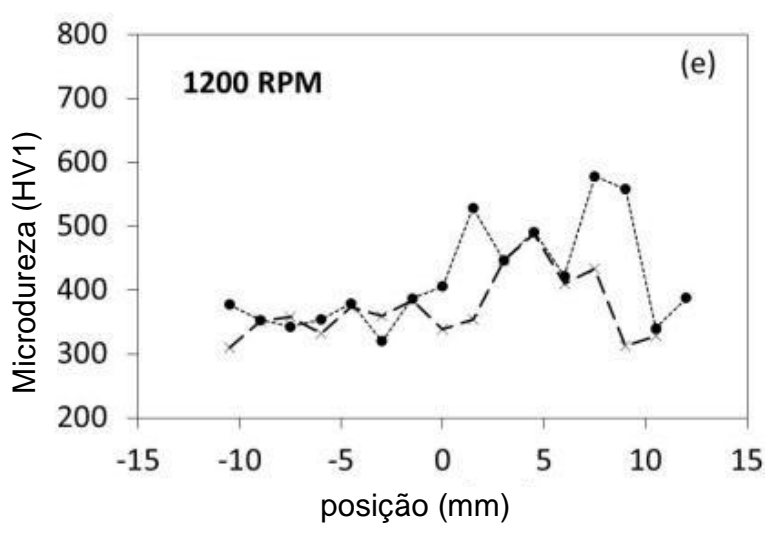

$+40 \mathrm{~mm} / \mathrm{min}-50 \mathrm{~mm} / \mathrm{min}$

- $60 \mathrm{~mm} / \mathrm{min} \rightarrow-50 \mathrm{~mm} / \mathrm{min}$

Figura 7-37 Microdureza em função da posição nas amostra.

Na Figura 7-37a e b, é possível verificar um ponto marcado com o círculo vermelho onde a dureza ficou acima dos demais. Conforme observado na Figura 7-35 e Figura 7-36, partículas da ferramenta se desprenderam durante o processo, este valor de dureza reflete uma medição na região de um fragmento da ferramenta (verificado posteriormente).

\subsection{Teste com ferramenta de material alternativo WLa}

Alternativamente para um ensaio independente foi adquirida uma ferramenta da liga tungstênio puro com lantânio. Em função da literatura pesquisada no Capítulo 2., optou-se pela liga WL10 da empresa fabricante Plansee (2013), uma liga de tungstênio puro dopado com $1 \%$ a $2 \%$ de óxido de lantânio $\left(\operatorname{La}_{2} \mathrm{O}_{3}\right)$. Ferramentas a base de tungstênio puro possuem uma alta temperatura operacional (acima de $1500^{\circ} \mathrm{C}$ ) e quando associados ao correto elemento de liga podem ser uma boa alternativa para o processamento por FSP. A Figura 7-38 apresenta o resultado 
de um processamento com a ferramenta mencionada. É possível observar um bom acabamento superficial diferente do encontrado na Figura 7-29 cujo aspecto superficial estava bastante riscado.

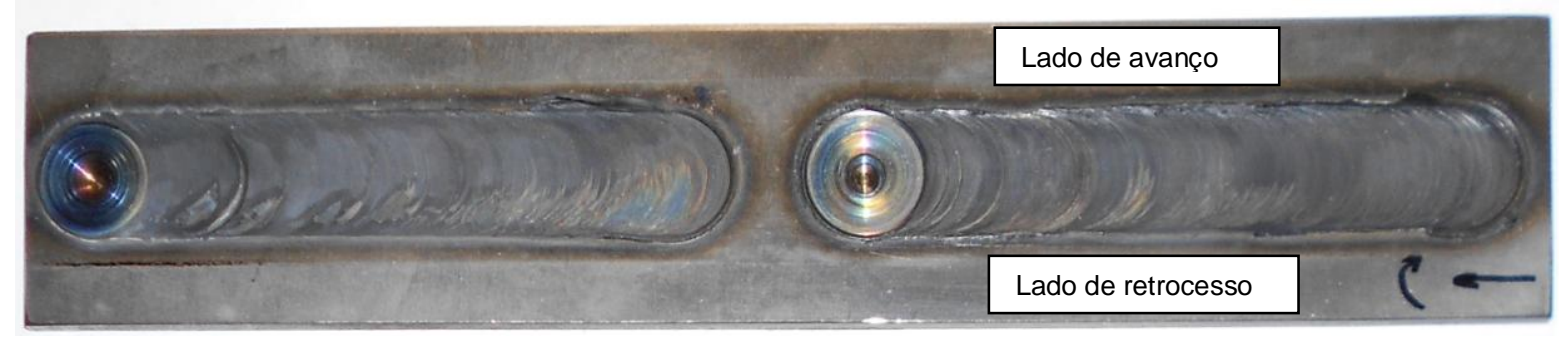

Figura 7-38 Chapa processada com ferramenta de WLa

Esta amostra foi processada com uma rotação de 1600RPM e avanço de 50 $\mathrm{mm} / \mathrm{min}$. Como pode ser observado na Figura 7-39 não houve lascamento da ponta da ferramenta durante o ensaio.

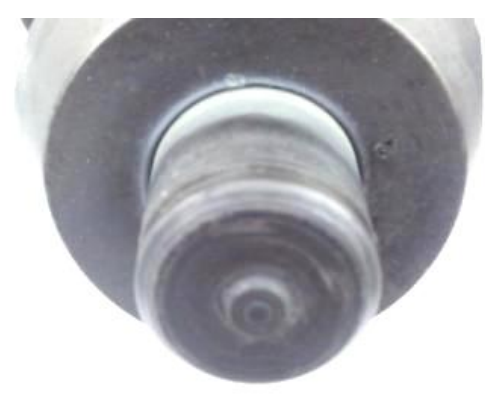

Figura 7-39 Ferramenta de WLa após o ensaio com 1600RPM x 50mm/min.

O aspecto final da ferramenta, que se mostrou muito mais íntegro indicando que o interior da região processada se apresenta com uma menor contaminação por partículas da ferramenta. $O$ processo executado também se mostrou muito mais estável indicando que esta ferramenta deve ser a empregada para o teste de FSP principal.

Uma metalografia e um ensaio de microdureza na região transversal desta amostra foi realizada e o resultado está na Figura 7-40 (a -f). A Figura 7-40 mostra as diferentes microestruturas observadas ao longo da direção transversal para a condição do ensaio, especificamente onde as medições de dureza foram realizadas. Em geral, observou-se 3 tipos de microestruturas (i) metal de base com a estrutura bimodal em (b); (ii) estrutura refinada bimodal em (c); (iii) a estrutura lamelar em (c) até (f). No geral estas regiões foram observadas em todas as condições dos testes 
anteriores com proporções diferentes. É importante observar que cada microestrutura está associada com um valor de dureza diferente, porém a condição utilizada neste ensaio (1600RPMx50 $\mathrm{mm} / \mathrm{min}$ ) apresentou uma microestrutura mais homogênea em termos de sua distribuição de microdureza Figura 7-40 (a).
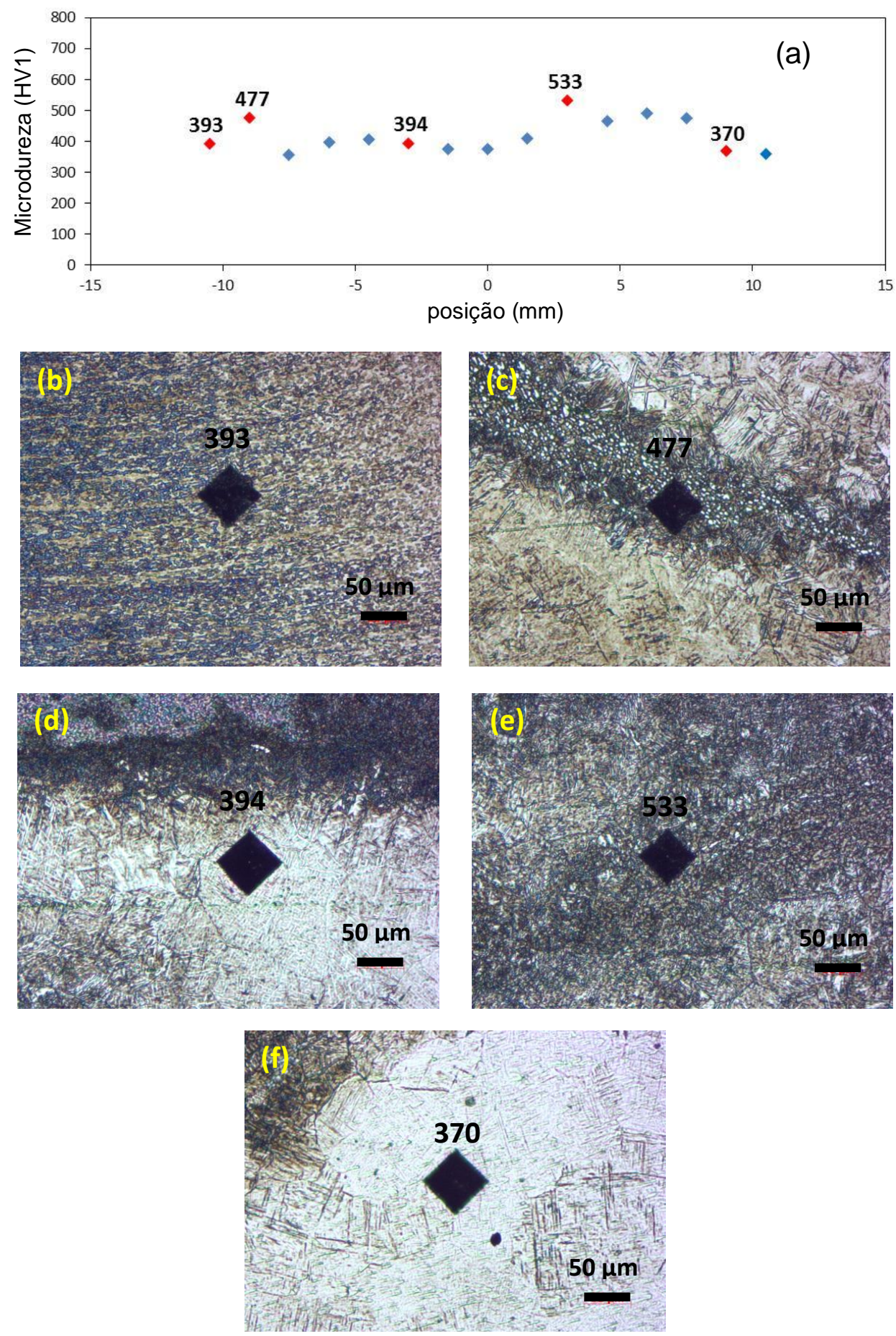

Figura 7-40 Microdureza em função da região transversal do ensaio, 1600 RPM $\times 50 \mathrm{~mm} / \mathrm{min}$ (a), (b) até (f) metalografias dos pontos característicos da amostra. 


\subsection{Medição de esforços na ferramenta}

Um teste para medição dos esforços atuantes na ferramenta foi executado na máquina de FSW do IPT de São José dos Campos (Figura 7-41a), esta é uma máquina especialmente construída para este tipo de processo em peças de grande dimensão. A máquina já dispõe de um conjunto de células de carga adaptadas ao cabeçote para tomada de medições de esforços na ferramenta (Figura 7-41b). 0 próprio software da máquina faz a aquisição dos valores em função do tempo e permite o levantamento de gráficos como o da Figura 7-42.

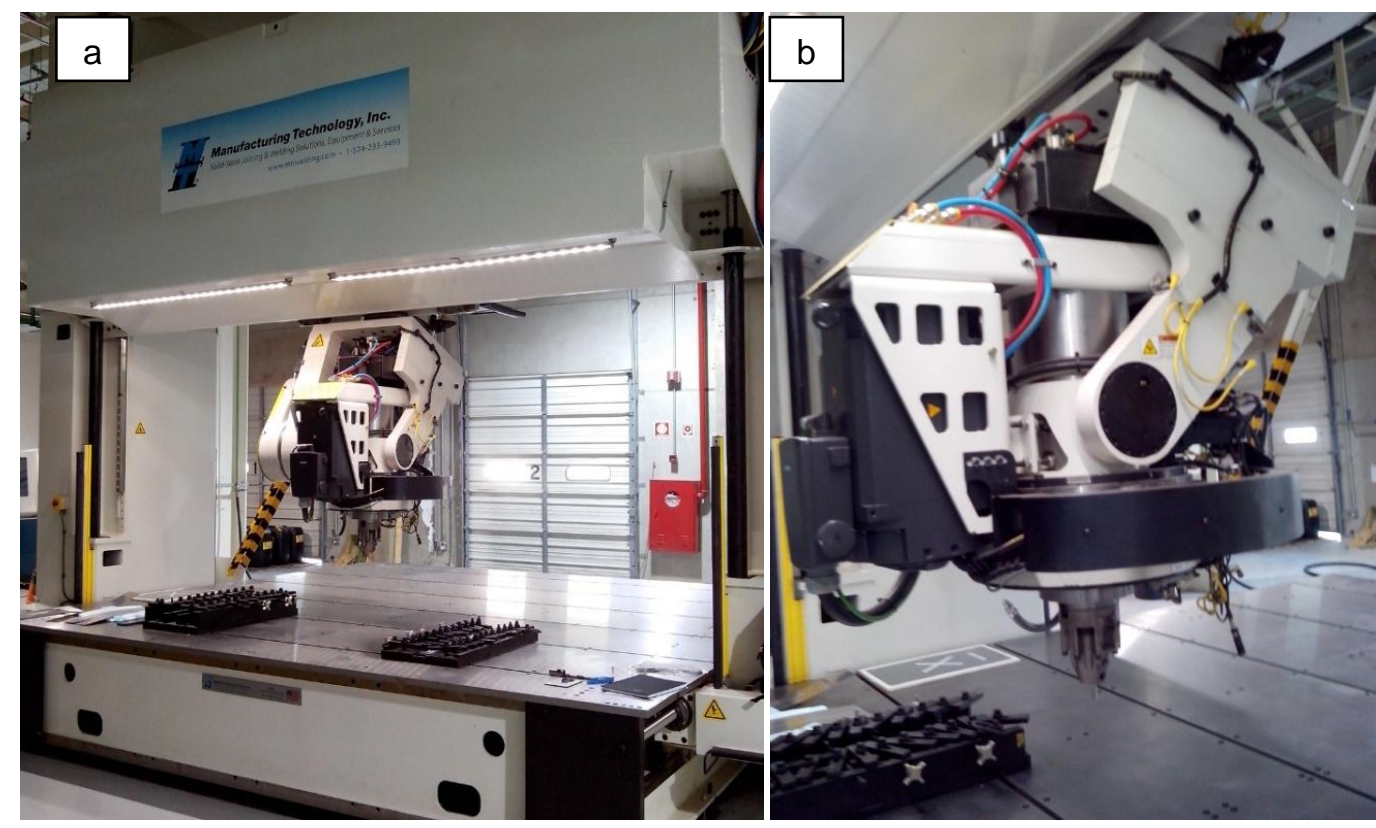

Figura 7-41 - (a)Máquina para FSW do IPT de São José dos Campos, (b) detalhe do cabeçote especial com células de carga embutidas.

Para o levantamento dos esforços foi utilizado a rotação de 1600RPM e avanço de $50 \mathrm{~mm} / \mathrm{min}$. O avanço de penetração utilizado foi de $1 \mathrm{~mm} / \mathrm{min}$ e compreende o trecho do gráfico marcado como penetração da ferramenta. É possível identificar o momento do toque (pico na força de $10.000 \mathrm{~N}$ ) da ponta da ferramenta na peça que aconteceu no tempo de 34s. O segundo pico no gráfico (força de $14.000 \mathrm{~N}$ no tempo de $61 \mathrm{~s})$ se refere ao momento do toque do ombro da ferramenta na peça. percurso executado pela ferramenta após a penetração na peça foi de $80 \mathrm{~mm}$, representado pelo trecho de avanço da ferramenta no gráfico (tempo de 120 s até 220s). O valor da força média para o trecho de avanço foi de $17.174 \mathrm{~N}(17,2 \mathrm{kN})$ com um desvio padrão de +/-442N. Recentemente (CAMPO et al., 2014) em seu estudo 
de soldas dissimilares de Ti-6Al-4V e aço inox 304 obteve valores da ordem de $35 \mathrm{kN}$, porém a ferramenta utilizada por eles possuía uma geometria do pino muito maior do que a utilizada no presente estudo.

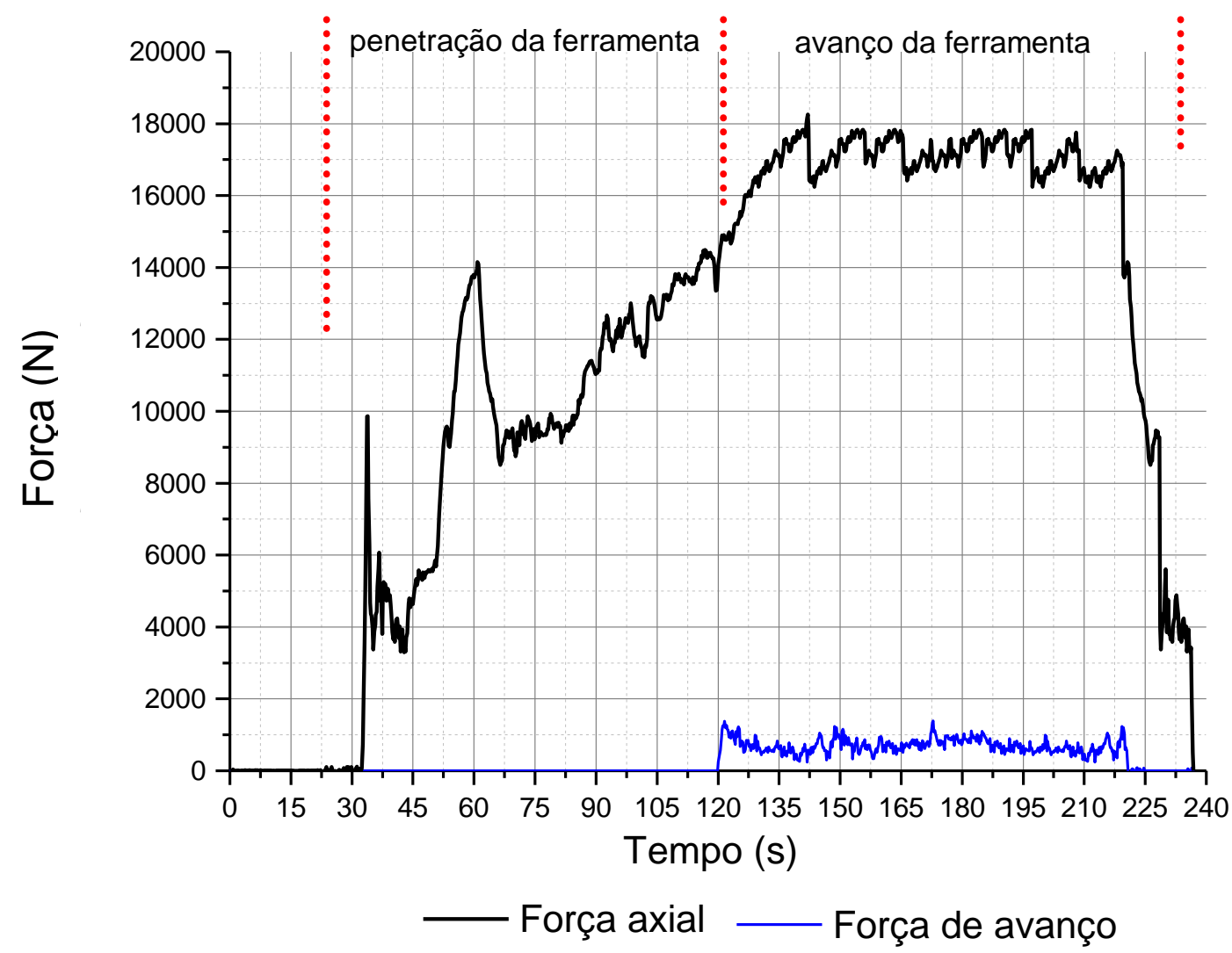

Figura 7-42 - Curva de esforços na ferramenta em para um FSW com rotação de 1600RPM e avanço de $50 \mathrm{~mm} / \mathrm{min}$.

O resultado final da solda efetuada com esta máquina não se mostrou satisfatório, o cabeçote da máquina não se estabilizou durante o processo e oscilou muito, fazendo com que o resultado final da solda fosse insatisfatório.

\subsection{Considerações sobre os ensaios preliminares}

Os resultados do segundo teste preliminar se mostraram mais satisfatórios. As alterações sugeridas para os ensaios (7.3 Readequação do Planejamento preliminar) mostraram que é possível executar o processamento com as condições empregadas. A ferramenta de carboneto de tungstênio ( $\mathrm{W}+6 \% \mathrm{Co})$, empregada no segundo teste, apesar de ter sido capaz de executar o processo, não apresentou estabilidade quanto a resistência ao lascamento. O material de ferramenta $\mathrm{W}+\mathrm{LaO}_{3}$ se mostrou muito mais estável e resistente ao lascamento. 


\section{EXPERIMENTO PRINCIPAL}

\subsection{Planejamento previsto para os Experimentos}

O trabalho experimental foi dividido em três partes:

- Execução do processamento por atrito linear em chapas da liga de titânio Ti6Al-4V em caráter exploratório - Experimentos Preliminares;

- Execução do processamento por atrito linear em chapas da liga de titânio Ti6Al-4V - Experimento Principal;

- Ensaios de tração multiaxial com corpos de prova retirados de tiras processadas com FSP para levantamento das propriedades mecânicas. A geometria dos corpos de prova para tração é apresentada na Figura 8-2.

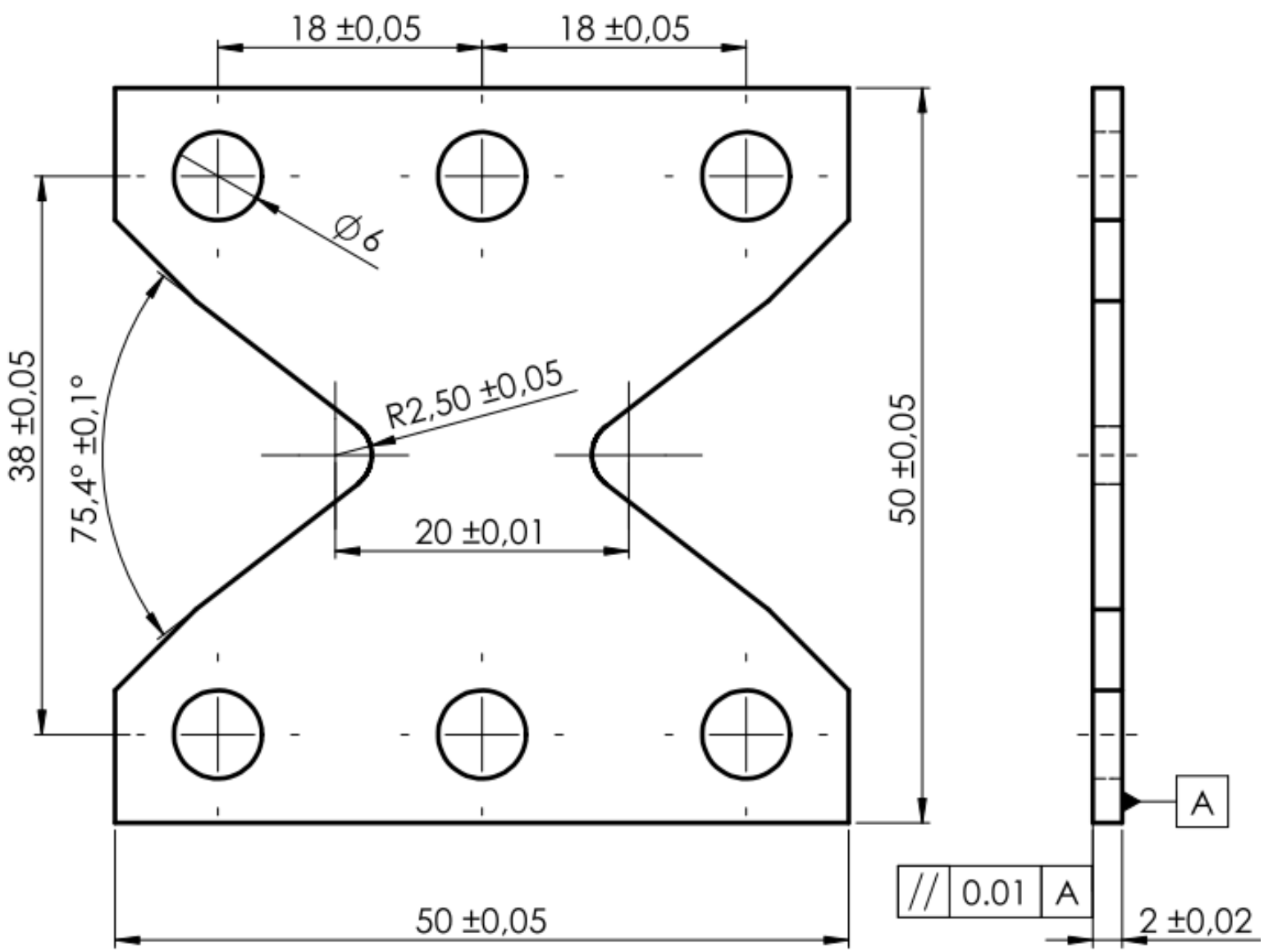

Figura 8-1 Corpo de prova para ensaio de ARCAN (dimensões em mm). 


\subsection{Material e métodos para o ensaio principal}

Após a conclusão dos testes preliminares e a definição do material da ferramenta, máquina, dispositivos e a faixa de parâmetros a serem empregados, o experimento principal foi delineado. Procurou-se empregar as observações resultantes dos ensaios preliminares visando a eliminação de possíveis problemas. Um novo planejamento fatorial foi empregado visando obter qualidade estatística nos resultados do processamento FSP. A princípio a preparação da máquina e ferramentas decorreu do mesmo modo como nos testes preliminares (Capitulo 7). Um planejamento robusto/Taguchi (BOX, HUNTER e HUNTER, 2005), L9 (4 fatores em 3 níveis) foi escolhido para pesquisa, gerando 9 chapas de prova que ao fim irão gerar 45 corpos de prova tipo borboleta idênticos ao da Erro! Fonte de referência ão encontrada.. A Tabela 8-1 apresenta a matriz resultante para o planejamento principal de FSP.

\begin{tabular}{ccc}
\multicolumn{3}{c}{ Tabela 8-1 Matriz robusta para o experimento FSP principal. } \\
\hline Sequência de ensaio & Rotação [RPM] & $\begin{array}{c}\mathbf{f} \\
\text { [mm/min] }\end{array}$ \\
\hline A & 1350 & 50 \\
B & 1350 & 60 \\
C & 1350 & 70 \\
D & 1500 & 50 \\
E & 1500 & 60 \\
F & 1500 & 70 \\
G & 1650 & 50 \\
H & 1650 & 60 \\
I & 1650 & 70 \\
\hline
\end{tabular}

\subsubsection{Condições fixas}

a) Inclinação da ferramenta: $0,5^{\circ}$

b) Máquina: Centro de usinagem vertical CNC MAZAK FJV35-60. (Figura 7-27)

\subsubsection{Resultados dependentes do experimento}
a) Tensão residual;
b) Microestrutura da região afetada;
c) Propriedades mecânicas da região afetada; 


\subsubsection{Corpos de prova para ensaio de FSP}

a) Material do corpo de prova: Ti-6Al-4V (vide Anexo D)

b) Geometria dos corpos de prova para experimento de tração: Figura 7-1

c) Espessura $=2 \mathrm{~mm}$

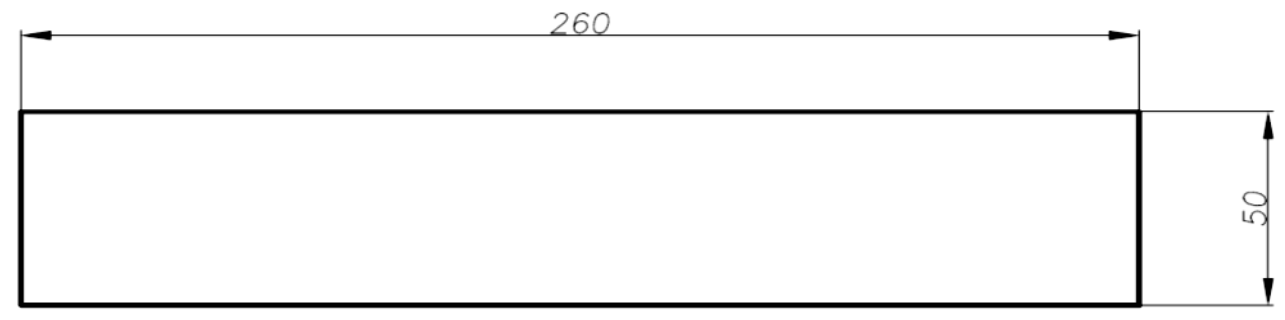

Figura 8-2 - Geometria dos corpos de prova para experimento de FSP, dimensões em milímetros.

Os Corpos de Prova foram cortados nas dimensões em milímetros especificadas, sem rebarbas nas laterais. Todos os Corpos de Prova são da mesma chapa para evitar variação de composição química. O sentido do FSP que será executado é apresentado na (Figura 8-3):

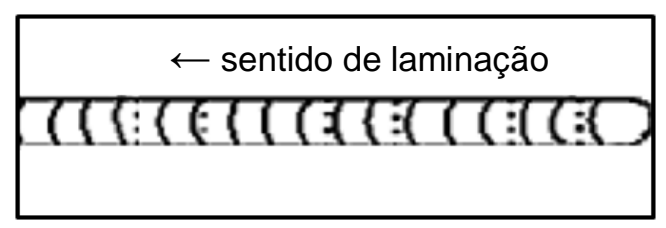

Figura 8-3 - Sentido do FSP

\subsubsection{Preparação da máquina dispositivo e ferramenta}

Para evitar repetições desnecessárias de procedimentos idênticos, é afirmado aqui que as mesmas etapas e cuidados observados na montagem da máquina, dispositivos e ferramenta do experimento preliminar (Capítulo 7), foram executados para o experimento principal. A exceção para este experimento é a montagem de 4 mangueiras para distribuição do gás argônio empregado como gás de proteção.

Na Figura 8-4 e Figura 8-5 é mostrada a montagem final do dispositivo de fixação das chapas. 


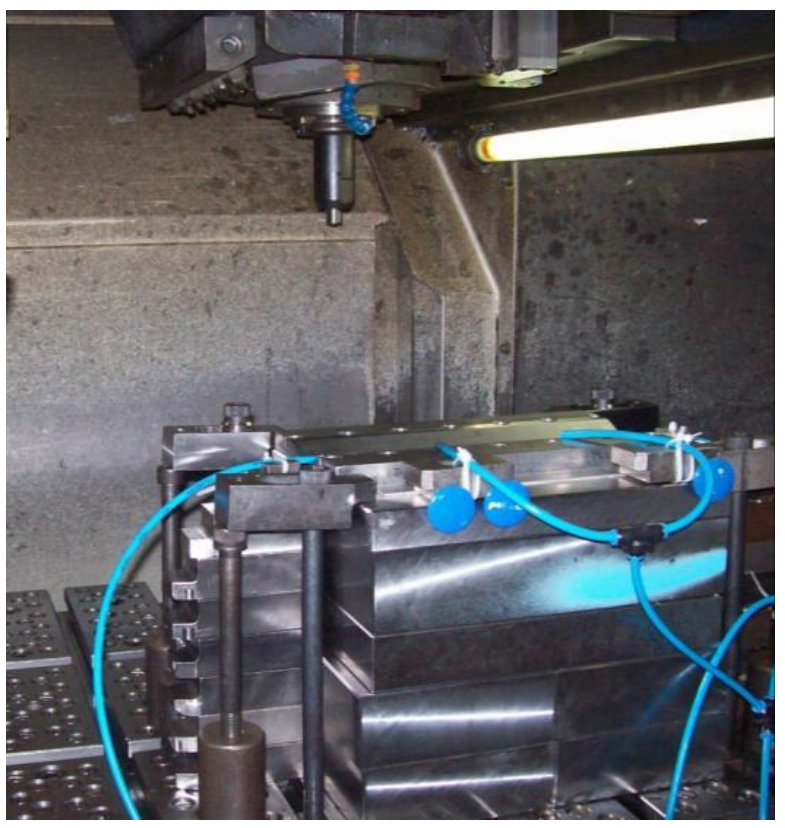

Figura 8-4 - Vista geral do interior da máquina preparada.

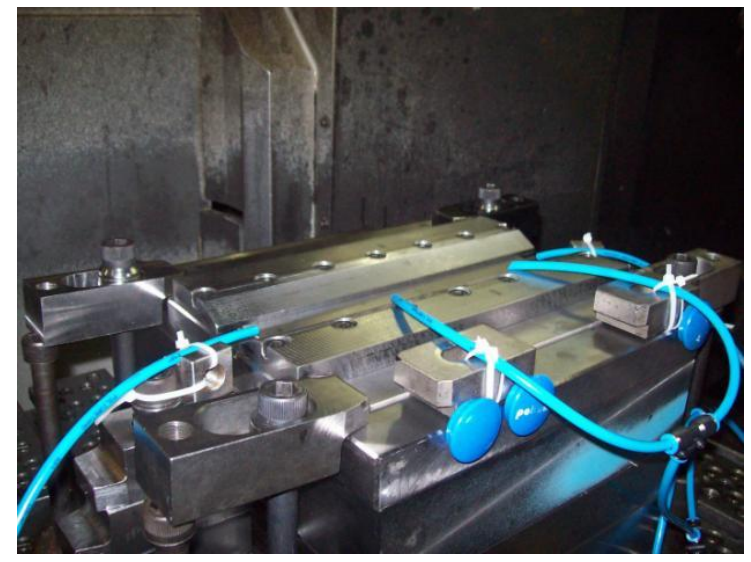

Figura 8-5 - Detalhe do dispositivo de fixação montado.

A Figura 8-6 a-b mostra o detalhe da ferramenta avançando sobre a chapa.

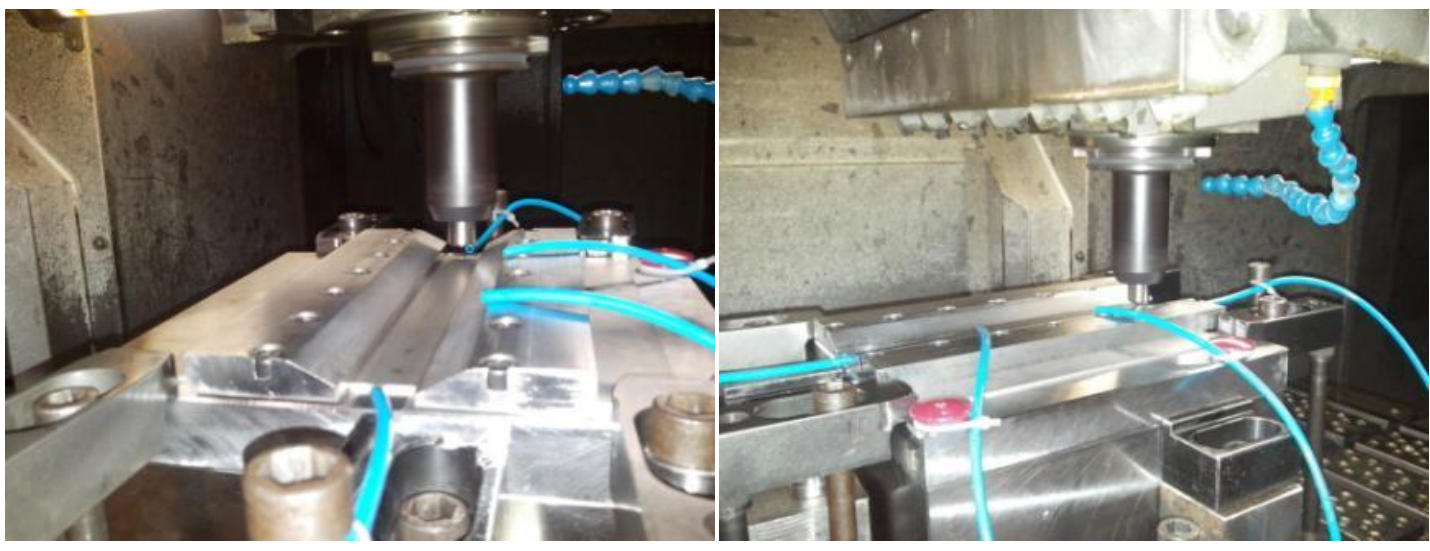

(a)

(b)

Figura 8-6 - Ferramenta simulando a descida na chapa (a) e (b). 
Ao lado da máquina foi posicionado um cilindro de argônio de $80 \mathrm{~kg}$ montado com um regulador de fluxo e pressão como mostra a Figura 8-7 (a) e (b).
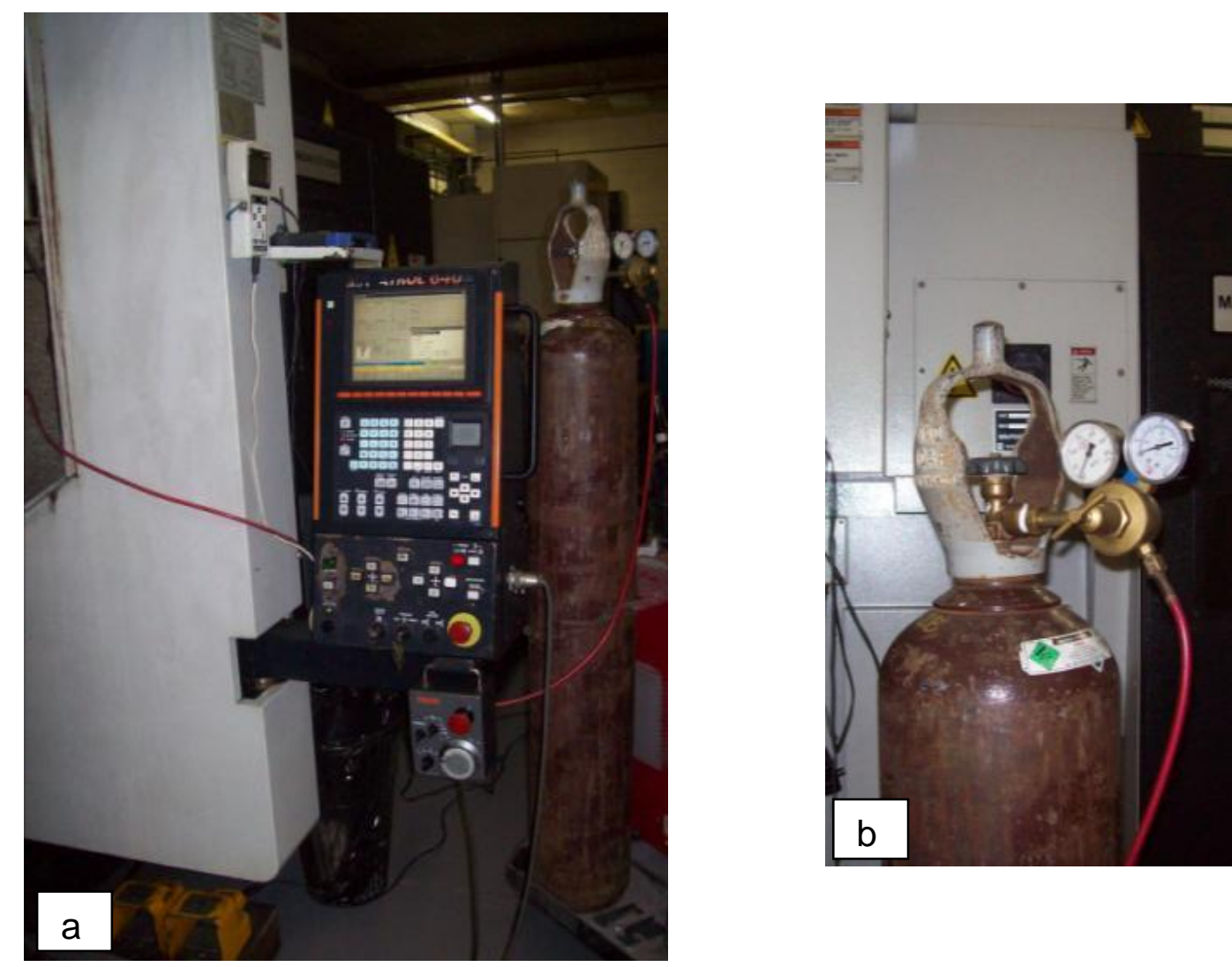

Figura 8-7 - (a) Cilindro de argônio, (b) regulador de fluxo e pressão.

\subsection{Execução do processamento}

A execução dos ensaios também a ocorreu de forma idêntica aos ensaios preliminares. A Figura 8-8 apresenta um momento da ferramenta executando o processamento da chapa de titânio, onde é possível observar que a temperatura se elevou bastante, chegando ao ponto de avermelhar o corpo da ferramenta. Mesmo nessas condições o ensaio se manteve estável sem nenhuma ocorrência extra.

O fluxo de gás argônio foi mantido constante em $0.6 \mathrm{~m}^{3} / \mathrm{h}(10 \mathrm{l} / \mathrm{min})$, desde o início do toque da ferramenta na peça até um minuto depois da sua saída para garantia de proteção da superfície. 


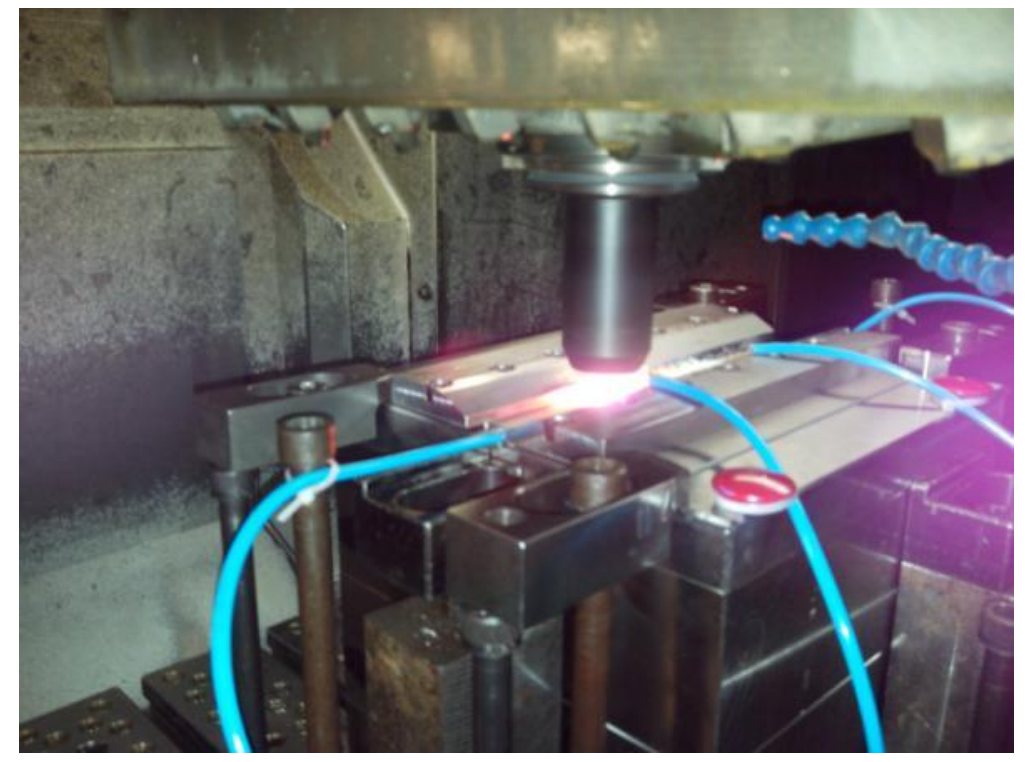

Figura 8-8 - Ensaio sendo executado.

\subsubsection{Medição de temperatura}

Para avaliação da temperatura foi utilizado um equipamento de medição por infra-vermelho da marca Raytek, modelo Marathon MT com capacidade de medição de $250^{\circ} \mathrm{C}$ a $1.100^{\circ} \mathrm{C}$. O equipamento foi montado no cabeçote da máquina, fixado através de base magnética de forma a acompanhar o movimento da ferramenta com o foco apontado na interface ferramenta/peça como é apresentado na Figura 8-9(a).

A temperatura média no ensaio foi tomada de forma discreta, uma leitura no momento em que a ferramenta atingia o ponto médio (aproximadamente $130 \mathrm{~mm}$ do início) e uma leitura a $20 \mathrm{~mm}$ do final do percurso (aproximadamente $240 \mathrm{~mm}$ do início). Os valores médios para as duas medições em cada ensaio são apresentados na Tabela 8-2.

Tabela 8-2 - Medição das temperaturas médias no FSP

\begin{tabular}{cccl}
\hline Sequência de ensaio & Rotação [RPM] & $\begin{array}{c}\mathbf{f} \\
{[\mathbf{m m} / \mathbf{m i n}]}\end{array}$ & $\begin{array}{c}\text { Temperatura } \\
{ }^{\circ} \mathbf{C}\end{array}$ \\
\hline A & 1350 & 50 & $995+/-12$ \\
B & 1350 & 60 & $993+/-9$ \\
C & 1350 & 70 & $993+/-7$ \\
D & 1500 & 50 & $997+/-15$ \\
E & 1500 & 60 & $998+/-18$ \\
F & 1500 & 70 & $995+/-9$ \\
G & 1650 & 50 & $1015+/-12$ \\
H & 1650 & 60 & $1010+/-18$ \\
I & 1650 & 70 & $1008+/-11$ \\
\hline
\end{tabular}




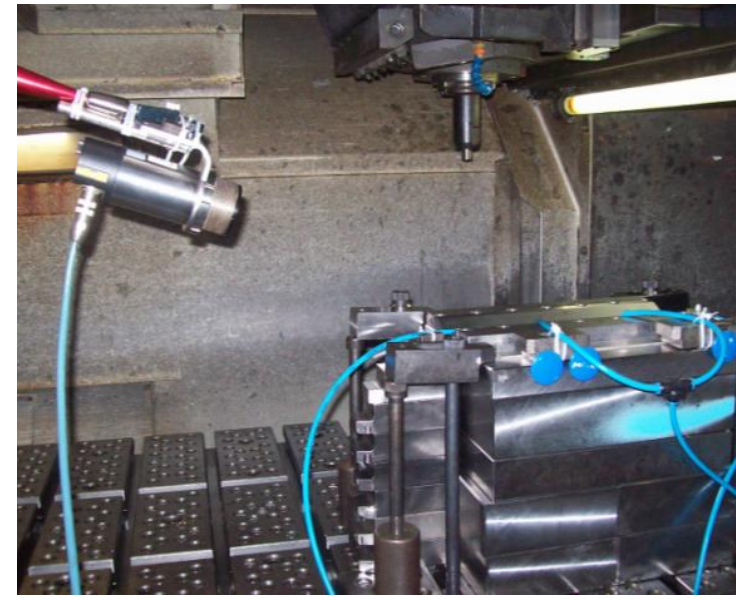

(a)

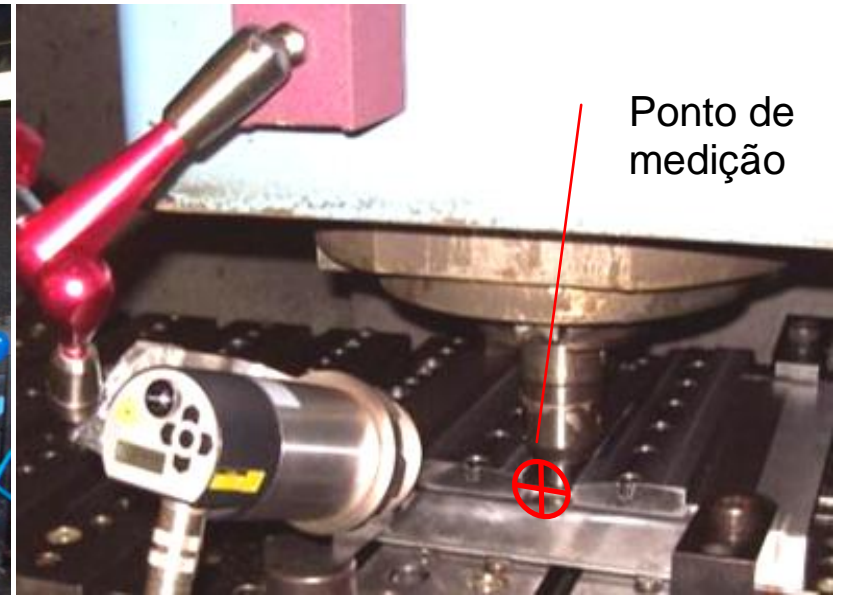

(b)

Figura 8-9 - (a)Montagem do equipamento de medição por infravermelho, (b) ponto para medição da temperatura.

O ponto escolhido para medição de temperatura foi a parte da frente da ferramenta (Figura 8-9b) o equipamento foi apontado na posição de interface entre o ombro da ferramenta e a peça (onde o ombro toca a chapa) podendo assim obter o valor mais próximo de medição na superfície da peça e no corpo da ferramenta.

Após a execução do ensaio, a troca da chapa era efetuada sempre após um intervalo de 10 minutos. Este tempo era suficiente para que a temperatura da região processada atingisse uma temperatura média de $48^{\circ} \mathrm{C}+/-12^{\circ} \mathrm{C}$ medidos com 0 mesmo equipamento de infravermelho ao longo da chapa. Este procedimento foi adotado em todas as condições visando uniformizar a taxa de resfriamento no mesmo valor. A Tabela 8-3 apresenta os valores para taxa de resfriamento em cada situação, sendo que a média global foi de $1.59^{\circ} \mathrm{C} / \mathrm{s}$. Este valor é importante para as discussões a serem efetuadas nas estruturas resultantes em função da distribuição de temperatura de processamento nas chapas.

Tabela 8-3 - Taxa de resfriamento da chapa para tempo=10min (600s)

\begin{tabular}{ccccc}
\hline $\begin{array}{c}\text { Sequência } \\
\text { de ensaio }\end{array}$ & $\begin{array}{c}\text { Rotação } \\
{[\text { RPM] }}\end{array}$ & $\begin{array}{c}\mathbf{f} \\
{[\mathbf{m m} / \mathbf{m i n}]}\end{array}$ & $\begin{array}{c}\text { Temperatura de } \\
\text { troca }{ }^{\circ} \mathbf{C}\end{array}$ & $\begin{array}{c}\text { Taxa de } \\
\text { resfriamento } \\
{ }^{\circ} \mathbf{C} / \mathbf{s}\end{array}$ \\
\hline A & 1350 & 50 & $48+/-5$ & 1.59 \\
\hline B & 1350 & 60 & $45+/-4$ & 1.59 \\
\hline C & 1350 & 70 & $44+/-6$ & 1.59 \\
\hline D & 1500 & 50 & $44+/-10$ & 1.59 \\
\hline E & 1500 & 60 & $48+/-11$ & 1.59 \\
\hline F & 1500 & 70 & $47+/-9$ & 1.59 \\
\hline G & 1650 & 50 & $56+/-5$ & 1.57 \\
\hline H & 1650 & 60 & $51+/-10$ & 1.58 \\
\hline I & 1650 & 70 & $50+/-9$ & 1.58 \\
\hline
\end{tabular}




\subsubsection{Avaliação das chapas processadas po FSP}

Todos os testes resultaram em chapas processadas aproveitáveis para continuação dos testes, a exceção foram para as condições de parâmetros 1350RPMx60 $\mathrm{mm} / \mathrm{min}, 1350 \mathrm{RPM} \times 70 \mathrm{~mm} / \mathrm{min}$ e 1500RPMx $50 \mathrm{~mm} / \mathrm{min}$ onde o início do processamento não resultou em um acabamento superficial satisfatório. Estas regiões da chapa não foram utilizadas para os testes posteriores de tração. Destas chapas foram usinados os corpos de prova para os ensaios subsequentes. As chapas não sofreram nenhum tratamento térmico posterior, as rebarbas remanescentes do processo de FSP foram removidas de forma mecânica, mas sem a geração de calor para não afetar a microestrutura original gerada pelo processamento de FSP. Sempre ao fim de cada chapa a ferramenta foi trocada ou teve sua geometria reparada (Figura 8-10). A Figura 8-11 e Figura 8-12 apresentam todas as chapas dispostas para comparação. Nelas foram anotadas as condições de cada ensaio. O processamento ocorreu da direita para esquerda, onde é possível notar o vestígio da saída da ferramenta. Na Figura 8-10a é apresentada uma ferramenta logo após a execução de um ensaio, é possível verificar que houve um desgaste da ponta. Este desgaste sugere que partículas da ferramenta podem ter se desprendido e permanecido como inclusões dentro do material, no estudo das metalografias ficou constatado este fato através de imagens de microscopia eletrônica de varredura e elétrons retroespalhados com EDS (energy dispersive $x$ ray detector).

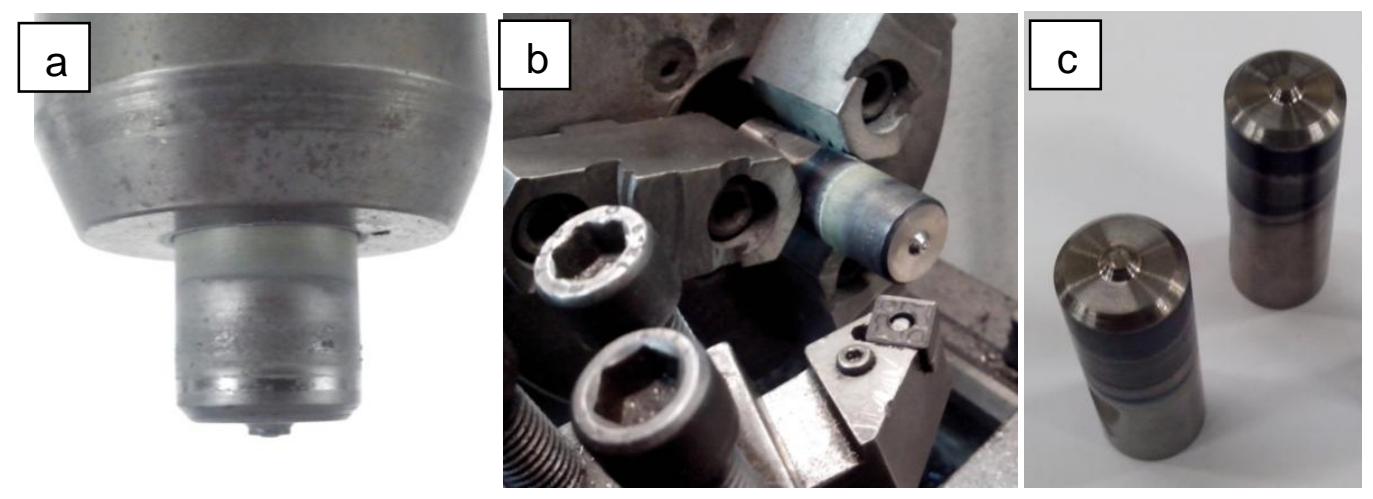

Figura 8-10 - Processo de conserto da geometria da ferramenta, (a)da ponta da ferramenta desgastada, (b) torneamento da ponta e (c) ferramenta com geometria reconstituida. 


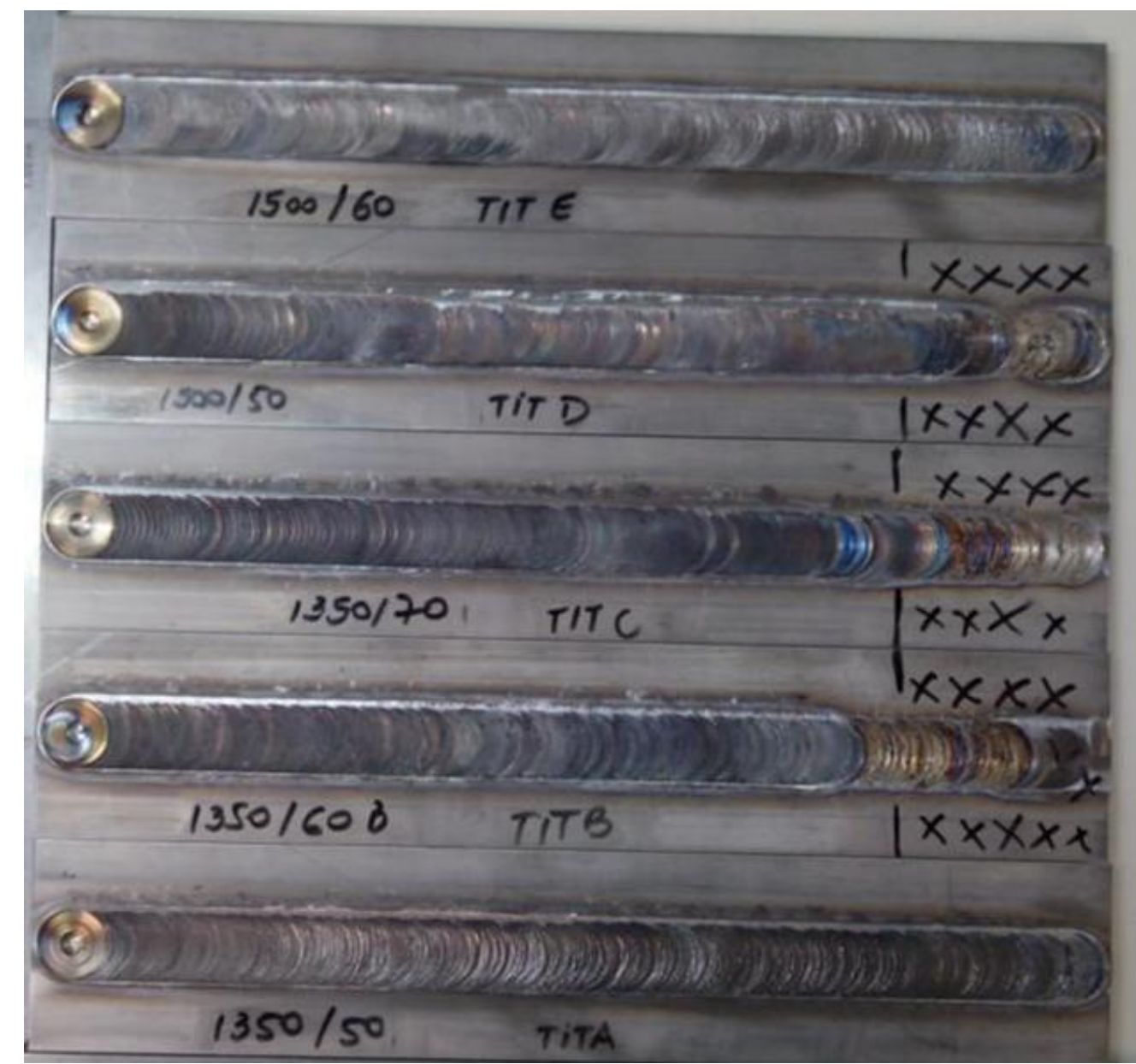

Figura 8-11 - Chapas processadas nas condições do planejamento robusto.

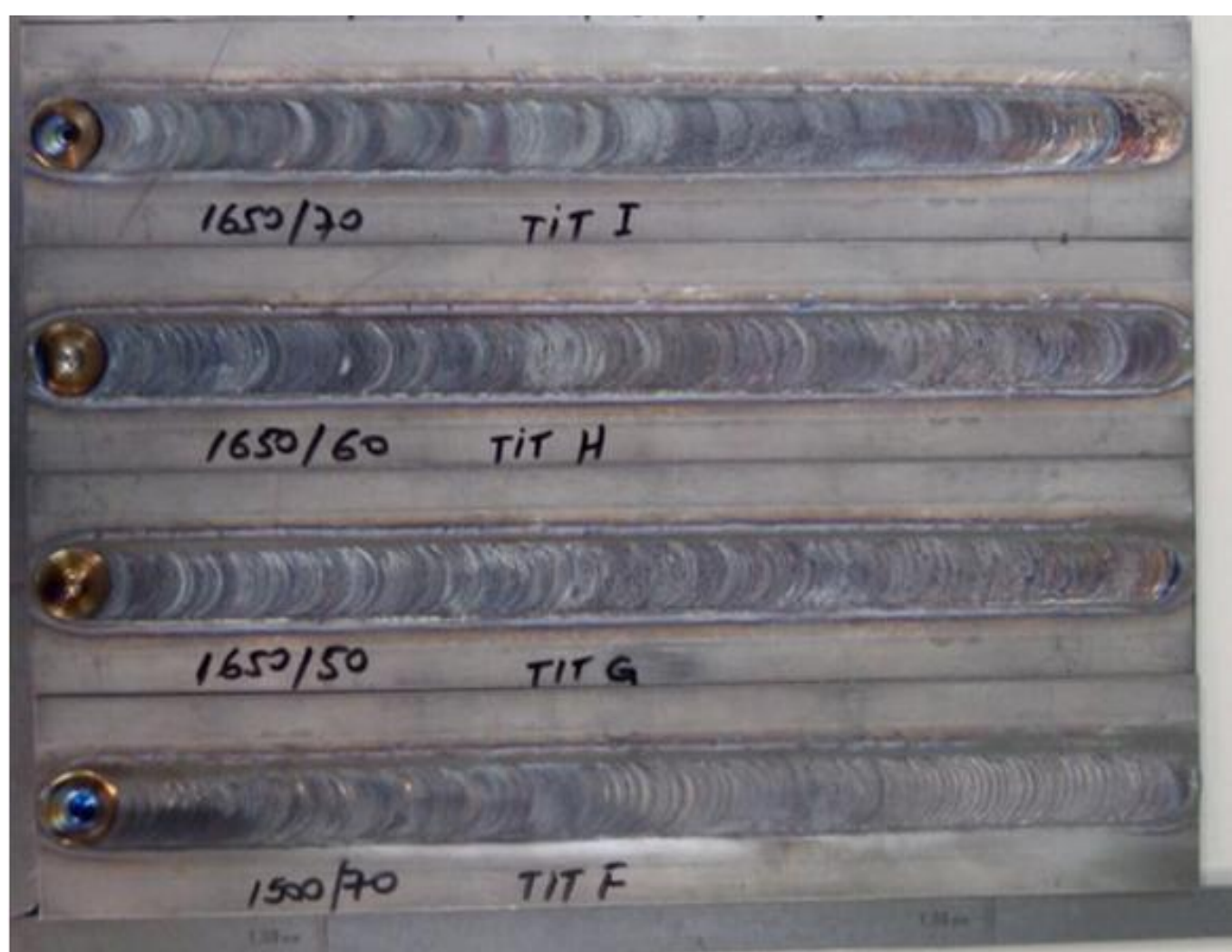

Figura 8-12 - continuação. Chapas processadas nas condições do planejamento robusto. 


\subsection{Ensaio de solicitação multiaxial ARCAN}

Para os ensaios de tração duas variáveis foram adicionadas ao planejamento fatorial robusto original, velocidade de acionamento da máquina e temperatura do teste. A Tabela 8-4 apresenta os valores utilizados no ensaio de tração. É importante resaltar que este planejamento foi executado em cada um dos ângulos disponíveis no dispositivo, resultando em 45 ensaios de tração.

Tabela 8-4 - Planejamento para os ensaios de tração.

\begin{tabular}{ccccc}
\hline Código de ensaio & Rotação [RPM] & $\begin{array}{c}\mathbf{f} \\
{[\mathbf{m m} / \mathbf{m i n}]}\end{array}$ & $\begin{array}{c}\text { Taxa-Tração } \\
{[\mathbf{m m} / \mathbf{s}]}\end{array}$ & $\begin{array}{c}\text { Temp.-Tração } \\
{\left[{ }^{\circ} \mathbf{C}\right]}\end{array}$ \\
\hline A & 1350 & 50 & 0.1 & 25 \\
B & 1350 & 60 & 0.01 & 200 \\
C & 1350 & 70 & 0.001 & 340 \\
D & 1500 & 50 & 0.01 & 340 \\
E & 1500 & 60 & 0.001 & 25 \\
F & 1500 & 70 & 0.1 & 200 \\
G & 1650 & 50 & 0.001 & 200 \\
H & 1650 & 60 & 0.1 & 340 \\
I & 1650 & 70 & 0.01 & 25 \\
\hline
\end{tabular}

Visando facilitar a identificação dos corpos de prova, uma codificação alfanumérica foi atribuída a cada condição de ensaio. Consistiu do código de ensaio constante na Tabela 8-4 atribuída de um índice indicando um dos cinco ângulos testados, conforme Tabela 8-5.

Tabela 8-5 Referência para os ângulos testados.

\begin{tabular}{ccc}
\hline Índice & Ângulo & Condição \\
\hline 1 & 0 & Tração pura \\
2 & 30 & Combinada \\
3 & 45 & Combinada \\
4 & 60 & Combinada \\
5 & 90 & Cisalhamento puro \\
\hline
\end{tabular}

\subsubsection{Garras para máquina de tração}

Pelo fato do ensaio de ARCAN não ser padronizado, para este trabalho foi desenvolvido um projeto especial de garras visando sua utilização com o material proposto das chapas (Ti6Al4V). No Anexo I é apresentado o desenho do conjunto de montagem e um detalhe da garra principal. Todo dispositivo foi usinado em máquina CNC para garantir a precisão dimensional do conjunto montado. Na Figura 8-13 é 
apresentada o conjunto montado com um corpo de provas no centro. O dispositivo proposto permite a execução dos ensaios em cinco condições de solicitação: tração pura $\left(0^{\circ}\right)$, cisalhamento puro $\left(90^{\circ}\right)$, tensões combinadas a $30^{\circ}, 45^{\circ}$ e $60^{\circ}$.

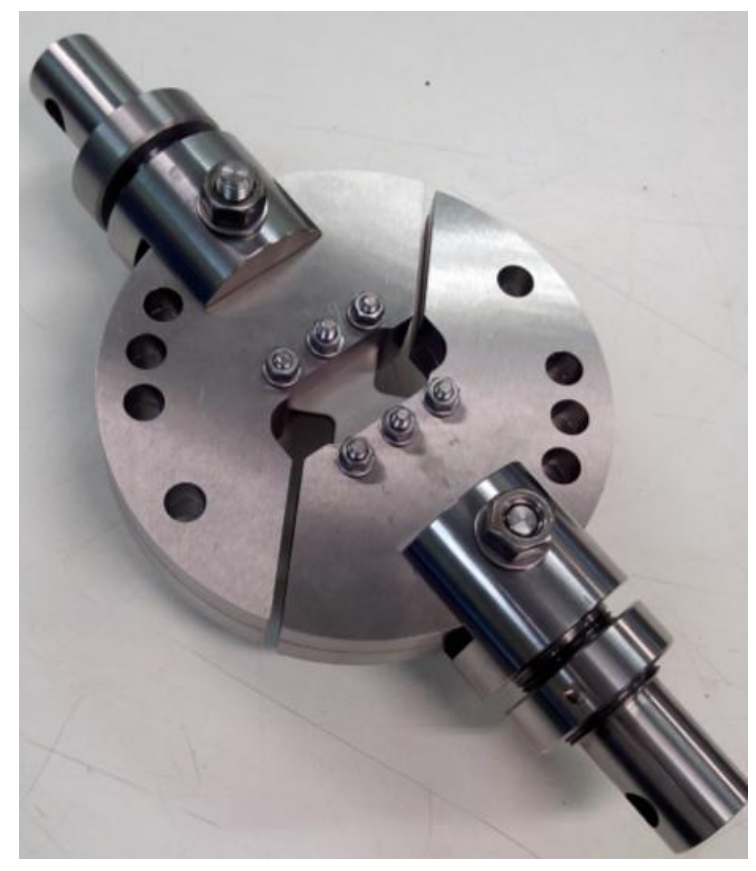

Figura 8-13 - Dispositivo de ARCAN montado.

\subsubsection{Corpos de prova para o ensaio de ARCAN}

Os ensaios de tração multiaxial foram executados com corpos de prova retirados de tiras processadas com FSP para identificação das propriedades mecânicas. Das 9 chapas processadas foram retirados 45 corpos de prova com a geometria apresentada na Figura 8-2. A Figura 8-14 apresenta o sentido do processamento realizado, a área sujeita ao FSP é indicada pela área hachurada.

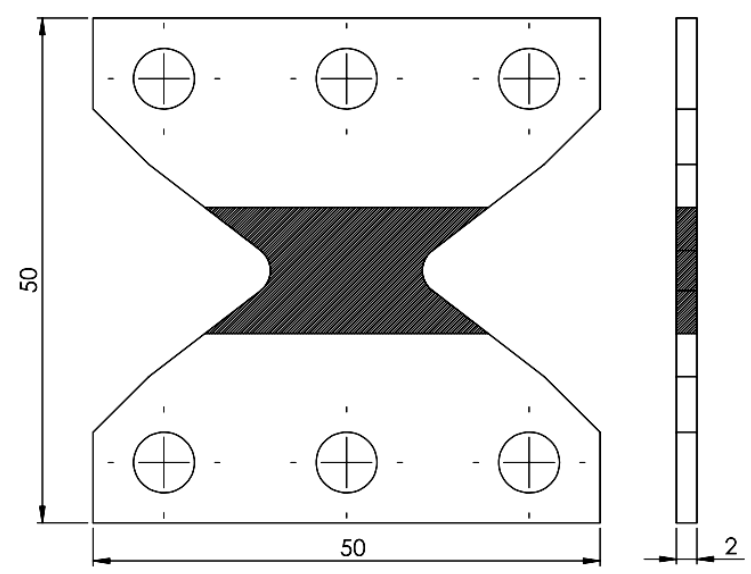

Figura 8-14 Corpo de prova para ensaio de ARCAN, dimensões em mm. 
Os corpos de prova recortados das chapas com equipamento de jato d'agua e depois foram usinados em máquina CNC para garantir que as tolerâncias ficassem dentro dos valores indicados na Erro! Fonte de referência não encontrada.

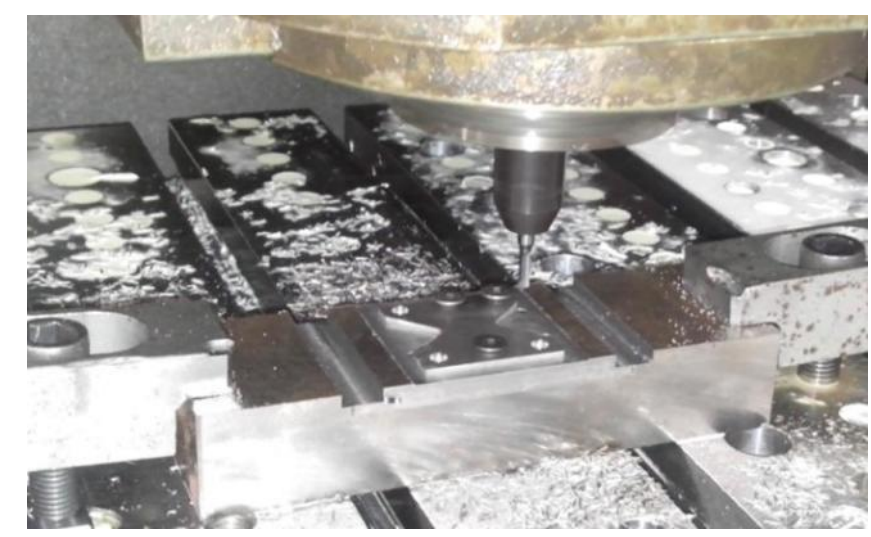

Figura 8-15 Usinagem dos corpos de prova.

\subsubsection{Execução dos ensaios de tração ARCAN}

A máquina utilizada no ensaio de tração foi uma Instron modelo $3369 \mathrm{com}$ capacidade para $50 \mathrm{kN}$ (5ton), Figura 8-16.

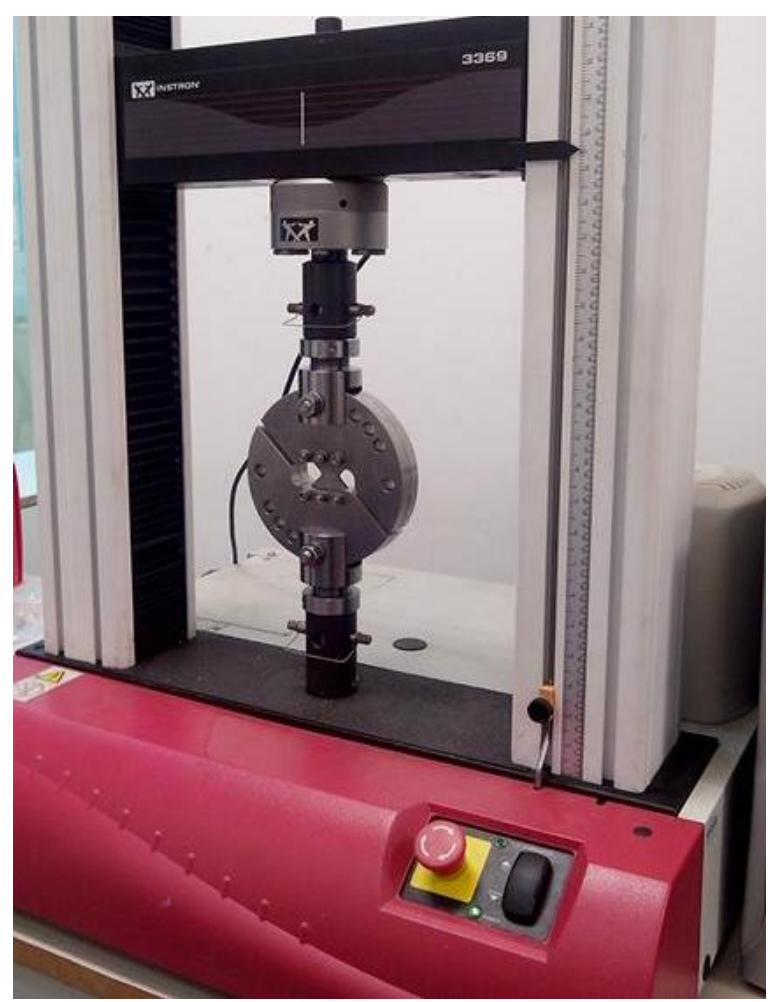

Figura 8-16 Máquina de tração Instron para $50 \mathrm{kN}$ com as garras montadas. 
O controle da temperatura do ensaio foi executado com o auxílio de uma resistência elétrica de $900 \mathrm{~W}$ de potência, com termopar tipo $\mathrm{J}$ embutido, montada na base da máquina e direcionada diretamente sobre o corpo de provas. Um controlador de potência da marca Polimold foi empregado para modular a temperatura da resistência elétrica.

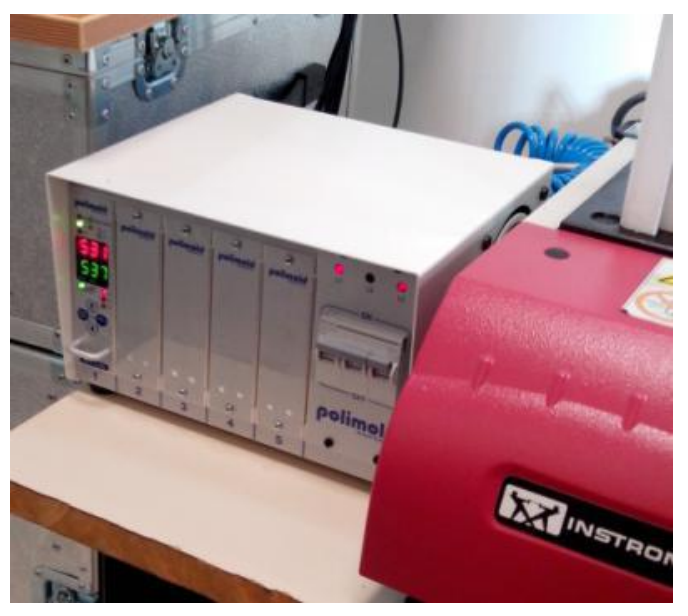

(a)

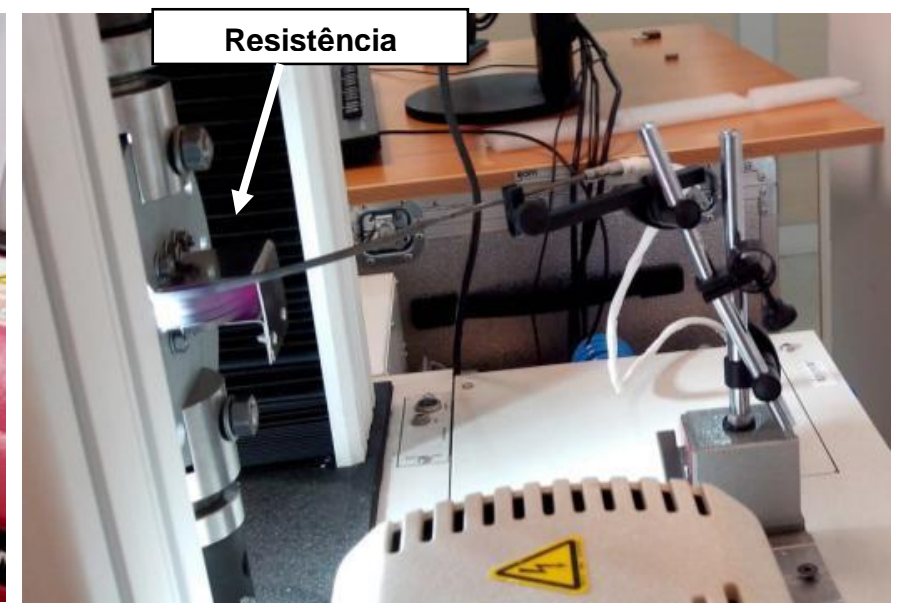

(b)

Figura 8-17 (a) Controlador de potência e (b) resistência montada.

Para o controle da temperatura da peça foi utilizado um pirômetro infravermelho com mira laser montado em um pedestal na frente da máquina de ensaios, Figura 8-18. O controle da temperatura foi executado de forma manual e mantido dentro de uma faixa de variação de $+10^{\circ} \mathrm{C} /-10^{\circ} \mathrm{C}$ para os testes mais longos, e $+5^{\circ} \mathrm{C} /-5^{\circ} \mathrm{C}$ para os testes mais rápidos.

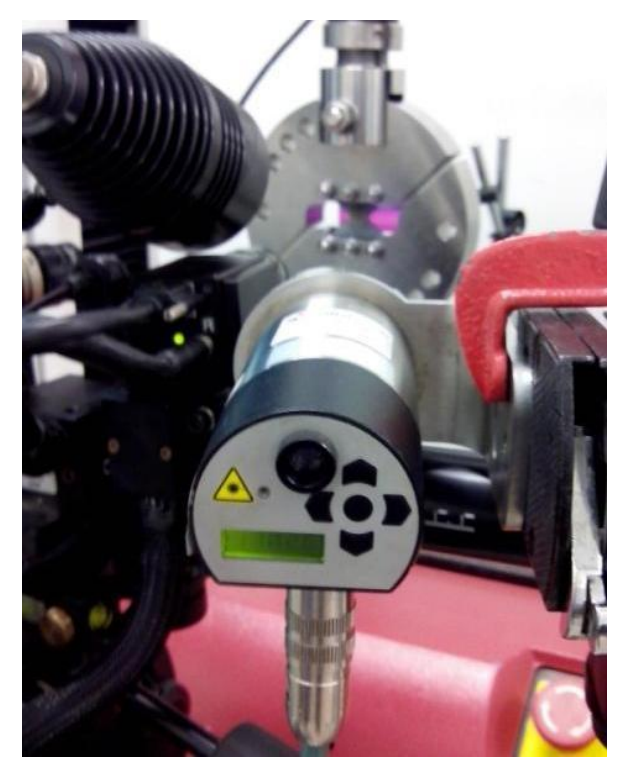

Figura 8-18 Pirômetro infravermelho com mira laser. 
A medição da deformação do corpo de prova foi efetuada com o sistema Aramis de aquisição e análise de imagens digitais apresentados nas Figura 8-19 e Figura 8-20. Todas as imagens foram capturadas a uma taxa de 1 imagem por segundo para todos os ensaios.

A força de tração foi registrada pelo programa da máquina Instron a uma taxa de amostragem de 10 leituras por segundo, posteriormente convertida em arquivo de texto simples. Devido ao fato dos dois equipamentos não estarem interligados estas duas medições de deformação e força necessitaram passar por um tratamento de sincronização executada pelo software GOM Aramis. Devido ao fato da taxa de leitura da Instron ser 10 vezes maior em relação à do GOM Aramis (10x1), este procedimento pode ser executado de forma precisa e confiável.

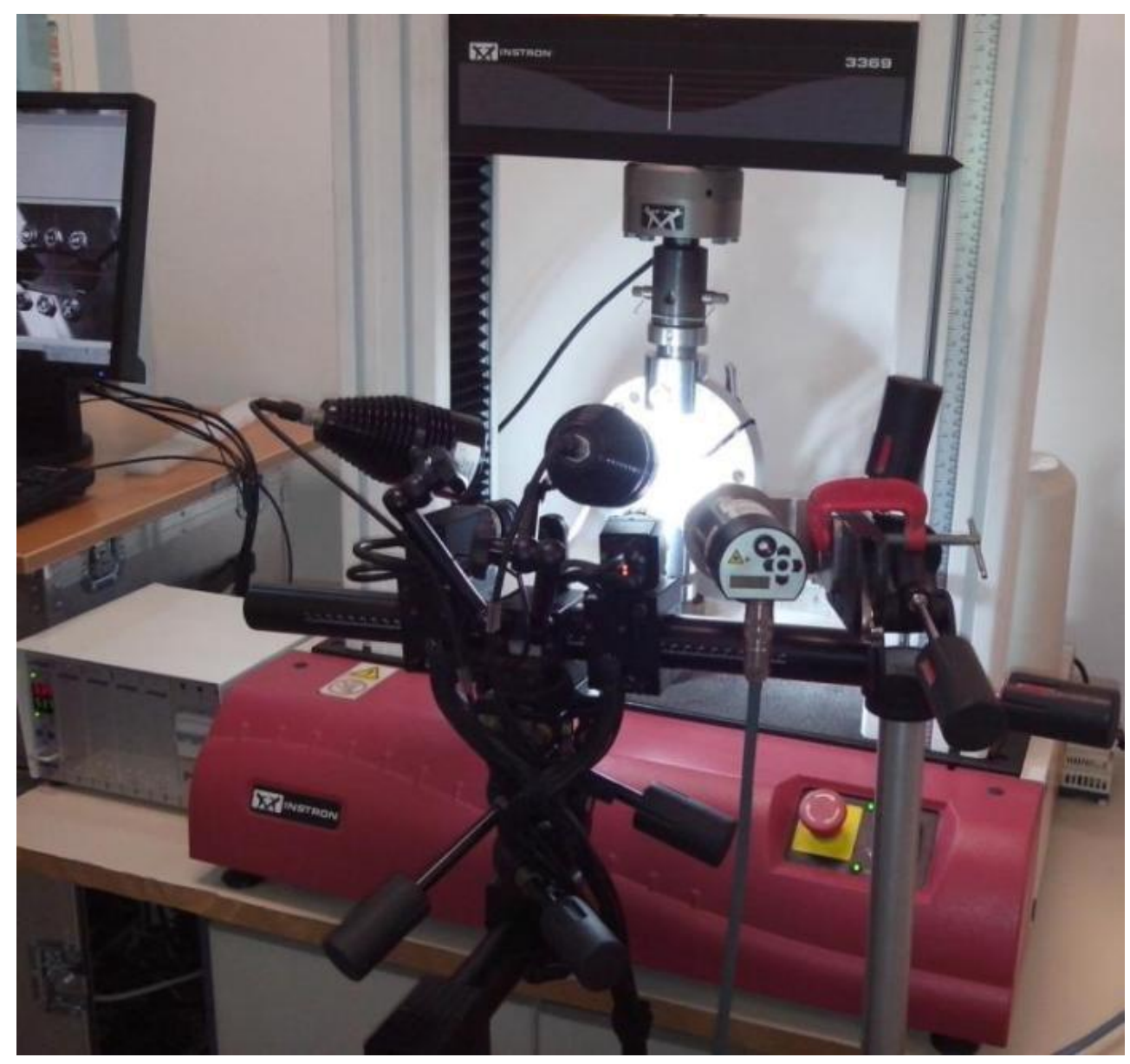

Figura 8-19 Sistema de câmeras e iluminação do Aramis. 


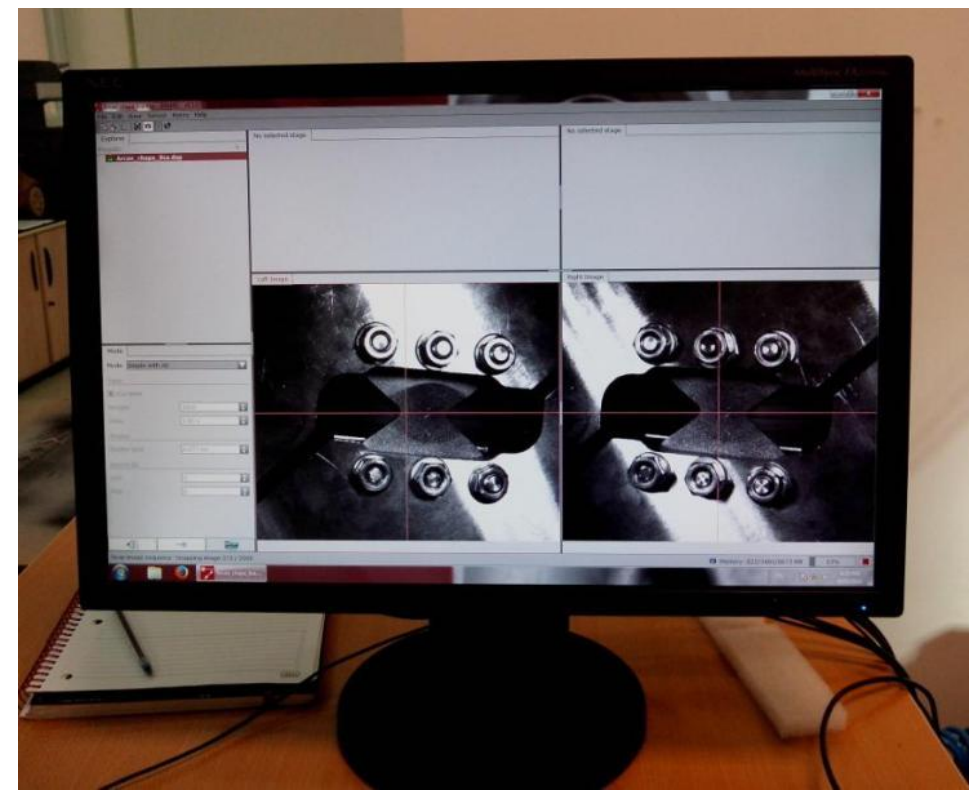

Figura 8-20 Software Aramis - módulo de aquisição de imagens.

Para o correto funcionamento do sistema de aquisição de imagens, este foi previamente calibrado em um dos corpos de prova antes da execução dos ensaios. O procedimento de calibração se encontra no Anexo J.

A Figura 8-21, Figura 8-22, Figura 8-23 e Figura 8-24 representam uma amostragem de todos os ensaios executados nas diversas condições ensaiadas, condição de tração pura Figura 8-21, condição de cisalhamento puro Figura 8-22 , condição de cisalhamento com temperatura de $340^{\circ} \mathrm{C}$ Figura $8-23$, condição mista a $45^{\circ}$, rompida Figura 8-24.

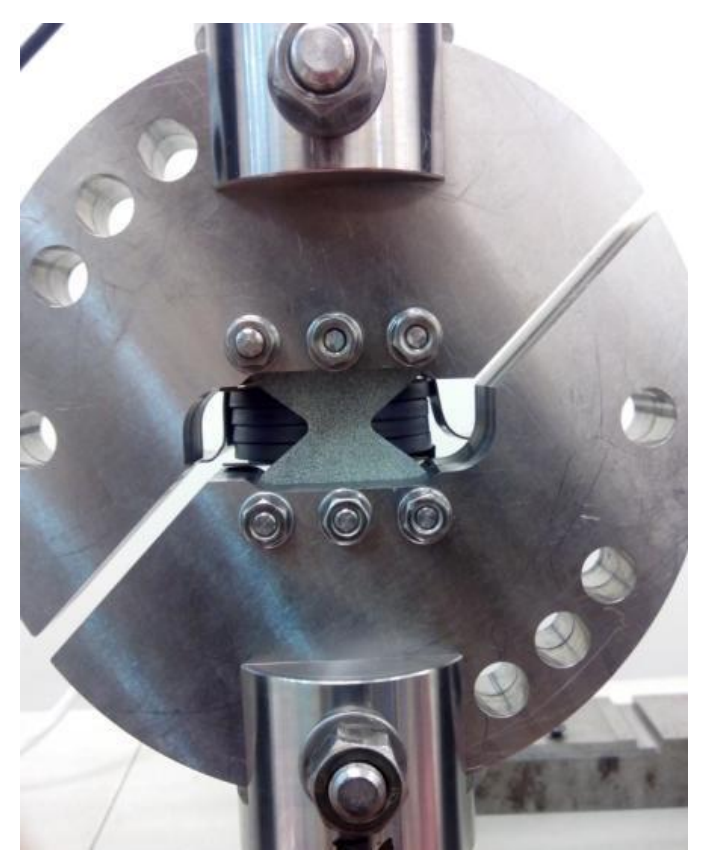

Figura 8-21 Condição de tração pura. 


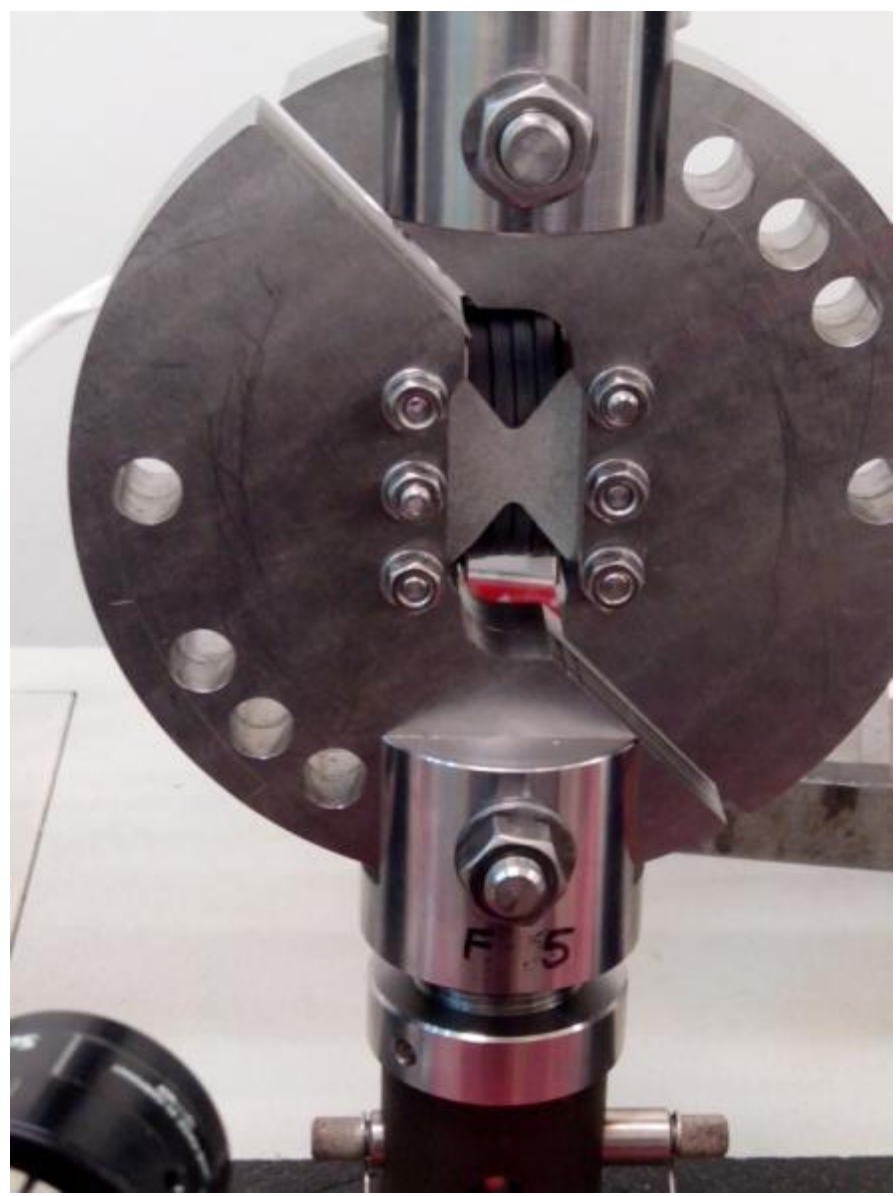

Figura 8-22 Condição de cisalhamento puro.

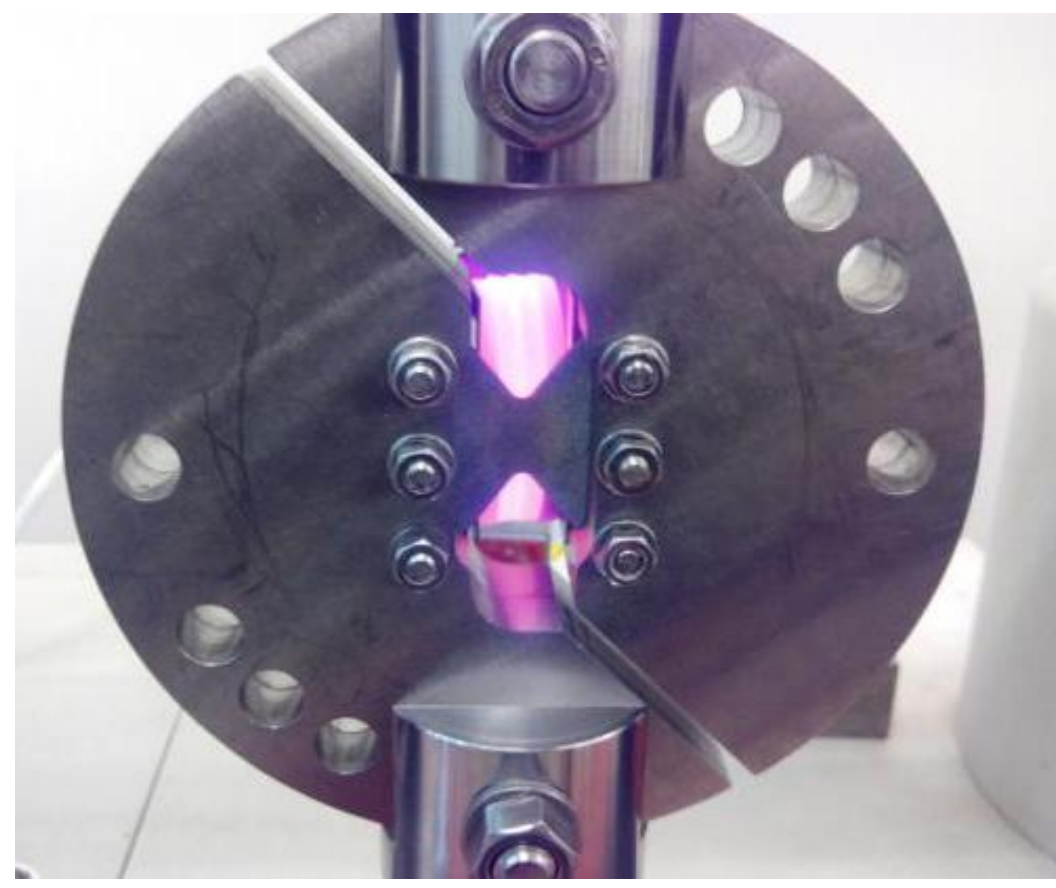

Figura 8-23 Condição de cisalhamento com temperatura de $340^{\circ} \mathrm{C}$. 


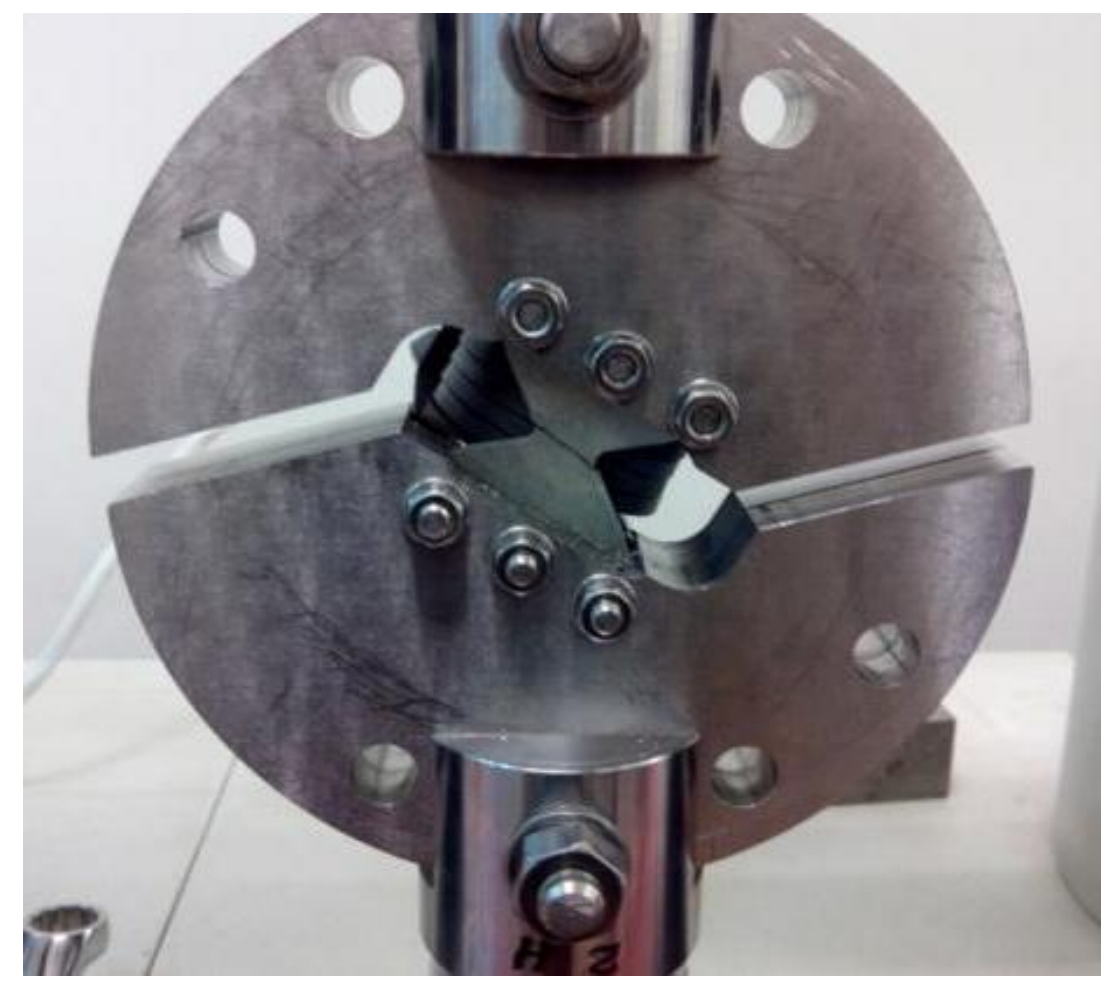

Figura 8-24 Condição mista a $45^{\circ}$, rompida.

Foram ensaiadas todas as condições processadas menos a situação G, e também as condições que servem de paradigma de comparação, corpos de provas lisos retiradas no sentido da laminação da chapa.

Após a aquisição das imagens dos ensaios com o software Aramis, procedeuse o pós-processamento de cada condição para o levantamento das curvas de tensão x deformação.

\subsubsection{Pós-processamento das imagens digitais}

Através do módulo de avaliação do software Aramis as imagens capturadas são processadas e os diversos possíveis resultados de deformação são analisados. A Figura 8-25 apresenta a avaliação para condição $F 1$, é apresentado na tela os valores de deformação máxima no momento de Máxima Tensão. Através de uma sub-rotina própria criada para o levantamento da curva de tensão $x$ deformação se executam os levantamentos de todas as curvas dos ensaios executados. Para o levantamento das curvas de tensão $x$ deformação é necessário que a força medida externamente pelo programa da máquina Instron, transformada em um arquivo de texto, seja sincronizada com as imagens capturadas pelo Aramis. Este procedimento 
é executado internamente pelo Aramis com o auxílio de uma sub-rotina própria onde é informado o ponto para sincronização dos arquivos, o ponto escolhido para sincronização em todos os casos é o momento de ruptura do corpo de provas, por ser de fácil observação visual em ambos os arquivos, de imagens e de texto (queda brusca dos valores de força).

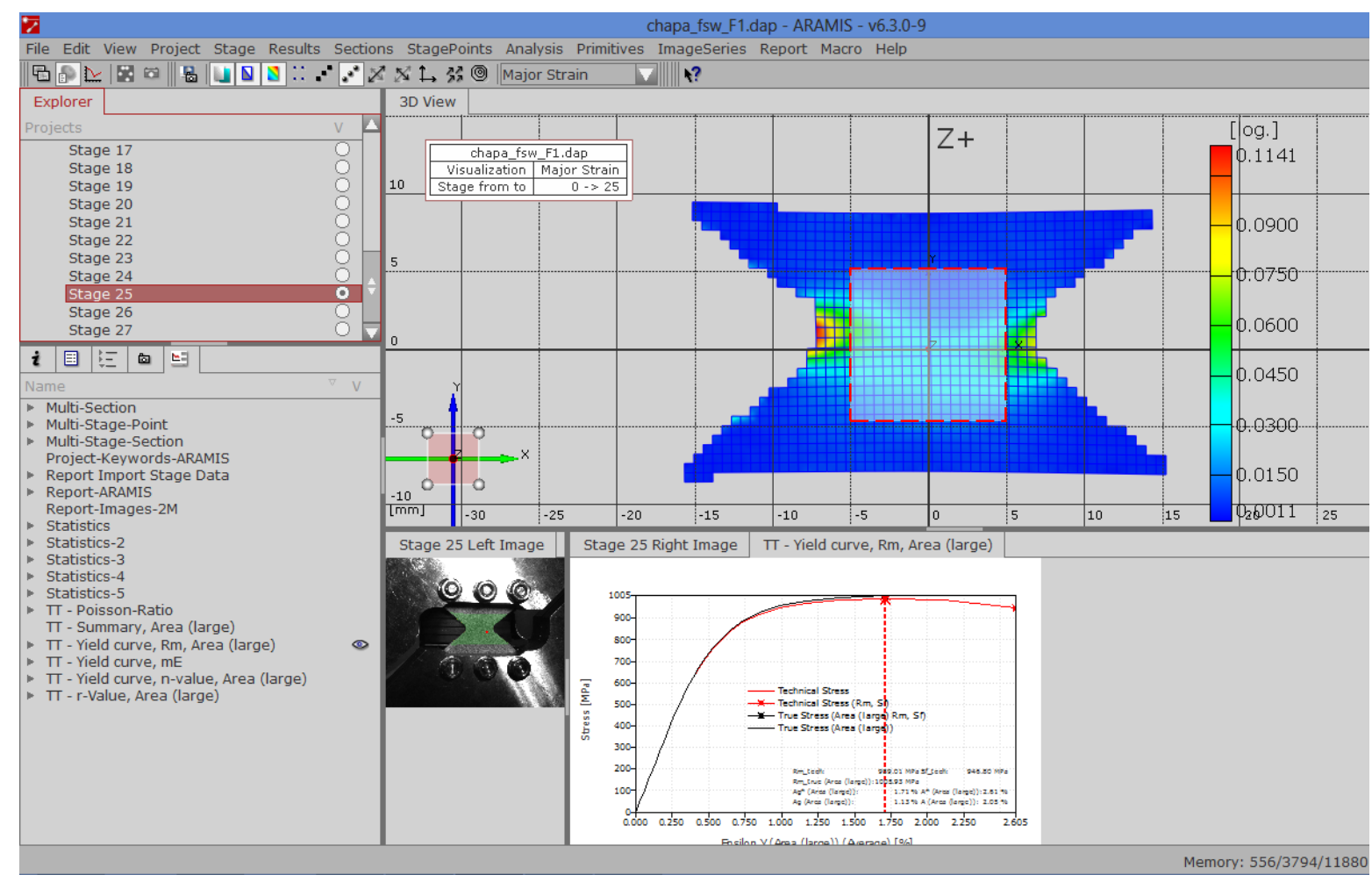

Figura 8-25 Módulo de avaliação do software GOM Aramis.

Após a aquisição das imagens, o software GOM Aramis possibilita a criação de janelas de seleção para regiões específicas do corpo de provas, em geral as regiões de interesse no estudo das deformações e tensões. É um recurso bastante útil na existência de restrições, como por exemplo, imperfeições na peça ou defeitos na aquisição das imagens. Em geral, qualquer condição que pode alterar ou distorcer significativamente os resultados deve ser eliminada do estudo.

No caso dos corpos de provas utilizados neste estudo, uma janela de $10 \mathrm{~mm} \times 10 \mathrm{~mm}$ centralizada no corpo de provas, indicada pelas linhas tracejadas em vermelho na Figura 8-25 foi empregada. A seleção desta região minimizou a influência da concentração de tensão causada pela geometria do corpo de provas, o entalhe em "V". Na região compreendida pela janela de $10 \mathrm{~mm} \times 10 \mathrm{~mm}$ a tensão foi considerada como uniforme para efeito das análises posteriores. 


\section{RESULTADOS E DISCUSSÕES}

\subsection{Metalografias}

As metalografias foram avaliadas em um microscópio ótico da marca Olympus modelo BX60MFS com uma câmera acoplada Sony CCD-IRIS. Todas as amostras foram cortadas transversalmente à direção de processamento respeitando-se o sentido de giro da ferramenta, sendo o lado direito nomeado como Lado de Avanço (LA) e o lado esquerdo da metalografia nomeado como Lado de Retrocesso (LR). O sentido de rotação e avanço da ferramenta para processamento é demonstrado na Figura 9-1, que resulta na classificação dos lados LA e LR.

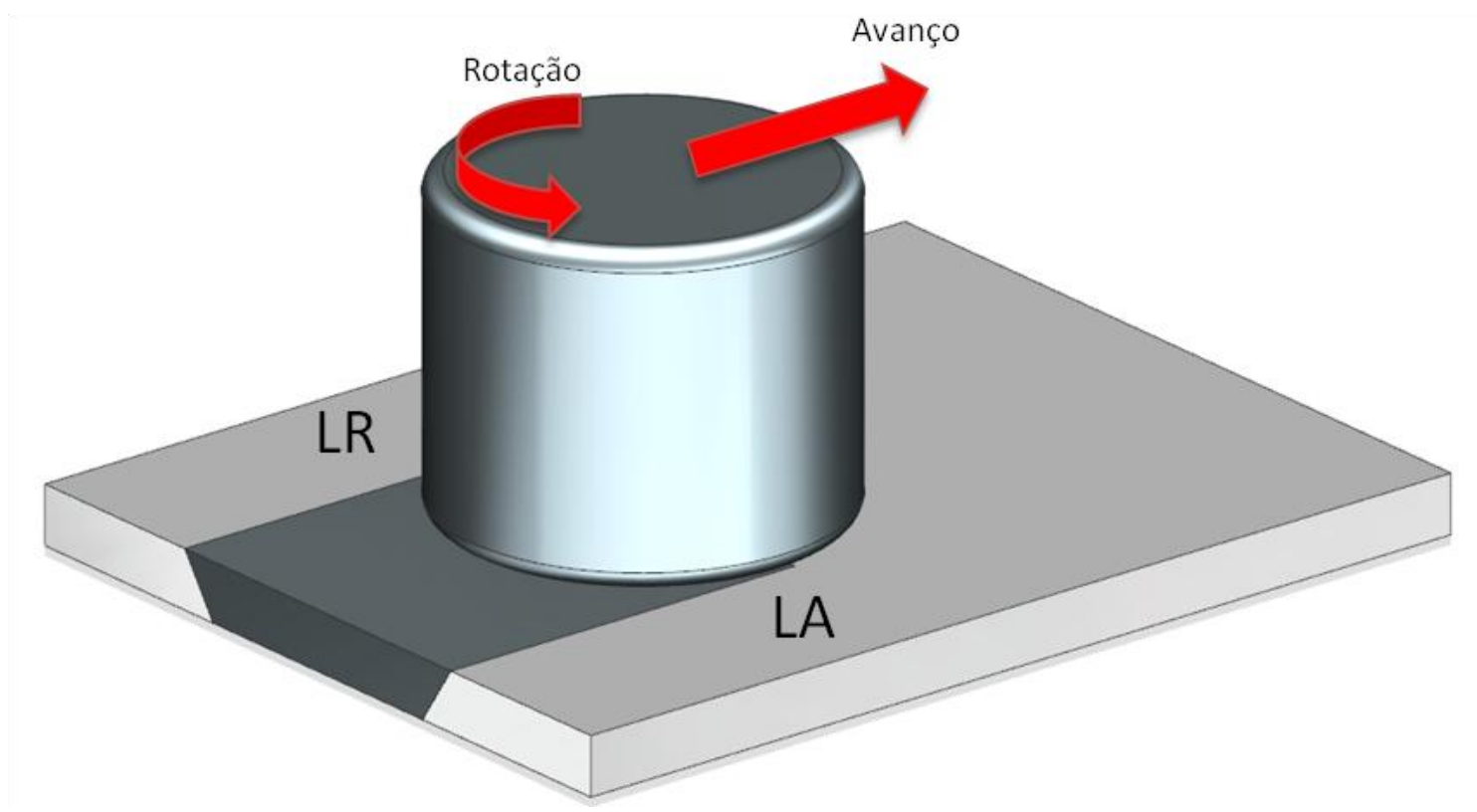

Figura 9-1 - Sentido de rotação e avanço da ferramenta.

Todas as amostras foram embutidas em baquelite e lixadas até a granulação \#1000mesh com posterior polimento utilizando uma solução coloidal de sílica de $1 \mu \mathrm{m}$. Para revelar a estrutura foi empregada a solução de $3 \mathrm{ml}$ de HF com $6 \mathrm{ml}$ de HNO3 e $100 \mathrm{ml}$ de $\mathrm{H}_{2} \mathrm{O}$ (Kroll). Para avaliação das metalografias utilizou-se a nomenclatura do esquema da Figura 9-2 associada aos valores do ensaio efetuado. A região 1 se refere ao meio da amostra (região processada) na zona termicamente e mecanicamente afetada (ZTMA), sendo 1T no topo e 1B na base da metalografia. A região 2 na transição da zona processada para o material de base (LA lado de 
avanço e LR lado de retrocesso), onde temos duas situações de zona termicamente afetada (ZTA), térmica+mecânica e somente térmica. E por fim na região 30 material de base.

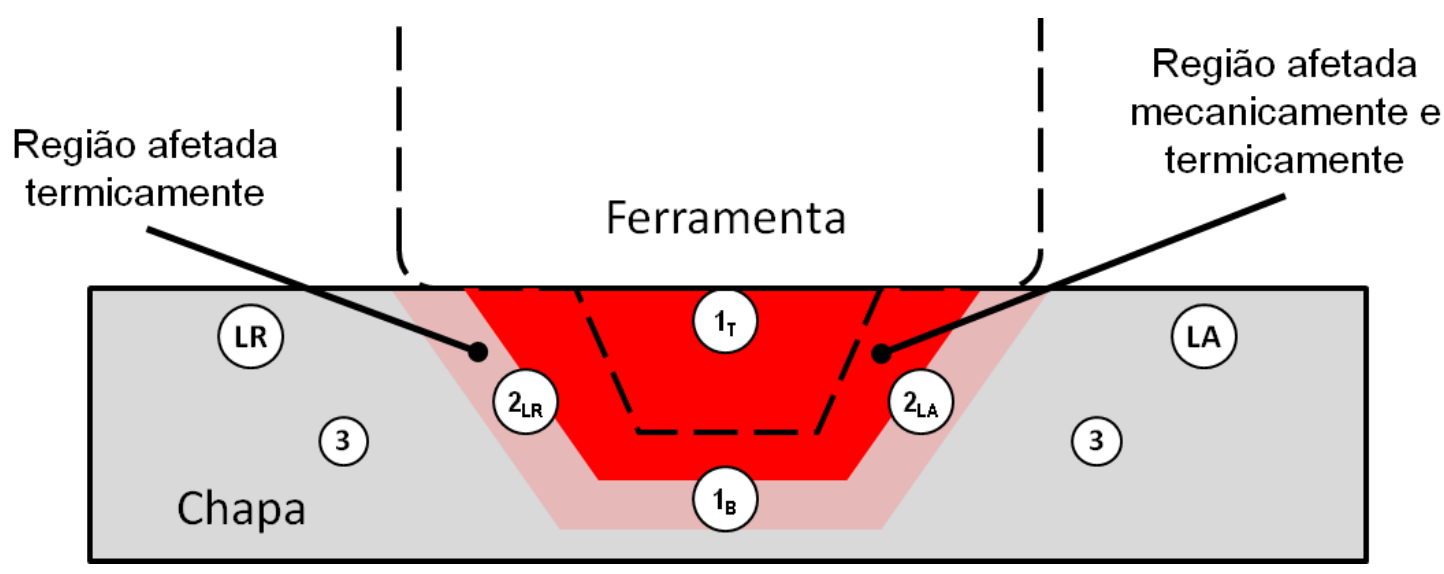

Figura 9-2 - Esquema para nomenclatura das regiões nas metalografias.

Para uma correta caracterização das regiões processadas é importante conhecer a distribuição das temperaturas que ocorreram durante o processamento das chapas. Se a temperatura $\beta$-transus foi superada é esperado um tipo de estrutura final após o resfriamento, se esta temperatura não foi atingida um outro tipo de estrutura será resultante conforme apresentado pelos estudos de Dabrowski (DĄBROWSKI, 2011a, 2011b). A Figura 9-3 apresenta a simulação em elementos finitos da distribuição das temperaturas médias encontradas durante 0 processamento para todo o conjunto ferramenta-dispositivo-peça. Esta simulação visou identificar a distribuição das temperaturas em função da condutividade térmica dos materiais. Não foi considerado o acoplamento do fluxo de argônio, rotação e avanço da ferramenta, somente a temperatura do processamento medida durante os ensaios foi aplicada ao modelo. Para esta simulação uma temperatura de processo de $1000.44^{\circ} \mathrm{C}$ foi aplicada nas superfícies da ferramenta (pino e ombro) que estavam contato com o material. A temperatura considerada para a simulação é a média dos valores da Tabela 8-2 e as propriedades do material da chapa foram retirados da literatura (ASM ALLOY CENTER DATABASE, 2015). A simulação foi executada no Instituto Mauá de Tecnologia com o módulo de simulação do software Solidworks. Todos os demais parâmetros da simulação térmica e valores dos materiais estão apresentados no Anexo L. É possível verificar uma grande diferença de camadas de temperaturas ao longo da espessura da chapa devido ao fato das ligas de titânio não 
apresentarem boa condução de calor (LEYENS; PETERS, 2003). A simulação apresentada na Figura 9-3 resultou em valores próximos aos valores simulados por Buffa (BUFFA et al., 2013), portanto considerados apropriados para discussão dos resultados das microestruturas.

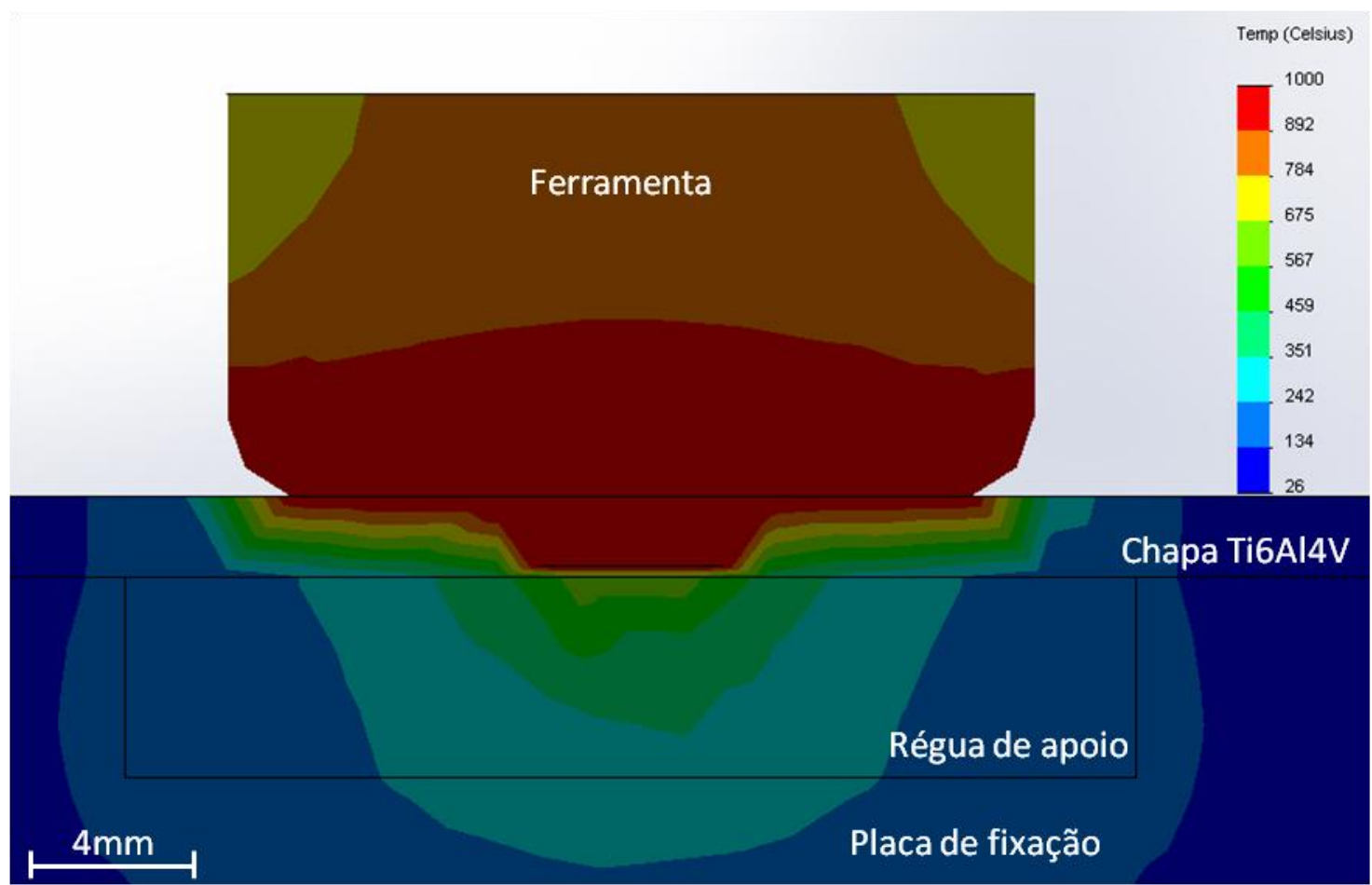

Figura 9-3 - Simulação em elementos finitos da distribuição das temperaturas médias para o conjunto ferramenta-dispositivo-peça.

A Figura 9-4, derivada da mesma simulação, apresenta a distribuição das temperaturas ao longo da chapa de $2 \mathrm{~mm}$. São indicadas duas regiões básicas através da linha tracejada: (a) região do material que certamente superou a temperatura de $\beta$-transus $\left(985^{\circ} \mathrm{C}\right)$ e (b) região do material que não atingiu a temperatura $\beta$-transus.
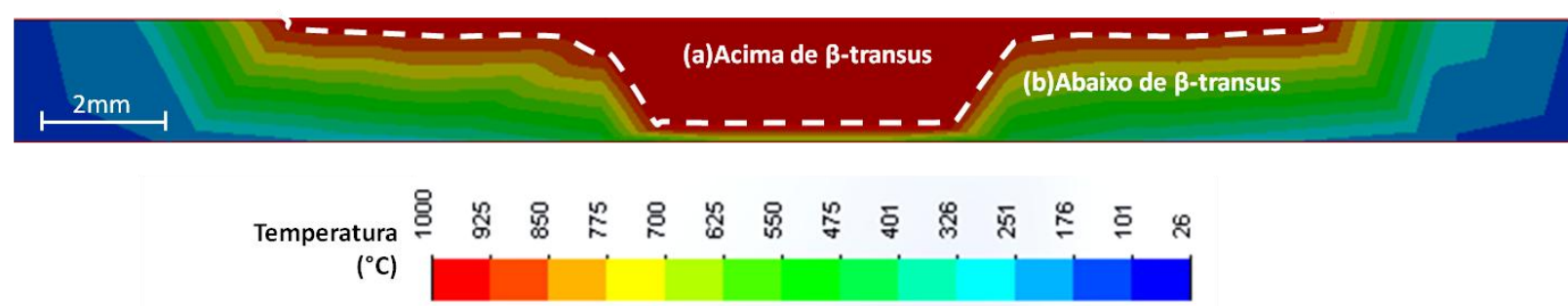

Figura 9-4 - Distribuição das temperaturas ao longo da chapa de Ti-6Al-4V. 


\section{- Metalografia:}

A Figura 9-5 apresenta a metalografia do corte na transversal da amostra processada com 1350RPM com avanço de 50mm/min. Na Figura 9-5a estão indicadas com linhas tracejadas e pontilhadas respectivamente as regiões de processamento FSP (ZTMA) e a região afetada termicamente (ZTA).

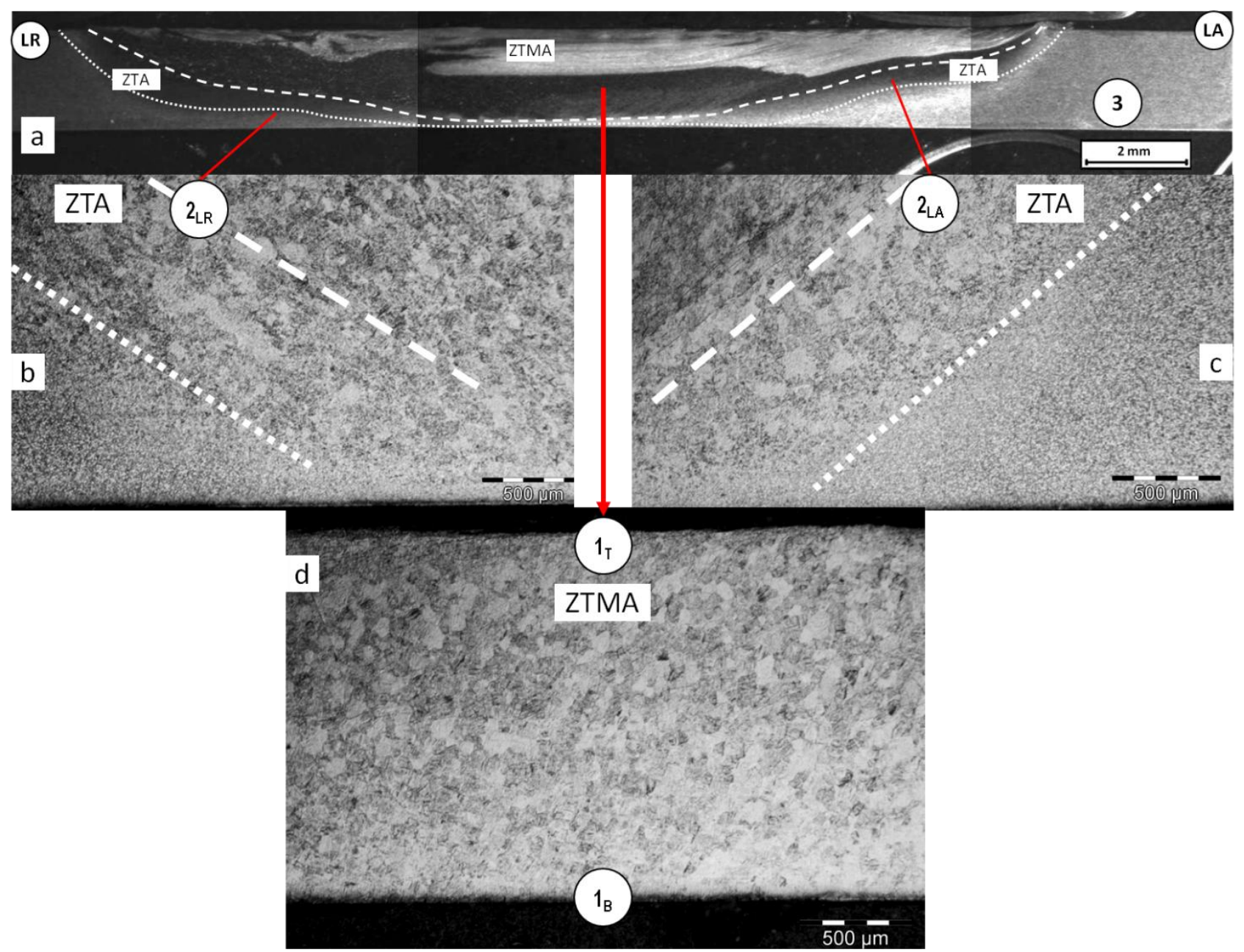

Figura 9-5 - (a) Metalografia ótica do corte na transversal da amostra processada com 1350RPM com avanço de $50 \mathrm{~mm} / \mathrm{min}$, (b) ZTA no lado de retrocesso, (c) ZTA no lado de avanço e (d) região de processamento.

Na Figura 9-5 é possível identificar mais de um tipo de microestrutura resultante do processamento na chapa. 

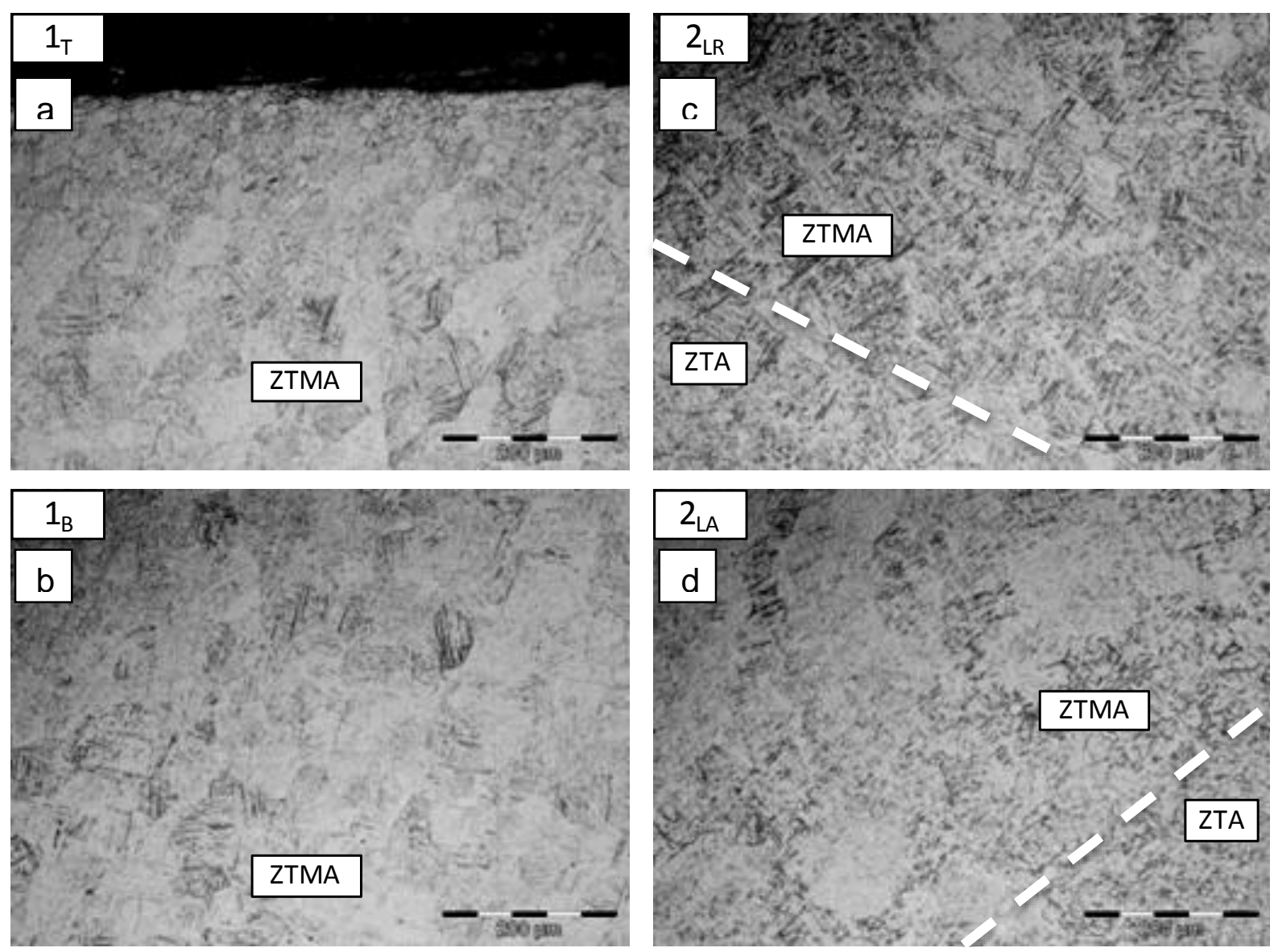

Figura 9-6 - Metalografia ótica do corte na transversal da amostra processada com 1350RPM com avanço de 50mm/min, (a) ZTMA no topo, (b) ZTMA na base, (c) transição ZTMA/ZTA no lado de retrocesso e (d) transição ZTMA/ZTA no lado de avanço.

A Figura 9-5d apresenta a região central que sofreu diretamente a ação da ferramenta (ZTMA), portanto esta região passou por um processo de deformação plástica em uma temperatura acima da $\beta$-transus. A Figura 9-6a e Figura 9-6b, relativas ao topo e base da ZTMA, correspondem a uma estrutura martensitica formada a partir de um resfriamento em temperatura acima da $\beta$-transus. A Figura 9-5b e Figura 9-5c apresentam microestruturas do tipo globular finamente dispersa na região abaixo da linha branca pontilhada relativo ao material de base da chapa. Entre as duas linhas brancas está situada a região afetada somente pela temperatura (ZTA) constituída de microestruturas bimodais dependendo do grau de afastamento da região deformada plasticamente: lamelar (Figura 9-6c e Figura 9-6d) e globular (à esquerda na Figura 9-5b e à direita na Figura 9-5c). Nesta região as características das microestruturas são relativas a um aquecimento abaixo da $\beta$ transus com posterior resfriamento. As microestruturas observadas se apresentaram em acordo com outros resultados publicados na literatura para titânio $\alpha-\beta$ 
(LÜTJERING; WILLIAMS, 2007; MOTYKA et al., 2007; WOLK, 2010; LIVINGSTON, 2011; PILCHAK et al., 2011; BUFFA et al., 2013).

As metalografias óticas para as demais condições são apresentadas no Anexo M. Todas apresentaram as mesmas estruturas características presentes na amostra da Figura 9-5. Em função da temperatura atingida no processo verificada na Tabela 8-2 e da taxa de resfriamento sofridas pela chapa (Tabela 8-3), eram esperados os mesmos tipos de microestruturas finais: Martensitica (lamelar fina) formada a partir de $\beta$-transus para região central da solda, e, bimodal (lamelar e globular grossas) na região de transição para o material de base. Para esta tese o processamento na ZTMA foi efetuado sempre em uma temperatura acima da $\beta$-transus. $O$ fator preponderante para esta constatação foi o fato de se empregar rotações muito elevadas, acima de 500RPM, em outros estudos (LIVINGSTON, 2011; BUFFA et al., 2013) relatam microestruturas com características de temperatura inferior à $\beta$ transus que apresentam características diferentes das encontradas aqui.

Para uma melhor visualização das estruturas formadas nas regiões indicadas pela Figura 9-5, imagens com microscopia eletrônica de varredura (MEV) foram efetuadas área do material de base $(\mathrm{MB})$, zona termicamente afetada (ZTA) e na região processada afetada termomecanicamente (ZTMA).

As microestruturas na região processada ZTMA são caracterizadas por uma estrutura $\beta$ totalmente transformada, Figura 9-7. Isto sugere que as temperaturas de pico na região processada excederam a temperatura $\beta$-transus durante 0 processamento, a transformação da fase $\beta \rightarrow \alpha+\beta$ ocorreu durante a fase de resfriamento à taxa de $1.59^{\circ} \mathrm{C} / \mathrm{s}$ conforme apresentado na Tabela 8-3. A estrutura é similar àquelas encontradas por Dabrowski (DĄBROWSKI, 2011b) em taxas de resfriamento de 0.94 a $2.5^{\circ} \mathrm{C} / \mathrm{s}$. A transformação da fase $\beta$ para a resultou na formação de colônias de agulhas de fase $\alpha$, Widmannstatten, formados nos contornos de grão $\beta$ e pelo interior dos grãos da fase $\beta$ ( $\alpha$ acicular). Uma região afetada termomecanicamente não foi claramente observada no presente estudo, embora esse comportamento seja frequente na literatura (ZHANG et al., 2008a; LIU et al., 2010; SU; WANG; MISHRA, RAJIV S.; et al., 2013). Supõe-se que o pico de temperatura nesta região seria suficientemente elevado para que ocorresse a transformação de fases $(\alpha+\beta \rightarrow \beta \rightarrow \alpha+\beta)$ devido ao ciclo térmico durante o FSP, sobrepujando transformações características por deformação da região afetada termomecanicamente (Su et al, 2013). 


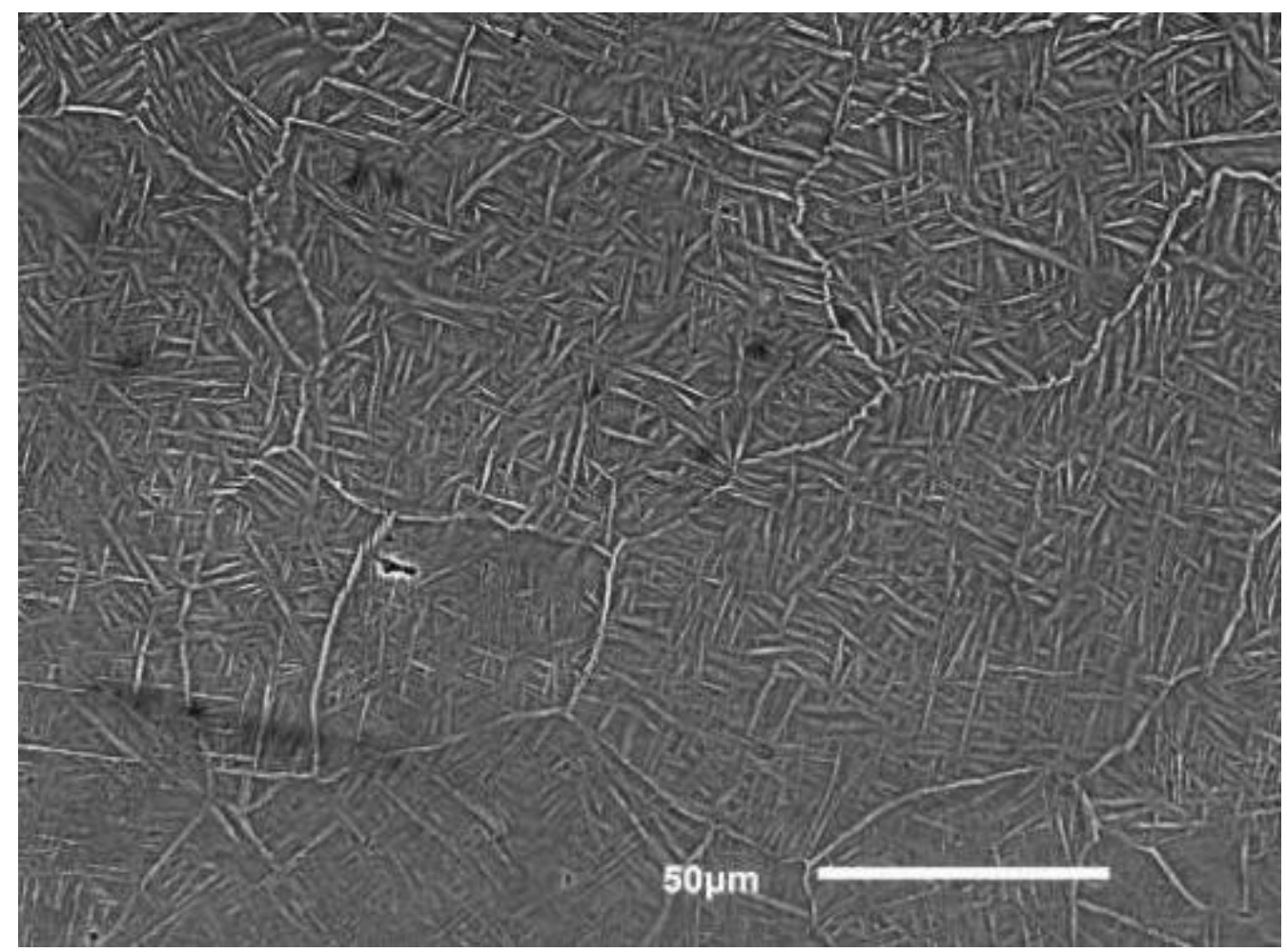

Figura 9-7 Imagem de elétrons retoespalhados da ZTMA.

Adicionalmente regiões com estrutura equiaxial de grãos (a globular) foram observadas na região de processamento ZTMA, Figura 9-8 e Figura 9-9. Em geral estas regiões foram identificadas ao longo dos limites entre as ZTMA e ZTA (linhas tracejadas na Figura 9-5b-c) onde a predominância dos efeitos da temperatura $\beta$ transus foi menor. Estudos (DEHGHAN-MANSHADI; DIPPENAAR, 2012) revelaram que deformação a quente no campo de fase $\beta$ acelera a transformação da fase $\beta$ em fase $\alpha$, presumivelmente devido a um aumento no número de locais de nucleação para a fase a conforme modelado por Seshacharyulu em seu estudo de deformação a quente da liga Ti-6Al-4V (SESHACHARYULU et al., 2000). Observa-se que a deformação aumenta a fração de volume de grãos a globulares que se formaram ao longo dos contornos de grão iniciais da fase $\beta$.

Não foram constatadas diferenças nas microestruturas resultantes entre os lados de avanço (LA) e retrocesso (LR) da ferramenta. Em função da utilização de rotações da ferramenta elevadas (acima de 500RPM), a possível influência do parâmetro da velocidade de avanço foi sobrepujada. Conforme mencionados nos estudos de Su et al (SU; WANG; MISHRA, RAJIV S; et al., 2013), Kitamura (KITAMURA et al., 2013), Zhang (ZHANG et al., 2008b; ZHANG; ZHANG, 2009) a 
velocidade de avanço possui influência na deformação plástica em temperaturas abaixo da $\beta$-transus, porém esta influência pode vir a ser eliminada devido efeitos térmicos oriundos da elevação da temperatura causada pela alta rotação da ferramenta (Su et al, 2013).

Outra hipótese para a existência destas regiões com estrutura equiaxial de grãos a globular, é que devido ao movimento de mistura do material, provocado pela rotação e avanço da ferramenta, o material que está na superfície, ou logo abaixo dela, pode ser movimentado para baixo. A taxa de resfriamento perto da superfície da peça é maior, por estar em contato com o ar e com o fluxo de argônio, portanto a estrutura já está em uma fase de transformação adiantada em relação ao núcleo. Segundo os estudos de Dabrowski (DĄBROWSKI, 2011a, 2011b) e Surand (SURAND, 2013), uma condição para a existência desta fase a globular $\left(\alpha_{p n}\right)$ na região da ZTMA observada na Figura 9-8, seria o resfriamento a partir de uma temperatura abaixo de $995^{\circ} \mathrm{C}$. A Figura 2-21b e Figura 2-21c (DĄBROWSKI, 2011a) para taxas de resfriamento de $3,2^{\circ} \mathrm{C} / \mathrm{s}$ e $0,9^{\circ} \mathrm{C} / \mathrm{s}$ respectivamente, apresentam estruturas a globular similares a estas observadas na Figura 9-8 e Figura 9-9, cuja taxa de resfriamento ficou próxima de $1.59^{\circ} \mathrm{C} / \mathrm{s}$.

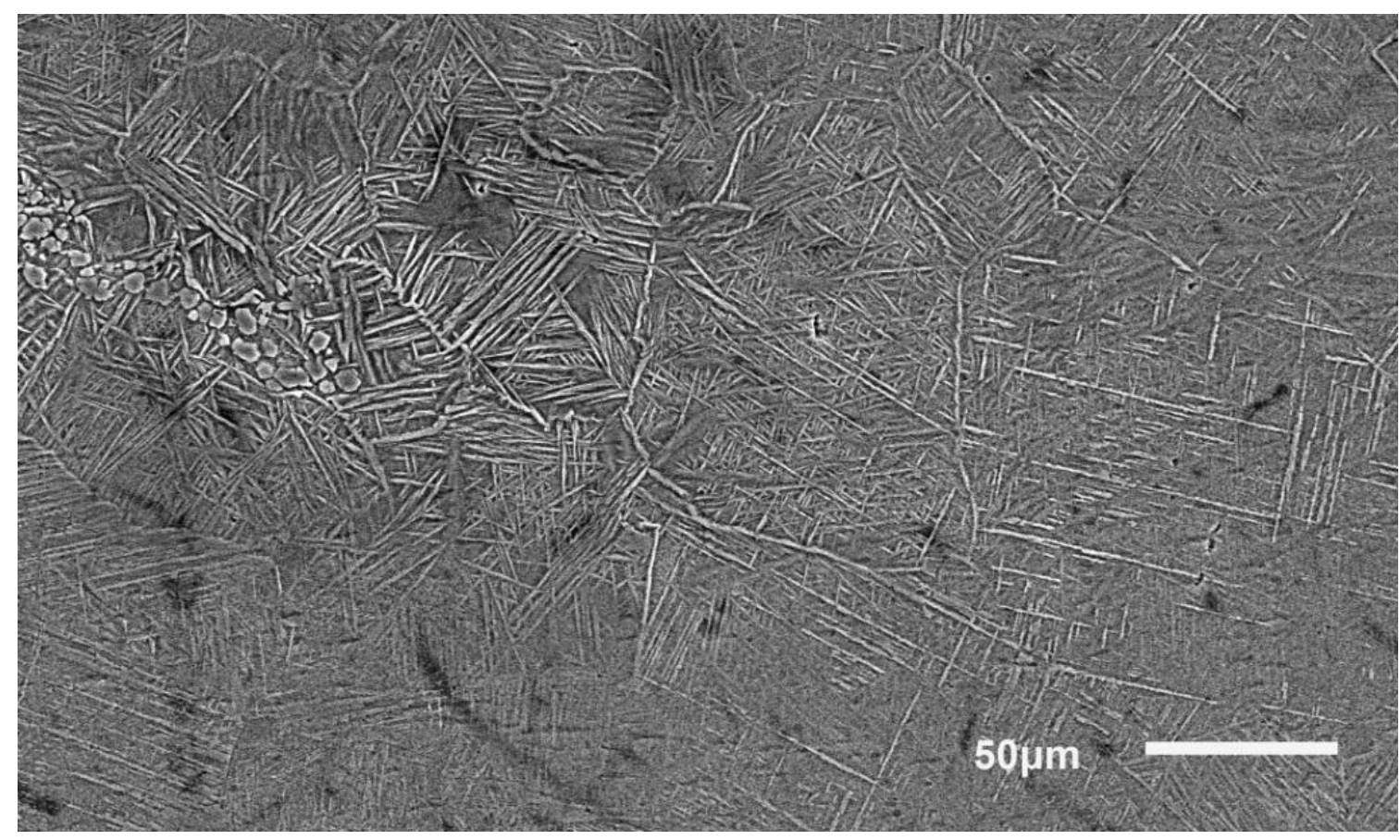

Figura 9-8 - Imagem de elétrons retoespalhados da ZTMA com formação de a globular. 


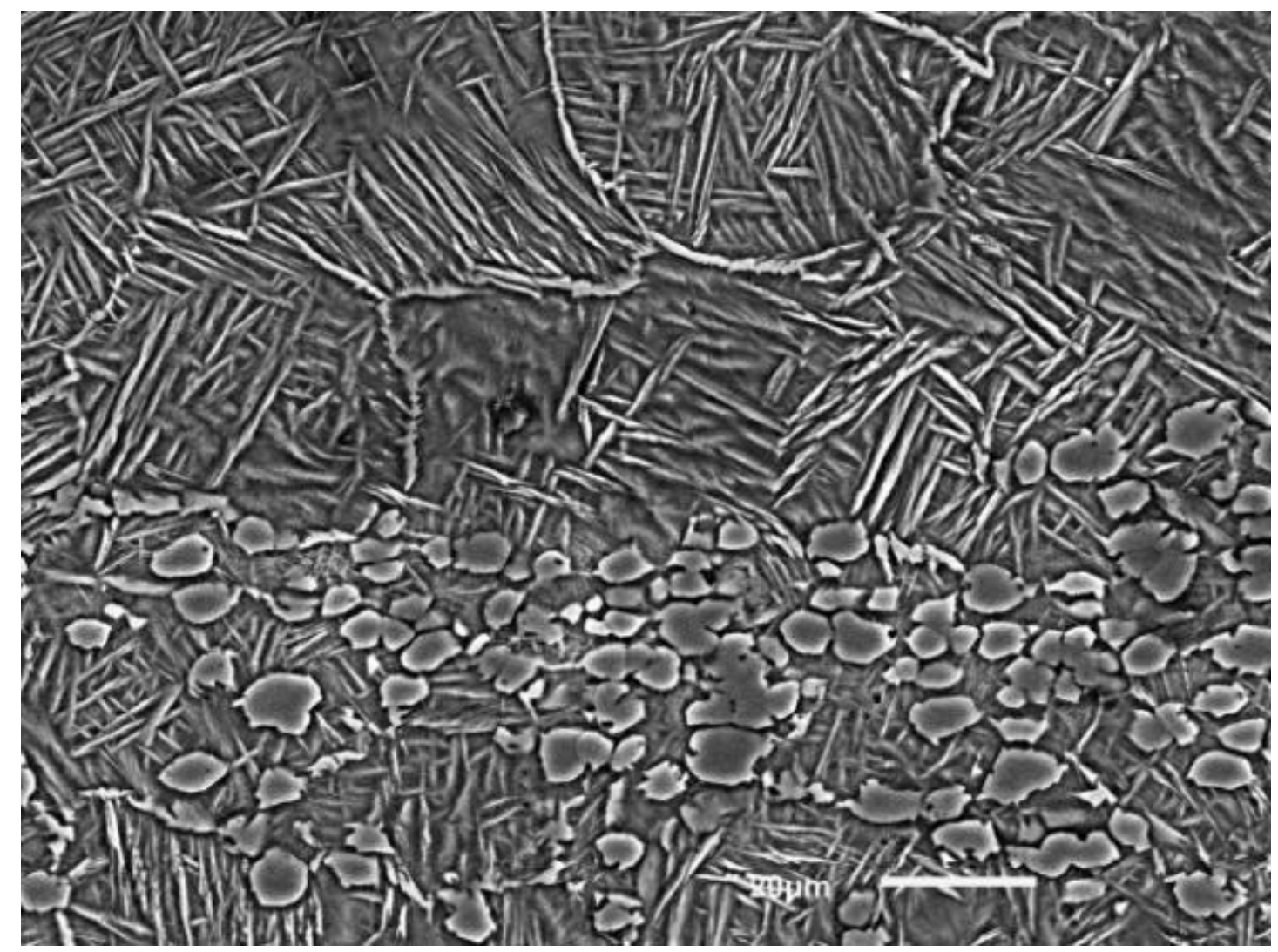

Figura 9-9 Imagem de elétrons retoespalhados ampliada, de outra região de processamento com formação de a globular.

O metal de base apresentou uma microestrutura bimodal consistindo nas fases $\alpha$ e $\beta$ (Figura 9-10).

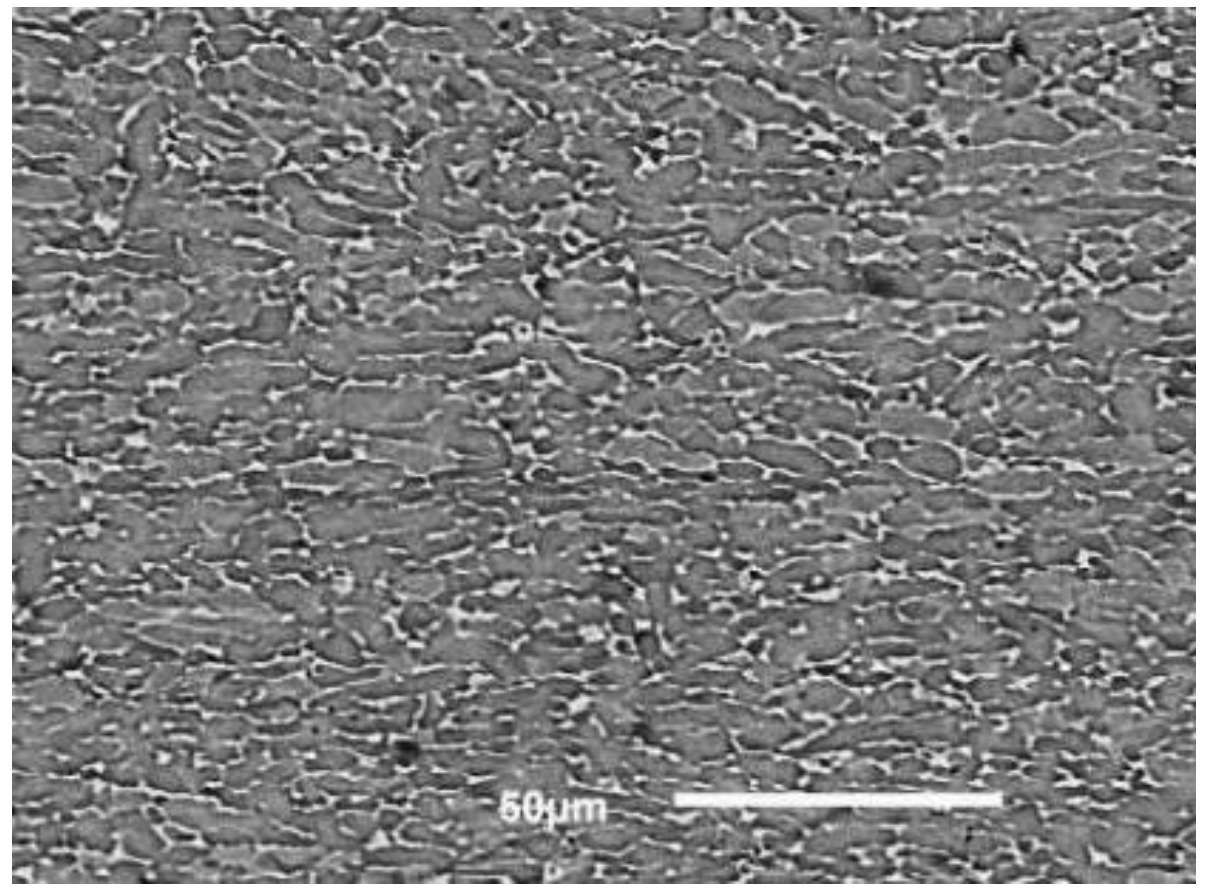

Figura 9-10 Imagem de elétrons retoespalhados da região do metal de base. 
A existência desta fase a globular na ZTMA e regiões limítrofes entre a ZTMA e ZTA, portanto, pode ser explicada pelos mecanismos descritos anteriormente agindo individualmente ou em conjunto. Em resumo:

- Deformação a quente no campo de fase $\beta$ que acelera a transformação da fase $\beta$ em fase $\alpha$, devido a um aumento no número de locais de nucleação para a fase $\alpha$ globular (SESHACHARYULU et al., 2000).

- O material que está na superfície, ou logo abaixo dela, com uma estrutura em fase de transformação adiantada, resfriado a partir de uma temperatura inferior à $\beta$-transus, que devido ao movimento de mistura do processo foi deslocado para baixo nas regiões de ZTMA da peça.

Na regiões de transição entre ZTA e MB (linha tracejada na Figura 9-11) é verificada uma microestrutura com característica de temperatura inferior à $\beta$-transus (DĄBROWSKI, 2011a), com uma taxa de resfriamento diferente daquela observada para a região ZTMA, provavelmente causado pela não homogeneidade de resfriamento do material da base de fixação, que pode demorou um tempo maior para resfriar devido à suas dimensões (placa com largura e comprimento de $300 \mathrm{~mm}$ e $30 \mathrm{~mm}$ de espessura).

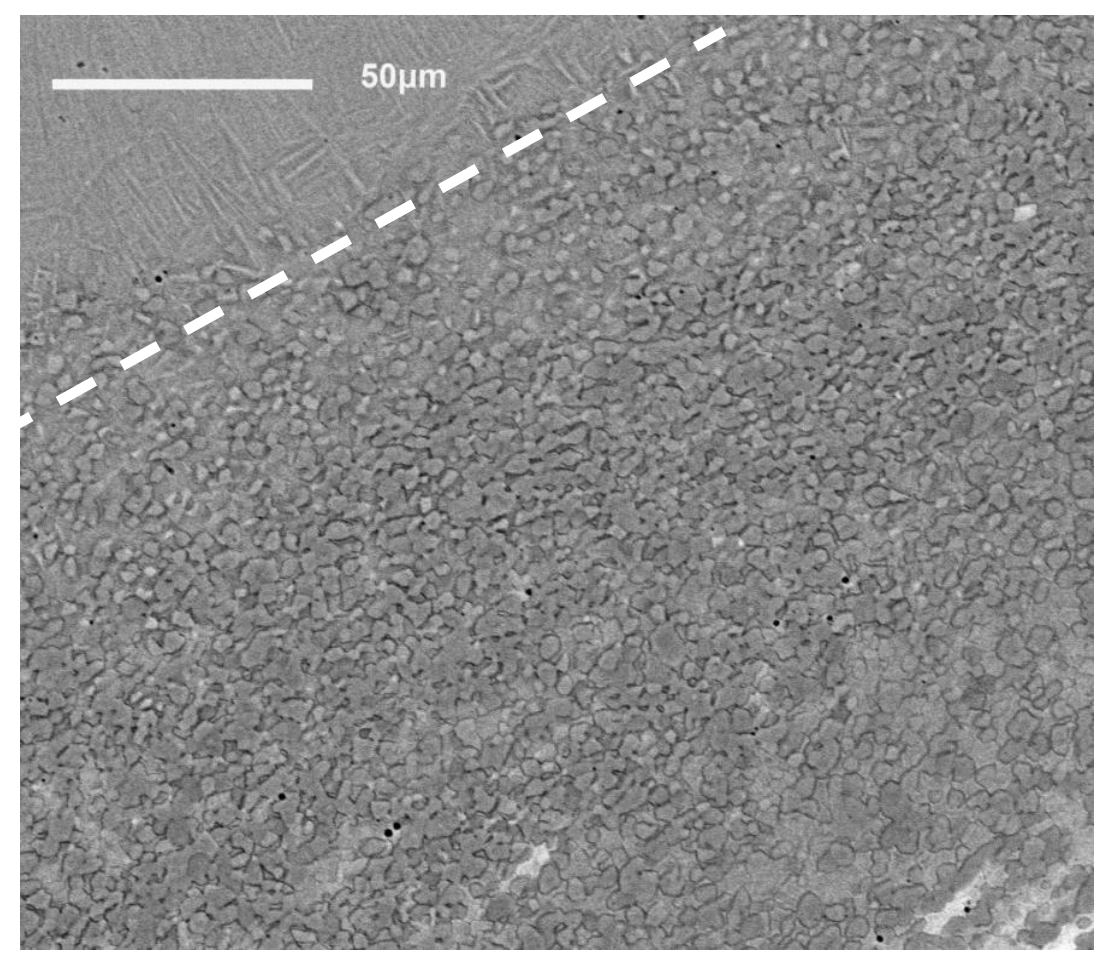

Figura 9-11 Imagem de elétrons retoespalhados da região ZTA. 
A Figura 9-12 mostra imagens de elétrons retroespalhados e EDS (energy dispersive $x$-ray detector) na amostra processada com 1500RPM e avanço de $50 \mathrm{~mm} / \mathrm{min}$, onde se confirma a existência de fragmentos de tungstênio. Embora a ferramenta fabricada com a liga de W-La tenha apresentado um melhor desempenho durante o processamento, o desgaste da ponta ainda provocou inclusões de W na região da solda. Problema semelhante ao encontrado nos testes acima foi relatado por Pilchak et al (PILCHAK et al., 2011).
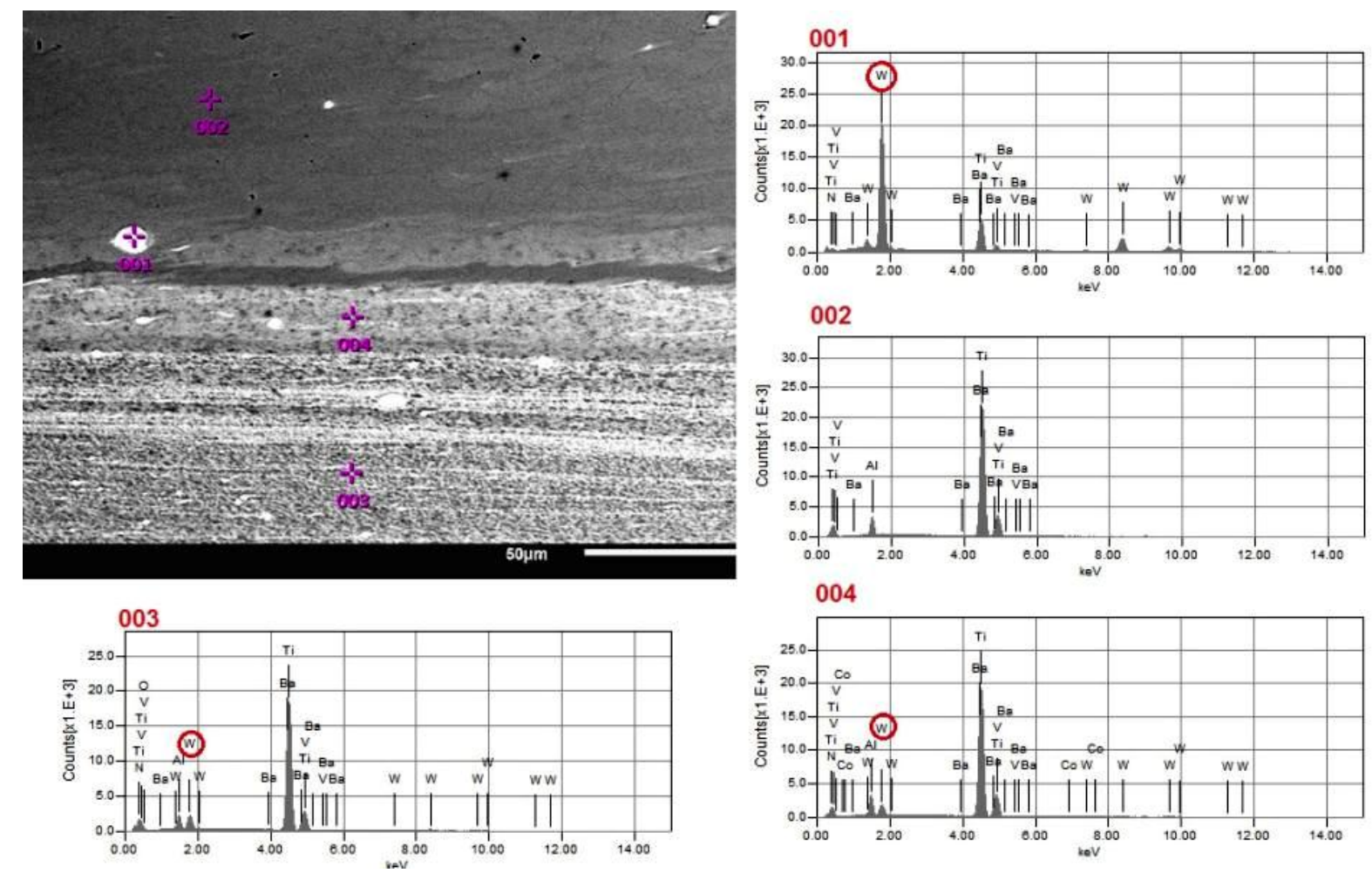

Figura 9-12 Imagem de elétrons retroespalhados e EDS na amostra processada com 1500RPM e $50 \mathrm{~mm} / \mathrm{min}$.

\subsection{Microdureza no ensaio principal}

O ensaio de microdureza foi realizado com um equipamento da Shimadzu com carga de $5 \mathrm{~N}$ (HV0.5) aplicada por 15 segundos. Foram levantados os perfis de microdureza para cada condição de ensaio da tabela Tabela 13-2 do Anexo K. As Figura 9-14 até Figura 9-22 apresentam o resultado das medições efetuadas. A tomada da medição foi efetuada ao longo da transversal da região processada e o centro dos gráficos foi alocado no centro da chapa como mostra a Figura 9-13. 


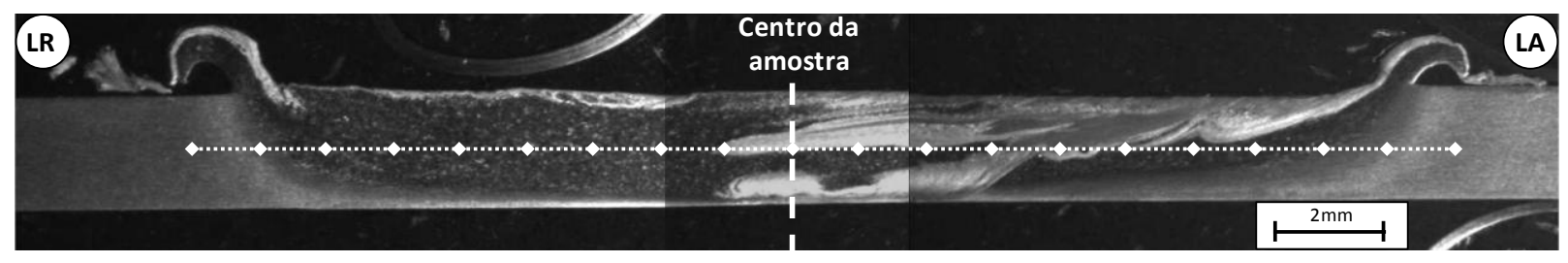

Figura 9-13 - Esquema de medição de durezas nas amostras embutidas, exemplo para condição B.

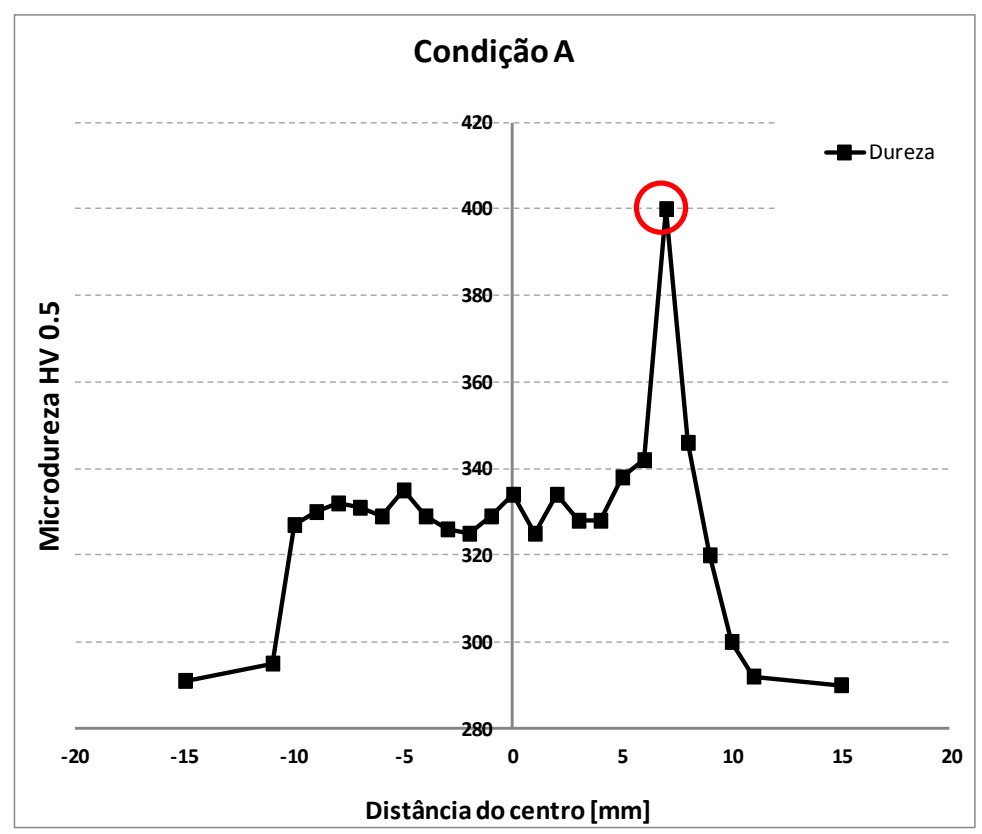

Figura 9-14 - Perfil de microdureza da chapa FSP na condição 1350RPM e 50mm/min de avanço.

Conforme nos afastamos do ponto central da chapa podemos notar a coerente redução dos valores de dureza, que distantes de aproximadamente quinze milímetros já se encontram na região que não sofreu processamento FSP. Neste ponto a microdureza resultante acompanha a situação proveniente do processo de fabricação anterior da chapa no valor de 290 a 300 HV0.5. Na Figura 9-14 é possível verificar um ponto marcado com o círculo vermelho onde a dureza se apresentou muito acima dos demais. Conforme evidenciado na Figura 9-12 partículas da ferramenta se desprenderam durante o processo, este alto valor de dureza é devido a uma medição na região de um fragmento da ferramenta (verificado posteriormente). 


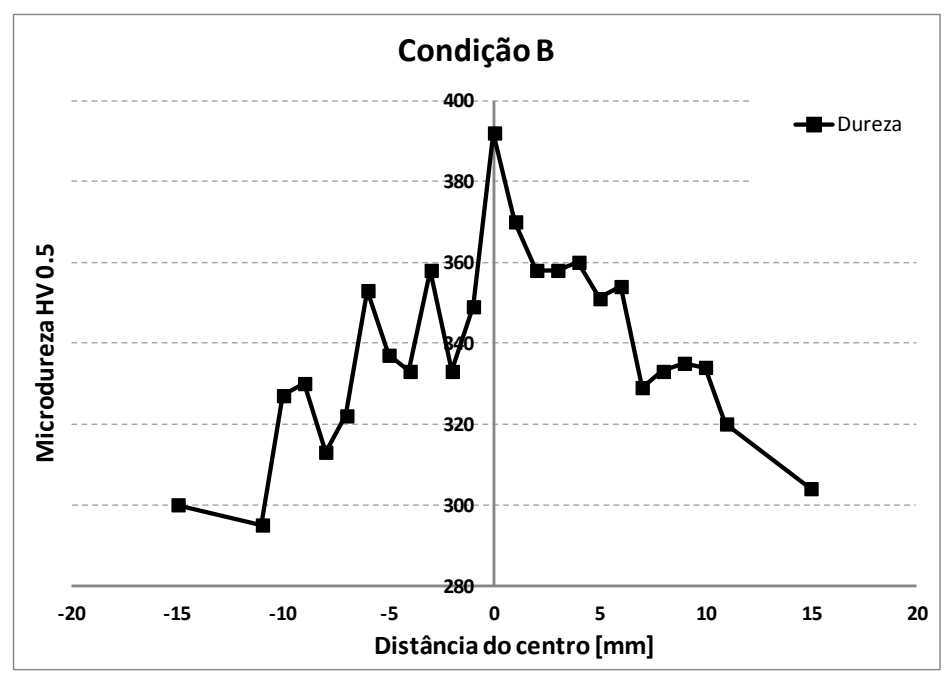

Figura 9-15 - Perfil de microdureza da chapa FSP na condição 1350RPM e 60mm/min de avanço.

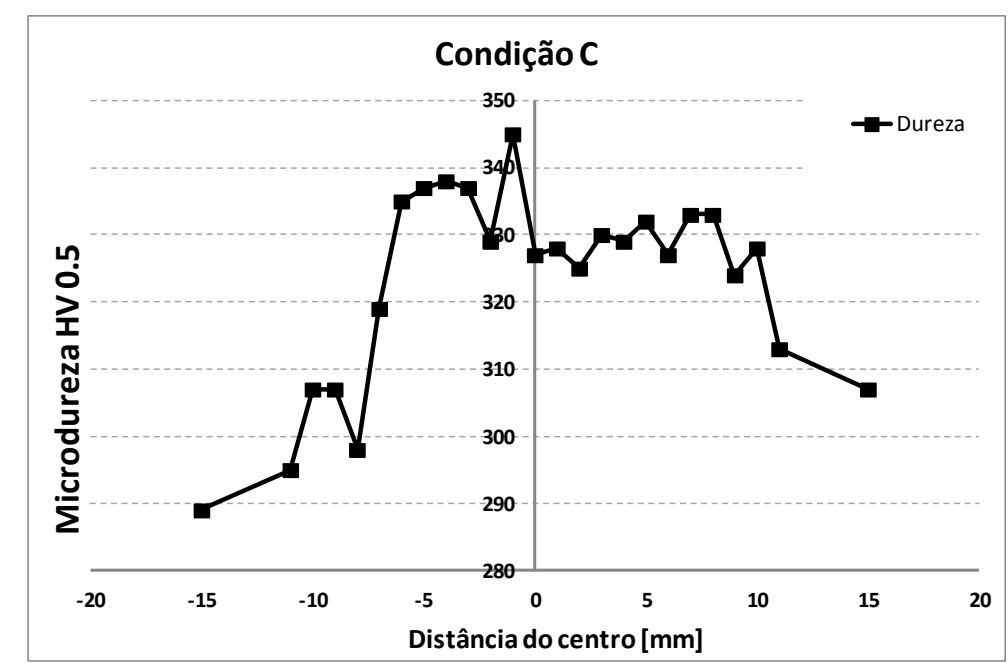

Figura 9-16 - Perfil de microdureza da chapa FSP na condição 1350RPM e 70mm/min de avanço.

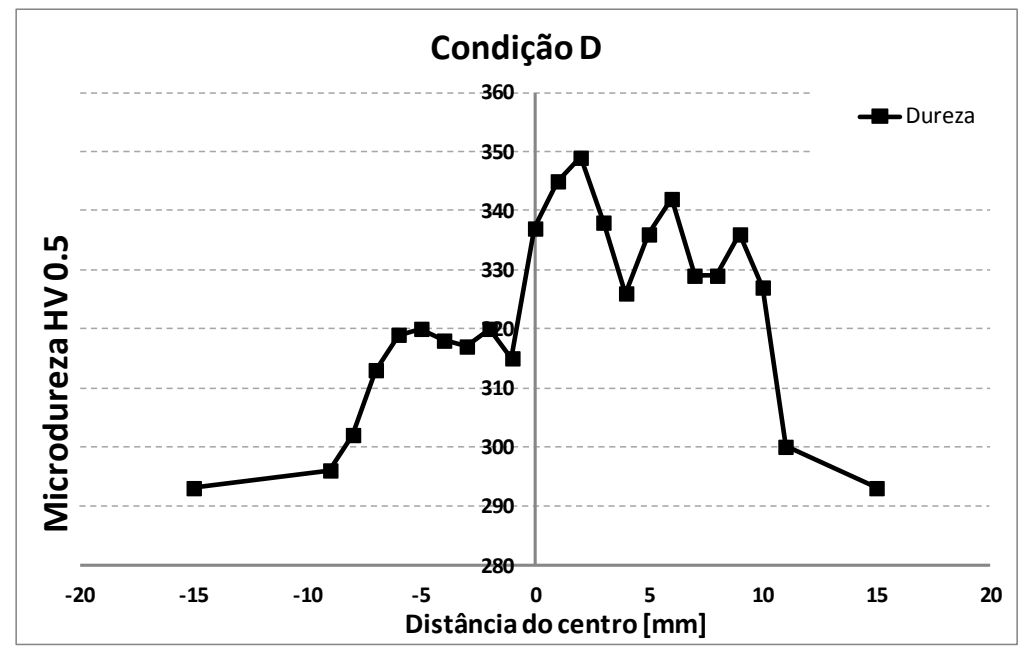

Figura 9-17 - Perfil de microdureza da chapa FSP na condição 1500RPM e 50mm/min de avanço. 


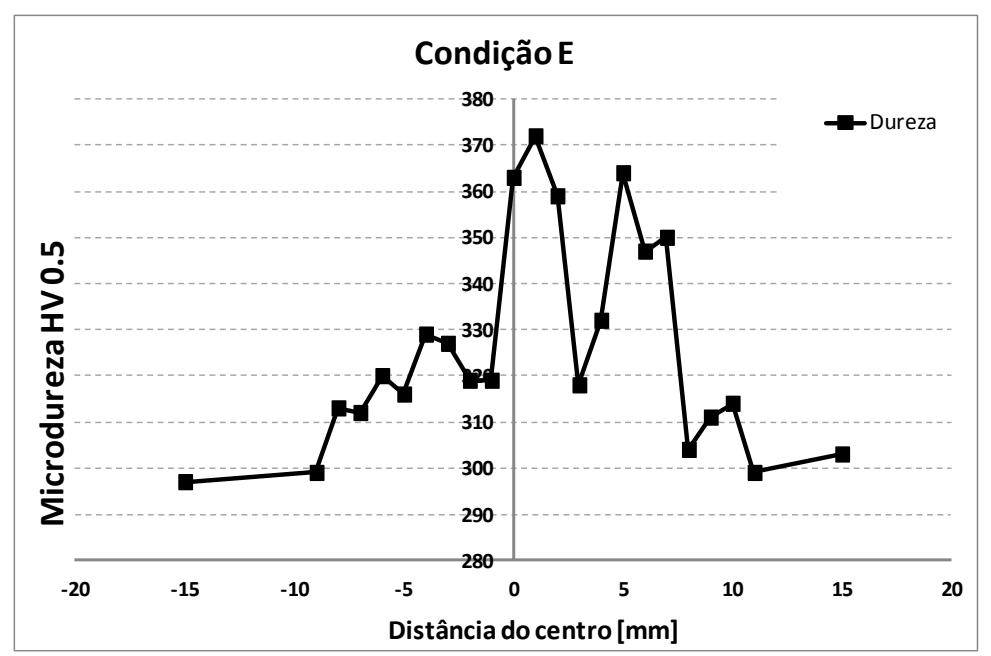

Figura 9-18 - Perfil de microdureza da chapa FSP na condição 1500RPM e 60mm/min de avanço.

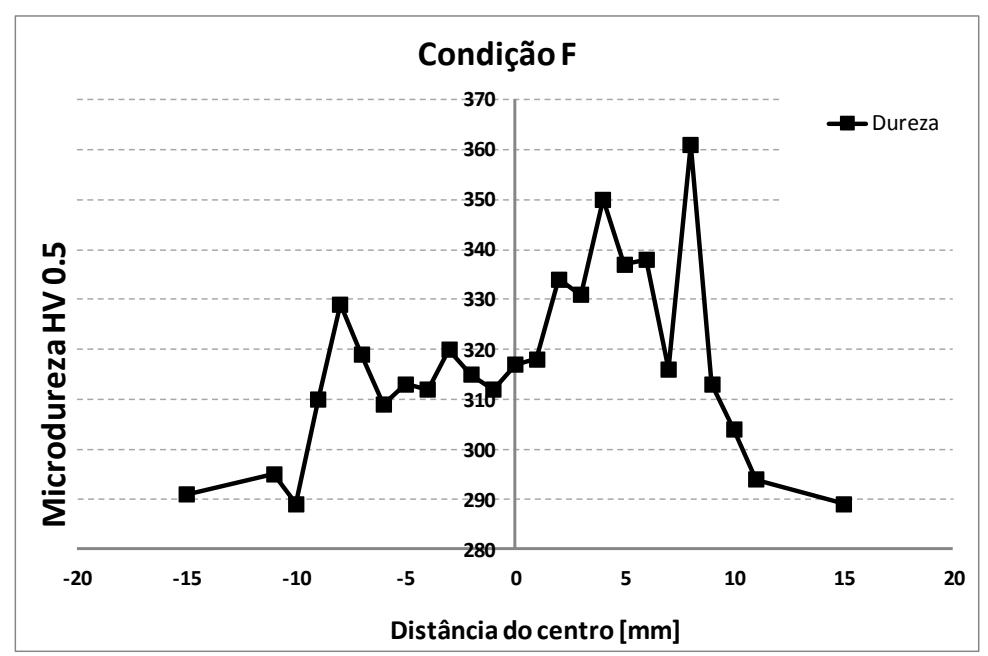

Figura 9-19 - Perfil de microdureza da chapa FSP na condição 1500RPM e 70mm/min de avanço.

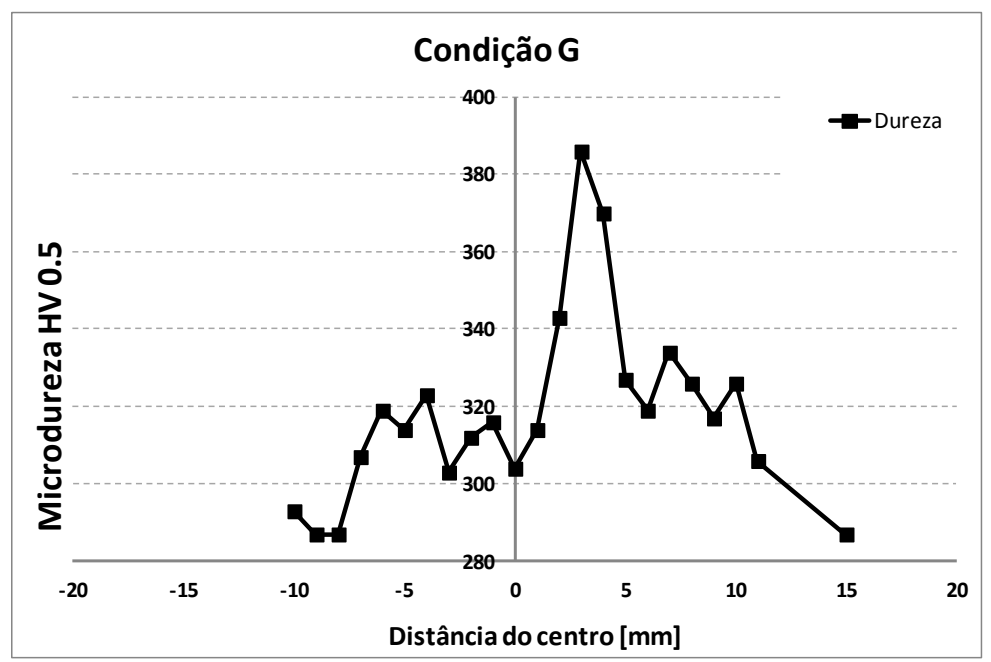

Figura 9-20 - Perfil de microdureza da chapa FSP na condição1650RPM e 50mm/min de avanço. 


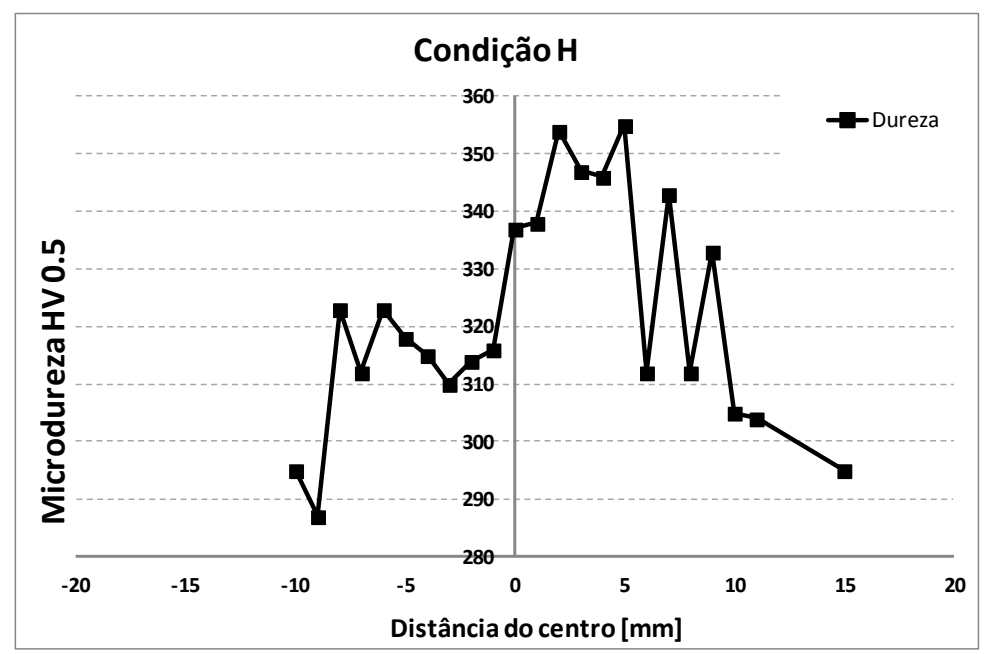

Figura 9-21 - Perfil de microdureza da chapa FSP na condição 1650RPM e 60mm/min de avanço.

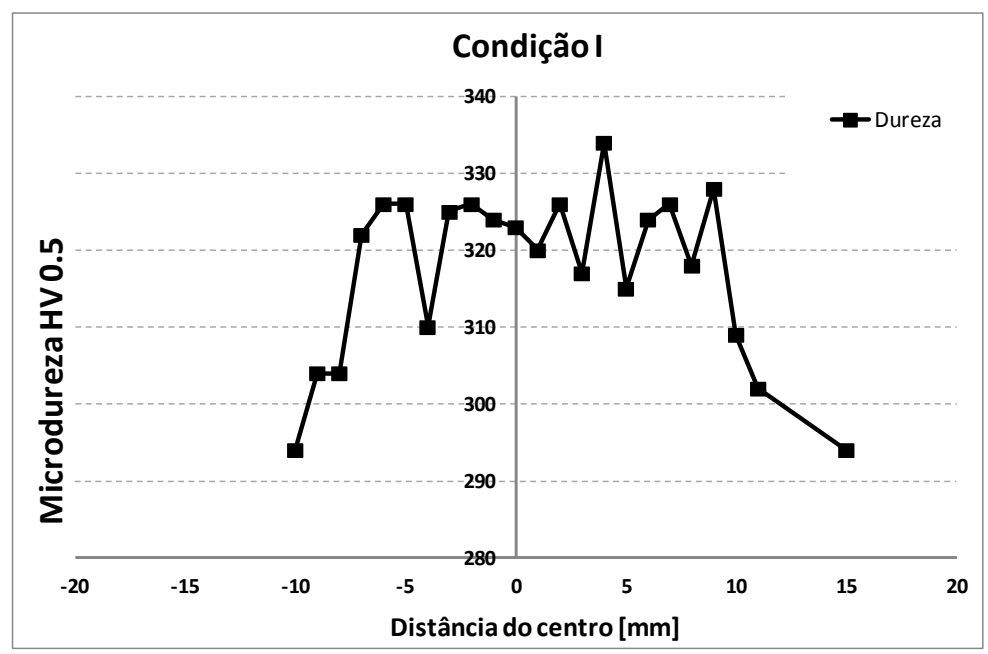

Figura 9-22 - Perfil de microdureza da chapa FSP na condição 1650RPM e 70mm/min de avanço.

A avaliação dos gráficos de microdureza mostra uma diminuição de valores na região central da amostra em função do aumento da rotação em RPM da ferramenta, e pouca interação com o avanço de processamento. Para confirmação desta afirmação foi executado um estudo de análise de variância dos resultados obtidos em função dos parâmetros empregados. A Tabela 9-1apresenta os resultados da análise de variância da microdureza em função da rotação e avanço da ferramenta usados no processamento com um intervalo de confiança (IC) de $95 \%$.

Tabela 9-1 Tabela de Análise de Variância para Microdureza

\begin{tabular}{ccccc}
\hline Parâmetro & Soma & Méd-quad & F & valor-p \\
\hline S (RPM) & 985499 & 985499 & 4456.89 & $7.598 \mathrm{E}-10$ \\
$\mathbf{f}(\mathbf{m m} / \mathbf{m i n})$ & 2422 & 2422 & 10.952 & 0.01622 \\
S:f & 7412 & 7412 & 33.520 & 0.001162 \\
\hline
\end{tabular}


Portanto para o caso da microdureza a rotação possui a maior influência no resultado final, e como pode ser verificado na Figura 9-23 as maiores rotações provocaram os menores valores de dureza.

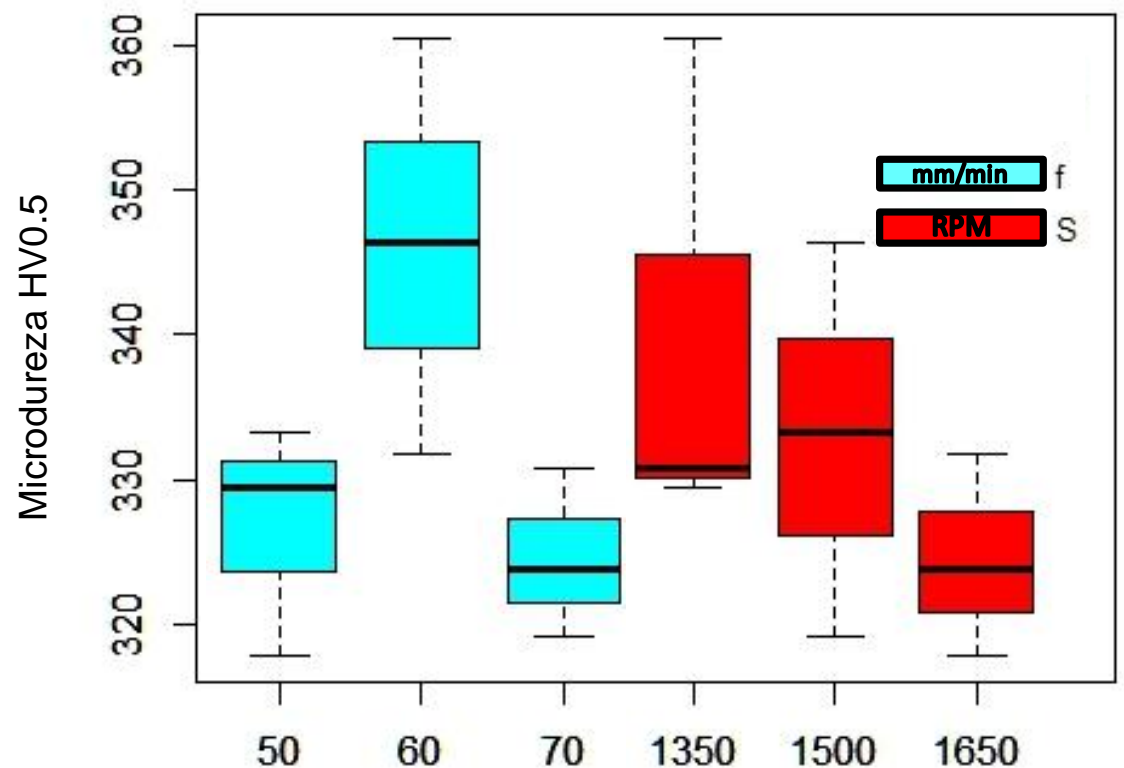

Figura 9-23 - Relação de dependência da microdureza em função das variáveis rotação $S$ e avanço f.

A interação entre os parâmetros $S$ e f (rotação e avanço) também se mostra significativa. Na Figura 9-24, que apresenta a variação da microdureza em função da interação de $\mathrm{S}$ e f, podemos observar melhor os resultados. É possível verificar que, a combinação da maior rotação com o menor avanço provoca a menor condição de microdureza nos corpos de prova ensaiados.

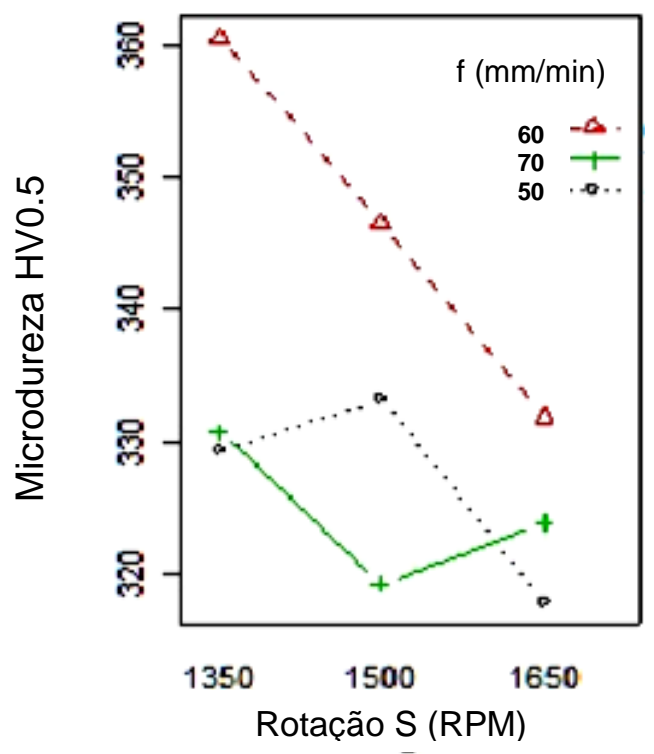

Figura 9-24 - Gráfico de Interações para microdureza em função das variáveis rotação S e avanço f. 
Para validação dos resultados da análise de variância foi verificado a normalidade da distribuição dos resíduos, ou seja, foi verificado se os valores residuais do estudo estatístico pertenciam a uma distribuição normal.

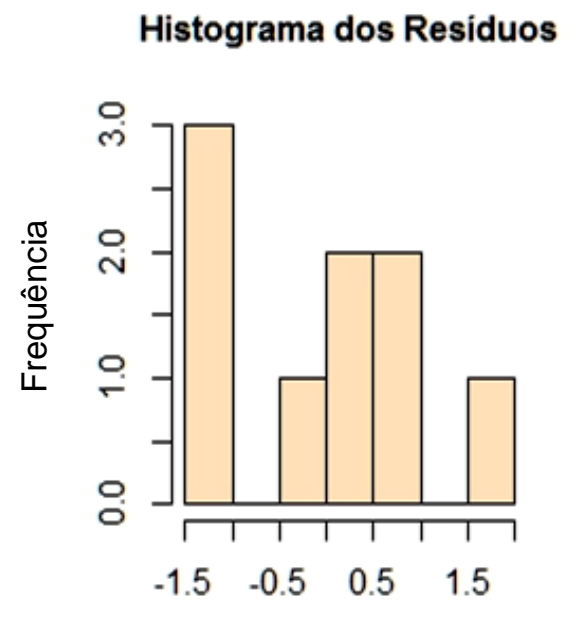

Residuos padronizados

(a)

\section{Normal Q-Q plot dos Residuos}

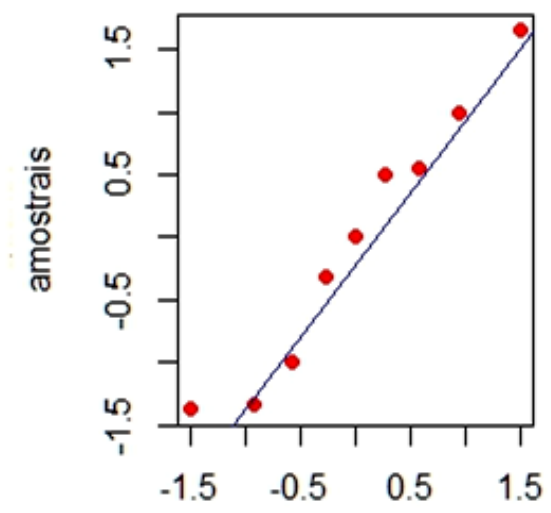

Quantis teóricos

(b)

Figura 9-25 - Avaliação dos resíduos do estudo estatístico

A Figura 9-25(a) apresenta o histograma dos resíduos e a Figura 9-25(b) apresenta a plotagem dos resíduos dos valores analisados no gráfico quantil-quantil que mostra a boa adequação dos resíduos a uma distribuição normal (reta preta).

\subsubsection{Microdureza na camada superficial}

Para verificação da existência de uma camada $\alpha$ endurecida foram executadas microdurezas com carga de $1 \mathrm{~N}(\mathrm{HV}, 1)$ aplicadas por 10 segundos no microdurômetro Shimadzu (Erro! Fonte de referência não encontrada.). As edições foram executadas a partir da superfície processada das amostras como mostrado na Figura 9-26b. Foram executadas 13 medições iniciando a $0.025 \mathrm{~mm}$ da superfície e terminando em aproximadamente $1 \mathrm{~mm}$.

A Figura 9-26a apresenta o perfil de microdureza superficial da chapa FSP na condição 1350RPM e $50 \mathrm{~mm} / \mathrm{min}$ de avanço. Os valores apresentados no gráfico são as médias de três medições para cada ponto, o desvio padrão para as medições da Figura 9-26a ficou em $+/-5 \mathrm{HV} 0,1$. A partir de $0.3 \mathrm{~mm}$ a dureza encontrada não apresenta variações extremas (dureza de núcleo), se mostrando com a média de aproximadamente $330 \mathrm{HV} 0.1$. É possível notar uma camada de aproximadamente 
0.15mm com dureza mais elevada (em torno de 390HV0.1, diferença de 60HV0.1). Esta não homogeneidade na camada superficial é provavelmente resultado de um resfriamento brusco à uma taxa muito acima da experimentada pelo restante da chapa. Em seu trabalho Dabrowski (DĄBROWSKI, 2011b) relata durezas maiores para condições de taxa de resfriamento maiores. Outra hipótese é a contaminação por oxigênio na camada superficial da chapa devido ao aumento da temperatura (formação de $\mathrm{TiO}_{2}$ ). Segundo diagrama de Ellinghan $\mathrm{TiO}_{2}$ seria um dos primeiros óxidos a aparecer na camada superficial em função da contaminação da região processada com o oxigênio da atmosfera. A região processada em todas as amostras foi protegida com a aplicação de gás argônio em fluxo constante de $\left(0.6 \mathrm{~m}^{3} / \mathrm{h}\right)$ através de mangueiras posicionadas ao longo do dispositivo (Figura 8-6). Este método de aplicação do gás ajuda a proteger contra contaminação, porém não pode garantir efetivamente que alguma região da chapa não tenha sido contaminada, uma vez que o dispositivo do FSP não foi totalmente isolado da atmosfera. A Figura 9-26b apresenta a metalografia de uma medição (do total de três) na chapa a partir da superfície.

(a)

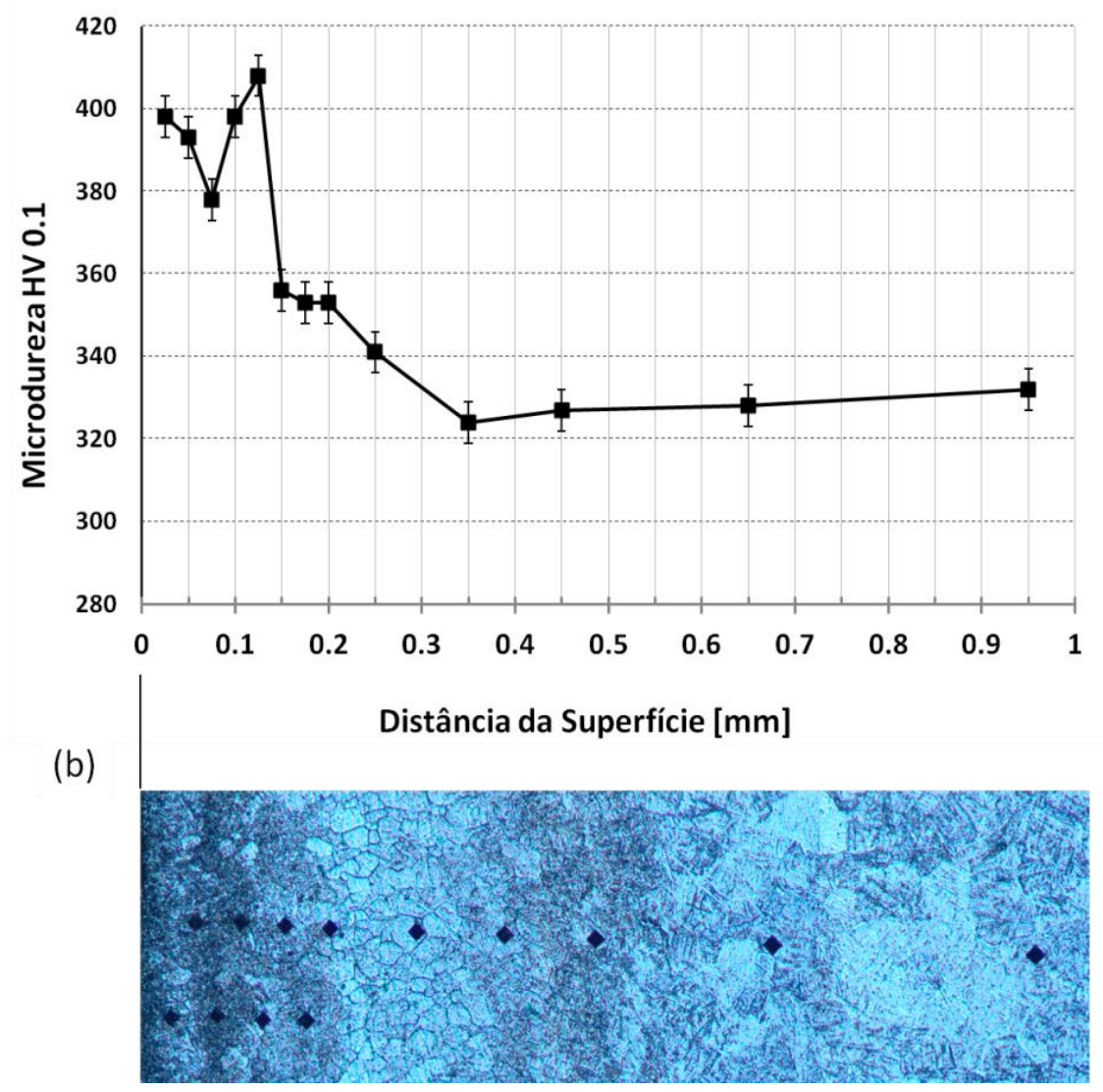

Figura 9-26 - (a) Perfil de microdureza superficial da chapa FSP na condição 1350RPM e 50mm/min de avanço, (b) metalografia de uma medição (do total de três) na chapa a partir da superfície. 
As Figura 9-27 e Figura 9-28 apresentam os resultados do perfis de dureza superficial para as condições de 1500RPM e $50 \mathrm{~mm} / \mathrm{min}$ de avanço (condição D) e 1650RPM e $50 \mathrm{~mm} / \mathrm{min}$ de avanço (condição $G$ ) respectivamente. Em ambas a condição de camada endurecida é diferente quando comparado com a condição $A$.

$\mathrm{Na}$ condição $\mathrm{D}$ a espessura aproximada de camada mais dura foi de $0.10 \mathrm{~mm} \mathrm{e}$ a diferença de aproximadamente +45HV0.1 em relação ao seu núcleo.

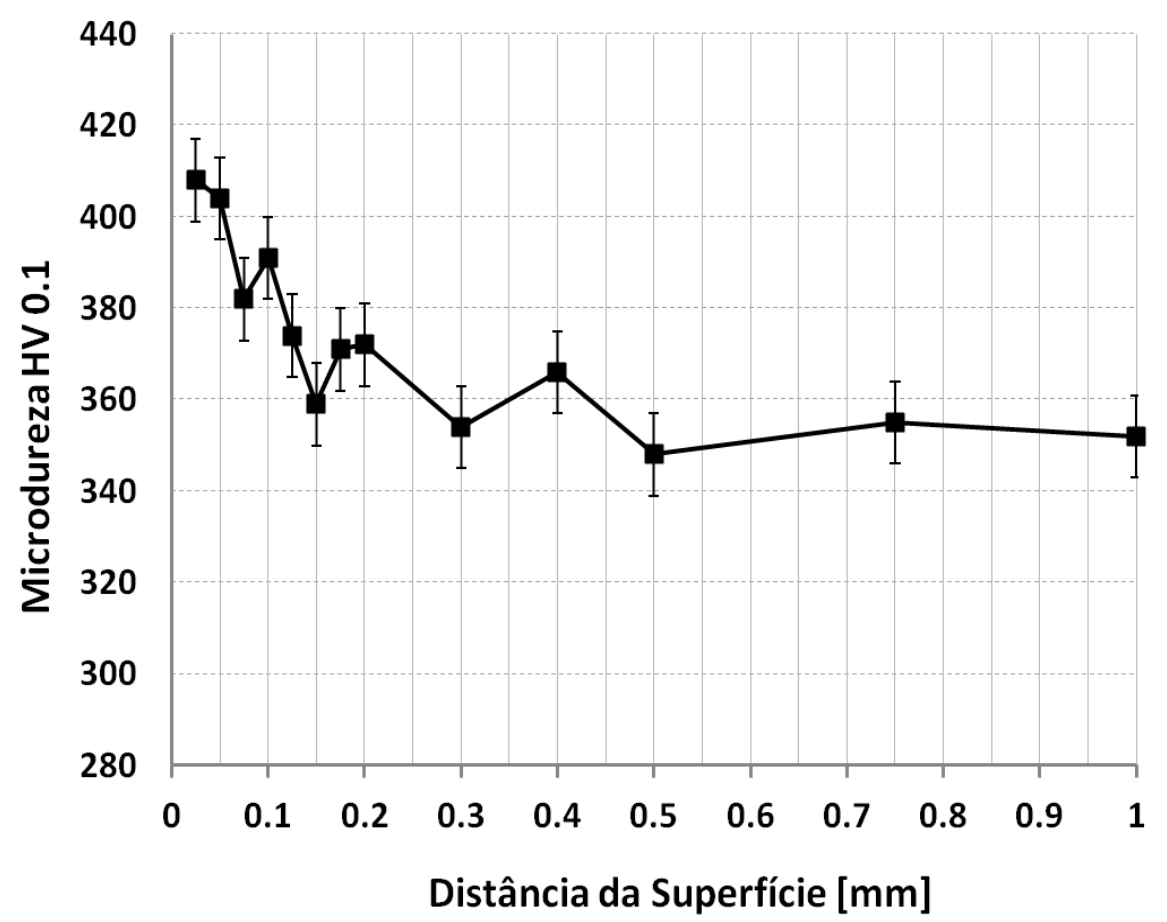

Figura 9-27 - Perfil de microdureza superficial da chapa FSP na condição 1500RPM e 50mm/min de avanço, desvio padrão de +/- 9HV0,1.

$\mathrm{Na}$ condição $\mathrm{G}$ a espessura aproximada de camada mais dura foi de $0.05 \mathrm{~mm}$ e a diferença de aproximadamente +40HV0.1 em relação ao seu núcleo. Em ambos os casos o provável motivo da diferença de dureza na camada superficial é provavelmente resultado de um resfriamento brusco à uma taxa acima da experimentada pelo restante da chapa. 


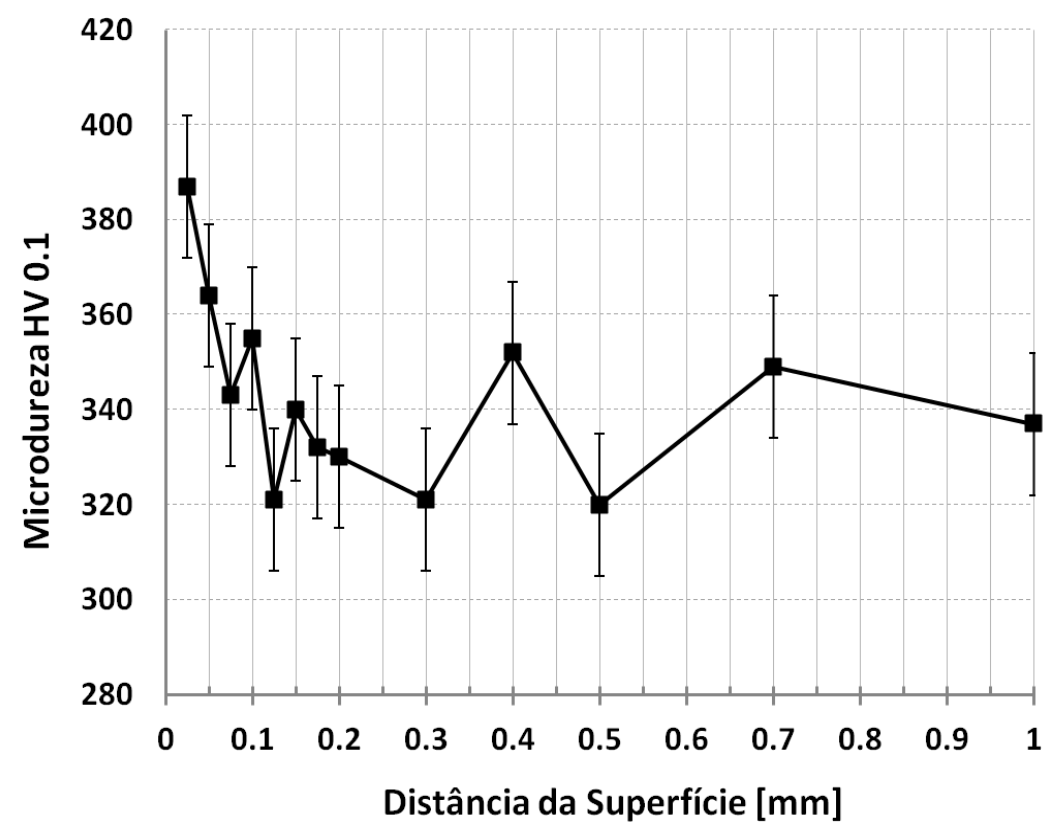

Figura 9-28 - Perfil de microdureza superficial da chapa FSP na condição 1650RPM e 50mm/min de avanço, desvio padrão de +/- 9HV0,1.

Dada as condições da montagem do experimento em uma máquina aberta, não foi possível aplicar uma metodologia para controle da taxa de resfriamento de forma homogênea nem tão pouco controle da atmosfera de forma apropriada. Tal metodologia implicaria em uma mudança estrutural na máquina, para que o dispositivo de FSP ficasse enclausurado possibilitando controle de atmosfera e temperatura de resfriamento.

\subsection{Tensão residual no ensaio principal}

Com o mesmo equipamento utilizado no tópico 7.5 foram levantados os perfis de tensão residual para cada condição de ensaio da tabela Tabela 13-2 do Anexo K.

A Figura 9-29 até Figura 9-37 apresentam o resultado da medição da tensão residual. Somente a medição da tensão longitudinal foi efetuada devido o fato de se apresentar com o maior valor, conforme verificado nos ensaios preliminares (Figura 7-32 até Figura 7-34). A tomada da medição foi efetuada ao longo da transversal da região processada e o centro dos gráficos foi alocado no centro da chapa. 


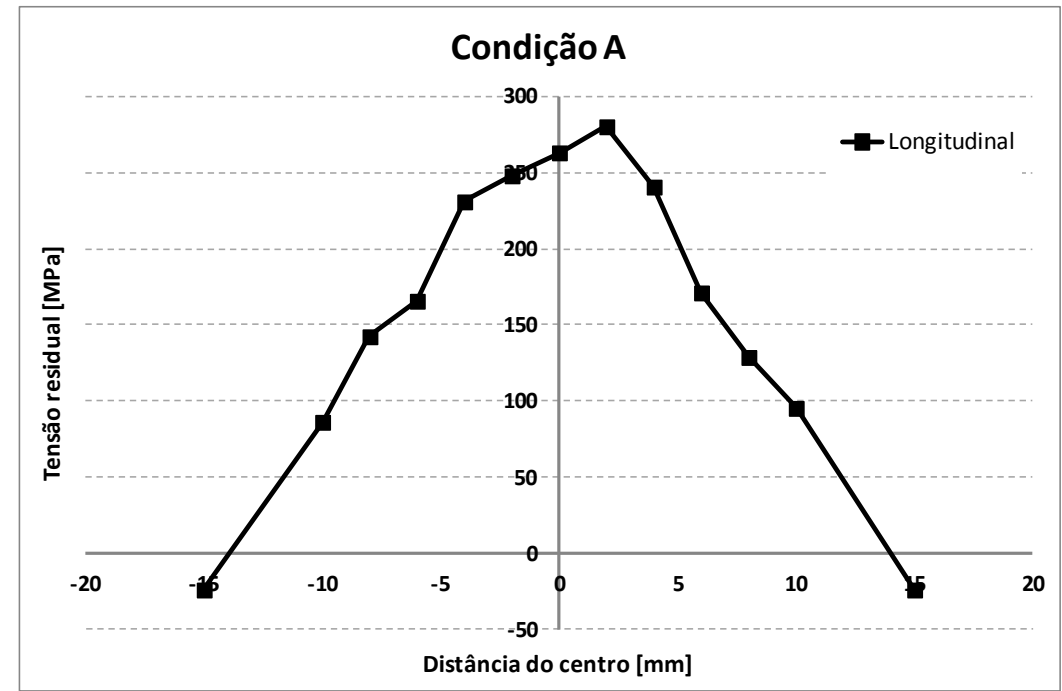

Figura 9-29 - Perfil de tensão residual da chapa FSP na condição 1350RPM e 50mm/min de avanço.

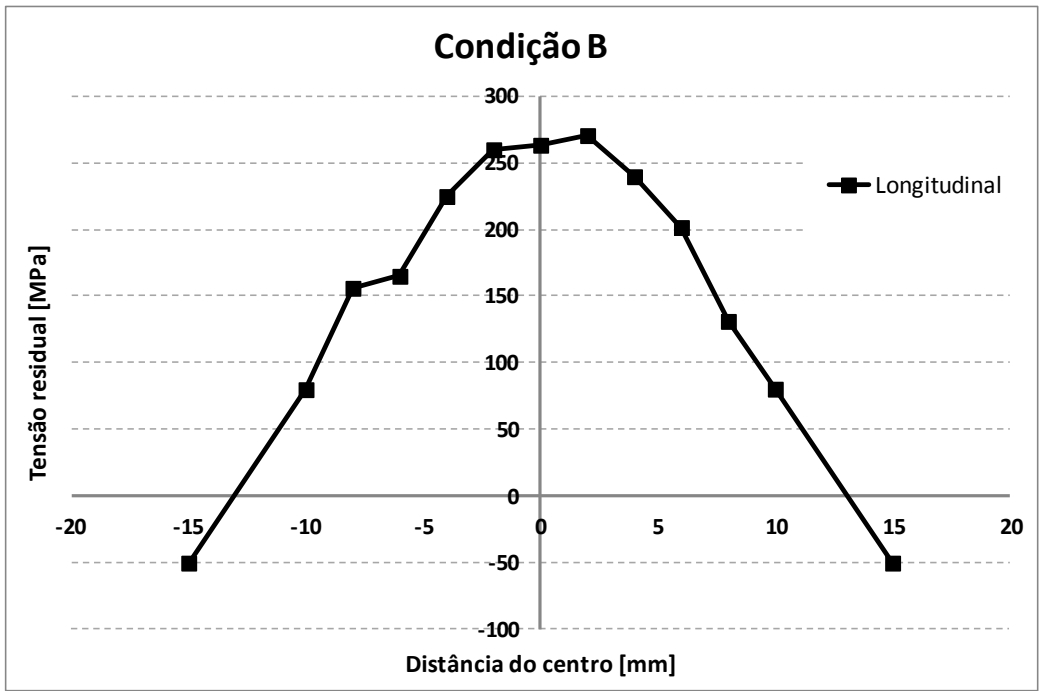

Figura 9-30 - Perfil de tensão residual da chapa FSP na condição 1350RPM e 60mm/min de avanço.

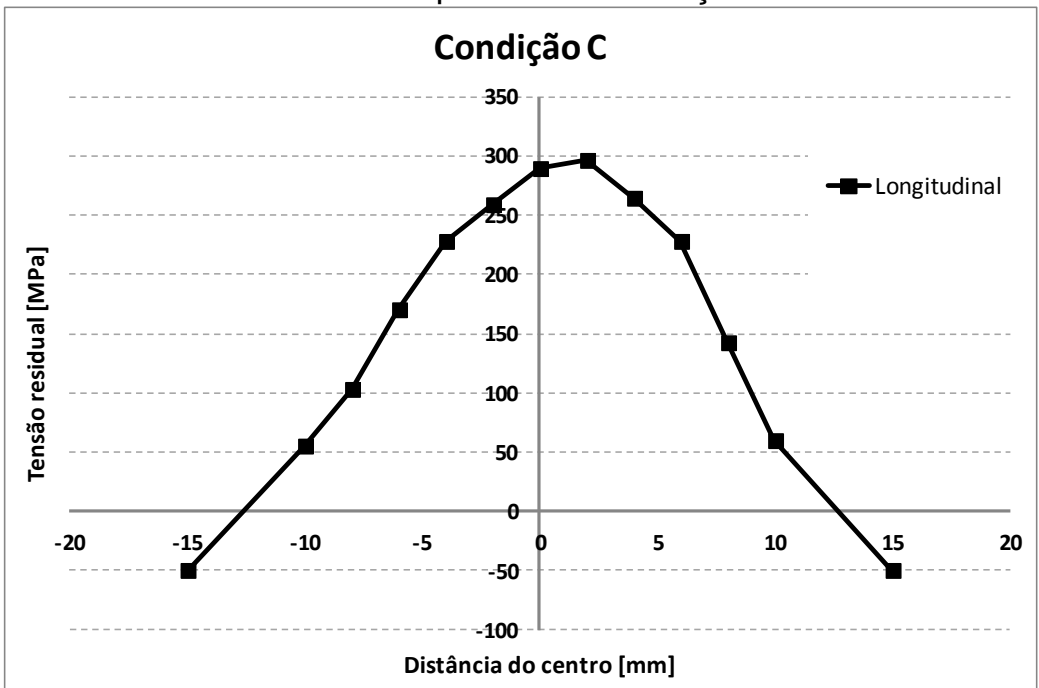

Figura 9-31 - Perfil de tensão residual da chapa FSP na condição 1350RPM e 70mm/min de avanço. 


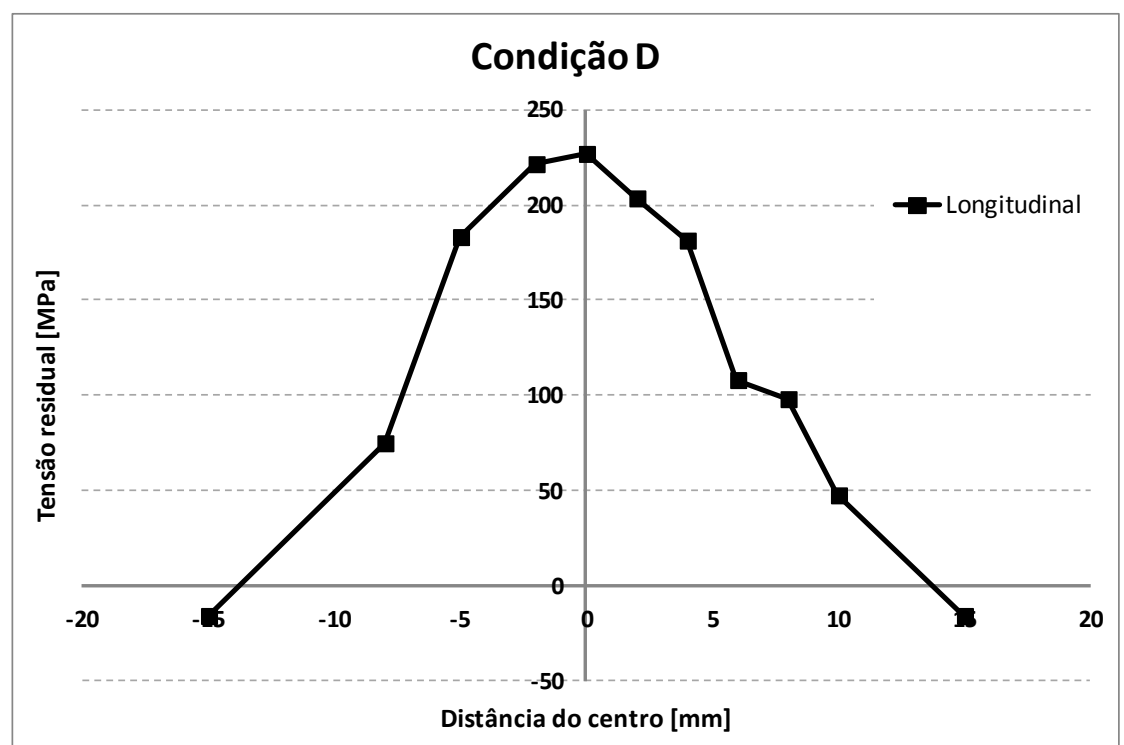

Figura 9-32 - Perfil de tensão residual da chapa FSP na condição 1500RPM e 50mm/min de avanço.

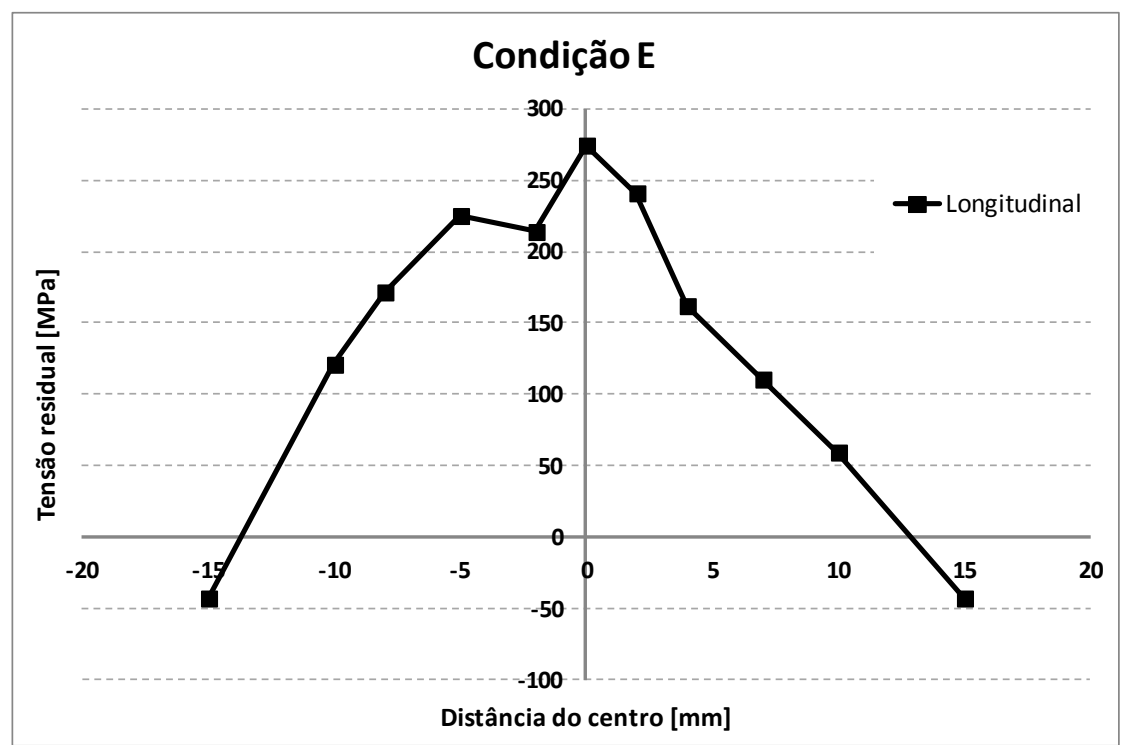

Figura 9-33 - Perfil de tensão residual da chapa FSP na condição 1500RPM e 60mm/min de avanço.

Conforme nos afastamos do ponto central da chapa podemos notar a coerente redução dos níveis de tensão residual, que distantes de aproximadamente quinze milímetros já se encontram na região que não sofreu processamento FSP. Neste ponto conforme visto anteriormente (Figura 7-32 até Figura 7-34) a tensão residual máxima troca de sentido e acompanha a situação proveniente do processo de fabricação anterior da chapa. 


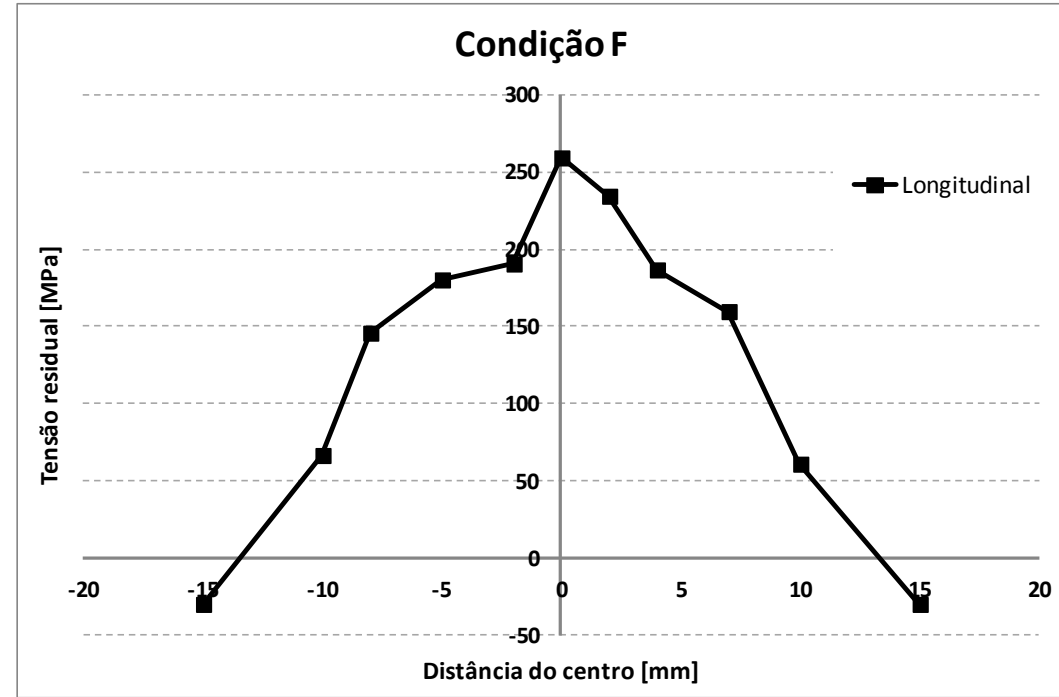

Figura 9-34 - Perfil de tensão residual da chapa FSP na condição 1500RPM e 70mm/min de avanço.

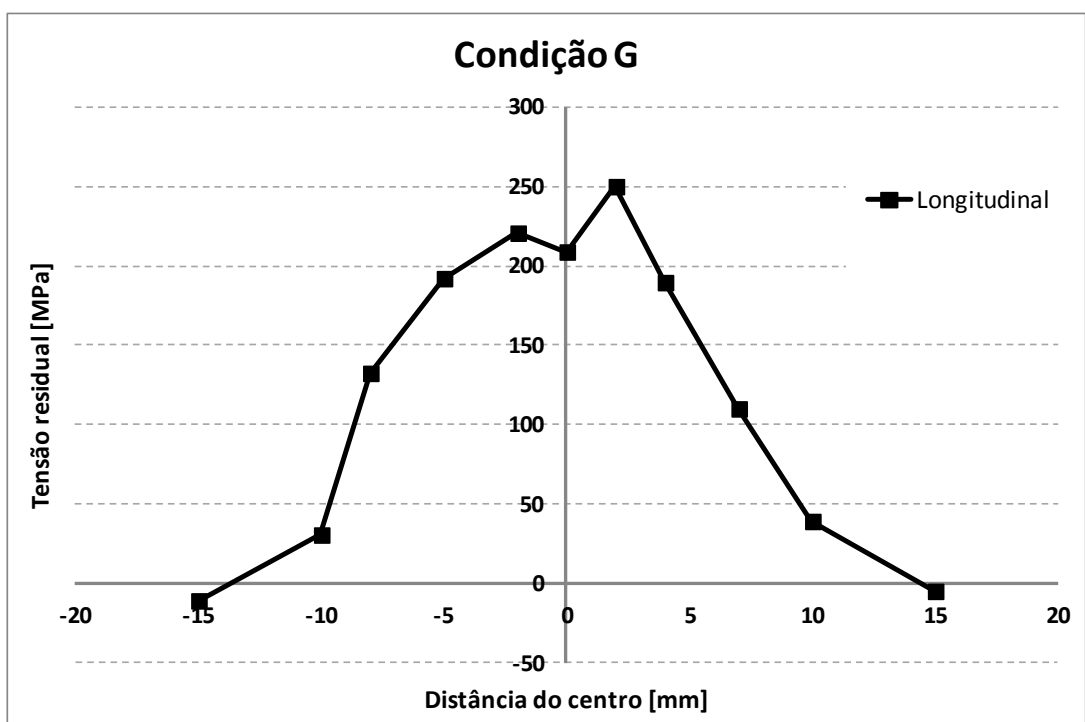

Figura 9-35 - Perfil de tensão residual da chapa FSP na condição1650RPM e 50mm/min de avanço.

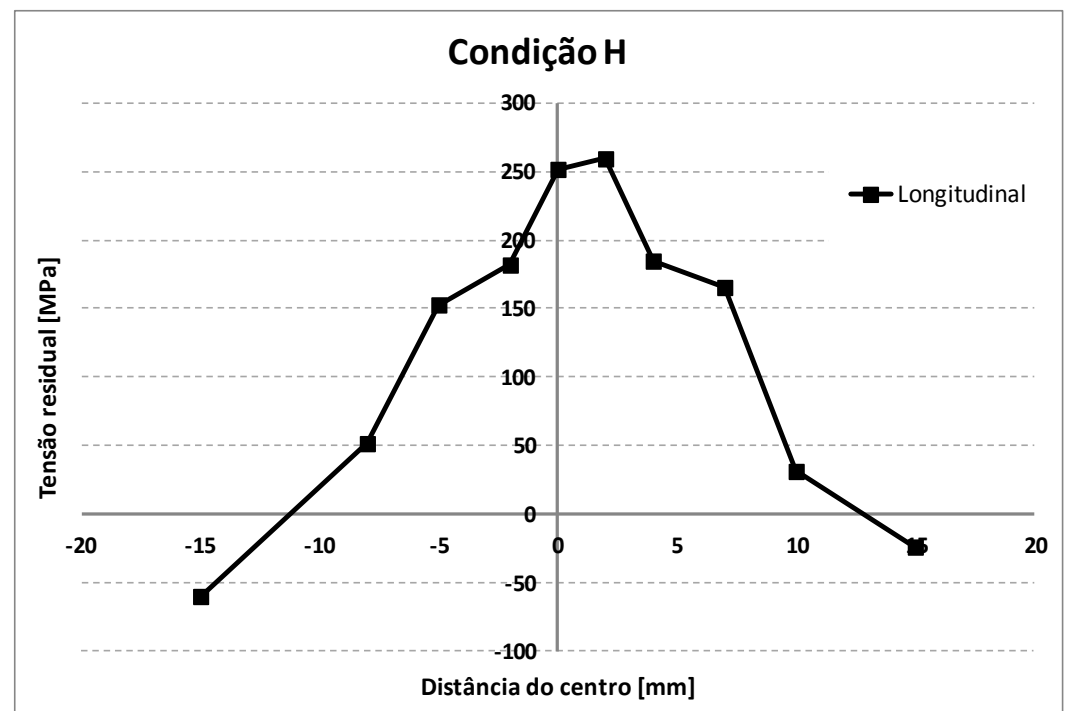

Figura 9-36 - Perfil de tensão residual da chapa FSP na condição 1650RPM e 60mm/min de avanço. 


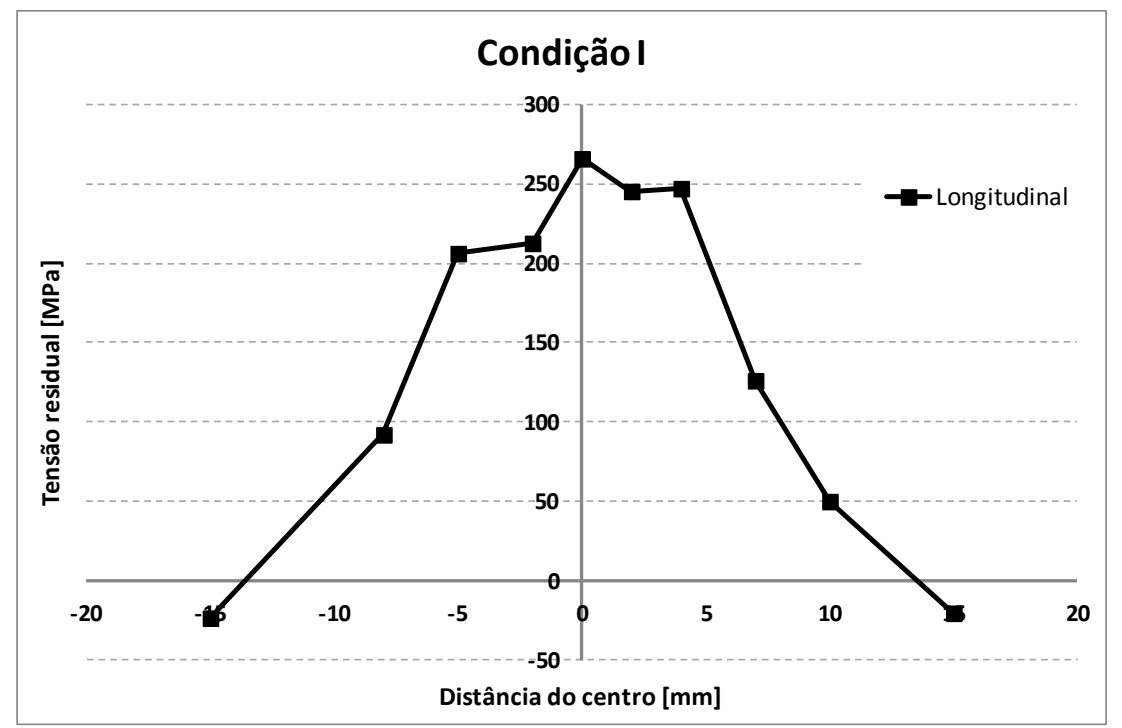

Figura 9-37 - Perfil de tensão residual da chapa FSP na condição 1650RPM e 70mm/min de avanço.

A avaliação dos gráficos de tensão residual mostra uma sugestiva diminuição da tensão na região central da amostra em função do aumento da rotação em RPM da ferramenta, e interação em menor intensidade, mas ainda considerável, com a velocidade de avanço no processamento. Para confirmação desta afirmação foi executado um estudo de análise de variância dos resultados obtidos em função dos parâmetros empregados. A Tabela 9-2 apresenta os resultados da análise de variância da tensão residual em função da rotação e avanço da ferramenta usados no processamento com um intervalo de confiança (IC) de 95\%.

Tabela 9-2 - Tabela de Análise de Variância para Tensão Residual

\begin{tabular}{ccccc}
\hline Parâmetro & Soma & Méd-quad & $\mathbf{F}$ & valor-p \\
\hline S (RPM) & 528260 & 528260 & 7762.56 & $9.95 E-8$ \\
$\mathbf{f}(\mathbf{m m} / \mathbf{m i n})$ & 4766 & 4766 & 70.03 & 0.00111 \\
S:f & 6415 & 6415 & 94.27 & 0.00063 \\
\hline
\end{tabular}

Para a análise da influência dos parâmetros, utilizou-se o processo do valor da probabilidade (valor-p) do teste, que diz:

a) Se o valor-p é menor ou igual a um determinado nível de significância (100IC), a hipótese de nulidade é rejeitada e a hipótese alternativa é apoiada.

b) Se o valor-p é maior que o nível de significância, a hipótese de nulidade não pode ser rejeitada e a hipótese alternativa não tem apoio.

Portanto para o caso estudado a rotação possui a maior influência no resultado final da tensão residual, e como pode ser verificado na Figura 9-38 as maiores rotações tendem a provocar os menores valores de tensão residual e em segundo 
lugar o avanço, indicando que com seu aumento o valor da tensão residual tende a aumentar de forma discreta. A interação entre os parâmetros $S$ e f (rotação e avanço) também se mostra significativa. Na Figura 9-39 é apresentada a variação da tensão residual em função da interação e podemos observar melhor os resultados.

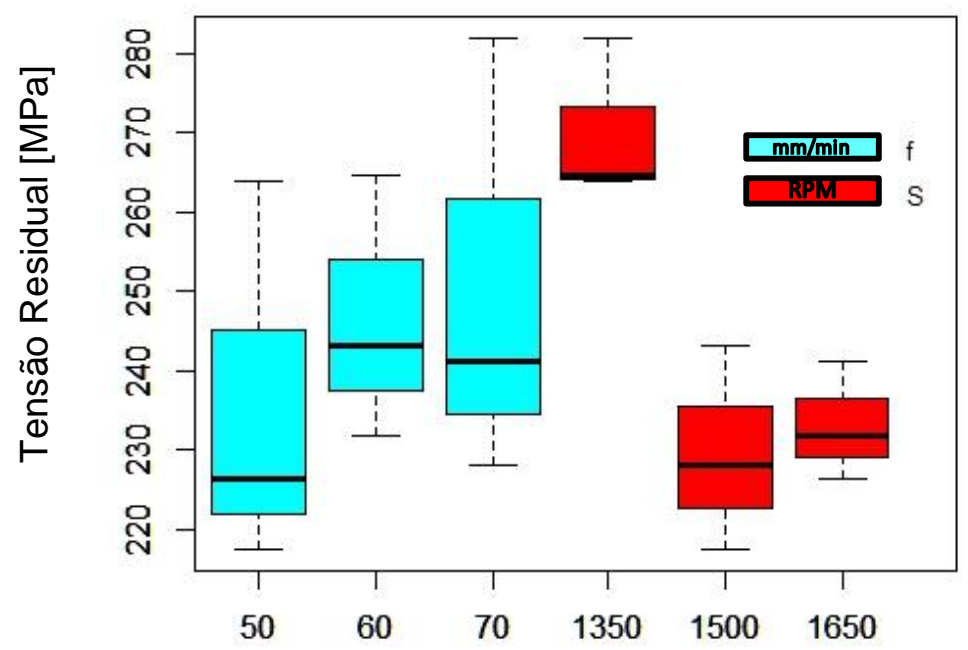

Figura 9-38 - Relação de dependência tensão residual em função das variáveis rotação $S$ e avanço f.

A constatação que se pode observar é em função da interação entre os dois parâmetros em estudo como mostra a Figura 9-39, é possível verificar que a combinação das maiores rotações (1500RPM e 1650 RPM) com o menor avanço de $50 \mathrm{~mm} / \mathrm{min}$ provocam a menor condição de tensão residual nos corpos de prova ensaiados.

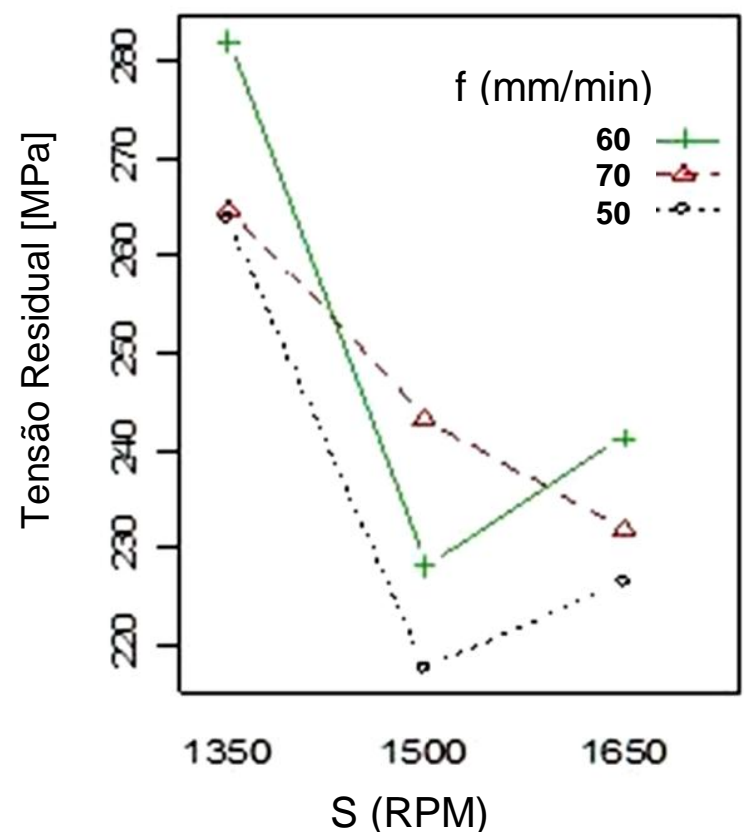

Figura 9-39 - Gráfico de Interações para tensão residual em função das variáveis rotação e avanço. 
Para validação dos resultados da análise de variância foi verificada a normalidade da distribuição dos resíduos, ou seja, foi verificado se os valores residuais do estudo estatístico pertenciam a uma distribuição normal.

Histograma dos Residuos

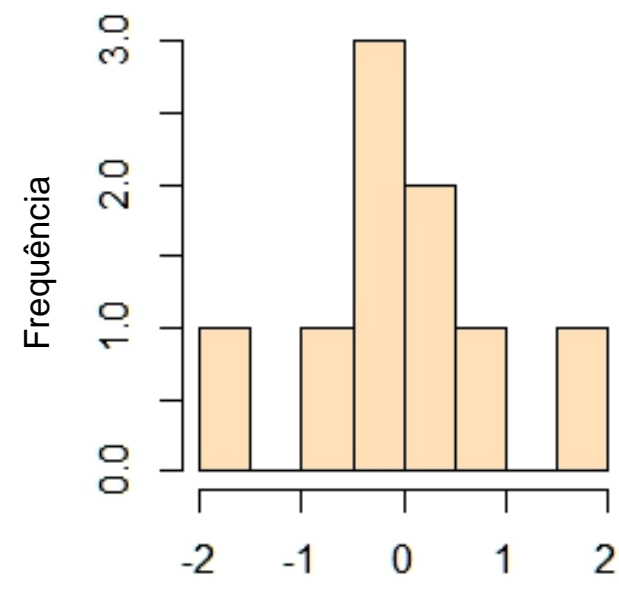

Residuos padronizados

(a)

\section{Normal Q-Q plot dos Resíduos}

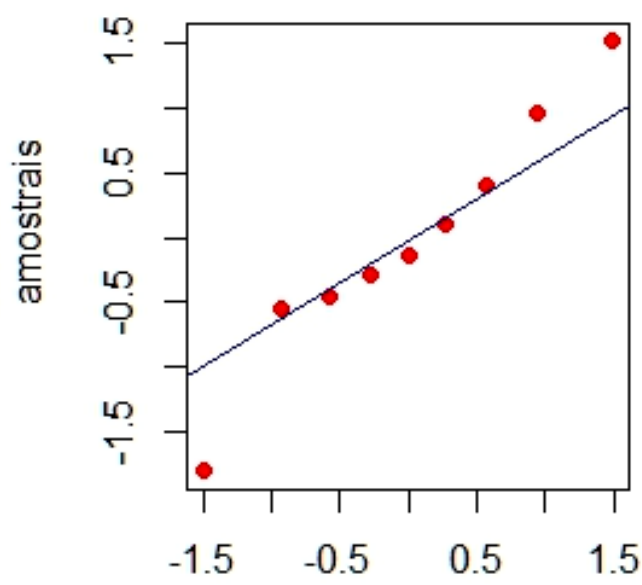

Quantis teóricos

(b)

Figura 9-40 - Avaliação dos resíduos do estudo estatístico

A Figura 9-40 (a) apresenta o histograma dos resíduos e a Figura 9-40 (b) apresenta a plotagem dos resíduos dos valores analisados no gráfico quantil-quantil que mostra a boa adequação dos resíduos a uma distribuição nomal (reta preta).

Embora a literatura disponível sobre tensão residual na liga Ti-6Al-4V seja escassa, os valores aqui encontrados encontram-se em conformidade com os valores levantados por Pasta (PASTA; REYNOLDS, 2008b; FRATINI et al., 2009) e Prime (PRIME et al., 2005) em seus estudos com a liga Ti-6Al-4V.

De acordo com Kumar et al (KUMAR et al., 2014) informações sobre tensão residual em ligas de titânio são pouco disponíveis na literatura. Dado este fato, é ressaltada a importância deste estudo para ajudar a compreender os mecanismos que influenciam seu surgimento nos processos FSP em chapas da liga Ti-6Al-4V.

Estes resultados corroboram para a melhora do seu controle uma vez que ficou comprovado que o principal fator de influência da tensão residual foi a rotação da ferramenta. A combinação das maiores rotações com o menor avanço provoca uma exposição prolongada da região processada da chapa à temperatura do processo. 
Não só a chapa mas todo o dispositivo se aquece, mudando a dinâmica do resfriamento, o que pode causar um pequeno alívio das tensões residuais após a passagem da ferramenta.

\subsection{Ensaios de tração ARCAN}

A Figura 9-41 apresenta a curva tensão x deformação fornecida pelo software, além do levantamento da curva, os dados de principais interesse também são fornecidos na legenda e no sumário. Todos os valores levantados pelo software são também armazenados em forma de arquivo texto para posterior conversão e utilização.

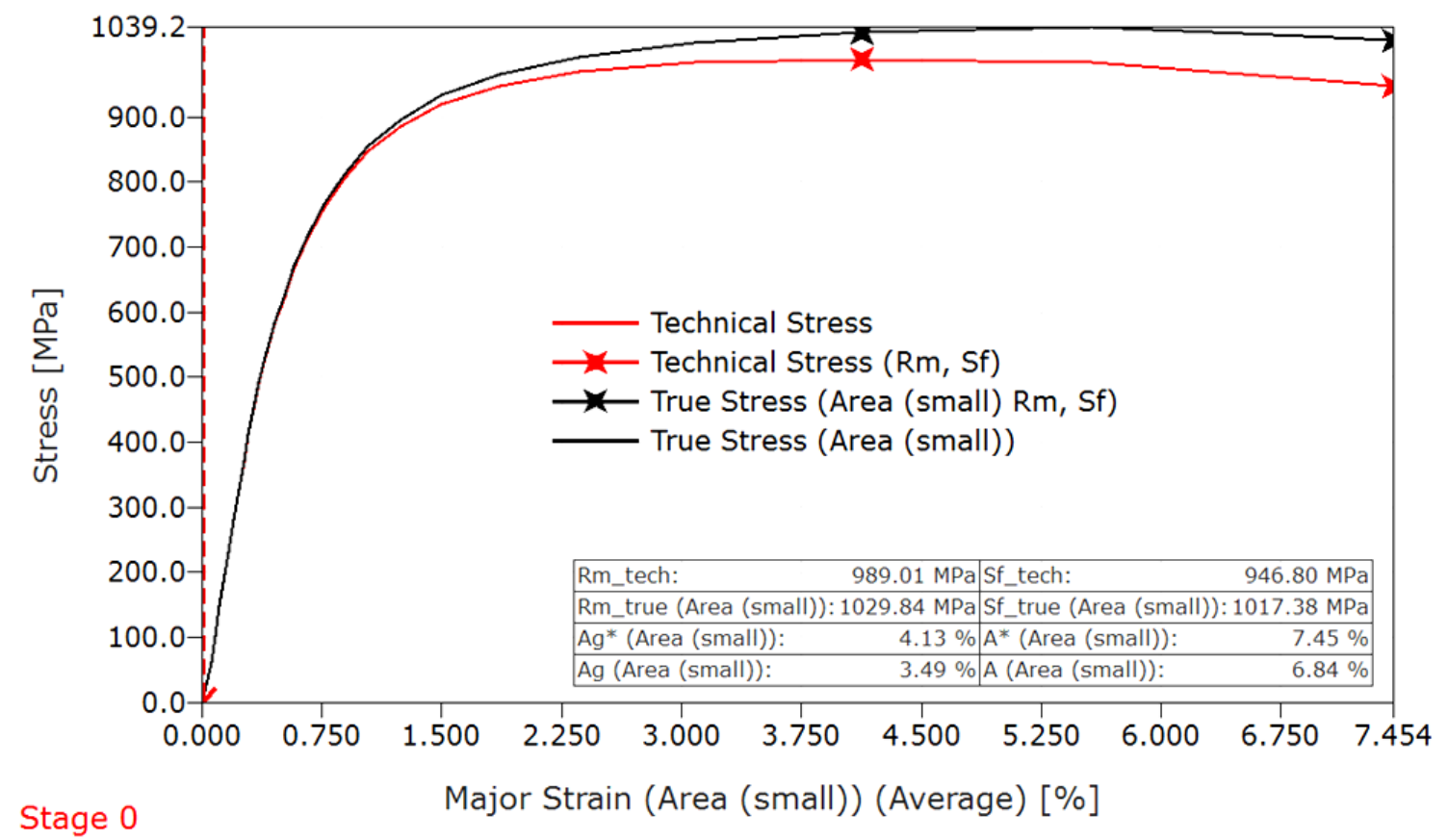

\section{ARAMIS}

Figura 9-41 - Curva tensão x deformação para o caso do ensaio na condição F1 fornecida pelo software Aramis.

Após o levantamento das curvas e dados relativos aos ensaios a planilha da Tabela 9-3 foi montada. Esta tabela tem o objetivo de compilar os valores mais importantes para a geração dos modelos de comportamento de escoamento que serão criados. Uma tabela completa com todos os valores dos ensaios efetuados se encontra no ANEXO K. 
Tabela 9-3 Dados dos ensaios de tração ARCAN

\begin{tabular}{|c|c|c|c|c|c|c|c|c|}
\hline Código & $\begin{array}{c}\text { Espessura } \\
\text { da solda }\end{array}$ & $\begin{array}{l}\text { RPM FSP } \\
\text { [rot/min] }\end{array}$ & $\begin{array}{c}\text { Avanço } \\
\text { FSP } \\
\text { [mm/min] }\end{array}$ & $\begin{array}{c}\text { Taxa } \\
\text { tração } \\
\text { ARCAN } \\
{[\mathrm{mm} / \mathrm{s}]} \\
\end{array}$ & $\begin{array}{c}\text { Temperatura } \\
\text { ARCAN }\end{array}$ & $\begin{array}{l}\text { ângulo } \\
\text { ARCAN }\end{array}$ & $\mathrm{E}[\mathrm{MPa}]$ & $\begin{array}{c}\text { Tensão de } \\
\text { escoamento } \\
\text { - Rp02 } \\
\text { [MPa] } \\
\end{array}$ \\
\hline A1 & 1.95 & 1350 & 50 & 0.1 & 25 & 0 & \multirow[t]{5}{*}{164.596} & 875.97 \\
\hline A2 & 1.94 & 1350 & 50 & 0.1 & 25 & 30 & & 742.58 \\
\hline A3 & 1.95 & 1350 & 50 & 0.1 & 25 & 45 & & 682.00 \\
\hline A4 & 1.97 & 1350 & 50 & 0.1 & 25 & 60 & & 557.38 \\
\hline A5 & 1.94 & 1350 & 50 & 0.1 & 25 & 90 & & 535.50 \\
\hline B1 & 1.95 & 1350 & 60 & 0.01 & 200 & 0 & \multirow[t]{5}{*}{164.729} & 785.38 \\
\hline B2 & 1.95 & 1350 & 60 & 0.01 & 200 & 30 & & 600.68 \\
\hline B3 & 1.97 & 1350 & 60 & 0.01 & 200 & 45 & & 421.78 \\
\hline B4 & 1.95 & 1350 & 60 & 0.01 & 200 & 60 & & 360.10 \\
\hline B5 & 2.00 & 1350 & 60 & 0.01 & 200 & 90 & & 325.00 \\
\hline C1 & 2.02 & 1350 & 70 & 0.001 & 340 & 0 & \multirow[t]{3}{*}{151.254} & 663.70 \\
\hline C3 & 2.03 & 1350 & 70 & 0.001 & 340 & 45 & & 404.13 \\
\hline C5 & 2.09 & 1350 & 70 & 0.001 & 340 & 90 & & 315.00 \\
\hline D1 & 1.84 & 1500 & 50 & 0.01 & 340 & 0 & \multirow[t]{5}{*}{159.514} & 728.97 \\
\hline D2 & 1.78 & 1500 & 50 & 0.01 & 340 & 30 & & 582.95 \\
\hline D3 & 1.85 & 1500 & 50 & 0.01 & 340 & 45 & & 497.69 \\
\hline D4 & 1.94 & 1500 & 50 & 0.01 & 340 & 60 & & 479.08 \\
\hline D5 & 1.93 & 1500 & 50 & 0.01 & 340 & 90 & & 348.6 \\
\hline E1 & 1.87 & 1500 & 60 & 0.001 & 25 & 0 & \multirow[t]{5}{*}{180.175} & 932.26 \\
\hline E2 & 1.83 & 1500 & 60 & 0.001 & 25 & 30 & & 684.97 \\
\hline E3 & 1.97 & 1500 & 60 & 0.001 & 25 & 45 & & 568.42 \\
\hline E4 & 1.82 & 1500 & 60 & 0.001 & 25 & 60 & & 507.08 \\
\hline E5 & 1.75 & 1500 & 60 & 0.001 & 25 & 90 & & 342.05 \\
\hline F1 & 2.00 & 1500 & 70 & 0.1 & 200 & 0 & \multirow[t]{5}{*}{157.699} & 796.84 \\
\hline F2 & 1.93 & 1500 & 70 & 0.1 & 200 & 30 & & 651.41 \\
\hline F3 & 1.84 & 1500 & 70 & 0.1 & 200 & 45 & & 569.01 \\
\hline F4 & 1.93 & 1500 & 70 & 0.1 & 200 & 60 & & 490.32 \\
\hline F5 & 1.80 & 1500 & 70 & 0.1 & 200 & 90 & & 456.67 \\
\hline H1 & 2.09 & 1650 & 60 & 0.1 & 340 & 0 & \multirow[t]{5}{*}{156.571} & 734.52 \\
\hline $\mathrm{H} 2$ & 2.00 & 1650 & 60 & 0.1 & 340 & 30 & & 570.47 \\
\hline H3 & 2.02 & 1650 & 60 & 0.1 & 340 & 45 & & 505.29 \\
\hline H4 & 2.04 & 1650 & 60 & 0.1 & 340 & 60 & & 500.50 \\
\hline H5 & 1.95 & 1650 & 60 & 0.1 & 340 & 90 & & 413.20 \\
\hline 11 & 2.05 & 1650 & 70 & 0.01 & 25 & 0 & \multirow[t]{5}{*}{164.109} & 853.11 \\
\hline 12 & 1.86 & 1650 & 70 & 0.01 & 25 & 30 & & 729.71 \\
\hline 13 & 2.07 & 1650 & 70 & 0.01 & 25 & 45 & & 640.99 \\
\hline 14 & 1.90 & 1650 & 70 & 0.01 & 25 & 60 & & 572.96 \\
\hline 15 & 1.95 & 1650 & 70 & 0.01 & 25 & 90 & & 487.12 \\
\hline
\end{tabular}


A avaliação dos resultados de valores de escoamento da Tabela 9-3 em função da correlação com os parâmetros utilizados é de difícil visualização. Para confirmação destas correlações foi executado um estudo de análise de variância dos resultados obtidos em função dos parâmetros empregados. O software empregado foi o "R" (The R Project for Statistical Computing). A Tabela 9-4 apresenta os resultados da análise de variância da tensão em função da rotação da ferramenta, avanço da ferramenta, taxa de tração ARCAN e temperatura no ensaio de ARCAN usados no processamento com um intervalo de confiança (IC) de $95 \%$.

\begin{tabular}{ccccc}
\multicolumn{5}{c}{ Tabela 9-4 Tabela de Análise de Variância para Tensão de Escoamento } \\
\hline Parâmetro & Soma & Méd-quad & F & valor-p \\
\hline S (RPM) & 5733248 & 5733248 & 5715.82 & $4.753 E-6$ \\
$\mathbf{f}(\mathbf{m m} / \mathbf{m i n})$ & 3005 & 3005 & 3.1401 & 0.1745 \\
e (mm/s) & 1334 & 1334 & 1.3941 & 0.3228 \\
T ( $\left.{ }^{\circ} \mathbf{C}\right)$ & 43674 & 43674 & 45.634 & 0.0066 \\
S:f & 39025 & 39025 & 40.777 & 0.0078 \\
f:T & 605 & 605 & 0.632 & 0.4845 \\
\hline
\end{tabular}

Para a análise da influência dos parâmetros, utilizou-se o processo do valor da probabilidade (valor-p) do teste, que diz que se o valor-p é menor ou igual a um determinado nível de significância (100-IC), a hipótese de nulidade é rejeitada e a hipótese alternativa é apoiada. Se o valor-p é maior que o nível de significância, a hipótese de nulidade não pode ser rejeitada e a hipótese alternativa não tem apoio.

Em resumo, um valor-p menor do que 0.05 indica uma relação entre a variável estudada e o fenômeno observado.

\section{Tensão de Escoamento}

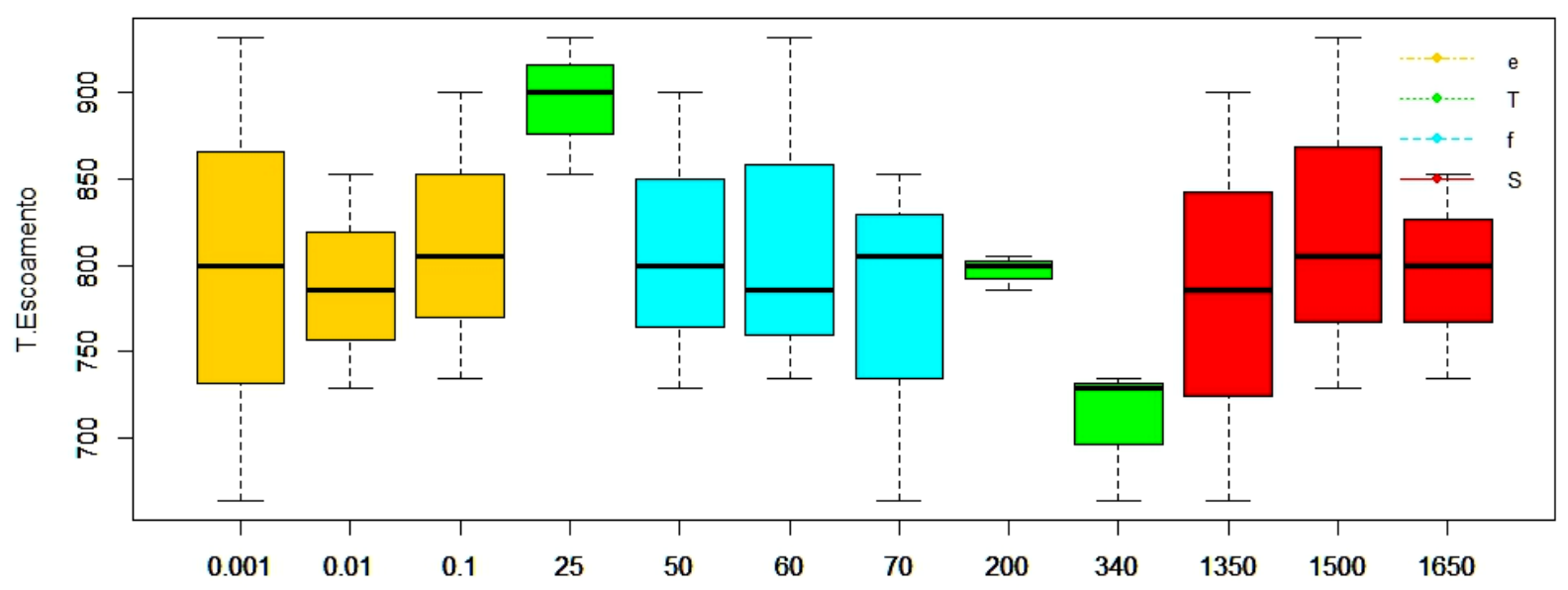

Figura 9-42 - Relação de dependência tensão de escoamento em função das variáveis rotação $S$, avanço f, taxa $e$ de tração e temperatura T. 
Portanto para o caso da tensão de escoamento a rotação possui a maior influência no resultado final da tensão de escoamento, seguida da temperatura do ensaio de ARCAN e da interação entre a rotação e o avanço, apesar do parâmetro avanço sozinho não apresentar influência no resultado. Pode ser verificado na Figura 9-42 a relação de dependência da tensão de escoamento para os parâmetros utilizados. A interação entre os parâmetros também se mostra significativa, e na Figura 9-43 que apresenta a variação da tensão em função da interação podemos observar melhor os resultados.
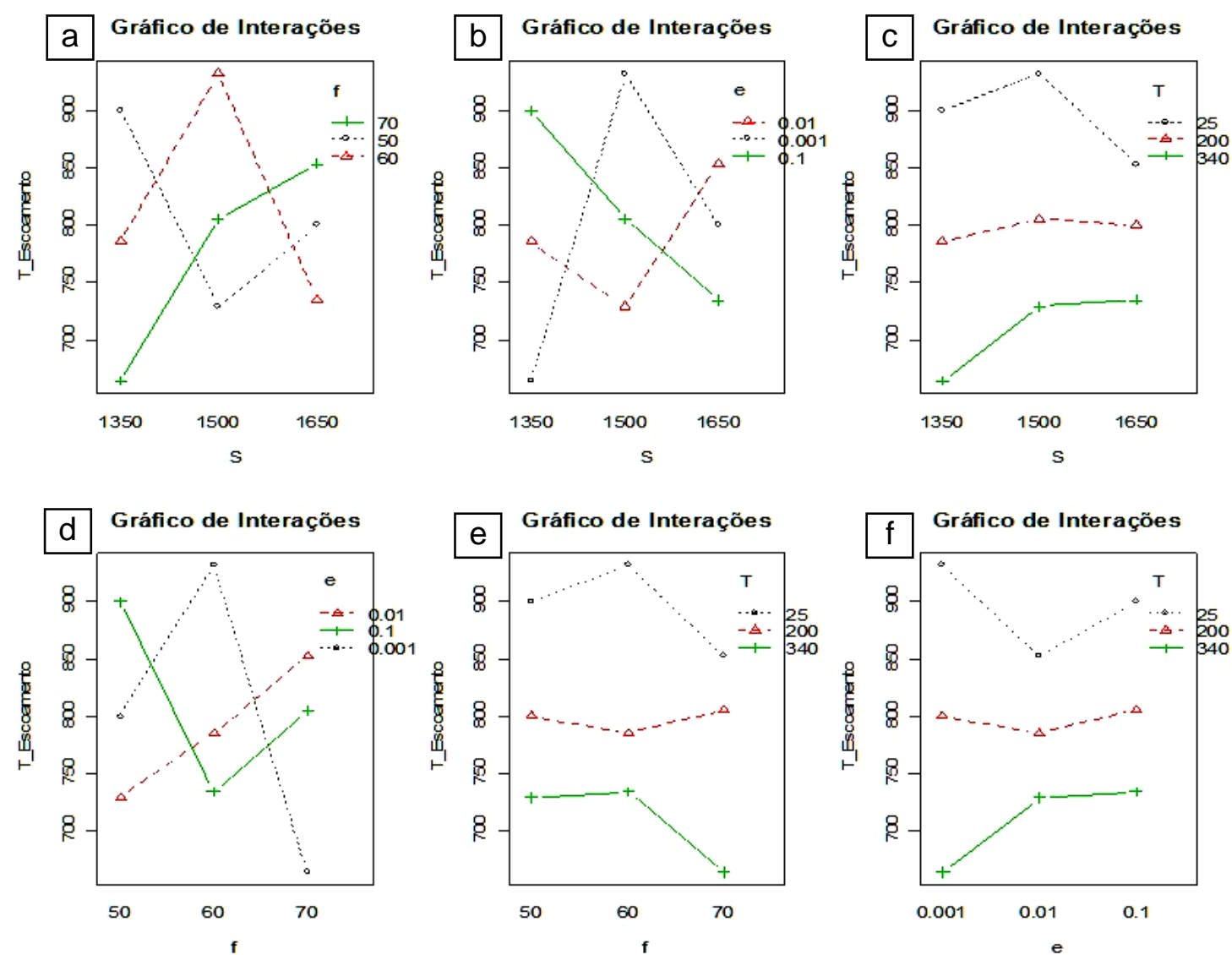

Figura 9-43 - Gráfico de Interações para tensão de escoamento, (a) interação entre Sxf, (b) interação entre Sxe (c), interação entre SxT (d) interação entre fxe (e) interação entre fxT e (f) interação entre exT.

Na Figura 9-43 pode se observar a interação entre os todos parâmetros em estudo, é possível verificar que a combinação da temperatura (Figura 9-43c-e-f) com os demais parâmetros não provocam variações mas apresentam patamares de valores mais definidos de tensão de escoamento nos corpos de prova ensaiados. As Figura 9-43b-d não são indicadas como relevantes pelo estudo de variância, e, a Figura 9-43a que indica a interação entre a rotação $S$ (RPM) e o avanço f $(\mathrm{mm} / \mathrm{min})$ 
é considerada relevante pelo estudo de variância no resultado da tensão de escoamento.

Para validação dos resultados da análise de variância foi verificado a normalidade da distribuição dos resíduos, ou seja, foi verificado se os valores residuais do estudo estatístico pertenciam a uma distribuição normal.

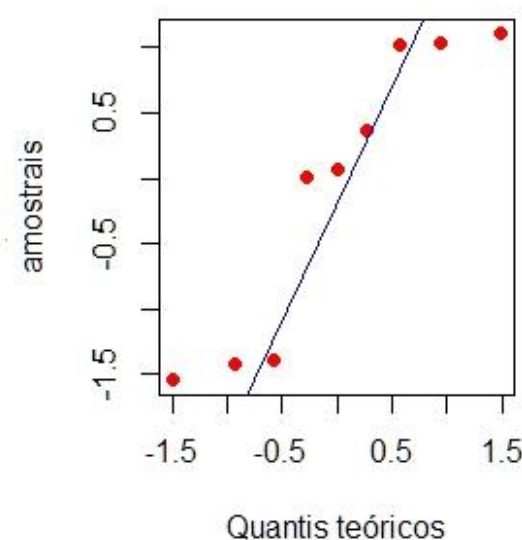

Figura 9-44 - Avaliação dos resíduos do estudo estatístico (Q-Q plot)

A Figura 9-44 apresenta a plotagem dos resíduos dos valores analisados no gráfico quantil-quantil que mostra uma relativa adequação dos resíduos a uma distribuição nomal (reta preta).

Apesar da variação de valores se encontrados na Figura 9-42 ser visualmente grande (indicação da barras de variância), a análise estatística de variância indicou a rotação como principal fonte de variação para a tensão de escoamento. Esta constatação se apresenta em acordo com o resultado informado para microdureza transversal do referente corpo de provas ensaiado. A microdureza da região diminui com o aumento da rotação do processo (Figura 9-23), portanto era esperado uma diminuição da sua tensão de escoamento em todos os tipos de ensaios efetuados.

As Figura 9-45 até Figura 9-52 apresentam os resultados dos ensaios de tração em todas as condições do Dispositivo de ARCAN, tração pura, $30^{\circ}, 45^{\circ}, 60^{\circ} \mathrm{e}$ cisalhamento puro. Devido à um problema técnico de software, o equipamento de medição ARAMIS não funcionou durante alguns ensaios e não foi possível efetuar o levantamento da curva correspondente. Este fato inviabilizou a obtenção das curvas na condição $A$ para $45^{\circ}$, condição $C$ para $30^{\circ} / 60^{\circ}$ e na condição $G$ em todos os casos. 


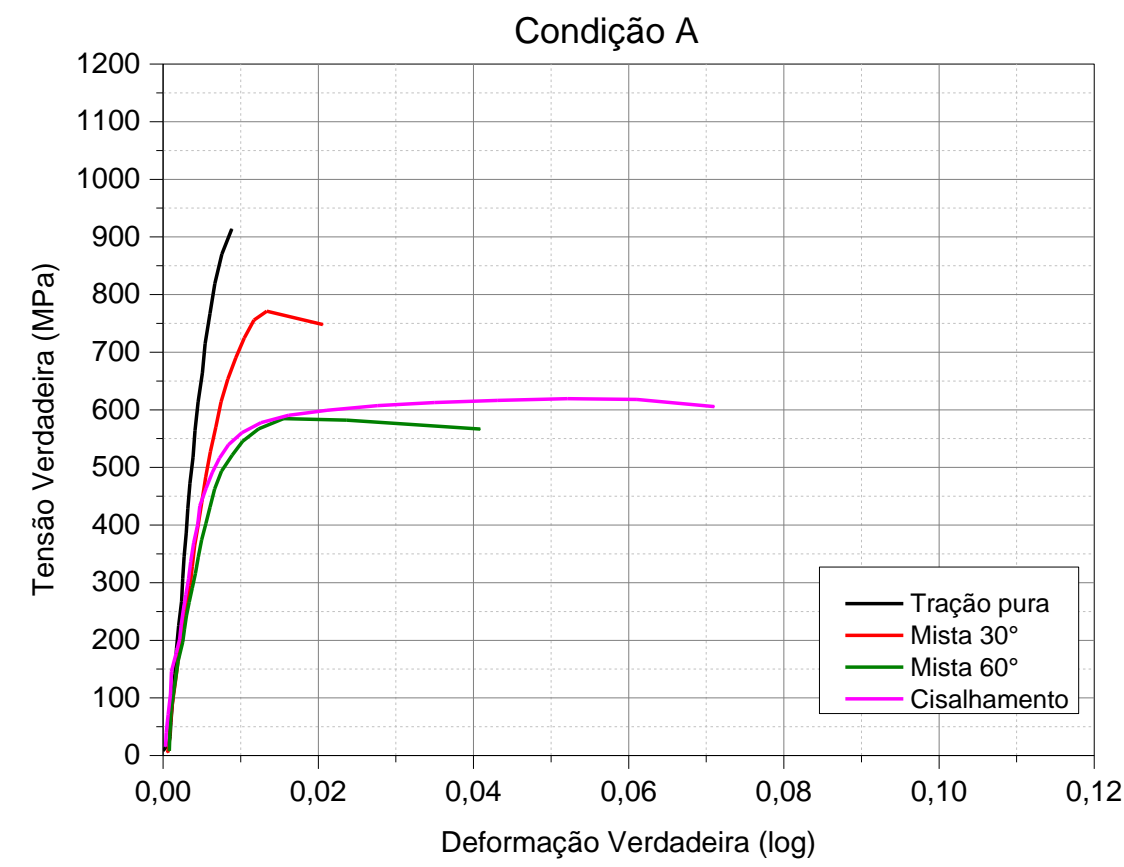

Figura 9-45 - Curvas do ensaio de tração na condição 1350RPM, $50 \mathrm{~mm} / \mathrm{min}$ de avanço, taxa de tração $0.1 \mathrm{~mm} / \mathrm{s}$ e temperatura de ensaio de $25^{\circ} \mathrm{C}$.

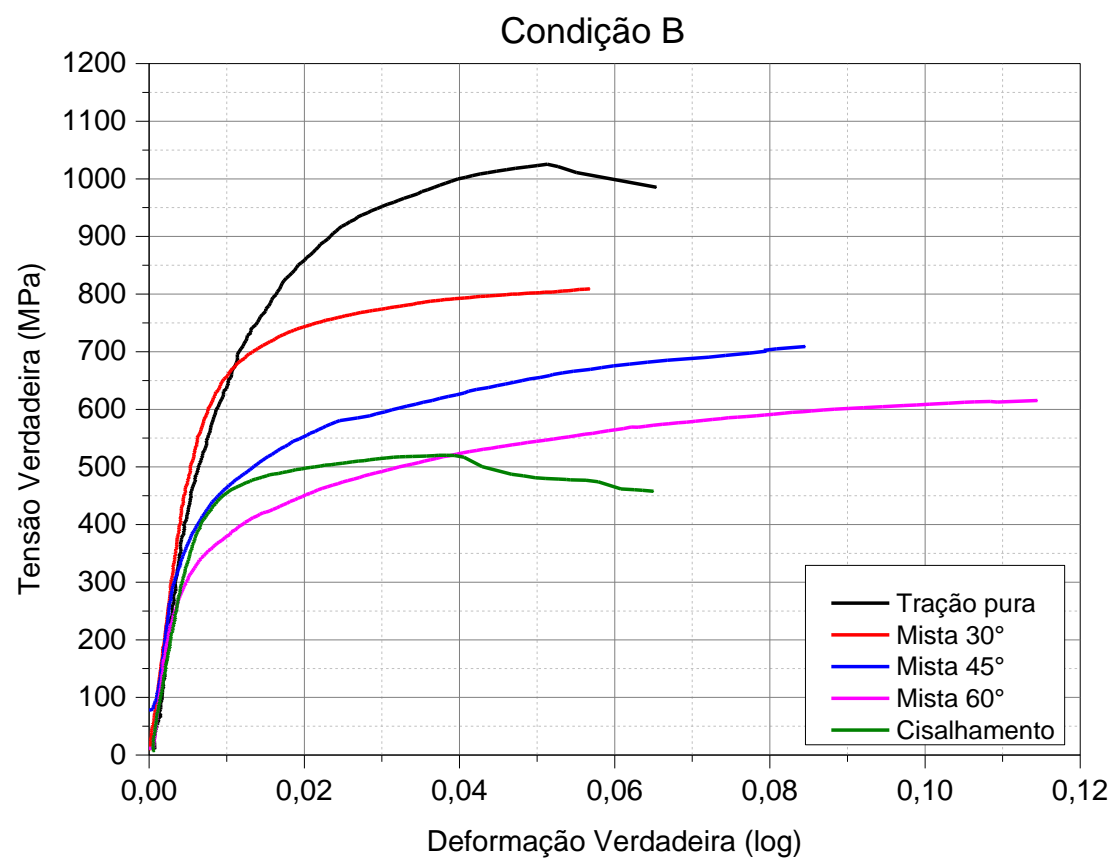

Figura 9-46 - Curvas do ensaio de tração na condição 1350RPM, $60 \mathrm{~mm} / \mathrm{min}$ de avanço, taxa de tração $0.01 \mathrm{~mm} / \mathrm{s}$ e temperatura de ensaio de $200^{\circ} \mathrm{C}$. 


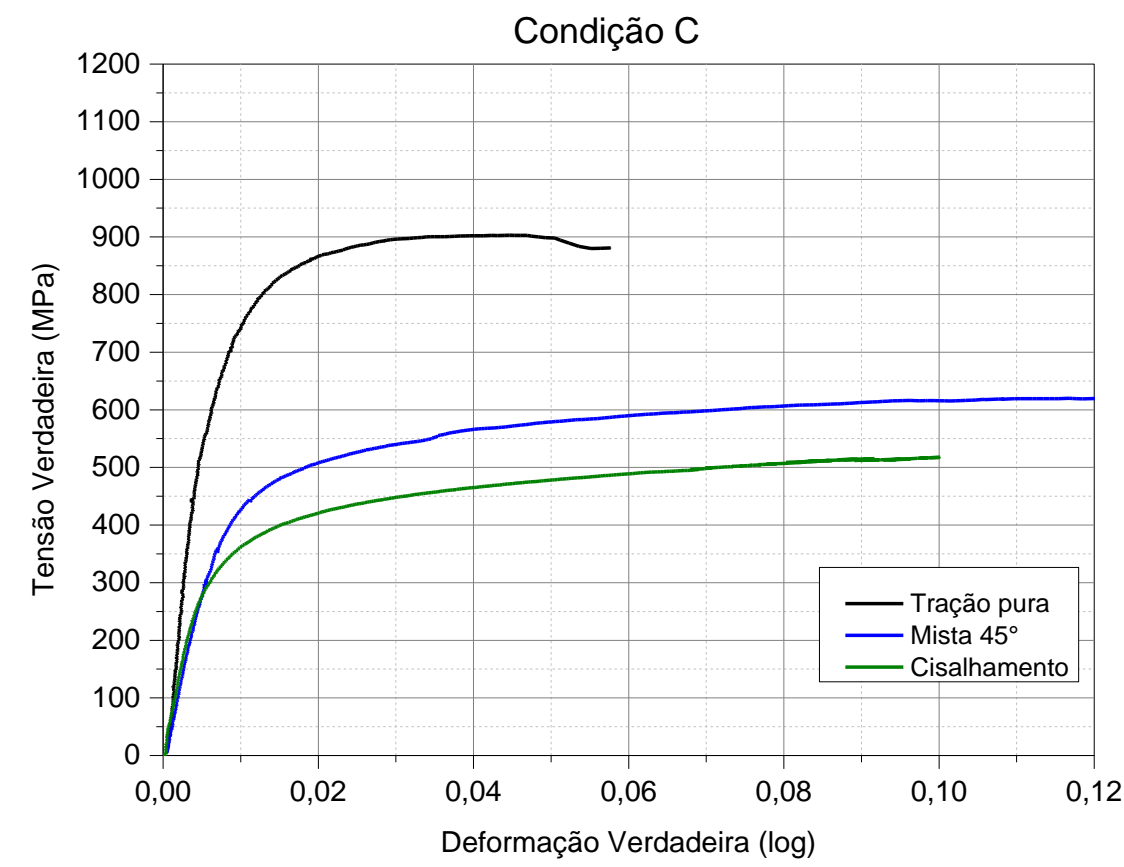

Figura 9-47 - Curvas do ensaio de tração na condição 1350RPM, $70 \mathrm{~mm} / \mathrm{min}$ de avanço, taxa de tração $0.001 \mathrm{~mm} / \mathrm{s}$ e temperatura de ensaio de $340^{\circ} \mathrm{C}$.

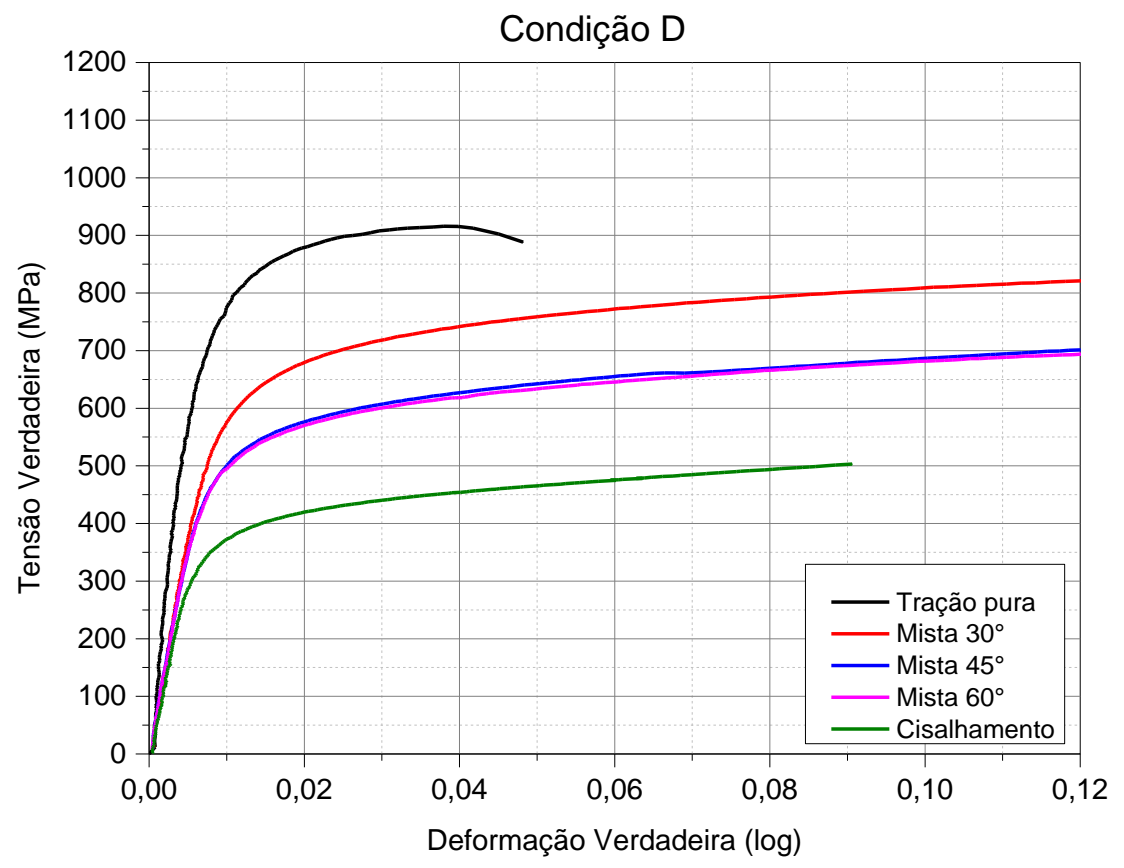

Figura 9-48 - Curvas do ensaio de tração na condição 1500RPM, $50 \mathrm{~mm} / \mathrm{min}$ de avanço, taxa de tração $0.01 \mathrm{~mm} / \mathrm{s}$ e temperatura de ensaio de $340^{\circ} \mathrm{C}$. 


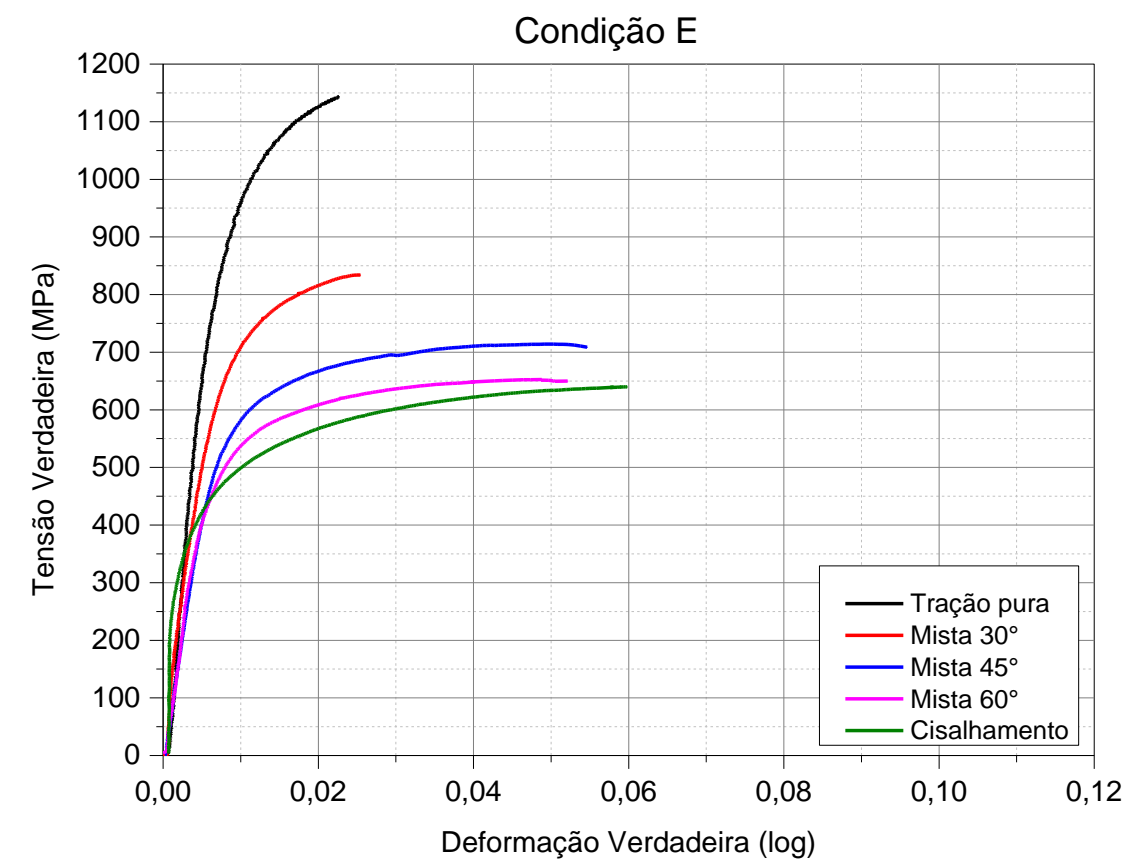

Figura 9-49 - Curvas do ensaio de tração na condição 1500RPM, $60 \mathrm{~mm} / \mathrm{min}$ de avanço, taxa de tração $0.001 \mathrm{~mm} / \mathrm{s}$ e temperatura de ensaio de $25^{\circ} \mathrm{C}$.

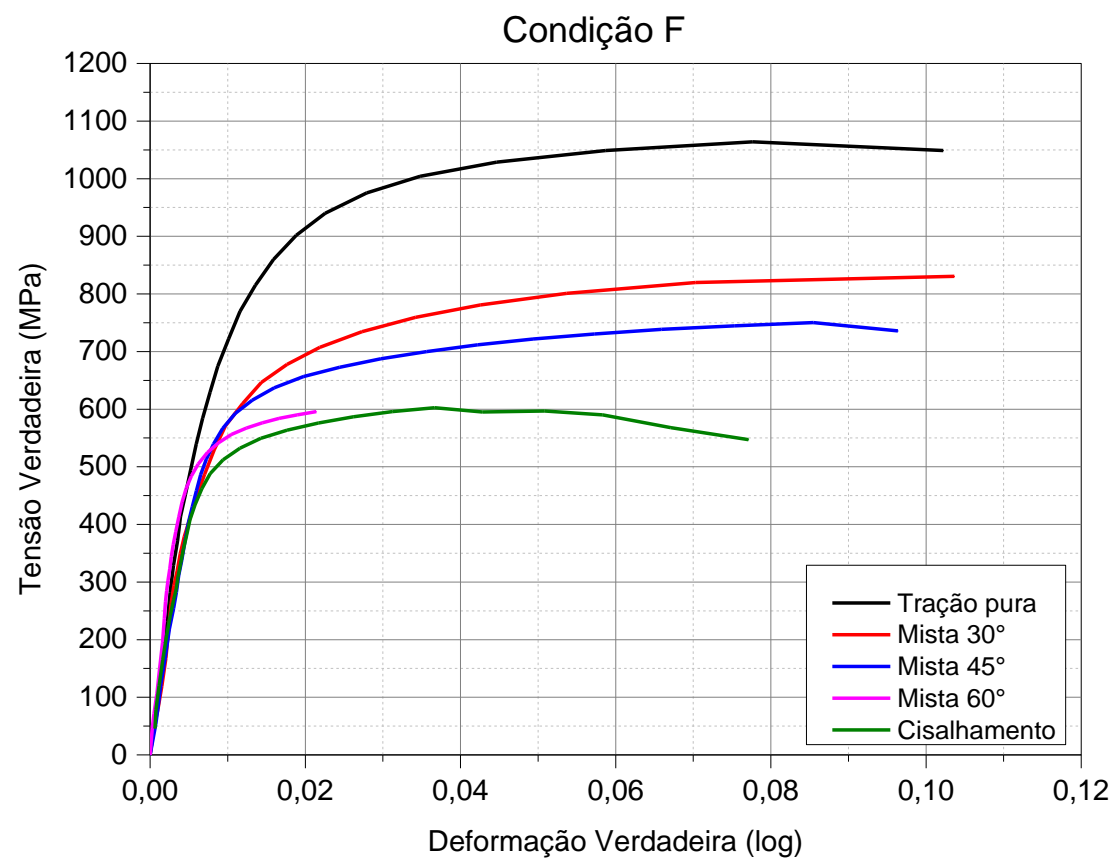

Figura 9-50 - Curvas do ensaio de tração na condição 1500RPM, 70mm/min de avanço, taxa de tração $0.1 \mathrm{~mm} / \mathrm{s}$ e temperatura de ensaio de $200^{\circ} \mathrm{C}$. 


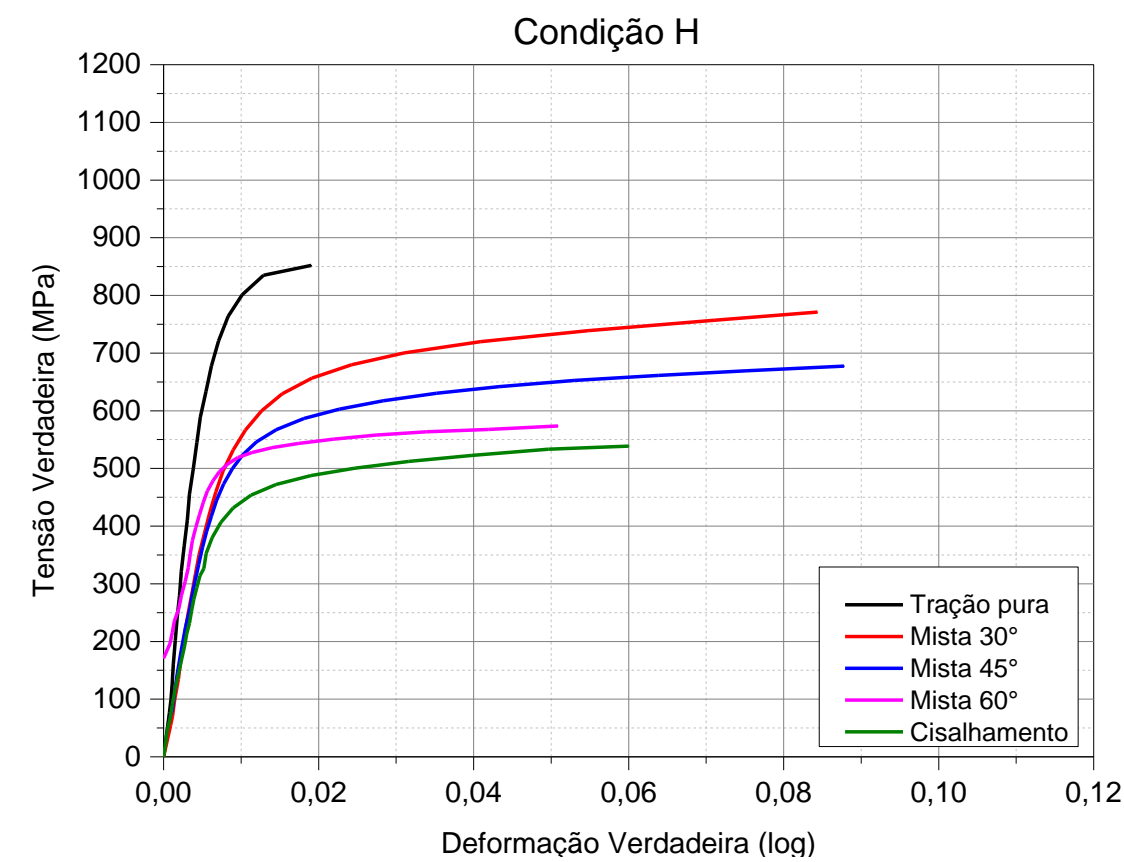

Figura 9-51 - Curvas do ensaio de tração na condição 1650RPM, $60 \mathrm{~mm} / \mathrm{min}$ de avanço, taxa de tração $0.1 \mathrm{~mm} / \mathrm{s}$ e temperatura de ensaio de $340^{\circ} \mathrm{C}$.

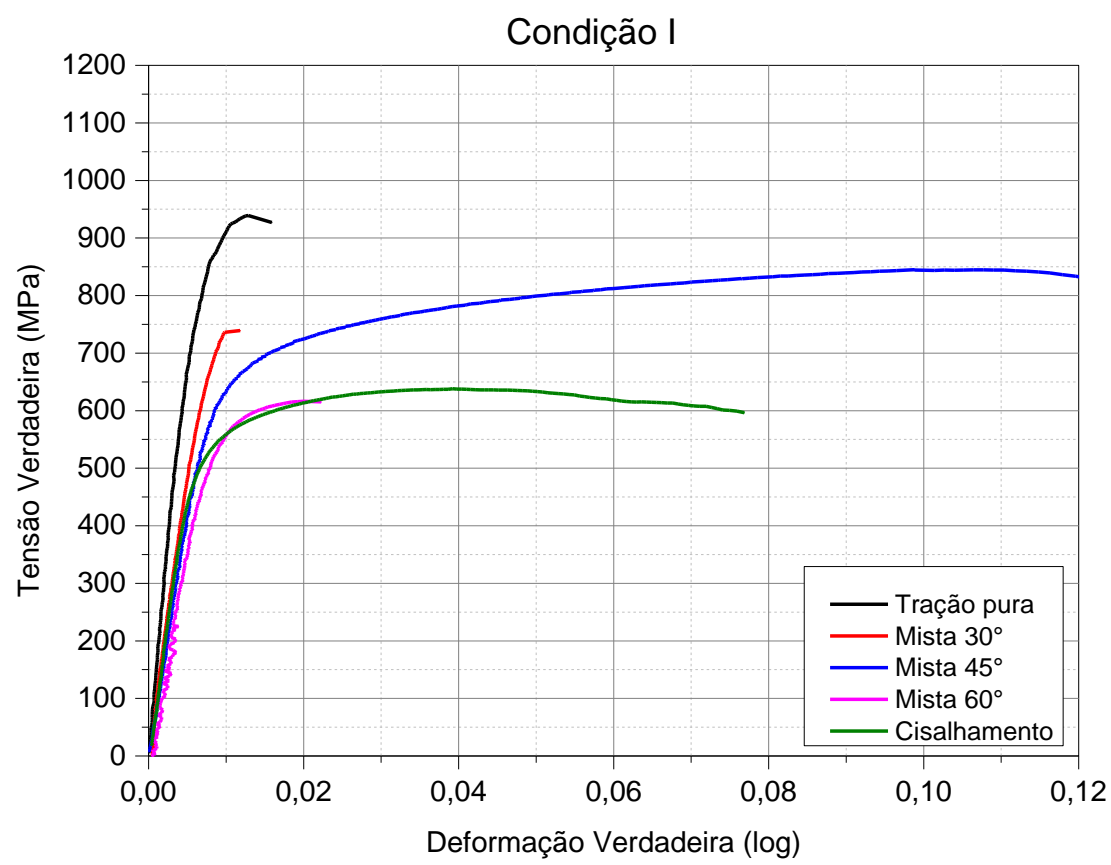

Figura 9-52 - Curvas do ensaio de tração na condição 1650RPM, $70 \mathrm{~mm} / \mathrm{min}$ de avanço, taxa de tração $0.01 \mathrm{~mm} / \mathrm{s}$ e temperatura de ensaio de $25^{\circ} \mathrm{C}$.

Para fins de validação um pré-modelo em elementos finitos (EF) foi criado para simular o comportamento da condição $\mathrm{F} 1$ (1500RPM, $70 \mathrm{~mm} / \mathrm{min}$ ) em tração pura, taxa de tração $0.1 \mathrm{~mm} / \mathrm{s}$ e temperatura de ensaio de $200^{\circ} \mathrm{C}$. O modelo foi criado e simulado no software Abaqus disponibilizado pelo Laboratório de Engenharia de Fabricação da Escola Politécnica da USP. Foi baseado na geometria dos corpos de 
prova ensaiados com ARCAN, porém somente a área de ruptura foi modelada visando economia computacional. A malha do modelo foi criada com 1288 elementos do tipo triangular-linear CPS3, este elemento conta com três nós e é próprio para modelos de tensão plana. Os dados utilizados para modelar o material foram retirados da condição $\mathrm{F} 1$ ensaiada:

- Módulo de Young: $176.766 \mathrm{MPa}$

- Coeficiente de Poisson: 0.3

- Curva de plasticidade: Figura 9-53

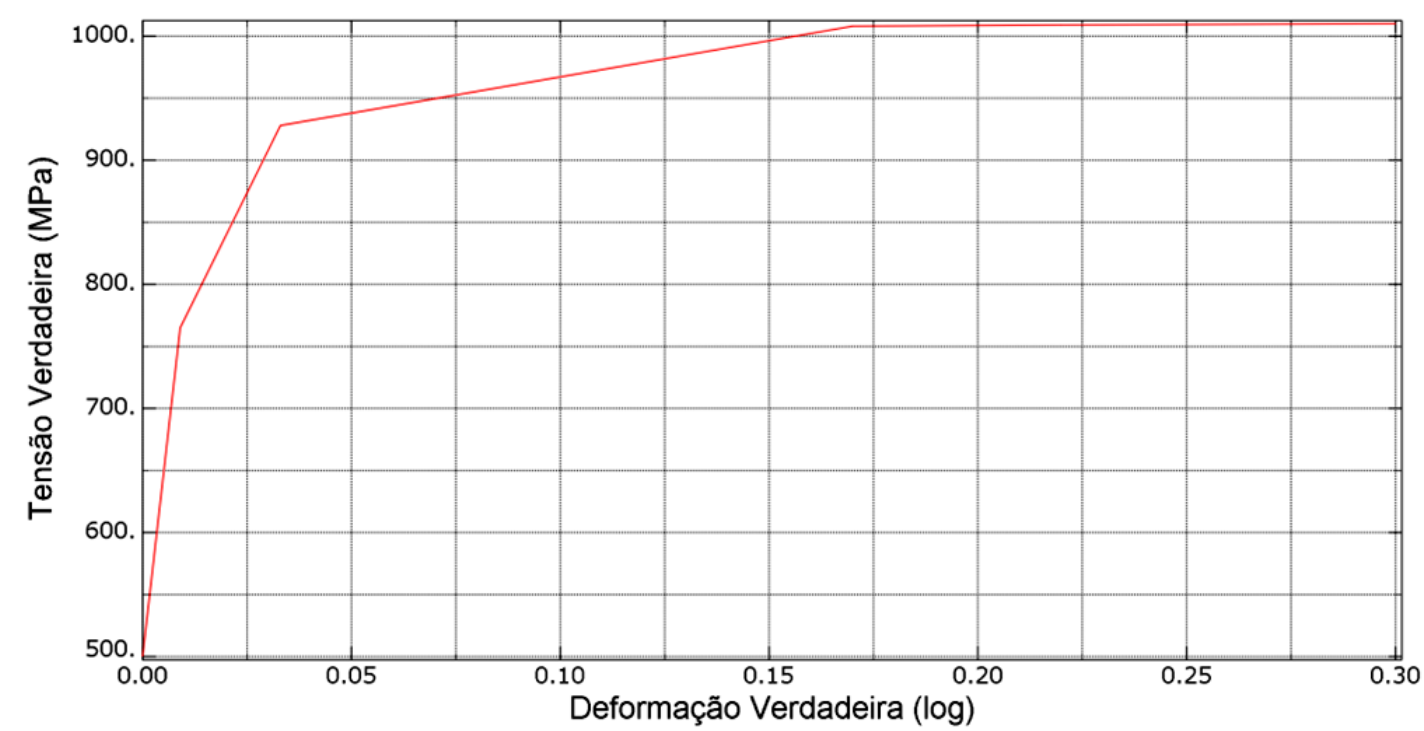

Figura 9-53 - Curva de plasticidade retirada do experimento F1: tração pura 1500RPM, $70 \mathrm{~mm} / \mathrm{min}$ de avanço, taxa de tração $0.1 \mathrm{~mm} / \mathrm{s}$ e temperatura de ensaio de $200^{\circ} \mathrm{C}$.

A Figura 9-54 apresenta o resultado da simulação. Quando comparada com a imagem real relativa à medição de imagens (Figura 9-55) é possível verificar correspondência entre os valores. Em ambos os casos a legenda de valores se encontra na escala logarítmica de deformação.

Observa-se uma clara correlação de comportamento mecânico, entre o cálculo da deformação pelas imagens digitais e a simulação em elementos finitos. $O$ valor de tensão para referência de comparação utilizado foi de aproximadamente $1000 \mathrm{MPa}$ em ambas as figuras. O erro apresentado na simulação foi de $18 \%$, indicando a necessidade de uma reavaliação do modelo a fim de diminuir a discrepância dos valores. 


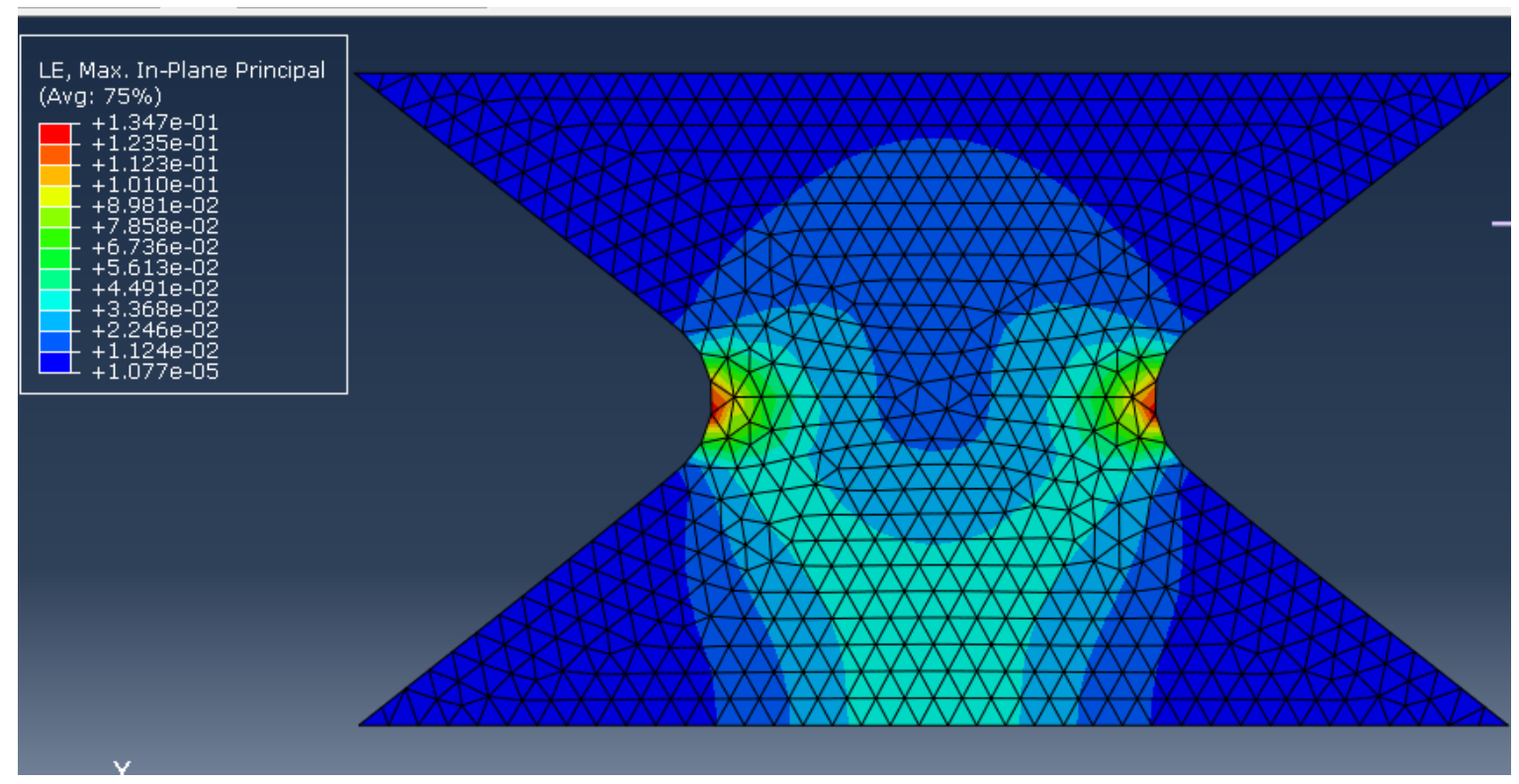

Figura 9-54 - Simulação em EF da condição F1 em tensão plana (tração pura 1500RPM, $70 \mathrm{~mm} / \mathrm{min}$ de avanço, taxa de tração $0.1 \mathrm{~mm} / \mathrm{s}$ e temperatura de ensaio de $200^{\circ} \mathrm{C}$ ).

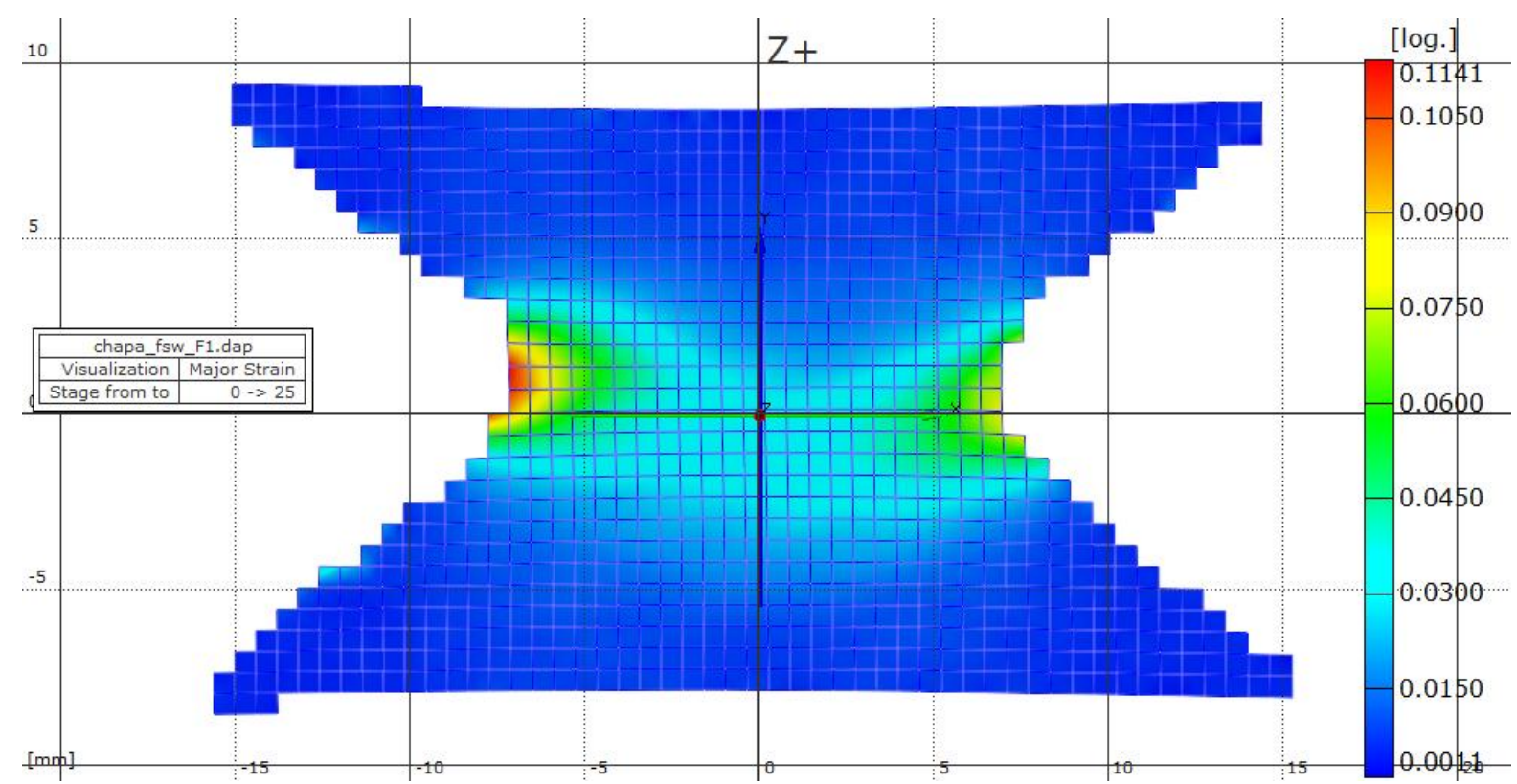

Figura 9-55 - Medição real da condição F1 para comparação com EF (tração pura 1500RPM, $70 \mathrm{~mm} / \mathrm{min}$ de avanço, taxa de tração $0.1 \mathrm{~mm} / \mathrm{s}$ e temperatura de ensaio de $200^{\circ} \mathrm{C}$ ). 


\subsection{Modelos de plasticidade}

\subsubsection{Proposição de um sistema de equações para condição mista}

Para ensaios com situação de condição mista em tração e cisalhamento, como é o caso do ensaio com dispositivo de ARCAN, são necessárias as deduções específicas além das apresentadas até aqui $(6.38,40,42,43)$ diferentes das encontradas até agora para cada caso ensaiado. $O$ ensaio de ARCAN permite ensaio nas situações de tração pura, cisalhamento puro, condição mista de tração e cisalhamento a $30^{\circ}, 45^{\circ}$ e $60^{\circ}$.

De acordo com (ARCAN et al., 1978; DOYOYO; MOHR, 2003) temos a seguinte situação para os ensaios executados:

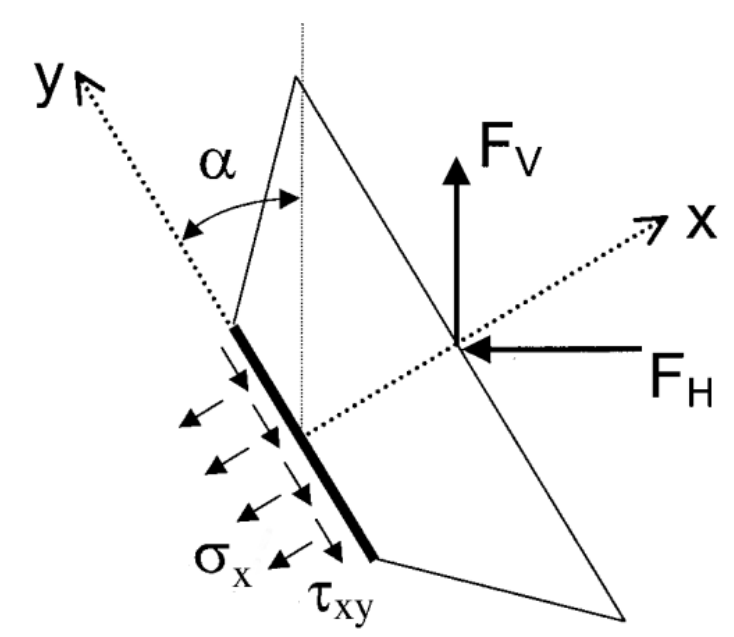

Figura 9-56 Diagrama de forças atuantes no ensaio de ARCAN, (MOHR; DOYOYO, 2003)

O conceito básico, é que o corpo de provas para o teste ARCAN possui uma secção bem definida, geralmente referida como a secção significativa $A$, onde as tensões são consideradas uniformes. A Figura 9-56 mostra a secção significativa considerada uniforme como a linha em negrito no centro do corpo de provas. Esta uniformidade é um resultado de uma escolha apropriada dos parâmetros geométricos do corpo de provas, de acordo com o material testado e o ângulo de carga biaxial. Outro resultado que é uma função da geometria do corpo de provas é que as tensões na secção significativa são as mais altas e, assim, a ruptura ou o escoamento inicial é mais provável que ocorra nesta região. 
Segundo Doyoyo (ARCAN et al., 1978; MOHR; DOYOYO, 2003) a tensão de cisalhamento média, $\tau_{x y}$, e a tensão normal média, $\sigma_{x x}$, na secção significativa são definidas num sistema de coordenadas local, em que o eixo y é paralelo e o eixo x é perpendicular à secção significativa (Figura 9-56). Ambos os componentes podem ser diretamente determinados a partir das forças que são transmitidas pela máquina de ensaios. A força que atua ao longo do eixo principal da máquina de ensaio universal, é denominada como a força vertical, FV. A força perpendicular à vertical é referida como a força horizontal, $\mathrm{FH}$. O ângulo entre os eixos fixos da máquina de teste (eixo vertical) e a direção da secção significativa (eixo x local) é referido como o ângulo de carga $\alpha$.

Portanto para o caso misto teremos que considerar a seguinte situação de tensões resultantes do ensaio de ARCAN:

$\sigma_{x x}^{\alpha}=\frac{F_{V}}{A} \cos \alpha$

$\tau_{x y}^{\alpha}=\frac{F_{V}}{A} \operatorname{sen} \alpha$

Do ensaio de tração uniaxial temos o valor da força em cada situação de inclinação $\alpha$ do dispositivo de ARCAN, a área da secção $A$ é considerada sempre constante devido a confecção dos corpos de prova por usinagem, o que garantiu tolerâncias estreitas de geometria $(+0,025 /-0.025 \mathrm{~mm})$. Para situação de cargas mistas teremos uma curva tensão por deformação cuja tensão resultante média será definida como:

$$
\sigma_{\alpha}=\frac{F_{V}}{A}
$$

E para cada situação teremos sempre dois valores diferentes de zero para cada ângulo $\alpha$ ensaiado, a tensão de cisalhamento média $\tau_{x y}$ e a tensão normal média $\sigma_{x x}$

Estes valores serão empregados nas fórmulas do critério de CPB06 para geração do sistema de equações para o levantamento dos parâmetros de anisotropia. 
Considerando $\sigma_{y y}=0$, e executando a substituição em $6.34(35,36,37)$ temos que:

$$
\begin{aligned}
& \Sigma_{\mathrm{xx}}=\Phi_{1} \sigma_{x x}^{\alpha} \\
& \Sigma_{\mathrm{yy}}=\Phi_{2} \sigma_{x x}^{\alpha} \\
& \Sigma_{\mathrm{zz}}=\Phi_{3} \sigma_{x x}^{\alpha} \\
& \Sigma_{\mathrm{xy}}=C_{66} \tau_{x y}^{\alpha}
\end{aligned}
$$

Para cada condição de ângulo $\alpha$ ensaiado, teremos as seguintes equações para os valores principais das transformadas:

Para o ângulo $\alpha$ igual a $30^{\circ}$ teremos:

$$
\begin{aligned}
& \Sigma_{1}=\sigma_{30}\left[\frac{\sqrt{3}}{4}\left(\Phi_{1}+\Phi_{2}\right)+\frac{\sqrt{\mathrm{C} 66^{2}+\left(\sqrt{\frac{3}{2}}\left(\Phi_{1}-\Phi_{2}\right)\right)^{2}}}{2}\right]=\sigma_{30}[\mathrm{~A}] \\
& \Sigma_{2}=\sigma_{30}\left[\frac{\sqrt{3}}{4}\left(\Phi_{1}+\Phi_{2}\right)-\frac{\sqrt{\mathrm{C} 66^{2}+\left(\sqrt{\frac{3}{2}}\left(\Phi_{1}-\Phi_{2}\right)\right)^{2}}}{2}\right]=\sigma_{30}[\mathrm{~B}] \\
& \Sigma_{3}=\sigma_{30}\left[\frac{\sqrt{3}}{2}\left(\Phi_{3}\right)\right]=\sigma_{30}[\mathrm{C}]
\end{aligned}
$$

Para o ângulo $\alpha$ igual a $45^{\circ}$ teremos:

$$
\begin{aligned}
& \Sigma_{1}=\sigma_{45}\left[\frac{\sqrt{2}}{4}\left(\Phi_{1}+\Phi_{2}\right)+\frac{\sqrt{2 \mathrm{C} 66^{2}+\left(\sqrt{\left.\frac{2}{2}\left(\Phi_{1}-\Phi_{2}\right)\right)^{2}}\right.}}{2}\right]=\sigma_{45}[\mathrm{D}] \\
& \Sigma_{2}=\sigma_{45}\left[\frac{\sqrt{2}}{4}\left(\Phi_{1}+\Phi_{2}\right)-\frac{\sqrt{2 \mathrm{C} 66^{2}+\left(\sqrt{\frac{2}{2}}\left(\Phi_{1}-\Phi_{2}\right)\right)^{2}}}{2}\right]=\sigma_{45}[\mathrm{E}] \\
& \Sigma_{3}=\sigma_{45}\left[\frac{\sqrt{2}}{2}\left(\Phi_{3}\right)\right]=\sigma_{45}[\mathrm{~F}]
\end{aligned}
$$


Para o ângulo $\alpha$ igual a $60^{\circ}$ teremos:

$$
\begin{aligned}
& \Sigma_{1}=\sigma_{60}\left[\frac{1}{4}\left(\Phi_{1}+\Phi_{2}\right)+\frac{\sqrt{3 \mathrm{C} 66^{2}+\left(\frac{\Phi_{1}-\Phi_{2}}{2}\right)^{2}}}{2}\right]=\sigma_{60}[\mathrm{G}] \\
& \Sigma_{2}=\sigma_{60}\left[\frac{1}{4}\left(\Phi_{1}+\Phi_{2}\right)-\frac{\sqrt{3 \mathrm{C} 66^{2}+\left(\frac{\Phi_{1}-\Phi_{2}}{2}\right)^{2}}}{2}\right]=\sigma_{60}[\mathrm{H}] \\
& \Sigma_{3}=\sigma_{60}\left[\frac{\Phi_{3}}{2}\right]=\sigma_{60}[\mathrm{I}]
\end{aligned}
$$

Substituindo as equações de 6.51 a 6.59 no critério de Cazacu (2006) teremos as seguintes equações para resolução do sistemas de equações:

$$
\begin{aligned}
& \sigma_{30}=\left\{\frac{F}{[|A|-k . A]^{a}-[|B|-k . B]^{a}-[|C|-k . C]^{a}}\right\}^{1 / a} \\
& \sigma_{45}=\left\{\frac{F}{[|D|-k . D]^{a}-[|E|-k . E]^{a}-[|F|-k . F]^{a}}\right\}^{1 / a} \\
& \sigma_{60}=\left\{\frac{F}{[|G|-k . G]^{a}-[|H|-k . H]^{a}-[|I|-k . I]^{a}}\right\}^{1 / a}
\end{aligned}
$$

Estas relações, somadas às equações de tração, cisalhamento puro e da anisotropia na tração pura $(6.38,42$ e 43$)$ resultarão no sistema de equações que irão determinar os coeficientes de anisotropia para o caso estudado.

\subsubsection{Implementação do sistema de equações na condição mista}

Para verificar a compatibilidade dos valores experimentais, alguns dados foram plotados em conjunto com o modelo CPB06. Na Figura 9-57 os valores são comparados aos critérios de escoamento de Tresca, Von Mises, CPB06 k=0,4 e CPB06 $\mathrm{k}=1$. Na região próxima ao cisalhamento puro é possível observar que os critérios de Tresca e Von Mises divergem dos experimentos. 
O critério CPB06 para k=0.4 e k=1 apresenta uma maior inflexão nesta região, o que o torna mais preciso para modelar estas condições em ligas que apresentam de anisotropia em função da estrutura.

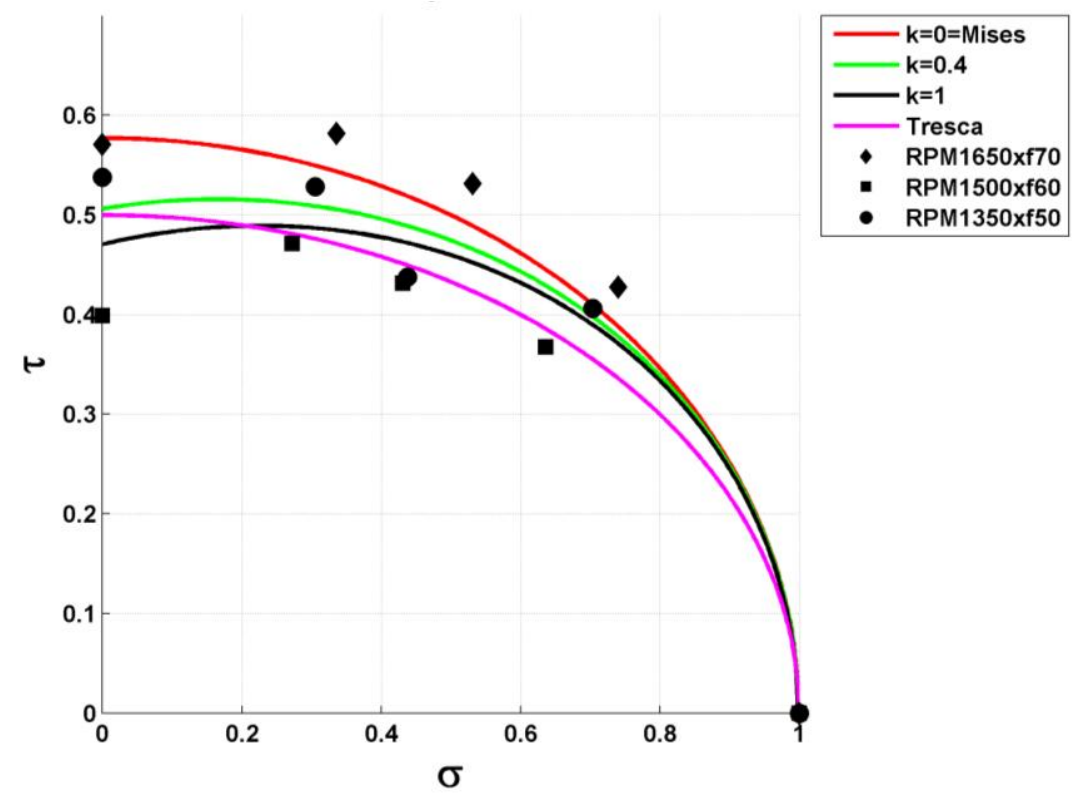

Figura 9-57 - Critério CPB06 em diversas condições em conjunto com os valores de alguns ensaios efetuados.

Para o levantamento através do critério CPB06 (CAZACU et al., 2006) dos coeficientes de anisotropia, os valores de tensão de escoamento $\mathrm{RP}_{02}$ da tabela Tabela 9-3 foram utilizados no modelo. Com a utilização do Software Matlab@ foi implementado o sistema de equações que deve respeitar a seguinte condição:

$$
F_{\alpha}=\frac{\Psi^{\text {num }}}{\Psi^{\exp }}-1=0
$$

Onde $i$ variando de 1 a 6 , indicará qual equação está sendo tratada em função do ensaio de ARCAN, sendo $0^{\circ}$ tração pura, $90^{\circ}$ cisalhamento puro, $30^{\circ} ; 45^{\circ} ; 60^{\circ}$, condições mistas e $i=6$ para a anisotropia.

As funções de erro para otimização dos valores são da seguinte forma:

$$
H_{\alpha_{i}}=\left[\frac{\left(\sigma_{\alpha} / \sigma_{\text {norm }}\right)^{\text {teo }}}{\left(\sigma_{\alpha} / \sigma_{\text {norm }}\right)^{\text {num }}}\right]_{i}^{2} \quad \text { para } i=1 \text { a } 6
$$


Onde o indice teo significa teórico (equações), num significa numérico (retirado do ensaio) e norm significa valor de referência para normalização. No caso destes experimentos o valor de referência para normalização é o valor na condição de tração pura. Após executar a rotina minimizadora do (Matlab Isqnonlin - Non linear least square) foram determinados os valores, apresentados na Tabela 9-5 para os parâmetros de anisotropia, considerando os seguintes valores como constantes: $a=2 ; C 66=1 \mathrm{k}=-0.15$.

Tabela 9-5 Valor das constantes de anisotropia para cada condição ensaiada

\begin{tabular}{ccccccccc}
\hline & $\mathbf{A}$ & $\mathbf{B}$ & $\mathbf{C}$ & $\mathbf{D}$ & $\mathbf{E}$ & $\mathbf{F}$ & $\mathbf{H}$ & $\mathbf{I}$ \\
\hline $\mathbf{C 1 1}$ & 0.4100 & 0.2030 & 0.0500 & 0.3100 & -0.1000 & 0.4203 & 0.4100 & 0.4100 \\
\hline $\mathbf{C 1 2}$ & -0.0010 & 0.2101 & -0.1100 & -0.1501 & -0.4500 & -0.0010 & -0.001 & -0.0110 \\
\hline $\mathbf{C 1 3}$ & -0.9178 & -0.689 & -0.7890 & -0.808 & -0.7900 & -0.8178 & -0.808 & -0.9178 \\
\hline $\mathbf{C 2 2}$ & 0.8067 & 1.6667 & 1.0667 & 1.1600 & 1.0400 & 1.0667 & 1.1600 & 0.8067 \\
\hline $\mathbf{C 2 3}$ & 0.2250 & 0.9006 & 0.6501 & 0.0508 & 0.3057 & 0.1057 & 0.1508 & 0.2250 \\
\hline $\mathbf{C 3 3}$ & -1.3580 & -1.2577 & -0.9700 & -1.207 & -1.9026 & -0.8577 & -1.070 & -1.3580 \\
\hline
\end{tabular}

Similar procedimento de adoção do parâmetro C66 e k como valores constantes é adotado por Cazacu (CAZACU et al., 2006) e depois por (GILLES, G et al., 2010; TUNINETTI et al., 2013), no caso desta tese visa suprir a falta de dados complementares que só podem ser levantados com ensaios de compressão pura e sua combinação com outro tipo de carregamento.

As Figura 9-58 até Figura 9-65 apresentam a plotagem da função CPB06 para os parâmetros da Tabela 9-5, em conjunto são plotados os valores experimentais (círculos em negrito) e o valor equivalente para modelagem com Von Mises (curva azul), é possível observar uma grande aderência da curva CPB06 (vermelha) aos pontos experimentais. É possível verificar também a possibilidade da utilização proposta neste trabalho das condições mistas no critério CPB06.

O método empregado no levantamento da curva CPB06 da Figura 9-58 até a Figura 9-65 apresenta os limites para as condições de escoamento em diversas situações de carregamento compostas. Porém, devido à falta de pontos experimentais que só podem ser obtidos em ensaios com compressão, o limite de validade dos gráficos abaixo fica restrito para o quadrante onde os pontos experimentais foram plotados. A linha tracejada em verde na Figura 9-58 indica esta região, que se repete para as demais figuras uma vez que o método empregado foi o mesmo. Embora o limite de aplicação deste modelo pareça pequeno, os esforços aplicados em chapas finas semelhantes às utilizadas nesta tese se encontram 
predominantemente nesta região. Quando submetidas aos processos de conformação, as chapas finas em geral sofrem esforços de tração e cisalhamento, que devidamente combinados podem ser expressos em função de uma tensão principal $\sigma_{1}$ e uma tensão secundária $\sigma_{2}$ conforme indicado nas Figura 9-58 até Figura 9-65.

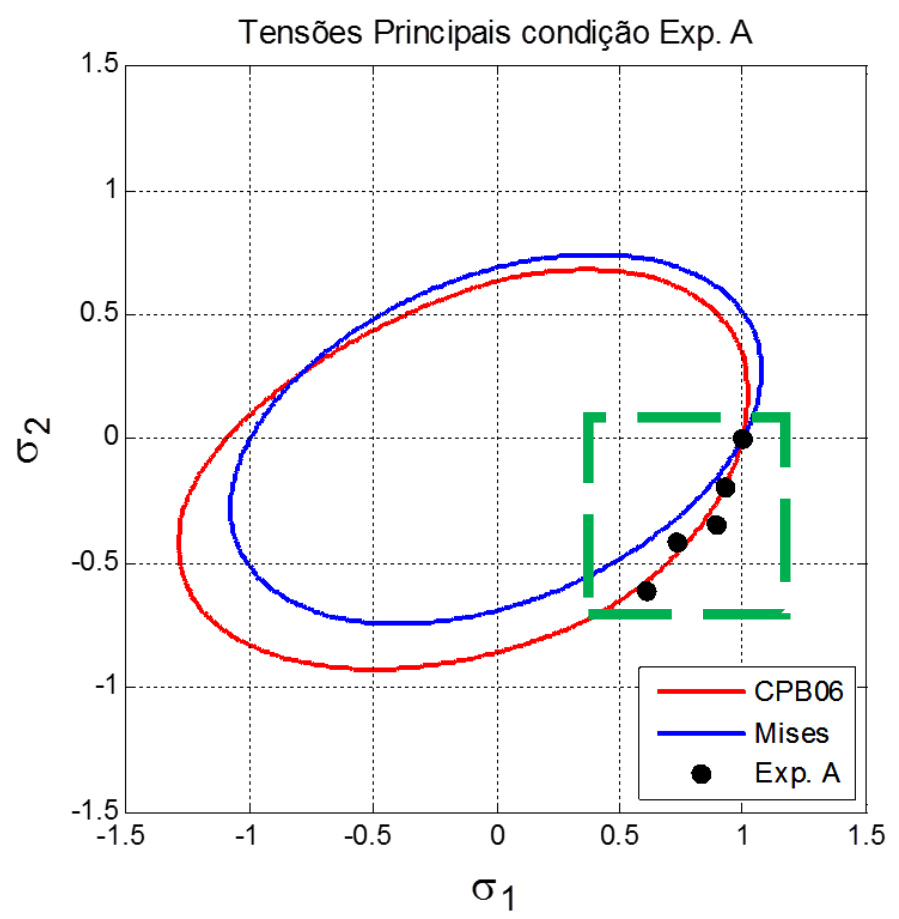

Figura 9-58 - Superfície de escoamento para a chapa FSP processadas na condição 1350RPM, $50 \mathrm{~mm} / \mathrm{min}$ de avanço, taxa de tração $0.1 \mathrm{~mm} / \mathrm{s}$ e temperatura de ensaio de $25^{\circ} \mathrm{C}$.

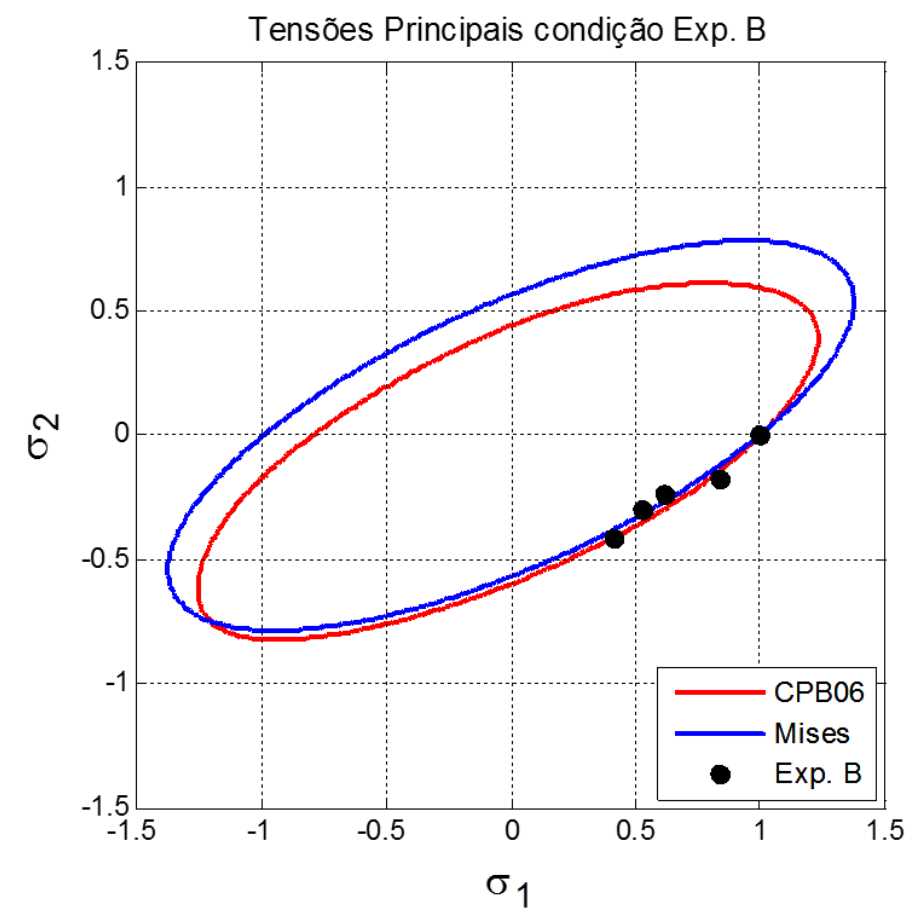

Figura 9-59 - Superfície de escoamento para a chapa FSP processadas na condição 1350RPM, $60 \mathrm{~mm} / \mathrm{min}$ de avanço, taxa de tração $0.01 \mathrm{~mm} / \mathrm{s}$ e temperatura de ensaio de $200^{\circ} \mathrm{C}$. 


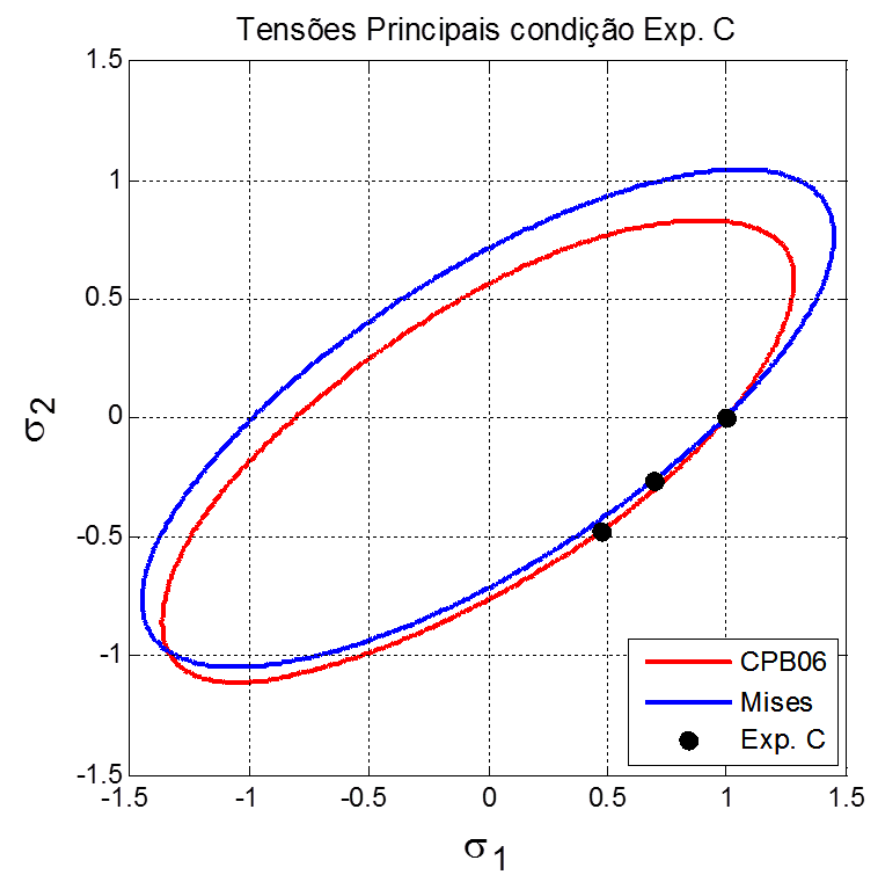

Figura 9-60 - Superfície de escoamento para a chapa FSP processadas na condição 1350RPM, $70 \mathrm{~mm} / \mathrm{min}$ de avanço, taxa de tração $0.001 \mathrm{~mm} / \mathrm{s}$ e temperatura de ensaio de $340^{\circ} \mathrm{C}$.

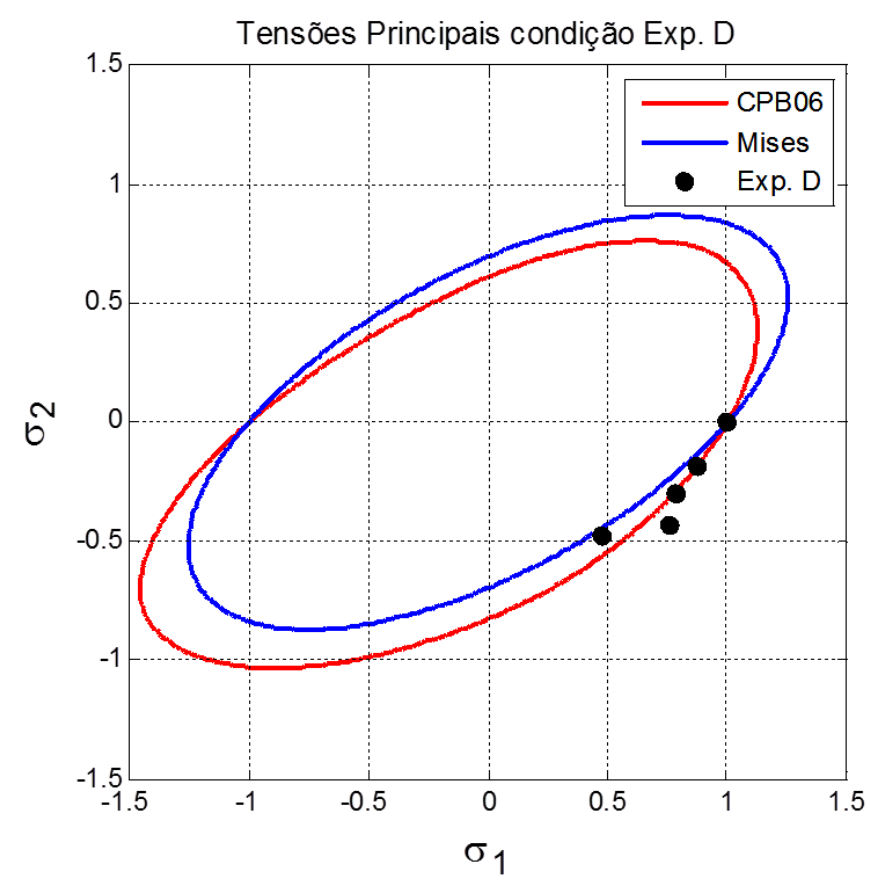

Figura 9-61 - Superfície de escoamento para a chapa FSP processadas na condição 1500RPM, $50 \mathrm{~mm} / \mathrm{min}$ de avanço, taxa de tração $0.01 \mathrm{~mm} / \mathrm{s}$ e temperatura de ensaio de $340^{\circ} \mathrm{C}$. 


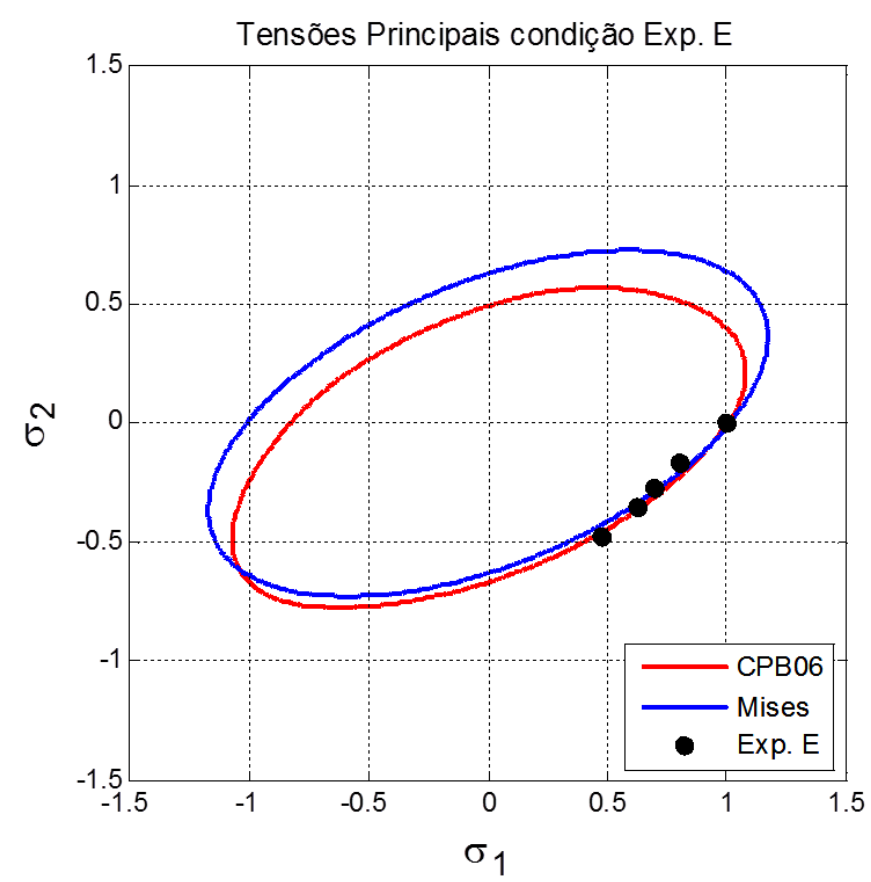

Figura 9-62 - Superfície de escoamento para a chapa FSP processadas na condição 1500RPM, $60 \mathrm{~mm} / \mathrm{min}$ de avanço, taxa de tração $0.001 \mathrm{~mm} / \mathrm{s}$ e temperatura de ensaio de $25^{\circ} \mathrm{C}$.

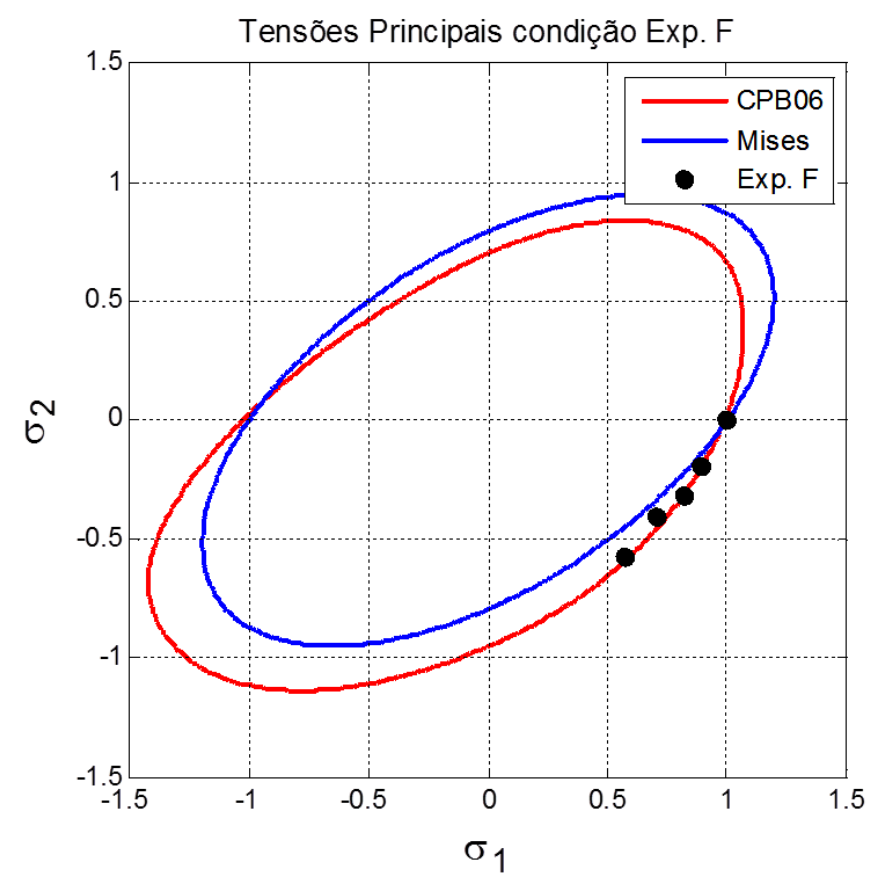

Figura 9-63 - Superfície de escoamento para a chapa FSP processadas na condição 1500RPM, $70 \mathrm{~mm} / \mathrm{min}$ de avanço, taxa de tração $0.1 \mathrm{~mm} / \mathrm{s}$ e temperatura de ensaio de $200^{\circ} \mathrm{C}$. 


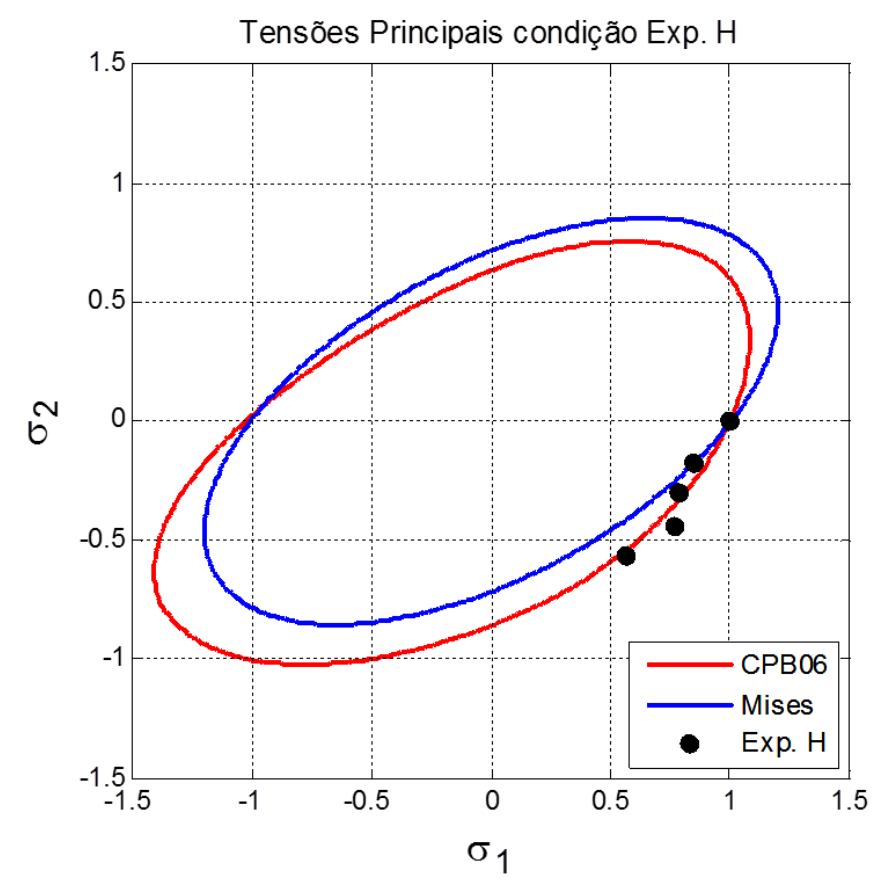

Figura 9-64 - Superfície de escoamento para a chapa FSP processadas na condição 1650RPM, $60 \mathrm{~mm} / \mathrm{min}$ de avanço, taxa de tração $0.1 \mathrm{~mm} / \mathrm{s}$ e temperatura de ensaio de $340^{\circ} \mathrm{C}$.

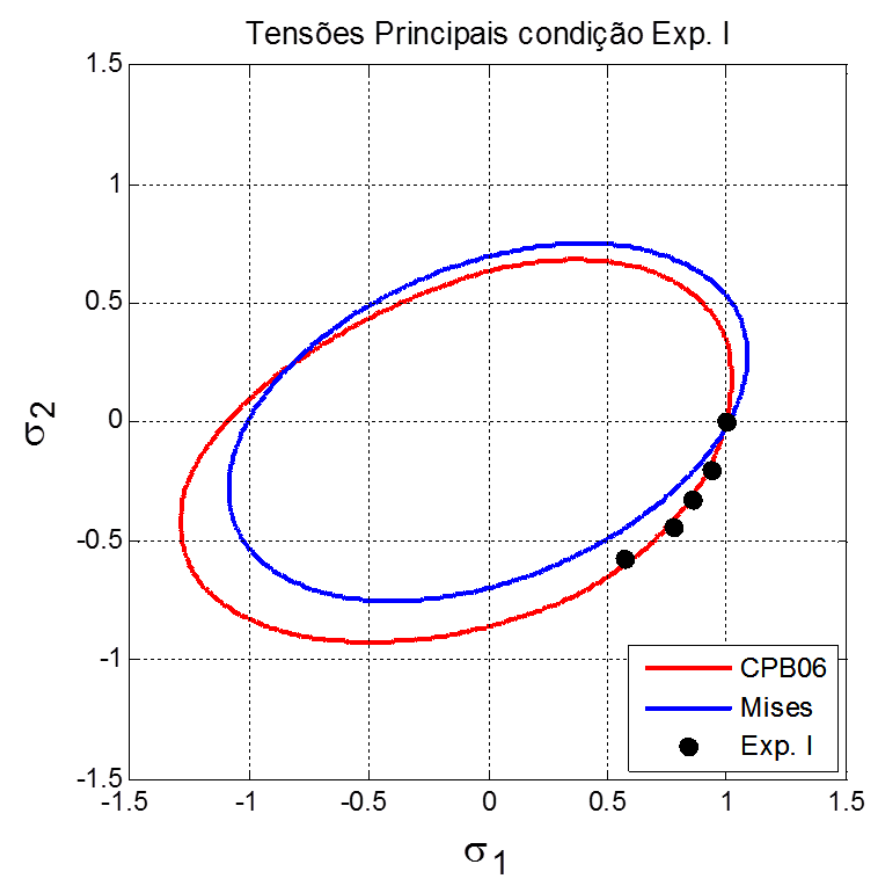

Figura 9-65 - Superfície de escoamento para a chapa FSP processadas na condição 1650RPM, $70 \mathrm{~mm} / \mathrm{min}$ de avanço, taxa de tração $0.01 \mathrm{~mm} / \mathrm{s}$ e temperatura de ensaio de $25^{\circ} \mathrm{C}$.

A maior parte dos critérios de escoamento são implementados em códigos de programas de elementos finito dedicado à simulação numérica. O critério de escoamento de Von Mises ainda é o mais utilizado na prática, graças à sua simplicidade em descrever o comportamento de materiais de forma isotrópica. Para 
materiais que apresentam anisotropia fraca ou forte, estas simulações perdem sua validade devido à falta da habilidade de seus parâmetros em indicar esta situação. Por outro lado, o aumento da complexidade de um critério, o que melhora o ajuste dos dados experimentais, resulta em um maior esforço experimental para identificar os parâmetros de materiais relacionados, que por sua vez, carecem frequentemente significado físico, especialmente se identificado através de técnicas numéricas como é caso dos parâmetros C11 a C66 empregados nesta tese.

A necessidade de realizar testes diversificados, em sua preferência multiaxiais, em conjunto com técnicas de análise inversas para identificar os parâmetros de material, pode restringir a aplicação dos modelos mais complexos para comunidade científica, limitando a sua utilização na prática industrial para somente casos específicos. Por outro lado, a extensão dos critérios de escoamento visando levar em conta a influência de outros parâmetros do processo, tais como a temperatura e taxa de deformação, requerem o acoplamento com modelos de encruamento, o que torna toda a avaliação mais complexa. Consequentemente haverá um aumento no esforço experimental para identificar os parâmetros do material necessários para correta validação de um critério mais completo.

Ferramentas de simulação virtual de processos de conformação são uma perspectiva para as industrias que carecem de previsões precisas sobre as características geométricas finais de uma peça e seus possíveis defeitos e falhas. Em função destas previsões e com base nos parâmetros do processo escolhido, decisões críticas no projeto do processo podem ser tomados, afetando fortemente 0 sucesso técnico e econômico do processo, tais como a seleção da cadeia de processo adequado, o projeto de ferramentas e equipamentos até o desenho do processo em relação à vida útil do produto. 


\section{CONCLUSÕES}

$\mathrm{Na}$ análise dos resultados desta tese tem-se as seguintes conclusões:

- Foi possível neste trabalho executar o processamento por atrito linear em chapas de titânio da liga Ti-6Al-4V em um equipamento não dedicado e de uso industrial. Na máquina foram adaptados dispositivos de fixação especialmente projetados para o processamento por atrito linear, sistema de medição de temperatura por infravermelho e um sistema de fornecimento de gás de proteção para o processo. Um programa CNC foi especialmente criado levando em conta as necessidade específicas do processo.

- As características mecânicas foram avaliadas em um ensaio não convencional de tração com o uso de um dispositivo que possibilitou a aplicação de cargas mistas de tração e cisalhamento nos corpos de prova. Para esta proposta foi projetado e construído um dispositivo especial (Garra para ensaio ARCAN) que possibilitou o posicionamento da seção principal do corpo de prova em ângulos diferentes no ensaio.

- A condição de tensão residual e dureza na região processada também pode ser avaliada e se mostrou também dependente das condições de rotação da ferramenta ensaiadas no FSP. Em todas as condições estudadas o pico dos valores obtidos se situou na região central do corpo de provas.

- Através das análises metalográficas pode se constatar que o metal de base apresenta uma microestrutura bimodal consistindo nas fases $\alpha$ equiaxial e $\beta$ nos contornos de grãos. A microestrutura na zona termicamente afetada é semelhante à do metal de base, e mais perto da zona de processamento a fração de volume da fase $\beta$ aumenta de forma gradual devido ao aumento da temperatura de pico provocada pelo processo. O pico de temperatura nesta região foi suficientemente elevado para que ocorresse a transformação de fases $(\alpha+\beta \rightarrow \beta \rightarrow \alpha+\beta)$ devido ao ciclo térmico durante o FSP.

- As microestruturas na região processada são caracterizadas por uma estrutura $\beta$ totalmente transformada. Isto sugere que as temperaturas de pico na região processada excederam a temperatura $\beta$-transus durante $o$ processamento e a transformação da fase $\beta \rightarrow \alpha+\beta$ ocorreu durante a fase de resfriamento. $A$ transformação da fase $\beta$ para $\alpha$ resultou na formação de agulhas de fase $\alpha$ 
formados nos contornos de grão $\beta$ e pelo interior dos grãos da fase $\beta$ ( $\alpha$ acicular). Adicionalmente pequenas regiões com estrutura equiaxial de grãos ( $\alpha$ globular) foram observados na zona de processamento.

- A existência de fase a globular na ZTMA e regiões limítrofes entre a ZTMA e ZTA, pode ser explicada por dois mecanismos agindo individualmente ou em conjunto.

- Primeiro mecanismo - A deformação a quente no campo de fase $\beta$ acelera a transformação da fase $\beta$ em fase $\alpha$, presumivelmente devido a um aumento no número de locais de nucleação para a nucleação da fase a globular (SESHACHARYULU et al., 2000). Além disso, observa-se que a deformação aumenta a fração de volume de grãos a globulares que se formaram ao longo dos contornos de grão iniciais da fase $\beta$. As características das microestruturas obtidas por deformação nas regiões afetadas termomecanicamente, podem ser mascaradas por transformações de fases subsequentes, portanto a avaliação desta região deve ser executada com cautela.

- Segundo mecanismo - Devido ao movimento de mistura do material, provocado pela rotação e avanço da ferramenta, o material que está na superfície, ou logo abaixo dela, pode ser movimentado para baixo. A taxa de resfriamento perto da superfície da peça é maior, por estar em contato com o ar e com o fluxo de argônio, portanto a estrutura já está em uma fase de transformação adiantada em relação ao núcleo. Segundo os estudos de Dabrowski (DĄBROWSKI, 2011a, 2011b) e Surand (SURAND, 2013), a condição para a existência desta fase a globular $\left(\alpha_{p n}\right)$ na região da ZTMA,é um resfriamento a partir de uma temperatura abaixo da $\beta$-transus.

- Nas análises de microdureza transversal a rotação possui a maior influência no resultado final, as maiores rotações provocaram os menores valores de dureza. A interação entre os parâmetros $S$ e f (rotação e avanço) também se mostrou significativa. Para estes experimentos foi possível notar uma camada superficial do material com dureza mais elevada. Esta não homogeneidade na camada superficial é resultado de um resfriamento brusco à uma taxa muito acima da experimentada pelo restante da chapa. Outra hipótese seria a contaminação por oxigênio na camada superficial da chapa devido ao aumento da temperatura (formação de uma camada de $\mathrm{TiO}_{2}$ ). A região processada, em todas as amostras, foi protegida com a aplicação de gás argônio através de mangueiras 
posicionadas ao longo do dispositivo. Este método não pode garantir efetivamente que alguma região da chapa não tenha sido contaminada, uma vez que o dispositivo do FSP não foi totalmente enclausurado, porém um mínimo de proteção contra a contaminação foi proporcionado.

- A caracterização de condições de tração e cisalhamento em chapas da liga de titânio Ti-6Al-4V, processadas por FSP, foi avaliada através de uma série de ensaios em condições de carga uniaxiais, mistas e em diversas condições de carregamento. Foi demonstrado que o critério de escoamento ortotrópico CPB06, adaptado para as condições dos testes ARCAN, capta as principais características do comportamento observado nas diversas condições de ensaios para o início do escoamento.

- O critério de escoamento ortotrópico CPB06 para metais com estrutura HCP se mostrou bastante versátil, pois foi possível efetuar a definição de equações para condições mistas de carregamento (nos casos de tração com $30^{\circ}, 45^{\circ}$ e $60^{\circ}$ ) a partir da compatibilização das equações características do ensaio de ARCAN.

- A modelagem de superfícies de escoamento foi executada para cada condição de chapa soldada por FSP. Estas superfícies servem de referência prática para avaliar a futura condição de trabalho do material com esta característica. Cada condição ensaiada produziu um resultado diferente nas superfícies de escoamento, o que de fato se espera, pois cada situação de FSP (rotação e avanço) induziu um diferente estado de temperatura e deformação plástica, que resultou conforme verificado, em diferentes condições de microdureza nas amostras. Foi verificado que as menores durezas resultaram em menores valores de tensão de escoamento. Verificação baseada nas análises estatísticas efetuadas em função dos resultados de tensão de escoamento e microdureza.

- O método empregado no levantamento das superfícies de escoamento CPB06, apresentou os limites para as condições de escoamento em diversas situações de carregamento executadas a partir de dados experimentais desta tese. Porém, devido à falta de pontos experimentais que só podem ser obtidos em ensaios com compressão, o limite de validade dos gráficos fica restrito para o quadrante onde os pontos experimentais foram plotados. Embora o limite de aplicação deste modelo pareça pequeno, os esforços aplicados em chapas finas, semelhantes às utilizadas nesta tese, se encontram predominantemente nesta região. 


\section{SUGESTÕES PARA TRABALHOS FUTUROS}

- Ensaios biaxiais de compressão com torção em chapas.

- Modelagem numérica em elementos finitos da superfície de escoamento.

- Modelagem numérica em elementos finitos dos ensaios de tração.

- Ensaios triaxiais ou ensaios de conformação a quente na liga de titânio com uma região de FSW.

- Modelagem numérica em elementos finitos da condição de tensão residual.

- Modelagem de fases resultantes por elementos finitos.

- Simulação física das microestruturas equivalentes em máquinas de ensaio a quente (Gleeble). 


\section{BIBLIOGRAFIA}

ABU-FARHA, F. K.; KHRAISHEH, M. K. An integrated approach to the Superplastic Forming of lightweight alloys: towards sustainable manufacturing. Int. J. Sustainable Manufacturing, v. 1, p. 18-40, 2008.

ADV-TI. Adv-Ti group. Disponível em: <www.adv-ti.com>. Acesso em: 3/3/2015.

AHMED, T.; RACK, H. J. Phase transformations during cooling in $\alpha+\beta$ titanium alloys. Materials Science and Engineering: A, v. 243, p. 206-211, 1998.

ANTONY, J. Design of Experiments for Engineers and Scientists. 1a. ed. Jordan Hill: Butterworth-Heinemann, 2003. 152 p.

ARCAN, M.; HASHIN, Z.; VOLOSHIN, A. A Method to Produce Uniform Plane-stress States with Applications to Fiber-reinforced Materials. Experimental Mechanics, v. 18, p. 141-146, 1978.

ASM ALLOY CENTER DATABASE. ASM Alloy Center Database Titanium Alloy Ti 6Al-4V. Disponível em: <http://asminternational.orgv>. Acesso em: 13/2/2015

BABU, B. Physically Based Model for Plasticity and Creep of Ti-6Al-4V. Doctoral Thesis. Luleå University of Technology. Mechanical Engineering Division of Material Mechanics, 2008.

BANABIC, D. Sheet Metal Forming Processes. Editora Springer Berlin Heidelberg, $1^{\circ}$ ed, p.115, 2010.

BARBOSA, J.; MONTEIRO, A. C.; MINHO, U. Controlled Residual Surface Contamination of y TiAl, Induction Melted in Ceramic Crucibles. European congress on advanced materials, processes and applications. p.100-108, 2001.

BARIANI, P. F. et al. Testing formability in the hot stamping of HSS. CIRP Annals Manufacturing Technology, v. 57, p. 265-268, 2008.

BARLAT, F. Linear transfomation-based anisotropic yield functions. International Journal of Plasticity, v. 21, p. 1009-1039, 2005.

BARLAT, F.; BECKER, R. C.; HAYASHIDA, Y.; et al. Yielding description for solution strengthened aluminum alloys. International Journal of Plasticity, v. 13, n. 4, p. 385401, 1997.

BARLAT, F.; LEGE, D. J.; BREM, J. C. A six-component yield function for anisotropic materials. International Journal of Plasticity, v. 7, n. 7, p. 693-712, 1991.

BLANCHARD, S.; LANGRAND, B.; FABIS, J.; DENQUIN, A. Arcan test and strain field measurement to study material behaviour in 6056T78 FSW specimens. 6th International FSW Symposium Montréal, Canada. p.16, 2006. 
BORDINASSI, E. C. Contribuição ao estudo da integridade superficial de um aço inoxidável super-duplex após usinagem, 221 p., Tese (Doutorado), Departamento de engenharia Mecânica, Escola Politécnica da USP, Universidade de São Paulo, São Paulo, 2006.

BOX, G. E. P.; HUNTER, W. H.; HUNTER, J. S. Statistics for Experiments. 2ª ed. New York: John Wiley Publications, 2005. 633 p.

BRINKSMEIER, E. et al. Residual Stresses - Measurement and causes in machining processes. Annals of the CIRP, v 31, 1982, p. 491-510.

BUFFA, G.; DUCATO, A.; FRATINI, L. FEM based prediction of phase transformations during Friction Stir Welding of Ti6Al4V titanium alloy. Materials Science and Engineering A, v. 581, p. 56-65, 2013.

BUFFA, G.; FRATINI, L.; MICARI, F. Mechanical and microstructural properties prediction by artificial neural networks in FSW processes of dual phase titanium alloys. Journal of Manufacturing Processes, v. 14, n. 3, p. 289-296, 2012.

BURGERS, W. G. On the process of transition of the cubic-body-centered modification into the hexagonal-close-packed modification of zirconium. Physica, v. 1, n. 7-12, p. 561-586, 1934.

CAMPO, K. N.; CAMPANELLI, L. C.; BERGMANN, L.; SANTOS, J. F. DOS; BOLFARINI, C. Microstructure and interface characterization of dissimilar friction stir welded lap joints between Ti-6Al-4V and AISI 304. Materials and Design, v. 56, p. 139-145, 2014.

CAZACU, O. A criterion for description of anisotropy and yield differential effects in pressure-insensitive metals. International Journal of Plasticity, v. 20, n. 11, p. 20272045, 2004.

CAZACU, O.; BARLAT, F. Application of the theory of representation to describe yielding of anisotropic aluminum alloys. International Journal of Engineering Science, v. 41, n. 12, p. 1367-1385, 2003.

CAZACU, O.; PLUNKETT, B.; BARLAT, F. Orthotropic yield criterion for hexagonal closed packed metals. International Journal of Plasticity, v. 22, n. 7, p. 1171-1194, 2006.

CERVEIRA, L. R. P. L. Caracterização experimental do comportamento mecânico sob solicitação multiaxial em junções de chapas aa2024-t3 soldadas por fricçãomistura ("fsw"). Dissertação de mestrado Escola Politécnica da Universidade de São Paulo, 2008.

CHEMIN FILHO, R. A. Avaliação das Deformações de Chapas Finas e Curvas CLC para Diferentes Geometrias de Punções. 2003. 97 p. Dissertação de mestrado: Programa de pósgraduaçã oem Engenharia Mecânica, UFPR, Curitiba, 2003. 
COLOMBO, D. TITANIO E SUO IMPIEGO NEL SETTORE MOTOCICLISTICO.

Disponível em:

<http://www.ing.unitn.it/ colombo/MOTOTITANIO/TitanioMOTO.htm>.

Acesso em: 10/2/2015.

COMLEY, P. N. ASTM E2448-A Unified Test for Determining SPF Properties. Journal of Materials Engineering and Performance, v. 17, p. 183-186, 2008.

CRIVELLARO, R. S. Estudo da estampabilidade de tailored blanks soldadas a laser. 203. 89 p. Dissertação de Mestrado: Univerdidade do Rio Grande do Sul, Porto Alegre, 2003.

DABROWSKI, R. The Kinetics of Phase Transformations During Continuous Cooling of Ti6Al4V Alloy from the Diphase $\alpha+\beta$ Range. Archives of Metallurgy and Materials, v. 56, p. $4-8,2011$ a.

DABROWSKI, R. The kinetics of phase transformations during continuous cooling of the Ti6Al4V alloy from the single phase $(\beta)$ range. Archives of Metallurgy and Materials, v. 56, p. 703-707, 2011b.

DĄBROWSKI, R. Investigations of $\alpha+\beta \rightarrow \beta$ phase transformation in monotonically heated ti6al7nb alloY. Archives of metallurgy and materials, v. 57, n. 4, p. 995-1000, 2012.

DAMASCENO, D. Análise das tensões residuais após torneamento e retificação do aço ABNT 52100 endurecido, 105p., Dissertação Mestrado, Faculdade de Engenharia Mecânica, Universidade Estadual de Campinas, Campinas, 1993.

DEHGHAN-MANSHADI, A.; DIPPENAAR, R. J. Strain-induced phase transformation during thermo-mechanical processing of titanium alloys. Materials Science and Engineering A: Structural Materials: Properties, Microstructure and Processing, v. 2, n. 552, p. 451-456., 2012.

DING, J.; CARTER, B.; LAWLESS, K.; et al. A Decade of Friction Stir Welding R \& D At NASA's Marshall Space Flight Center And a Glance into the Future. NASA Marshall Space Flight Center, 1994.

DONACHIE, M. J. Titanium: A Technical Guide. ASM international, $2^{\circ}$ ed., 216 p. 2000.

DOYOYO, M.; MOHR, D. Microstructural response of aluminum honeycomb to combined out-of-plane loading. Mechanics of Materials, v. 35, n. 9, p. 865-876, 2003.

DRUCKER, D. . The significance of the criterion for additional plastic deformation of metals. Journal of Colloid Science, v. 4, n. 3, p. 299-311, 1949.

EDWARDS, P.; RAMULU, M. Effect of process conditions on superplastic forming behaviour in Ti-6Al-4V friction stir welds. Science and Technology of Welding and Joining, v. 14, p. 669-680, 2009. 
EDWARDS, P.; RAMULU, M. Identification of Process Parameters for Friction Stir Welding Ti-6Al-4V. Journal of Engineering Materials and Technology, Transactions of the ASME, v. 132, p. 10, 2010a.

EDWARDS, P.; RAMULU, M. Peak temperatures during friction stir welding of Ti6Al-4V. Science and Technology of Welding and Joining, v. 15, p. 468-472, 2010b.

ELANGOVAN, K.; BALASUBRAMANIAN, V.; BABU, S. Developing an Empirical Relationship to Predict Tensile Strength of Friction Stir Welded AA2219 Aluminum Alloy. Journal of Materials Engineering and Performance, v. 17, p. 820-830, 2008.

ELBANHAWY, A.; CHEVALLIER, E.; DOMIN, K. Numerical investigations of friction stir welding of high temperature materials. Disponível em: <http://www.twiglobal.com/technical-knowledge/published-papers/numerical-investigations-offriction-stir-welding/>. Acesso em: 2/2/2015.

ELLINGHAM, H. J. T. Transactions and Communications. J. Soc. Chem. Ind., v. 63, n. 5, p. 125, 1944.

FAIRWHEELBIKES. Fairwheelbikes.

Disponível em:

$<$ https://fairwheelbikes.com/c/custom-bikes-and-builders/hollandcycles/hollandtitanium/>. Acesso em: 3/3/2015.

FÉLIX, R. M. C. Desenvolvimento do Fabrico de Próteses por Fundição de Precisão à Medida do Paciente, Trabalho de conclusão de curso. Faculdade de Engenharia da Universidade do Porto. 2008

FLORES, P. Development of Experimental Equipment and Identification Procedures for Sheet Metal Constitutive Laws PhD Thesis presented by Paulo FLORES. , v. 1, n. November, 2005.

FOWLKES, W. Y.; CREVELING, C. M. Engineering Methods for Robust Product Design. Addison-Wesley Publishing Company, 1995.

FRATINI, L.; MACALUSO, G.; PASTA, S. Residual stresses and FCP prediction in FSW through a continuous FE model. Journal of Materials Processing Tech., 2009. Elsevier B.V. Disponível em: <http://dx.doi.org/10.1016/j.jmatprotec.2009.05.001>. .

GILLES, G.; HABRAKEN, A. M.; DUCHÊNE, L. Material Parameter Identification of Cazacu's Model for Ti6Al4V Using the Simulated Annealing Algorithm. Materials Science Forum, v. 636-637, p. 1125-1130, 2010.

GILLES, G.; HAMMAMI, W.; LIBERTIAUX, V.; et al. Experimental characterization and elasto-plastic modeling of the quasi-static mechanical response of TA-6V at room temperature. International Journal of Solids and Structures, v. 48, n. 9, p. 1277-1289, 2011.

GILLES, G.; HAMMAMI, W.; LIBERTIAUX, V.; HABRAKEN, A. M.; CAZACU, O. Experimental characterization and constitutive modeling of ta6v titanium mechanical 
behavior in tension and compression. 37th Solid Mechanics Conference Warsaw, Poland, 2010.

GIULIANO, G. (Ed.). Superplastic forming of advanced metallic materials: Methods and applications. 1… ed. Sawston, Cambridge: Woodhead Publishing Limited, 2011. $369 \mathrm{p}$.

GOM. ARAMIS, Deformation Measurement using the Grating Method. GOM mbh, Braunschweig, 2001.

GOM. Aramis user M manual - Software. 2013.

GORDANA. Gordana dental. Disponível em: <http://gdas.kodiakdev.com/gallery/>. Acesso em: 3/3/2015.

GOODWIN, G. M. Application of the strain analysis to sheet metal forming in the press shop. La Metallurgia Italiana, v. 8, p. 767-774, 1968.

GRUJICIC, M. et al. Computational analysis and experimental validation of the ti-6al$4 \mathrm{v}$ friction stir welding behavior. Department of Mechanical Engineering, Clemson University. Clemson, EUA, p. 44. 2011.

GRUJICIC, M.; ARAKERE, G.; PANDURANGAN, B.; HARIHARAN, A. Computational analysis and experimental validation of the friction-stir welding behaviour of $\mathrm{Ti}-6 \mathrm{Al}-4 \mathrm{~V}$. Proceedings of the Institution of Mechanical Engineers, Part B: Journal of Engineering Manufacture, v. 225, p. 208-223, 2011.

HEDLUND, M. Soldadura de aleaciones de titanio de aplicación en motores de aviones. Master thesis, Universitat Politècnica de Catalunya. Departament de Ciencia dels Materials i Enginyeria Metalúrgica. 2005.

HILL, R. A Theory of the Yielding and Plastic Flow of Anisotropic Metals. Proceedings of the Royal Society A: Mathematical, Physical and Engineering Sciences, v. 193, n. 1033, p. 281-297, 1948.

HILL, R. Theoretical plasticity of textured aggregates. Mathematical Proceedings of the Cambridge Philosophical Society, v. 85, n. 01, p. 179, 2008.

HINKELMANN, K.; KEMPTHORNE, O. Design and Analysis of Experiments. Advanced Experimental Design. John Wiley \& Sons, Inc., 2005.

HORA, P.; FEURER, U.; WAHLEN, A.; REISSNER, J. Methods for handling of fem input and ouput data with the goal of higher computational raliability. European Congress on Computational Methods in Applied Sciences and Enginenring, Barcelona, September, p. 11-14, 2000.

HORITA, Z.; LANGDON, T. G. Achieving exceptional superplasticity in a bulk aluminum alloy processed by high-pressure torsion. Scripta Materialia, v. 58, p. 1029-1032, 2008. 
HOSFORD, W. Mechanical Behavior of Materials. Cambridge Press, 2 $2^{\mathrm{a}}$ Edição, 2005.

HOSFORD, W. F. Reflections on the dependence of plastic anisotropy on texture. Materials Science and Engineering: A, v. 257, n. 1, p. 1-8, 1998.

IMAI, T.; MAO, J.; DONG, S.; et al. High strain rate superplasticity of TiC particulate reinforced 2014 aluminum alloy composites. , v. 364, n. 2004, p. 281-286, 2014.

INTEREMPRESAS. La soldadura por friccion en componentes aeronauticos. Disponível em: <http://www.interempresas.net>. Acesso em: 5/10/2015.

ISO 12004. Standard ISO 12004-2 - TC 164/SC 2, 1997.

JIANG, S. S.; ZHANG, K. F. Superplastic Forming of Ti6Al14V Alloy Using ZrO2TiO2 Ceramic Die With Adjustable Linear Thermal Expansion Coefficient. Transactions of Nonferrous Metals Society of China, v. 19, p. 418-422, 2009.

JOSHI, A. V. Titanium alloys: an atlas of structures and fracture features. Boca Raton: CRC Press, 2006. 247 p.

KARAFILLIS, A. P.; BOYCE, M. C. A general anisotropic yield criterion using bounds and a transformation weighting tensor. Journal of the Mechanics and Physics of Solids, v. 41, n. 12, p. 1859-1886, 1993.

KAVAMURA, H. A.; BATALHA, G. F. Mechanical strength evaluation for Nd-YAG laser and electric resistance spot weld (ERSW) joint under multiaxial loading. Journal of Materials Processing Technology, v. 201, n. 1-3, p. 507-514, 2008.

KEELER, S. P. Determination of the forming limits in automotive stamping. Sheet Metal Industries, v. 42, p. 683-691, 1965.

KHAN, A. S.; KAZMI, R.; FARROKH, B. Multiaxial and non-proportional loading responses, anisotropy and modeling of Ti-6Al-4V titanium alloy over wide ranges of strain rates and temperatures. International Journal of Plasticity, v. 23, n. 6, p. 931950, 2007.

KITAMURA, K.; FUJII, H.; IWATA, Y.; SUN, Y. S.; MORISADA, Y. Flexible control of the microstructure and mechanical properties of friction stir welded $\mathrm{Ti}-6 \mathrm{Al}-4 \mathrm{~V}$ joints. , v. 46, p. 348-354, 2013.

KOMANDURI, R.; TURKOVICH, B. F. New observations on the mechanism of chip formation when machining titanium alloys. Wear, v. 69, p. 179-188, 1981.

KNOCKAERT, R. Numerical and Experimental Study of the Strain Localization During Sheet Forming Operations. Ph. D. Thesis, Ecole National Supérieure des Mines de Paris, 2001. 
KOC,, M.; AGCAYAZI, A.; CARSLEY, J. An experimental study on robustness and process capability of the warm hydroforming process. Journal of Manufacturing Science and Engineering, v. 133, p. 12, Abril 2011.

KOTKUNDE, N.; DEOLE, A. D.; KUMAR, A.; KUMAR, S. Experimental and numerical investigation of anisotropic yield criteria for warm deep drawing of $\mathrm{Ti}-6 \mathrm{Al}$ -4V alloy. Materials and Design, v. 63, p. 336-344, 2014.

KUBIAK, K.; SIENIAWSKI, J. Development of the microstructure and fatigue strength of two phase titanium alloys in the processes of forging and heat treatment. Journal of Materials Processing Technology, v. 78, n. 1-3, p. 117-121, 1998.

KUMAR, N.; MISHRA, R. S.; BAUMANN, J. A. Residual Stresses in Friction Stir Welding. In: J. F. Steve Merken (Ed.); Residual Stresses in Friction Stir Welding. 1st ed., p.347-358, 2014.

KUWABARA, T. Advances in experiments on metal sheets and tubes in support of constitutive modeling and forming simulations. , v. 23, p. 385-419, 2007.

KUWABARA, T. Biaxial Stress Testing Methods for Sheet Metals. Comprehensive Materials Processing. v. 1, p.95-111, 2014.

KUWABARA, T.; IKEDA, S.; KURODA, K. Measurement and analysis of differential work hardening in cold-rolled steel sheet under biaxial tension. , v. 81, p. 517-523, 1998.

LANGDON, T. G. Seventy-five years of superplasticity: historic developments and new opportunities. J Mater Sci, v. 44, p. 5998-6010, 2009.

LEYENS, C.; PETERS, M. Titanium and Titanium Alloys. Fundamentals and Applications. Weinheim: WILEY-VCH Verlag, 2003. $532 \mathrm{p}$.

LIMA, F. E. Características do processo de torneamento de materiais endurecidos. Tese Doutorado - Faculdade de Engenharia Mecânica, Universidade de Campinas. Campinas 2001., 2001.

LIMA, N. B. Influência da textura em medidas de tensão residual, 105 p., Tese Doutorado, Instituto de Pesquisas Energéticas e Nucleares, Universidade de São Paulo, São Paulo, 1991.

LIU, H. J.; ZHOU, L.; LIU, Q. W. Microstructural characteristics and mechanical properties of friction stir welded joints of $\mathrm{Ti}-6 \mathrm{Al}-4 \mathrm{~V}$ titanium alloy. Materials and Design, v. 31, p. 1650-1655, 2010.

LIVINGSTON, J. J. A PHYSICAL SIMULATION OF FRICTION STIR PROCESSING OF Ti-6Al-4V. Master of Science in the Graduate School of The Ohio State University, p. 226, 2011. 
LÜTJERING, G. Influence of processing on microstructure and mechanical properties of $(\alpha+\beta)$ titanium alloys. Materials Science and Engineering: A, v. 243, n. 1-2, p. 3245, 1998.

LÜTJERING, G.; WILLIAMS, J. C. Titanium. Springer edition, 2ª edição, 449 p, 2007.

MACHADO, A. R. et al. Teoria da Usinagem dos Materiais. 1ª ed. São Paulo: Edgard Blucher, 2009. 176-227 p.

MAHGOUB, E.; DENG, X.; SUTTON, M. A. Three-dimensional stress and deformation fields around flat and slant cracks under remote Mode I loading conditions. Engineering Fracture Mechanics, v. 70, n. 18, p. 2527-2542, 2003.

MARQUES, H. Modelação das Propriedades Mecânicas de Juntas Soldadas por Friç̧ão Linear. 2009. 103 p. Dissertação de Mestrado: Faculdade de Ciências e Tecnologia da Universidade Nova de Lisboa, Lisboa, 2009.

MASHININI, P. M. Process window for Friction Stir Welding of $3 \mathrm{~mm}$ Titanium (Ti-6Al4V). 2010. 143 p. Dissertação de Mestrado: Faculty of Engineering, the Built Environment and Information Technology.Port Elizabeth, South Africa, 2010.

MINTON, T. J. Friction Stir Welding of Commercially available Superplastic Aluminium. 2008. 252 p. (Ph. D. thesis) : Brunel University, Brunel, 2008.

MISHRA, R. S.; MAHONEY, M. W. (Eds.). Friction Stir Welding and Processing. 1a . ed. Materials Park: ASM International, 2007. 353 p.

MISHRA, R. S.; MA, Z. Y. Friction stir welding and processing. , v. 50, p. 1-78, 2005.

MIYAUCHI, K. A proposal of a planar simple shear test in sheet metals. Scientific Papers of RIKEN, v. 78, n. 3, p. 27-42, 1984.

MOHR, D.; DOYOYO, M. Analysis of the Arcan Apparatus in the Clamped Configuration. Journal of Composite Materials, v. 36, n. 22, p. 2583-2594, 2002.

MOHR, D.; DOYOYO, M. A New Method for the Biaxial Testing of Cellular Solids. 02003 Society for Experimental Mechanics Experimental Mechanics, p. 173-182, 2003.

MONTGOMERY, D. C. Design and analysis of Experiments. 5a . ed. New York: John Wiley \& Sons, 2001. $684 \mathrm{p}$.

MOTYKA, M.; KUBIAK, K.; SIENIAWSKI, J.; WALDEMAR, Z. Hot Plasticity of Alpha Beta Alloys. In: A. K. M. Nurul Amin (Ed.); Titanium Alloys - Towards Achieving Enhanced Properties for Diversified Applications. 1st ed., p.87-116, 2007.

MURR, L. E.; LIU, G.; MCCLURE, J. C. Dynamic recrystallization in friction-stir welding of aluminium alloy 1100. Journal of Materials Science, v. 6, p. 1801-1803, 1997. 
NIEH, T. G.; WADSWORTH, J.; SHERBY, O. D. Superplasticity in metals and ceramics. 1‥ ed. New York: Cambridge University Press, 1997. 273 p.

NURUL AMIN, A. K. M. Titanium Alloys - Towards Achieving Enhanced Properties for Diversified Applications. 1st ed. Rijeka, Croácia: InTech, 2012.

ORTEU, J.-J. 3-D computer vision in experimental mechanics. Optics and Lasers in Engineering, v. 47, n. 3-4, p. 282-291, 2009.

PADMANABHAN, K. A.; VASIN, R. A.; ENIKEEV, F. U. Superplastic Flow: Phenomenology and Mechanics. Berlin: Springer-Verlag, 2001. 361 p.

PASTA, S.; REYNOLDS, A. P. Evaluation of residual stresses during fatigue test in an FSW joint. Strain, v. 44, n. 2, p. 147-152, 2008a.

PASTA, S.; REYNOLDS, A. P. Residual stress effects on fatigue crack growth in a Ti-6Al-4V friction stir weld. Fatigue Fracture of Engineering Materials Structures, v. 31, p. 569-580, 2008b.

PELLEGRINI, D. Study on thermal and rheological parameters of highstrength steels in hot forming conditions. 2011. 109 p. Tese de Doutorado: Università degli Studi di Padova. Padova, 2011.

PIJLMAN, H. Sheet material characterisation by multi-axial experiments. The Netherlands Printed by Ponsen \& Looijen, Wageningen, ISBN 90-36516951, 229 p., 2001.

PILCHAK, A. L.; TANG, W.; SAHINER, H.; REYNOLDS, A. P.; WILLIAMS, J. C. Microstructure Evolution during Friction Stir Welding of Mill-Annealed Ti-6Al-4V. , v. 42, n. March, p. 745-762, 2011.

PLANSEE. Brochure "DENSIMET-INERMET-Tungsten Alloys". [S.I.], p. 16. 2011.

PLUNKETT, B. Plastic anisotropy of hexagonal closed packed metals. Dissertation for the degree of doctor of philosophy, University of Florida, 2005.

PREVÈY, P.S. Current applications of X-Ray diffraction residual stress measurements. ASTM International, Materials Park, 1996, p. 103-110.

PRIME, M. B.; LIENERT, T. J.; STELLWAG, W. L.; CASEY, R. S. Residual Stress Measurement in Friction Stir Welded Ti-6Al-4V. Fabtech International and AWS Welding Show 2005, November 13-16, 2005, Chicago, Illinois. p.3-4, 2005.

PROJECT, M. Materialsproject.

Disponível em: <https://www.materialsproject.org/\#apps/pourbaixdiagram>. Acesso em: 9/1/2015.

QUADRILCIRURGIA. Tipos de proteses.

Disponível em: <http://www.quadrilcirurgia.com.br/tipos-de-proacuteteses.html>. Acesso em: 3/3/2015. 
REVIL-BAUDARD, B. Simulation du comportement mécanique des alliages de titane pour les procédés de mise en forme à froid, Paris: MINES ParisTech, 2010.

RICKHEY, F.; KIM, M.; LEE, H.; KIM, N. Evaluation of combined hardening coefficients of zircaloy-4 sheets by simple shear test. Materials \& Design, v. 65, p. 995-1000, 2015.

RUSSELL, M. J. et al. Static shoulder friction stir welding of Ti-6Al-4V; process and evaluation. The Welding linstitute, p. 6, 2007. Acesso em: ago. 2011.

SANDERS, D. G. et al. Effects on the Surface Texture, Superplastic Forming and Fatigue Performance of Titanium 6AL-4V Friction Stir Welds. Journal of Materials Engineering and Performance, v. 19, p. 503-509, 2010.

SATO, Y. S.; YAMANOI, H.; KOKAWA, H.; FURUHARA, T. Microstructural evolution of ultrahigh carbon steel during friction stir welding. , v. 57, p. 557-560, 2007.

SENKOV, O. N.; MIRACLE, D. B.; FIRSTOV, S. A. (Eds.). Metallic Materials with High Structural Efficiency. [S.I.]: Kluwer Academic Publishers, 2004. 391-400 p.

SESHACHARYULU, T.; MEDEIROS, S. C.; MORGAN, J. T.; et al. Hot deformation and microstructural damage mechanisms in extra-low interstitial (ELI) grade Ti-6Al4V. Materials Science and Engineering A, v. 279, n. 1-2, p. 289-299, 2000.

SHA, W.; MALINOV, S. Titanium alloys: modelling of microstructure, properties and applications. CRC Press, Boca Raton, Florida, 598 p., 2009.

SHIRZADI, A. Diffusion Bonding Aluminium Alloys and Composites: New Approaches and Modelling, University of Cambridge. King's College. Doctoral Thesis. 1997.

SHIRZADI, A. Diffusion Bonding. University of Cambridge, v. 1, p. 10, 2015. Disponível em: <http://www.msm.cam.ac.uk/phase-trans/2005/Amir/bond.html>. Acesso em: 19/3/2015.

SU, J.; WANG, J.; MISHRA, R. S.; XU, R.; BAUMANN, J. A. Microstructure and mechanical properties of a friction stir processed Ti-6Al-4V alloy. Materials Science and Engineering A, v. 573, p. 67-74, 2013.

SU, J.; WANG, J.; MISHRA, R. S.; XU, R.; BAUMANN, J. A. Microstructure and mechanical properties of a friction stir processed Ti-6Al-4V alloy. Materials Science and Engineering: A, v. 573, p. 67-74, 2013. Elsevier.

SURAND, M. M. ETUDE DU COMPORTEMENT VISCOPLASTIQUE EN TRACTION ET EN FLUAGE DE L' ALLIAGE TA6V DE 20 A 600 DEGRES CELSIUS, 2013.

TUNINETTI, V.; GILLES, G.; MILIS, O.; NEIRA, I. QUASI-STATIC MECHANICAL BEHAVIOUR OF TI-6AL-4V ALLOY AT ROOM TEMPERATURE. Special issue COMPUTATIONAL PLASTICITY, , n. Special issue, p. 51-62, 2013. 
UC. The Interactive Ellingham Diagram.

Disponível em: <www.doitpoms.ac.uk/ttplib/ellingham_diagrams/printall.php>. Acesso em: 1/12/2014.

VALENTE, C. D. R. D. J. Crescimento e reconstrução de óxidos em meio que simulam fluídos corpóreos. Universidade Federal do Paraná, p. 111, 2011.

VASQUEZ, C. T. Experimental and numerical study of the quasi-static behavior of $\mathrm{Ti}$ $-6 \mathrm{Al}-4 \mathrm{~V}$, Tese de doutorado, Université de Liège, Belgium. April, 2014.

VILAÇA DA SILVA, P. M. S. Fundamentos do processo de soldadura por fricção linear - Análise experimental e modelação analítica. 2003. 252 p. Dissertação (Doutor em engenharia): Instituto Superior Técnico - Universidade Técnica de Lisboa. Lisboa, 2003.

WAGNER, M. F.-X.; ZILLMANN, B.; SEIPP, S.; LAMPKE, T.; HALLE, T. Biaxial Compression Testing of Metals and Alloys - Investigating Tension-Compression Asymmetry in the Third Quadrant. $16^{\circ}$ International Conference on Strength of Materials. Bangalore, p.1, 2012.

WOODTHORPE, J.; PEARCE, R. The effect of $r$ and $n$ upon the forming limit diagrams of sheet metal. Sheet Metal Industries, p. 1061-1067, 1969.

WOLK, J. MICROSTRUCTURAL EVOLUTION IN FRICTION STIR. Dissertation submitted to the Faculty of the Graduate School of the University of Maryland, degree of Doctor of Philosophy, 2010.

YOON, J. W.; CAZACU, O. On linear transformations of stress tensors for the description of plastic anisotropy. International Journal of Plasticity, v. 23, p. 876-896, 2007.

ZHANG, Y.; SATO, Y. S.; KOKAWA, H.; et al. Stir zone microstructure of commercial purity titanium friction stir welded using pcBN tool. , v. 488, p. 25-30, 2008 .

ZHANG, Y.; SATO, Y. S.; KOKAWA, H.; et al. Microstructural characteristics and mechanical properties of $\mathrm{Ti}-6 \mathrm{Al}-4 \mathrm{~V}$ friction stir welds. , v. 485, p. 448-455, 2008b.

ZHANG, Z.; ZHANG, H. W. Numerical studies on the effect of transverse speed in friction stir welding. Materials and Design, v. 30, n. 3, p. 900-907, 2009. 


\section{ANEXOS}

\subsection{Anexo A}

Desenho do dispositivo de processamento das chapas.
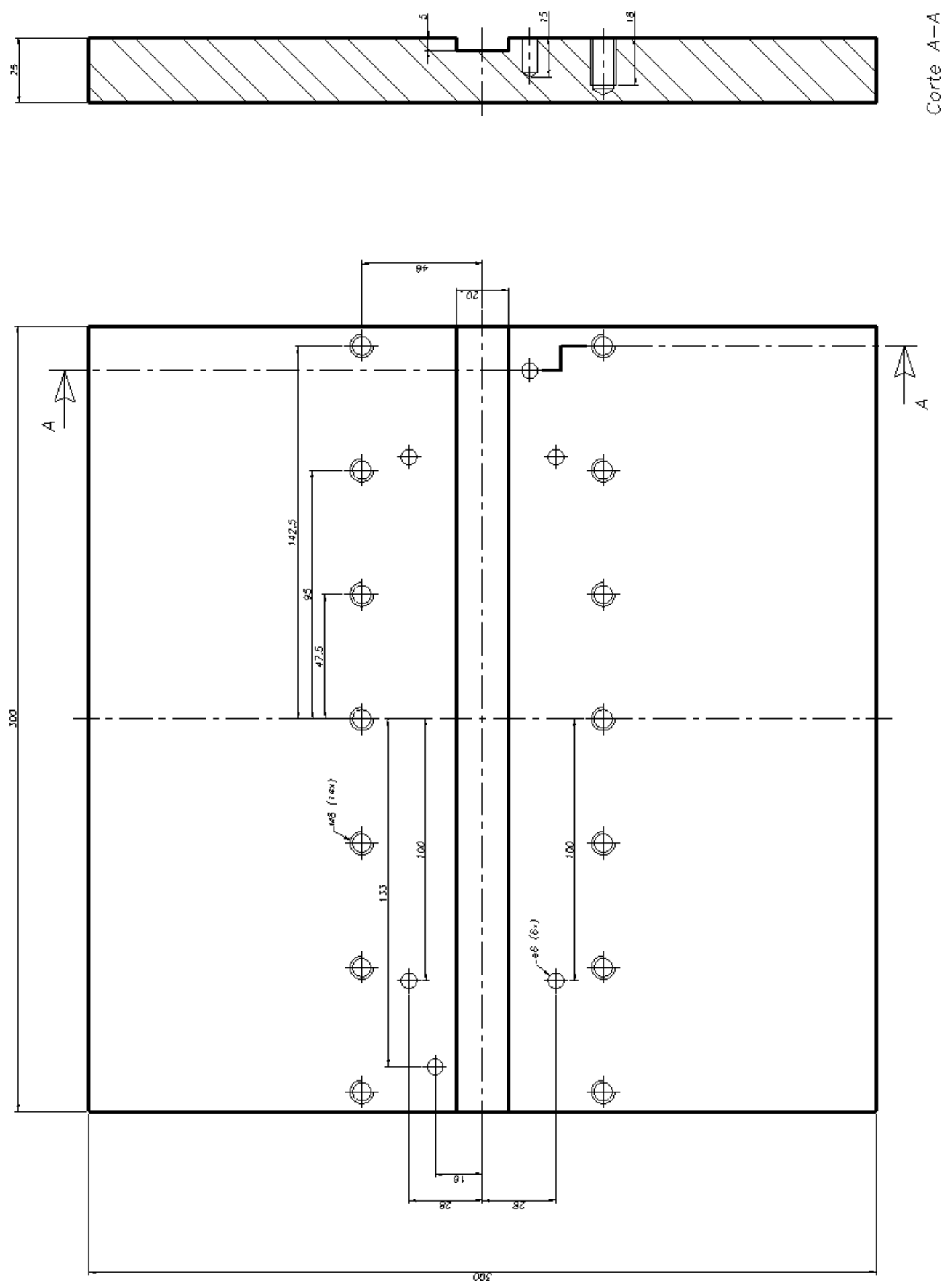

Desenho do dispositivo. 


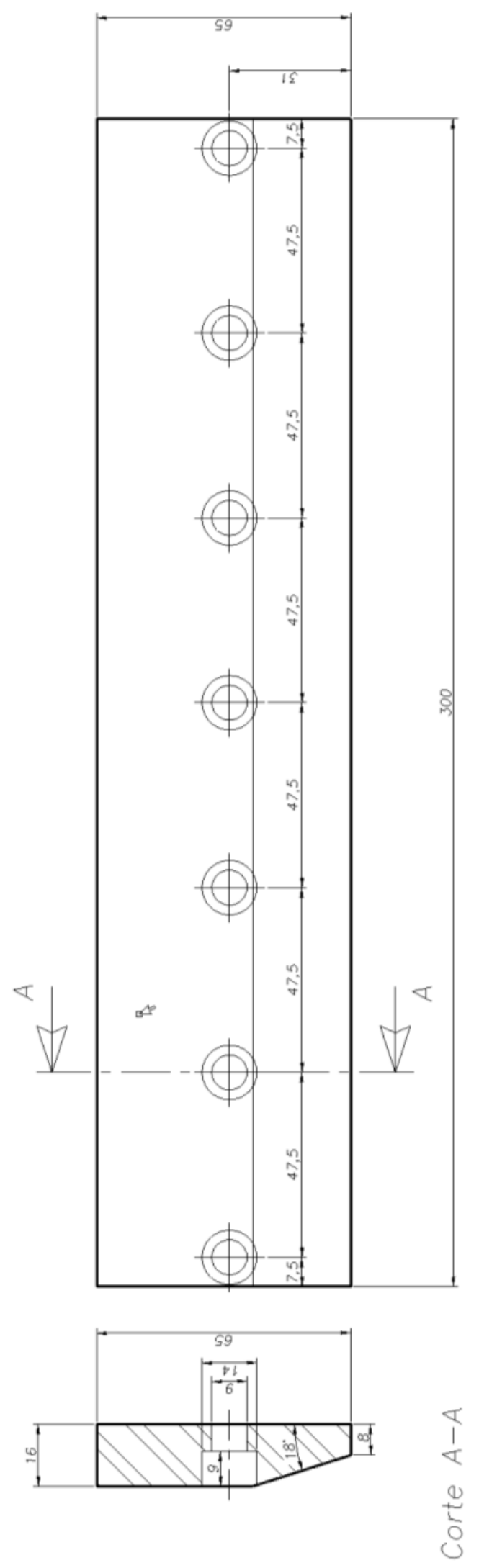


13.2. Anexo B

Cálculo da inclinação de $1^{\circ}$ na base.

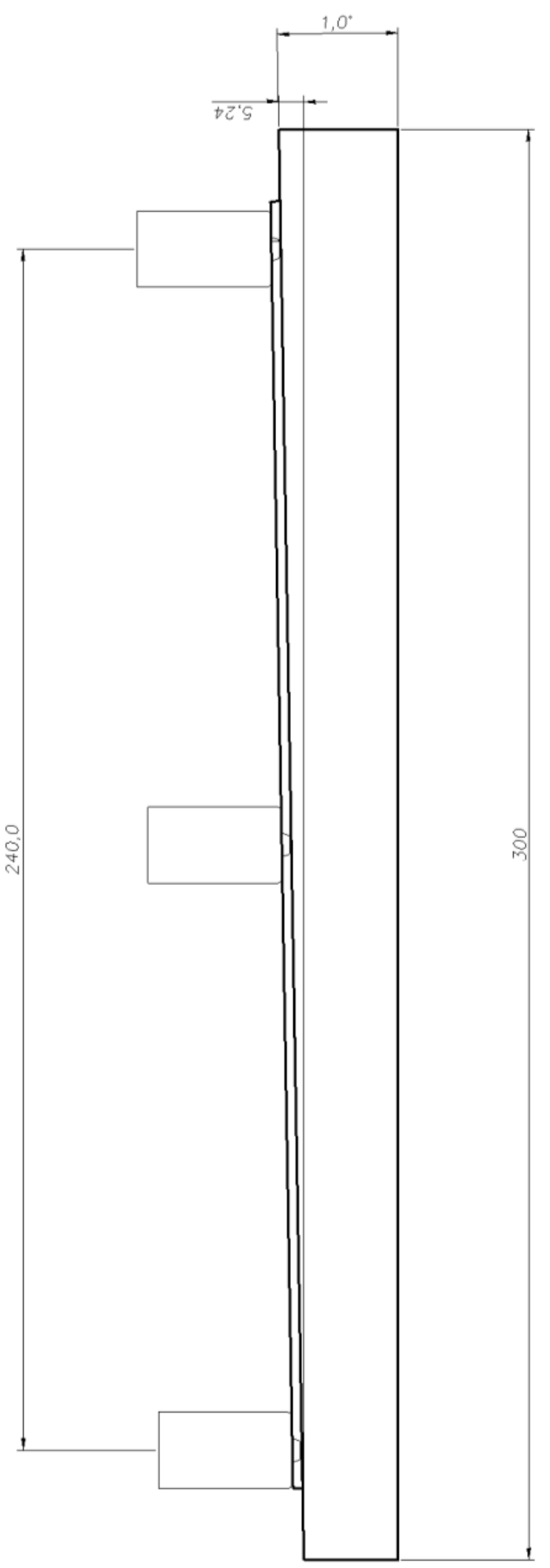




\subsection{Anexo C}

Desenho da ferramenta número 1.

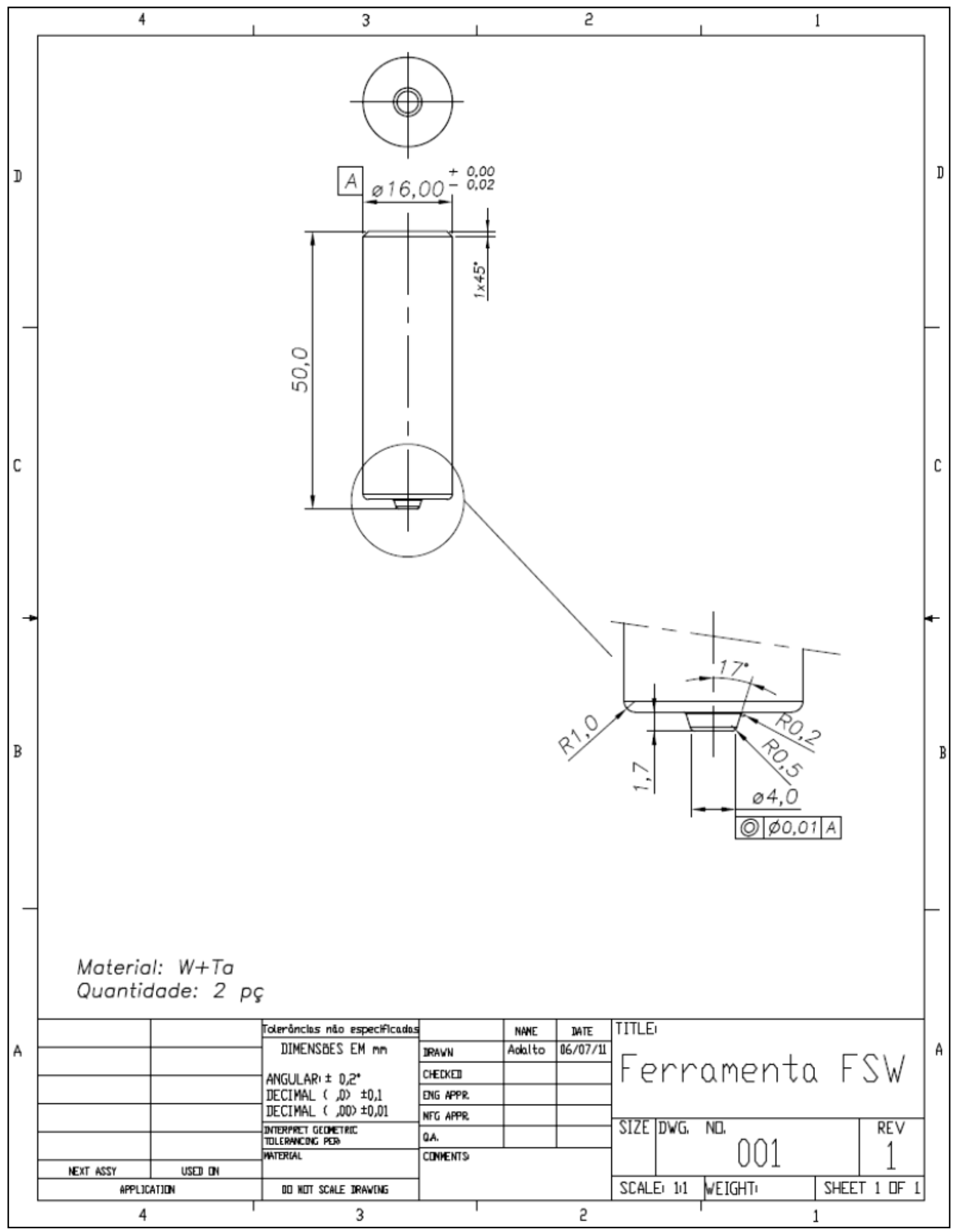




\subsection{Anexo D}

Certificado de qualidade do Ti-6Al-4V.

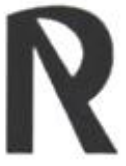

REALUM INDÜSTRIA E COMERCIO DE METAIS PUROS E LIGAS LTDA.

Rua Pires Pimentel, 442/460 - Vila Prudente - Săo Paulo - SP CEP: 03138-040

Tel: (11) 2343-2300 Fax: (11) 2343-2303e-mail: realum@realum.com.br

Sistema de gestâo da Qualidade Certificado ISO 9001:2008

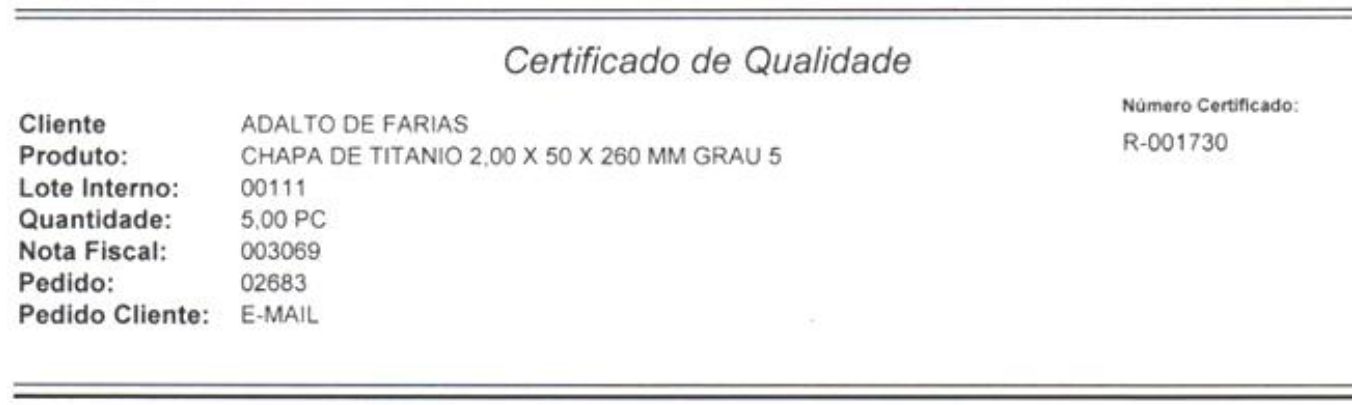

\begin{tabular}{|lr|}
\hline \multicolumn{2}{|c|}{ COMPOSıÇÃO QUiMICA } \\
\hline Elemento & Teor $\%$ \\
\hline Al & 5.72 \\
\hline C & 0,065 \\
\hline $\mathrm{Fe}$ & 0.37 \\
\hline $\mathrm{H}$ & 0.013 \\
\hline $\mathrm{N}$ & 0.04 \\
\hline O2 & 0.15 \\
\hline $\mathrm{Ti}$ & $\mathrm{BAL}$ \\
\hline $\mathrm{V}$ & 4,1 \\
\hline
\end{tabular}

\begin{tabular}{|lc|}
\hline \multicolumn{2}{|c|}{ PROPRIEDADES MECĀNICAS } \\
\hline Elemento & Valor \\
\hline DUREZA & $36 \mathrm{HRC}$ \\
\hline
\end{tabular}

Informaçōes Complementares:

Sao Paulo, 02 de Dezembro de 2011. 
13.5. Anexo $\mathrm{E}$

Programa para máquina CNC.

G21G40G80G90

M98P9800

T7

M3 S1000

G54

G1 X0 Y0 Z50.0 F5000

G1 Z5.0 F1000

G1 Z0.0 F500

G1 Z-1.65 F1

F30

G1 Y240.0 Z-5.732

G1 Z0.0 F75

G1 Z50.0 F1000

M30 


\subsection{Anexo F}

Classes de metal duro para usinagem.

Tabela 13-1 - Classes de metal duro (MACHADO, COELHO, et al., 2009).

\begin{tabular}{|c|c|c|c|c|c|c|}
\hline \multicolumn{3}{|c|}{ Principais classes } & \multicolumn{4}{|c|}{ Classes de aplicação } \\
\hline $\begin{array}{c}\text { Letra de } \\
\text { identificação }\end{array}$ & $\begin{array}{c}\text { Cor de } \\
\text { identificação }\end{array}$ & $\begin{array}{c}\text { Materiais a serem } \\
\text { usinados }\end{array}$ & \multicolumn{2}{|c|}{ Metais duros } & \multirow[b]{2}{*}{, } & \\
\hline $\mathrm{P}$ & Azul & $\begin{array}{c}\text { Aços: } \\
\text { Todos os tipos } \\
\text { de aços e aços } \\
\text { fundidos, exceto } \\
\text { aços inoxidáveis com } \\
\text { estrutura austenitica }\end{array}$ & $\begin{array}{l}\text { P01 } \\
\text { P10 } \\
\text { P20 } \\
\text { P30 } \\
\text { P40 } \\
\text { P50 }\end{array}$ & $\begin{array}{l}\text { P05 } \\
\text { P15 } \\
\text { P25 } \\
\text { P35 } \\
\text { P45 }\end{array}$ & & b \\
\hline M & Amarelo & $\begin{array}{l}\text { Aço Inoxidável: } \\
\text { aço inoxidável } \\
\text { austenítico e aço } \\
\text { duplex (austenítico/ } \\
\text { ferrítico) e aço } \\
\text { fundido }\end{array}$ & $\begin{array}{l}\text { M01 } \\
\text { M10 } \\
\text { M20 } \\
\text { M30 } \\
\text { M40 }\end{array}$ & $\begin{array}{l}\text { M05 } \\
\text { M15 } \\
\text { M25 } \\
\text { M35 }\end{array}$ & & b \\
\hline $\mathrm{K}$ & Vermelho & $\begin{array}{l}\text { Ferro fundido: } \\
\text { Ferro fundido } \\
\text { cinzento, ferro } \\
\text { fundido com grafita } \\
\text { esferoidal, ferro } \\
\text { fundido maleável }\end{array}$ & $\begin{array}{l}\mathrm{K} 01 \\
\mathrm{~K} 10 \\
\mathrm{~K} 20 \\
\mathrm{~K} 30 \\
\mathrm{~K} 40\end{array}$ & $\begin{array}{l}\text { K05 } \\
\text { K15 } \\
\text { K25 } \\
\text { K35 }\end{array}$ & & b \\
\hline $\mathrm{N}$ & Verde & $\begin{array}{l}\text { Metais não ferrosos: } \\
\text { Alumínio e outros } \\
\text { metais não ferrosos, } \\
\text { materiais não } \\
\text { metálicos }\end{array}$ & $\begin{array}{l}\text { N01 } \\
\text { N10 } \\
\text { N20 } \\
\text { N30 }\end{array}$ & $\begin{array}{l}\text { N05 } \\
\text { N15 } \\
\text { N25 }\end{array}$ & & b \\
\hline $\mathrm{S}$ & Marrom & $\begin{array}{l}\text { Superligas e titânio: } \\
\text { Ligas especiais } \\
\text { resistentes ao calor à } \\
\text { base de ferro, níquel } \\
\text { e cobalto, titânio e } \\
\text { ligas de titânio }\end{array}$ & $\begin{array}{l}\text { s01 } \\
\text { s10 } \\
\text { s20 } \\
\text { s30 }\end{array}$ & $\begin{array}{l}\text { S05 } \\
\text { S15 } \\
\text { S25 }\end{array}$ & & b \\
\hline $\mathrm{H}$ & Cinza & $\begin{array}{l}\text { Materiais duros: } \\
\text { Aços endurecidos, } \\
\text { ferros fundidos } \\
\text { endurecidos, ferros } \\
\text { fundidos resfriados }\end{array}$ & $\begin{array}{l}\mathrm{H} 01 \\
\mathrm{H} 10 \\
\mathrm{H} 20 \\
\mathrm{H} 30\end{array}$ & $\begin{array}{l}\mathrm{H} 05 \\
\mathrm{H} 15 \\
\mathrm{H} 25\end{array}$ & & b \\
\hline $\begin{array}{r}\text { a- Aumento } \\
\text { da ferram } \\
b \text { - Aumento }\end{array}$ & $\begin{array}{l}\text { velocidade } \mathrm{d} \\
\text { ta. }\end{array}$ & $\begin{array}{l}\text { corte, aumento da res } \\
\text { nto da tenacidade do }\end{array}$ & enci & des & & \\
\hline
\end{tabular}




\subsection{Anexo G}

Projeto da garra ARCAN.

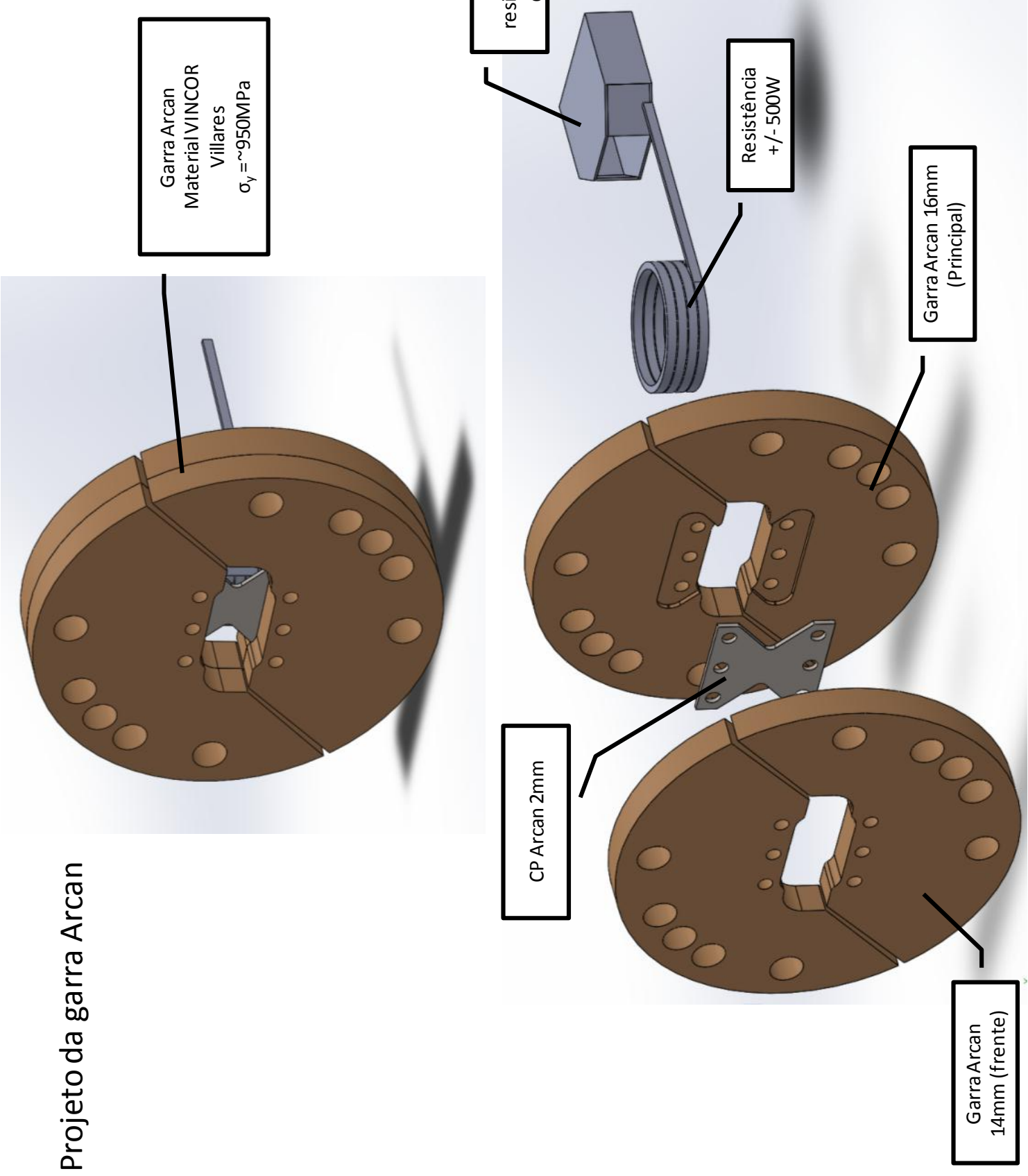




\subsection{Anexo $\mathrm{H}$}

Desenho da ferramenta número 2.

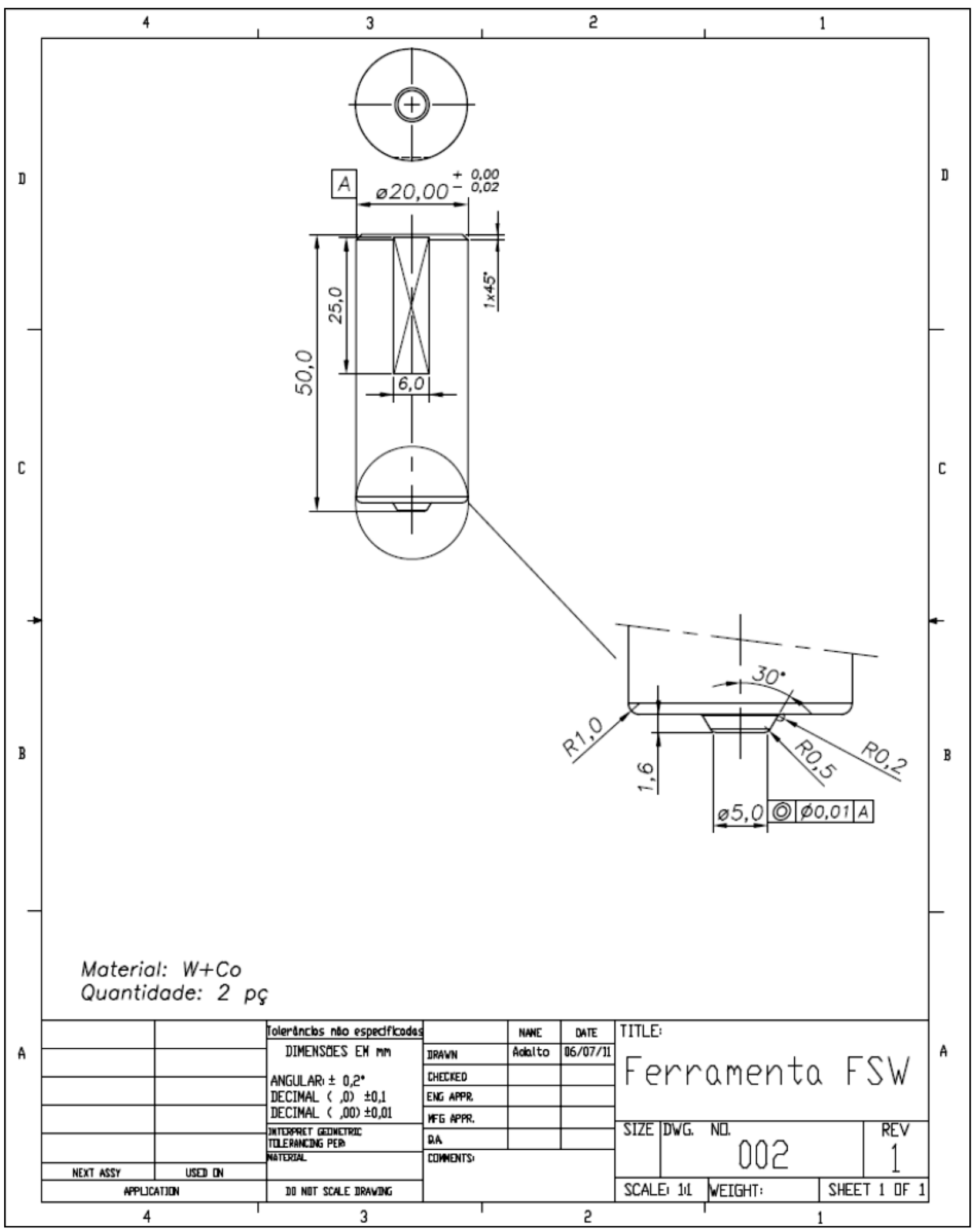




\subsection{Anexo I}

Desenho do dispositivo de ARCAN.
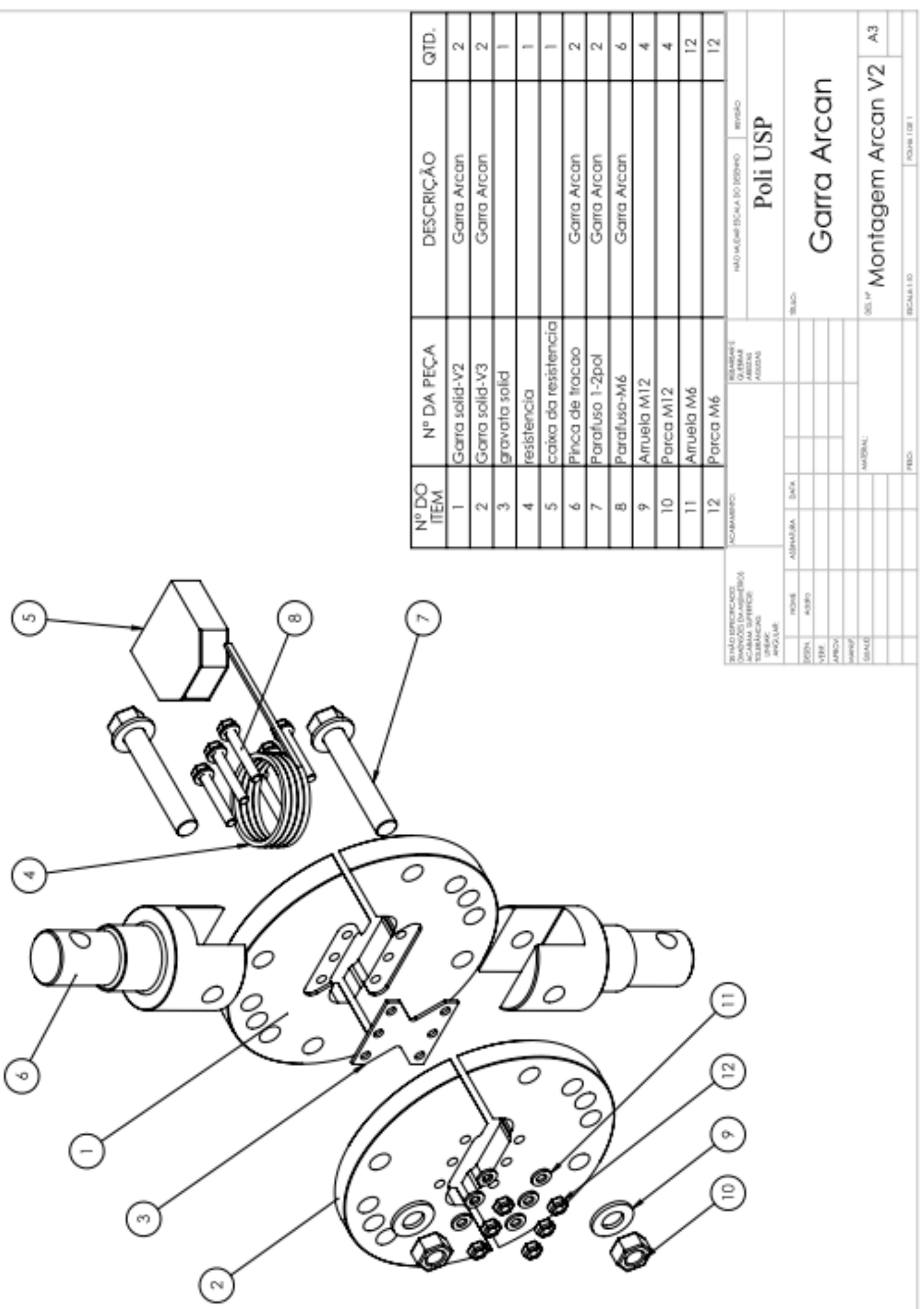
Desenho da garra principal.

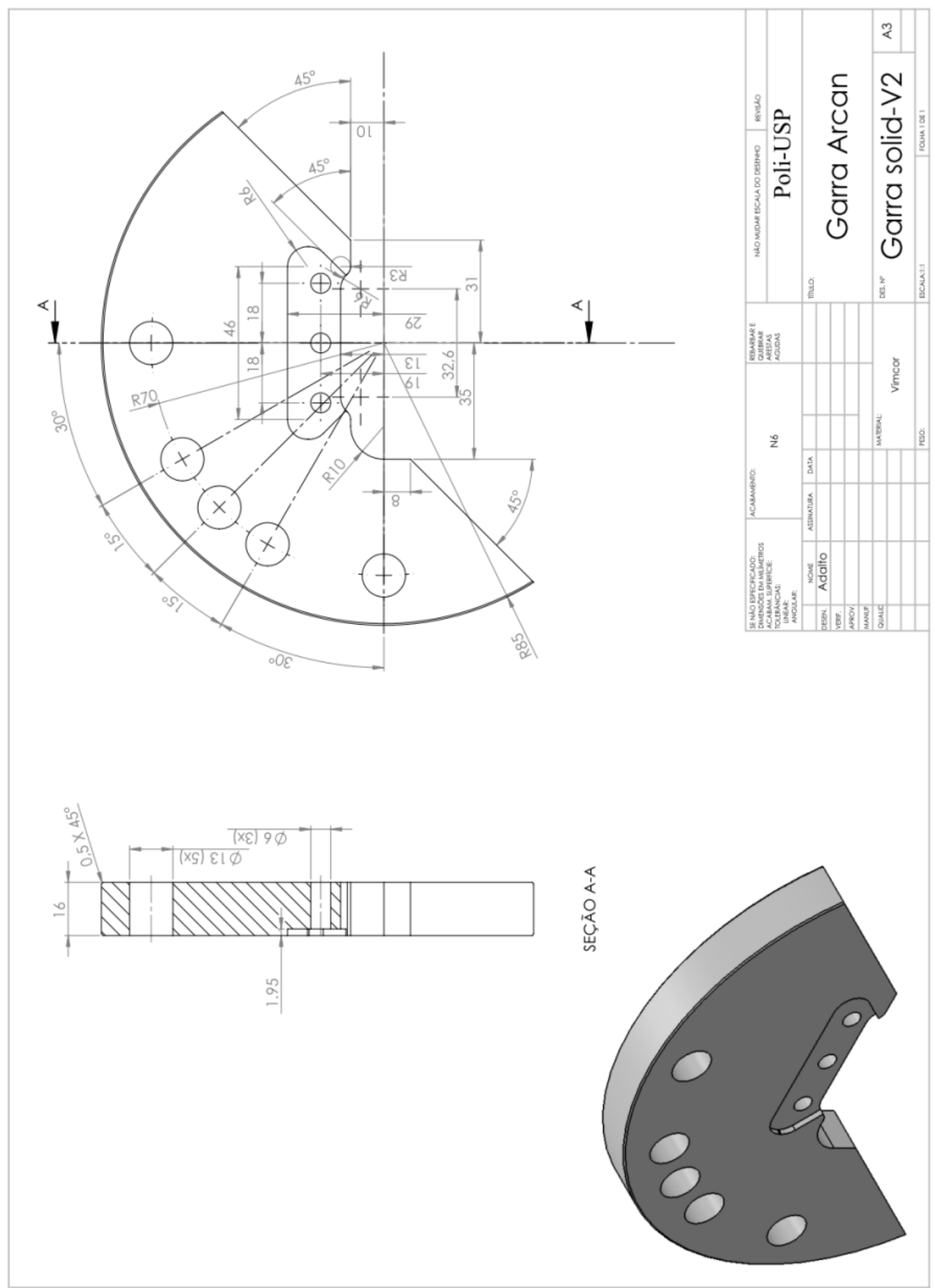




\subsection{Anexo J}

Procedimento de calibração do Aramis.

- Pintura do copo de prova: Padrão estocástico em escala de cinza;

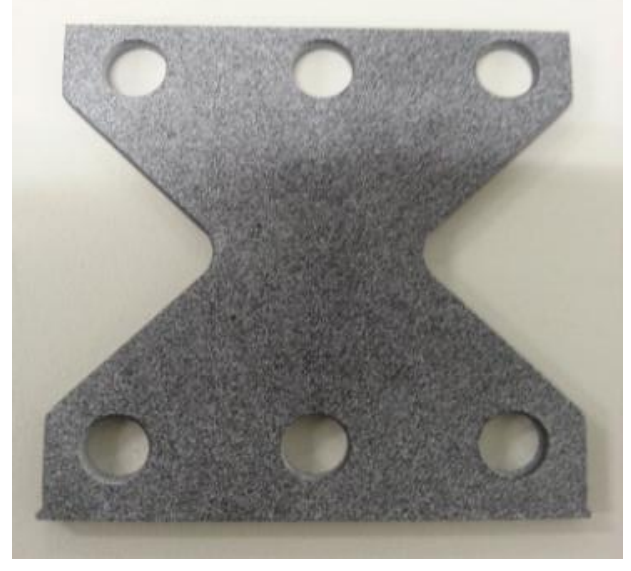

- Aquisição de imagens estáticas;

- Definição de máscara e "start point" (ponto vermelho)

- Sabe-se que a região de interesse/medição será delimitado pela pelo dispositivo de Arcan (área do retângulo), porém para esta calibração foi considerado toda a geometria do corpo de prova.

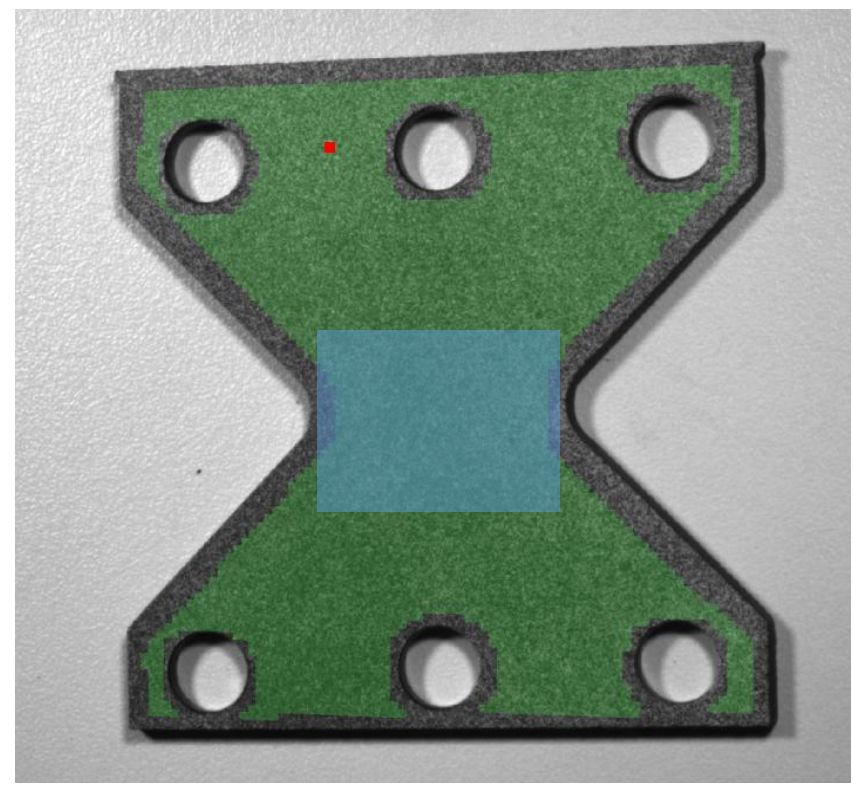


- Resultados: Determinação das secções a serem analisadas: de 0 a 5
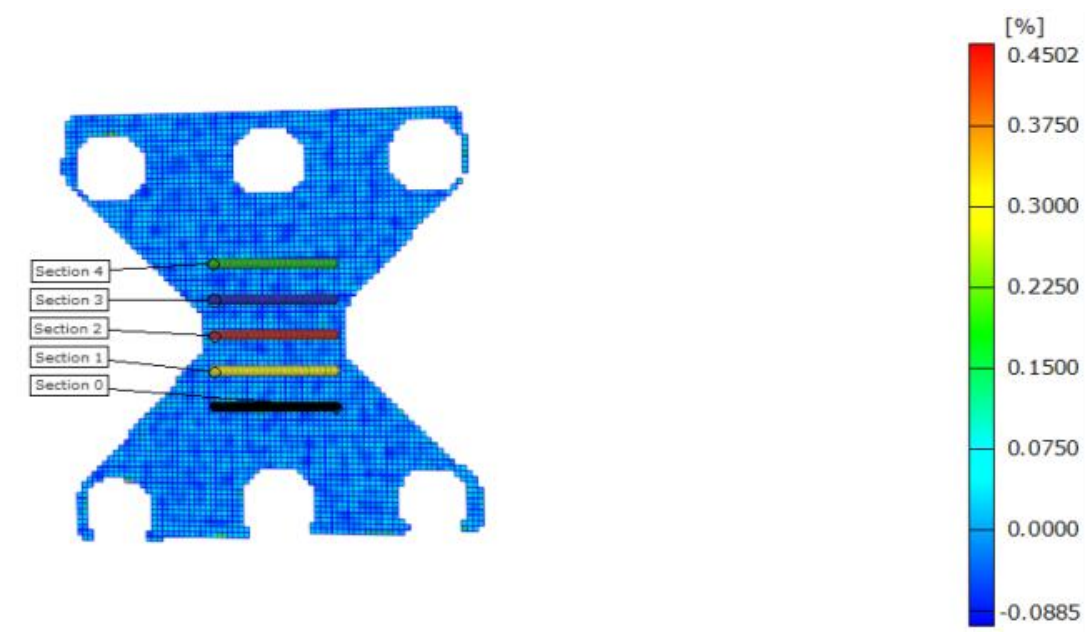

\section{RESULTADO: VISTA DE RELATÓRIO}

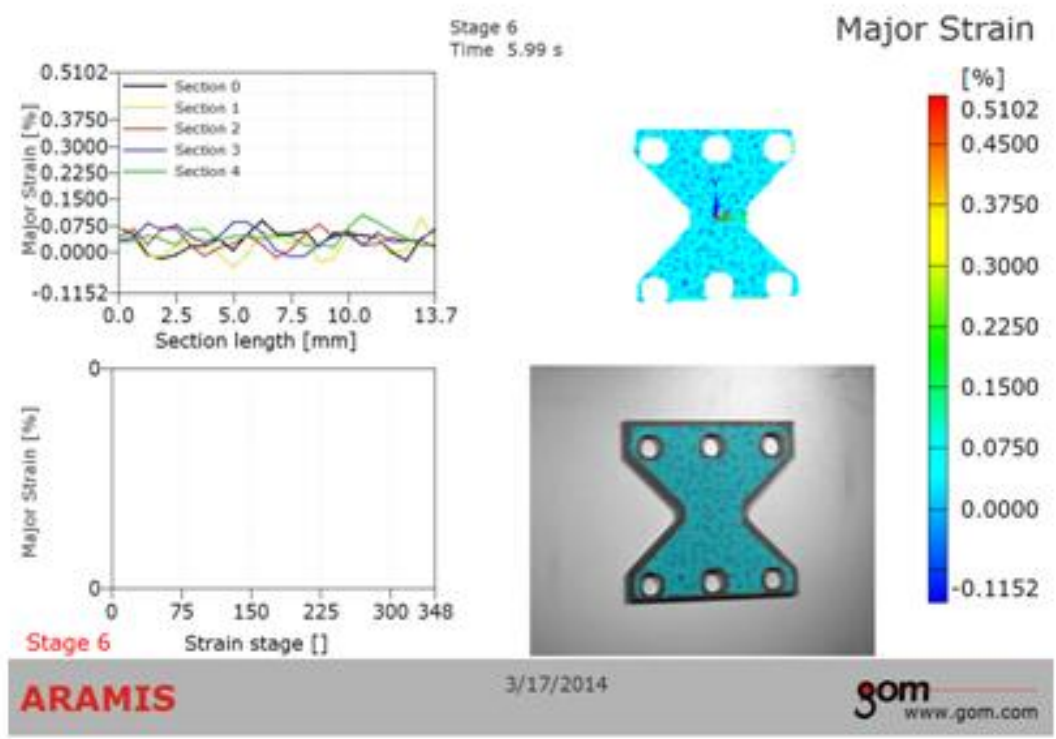

- Resultado calibrado: Geração das curvas de medidas das secções; 


\subsection{Anexo $\mathrm{K}$}

Tabela 13-2 Valores medidos e tabelados por condição de corpo de provas

\begin{tabular}{|c|c|c|c|c|c|c|c|c|c|c|c|c|c|c|}
\hline வ் & $\begin{array}{l}\bar{E} \\
\underline{\xi} \\
\frac{\pi}{0} \\
0 \\
0 \\
\dot{0} \\
\dot{5}\end{array}$ & 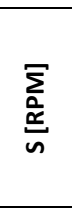 & 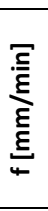 & 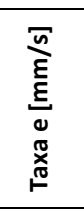 & $\stackrel{\bar{\Xi}}{\stackrel{\Xi}{\circ}}$ & 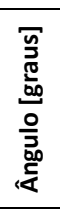 & 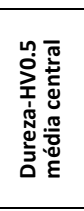 & 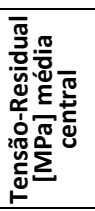 & 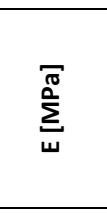 & 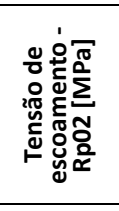 & 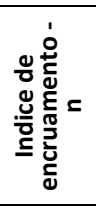 & 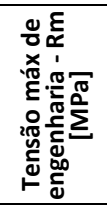 & 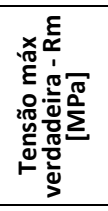 & 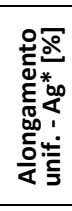 \\
\hline $\mathrm{A} 1$ & 1.95 & 1350 & 50 & 0.1 & 25 & 0 & 329.4 & 263.8 & 164596 & 875.97 & 0.179 & 905.73 & 913.28 & 0.9 \\
\hline $\mathrm{A} 2$ & 1.94 & 1350 & 50 & 0.1 & 25 & 30 & 329.4 & 263.8 & & 742.58 & 0.293 & 760.88 & 771.23 & 1.35 \\
\hline A4 & 1.97 & 1350 & 50 & 0.1 & 25 & 60 & 329.4 & 263.8 & & 557.38 & 0.157 & 575.83 & 584.84 & 1.56 \\
\hline A5 & 1.94 & 1350 & 50 & 0.1 & 25 & 90 & 329.4 & 263.8 & & 535.5 & 0.142 & 591.46 & 612.5 & 3.56 \\
\hline B1 & 1.95 & 1350 & 60 & 0.01 & 200 & 0 & 360.4 & 264.7 & 164729 & 785.38 & 182 & 974.15 & 1000.39 & 2.69 \\
\hline B2 & 1.95 & 1350 & 60 & 0.01 & 200 & 30 & 360.4 & 264.7 & & 600.68 & 0.116 & 764.5 & 838.81 & 9.72 \\
\hline B3 & 1.97 & 1350 & 60 & 0.01 & 200 & 45 & 360.4 & 264.7 & & 421.78 & 0.149 & 651.58 & 709.07 & 8.82 \\
\hline B4 & 1.95 & 1350 & 60 & 0.01 & 200 & 60 & 360.4 & 264.7 & & 360.1 & 0.189 & 551.27 & 612.37 & 11.08 \\
\hline B5 & 2.0 & 1350 & 60 & 0.01 & 200 & 90 & 360.4 & 264.7 & & 325 & 0.093 & 501.22 & 520.28 & 3.8 \\
\hline $\mathrm{C} 1$ & 2.02 & 1350 & 70 & 0.001 & 340 & 0 & 330.8 & 282 & 151254 & 663.7 & 0.101 & 869.92 & 899.92 & 3.45 \\
\hline C3 & 2.03 & 1350 & 70 & 0.001 & 340 & 45 & 330.8 & 282 & & 404.13 & 0.133 & 560.28 & 608.17 & 8.55 \\
\hline C5 & 2.09 & 1350 & 70 & 0.001 & 340 & 90 & 330.8 & 282 & & 315 & 0.126 & 470.37 & 513.74 & 9.22 \\
\hline D1 & 1.84 & 1500 & 50 & 0.01 & 340 & 0 & 333.2 & 217.5 & 159514 & 728.97 & 0.109 & 882.55 & 912.44 & 3.39 \\
\hline D2 & 1.78 & 1500 & 50 & 0.01 & 340 & 30 & 333.2 & 217.5 & & 582.95 & 0.101 & 732.49 & 801.84 & 9.47 \\
\hline D3 & 1.85 & 1500 & 50 & 0.01 & 340 & 45 & 333.2 & 217.5 & & 497.69 & 0.122 & 622.4 & 698.82 & 12.28 \\
\hline D4 & 1.94 & 1500 & 50 & 0.01 & 340 & 60 & 333.2 & 217.5 & & 479.08 & 0.098 & 617.21 & 686.14 & 11.17 \\
\hline D5 & 1.93 & 1500 & 50 & 0.01 & 340 & 90 & 333.2 & 217.5 & & 348.6 & 0.132 & 459.51 & 503.08 & 9.48 \\
\hline E1 & 1.87 & 1500 & 60 & 0.001 & 25 & 0 & 346.4 & 243.2 & 180175 & 932.26 & 0.172 & 1117.84 & 1143.52 & 2.3 \\
\hline E2 & 1.83 & 1500 & 60 & 0.001 & 25 & 30 & 346.4 & 243.2 & & 684.97 & 0.203 & 813.33 & 833.9 & 2.53 \\
\hline E3 & 1.97 & 1500 & 60 & 0.001 & 25 & 45 & 346.4 & 243.2 & & 568.42 & 0.195 & 682.82 & 711.53 & 4.2 \\
\hline E4 & 1.82 & 1500 & 60 & 0.001 & 25 & 60 & 346.4 & 243.2 & & 507.08 & 0.178 & 623.12 & 649.93 & 4.3 \\
\hline E5 & 1.75 & 1500 & 60 & 0.001 & 25 & 90 & 346.4 & 243.2 & & 342.05 & 0.19 & 603.08 & 650.92 & 7.93 \\
\hline $\mathrm{F} 1$ & 2.00 & 1500 & 70 & 0.1 & 200 & 0 & 319.2 & 228.1 & 157699 & 796.84 & 0.131 & 989.01 & 1016.33 & 4.13 \\
\hline $\mathrm{F} 2$ & 1.93 & 1500 & 70 & 0.1 & 200 & 30 & 319.2 & 228.1 & & 651.41 & 0.154 & 764.03 & 782.67 & 6.91 \\
\hline F3 & 1.84 & 1500 & 70 & 0.1 & 200 & 45 & 319.2 & 228.1 & & 569.01 & 0.121 & 691.37 & 714.94 & 7.47 \\
\hline F4 & 1.93 & 1500 & 70 & 0.1 & 200 & 60 & 319.2 & 228.1 & & 490.32 & 0.147 & 583.2 & 595.83 & 7.53 \\
\hline F5 & 1.8 & 1500 & 70 & 0.1 & 200 & 90 & 319.2 & 228.1 & & 456.67 & 0.092 & 580.7 & 602.16 & 3.96 \\
\hline $\mathrm{H} 1$ & 2.09 & 1650 & 60 & 0.1 & 340 & 0 & 331.8 & 231.8 & 156571 & 734.52 & 0.151 & 835.89 & 851.98 & 1.92 \\
\hline $\mathrm{H} 2$ & 2.0 & 1650 & 60 & 0.1 & 340 & 30 & 331.8 & 231.8 & & 570.47 & 0.152 & 708.83 & 771.23 & 8.8 \\
\hline $\mathrm{H} 3$ & 2.02 & 1650 & 60 & 0.1 & 340 & 45 & 331.8 & 231.8 & & 505.29 & 0.105 & 620.77 & 669.29 & 7.82 \\
\hline $\mathrm{H} 4$ & 2.04 & 1650 & 60 & 0.1 & 340 & 60 & 331.8 & 231.8 & & 500.5 & 0.109 & 545.08 & 573.53 & 5.22 \\
\hline H5 & 1.95 & 1650 & 60 & 0.1 & 340 & 90 & 331.8 & 231.8 & & 413.2 & 0.113 & 507.54 & 533.37 & 5.09 \\
\hline 11 & 2.05 & 1650 & 70 & 0.01 & 25 & 0 & 323.8 & 241.2 & 164109 & 853.11 & 0.132 & 927.2 & 939.2 & 1.29 \\
\hline 12 & 1.86 & 1650 & 70 & 0.01 & 25 & 30 & 323.8 & 241.2 & & 729.71 & 0.29 & 730.42 & 739.09 & 1.19 \\
\hline 13 & 2.07 & 1650 & 70 & 0.01 & 25 & 45 & 323.8 & 241.2 & & 640.99 & 0.108 & 768.49 & 833.76 & 8.49 \\
\hline 14 & 1.9 & 1650 & 70 & 0.01 & 25 & 60 & 323.8 & 241.2 & & 572.96 & 0.117 & 604.19 & 616.36 & 2.01 \\
\hline 15 & 1.95 & 1650 & 70 & 0.01 & 25 & 90 & 323.8 & 241.2 & & 487.124 & 0.123 & 614.68 & 646.12 & 5.12 \\
\hline
\end{tabular}




\subsection{Anexo $L$}

Propriedades do material

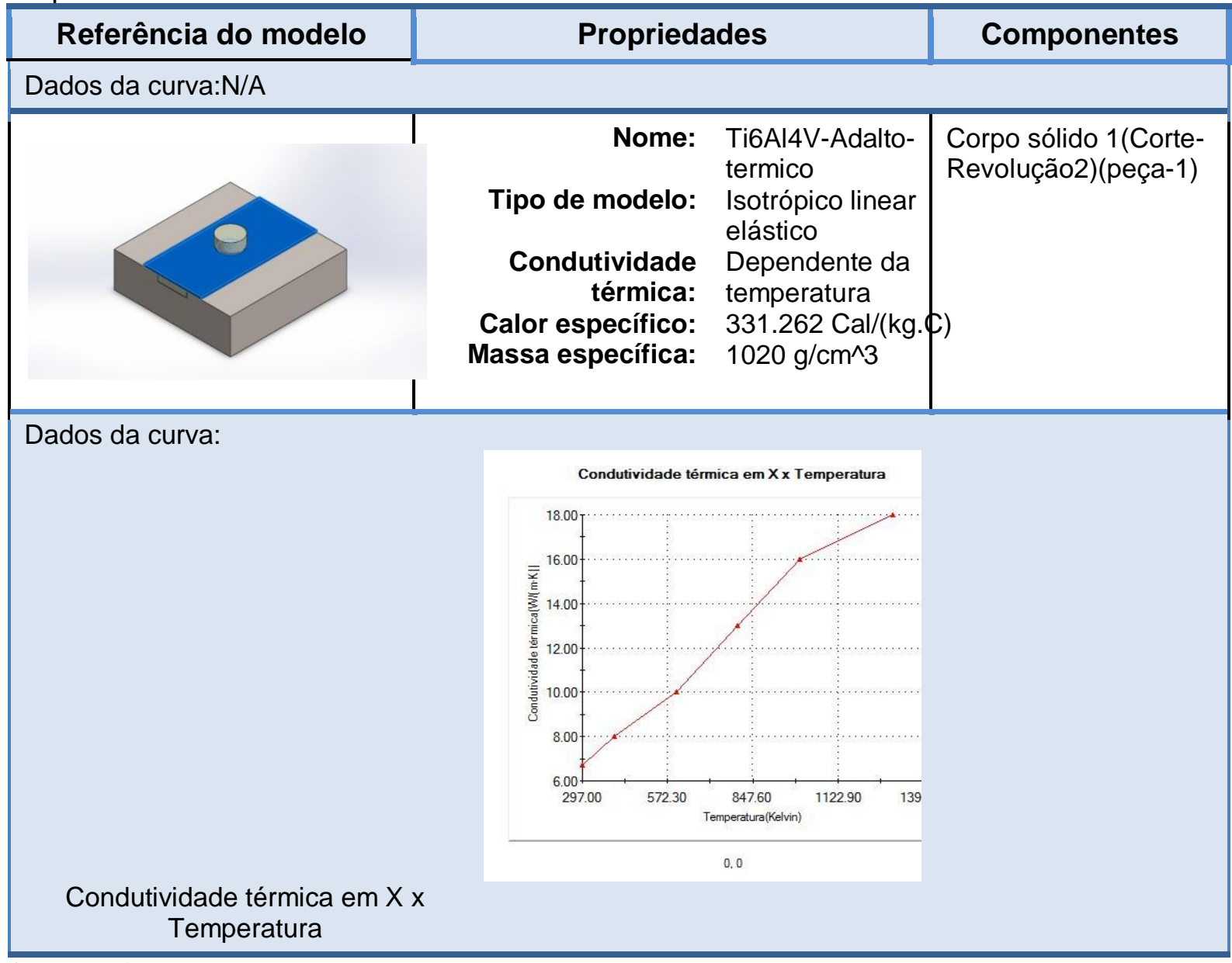

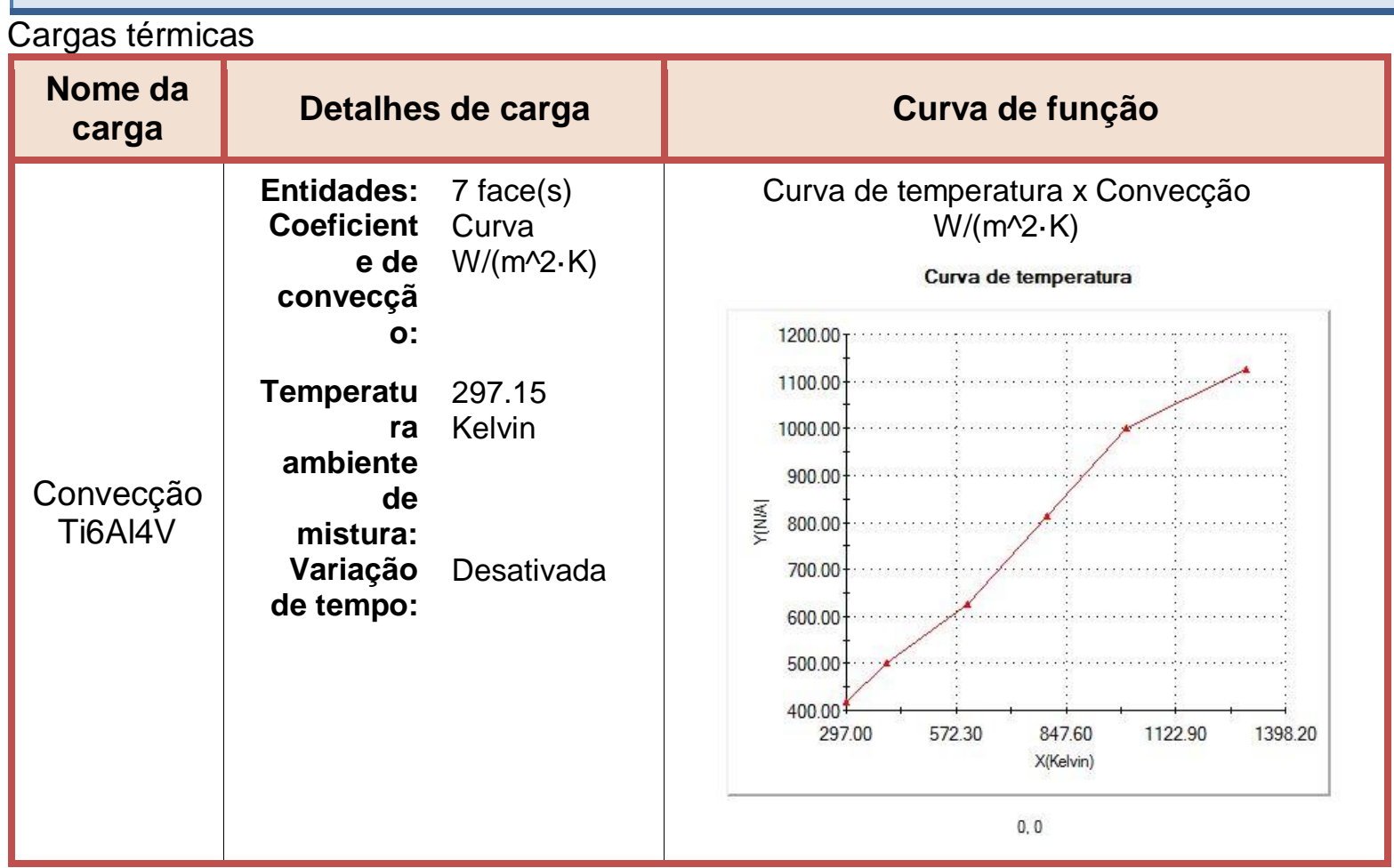




\begin{tabular}{|c|c|c|}
\hline $\begin{array}{l}\text { Convecção } \\
\text { Régua WC }\end{array}$ & $\begin{array}{r}\text { Entidades: } \\
\text { Coeficiente de } \\
\text { convecção: } \\
\text { Variação de tempo: } \\
\text { Variação de } \\
\text { temperatura: } \\
\text { Temperatura ambiente } \\
\text { de mistura: } \\
\text { Variação de tempo: }\end{array}$ & $\begin{array}{l}1 \text { face }(\mathrm{s}) \\
12000 \mathrm{~W} /\left(\mathrm{m}^{\wedge} 2 \cdot \mathrm{K}\right) \\
\text { Desativada } \\
\text { Desativada } \\
297.15 \mathrm{Kelvin} \\
\text { Desativada }\end{array}$ \\
\hline $\begin{array}{c}\text { Convecção } \\
\text {-Base } \\
\text { ABNT P20 }\end{array}$ & $\begin{array}{r}\text { Entidades: } \\
\text { Coeficiente de } \\
\text { convecção: } \\
\text { Variação de tempo: } \\
\text { Variação de } \\
\text { temperatura: } \\
\text { Temperatura ambiente } \\
\text { de mistura: } \\
\text { Variação de tempo: }\end{array}$ & $\begin{array}{l}5 \text { face }(\mathrm{s}) \\
1000 \mathrm{~W} /\left(\mathrm{m}^{\wedge} 2 \cdot \mathrm{K}\right) \\
\text { Desativada } \\
\text { Desativada } \\
297.15 \mathrm{Kelvin} \\
\text { Desativada }\end{array}$ \\
\hline
\end{tabular}

Informações de malha

\begin{tabular}{|l|l|}
\hline Tipo de malha & Malha sólida \\
\hline Gerador de malhas usado: & Malha com base em curvatura \\
\hline Pontos Jacobianos & 4 Pontos \\
\hline Tamanho máximo de elemento & $0 \mathrm{~mm}$ \\
\hline Tamanho de elemento mínimo & $0 \mathrm{~mm}$ \\
\hline Qualidade da malha & Alta \\
\hline $\begin{array}{l}\text { Refazer malha de peças falhas com } \\
\text { malha incompatível }\end{array}$ & Desativada \\
\hline
\end{tabular}

Informações de malha - Detalhes

\begin{tabular}{|l|l|}
\hline Total de nós & 248148 \\
\hline Total de elementos & 175755 \\
\hline Proporção máxima & 11.011 \\
\hline $\begin{array}{l}\text { \% de elementos com Proporção }< \\
\mathbf{3}\end{array}$ & 99.8 \\
\hline $\begin{array}{l}\text { \% de elementos com Proporção }< \\
\mathbf{1 0}\end{array}$ & 0.00853 \\
\hline
\end{tabular}




\begin{tabular}{|l|l|}
\hline $\begin{array}{l}\text { \% de elementos } \\
\text { distorcidos(Jacobiana) }\end{array}$ & 0 \\
\hline $\begin{array}{l}\text { Tempo para conclusão da malha } \\
\text { (hh;mm;ss): }\end{array}$ & 00:00:06 \\
\hline Nome do computador: & ADALTO \\
\hline
\end{tabular}




\subsection{Anexo $M$}

\section{Condição A}

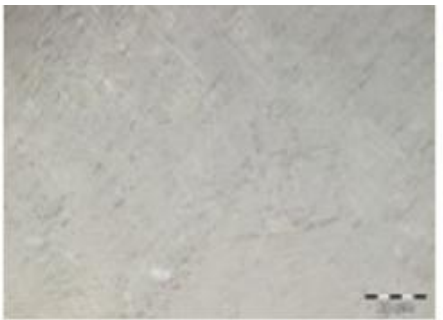

A-1000x-ZTA-DIREITA.jpg

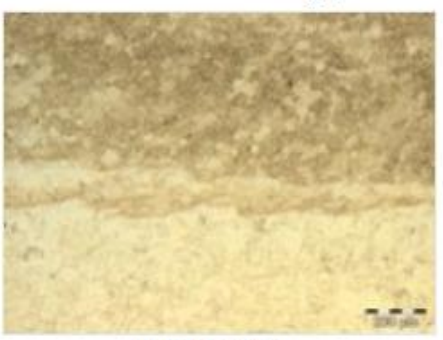

A-200xBASE-5.jpg

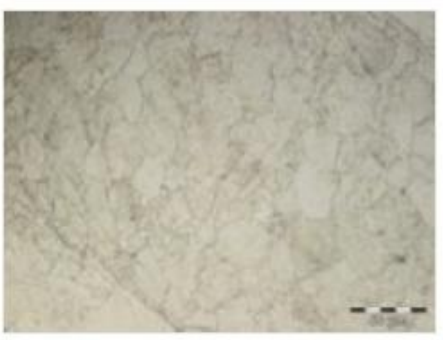

A-500x-ZTA-ESQUERDA.jpg

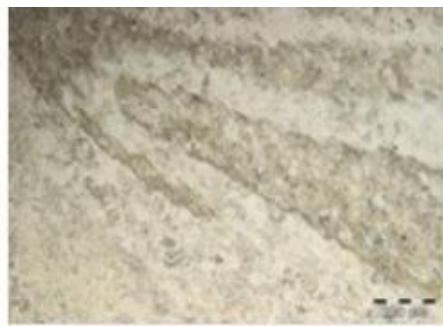

A-100x-ZTA-ESQUERDA.jpg

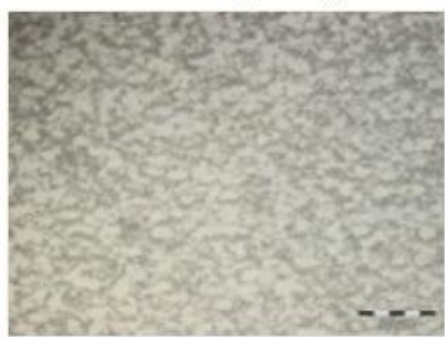

A-500x.jpg

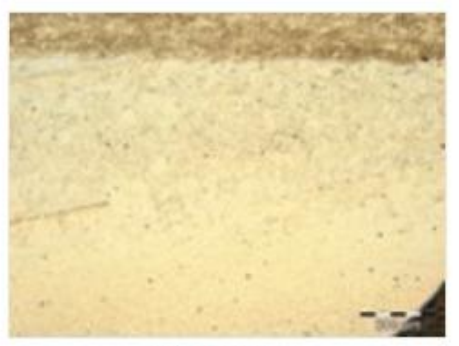

A-50xBASE-2.jpg

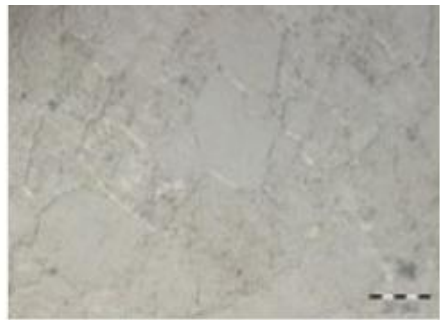

A-1000x-ZTA-ESQUERDA.jpg

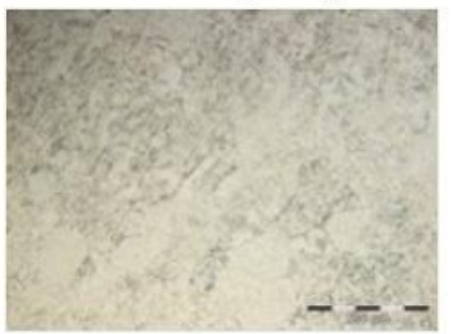

A-200x-ZTA-DIREITA.jpg

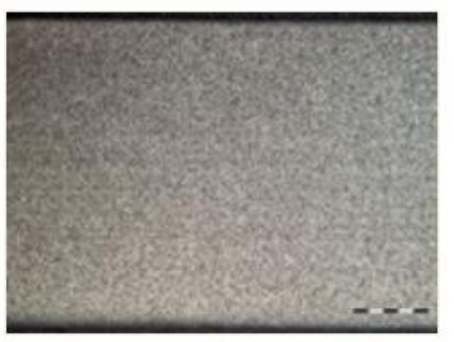

A-50x.jpg

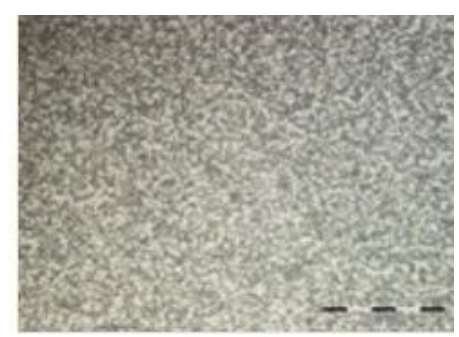

A-200x.jpg

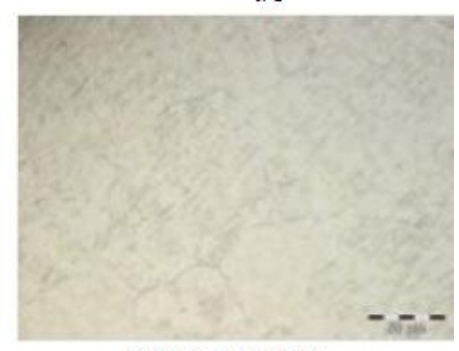

A-500x-ZTA-DIREITA.jpg

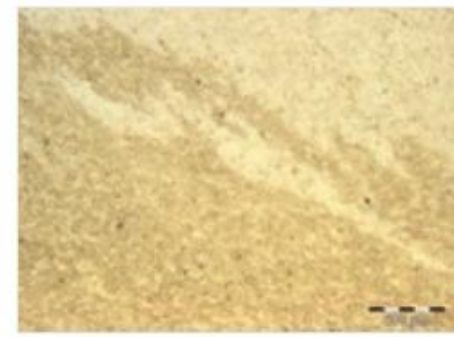

A-50xBASE-3.jpg

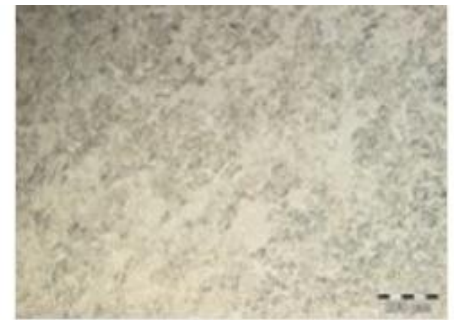

A-100x-ZTA-DIREITA.jpg

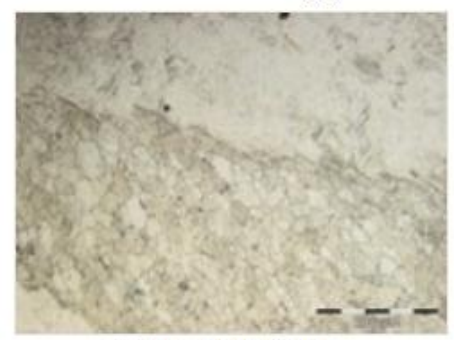

A-200x-ZTA-ESQUERDA.jpg

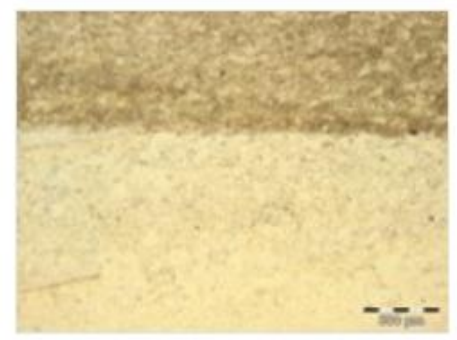

A-50xBASE-1.jpg

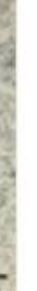

(n) 


\section{Condição B}

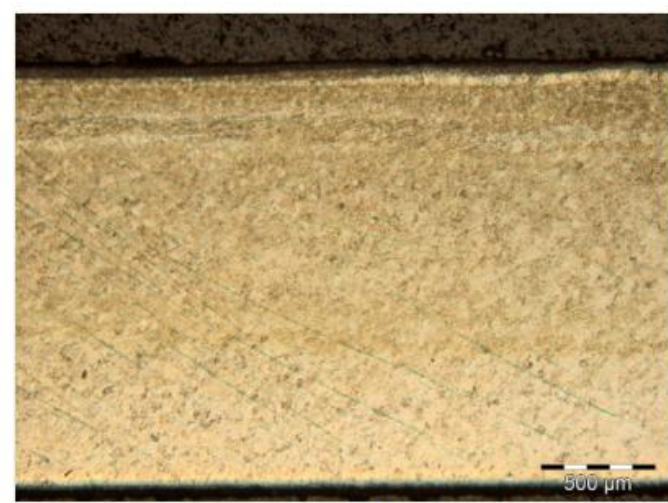

B-50X-MEIO.jpg

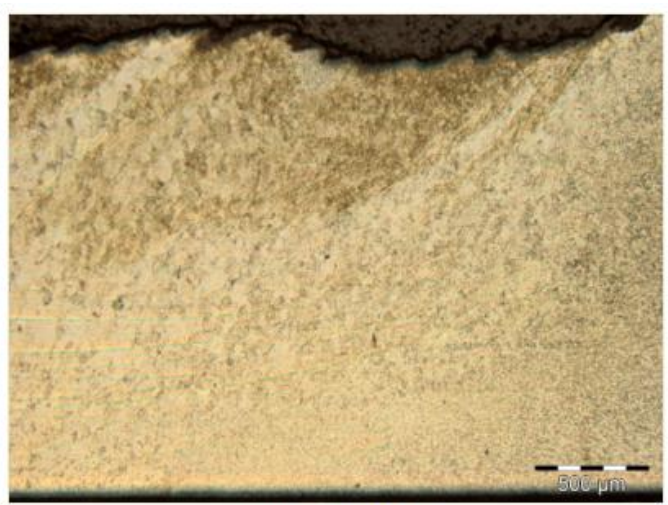

B-50x-ZTA-DIREITA.jpg

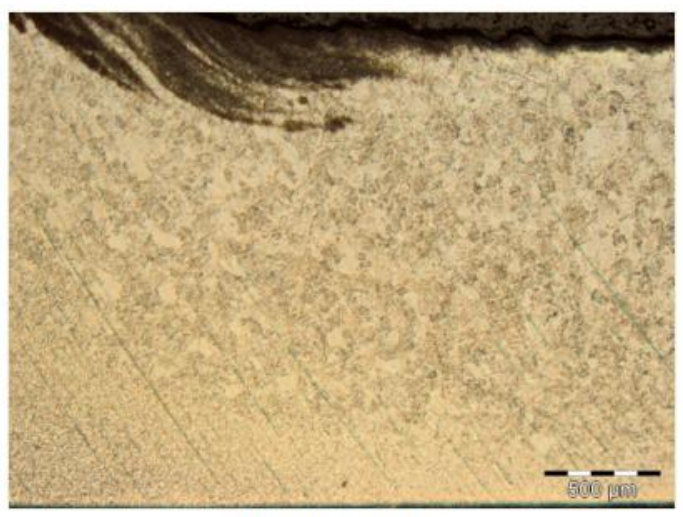

B-50X-ZTA-ESQUERDA.jpg

\section{Condição C}
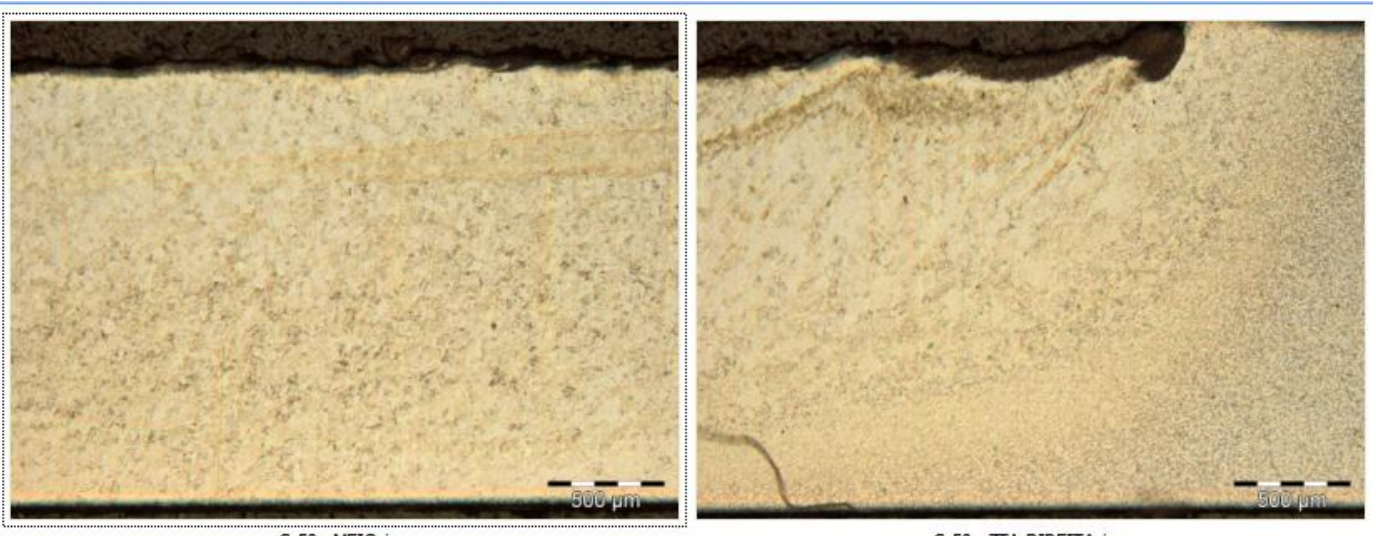

C-50x-ZTA-DIRETTA.jpg

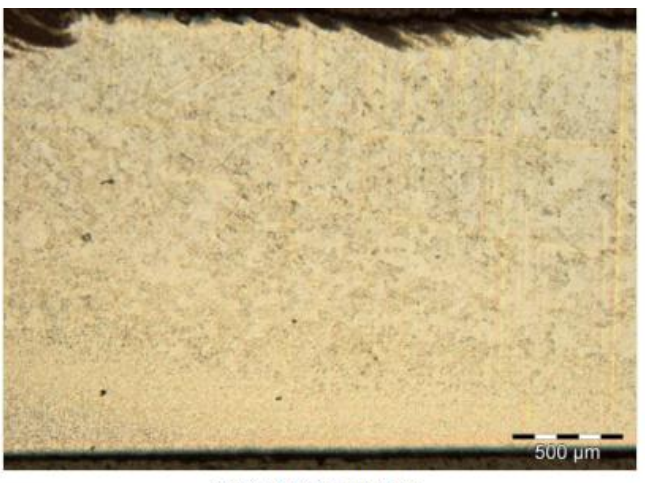

C-50x-ZTA-ESQUERDA.jpg 


\section{Condição D}

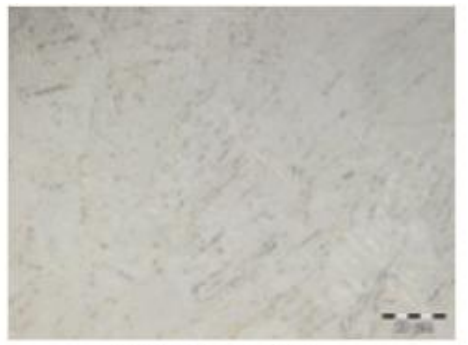

D-1000XMEIO-TOPO.jpg

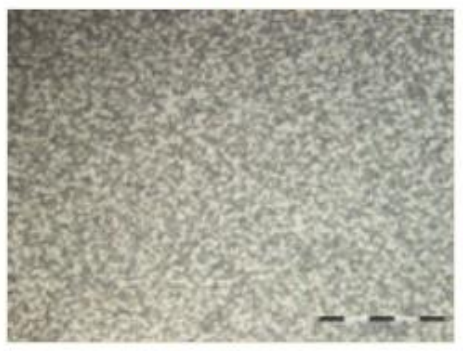

D-200x.jpg

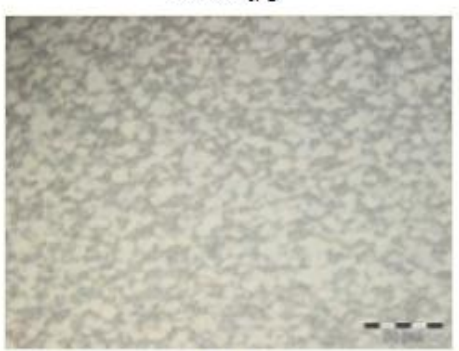

D-500x.jpg

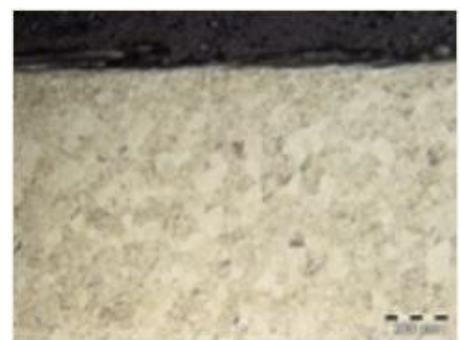

D-100XMEIO-TOPO.jpg

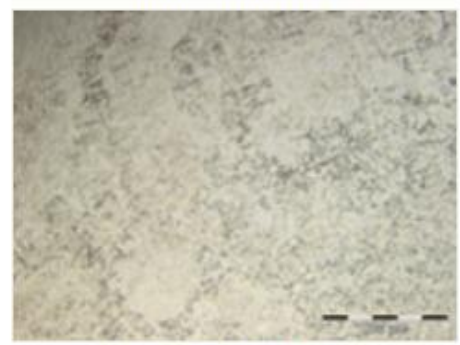

D-200xZTA-DIREITA.jpg

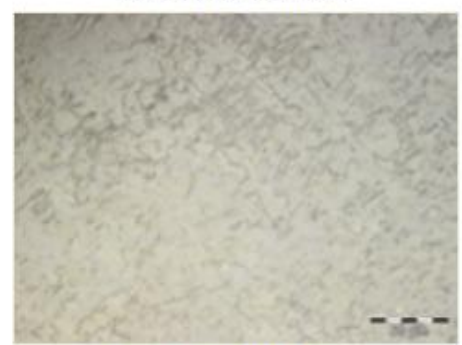

D-500xZTA-DIREITA.jpg

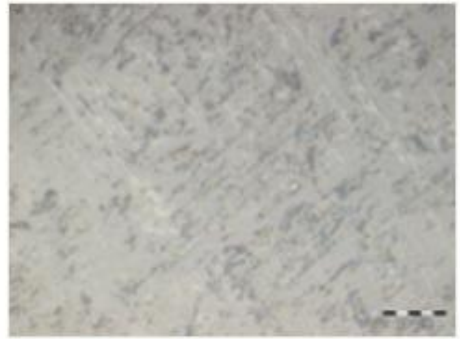

D-1000xZTA-ESQUERDA.jpg

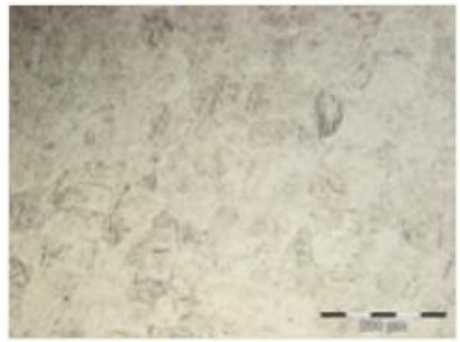

D-200XMEIO-INF.jpg

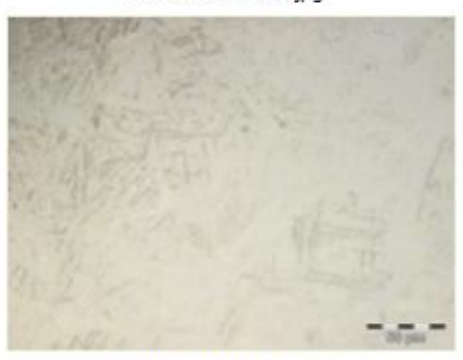

D-500xMEIO-INF.jpg

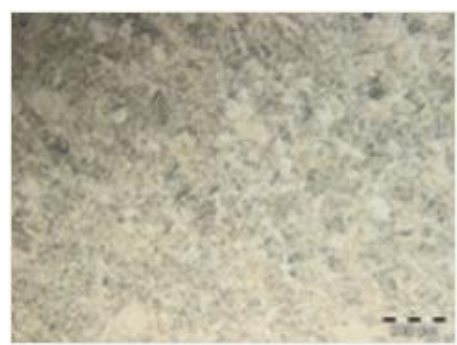

D-100xZTA-ESQUERDA.jpg

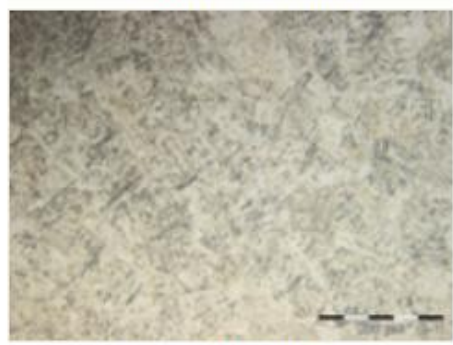

D-200xZTA-ESQUERDA.jpg

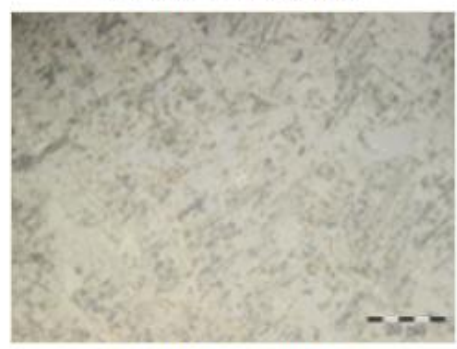

D-500xZTA-ESQUERDA.jpg

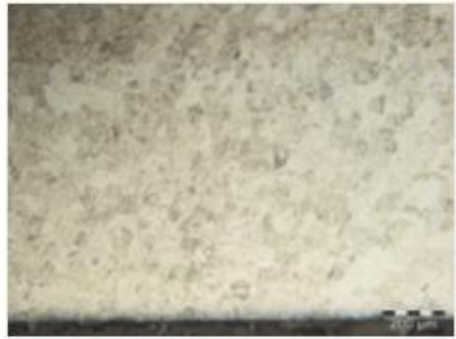

D-100xMEIO-INF.jpg

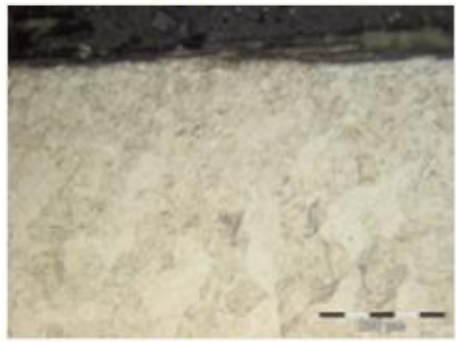

D-200XMEIO-TOPO.jpg

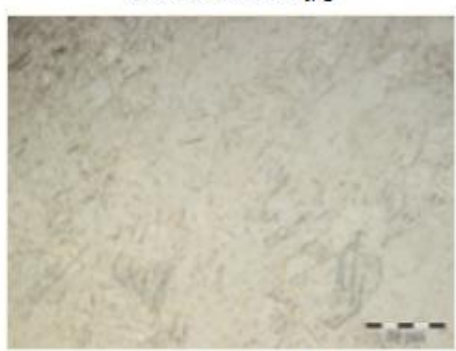

D-500XMEIO-TOPO.jpg 


\section{Condição E}

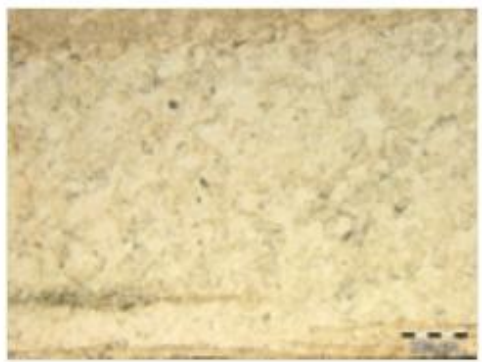

E-100x-MEIO-INF.jpg

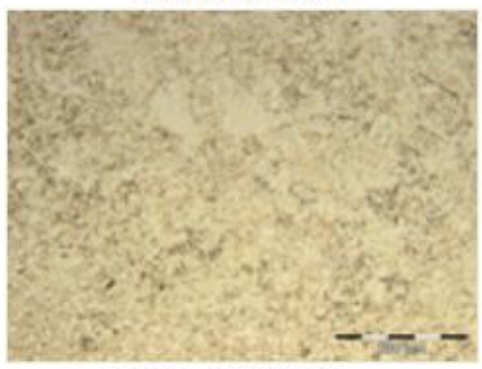

E-200x-ZTA-ESQUERDA.jpg

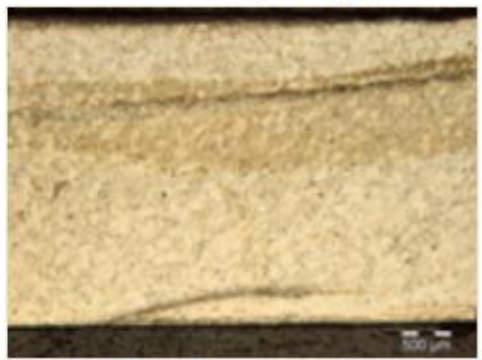

E-50X-MEIO.jpg

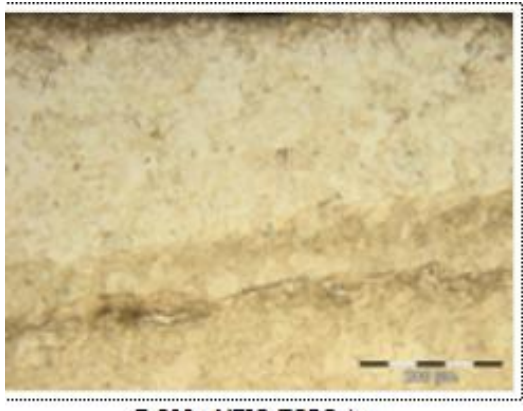

E-200x-MEIO-TOPO.jpg

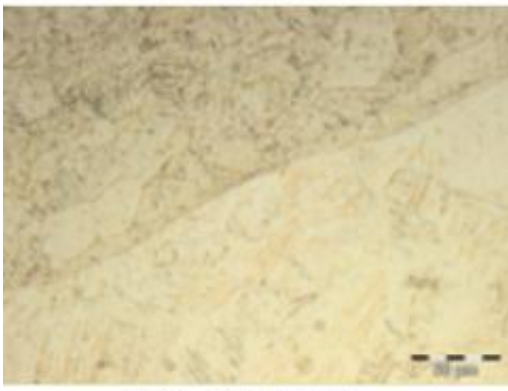

E-500x-ZTA-DIREITA.jpg

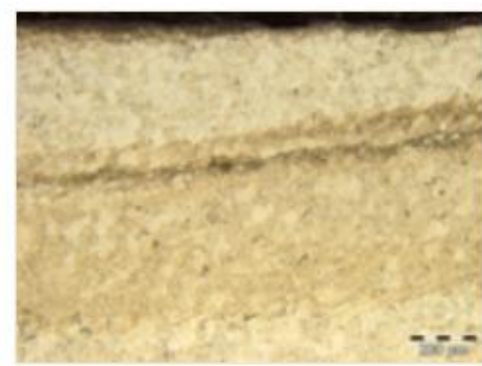

E-100X-MEIO-TOPO.jpg

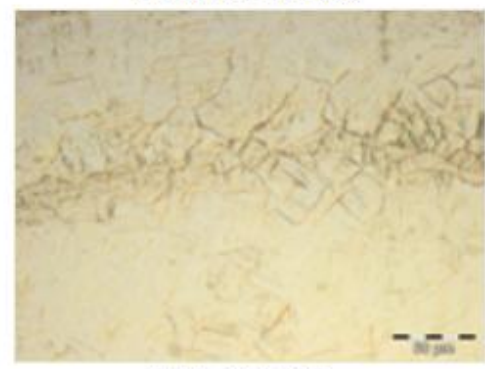

E-500X-MEIO-INF.jpg

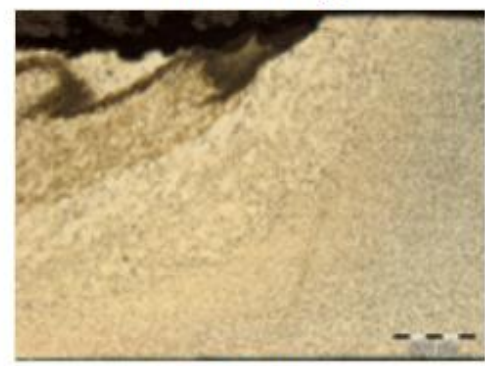

E-50x-ZTA-DIREITA.jpg

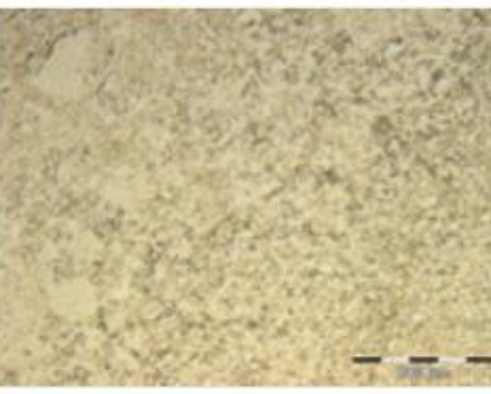

E-200x-ZTA-DIREITA.jpg

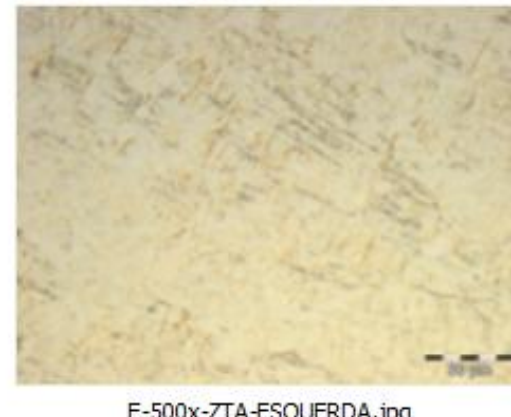

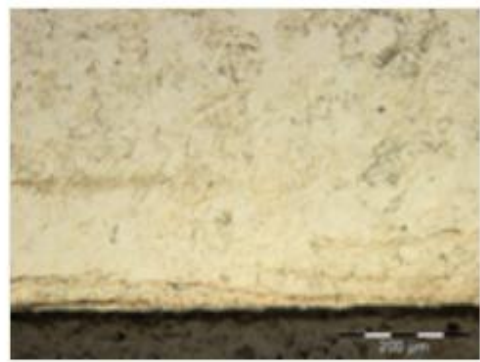

E-200X-MEIO-INF.jpg

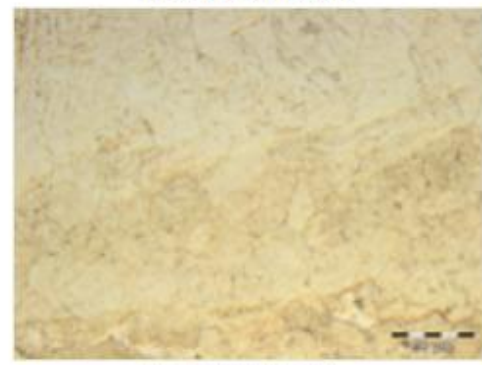

E-500x-MEIO-TOPO.jpg

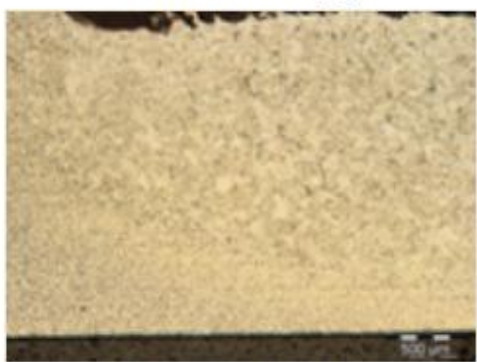

E-50x-ZTA-ESQUERDA.jpg

E-500x-ZTA-ESQUERDA.jpg 


\section{Condição F}

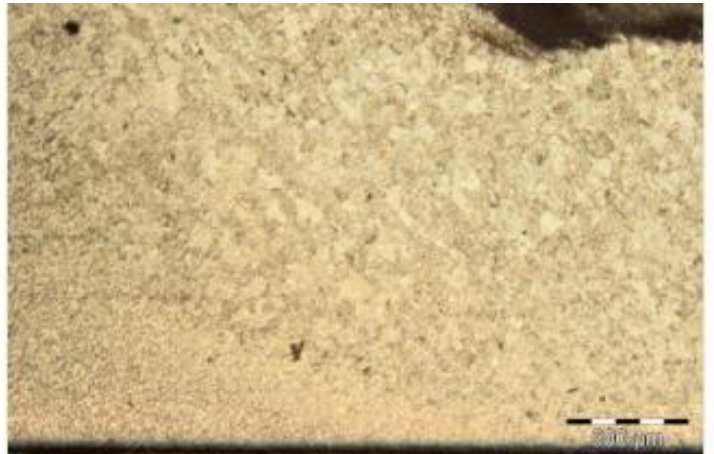

F-50x-ZTA-DIREITA.jpg

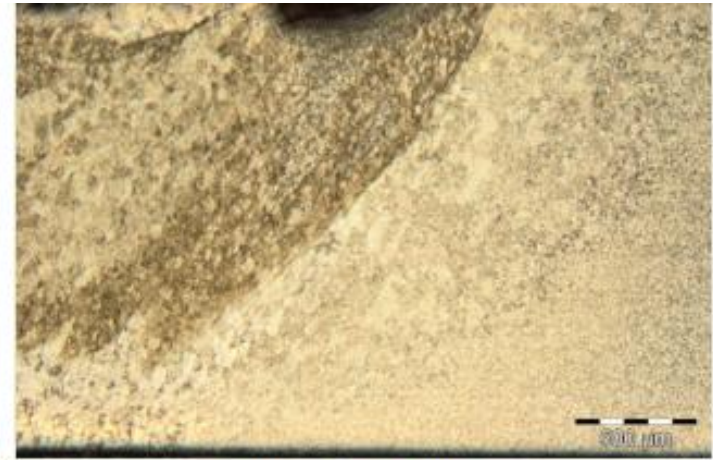

F-50x-ZTA-ESQUERDA.jpg

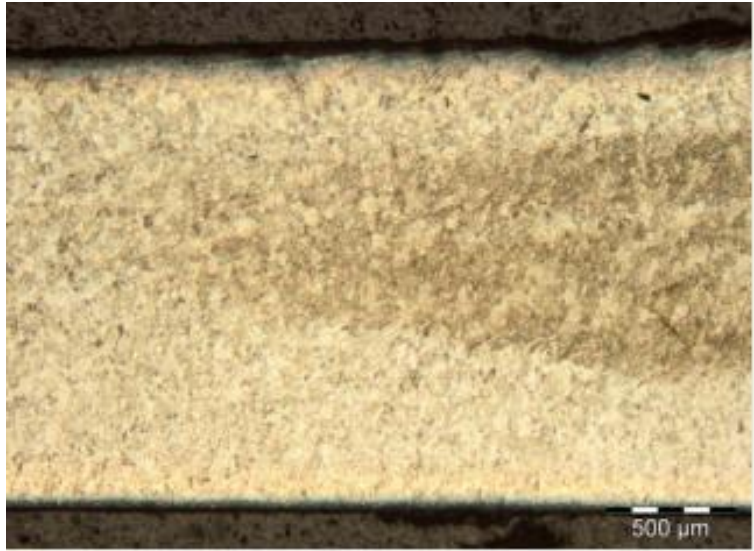

F-50x-ZTA-MEIO.jpg

\section{Condição G}

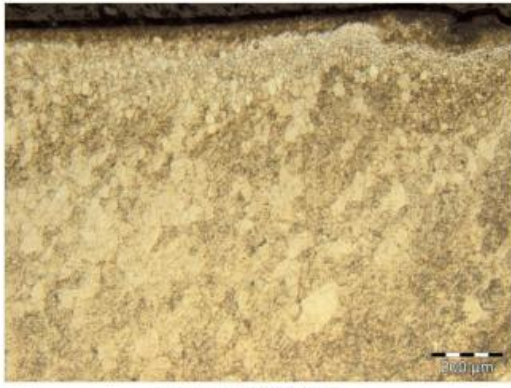

G-100x-ZTA-DIREITA.jpg

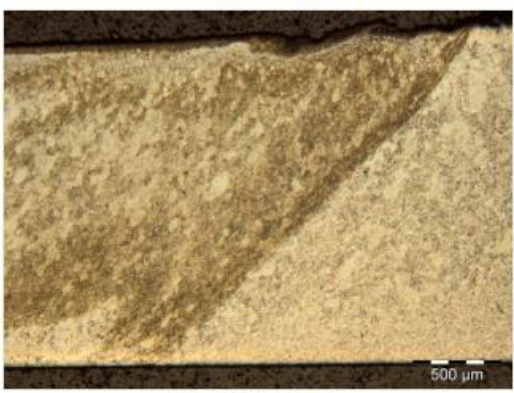

G-50x-ZTA-DIREITA.jpg

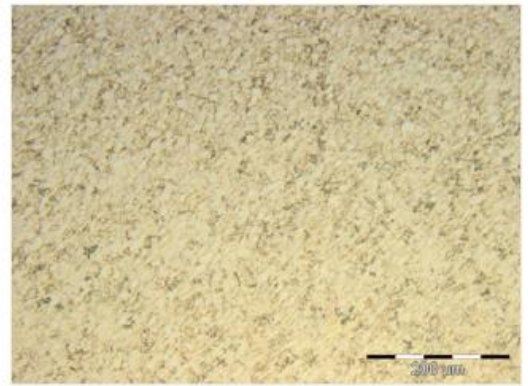

G-200xZTA-BASE 1.jpg

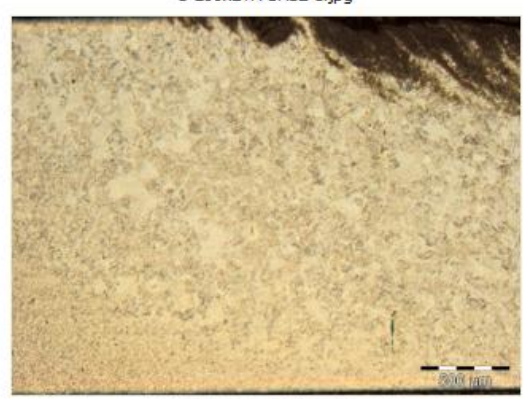

G-50X-ZTA-ESQUERDA.jpg

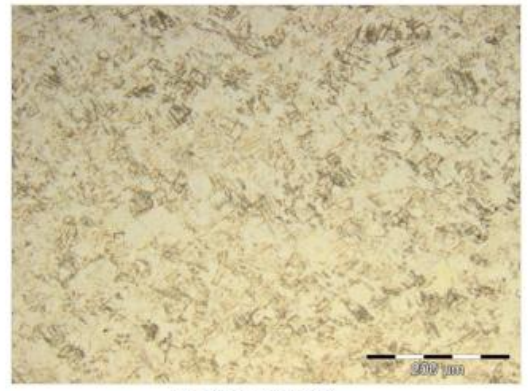

G-200xZTA-BASE 2.jpg

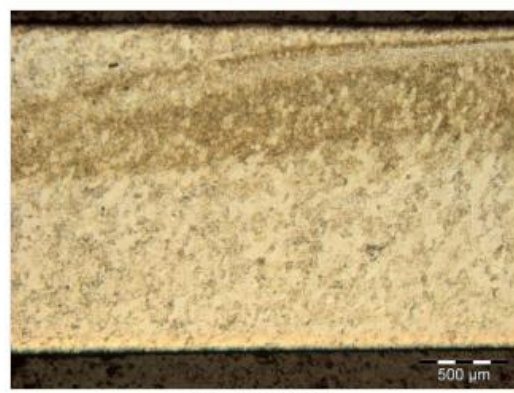

G-50x-ZTA-MEIO.jpg 


\section{Condição H}

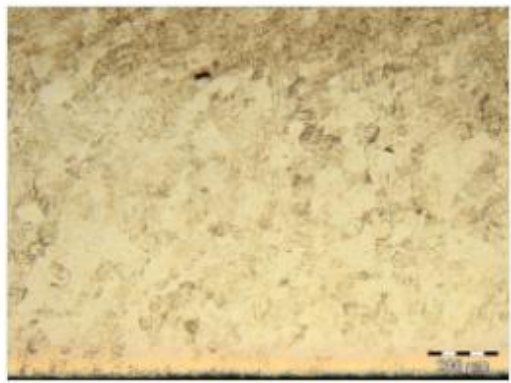

H-100x-ZTA-MEIO-INF.jpg

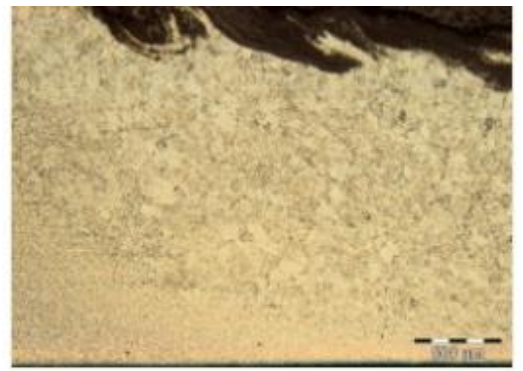

H-50x-ZTA-ESQUERDA.jpg

\section{Condição I}

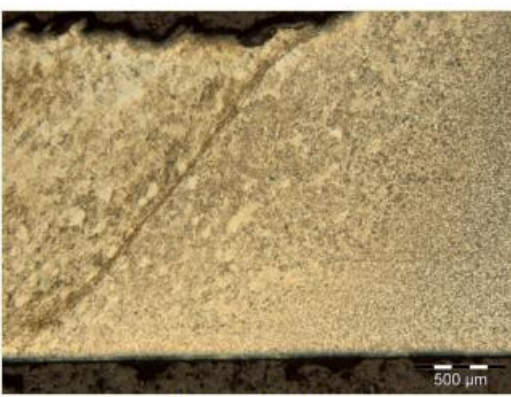

I-50x-ZTA-DIREITA.jpg

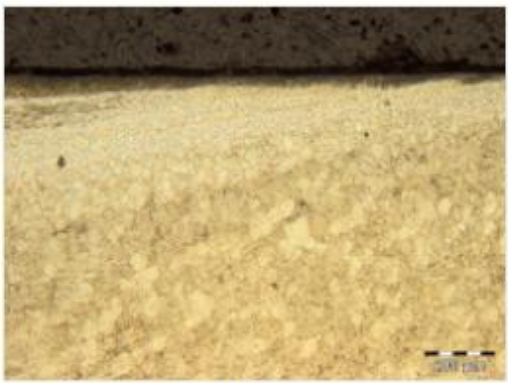

H-100X-ZTA-MEIO-TOPO.jpg

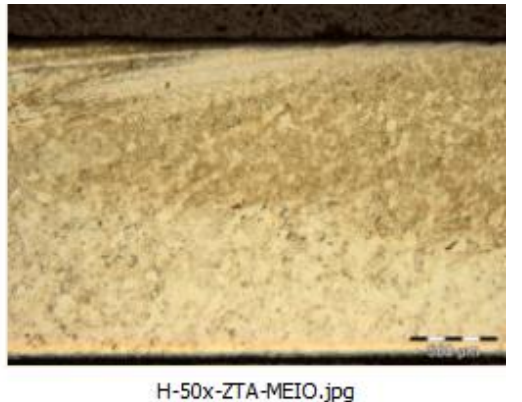

H-50X-ZTA-MEIO.jpg

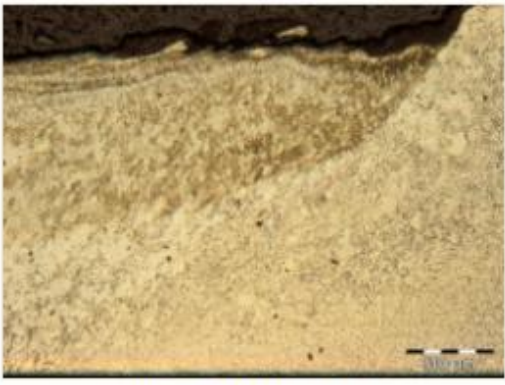

H-50x-ZTA-DIREITA.jpg

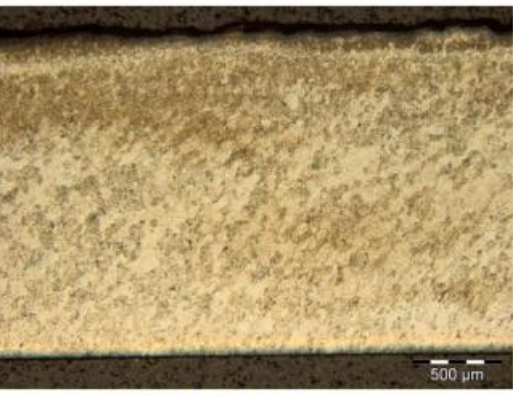

I-50x-ZTA-ESQUERDA.jpg

I-50x-ZTA-MEIO.jpg 